ADVANCED STEEL CONSTRUCTION

An International Journal

Volume 17 Number 2

June 2021

CONTENTS

Technical Papers

Equivalent Properties for Analysis as Be

Alberto M. Guzmán and Victor A. Roldan

Study on Micromechanical Fracture Models of Structural Steel and Its Welds

Xi-Yue Liu, Yuan-Qing Wang, Yi-Du Bu and Yang Guan

Numerical Study and Design Method of High Stren

Yong-Jun Lin, Kai-Qi Liu, Tian-Ji Li and Yi Zhou

Experimental Study on The Mechanical Behaviour
Jing-Yao Li, Shi-Dong Nie, Jia Zeng and Bo Yang

Experiment of Hysteretic Behavior and Stability Performance of

Ming-Ming Jia, Liang Li, Cheng Hong, Kai Liu and Lin Sun

Axial Behavior of High-Strength Concrete-Filledhigh-Strength Square
Guo-Chang Li, Bo-Wen Chen, Zhi-Jian Yang, Han-bin Ge and Xiao Li

Damping Performance Experiment and Damage $A$
Hao-Xiang He, Li-Can Liao and Shi-Tao Cheng

Design Optimization
Tugrul Talaslioglu

Progressive Collapse Mechanism of Steel Framed-Structures Subjected to A Middle-Column Loss

Wen-Jin Zhang, Guo-Qiang Li and Jing-Zhou Zhang

Line-Element Formulation for Upheaval Buckling Analysis of Buried Subsea Pipelines Due to Thermal Expansion Ji-Hui Ning, Si-Wei Liu, Jian-Hong Wan and Wei Huang

Copyright $\odot 2021$ by

The Hong Kong Institute of Steel Construction

Website: http://www.hkisc.org

ISSN 1816-112X

Science Citation Index Expanded, Materials Science Citation Index and ISI Alerting

Cover: Project: Dount; Structural Engineers: XinY; Architect: AAI; Client: Vanke; Co-design: Beiyang Design: Principal Contractor: Beijing Shengshiweei; Curtaii Consultant: CAC Shanghhi; Pho
a-copy of IIASC is free to download at "wwww.ascjournal.com" in internet and mobile apps.

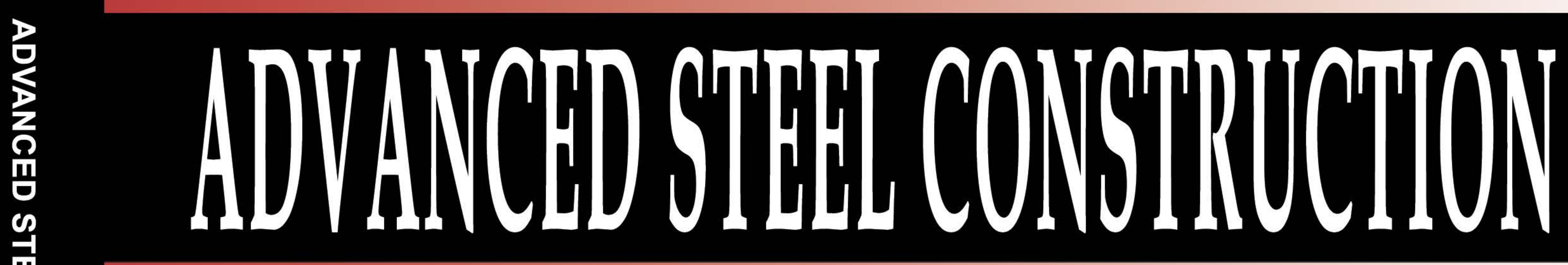

an International Jownal

ISSN 1816-112X

Volume 17 Number 2

June 2021

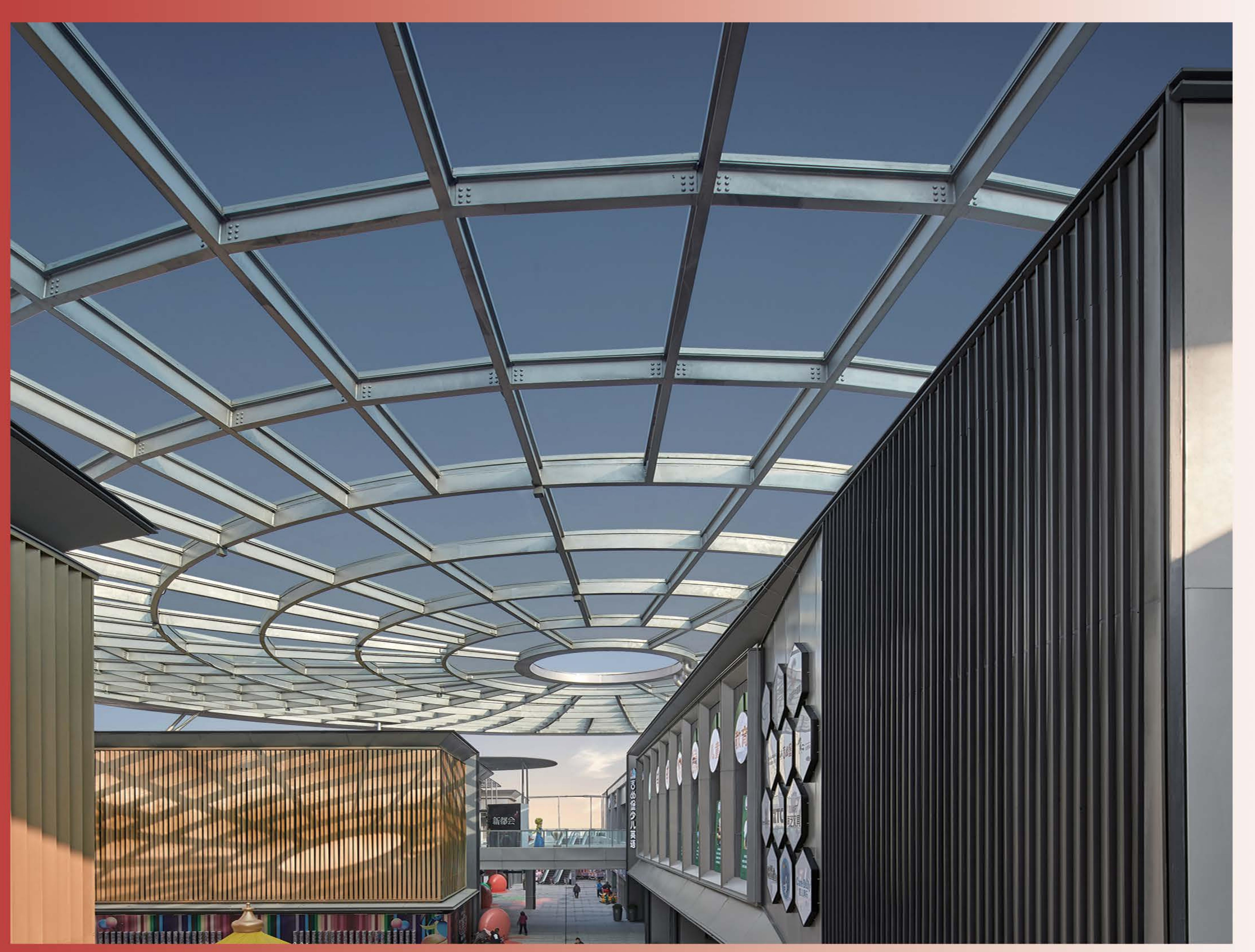

Editors-in-Chief

S.L. Chan, The Hong Kong Polytechnic University, Hong Kong, China

W.F. Chen, University of Hawaii at Manoa, USA

R. Zandonini, Trento University, Italy 
ISSN 1816-112X

Science Citation Index Expanded, Materials Science Citation Index and ISI Alerting

\begin{tabular}{|c|c|}
\hline EDITORS-IN-CHIEF & L.H. Han \\
\hline $\begin{array}{l}\text { Asian Pacific, African } \\
\text { and organizing Editor } \\
\text { S.L. Chan } \\
\text { The Hong Kong Polyt. Univ., } \\
\text { Hong Kong, China }\end{array}$ & $\begin{array}{l}\text { Tsinghua Univ. China } \\
\text { S. Herion } \\
\text { University of Karlsruhe, Germany }\end{array}$ \\
\hline $\begin{array}{l}\text { American Editor } \\
\text { W.F. Chen } \\
\text { Univ. of Hawaii at Manoa, USA }\end{array}$ & $\begin{array}{l}\text { G.W.M. Ho } \\
\text { Ove Arup \& Partners Hong Kong Ltd., Hong Kong, } \\
\text { China }\end{array}$ \\
\hline $\begin{array}{l}\text { European Editor } \\
\text { R. Zandonini } \\
\text { Trento Univ., Italy }\end{array}$ & $\begin{array}{l}\text { B.A. Izzuddin } \\
\text { Imperial College of Science, Technology and } \\
\text { Medicine, UK }\end{array}$ \\
\hline ASSOCIATE EDITORS & J.P. Jaspart \\
\hline $\begin{array}{l}\text { Y.P. Liu } \\
\text { The Hong Kong Polyt. Univ., Hong Kong, China }\end{array}$ & Univ. of Liege, Belgium \\
\hline $\begin{array}{l}\text { S.W. Liu } \\
\text { Sun Yat-Sen Univ., China }\end{array}$ & $\begin{array}{l}\text { S. A. Jayachandran } \\
\text { IIT Madras, Chennai, India } \\
\text { S.E. Kim }\end{array}$ \\
\hline $\begin{array}{l}\text { INTERNATIONAL } \\
\text { EDITORIAL BOARD }\end{array}$ & Sejong Univ., South Korea \\
\hline $\begin{array}{l}\text { F.G. Albermani } \\
\text { Central Queensland Univ., Australia }\end{array}$ & $\begin{array}{l}\text { S. Kitipornchai } \\
\text { The Univ., of Queensland, Australia }\end{array}$ \\
\hline $\begin{array}{l}\text { I. Burgess } \\
\text { Univ. of Sheffield, UK }\end{array}$ & $\begin{array}{l}\text { D. Lam } \\
\text { Univ. of Bradford, UK }\end{array}$ \\
\hline $\begin{array}{l}\text { F.S.K. Bijlaard } \\
\text { Delft Univ. of Technology, The Netherlands }\end{array}$ & $\begin{array}{l}\text { H.F. Lam } \\
\text { City Univ. of Hong Kong, Hong Kong, China }\end{array}$ \\
\hline $\begin{array}{l}\text { R. Bjorhovde } \\
\text { The Bjorhovde Group, USA }\end{array}$ & $\begin{array}{l}\text { G.Q. Li } \\
\text { Tongji Univ., China }\end{array}$ \\
\hline $\begin{array}{l}\text { M.A. Bradford } \\
\text { The Univ. of New South Wales, Australia }\end{array}$ & $\begin{array}{l}\text { J.Y.R. Liew } \\
\text { National Univ. of Singapore, Singapore }\end{array}$ \\
\hline $\begin{array}{l}\text { D. Camotim } \\
\text { Technical Univ. of Lisbon, Portugal }\end{array}$ & $\begin{array}{l}\text { E.M. Lui } \\
\text { Syracuse Univ., USA }\end{array}$ \\
\hline $\begin{array}{l}\text { C.M. Chan } \\
\text { Hong Kong Univ. of Science \& Technology, Hong Kong, China }\end{array}$ & $\begin{array}{l}\text { Y.L. Mo } \\
\text { Univ. of Houston, USA }\end{array}$ \\
\hline $\begin{array}{l}\text { T.H.T. Chan } \\
\text { Queensland Univ. of Technology, Australia }\end{array}$ & $\begin{array}{l}\text { J.P. Muzeau } \\
\text { CUST, Clermont Ferrand, France }\end{array}$ \\
\hline $\begin{array}{l}\text { T.M. Chan } \\
\text { The Hong Kong Polyt. Univ., Hong Kong, China }\end{array}$ & $\begin{array}{l}\text { D.A. Nethercot } \\
\text { Imperial College of Science, Technology and } \\
\text { Medicine, UK }\end{array}$ \\
\hline $\begin{array}{l}\text { Z.H. Chen } \\
\text { Tianjin Univ., China }\end{array}$ & $\begin{array}{l}\text { Y.Q. Ni } \\
\text { The Hong Kong Polyt. Univ., Hong Kong, China }\end{array}$ \\
\hline $\begin{array}{l}\text { S.P. Chiew } \\
\text { Nanyang Technological Univ., Singapore }\end{array}$ & $\begin{array}{l}\text { D.J. Oehlers } \\
\text { The Univ. of Adelaide, Australia }\end{array}$ \\
\hline $\begin{array}{l}\text { W.K. Chow } \\
\text { The Hong Kong Polyt. Univ., Hong Kong, China }\end{array}$ & $\begin{array}{l}\text { J.L. Peng } \\
\text { Yunlin Uni. of Science \& Technology, Taiwan, China }\end{array}$ \\
\hline $\begin{array}{l}\text { G.G. Deierlein } \\
\text { Stanford Univ., California, USA }\end{array}$ & $\begin{array}{l}\text { K. Rasmussen } \\
\text { The Univ. of Sydney, Australia }\end{array}$ \\
\hline $\begin{array}{l}\text { L. Dezi } \\
\text { Univ. of Ancona, Italy }\end{array}$ & $\begin{array}{l}\text { J.M. Rotter } \\
\text { The Univ. of Edinburgh, UK }\end{array}$ \\
\hline $\begin{array}{l}\text { D. Dubina } \\
\text { The Politehnica Univ. of Timosoara, Romania }\end{array}$ & $\begin{array}{l}\text { C. Scawthorn } \\
\text { Scawthorn Porter Associates, USA }\end{array}$ \\
\hline $\begin{array}{l}\text { R. Greiner } \\
\text { Technical Univ. of Graz, Austria }\end{array}$ & $\begin{array}{l}\text { P. Schaumann } \\
\text { Univ. of Hannover, Germany }\end{array}$ \\
\hline $\begin{array}{l}\text { L. Gardner } \\
\text { Imperial College of Science, Technology and Medicine, UK }\end{array}$ & $\begin{array}{l}\text { Y.J. Shi } \\
\text { Tsinghua Univ., China }\end{array}$ \\
\hline $\begin{array}{l}\text { Y. Goto } \\
\text { Nagoya Institute of Technology, Japan }\end{array}$ & $\begin{array}{l}\text { G.P. Shu } \\
\text { Southeast Univ. China }\end{array}$ \\
\hline
\end{tabular}

\section{Advanced Steel \\ Construction an international journal}

L. Simões da Silva

Department of Civil Engineering, University of Coimbra, Portugal

J.G. Teng

The Hong Kong Polyt. Univ., Hong Kong, China

G.S. Tong

Zhejiang Univ., China

K.C. Tsai

National Taiwan Univ., Taiwan, China

C.M. Uang

Univ. of California, USA

B. Uy

University of Western Sydney, Australia

M. Veljkovic

Univ. of Lulea, Sweden

F. Wald

Czech Technical Univ. in Prague, Czech

Y.C. Wang

The Univ. of Manchester, UK

Y.L. Xu

The Hong Kong Polyt. Univ., Hong Kong, China

D. White

Georgia Institute of Technology, USA

E. Yamaguch

Kyushu Institute of Technology, Japan

Y.B. Yang

National Taiwan Univ., Taiwan, China

Y.Y. Yang

China Academy of Building Research, Beijing, China

B. Young

The Univ. of Hong Kong, Hong Kong, China

X.L. Zhao

Monash Univ., Australia

X.H. Zhou

Chongqing University, China

Z.H. Zhou

The Hong Kong Polyt. Univ., Hong Kong, China

S.Y. Zhu

The Hong Kong Polyt. Univ., Hong Kong, China

R.D. Ziemian

Bucknell Univ., USA

Cover: Project: Dount; Structural Engineers: Xin Y; Architect: AAl; Client: Vanke; Co-design: Beiyang Design

Principal Contractor: Beijing Shengshiwei; Curtain Consultant: CAC Shanghai; Photo Cvanke

e-copy of IJASC is free to download at "www.ascjournal.com" in internet and mobile apps. 


\section{General Information Advanced Steel Construction, an international journal}

\section{Aims and scope}

The International Journal of Advanced Steel Construction provides a platform for the publication and rapid dissemination of original and up-to-date research and technological developments in steel construction, design and analysis. Scope of research papers published in this journal includes but is not limited to theoretical and experimental research on elements, assemblages, systems, material, design philosophy and codification, standards, fabrication, projects of innovative nature and computer techniques. The journal is specifically tailored to channel the exchange of technological know-how between researchers and practitioners. Contributions from all aspects related to the recent developments of advanced steel construction are welcome. 


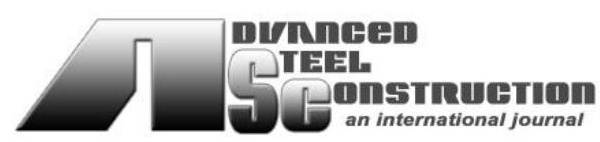

ISSN 1816-112X

Science Citation Index Expanded, Materials Science Citation Index and ISI Alerting

\section{EDITORS-IN-CHIEF}

\section{Asian Pacific, African and organizing Editor}

S.L. Chan

The Hong Kong Polyt. Univ., Hong Kong, China

Email: ceslchan@polyu.edu.hk

\section{American Editor}

W.F. Chen

Univ. of Hawaii at Manoa, USA

Email:waifah@hawaii.edu

\section{European Editor}

R. Zandonini

Trento Univ., Italy

Email: riccardo.zandonini@ing.unitn.it

\section{Advanced Steel Construction an international journal}

VOLUME 17 NUMBER 2

June 2021

Technical Papers

Equivalent Properties for Analysis as Beam-Column of Steel Spatial Lattices of 95 Rectangular Cross-Section

Alberto M. Guzmán* and Victor A. Roldan

Study on Micromechanical Fracture Models of Structural Steel and Its Welds 104 Xi-Yue Liu, Yuan-Qing Wang, Yi-Du Bu* and Yang Guan

Numerical Study and Design Method of High Strength Steel Welded Box 127 Columns

Yong-Jun Lin, Kai-Qi Liu, Tian-Ji Li and Yi Zhou*

Experimental Study on The Mechanical Behaviour of Q345 Steel High-Strength 136 Bolt Bearing-Type Connections

Jing-Yao Li, Shi-Dong Nie*, Jia Zeng and Bo Yang

Experiment of Hysteretic Behavior and Stability Performance of 149 Buckling-Restrained Braced Composite Frame

Ming-Ming Jia*, Liang Li, Cheng Hong, Kai Liu and Lin Sun

Axial Behavior of High-Strength Concrete-Filledhigh-Strength Square Steel 158 Tubular Stub Columns

Guo-Chang Li, Bo-Wen Chen, Zhi-Jian Yang*, Han-bin Ge and Xiao Li

Damping Performance Experiment and Damage Analysis of Replacement 169 Connection with Low-Yield-Point Steel

Hao-Xiang He*, Li-Can Liao and Shi-Tao Cheng

Design Optimization of Lattice Girders According to Member and Joint-Related 181 Design Constraints

Tugrul Talaslioglu

Progressive Collapse Mechanism of Steel Framed-Structures Subjected to A 199 Middle-Column Loss

Wen-Jin Zhang, Guo-Qiang Li and Jing-Zhou Zhang*

Line-Element Formulation for Upheaval Buckling Analysis of Buried Subsea 210 Pipelines Due to Thermal Expansion

Ji-Hui Ning, Si-Wei Liu, Jian-Hong Wan and Wei Huang* 



\title{
EQUIVALENT PROPERTIES FOR ANALYSIS AS BEAM-COLUMN OF STEEL SPATIAL LATTICES OF RECTANGULAR CROSS-SECTION
}

\author{
Alberto M. Guzmán * and Victor A. Roldan \\ CeReDeTeC, Facultad Regional Mendoza, Universidad Tecnológica Nacional, Mendoza, Argentina \\ * (Corresponding author: E-mail: mguzman@frm.utn.edu.ar)
}

\section{A B S T R A C T}

Space lattices are widely used in various metal structural systems to form elements such as columns, beams, trusses, among others. These lattices are also used, for example, within the telecommunications industry to constitute the mast that support the transmission devices. The spatial lattices have a large number of elements (legs, diagonals and struts). For its representation the equivalent beam-column model is very convenient, due to its low cost and computational effort. In previous studies, the author's analyze of spatial lattice of triangular cross-section, have obtained continuous representation models from an energetic approach, as well as the equivalent properties for the modeling of lattice as beam-columns. Also adopting an energy approach, the study of four spatial lattice patterns of rectangular cross-section (Pattern 1,2,3 and 4) is carried out, obtaining the elastic properties and equivalent inertias necessary for the representation of the problem as column-beam. For the purpose of validating the proposed method, several numerical examples of spatial lattice implementing the beam-column model were evaluated. The results reached allow us to establish an excellent performance of the equivalent properties obtained for each of the lattices patterns considered, with the advantage of the low computation al cost involved in its implementation, modeling and processing.
A R T I C L E H I S T O R Y

$\begin{array}{ll}\text { Received: } & 22 \text { April } 2020 \\ \text { Revised: } & \text { 11 December } 2020 \\ \text { Accepted: } & \text { 12 December } 2020\end{array}$

\section{K E Y W O R D S}

Spatial lattices;

Rectangular cross-section

Beam-column;

Equivalent properties

\section{Copyright $\odot 2021$ by The Hong Kong Institute of Steel Construction. All rights reserved.}

\section{Introduction}

Spatial lattice structures are structures made up of a large number of simple elements such as legs, diagonals and struts. Due to this large number of elements that are part of the lattices, numerical modeling can involve significant computational effort and cost.

Several authors have developed and proposed continuous models for the representation of plane lattices, [1,2,3,4,5], while others, are based on an energetic approach, have developed continuous models for the representation of spatial lattices $[6,7,8]$. But the main research has been aimed at developing simplified representation models that allow less effort and computational cost at the time of structural analysis of spatial lattices. In this sense, we can cite [7] who developed a continuous 1D model for the representation of a spatial lattice of triangular cross-section used to support satellites solar panels. Or also the continuous 1D model developed by [9] for the dynamic, static and stability analysis of spatial lattices of triangular cross-section. Both indicated models were obtained from an energy statement.

As an alternative to the use of continuous 1D models, some authors have developed equivalent models for the discrete representation of spatial lattices $[10,11,12]$. In these developments, the equivalent elastic properties were obtained for the representation of the lattice as beam-column. In this particular case of what was developed by [9], equivalent elastic and inertia properties were obtained, allowing the dynamic and static analysis of spatial lattices of triangular cross- section. Four different lattice patterns were considered in the analysis.

These equivalent models of representation can be applied to various structural systems consisting of spatial lattices. For example, Páez and Sensale [13] analyzed a guyed mast against wind loads, modeling the mast as a beamcolumn and the guys as non-linear elastic springs. The equivalent properties adopted [14] corresponding only to elastic properties and without considering the rotational stiffness of the lattice.

The continuous 3D model presented by [8] was developed from an energetic approach, obtaining a system of 9 differential equations (9DE) for the representation of the structural behavior of a spatial lattice of triangular crosssection. From this model, [9] obtained a simplified 1D continuous model (6DE) by reducing the kinematics of the problem to the barycentric axis of the lattice.

As previously indicated, the developed models allow the representation of spatial lattices of triangular cross-section. For this reason and continuing with the developed energy methodology [9], the study of four spatial lattice patterns of rectangular cross-section (Pattern 1, 2, 3 and 4) is carried out, obtaining the elastic properties and equivalent inertias necessary for the representation of the problem as column-beam.

The interest in developing simplified models of representation of spatial lattices of rectangular cross-section, is mainly due to the fact that they are widely used to constitute various structural systems such as columns, beams, trusses, among others. (Fig. 1).

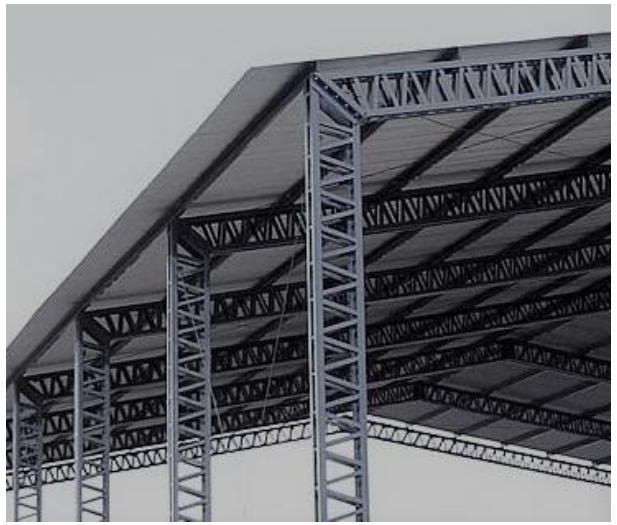

Fig. 1 Lattices of rectangular cross-section

In this way, the development of a simplified representation such that of the equivalent beam-column model, contributes to a significant time savings of modeling and computational processing of structural systems formed by lattices of rectangular cross-section.

\section{Lattices analyzed}

Four lattice patterns (Pattern 1, 2, 3 and 4) of rectangular cross-section of sides $B$ and $D$ are analyzed (Fig. 2)

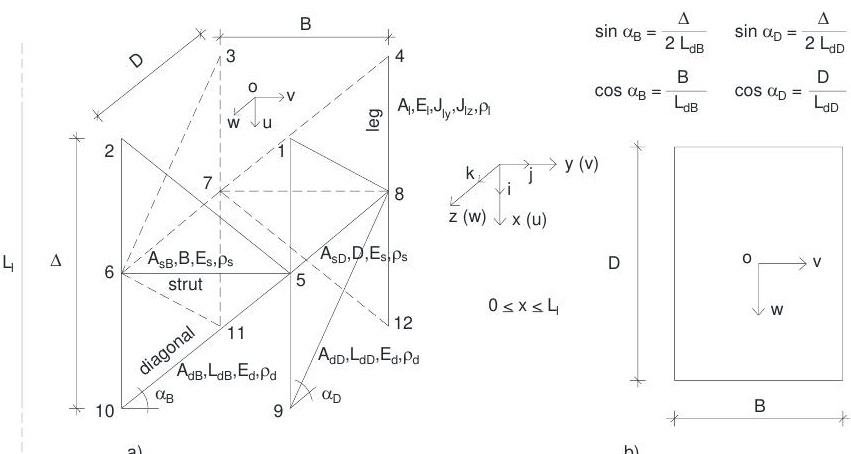

Fig. 2 Lattice analyzed. a) General view. b) Section view 
Pattern 1 has zig-zag diagonals, Pattern 2 incorporates struts to the previous diagonalization, while Pattern 3 has double zig-zag diagonalization, and finally, Pattern 4 incorporates struts to the latter (Fig. 3).

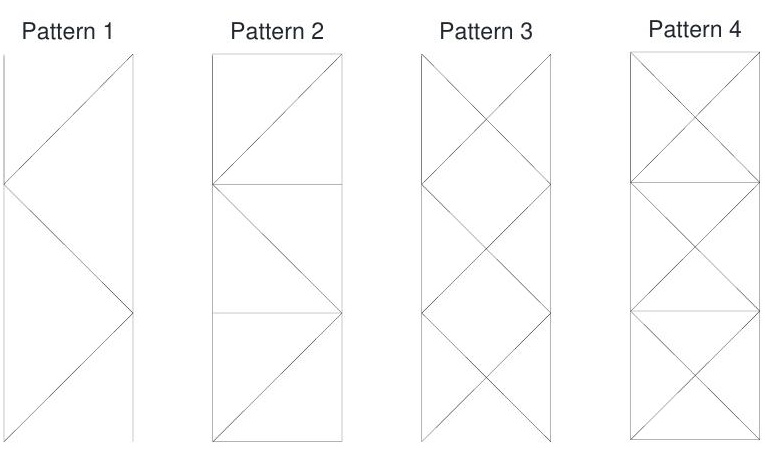

Fig. 3 Patterns considered

\section{Energy approach for the analyzed spatial lattice}

For the energy approach, it is initially considered that the spatial lattice is in an equilibrium configuration. When an external action acts upon it, it is deformed adopting a new equilibrium configuration. Given this, the lattice nodes experienced kinematically admissible displacements in the main directions. These displacements cause the elements that are part of the lattice to develop energy contributions [8].

From this approach, the energy expressions presented below, correspond to the energies developed by the elements (legs and diagonals) that are part of the spatial lattice of rectangular cross-section with a diagonal pattern of type Pattern 1 (Fig. 3).

\subsection{Elastic deformation energy}

$U=\frac{1}{2} \frac{E_{d} A_{d B}}{L_{d B} \Delta} \int_{0}^{L_{l}}\left(A_{1 B} \sin ^{2} \alpha_{B}+A_{2 B} \cos ^{2} \alpha_{B}+A_{3 B} \sin \alpha_{B} \cos \alpha_{B}\right) d x+$

$+\frac{1}{2} \frac{E_{d} A_{d D}}{L_{d D} \Delta} \int_{0}^{L_{l}}\left(A_{1 D} \sin ^{2} \alpha_{D}+A_{2 D} \cos ^{2} \alpha_{D}+A_{3 D} \sin \alpha_{D} \cos \alpha_{D}\right) d x+$

$\frac{1}{2} E_{l} A_{l} \int_{0}^{L_{l}} A_{4} d x+\frac{1}{2} E_{l} J_{l y} \int_{0}^{L_{l}} A_{5} d x+\frac{1}{2} E_{l} J_{l z} \int_{0}^{L_{l}} A_{6} d x$

in which the coefficients are:

$A_{1 B}=2 \mathrm{u}_{\mathrm{j}}(\mathrm{x}, \mathrm{t}) \mathrm{u}_{\mathrm{j}}(\mathrm{x}, \mathrm{t})-4\left(\mathrm{u}_{\mathrm{a}}(\mathrm{x}, \mathrm{t}) \mathrm{u}_{\mathrm{b}}(\mathrm{x}, \mathrm{t})+\mathrm{u}_{\mathrm{c}}(\mathrm{x}, \mathrm{t}) \mathrm{u}_{\mathrm{d}}(\mathrm{x}, \mathrm{t})\right)+$

$+\frac{1}{2}\left(\mathrm{u}_{\mathrm{b}}^{\prime 2}(\mathrm{x}, \mathrm{t})+\mathrm{u}_{\mathrm{d}}^{\prime 2}(\mathrm{x}, \mathrm{t})\right) \Delta^{2}$

$A_{2 B}=2 \mathrm{v}_{\mathrm{j}}(\mathrm{x}, \mathrm{t}) \mathrm{v}_{\mathrm{j}}(\mathrm{x}, \mathrm{t})-4\left(\mathrm{v}_{\mathrm{a}}(\mathrm{x}, \mathrm{t}) \mathrm{v}_{\mathrm{b}}(\mathrm{x}, \mathrm{t})+\mathrm{v}_{\mathrm{c}}(\mathrm{x}, \mathrm{t}) \mathrm{v}_{\mathrm{d}}(\mathrm{x}, \mathrm{t})\right)+$

$+\frac{1}{2}\left(\mathrm{v}_{\mathrm{b}}^{\prime 2}(\mathrm{x}, \mathrm{t})+\mathrm{v}_{\mathrm{d}}^{\prime 2}(\mathrm{x}, \mathrm{t})\right) \Delta^{2}$

$A_{3 B}=2\left[\left(\mathrm{u}_{\mathrm{a}}(\mathrm{x}, \mathrm{t})-\mathrm{u}_{\mathrm{b}}(\mathrm{x}, \mathrm{t})\right) v_{b}^{\prime}(x, t)-\left(\mathrm{u}_{\mathrm{c}}(\mathrm{x}, \mathrm{t})-\mathrm{u}_{\mathrm{d}}(\mathrm{x}, \mathrm{t})\right) v_{d}^{\prime}(x, t)+\right.$

$\left.\left(\mathrm{v}_{\mathrm{a}}(\mathrm{x}, \mathrm{t})-\mathrm{v}_{\mathrm{b}}(\mathrm{x}, \mathrm{t})\right) u_{b}^{\prime}(x, t)-\left(\mathrm{v}_{\mathrm{c}}(\mathrm{x}, \mathrm{t})-\mathrm{v}_{\mathrm{d}}(\mathrm{x}, \mathrm{t})\right) u_{d}^{\prime}(x, t)\right] \Delta$

$A_{1 D}=2 \mathrm{u}_{\mathrm{j}}(\mathrm{x}, \mathrm{t}) \mathrm{u}_{\mathrm{j}}(\mathrm{x}, \mathrm{t})-4\left(\mathrm{u}_{\mathrm{a}}(\mathrm{x}, \mathrm{t}) \mathrm{u}_{\mathrm{d}}(\mathrm{x}, \mathrm{t})+\mathrm{u}_{\mathrm{b}}(\mathrm{x}, \mathrm{t}) \mathrm{u}_{\mathrm{c}}(\mathrm{x}, \mathrm{t})\right)+$

$+\frac{1}{2}\left(\mathrm{u}_{\mathrm{a}}^{\prime 2}(\mathrm{x}, \mathrm{t})+\mathrm{u}_{\mathrm{c}}^{\prime 2}(\mathrm{x}, \mathrm{t})\right) \Delta^{2}$

$A_{2 D}=2 \mathrm{w}_{\mathrm{j}}(\mathrm{x}, \mathrm{t}) \mathrm{w}_{\mathrm{j}}(\mathrm{x}, \mathrm{t})-4\left(\mathrm{w}_{\mathrm{a}}(\mathrm{x}, \mathrm{t}) \mathrm{w}_{\mathrm{d}}(\mathrm{x}, \mathrm{t})+\mathrm{w}_{\mathrm{b}}(\mathrm{x}, \mathrm{t}) \mathrm{w}_{\mathrm{c}}(\mathrm{x}, \mathrm{t})\right)+$

$+\frac{1}{2}\left(\mathrm{w}_{\mathrm{a}}^{\prime 2}(\mathrm{x}, \mathrm{t})+\mathrm{w}_{\mathrm{c}}^{\prime 2}(\mathrm{x}, \mathrm{t})\right) \Delta^{2}$

$A_{3 D}=2\left[\left(\mathrm{u}_{\mathrm{a}}(\mathrm{x}, \mathrm{t})-\mathrm{u}_{\mathrm{d}}(\mathrm{x}, \mathrm{t})\right) w_{a}^{\prime}(x, t)-\left(\mathrm{u}_{\mathrm{b}}(\mathrm{x}, \mathrm{t})-\mathrm{u}_{\mathrm{c}}(\mathrm{x}, \mathrm{t})\right) w_{c}^{\prime}(x, t)+\right.$

$\left.\left(\mathrm{w}_{\mathrm{a}}(\mathrm{x}, \mathrm{t})-\mathrm{w}_{\mathrm{d}}(\mathrm{x}, \mathrm{t})\right) u_{a}^{\prime}(x, t)-\left(\mathrm{w}_{\mathrm{b}}(\mathrm{x}, \mathrm{t})-\mathrm{w}_{\mathrm{c}}(\mathrm{x}, \mathrm{t})\right) u_{c}^{\prime}(x, t)\right] \Delta$

$A_{4}=u_{j}^{\prime}(x, t) u_{j}^{\prime}(x, t)$

$A_{5}=v_{j}^{\prime \prime}(x, t) v_{j}^{\prime \prime}(x, t)$

$A_{6}=w_{j}^{\prime \prime}(x, t) w_{j}^{\prime \prime}(x, t)$ where the notation has been used: $(\boldsymbol{\square})^{\prime} \equiv \frac{\partial(\boldsymbol{\bullet})}{\partial x} ;(\boldsymbol{\square})^{\prime \prime} \equiv \frac{\partial^{2}(\boldsymbol{\bullet})}{\partial x^{2}} ; j=a, b, c, d$

3.2. Energy by the external work of the acting loads

3.2.1. Sefl-weight

$W_{p}=p_{j} \int_{0}^{L_{l}} u_{j}(x, t) d x$

3.2.2. Concentrated loads acting on the legst

$W_{P}=p_{u j}(t) u_{j}(x, t)+p_{v j}(t) v_{j}(x, t)+p_{w j}(t) w_{j}(x, t)$

3.2.3. Distributed loads acting on the legst

$W_{q}=\int_{0}^{L_{l}}\left(q_{u j}(x, t) u_{j}(x, t)+q_{v j}(x, t) v_{j}(x, t)+q_{w j}(x, t) w_{j}(x, t)\right) d x$

3.2.4. Local moments acting on the legst

$W_{m}=M_{v j}(t) w_{j}^{\prime}(x, t)+M_{w j}(t) v_{j}^{\prime}(x, t)$

3.2.5. Second order effect by self-weight and by axial loads applied on the legs $W_{2^{\circ}}=\frac{1}{2} P_{u j}(t) \int_{0}^{L_{l}}\left[\left(v_{j}^{\prime}(x, t)\right)^{2}+\left(w_{j}^{\prime}(x, t)\right)^{2}\right] d x+$ $+\frac{1}{2} p_{j}(t) \int_{0}^{L_{l}}\left[\left(v_{j}^{\prime}(x, t)\right)^{2}+\left(w_{j}^{\prime}(x, t)\right)^{2}\right] x d x$

where has been defined: $p_{j}=\rho_{l} g A_{l}+\frac{1}{2} \rho_{d} g\left(\frac{A_{d B}}{\sin \alpha_{B}}+\frac{A_{d D}}{\sin \alpha_{D}}\right)$

and the notation has been used: $(\mathbf{\square})^{\prime} \equiv \frac{\partial(\mathbf{\bullet})}{\partial x} ;(\mathbf{\square})^{\prime \prime} \equiv \frac{\partial^{2}(\mathbf{\bullet})}{\partial x^{2}} ; j=a, b, c, d$

3.3. Kinetic energy

$T=\frac{1}{3} \rho_{d} A_{d B} \frac{L_{d B}}{\Delta} \int_{0}^{L_{l}}\left(B_{1 B}+B_{2 B}\right) d x+\frac{1}{3} \rho_{d} A_{d D} \frac{L_{d D}}{\Delta} \int_{0}^{L_{l}}\left(B_{1 D}+B_{2 D}\right) d x+$

$+\frac{1}{2} \rho_{l} A_{l} \int_{0}^{L_{l}} B_{3} d x+\frac{1}{2} \rho_{l} J_{l y} \int_{0}^{L_{l}} B_{4} d x+\frac{1}{2} \rho_{l} J_{l z} \int_{0}^{L_{l}} B_{5} d x$

in which the coefficients are:

$B_{1 B}=\dot{u}_{j}(x, t) \dot{u}_{j}(x, t)+\dot{v}_{j}(x, t) \dot{v}_{j}(x, t)+\dot{w}_{j}(x, t) \dot{w}_{j}(x, t)+$

$+\dot{u}_{a}(x, t) \dot{u}_{b}(x, t)+\dot{v}_{a}(x, t) \dot{v}_{b}(x, t)+\dot{w}_{a}(x, t) \dot{w}_{b}(x, t)+$

$+\dot{u}_{c}(x, t) \dot{u}_{d}(x, t)+\dot{v}_{c}(x, t) \dot{v}_{d}(x, t)+\dot{w}_{c}(x, t) \dot{w}_{d}(x, t)$

$B_{2 B}=\frac{1}{4}\left(\dot{u}_{b}^{\prime 2}(x, t)+\dot{v}_{b}^{\prime 2}(x, t)+\dot{w}_{b}^{\prime 2}(x, t)+\dot{u}_{d}^{\prime 2}(x, t)+\dot{v}_{d}^{\prime 2}(x, t)+\right.$

$\left.+\dot{w}_{d}^{\prime 2}(x, t)\right) \Delta^{2}$

$B_{1 D}=\dot{u}_{j}(x, t) \dot{u}_{j}(x, t)+\dot{v}_{j}(x, t) \dot{v}_{j}(x, t)+\dot{w}_{j}(x, t) \dot{w}_{j}(x, t)+$

$+\dot{u}_{a}(x, t) \dot{u}_{d}(x, t)+\dot{v}_{a}(x, t) \dot{v}_{d}(x, t)+\dot{w}_{a}(x, t) \dot{w}_{d}(x, t)+$

$+\dot{u}_{b}(x, t) \dot{u}_{c}(x, t)+\dot{v}_{b}(x, t) \dot{v}_{c}(x, t)+\dot{w}_{b}(x, t) \dot{w}_{c}(x, t)$

$B_{2 D}=\frac{1}{4}\left(\dot{u}_{a}^{\prime 2}(x, t)+\dot{v}_{a}^{\prime 2}(x, t)+\dot{w}_{a}^{\prime 2}(x, t)+\dot{u}_{c}^{\prime 2}(x, t)+\dot{v}_{c}^{\prime 2}(x, t)+\right.$ $\left.+\dot{w}_{c}^{\prime 2}(x, t)\right) \Delta^{2}$

where the notation has been used: $(\dot{\boldsymbol{\square}}) \equiv \frac{\partial(\boldsymbol{\bullet})}{\partial t} ; j=a, b, c, d$

It should be noted that if we apply the Hamilton's principle to the Lagrangian $L$ of the system with the determined energy expressions, a continuous 3D model is obtained constituted of 12 differential equations (12DE) that represent the behavior of spatial lattice of rectangular cross-section.

But on the other hand, with the determined expressions as it will be seen in the next section, we obtain a simplified 1D continuous model of representation. This 1D model leads to obtaining the equivalent properties necessary for the representation of the lattice as a discrete beam-column model.

\section{Continuous 1D model}

The continuous 3D representation model for the spatial lattice of rectangular cross-section has particularity that of the $12 \mathrm{DE}$ system coupled to each other, which makes its numerical resolution more complex. Given the fact that, a valid alternative for a simplified representation is the construction of a continuous 1D model. In this case, the model is made up of a 6 DE system, with 
a simpler numerical resolution than that of the 3D model.

From this continuous 1D model and as previously stated, it is possible to obtain the equivalent properties necessary for the representation of the spatial lattice as a discrete beam-column model. This last form of representation constitutes the simplest model capable of numerically evaluating the mechanical behavior of spatial lattice, with a very low computational cost.

The development of a simplified 1D continuous model involves first defining a displacement field that allows the displacements of any point $P$ located on the cross-section of the lattice (Fig. 4) to be related to the displacements experienced by the barycentric axis $o$ of the section.
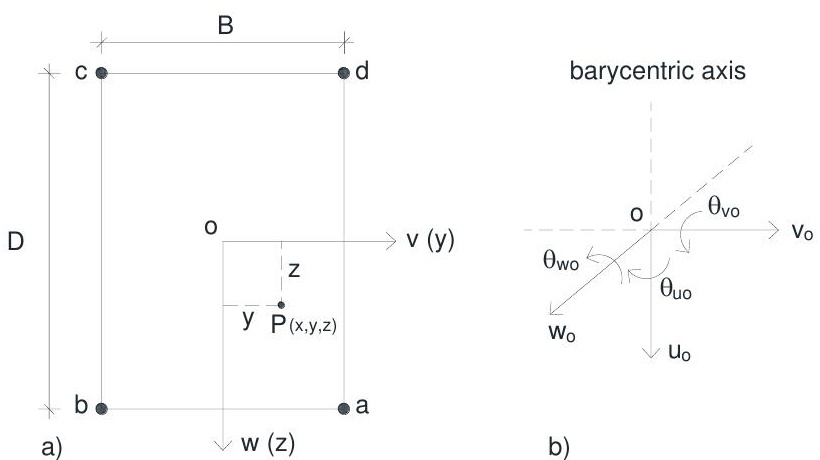

Fig. 4 a) Arbitrary point $P$. b) Sign convention (positive)

Thus, the displacement field is:

$$
\begin{aligned}
& u(x, y, z, t)=u_{o}(x, t)-\theta_{w o}(x, t) y+\theta_{v o}(x, t) z \\
& v(x, y, z, t)=v_{o}(x, t)-\theta_{u o}(x, t) z \\
& w(x, y, z, t)=w_{o}(x, t)+\theta_{u o}(x, t) y
\end{aligned}
$$

At this point, it has been assumed that displacements present linear variation and that torsional warping is not considered.

The six unknown functions represent:

. $u_{o}$ ( $x$ direction) the axial displacement

. $v_{\mathrm{o}}$ and $w_{\mathrm{o}}$ ( $y$ and $z$ directions, respectively) the transverse displacements

. $\theta_{\text {uо }}$ (around the $x$ axis) the torsional slop

. $\theta_{\mathrm{vo}}$ and $\theta_{\mathrm{wo}}$ (around the $y$ and $z$ axes, respectively) the bending slopes with which, the displacements of each leg can be expressed as follows:

$$
\begin{aligned}
& u_{a}(x, t)=u_{o}(x, t)-\theta_{w o}(x, t) \frac{B}{2}+\theta_{v o}(x, t) \frac{D}{2} \\
& u_{b}(x, t)=u_{o}(x, t)+\theta_{w o}(x, t) \frac{B}{2}+\theta_{v o}(x, t) \frac{D}{2} \\
& u_{c}(x, t)=u_{o}(x, t)+\theta_{w o}(x, t) \frac{B}{2}-\theta_{v o}(x, t) \frac{D}{2} \\
& u_{d}(x, t)=u_{o}(x, t)-\theta_{w o}(x, t) \frac{B}{2}-\theta_{v o}(x, t) \frac{D}{2} \\
& v_{a}(x, t)=v_{o}(x, t)-\theta_{u o}(x, t) \frac{D}{2} \\
& v_{b}(x, t)=v_{o}(x, t)-\theta_{u o}(x, t) \frac{D}{2} \\
& v_{c}(x, t)=v_{o}(x, t)+\theta_{u o}(x, t) \frac{D}{2} \\
& v_{d}(x, t)=v_{o}(x, t)+\theta_{u o}(x, t) \frac{D}{2} \\
& w_{a}(x, t)=w_{o}(x, t)+\theta_{u o}(x, t) \frac{B}{2} \\
& w_{b}(x, t)=w_{o}(x, t)-\theta_{u o}(x, t) \frac{B}{2} \\
& w_{c}(x, t)=w_{o}(x, t)-\theta_{u o}(x, t) \frac{B}{2} \\
& w_{d}(x, t)=w_{o}(x, t)+\theta_{u o}(x, t) \frac{B}{2}
\end{aligned}
$$

Replacing these displacements obtained for the legs (Eqs. 11) in the energy expressions corresponding to the 3D model (Eqs. 1, 3 to 8), we obtain the energy expressions referring to the barycentric axis of the cross-section, that is, the energy expressions of the 1D model.

On the other hand the Lagrangian $\left(L_{o}\right)$ of the simplified system results:

$L_{o}=V_{o}-T_{o}$

where $V_{o}=\left(U_{o}-W_{o}\right)$ and $T_{o}$ are the potential and the kinetic energies, respectively, of $1 \mathrm{D}$ model. Whereas $U_{o}$ is the elastic deformation energy, and $W_{o}$ is the work of external loads.
Thus, applying the Hamilton's principle to the Lagrangian $L_{o}$ (Eq. 12), we obtain a system of differential and linear equations (6DE) in the variables $x$ and $t$, that represents the behavior of the lattice analyzed in the continuous domain (1D model).

$(E A)_{o 1} u_{o}^{\prime \prime}(x, t)-(\rho A)_{o 1} \ddot{u}_{o}(x, t)+r_{d o 1} \ddot{u}_{o}^{\prime \prime}(x, t)-4\left(p_{o}+q_{u o}(x, t)\right)=0(13)$

$4 E_{l} J_{l y} v_{o}^{\prime \prime}(x, t)-\left(G A_{B}\right)_{o 1}\left(v_{o}^{\prime \prime}(x, t)-\theta_{w o}^{\prime}(x, t)\right)+4\left(P_{u o}(t)+\right.$

$\left.p_{o} x\right) v_{o}^{\prime \prime}(x, t)+4 p_{o} v_{o}^{\prime}(x, t)+(\rho A)_{o 1} \ddot{v}_{o}(x, t)-\left(4 \rho_{l} J_{l y}+r_{d o 1}\right) \ddot{v}_{o}^{\prime \prime}(x, t)-$

$-q_{v o}(x, t)=0$

$4 E_{l} J_{l z} w_{o}^{\prime \prime}(x, t)-\left(G A_{D}\right)_{o 1}\left(w_{o}^{\prime \prime}(x, t)+\theta_{v o}^{\prime}(x, t)\right)+4\left(P_{u o}(t)+\right.$ $\left.p_{o} x\right) w_{o}^{\prime \prime}(x, t)+4 p_{o} w_{o}^{\prime}(x, t)+(\rho A)_{o 1} \ddot{w}_{o}(x, t)-\left(4 \rho_{l} J_{l z}+r_{d o 1}\right) \ddot{w}_{o}^{\prime \prime}(x, t)-$

$-4 q_{w o}(x, t)=0$

$E_{l}\left(J_{l y} D^{2}+J_{l z} B^{2}\right) \theta_{u o}^{\prime \prime \prime \prime}(x, t)-\left(G J_{x}\right)_{01}-\left[\left(P_{u o}(t)+p_{o} x\right)\left(D^{2}+\right.\right.$

$\left.\left.B^{2}\right)\right] \theta_{u o}^{\prime \prime}(x, t)+p_{o}\left(D^{2}+B^{2}\right) \theta_{u o}^{\prime}(x, t)+\left(\rho J_{x}\right)_{o 1} \ddot{\theta}_{u o}(x, t)-\left[\rho_{l}\left(J_{l y} D^{2}+\right.\right.$

$\left.\left.J_{l z} B^{2}\right)+\frac{1}{4} r_{d o 1}\left(D^{2}+B^{2}\right)\right] \ddot{\theta}_{u o}^{\prime \prime}(x, t)=0$

$\frac{1}{4}(E A)_{01} D^{2} \theta_{v o}^{\prime \prime}(x, t)-\left(G A_{D}\right)_{o 1}\left(w_{o}^{\prime}(x, t)+\theta_{v o}(x, t)\right)-\left(\rho J_{x D}\right)_{o 1} \ddot{\theta}_{v o}(x, t)+$ $+\frac{1}{4} r_{d o 1} D^{2} \ddot{\theta}_{v o}^{\prime \prime}(x, t)-\frac{1}{2}\left(A_{d D} \sin ^{3} \alpha_{D}-A_{d B} \sin ^{3} \alpha_{B}\right) B D \theta_{w o}^{\prime \prime}(x, t)-$

$-\frac{1}{48} \rho_{d}\left(\frac{A_{d D}}{\sin \alpha_{D}}-\frac{A_{d B}}{\sin \alpha_{B}}\right) B D \Delta^{2} \ddot{\theta}_{w o}^{\prime \prime}(x, t)=0$

$\frac{1}{4}(E A)_{01} B^{2} \theta_{w o}^{\prime \prime}(x, t)-\left(G A_{B}\right)_{o 1}\left(v_{o}^{\prime}(x, t)-\theta_{w o}(x, t)\right)-\left(\rho J_{x B}\right)_{o 1} \ddot{\theta}_{w o}(x, t)+$ $+\frac{1}{4} r_{d o 1} B^{2} \ddot{\theta}_{w o}^{\prime \prime}(x, t)-\frac{1}{2}\left(A_{d D} \sin ^{3} \alpha_{D}-A_{d B} \sin ^{3} \alpha_{B}\right) B D \theta_{v o}^{\prime \prime}(x, t)-$

$-\frac{1}{48} \rho_{d}\left(\frac{A_{d D}}{\sin \alpha_{D}}-\frac{A_{d B}}{\sin \alpha_{B}}\right) B D \Delta^{2} \ddot{\theta}_{v o}^{\prime \prime}(x, t)=0$

The introduced notation $(E A)_{o l},(G A B)_{o l},(G A D)_{o l},(G J x)_{o l},(\rho A)_{o l},(\rho J x)_{o l}$ $=\left(\rho J_{x D}\right)_{o l}+\left(\rho J_{x B}\right)_{o l}$ and $r_{d o l}$, correspond to the equivalent beam-column properties presented in the following section. The subscript $o$ represents the reference with respect to the barycentric axis of the cross-section, while subscript 1 represents the type of diagonalization pattern analyzed.

\section{Equivalent properties for the beam-column model}

The notation introduced in the expressions of the differential system (Eqs. 13 to 18 ) represents the beam-column equivalent properties corresponding to Pattern 1, which result:

$(E A)_{01}=4 E_{l} A_{l}+\frac{1}{2} E_{d}\left(A_{d D} \sin ^{3} \alpha_{D}+A_{d B} \sin ^{3} \alpha_{B}\right)$

$\left(G A_{B}\right)_{01}=2 E_{d} A_{d B} \sin \alpha_{B} \cos ^{2} \alpha_{B}$

$\left(G A_{D}\right)_{01}=2 E_{d} A_{d D} \sin \alpha_{D} \cos ^{2} \alpha_{D}$

$\left(G J_{x}\right)_{01}=\frac{1}{4}\left(\left(G A_{B}\right)_{01} D^{2}+\left(G A_{D}\right)_{01} B^{2}\right)$

$(\rho A)_{01}=4 \rho_{l} A_{l}+2 \rho_{d}\left(\frac{A_{d D}}{\sin \alpha_{D}}+\frac{A_{d B}}{\sin \alpha_{B}}\right)$

$\left(\rho J_{x}\right)_{01}=\left(\rho J_{x B}\right)_{01}+\left(\rho J_{x D}\right)_{01}$

$\left(\rho J_{x B}\right)_{01}=\left[\rho_{l} A_{l}+\frac{1}{6} \rho_{d}\left(3 \frac{A_{d D}}{\sin \alpha_{D}}+\frac{A_{d B}}{\sin \alpha_{B}}\right)\right] B^{2}$

$\left(\rho J_{x D}\right)_{01}=\left[\rho_{l} A_{l}+\frac{1}{6} \rho_{d}\left(\frac{A_{d D}}{\sin \alpha_{D}}+3 \frac{A_{d B}}{\sin \alpha_{B}}\right)\right] D^{2}$

$(E A)_{o l},\left(G A_{B}\right)_{o l},\left(G A_{D}\right)_{o l}$ and $\left(G J_{x}\right)_{o l}$ are the axial, shear (directions $y$ and $z$ ) and torsional stiffness, while $(\rho A)_{o l}$ is the translational inertia and $\left(\rho J_{x}\right)_{o l}=$ $\left(\rho J_{x D}\right)_{o l}+\left(\rho J_{x B}\right)_{o l}$ is the global torsional inertia of the system (Pattern 1) with respect to the centroid axis. Regarding the term $r_{d o l}$, it is related to the inertial contribution of the diagonals: 
$r_{d 01}=\frac{1}{6} \rho_{d}\left(\frac{A_{d D}}{\sin \alpha_{D}}+\frac{A_{d B}}{\sin \alpha_{B}}\right) \Delta^{2}$

On the other hand, the relationship between $\theta_{w o}(x, t)$ and $v_{o}(x, t)$, and between $\theta_{v o}(x, t)$ and $w_{o}(x, t)$, allow the definition of the following expressions:

$\left(E J_{y}\right)_{01}=4 E_{l} J_{l y}+\frac{1}{4}(E A)_{01} B^{2}$

$\left(E J_{z}\right)_{01}=4 E_{l} J_{l z}+\frac{1}{4}(E A)_{01} D^{2}$

$\left(\rho J_{y}\right)_{01}=4 \rho_{l} J_{l y}+\left(\rho J_{x B}\right)_{01}+\frac{1}{4}(\rho A)_{01} \frac{(E A)_{01}}{\left(G A_{B}\right)_{01}} B^{2}+r_{d 01}$

$\left(\rho J_{z}\right)_{01}=4 \rho_{l} J_{l z}+\left(\rho J_{x D}\right)_{01}+\frac{1}{4}(\rho A)_{01} \frac{(E A)_{01}}{\left(G A_{D}\right)_{01}} D^{2}+r_{d 01}$

$\left(E J_{y}\right)_{o l}$ and $\left(E J_{z}\right)_{o l}$ are bending stiffness, and $\left(\rho J_{y}\right)_{o l}$ and $\left(\rho J_{z}\right)_{o l}$ are the global bending inertias with respect to the barycentric axis. Thus, expressions 19 to 31 result to be the equivalent properties necessary for the simplified modeling of the lattice as beam-column.

Following a similar mathematical development, the equivalent properties for other three diagonal patterns (Pattern 2, 3 and 4) have been derived. These will be presented in a corresponding section.

Therefore, the equivalent properties determined (elastic and inertial) for each of the diagonalization patterns analyzed (Pattern 1, 2, 3 and 4), allow to implement the simplified beam-column model for the static and dynamic evaluation of rectangular cross-section spatial lattices.

\section{Implementation of the equivalent beam-column properties}

\subsection{Lattice column}

Fig. 5 shows the lattice column (Pattern 1) to be analyzed using the equivalent beam-column (BC) model and under different boundary conditions (Fig. 6).

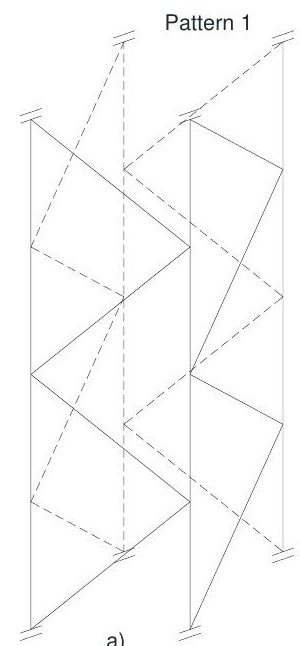

$\left(\mathrm{GA}_{\mathrm{B}}\right)_{01}$

$\left(\mathrm{GA}_{\mathrm{D}}\right)_{01}$

$\left(G J_{x}\right)_{01}$

$\left(E J_{y}\right)_{01}$

$\left(E J_{z}\right)_{01}$

$\left(E J_{z}\right)_{01}$

$(\rho \mathrm{A})_{01}$

$\left(\rho J_{x}\right)_{01}$

$\left(\rho J_{y}\right)_{01}$

$\left(\rho J_{z}\right)_{01}$

Fig. 5 Lattice column under study. a) SL-FEM model. b) BC-FEM model
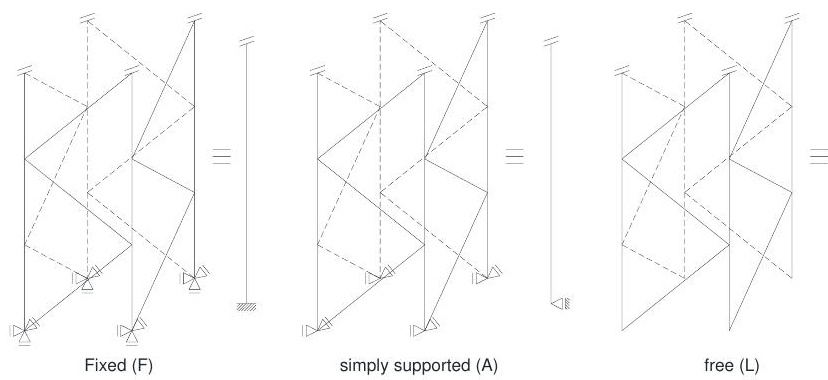

Fig. 6 Boundary conditions

For the sake of comparison, the spatial lattice is modeled with the finite element method (FEM) using a full 3D model denoted SL-FEM. Each leg is modeled using two-node beam elements, and two-node truss elements to represent the diagonals. The second FEM model named BC-FEM consist of a one dimensional beam-column representation of the lattice with equivalent properties obtained, using 6 two-node beam elements. The model was solved using the software SAP2000 [15], and the the results from static deflection and natural frequencies were compared.

The geometric and mechanical properties of the lattice analyzed are indicated in Table 1, while the equivalent beam-column properties are indicated in Table 2.

As applied loads, a transverse load is considered uniformly distributed in the $y$ and $z$ directions of value $q_{v o}=q_{w o}=200 \mathrm{~N} / \mathrm{m}$, and an axial load of value $P_{u o}=1000 \mathrm{~N}$.

Table 1

Numerical values of geometrical and mechanical properties of the analyzed lattice

\begin{tabular}{cccc}
\hline Parameter & Notation & Value & Unit \\
\hline Leg length & $\mathrm{L}_{\mathrm{l}}$ & 6.0 & $\mathrm{~m}$ \\
Diagonals separation seseparation & $\Delta$ & 0.4 & $\mathrm{~m}$ \\
Side B & $\mathrm{B}$ & 0.2 & $\mathrm{~m}$ \\
Side D & $\mathrm{D}$ & 0.4 & $\mathrm{~m}$ \\
Area of legs & $\mathrm{A}_{\mathrm{l}}$ & $2.01 \times 10^{-4}$ & $\mathrm{~m}^{2}$ \\
Area 2 ${ }^{\text {nd }}$ moment of legs & $\mathrm{J}_{\mathrm{ly}}=\mathrm{J}_{\mathrm{lz}}$ & $3.22 \times 10^{-9}$ & $\mathrm{~m}^{4}$ \\
Area of diagonals side B & $\mathrm{A}_{\mathrm{dB}}$ & $5.03 \times 10^{-5}$ & $\mathrm{~m}^{2}$ \\
Area of diagonals side D & $\mathrm{A}_{\mathrm{dD}}$ & $1.13 \times 10^{-4}$ & $\mathrm{~m}^{2}$ \\
Modulus of elasticity & $\mathrm{E}_{\mathrm{l}}=\mathrm{E}_{\mathrm{d}}$ & 200000 & $\mathrm{MPa}$ \\
Mass density & $\rho_{\mathrm{l}}=\rho_{\mathrm{d}}$ & 7850 & $\mathrm{~kg} / \mathrm{m}^{3}$ \\
\hline
\end{tabular}

Table 2

Beam-column equivalent properties for analyzed lattice

\begin{tabular}{cccc}
\hline Properties & Notation & Value & Unit \\
\hline Axial stiffnes (direction $\mathrm{x})$ & $(\mathrm{EA})_{\mathrm{o} 1}$ & $1.64 \times 10^{8}$ & $\mathrm{~N}$ \\
Shear stiffnes (direction y) seseparation & $\left(\mathrm{GA}_{\mathrm{B}}\right)_{\mathrm{o} 1}$ & $7.11 \times 10^{6}$ & $\mathrm{~N}$ \\
Shear stiffnes (direction $\mathrm{z})$ & $\left(\mathrm{GA}_{\mathrm{D}}\right)_{\mathrm{o} 1}$ & $1.62 \times 10^{7}$ & $\mathrm{~N}$ \\
Torsional stiffnes (around the $\mathrm{x}$ axis) & $\left(\mathrm{GJ}_{\mathrm{x}}\right)_{\mathrm{ol}}$ & $4.46 \times 10^{5}$ & $\mathrm{~N} \cdot \mathrm{m}^{2}$ \\
Bending stiffnes (around the $\mathrm{z}$ axis) & $\left(\mathrm{EJ}_{\mathrm{y}}\right)_{\mathrm{ol}}$ & $1.64 \times 10^{6}$ & $\mathrm{~N} \cdot \mathrm{m}^{2}$ \\
Bending stiffnes (around the y axis) & $\left(\mathrm{EJ}_{\mathrm{z}}\right)_{\mathrm{ol}}$ & $6.55 \times 10^{6}$ & $\mathrm{~N} \cdot \mathrm{m}^{2}$ \\
Translational inertia (direction $\mathrm{x})$ & $(\rho \mathrm{\rho A})_{\mathrm{o} 1}$ & $1.14 \times 10^{1}$ & $\mathrm{~kg} / \mathrm{m}$ \\
Torsional inertia (around the $\mathrm{x}$ axis) & $\left(\rho \mathrm{J}_{\mathrm{x}}\right)_{\mathrm{ol}}$ & $4.57 \times 10^{-1}$ & $\mathrm{~kg} \cdot \mathrm{m}$ \\
Bending inertia (around the z axis) & $\left(\rho \mathrm{J}_{\mathrm{y}}\right)_{\mathrm{ol}}$ & 2.80 & $\mathrm{~kg} \cdot \mathrm{m}$ \\
Bending inertia (around the y axis) & $\left(\rho \mathrm{J}_{\mathrm{z}}\right)_{\mathrm{ol}}$ & 5.03 & $\mathrm{~kg} \cdot \mathrm{m}$ \\
Inertial contribution of the diagonals & $\mathrm{r}_{\mathrm{do} 1}$ & $6.78 \times 10^{-2}$ & $\mathrm{~kg} \cdot \mathrm{m}$ \\
\hline
\end{tabular}

The results obtained by implementing the different models (SL-FEM and $\mathrm{BC}-\mathrm{FEM}$ ) are reported, allowing to establish the performance of the BC-FEM model developed.

Table 3 and 4 shows respectively the obtained values of the maximum lateral displacement in the $y\left(v_{o(\max )}\right)$ and $z\left(w_{o(\max )}\right)$ directions, for the different boundary conditions. Table 5 shows the obtained values of the maximum axial displacement in the $x$ direction $\left(u_{o(\max )}\right)$, and Table 6 shows the results obtained of the first circular frequencies for axial and bending mode types (denoted with superscripts $a$ and $b$ respectively).

Table 3

Static deflection case. Maximum transverse displacements in direction $y$

\begin{tabular}{cccc}
\hline \multirow{2}{*}{ Boundary condition } & \multicolumn{3}{c}{$\mathrm{V}_{\text {o(max) }}[\mathrm{mm}]$} \\
\cline { 2 - 4 } & SL-FEM & BC-FEM & Difference [\%] \\
\hline A-A & 2.228 & 2.186 & 1.92 \\
F-F & 0.552 & 0.538 & 2.60 \\
F-A & 1.024 & 1.002 & 2.20 \\
F-L & 20.635 & 20.276 & 1.77 \\
\hline
\end{tabular}


Table 4

Static deflection case. Maximum transverse displacements in direction $z$

\begin{tabular}{cccc}
\hline \multirow{2}{*}{ Boundary condition } & \multicolumn{3}{c}{$\mathrm{w}_{\mathrm{o}(\max )}[\mathrm{mm}]$} \\
\cline { 2 - 4 } & SL-FEM & BC-FEM & Difference [\%] \\
\hline A-A & 0.583 & 0.571 & 2.10 \\
/BF-F & 0.164 & 0.159 & 3.14 \\
F-A & 0.286 & 0.278 & 2.88 \\
F-L & 5.260 & 5.170 & 1.74 \\
\hline
\end{tabular}

Table 5

Static deflection case. Maximum axial displacements

\begin{tabular}{cccc}
\hline \multirow{2}{*}{ Boundary condition } & \multicolumn{3}{c}{$\mathrm{u}_{\mathrm{o}(\max )}[\mathrm{mm}]$} \\
\cline { 2 - 4 } & SL-FEM & BC-FEM & Difference [\%] \\
\hline A-A & & & \\
F-F & 0.0373 & 0.0367 & 1.63 \\
F-A & & & \\
F-L & - & - & - \\
\hline
\end{tabular}

\section{Table 6}

Natural vibrations case. First natural frequency $\left(a: a x i a l ; b_{v}\right.$ : bending in $y ; b_{w}$ : bending in $\mathrm{z}$ )

\begin{tabular}{ccccc}
\hline \multirow{2}{*}{ Boundary condition } & \multicolumn{4}{c}{$1^{\text {st }}$ frequency [rad/seg] } \\
\cline { 2 - 5 } & mode & SL-FEM & BC-FEM & Difference [\%] \\
\hline \multirow{2}{*}{ A-A } & $\omega_{1 \mathrm{a}}$ & 312.871 & 312.171 & 0.22 \\
& $\omega_{1 \mathrm{bv}}$ & 15.866 & 16.034 & 1.05 \\
& $\omega_{1 \mathrm{bw}}$ & 30.921 & 31.338 & 1.33 \\
F-F & $\omega_{1 \mathrm{a}}$ & 313.051 & 312.171 & 0.28 \\
& $\omega_{1 \mathrm{bv}}$ & 32.146 & 32.557 & 1.26 \\
& $\omega_{1 \mathrm{bw}}$ & 58.973 & 59.732 & 1.27 \\
& $\omega_{1 \mathrm{a}}$ & 156.523 & 157.447 & 0.59 \\
F-A & $\omega_{1 \mathrm{bv}}$ & 23.530 & 23.632 & 0.43 \\
& $\omega_{1 \mathrm{bw}}$ & 44.464 & 44.761 & 0.66 \\
& $\omega_{1 \mathrm{a}}$ & 156.404 & 157.432 & 0.65 \\
& $\omega_{1 \mathrm{bv}}$ & 5.750 & 5.737 & 0.23 \\
& $\omega_{1 \mathrm{bw}}$ & 11.351 & 11.346 & 0.04 \\
\hline
\end{tabular}

The $\Delta$ step between diagonals is a necessary parameter for the passage from the discrete domain to the continuous domain of the energy terms provided by the diagonals and legs [8].

Consequently, the determination of the proposed equivalent properties depends on this passage previously indicated. Therefore, a spatial lattice (Pattern 1) of square cross-section is analyzed using different $\Delta$ values. This allows to establish its influence on the numerical results obtained using the BCFEM model with 6 two-nodes beam elements. For the indicated analysis, $\Delta /$ side ratios (side B or D) are adopted between 0.25 and 2.00 (Fig. 7). The geometric and mechanical properties of the lattice analyzed are indicated in Table 7 . The loads applied correspond to the same as in the previous case.
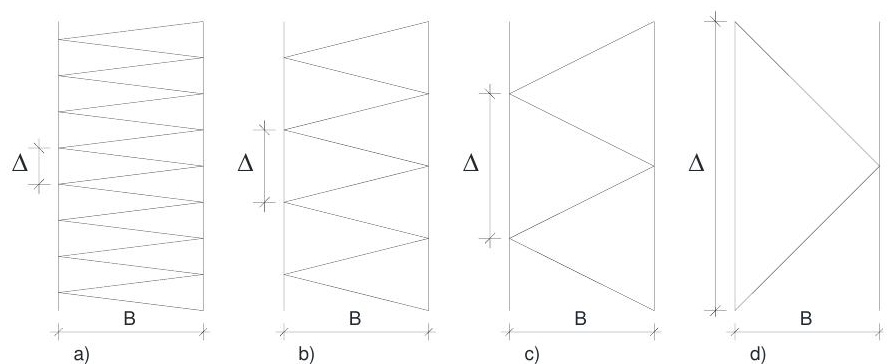

Fig. 7 a) $\Delta / B=0.25$. b) $\Delta / B=0.50$. c) $\Delta / B=1.00$. d) $\Delta / B=2.00$
Table 7

Properties of the analyzed lattice for different values $\Delta$

\begin{tabular}{cccc}
\hline Parameter & Notation & Value & Unit \\
\hline Leg length & $\mathrm{L}_{\mathrm{l}}$ & 6.0 & $\mathrm{~m}$ \\
Diagonals separation seseparation & $\Delta$ & $0.1 ; 0.2 ; 0.4 ; 0.8$ & $\mathrm{~m}$ \\
Side & $\mathrm{B}=\mathrm{D}$ & 0.4 & $\mathrm{~m}$ \\
Area of legs & $\mathrm{A}_{\mathrm{l}}$ & $2.01 \times 10^{-4}$ & $\mathrm{~m}^{2}$ \\
Area 2 $2^{\text {nd }}$ moment of legs & $\mathrm{J}_{\mathrm{ly}}=\mathrm{J}_{\mathrm{lz}}$ & $3.22 \times 10^{-9}$ & $\mathrm{~m}^{4}$ \\
Area of diagonals & $\mathrm{A}_{\mathrm{dB}}=\mathrm{A}_{\mathrm{dD}}$ & $1.13 \times 10^{-4}$ & $\mathrm{~m}^{2}$ \\
Modulus of elasticity & $\mathrm{E}_{\mathrm{l}}=\mathrm{E}_{\mathrm{d}}$ & 200000 & $\mathrm{MPa}$ \\
Mass density & $\rho_{\mathrm{l}}=\rho_{\mathrm{d}}$ & 7850 & $\mathrm{~kg} / \mathrm{m}^{3}$ \\
\hline
\end{tabular}

The results of the maximum transverse displacements obtained for different $\Delta / \mathrm{B}$ ratios are presented in Tables 8 to 11 .

Table 8

Case A-A. Maximum transverse displacements

\begin{tabular}{ccccc}
\hline \multirow{2}{*}{ Boundary condition } & $\Delta / \mathrm{B}$ & \multicolumn{3}{c}{$\mathrm{V}_{\mathrm{o}(\max )}[\mathrm{mm}]$} \\
\cline { 3 - 5 } & & SL-FEM & BC-FEM & Difference [\%] \\
\hline \multirow{3}{*}{ A-A } & 0.25 & 0.687 & 0.687 & 0.00 \\
& 0.50 & 0.610 & 0.610 & 0.00 \\
& 1.00 & 0.568 & 0.573 & 0.87 \\
& 2.00 & 0.535 & 0.543 & 1.47 \\
\hline
\end{tabular}

Table 9

Case F-F. Maximum transverse displacements

\begin{tabular}{ccccc}
\hline \multirow{2}{*}{ Boundary condition } & $\Delta / \mathrm{B}$ & \multicolumn{3}{c}{$\mathrm{V}_{\text {o(max) }}[\mathrm{mm}]$} \\
\cline { 3 - 5 } & & SL-FEM & BC-FEM & Difference [\%] \\
\hline \multirow{3}{*}{ F-F } & 0.25 & 0.268 & 0.268 & 0.00 \\
& 0.50 & 0.192 & 0.192 & 0.00 \\
& 1.00 & 0.159 & 0.159 & 0.00 \\
& 2.00 & 0.156 & 0.156 & 0.00 \\
\hline
\end{tabular}

Table 10

Case F-A. Maximum transverse displacements

\begin{tabular}{ccccc}
\hline \multirow{2}{*}{ Boundary condition } & \multirow{2}{*}{$\mathrm{B}$} & \multicolumn{3}{c}{$\mathrm{V}_{\mathrm{o}(\max )}[\mathrm{mm}]$} \\
\cline { 3 - 5 } & & SL-FEM & BC-FEM & Difference [\%] \\
\hline \multirow{2}{*}{ F-A } & 0.25 & 0.405 & 0.404 & 0.25 \\
& 0.50 & 0.317 & 0.318 & 0.31 \\
& 1.00 & 0.278 & 0.277 & 0.36 \\
& 2.00 & 0.268 & 0.272 & 1.47 \\
\hline
\end{tabular}

Table 11

Case F-L. Maximum transverse displacements

\begin{tabular}{ccccc}
\hline \multirow{2}{*}{ Boundary condition } & $\Delta / \mathrm{B}$ & \multicolumn{3}{c}{$\mathrm{V}_{\mathrm{o}(\max )}[\mathrm{mm}]$} \\
\cline { 3 - 5 } & & SL-FEM & BC-FEM & Difference [\%] \\
\hline \multirow{2}{*}{ F-L } & 0.25 & 5.683 & 5.682 & 0.02 \\
& 0.50 & 5.363 & 5.372 & 0.17 \\
& 1.00 & 5.137 & 5.194 & 1.10 \\
& 2.00 & 4.825 & 5.021 & 3.90 \\
\hline
\end{tabular}

Finally, the performance of the BC-FEM model is evaluated for different discretizations of the finite beam elements that are part of it. For this purpose, the example of the previous case corresponding to the ratio $\triangle B=1.00$ and the boundary condition F-L is taken. The discretizations evaluated correspond to a number of frames between $L_{l} / L_{l}$ and $L_{l} / 0.01$ ( $L_{l}$ : height lattice). Tables 12 to 15 show the results obtained from the evaluation. 
Table 12

Performance of the BC-FEM model for different discretization's. Case F-L. Maximum axial displacements

\begin{tabular}{ccccc}
\hline \multicolumn{5}{c}{$\mathrm{u}_{\mathrm{o}(\max )}[\mathrm{mm}]$} \\
\hline Discretization & $\mathrm{n}^{\circ}$ frame & SL-FEM & BC-FEM & Difference [\%] \\
\hline $\mathrm{L}_{\mathrm{l} / \mathrm{Ll}}$ & 1 & & 0.0368 & 0.82 \\
$\mathrm{~L}_{\mathrm{l}} / 1$ & 6 & & 0.0368 & 0.82 \\
$\mathrm{~L}_{\mathrm{l}} / 0.1$ & 60 & 0.0365 & 0.0368 & 0.82 \\
$\mathrm{~L}_{\mathrm{l}} / 0.01$ & 600 & & 0.0368 & 0.82 \\
\hline
\end{tabular}

Table 13

Performance of the BC-FEM model for different discretization's. Case F-L. Maximum transverse displacements

\begin{tabular}{ccccc}
\hline \multicolumn{5}{c}{$\mathrm{u}_{\mathrm{o}(\max )}[\mathrm{mm}]$} \\
\hline Discretization & $\mathrm{n}^{\circ}$ frame & SL-FEM & BC-FEM & Difference [\%] \\
\hline $\mathrm{L}_{1} / \mathrm{L}_{1}$ & 1 & & 5.194 & 1.10 \\
$\mathrm{~L}_{\mathrm{l}} / 1$ & 6 & & 5.194 & 1.10 \\
$\mathrm{~L} / 0.1$ & 60 & 5.137 & 5.194 & 1.10 \\
$\mathrm{~L} / 0.01$ & 600 & & 5.194 & 1.10 \\
\hline
\end{tabular}

\section{Table 14}

Performance of the BC-FEM model for different discretization's. Case F-L. First natural frequency axial

\begin{tabular}{ccccc}
\hline \multicolumn{5}{c}{$\mathrm{u}_{\mathrm{o}(\max )}[\mathrm{mm}]$} \\
\hline Discretization & $\mathrm{n}^{\circ}$ frame & SL-FEM & BC-FEM & Difference [\%] \\
\hline $\mathrm{L}_{\mathrm{l} / \mathrm{L}}$ & 1 & & 126.812 & 11.73 \\
$\mathrm{~L}_{\mathrm{l}} / 1$ & 6 & & 140.451 & 0.88 \\
$\mathrm{~L} / 0.1$ & 60 & 141.689 & 140.849 & 0.60 \\
$\mathrm{~L} / / 0.01$ & 600 & & 140.853 & 0.59 \\
\hline
\end{tabular}

Table 15

Performance of the BC-FEM model for different discretizations. Case F-L. First natural frequency bending

\begin{tabular}{ccccc}
\hline \multicolumn{5}{c}{$\mathrm{u}_{\mathrm{o}(\max )}[\mathrm{mm}]$} \\
\hline Discretization & $\mathrm{n}^{\circ}$ frame & SL-FEM & BC-FEM & Difference [\%] \\
\hline $\mathrm{L}_{\mathrm{l} / \mathrm{L} l}$ & 1 & & 7.203 & 42.57 \\
$\mathrm{~L}_{\mathrm{l}} / 1$ & 6 & & 10.124 & 1.43 \\
$\mathrm{~L} / 0.1$ & 60 & 10.269 & 10.246 & 0.22 \\
$\mathrm{~L}_{\mathrm{l}} / 0.01$ & 600 & & 10.247 & 0.21 \\
\hline
\end{tabular}

The internal forces in each element of the lattice (legs, diagonals) are easily obtained after knowing the efforts of the BC-FEM model.

Knowing the bending moment and the normal effort acting in a certain section of the BC, the axial efforts in the legs are obtained.

Being for example, $M_{\theta v o}(x)$ (bending moment around the axis $\left.w_{o}\right), M_{\theta v o}(x)$ (bending moment around the axis $v_{o}$ ), and $N_{u o(x)}$ (normal effort in the direction $u_{o}$ ) the forces acting in the beam-column (BC) at a height $x$, the axial effort in each leg then results:

$N_{l}=\frac{N_{u o}(x)}{4}+\frac{M_{\theta w o}(x)}{2 B}+\frac{M_{\theta v o}(x)}{2 D}$

taking into account in this determination the sign that corresponds to each effort and the location of the leg.

Knowing the shear effort acting in the BC, the axial forces in the diagonals are obtained. For example, $S_{v o}(x)$ (shear effort in the direction of the $v_{o}$ axis) and $S_{w o}(x)$ (shear effort in the direction of the $w_{o}$ axis) acting in the $\mathrm{BC}$ at a height $x$, the axial effort in each diagonal then results:

$N_{d B}=\frac{S_{v o}(x)}{2 \cos \alpha_{B}}$

$N_{d D}=\frac{S_{w o}(x)}{2 \cos \alpha_{D}}$
In this way, from the efforts obtained in the BC-FEM representation model, the internal forces acting on each of the elements of the spatial lattice are recovered.

Taking the previous example corresponding to the relation $\triangle B=1.00$, with a discretization $L_{l} / 1$, with F-L boundary conditions, and with a lateral load uniformly distributed in the direction of $y$ of value $q_{v o}=200 \mathrm{~N} / \mathrm{m}$.

In this case, the efforts in the BC-FEM representation model and in the $x$ section result $M_{\theta v o}(x)=3373$ N.m and $S_{v o}(x)=1160 \mathrm{~N}$.

Fig. 8 shows the elements of the SL-FEM evaluated.

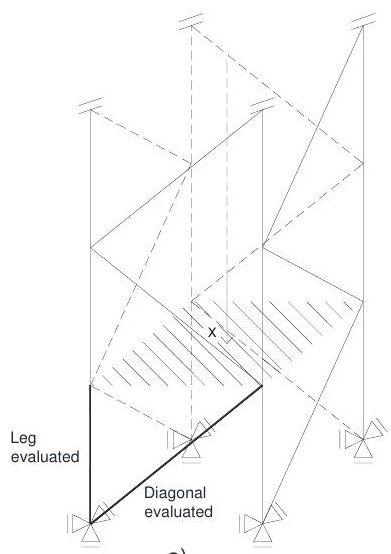

a) b)

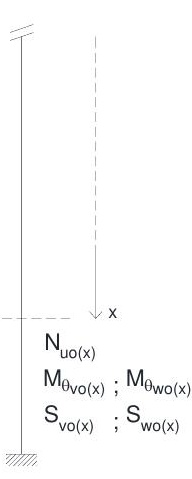

Fig. 8 Determination of internal efforts. a) SL-FEM. b) BC-FEM

Table 16 compares the internal efforts for the diagonal and leg evaluated, obtained in the SL-FEM model and from the resulting efforts in the BC-FEM model applying the Eqs. 32 to 34 .

Table 16

Internal efforts in elements of spatial lattice. Case F-L

\begin{tabular}{ccccc}
\hline \multicolumn{5}{c}{ Internal efforts [N] } \\
\hline Element & Effort & SL-FEM & BC-FEM & Difference [\%] \\
\hline Leg & Axial N & 4117 & 4226 & 2.35 \\
Diagonal & Axial N & 663 & 649 & 2.16 \\
\hline
\end{tabular}

\subsection{Lattice frame}

Fig. 9 shows the case of a lattice frame analyzed using the equivalent beamcolumn (BC). This is subject to a $2000 \mathrm{~N} / \mathrm{m}$ vertical uniformly distributed load on the beam. The lattice frame is represented by the SL-FEM (Fig. 9a) and BCFEM (Fig. 9b) models, comparing the numerical results for the maximum vertical deformation and for the first natural frequencies.

It should be noted that in the SL-FEM model 508 finite elements were used for the discretization of the problem, while in the BC-FEM model only 24 elements were used, which is, less than $5 \%$ of what was used in the spatial model.

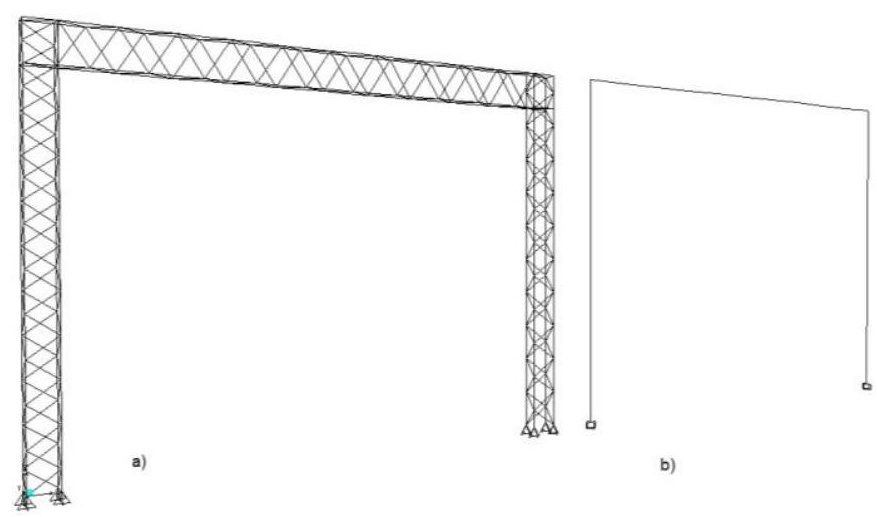

Fig. 9 Lattice frame. a) SL-FEM space model. b) BC-FEM equivalent model

The geometric and mechanical properties are indicated in Table 17. 
Table 17

Numerical values of geometrical and mechanical properties of the lattice frame

\begin{tabular}{|c|c|c|c|c|}
\hline Element & Parameter & Notation & Value & Unit \\
\hline \multirow{10}{*}{$\frac{\text { 目 }}{\text { ல }}$} & Leg length & $\mathrm{L}_{1}$ & 7.35 & $\mathrm{~m}$ \\
\hline & Diagonals separation & $\mathrm{D}$ & 0.7 & $\mathrm{~m}$ \\
\hline & Side B & B & 0.5 & $\mathrm{~m}$ \\
\hline & Side D & $\mathrm{D}$ & 0.3 & $\mathrm{~m}$ \\
\hline & Area of legs & $\mathrm{A}_{l}$ & $2.01 \times 10^{-4}$ & $\mathrm{~m}^{2}$ \\
\hline & Area $2^{\text {nd }}$ moment of legs & $\mathrm{J}_{\mathrm{ly}}=\mathrm{J}_{\mathrm{lz}}$ & $3.22 \times 10^{-9}$ & $\mathrm{~m}^{4}$ \\
\hline & Area of diagonals side B & $A_{d B}$ & $1.13 \times 10^{-4}$ & $\mathrm{~m}^{2}$ \\
\hline & Area of diagonals side D & $A_{d D}$ & $5.03 \times 10^{-5}$ & $\mathrm{~m}^{2}$ \\
\hline & Modulus of elasticity & $\mathrm{E}_{\mathrm{l}}=\mathrm{E}_{\mathrm{d}}$ & 200000 & $\mathrm{MPa}$ \\
\hline & Mass density & $\rho_{\mathrm{l}}=\rho_{\mathrm{d}}$ & 7850 & $\mathrm{~kg} / \mathrm{m}^{3}$ \\
\hline \multirow{10}{*}{ ఐే } & Leg length & $\mathrm{L}_{1}$ & 9.0 & $\mathrm{~m}$ \\
\hline & Diagonals separation & $\mathrm{D}$ & 0.9 & $\mathrm{~m}$ \\
\hline & Side B & B & 0.7 & $\mathrm{~m}$ \\
\hline & Side D & $\mathrm{D}$ & 0.3 & $\mathrm{~m}$ \\
\hline & Area of legs & $\mathrm{A}_{\mathrm{l}}$ & $2.01 \times 10^{-4}$ & $\mathrm{~m}^{2}$ \\
\hline & Area $2^{\text {nd }}$ moment of legs & $\mathrm{J}_{\mathrm{ly}}=\mathrm{J}_{\mathrm{lz}}$ & $3.22 \times 10^{-9}$ & $\mathrm{~m}^{4}$ \\
\hline & Area of diagonals side B & $A_{d B}$ & $1.13 \times 10^{-4}$ & $\mathrm{~m}^{2}$ \\
\hline & Area of diagonals side D & $A_{d D}$ & $5.03 \times 10^{-5}$ & $\mathrm{~m}^{2}$ \\
\hline & Modulus of elasticity & $\mathrm{E}_{\mathrm{l}}=\mathrm{E}_{\mathrm{d}}$ & 200000 & $\mathrm{MPa}$ \\
\hline & Mass density & $\rho_{\mathrm{l}}=\rho_{\mathrm{d}}$ & 7850 & $\mathrm{~kg} / \mathrm{m}^{3}$ \\
\hline
\end{tabular}

Table 18 demonstrates the values obtained for the maximum vertical deformation of the beam, while Table 19 demonstrates the values for the first bending frequencies (transverse to the plane and longitudinal to this) and the torsional frequency of the lattice frame.

\section{Table 18}

Static deflection case. Maximum vertical displacement of the beam

\begin{tabular}{cccc}
\hline \multirow{2}{*}{ Boundary condition } & \multicolumn{3}{c}{ Vertical displacement [mm] } \\
\cline { 2 - 4 } & SL-FEM & BC-FEM & Difference [\%] \\
\hline F-F & 7.790 & 7.632 & 2.07 \\
\hline
\end{tabular}

\section{Table 19}

Natural vibrations case. First natural frequencies bending and torsional (b: bending; t: torsional)

\begin{tabular}{ccccc}
\hline \multirow{2}{*}{ Boundary condition } & \multicolumn{4}{c}{$1^{\text {st }}$ frequency [rad/seg] } \\
\cline { 2 - 5 } & mode & SL-FEM & BC-FEM & Difference [\%] \\
\hline \multirow{2}{*}{ F-F } & $\omega_{1 \text { b(transverse) }}$ & 3.155 & 3.079 & 2.47 \\
& $\omega_{1 \text { (longitudinal) }}$ & 8.319 & 8.430 & 1.33 \\
& $\omega_{1 \text { (t(torsional) }}$ & 5.014 & 5.153 & 2.77 \\
\hline
\end{tabular}

Finally, the Figs. 10 to 13 show each of the evaluated responses.

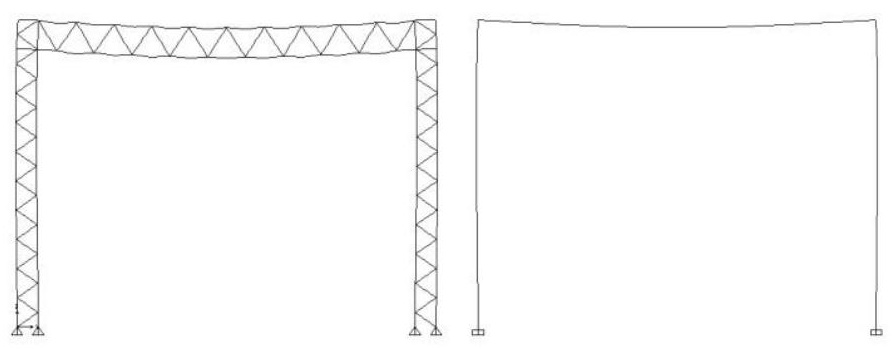

Fig. 10 Static deflection case. Maximum vertical displacement of the beam
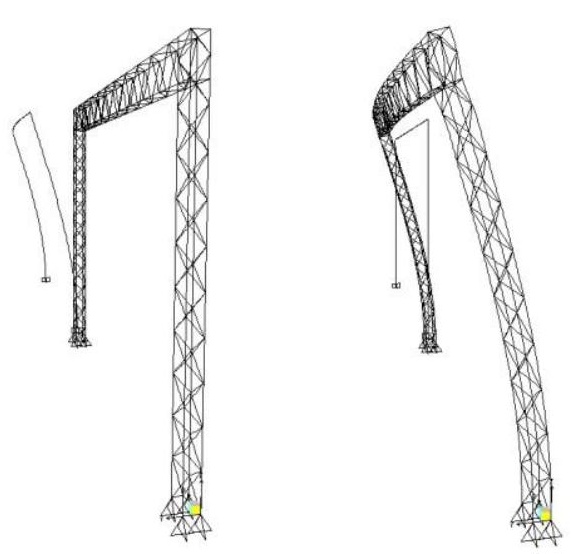

Fig. 11 Natural vibrations case. First bending frequency transverse to the plane of the lattice frame

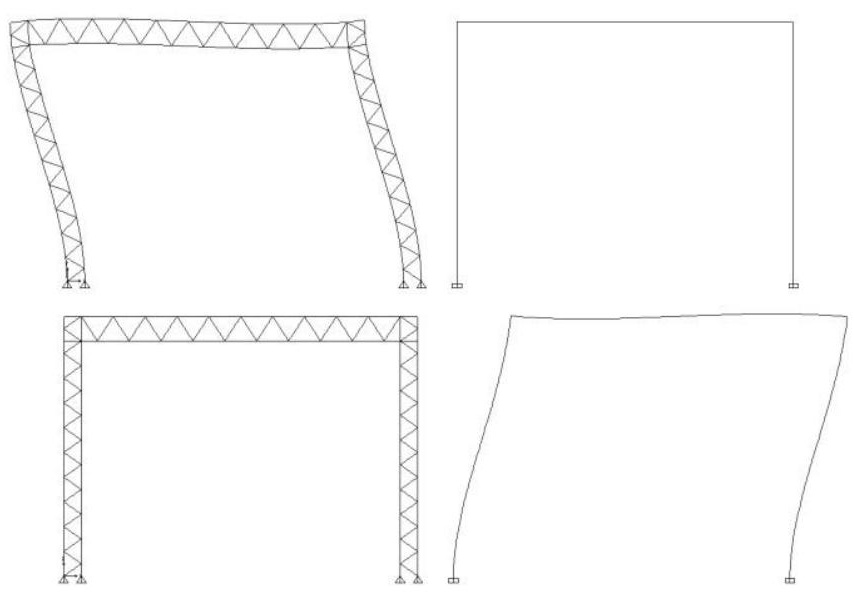

Fig. 12 Natural vibrations case. First bending frequency longitudinal to the plane of the lattice frame
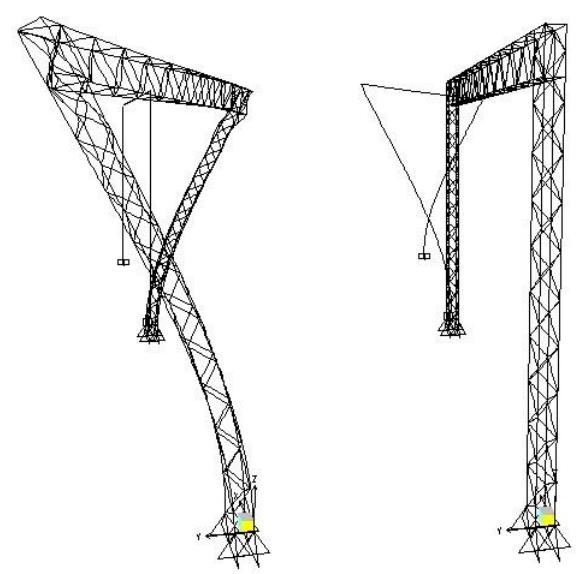

Fig. 13 Natural vibrations case. First torsional frequency of the lattice frame

\section{Equivalent properties for different patterns}

With mathematical statements similar to those suggested for the lattice structure (Pattern 1) described above, three other patterns were analyzed (Pattern 2, 3 and 4). New differential equations are stated resulting in the corresponding equivalent properties. Table 18 shows the obtained equivalent properties. The parameters with subscripts $s$ represent the contributions of the struts for Pattern 2 and Pattern 4. 
Table 20

Equivalent properties. Rectangular cross-sectional lattice

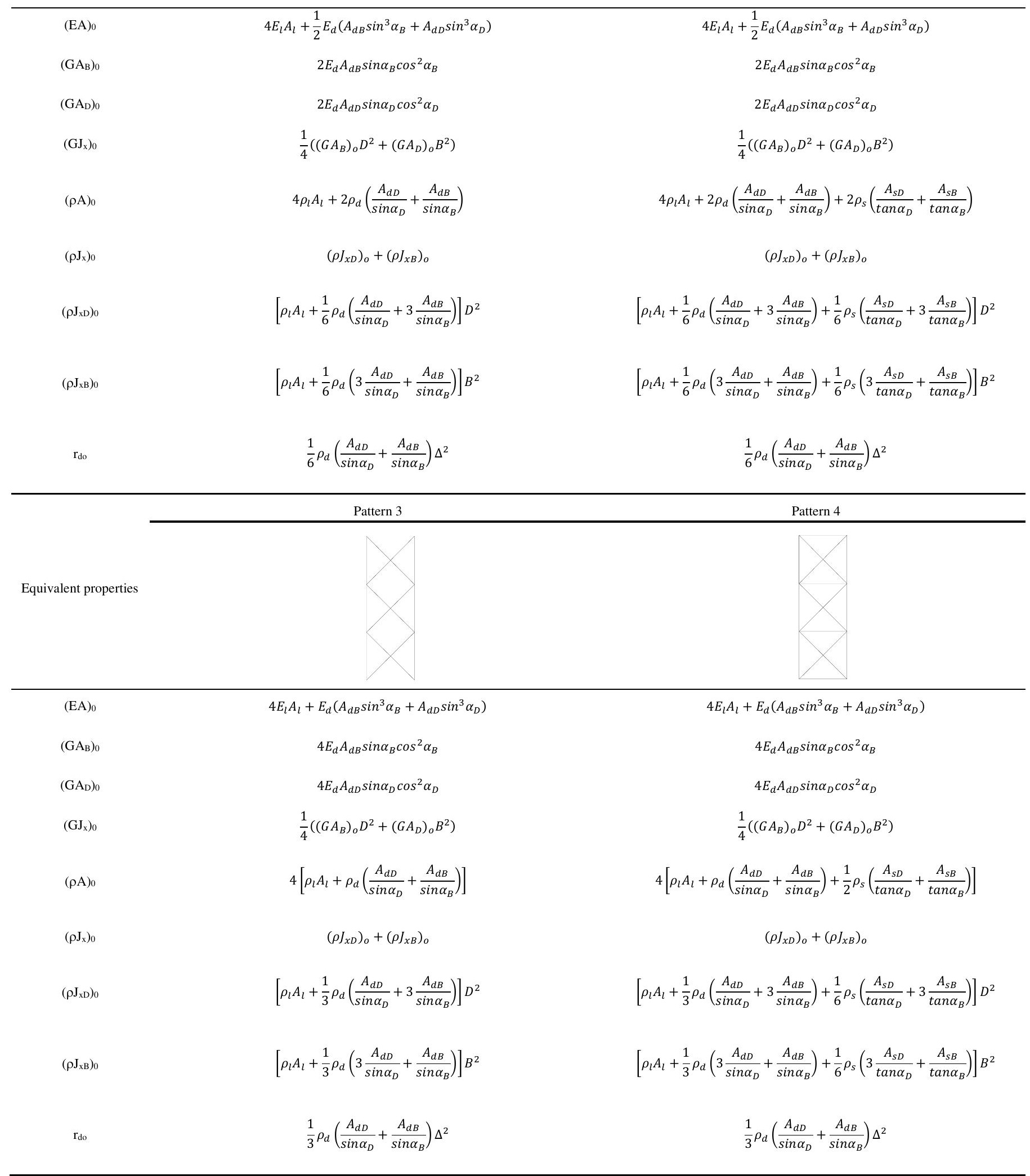




\section{Conclusions}

In the present research, a study was carried out of four spatial lattice patterns of rectangular cross-section, obtaining the elastic properties and equivalent inertias necessary for the representation of the problem as columnbeam.

The proposed representation method, BC-FEM, based on the equivalent properties determined, has been validated numerically from comparing the results obtained in various case studies. From the results presented, the following conclusions can be deduced:

(1) The availability of a representation of lower complexity such as the beam-column formulation, reduces significantly the time needed for the model construction. This indicated formulation can be carried out from the equivalent properties determined in the research.

(2) The discretization of the geometry problem does not affect the performance of the static response of the model, even if the domain is represented by a single element. However, the dynamic response is affected by the discretization, but a $L_{l} / 1$ ratio is sufficient to achieve adequate performance of the model. This robustness of the model allows a significant reduction in computational cost.

(3) Comparing the results of the different responses evaluated with the results obtained from the SL-FEM model, for a discretization of not less than $L_{l} / 1$, the maximum difference found for the totality of the cases evaluated turned out to be less than $4 \%$.

(4) Being $\Delta$ a necessary parameter in the energy approach to obtain the equivalent properties, these determined properties showed excellent performance even for cases in which the $\Delta$ side ratio was higher than the unit. This indicates the appropriate use of the $\mathrm{BC}$ model with these equivalent properties even for lattice cases with important diagonal spacing.

(5) The internal efforts that determine the structural behavior of each element of the spatial lattice (axial efforts), are easily recoverable from knowing in the BC-FEM model the forces acting at the height $x$ of interest and applying the proposed analytical equations.

\section{Acknowledgements}

The authors are grateful for the financial support of the Universidad Tecnológica Nacional, Facultad Regional Mendoza, CeReDeTeC, (SeCyT, Project UTI6619TC).

\section{References}

[1] Abrate S., "Continuum modeling of lattice structures", Shock and Vibration Digest, 17(1), $815-821,1985$.

[2] Abrate S., "Continuum modeling of lattice structures for dynamic analysis", Shock and Vibration Digest, 20(10), 3-8, 1988.

[3] Noor A. and Mikulas M., "Continuum Modeling of Large Lattice Structures: Status and Projections", In: Atluri S.N., Amos A.K. (eds.), Large Space Structures: Dynamics and Control. Springer Series in Computational Mechanics. Springer, Berlin, Heidelberg. 1988.

[4] McCallen D. and Romstad K., "A continuum model for the nonlinear analysis of beam-like lattice structures", Computer and Structures, 29(2), 177-197, 1988.

[5] Filipich C. and Bambill E., "Natural frequencies of braced elements via power series", In: AMCA (ed.), Macánica Computacional, 22, 877-891, 2003.

[6] Teughels A. and De Roeck G., "Continuum Modeling for beam-and platelike lattice structures", Fourth International Colloquium on Computation of Shell $\{\$ 1 \& \$\}$ Spatial Structures, IASSS-IACM 2000, Chania, Crete, Greece, 2000.

[7] Salehian A., "Micropolar Continuum Modeling of Large Space Structures with Flexible Joints and Thermal Effects: Theory and Experiment”, Ph.D. thesis, Virginia Polytechnic Institute and State University, 2008.

[8] Guzmán A., Rosales M. and Filipich C., "Natural vibrations and buckling of a spatial lattice structure using a continuous model derived from an energy approach", International Journal of Steel Structures, 17(2), 565-578, 2017.

[9] Guzmán A., Rosales M. and Filipich C., "Continuous one-dimensional model of a spatial lattice. Deformation, vibration and buckling problems", Engineering Structures, 182, 290300, 2019

[10] Madugula M., Wahba Y. and Monforton G., "Dynamic response of guyed mast", Engineering Structures, 20(12), 1097-1101, 1998.

[11] Wahba Y., Madugula M. and Monforton G., "Evaluation of non-linear analysis of guyed antenna towers", Computers and Structures, 68, 207-212, 1998.

[12] Ben Kahla N., "Equivalent beam-column analysis of guyed towers", Computers and Structures, 55(4), 631-645, 1993.

[13] Páez P. and Sensale B., "Analysis of guyed masts by the stability functions based on the Timoshenko beam-column", Engineering Structures, 152, 597-606, $2017 \mathrm{a}$.

[14] Páez P. and Sensale B., "Cálculo de torres atirantadas sin utilizar elementos finitos", Hormigón y Acero, 68(283), 229-240, 2017 b.

[15] Computers and Structures, Inc. (CSI), SAP2000, 2007. 


\title{
STUDY ON MICROMECHANICAL FRACTURE MODELS OF STRUCTURAL STEEL AND ITS WELDS
}

\author{
Xi-Yue Liu ${ }^{1}$, Yuan-Qing Wang ${ }^{2}$, Yi-Du Bu ${ }^{3, *}$ and Yang Guan ${ }^{4}$ \\ ${ }^{1}$ National University of Defense Technology \\ ${ }^{2}$ Tsinghua University \\ ${ }^{3}$ Beijing University of Technology \\ ${ }^{4}$ Zhuzong Real Estate Development Co., Ltd \\ *(Corresponding author: E-mail: yidubu@bjut.edu.cn)
}

\section{A B S T R A C T}

Steel structures have been widely used in constructions due to their advantages of lightweight, high strength, short construction time and high recycling and reuse potential. Fracture failure in steel structures should be prevented to avoid collapse of the whole structures. Micromechanical fracture models can capture the fracture initiation mechanisms and therefore can be used to predict ductile fractures in steel. Twelve smooth round bars were carried out to obtain the material properties and 36 notched round bars were tested to calibrate the parameters of stress modified critical strain (SMCS) model and the void growth model (VGM) for structural steels (Q235B and Q345B) and the corresponding welds. Specimens were extracted from the base metal, the weld metal and the heat affected zone (HAZ) to investigate fracture behaviour in different parts of the welded joint. Scanning electron microscope (SEM) measurements were taken and finite element models were developed to calibrate the models. The test results and calibrated parameters are reported. Moreover, the calibrated models are applied to analyses the fracture behaviour of welded joints and their accuracy are validated. The calibrated and validated models can be used for further numerical fracture analysis in welded steel structures.

\section{A R T I C LE H IS T O R Y}

$\begin{array}{ll}\text { Received: } & 15 \text { April } 2020 \\ \text { Revised: } & 15 \text { April } 2020 \\ \text { Accepted: } & 21 \text { November } 2020\end{array}$

\section{K E Y W O R D S}

Steel structure;

Fracture prediction;

Micromechanical models;

Tests;

Finite element analyses;

Parameter calibration

\section{Introduction}

Fracture failure in steel structures should be prevented to avoid collapse of the whole structures. Structural steel generally exhibits ductile fracture behaviour with significant plasticity. Conventional fracture mechanics, however, assumes pre-existing cracks with high strain constraint, offering better fit for brittle fracture with low plasticity. Moreover, the conventional fracture mechanic methods do not take triaxiality into consideration, thus it is not suitable to predict the fracture for welded steel connections or other welded steel components controlled by triaxial stress condition. Micromechanical facture models assume three stages of microvoid nucleation, void growth, and void coalescence, which capture the effect of stress and strain state on fracture behaviour and can be used in finite element analyses to predict the fracture initiation more accurately.

Earlier models ${ }^{[1]}$ for ductile failure assume homogenous continuum with no stress state. In 1969, Rice and Tracey ${ }^{[2]}$ investigated the influence of triaxial hydrostatic stresses on the process of micromechanical void coalescence analytically, which served as the basis of void growth model (VGM). In 1976, Hancock and Mackenzie ${ }^{[3]}$ carried out tests in different steels to determine the strain required to initiate ductile failure in multi-axial stress-states and proposed that void expansion and coalescence is related to orientation and stress triaxiality. Hancock and Cowling ${ }^{[4]}$ presented the failure mechanisms in three stages: micro void nucleation, growth, and coalescence. Later in 1983, Hancock and Brown ${ }^{[5]}$ conducted experiments and finite deformation stress analysis in a range of structural steels and proposed that the strain to initiate failure is related to the stress state. Similar models have been proposed and tested for various materials by Johnson and $\mathrm{Cook}^{[6]}$, Marini et al. ${ }^{[7]}$, Panontin and Sheppard ${ }^{[8]}$ and Bandstra et al. ${ }^{[9]}$. More recently in 2006, Kanvinde and Deierlein $^{[10]}$ carried out material tests and finite-element analyses for seven varieties of structural steels to validate the material dependent parameters. In 2006, $\mathrm{Chi}^{[11]}$ calibrated the toughness parameters of stress modified critical strain model (SMCS) model for mild A572 Grade 50 steel from a series of notched tensile tests. In 2010, Benzerga and Leblond ${ }^{[12]}$ examined the micromechanical models of various stages of ductile fracture and conducted fracture prediction by crack growth simulation. In 2010, Myers et al. ${ }^{[13]}$ conducted 23 uniaxial tensile tests and verified that the sample size was not significantly related to the toughness parameters of the SMCS model. In 2011, Wang et al. ${ }^{[14]}$ compared VGM , SMCS models and J-integral methods in the ductile fracture analysis of welded steel joints and found out that the VGM and SMCS models offered more accurate predictions. In 2012, Kossakowski ${ }^{[15]}$ conducted fracture prediction for S235JR steel using SMCS fracture criterion and concluded that using the characteristic length of the material as mesh size in finite element analysis offered better accuracy. In 2012, Liao et al. ${ }^{[16}$ conducted material tests on the base material of Q345 steel, weld deposit metal and heat affected zone, and calibrated the toughness parameters of VGM and SMCS model. Steel joint test data was used to verify the applicability of VGM and SMCS prediction. In 2013, Kiran et al. ${ }^{[17]}$ studied the ductile fracture behaviour of A992 steel under high stress triaxiality, and calibrated the toughness parameters of VGM and SMCS models. In 2015, Liu et al. ${ }^{[18]}$ and $\mathrm{Lu}^{[19]}$ calibrated the toughness parameters of VGM model, SMCS model for Q460C high-strength steel and Q235 steel, respectively.

Recent studies have focused on the toughness parameter calibration for different materials. With calibrated material dependent parameters, the micromechanical models can be used in ductile fracture prediction and offer good prediction. Q235B and Q345B are two most commonly used structural steels and previous studies have investigated the parameters separately. In this paper, the ductile fracture behaviour of the base metal, the weld metal and the heat affect zone for these two steels were studied and compared systematically. The micromechanical models of structural steels under monotonic loading were investigated, including the void growth model (VGM) and the stress modified critical strain model (SMCS). Material dependent parameters in the models were calibrated, including the toughness parameters $\eta_{\text {mon }}$ and $\gamma$. Scanning electron microscope (SEM) measurements were taken to determine the characteristic length $l^{*}$. Even though Q235B and Q345B are the most commonly used structural steels in China, the calibrations of the above three material dependent parameters for Q235B and Q345B welded steels is scarce. The calibrated micromechanical models can be used for further numerical fracture analysis of different types of welded steel joints and offer more accurate prediction in fractural behaviour.

\section{Theory}

Previous studies show that fracture initiation is dependent on both the strain state and the stress triaxiality of the material. Micromechanical model can be used to capture the initiation of the cracks and to predict the fracture failure of the component. The models reveal the interaction between stress and strain state and combine micromechanical level void deformation with crack initiation. Two micromechanical models have been considered in this paper and are described below.

\subsection{Void growth model (VGM model)}

In 1969 Rice and Tracey ${ }^{[2]}$ deduced the analytical solutions in elastic-plastic materials, considering the influence of stress triaxiality and 
plastic strain on microvoid expansion of individual cylindrical and spherical void. Expanding on the derivations a critical value $\eta_{\text {mon }}$ is defined to represent the critical state of crack initiation, corresponding to the state of void coalescence. $\eta_{\text {mon }}$ is defined as follow:

$\eta_{\text {mon }}=\frac{\ln \left(\frac{R}{R_{0}}\right)_{\text {critical }}}{C}=\int_{0}^{\varepsilon_{p}} \exp (1.5 T) \cdot d \varepsilon_{p}$

where $R$ is radius at fracture, $R_{0}$ is the initial radius, $T$ is the triaxiality of the stress and $T=\sigma_{m} / \sigma_{e}, \sigma_{m}$ is the mean stress and $\sigma_{\mathrm{e}}$ is the von Mises stress. $\eta_{\text {mon }}$ is a material dependent parameter which determines the toughness of the material. A larger value of $\eta_{\text {mon }}$ shows better ductility of a material. $\eta_{\text {mon }}$ can be calibrated from notched bar material tests. The fracture criterion of void growth model is expressed as fracture index $F I_{\mathrm{VGM}}$ :

$F I_{\mathrm{VGM}}=\int_{0}^{\varepsilon_{p}^{\text {cinitacl }}} \exp (1.5 T) d \varepsilon_{p}-\eta_{\mathrm{mon}}>0$

where $\varepsilon_{p}^{\text {critical }}$ is the equivalent plastic strain at the critical state. $F I_{\mathrm{VGM}}=0$ represents the critical state while $F I_{\mathrm{VGM}}>0$ indicates the initiation of the fracture.

\subsection{Stress modified critical strain (SMCS model)}

In VGM, the stress triaxiality is integrated with respect to the material's plastic strain throughout the loading process. In reality the variation of the stress triaxiality throughout the loading process is normally small, therefore the integral term can be substituted with a material dependent constant, as shown in Eq. 3.

$\ln \left(\frac{R}{R_{0}}\right)_{\text {monoionic }}^{\text {critical }}=C \exp \left(\frac{1.5 \sigma_{\mathrm{m}}}{\sigma_{\mathrm{c}}}\right) \cdot \varepsilon_{p}^{\text {critical }}$

The critical equivalent plastic strain $\varepsilon_{p}^{c r i t i c a l}$ and toughness parameter $\gamma$ can be expressed as follow:

$\gamma=\frac{\ln \left(\frac{R}{R_{0}}\right)_{\text {monotonic }}^{\text {critical }}}{C}=\varepsilon_{p}^{\text {critical }} \cdot \exp (1.5 T)$

The fracture criterion of SMCS is expressed as fracture index $F I_{\text {SMCS }}$ :
$F I_{\text {SMCS }}=\varepsilon_{p}-\gamma \cdot \exp (-1.5 T)>0$

where SMCS is the fracture criterion. $F I_{\mathrm{SMCS}}=0$ represents the critical state while $F I_{\mathrm{SMCS}}>0$ indicates the initiation of the fracture.

The VGM model considers the variation of stress triaxiality during the loading process, offering a more accurate theoretical solution. The SMCS model which assumes that the stress triaxiality does not change with respect to equivalent plastic strain offers a more efficient calculation. It is worth noting that the microstructural void growth and coalescence should also be considered, and failure criterion can only be reached, for both VGM and SMCS, if multiple material points within a certain length scale reach the fracture criterion. This length serves as another parameter, known as characteristic length $l^{*} . l^{*}$ is based on the microstructure of the material, thus can be measured by a microscope.

\section{Ductile fracture tests}

\subsection{Material}

The materials studied in this paper are two of the most commonly used structural steel materials in China: Q235B and Q345B, with nominal yield strength of $235 \mathrm{MPa}$ and $345 \mathrm{MPa}$, respectively. All specimens were extracted from $24 \mathrm{~mm}$ thick plates. The chemical compositions of the plate material, as provided in the manufacturer's mill certificates, are reported in Tables 1 and 2. Two steel plates of $24 \mathrm{~mm}$ were connected with full penetration butt weld as shown in Fig. 1. Welding parameters are listed in Table 3. Specimens from three parts were extracted and investigated: base metal, weld metal and heat affected zone. The relative position of the coupons and the weld is described later.

\section{Table 1}

Chemical composition of Q235B steel

\begin{tabular}{cccccc}
\hline \multicolumn{7}{c}{ Chemical composition quality score $/ \%$} \\
\hline $\mathrm{C}$ & $\mathrm{Mn}$ & $\mathrm{Si}$ & $\mathrm{P}$ & $\mathrm{S}$ & $\mathrm{Ni}$ \\
\hline$\leq 0.2$ & $0.3 \sim 0.7$ & $\leq 0.35$ & $\leq 0.045$ & $\leq 0.045$ & $\leq 0.80$ \\
\hline
\end{tabular}

Table 2

Chemical composition of Q345B steel

\begin{tabular}{cccccccccc}
\hline \multicolumn{10}{c}{ Chemical composition quality score $/ \%$} \\
\hline $\mathrm{C}$ & $\mathrm{Mn}$ & $\mathrm{Si}$ & $\mathrm{P}$ & $\mathrm{S}$ & $\mathrm{V}$ & $\mathrm{Nb}$ & $\mathrm{Ti}$ & $\mathrm{Al}$ \\
\hline$\leq 0$. & $1.00 \sim 1$. & $\leq 0.5$ & $\leq 0.0$ & $\leq 0.0$ & $0.02 \sim 0$. & $0.015 \sim 0.0$ & $0.02 \sim 0$. & $\geq 0.0$ \\
\hline
\end{tabular}

Table 3

Welding Process Parameters

\begin{tabular}{|c|c|c|c|c|c|c|c|c|}
\hline Welding method & Position of welding & Wire model & $\begin{array}{l}\text { Wire diameter } \\
\qquad / \mathrm{mm}\end{array}$ & Gas & $\begin{array}{c}\text { Electric current } \\
\text { /A }\end{array}$ & Voltage /V & $\begin{array}{c}\text { Pre-heat } \\
\text { temperature } /{ }^{\circ} \mathrm{C}\end{array}$ & $\begin{array}{c}\text { Welding speed } \\
/ \mathrm{cm} / \mathrm{min}\end{array}$ \\
\hline $\begin{array}{c}\text { Gas shielded } \\
\text { welding }\end{array}$ & Flat welding & E4303/ER50-6 & $\phi_{1.2}$ & $\mathrm{CO}_{2}$ & 260 & 30 & 60 & $20-35$ \\
\hline
\end{tabular}

\subsection{Smooth round bar tensile tests}

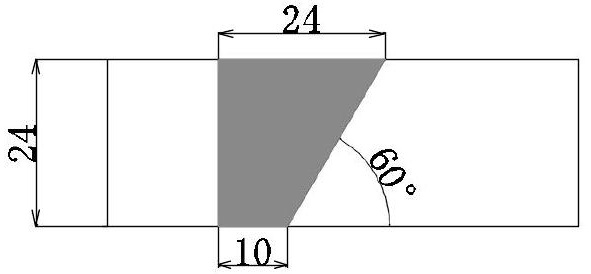

Fig. 1 Schematic drawing of the butt weld $(\mathrm{mm})$

\subsubsection{Test specimens and test setup}

Standard round bar specimens were designed according to the Chinese standard GB/T228.1-2010 $0^{[20]}$ and extracted from the base metal, the weld metal, and the heat affected zone (HAZ), which is within $10 \mathrm{~mm}$ from the edge of the welding seam, as shown in Fig. 2. For each type of coupon two repetitive tests were carried out and the average response were used. The tested coupons are listed in Table 4. The specimens are designated with three letters, with the first two representing the position of the coupon (BM for base metal, WM for weld metal and HM for heat affected zone) and the last letter representing the material of the coupon ( $\mathrm{L}$ for Q235B and $\mathrm{H}$ for Q345B). The geometries of the coupons are presented in Fig. 3. Note that the coupons from $\mathrm{HAZ}$ were designed smaller so only material in HAZ was considered. 


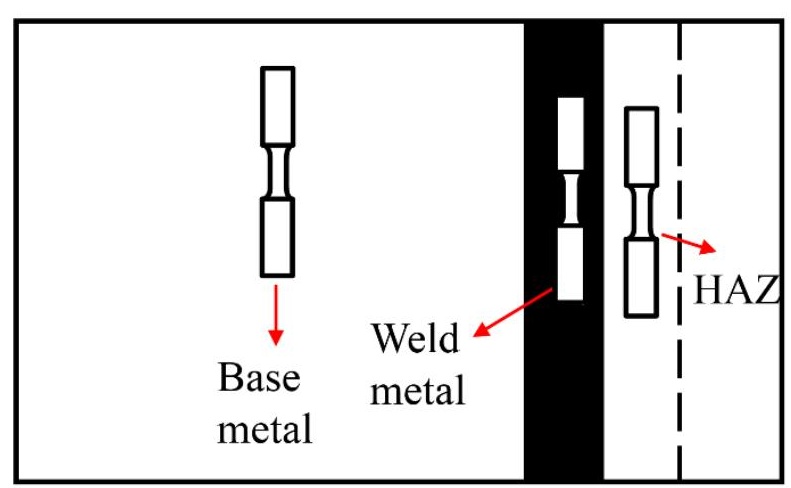

Table 4

List of test coupons

\begin{tabular}{ccccc}
\hline Position & Material & ID & Gauge length $(\mathrm{mm})$ & Quantity \\
\hline \multirow{2}{*}{ Base metal } & Q235B & BML & 12.5 & 2 \\
\cline { 2 - 5 } & Q345B & BMH & 12.5 & 2 \\
\hline \multirow{2}{*}{ Weld metal } & Q235B & WML & 12.5 & 2 \\
\cline { 2 - 5 } & Q345B & WMH & 12.5 & 2 \\
\hline \multirow{2}{*}{ Heat affected } & Q235B & HML & 25.0 & 2 \\
\cline { 2 - 5 } zone & Q345B & HMH & 25.0 & 2 \\
\hline
\end{tabular}

Fig. 2 Specimens layout

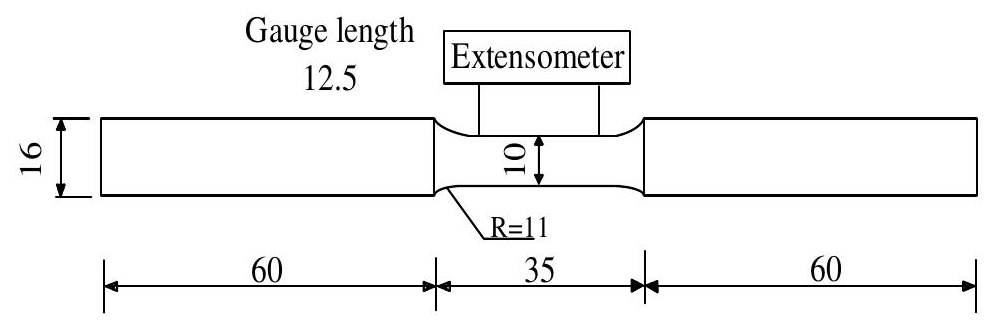

(a) Dimensions of base metal and weld metal specimens ( $\mathrm{mm}$ )

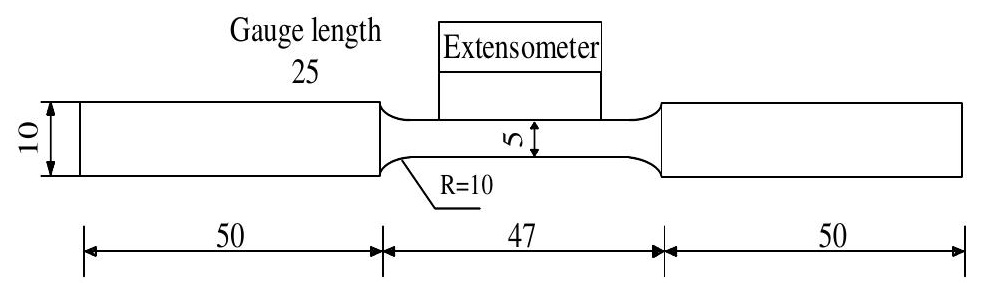

(b) Dimensions of HAZ specimens (mm)

Fig. 3 Standard round bar specimen dimensions

The experiments were conducted in the State Key Laboratory of Metal Matrix Composites of Shanghai Jiao Tong University. All tensile tests were conducted using a $100 \mathrm{kN}$ Zwick Roell universal material testing machine, following the procedure set out in the Chinese standard GB/T228.1-2010 ${ }^{[20]}$. A two-stage loading protocol was used to capture the initiation of the fracture, with a loading rate of $0.5 \mathrm{~mm} / \mathrm{min}$ prior to the yielding point of the material and $1.0 \mathrm{~mm} / \mathrm{min}$ afterwards. In previous studies, the extensometer is often taken off the specimen after the onset of necking to avoid damage from vibration upon fracture. The extensometer used herein is connected with springs to protect it from the vibration damage caused by the sudden failure of the specimen, thus the whole process can be captured. The gauge length was $12.5 \mathrm{~mm}$. The test loading device and measurement are shown in Fig. 4.

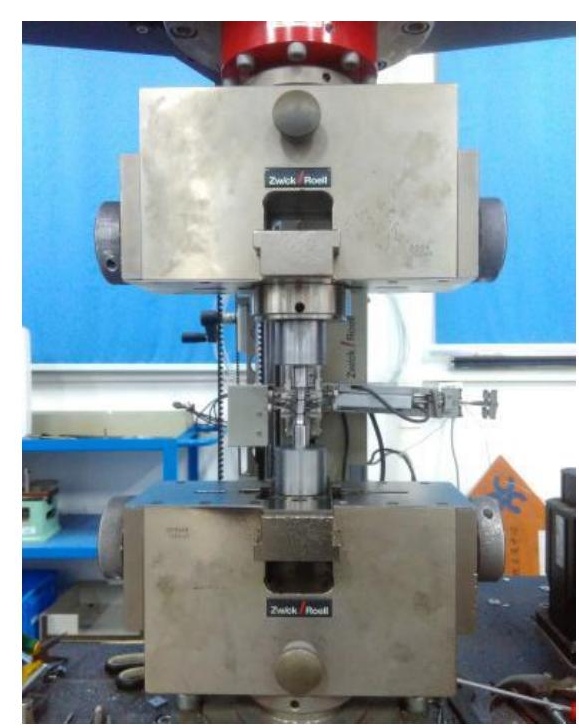

(a) Loading device

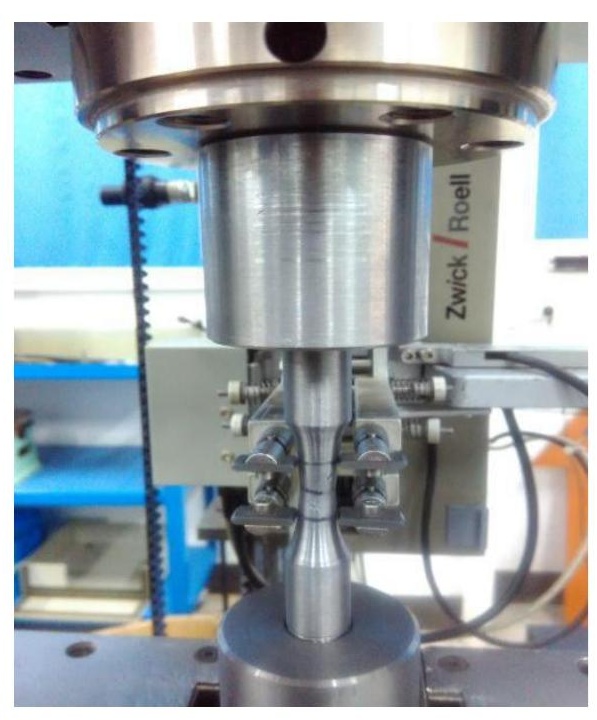

(b) Extensometer 


\subsubsection{Test results}

The stress and strain curves obtained during the test are shown in Fig. 5. Only one typical stress-strain curve for each type of the specimens was presented while the obtained mechanical properties were averaged and listed in
Table 5, including the yield strength $\sigma_{\mathrm{y}}$, tensile strength $\sigma_{\mathrm{u}}$, elastic modulus $E$, diameter at fracture $d_{\mathrm{f}}$ which was measured by a microscope after the tests, as shown in Fig. 6, fracture load $N_{\mathrm{f}}$, fracture stress $\sigma_{\text {true,f, }}$ and the calculated corresponding fracture strain $\varepsilon_{\text {true,f. }}$

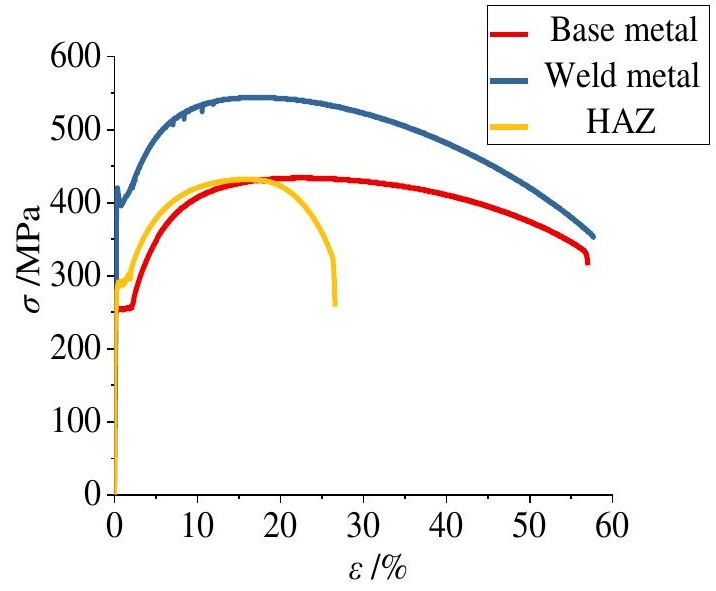

(a) Q235B

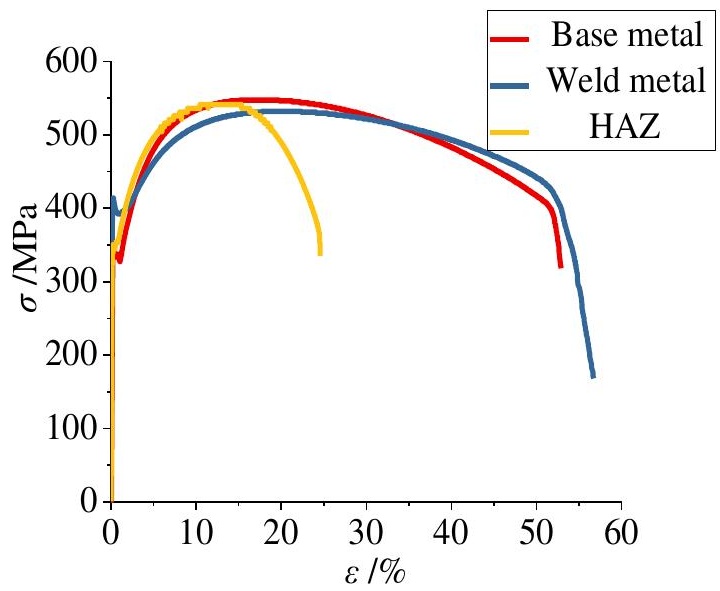

(b) Q345B

Fig. 5 Stress-strain curves

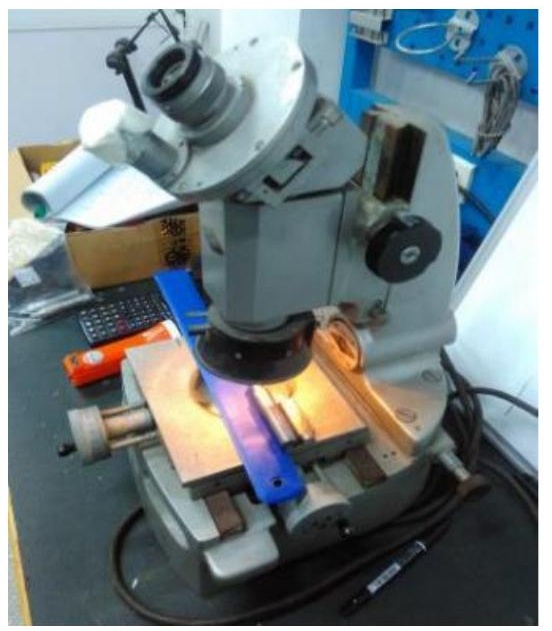

Fig. 6 Microscope setup

Table 5

Measured material properties from tensile coupon tests

\begin{tabular}{|c|c|c|c|c|c|c|c|c|c|}
\hline Material & Position & ID & $\sigma_{\mathrm{y}} / \mathrm{MPa}$ & $\sigma_{\mathrm{u}} / \mathrm{Mpa}$ & $E / \mathrm{Mpa}$ & $d_{\mathrm{f}} / \mathrm{mm}$ & $N_{\mathrm{f}} / \mathrm{kN}$ & $\sigma_{\text {true }, \mathrm{f}} / \mathrm{Mpa}$ & $\varepsilon_{\text {ture, }}$ \\
\hline \multirow{9}{*}{ Q235B } & \multirow{3}{*}{$\begin{array}{l}\text { Base } \\
\text { metal }\end{array}$} & BML-1 & 258.03 & 437.96 & 219164 & 6.339 & 25.10 & 795.42 & 0.903 \\
\hline & & BML-2 & 253.78 & 427.16 & 217251 & 5.966 & 26.20 & 937.19 & 1.031 \\
\hline & & Average & 255.91 & 432.56 & 218208 & 6.153 & 25.65 & 866.31 & 0.967 \\
\hline & \multirow{3}{*}{$\begin{array}{l}\text { Weld } \\
\text { metal }\end{array}$} & WML-1 & 396.64 & 544.59 & 208176 & 5.410 & 27.70 & 1205.02 & 1.227 \\
\hline & & WML-2 & 398.40 & 547.35 & 203673 & 5.407 & 28.40 & 1237.08 & 1.230 \\
\hline & & Average & 397.52 & 545.97 & 205924 & 5.559 & 28.05 & 1159.35 & 1.170 \\
\hline & \multirow{3}{*}{ HAZ } & HML-1 & 287.58 & 433.40 & 115861 & 3.047 & 6.36 & 872.50 & 1.000 \\
\hline & & HML-2 & 301.10 & 448.57 & 114105 & 3.044 & 6.48 & 890.66 & 0.967 \\
\hline & & Average & 295.09 & 437.95 & 114983 & 3.058 & 6.32 & 860.80 & 0.976 \\
\hline \multirow{9}{*}{ Q345B } & \multirow{3}{*}{$\begin{array}{l}\text { Base } \\
\text { metal }\end{array}$} & BMH-1 & 346.64 & 558.30 & 184330 & 6.023 & 31.01 & 1088.18 & 0.994 \\
\hline & & BMH-2 & 342.57 & 560.22 & 196011 & 5.991 & 31.30 & 1110.38 & 1.002 \\
\hline & & Average & 344.61 & 559.26 & 190171 & 6.007 & 31.15 & 1099.28 & 0.998 \\
\hline & \multirow{3}{*}{ Weld metal } & WMH-2 & 390.10 & 526.10 & 212135 & 6.209 & 31.90 & 1053.50 & 0.955 \\
\hline & & WMH-3 & 394.60 & 535.54 & 205078 & 6.340 & 32.60 & 1032.74 & 0.905 \\
\hline & & Average & 392.35 & 530.82 & 208607 & 6.275 & 32.25 & 1043.12 & 0.930 \\
\hline & \multirow{3}{*}{ HAZ } & НMH-1 & 353.06 & 541.30 & 112120 & 2.729 & 7.18 & 1227.60 & 1.218 \\
\hline & & HMH-2 & 358.42 & 559.24 & 118395 & 2.928 & 7.69 & 1142.67 & 1.070 \\
\hline & & Average & 355.74 & 550.27 & 115258 & 2.829 & 7.44 & 1185.14 & 1.144 \\
\hline
\end{tabular}


The measured engineering stress-strain responses were converted into true stress $\sigma_{\text {true }}$ and $\log$ plastic strain $\varepsilon_{\text {p }}$ using Eqs. 6 and 7

$\varepsilon_{\text {true }}=\ln \left(1+\varepsilon_{\text {eng }}\right)$

$\sigma_{\text {true }}=\sigma_{\text {eng }}\left(1+\varepsilon_{\text {eng }}\right)$

$\varepsilon_{p}=\varepsilon_{\text {true }}-\frac{\sigma_{\text {true }}}{E}$

where $\sigma_{\text {eng }}$ and $\varepsilon_{\text {eng }}$ are the engineering stress and strain, respectively while $E$ is the Young's modulus. From the onset of necking during the tensile tests, the elongation was no longer uniform within the gauge length but concentrated in the necking area. Therefore, the stress-strain curves obtained from the tests were used till the onset of necking and extended to the point of fracture, which can be calculated with Eqs. 9 and 10.

$\sigma_{\text {true }, f}=P_{f} /\left(\pi d_{f}^{2} / 4\right)$

$\varepsilon_{\text {true }, f}=\ln \left[\left(d_{0} / d_{f}\right)^{2}\right]$

where $d_{f}$ is the fracture diameter and was measured by a microscope, as shown in Fig. 6. The obtained true stress-plastic strain response was extended to fracture and is shown in Fig. 7 and was later input into finite element analyses software in multi-linear form.

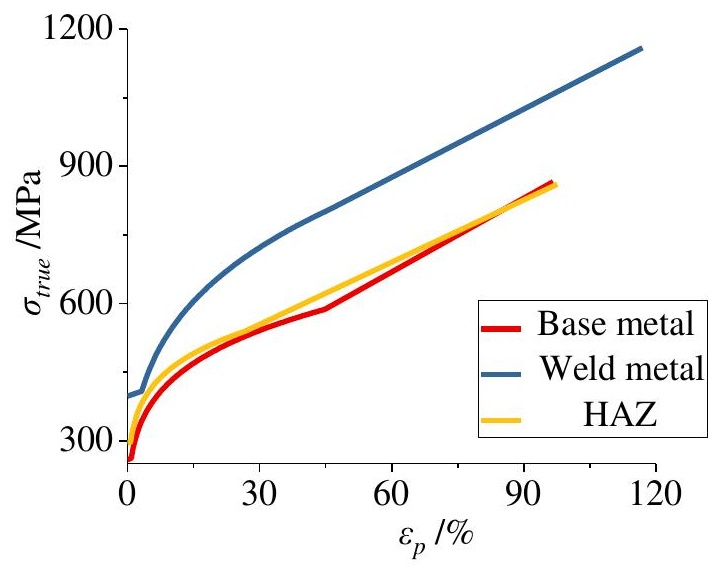

(a) Q235B

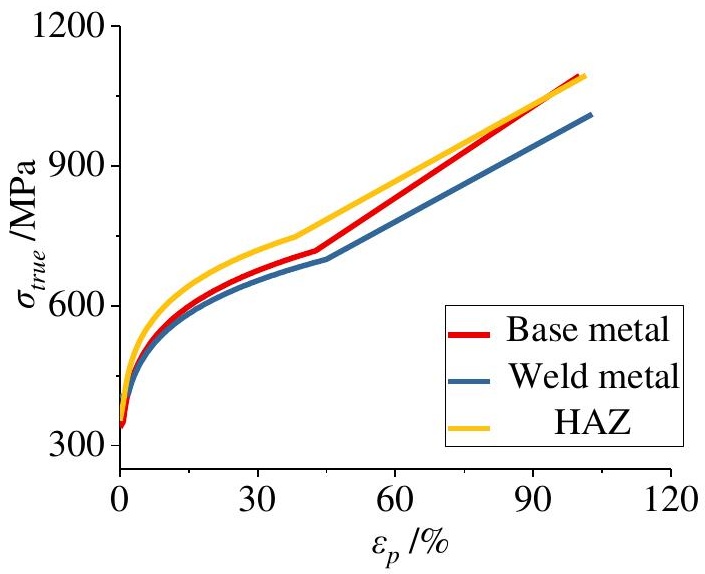

(b) Q345B

Fig. 7 True stress-plastic strain curves

\subsubsection{Fracture surface analysis}

Scanning electron microscope (SEM) measurements were taken at the Electron Microscopy Scanning Laboratory of School of Materials Science and Technology, Tsinghua University. Scanning electron microscope Quanta FEG 450 was used to observe the crystal shapes and fracture morphologies of all tested samples.

The macroscopic morphology of a typical fracture section is shown in Fig. 8. The fracture surface is composed of three parts: fibre zone, radiation zone, and shear lip zone, which corresponds to crack initiation zone, crack propagation zone, and shear fracture zone ${ }^{[19,21]}$. The fibre zone is located at the centre of the fracture. The macroscopic morphology of this zone shows a sawtooth fracture surface formed by microscopic voids. The radiation zone shows the rapid and unstable crack propagation. The out edge of the fracture surface is the shear lip zone, where the material fractured under shear force, with a smooth surface. The morphology shows that crack initiated from the centre and propagated through the whole section.

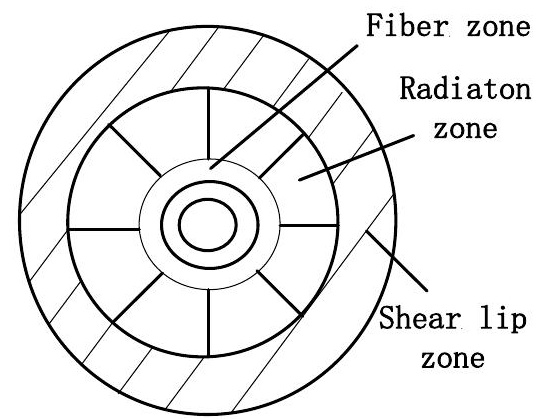

(a) Schematic drawing of the fracture section

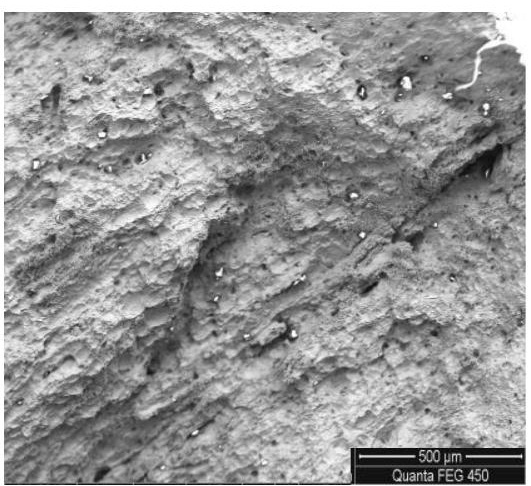

(b) Fibre zone fracture morphology

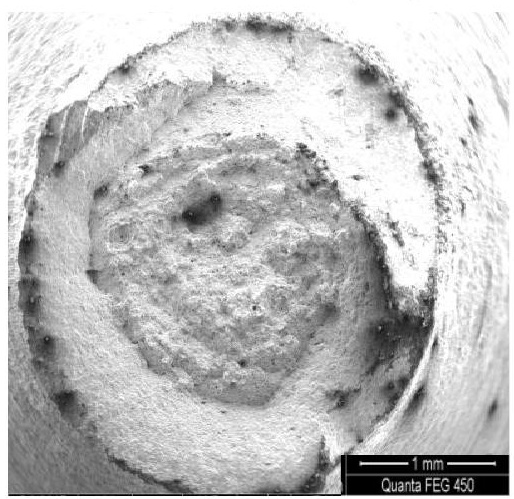

(c) Fracture section morphology

Fig. 8 Macroscopic fracture morphology

The commonly used structure steel often experiences ductile fracture with high level of plastic deformation. The microscopic morphology of a typical fracture surface is shown in Fig. 9. Dimples with different shapes, sizes, and depths can be observed on the fracture surface. The size and depth of the dimples are related to the stress state and the number of void nucleation. The dimples observed from the centre of fracture surface are mostly large and deep, showing good plasticity of the Q235B and Q345B. 

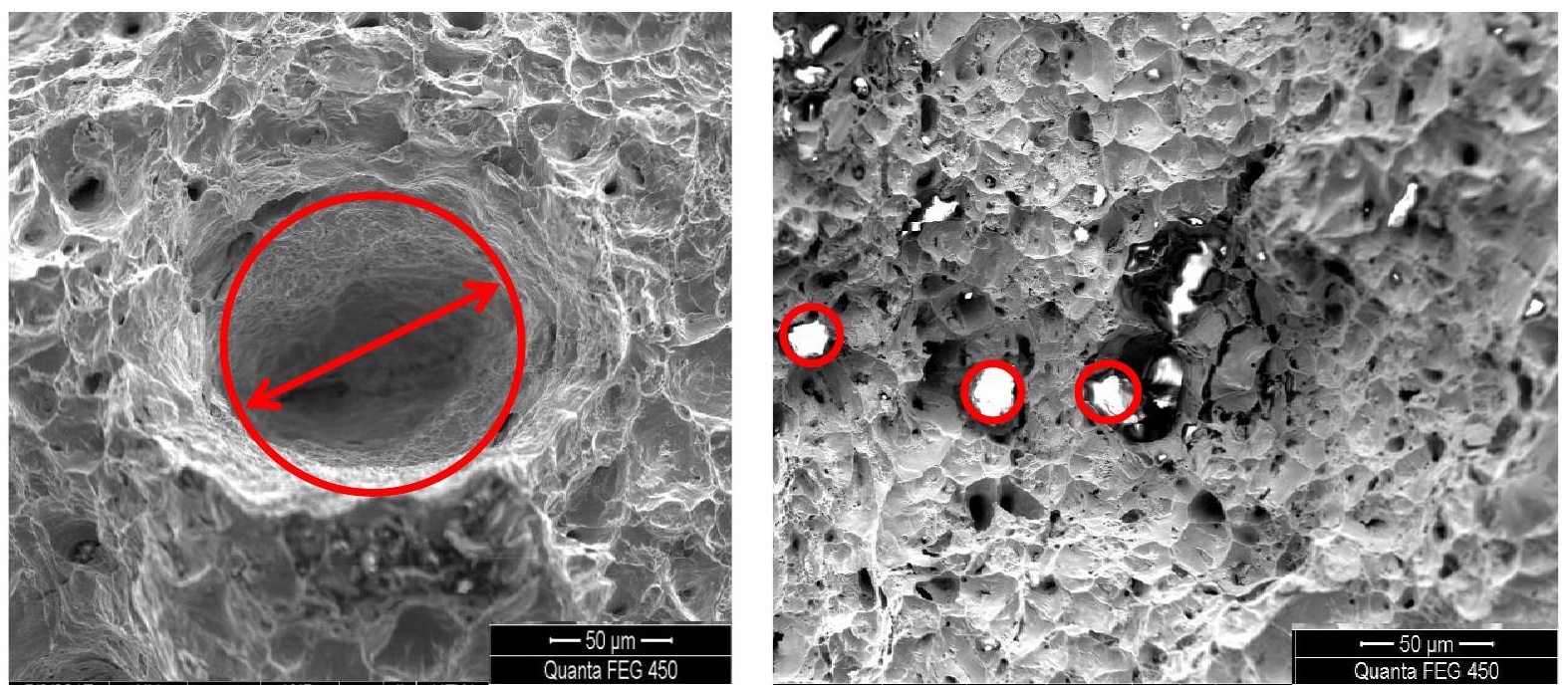

Fig. 9 Scanning electron microscope morphology

\subsection{Smooth-notched tensile test (SNTT)}

\subsubsection{Test specimens and test setup}

Smooth-notched tensile coupons were extracted from steel Q235B and Q345B welded plates at the positions of base metal, weld metal and HAZ. Three notch radii $R, 1.25,2.50$ and $5.00 \mathrm{~mm}$ were designed to consider different stress triaxiality conditions. The geometry of notched specimens is shown in Fig. 10, while the relative positions of specimens on the welded plate are shown in Fig. 11. Two repetitive tests were carried out for each type of coupon and the average response were used later on. A total of 36 specimens were carried out. All specimens were tested using the Zwick universal material testing machine and the whole stress-strain response was recorded until fracture. The test setup is shown in Fig. 12.

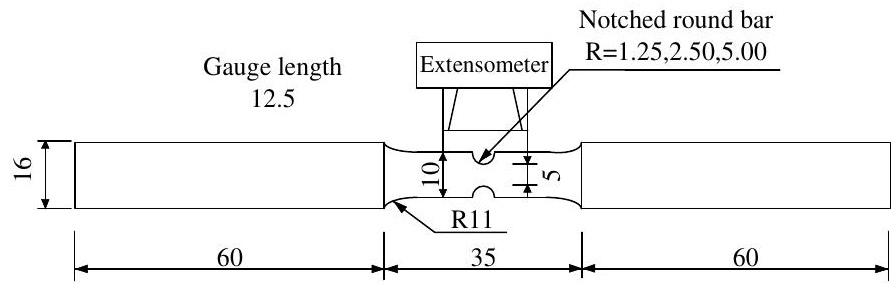

Fig. 10 Geometry of notched round bar specimen

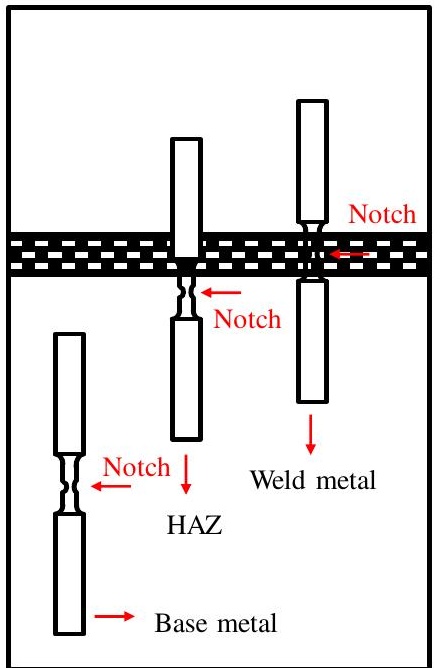

Fig. 11 Specimens layout

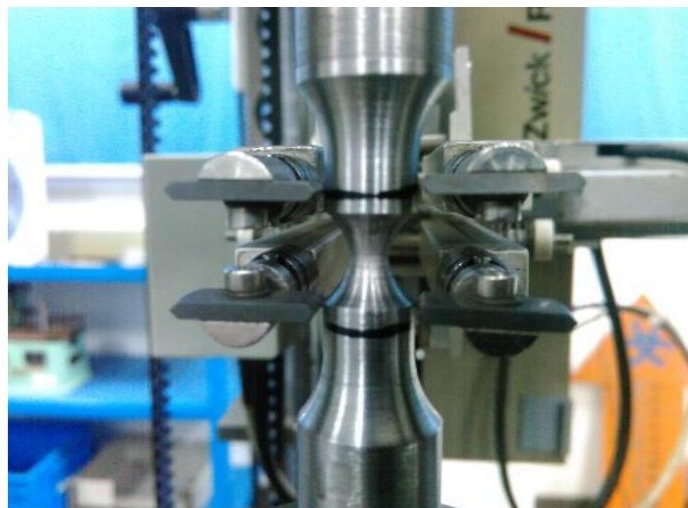

Fig. 12 Test setup

\subsubsection{Test results}

The load-displacement curves obtained from the notched bar tensile tests are shown in Fig. 13. It can be observed that all the curves have a sudden change in slope, the point with slope discontinuity is taken as the fracture initiation point. The displacement at this point was later used in the finite element analysis for the micromechanical model calibration. The obtained test results including ultimate load $N_{\mathrm{u}}$, fracture load $N_{\mathrm{f}}$ and fracture displacement $\delta_{\mathrm{f}}$ are summarised in Tables 6 and 7, for Q235B and Q345B, respectively. $d_{0}$ represents the diameter of the specimens prior to the tests. The specimens are designated with 4 letters here: the first one represents the position of the coupon (B for base metal, W for weld metal and $\mathrm{H}$ for heat affected zone); the second one represents the size of the notch radius in $\mathrm{mm}$ ( $\mathrm{S}$ for $1.25, \mathrm{M}$ for 2.50 and $\mathrm{L}$ for 5.00); the third letter $\mathrm{M}$ represents monotonic loading; the last one represents the material of the coupon (L for Q235B and H for Q345B). According to the experimental results, it can be concluded that with the increase of the notch radius of the test piece, the yield load and ultimate load of the test piece both decreases, and the displacement of the fracture increases, indicating that the larger the notch radius, the better the test piece toughness. 


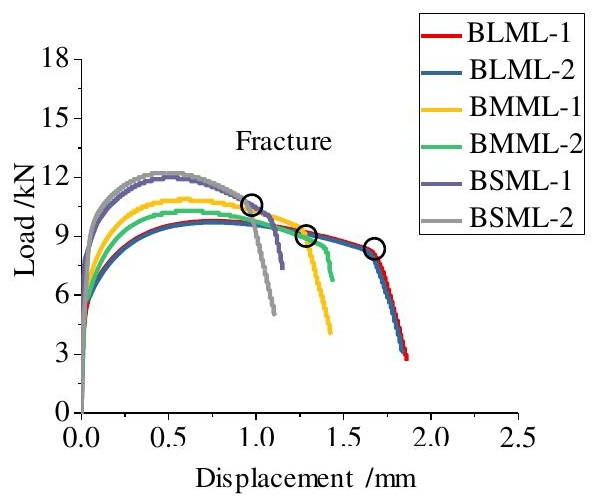

(a) Q235B base metal

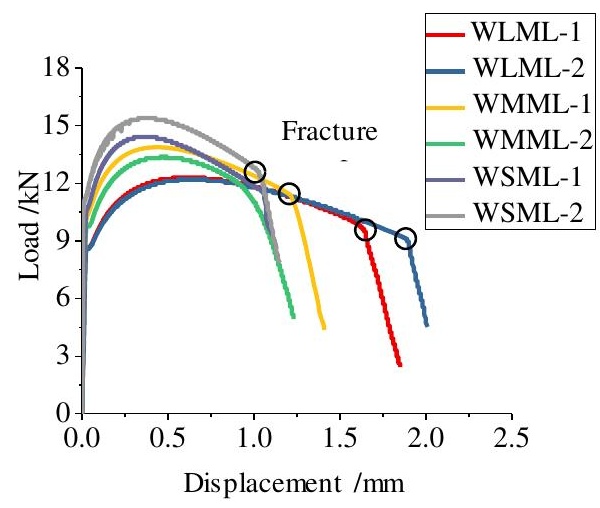

(c) Q235B weld metal

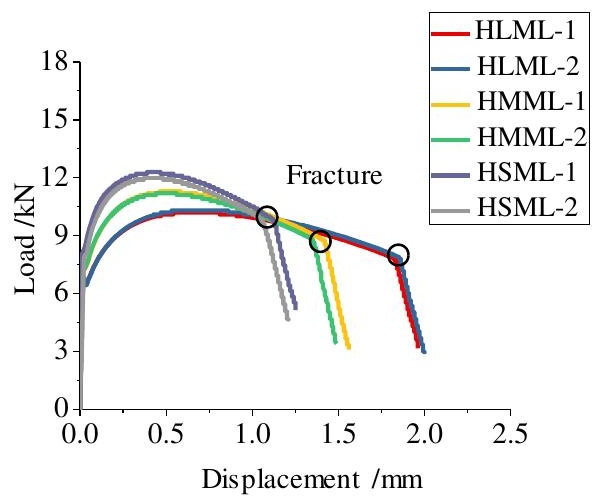

(e) Q235B HAZ

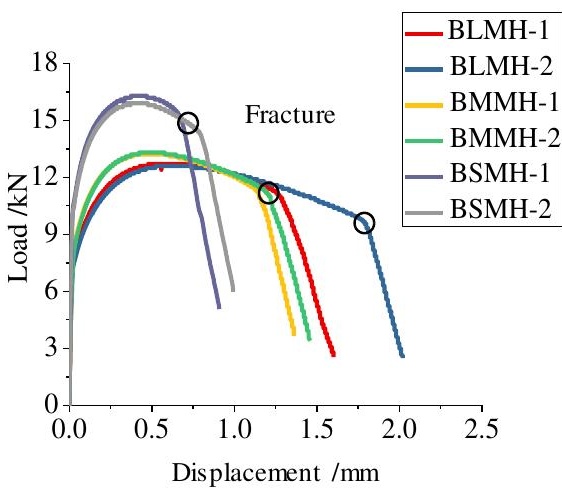

(b) Q345B base metal

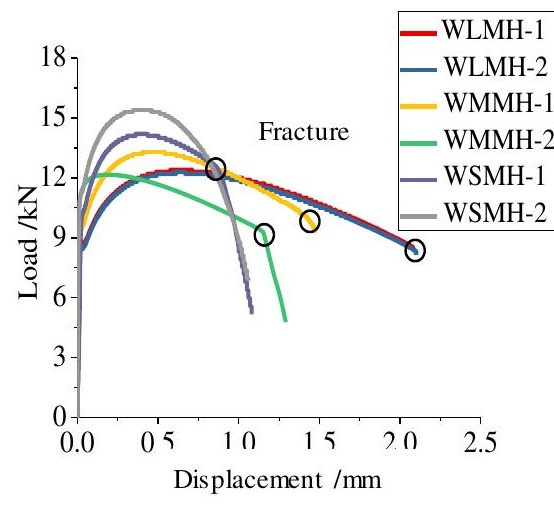

(d) Q345B weld metal

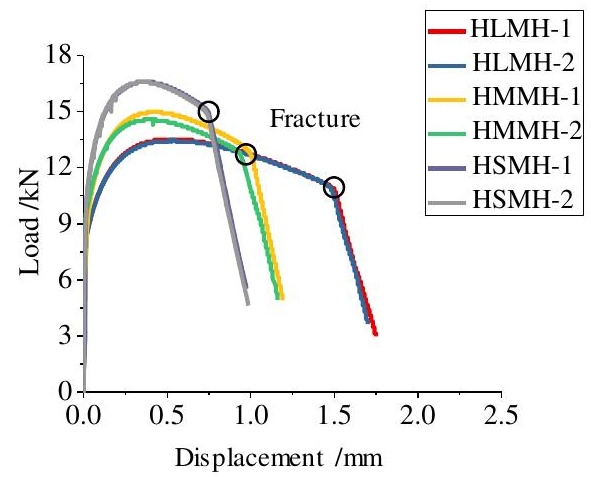

(f) Q345B HAZ

Fig. 13 Load-displacement curves

Table 6

Experimental results of Q235B steel

\begin{tabular}{|c|c|c|c|c|c|c|}
\hline Position & $R / \mathrm{mm}$ & ID & $d_{f} / d_{0}$ & $\delta_{f} / \mathrm{mm}$ & $N_{\mathrm{f}} / \mathrm{kN}$ & $N_{\mathrm{u}} / \mathrm{kN}$ \\
\hline \multirow{6}{*}{ Base metal } & \multirow{2}{*}{1.25} & BSML-1 & 0.768 & 1.08 & 10.11 & 12.00 \\
\hline & & BSML-2 & 0.762 & 0.94 & 10.90 & 12.20 \\
\hline & \multirow{2}{*}{2.50} & BMML-1 & 0.756 & 1.27 & 9.30 & 10.90 \\
\hline & & BMML-2 & 0.759 & 1.40 & 8.36 & 10.30 \\
\hline & \multirow{2}{*}{5.00} & BLML-1 & 0.699 & 1.66 & 8.25 & 9.77 \\
\hline & & BLML-2 & 0.722 & 1.65 & 8.18 & 9.71 \\
\hline \multirow{6}{*}{ Weld metal } & \multirow{2}{*}{1.25} & WSML-1 & 0.748 & 1.06 & 11.50 & 14.40 \\
\hline & & WSML-2 & 0.699 & 1.03 & 12.60 & 15.40 \\
\hline & \multirow{2}{*}{2.50} & WMML-1 & 0.694 & 1.22 & 10.30 & 13.40 \\
\hline & & WMML-2 & 0.711 & 1.04 & 11.36 & 13.88 \\
\hline & \multirow{2}{*}{5.00} & WLML-1 & 0.665 & 1.65 & 9.48 & 12.30 \\
\hline & & WLML-2 & 0.621 & 1.89 & 9.11 & 12.20 \\
\hline \multirow{3}{*}{ HAZ } & \multirow{2}{*}{1.25} & HSML-1 & 0.735 & 1.13 & 9.75 & 12.30 \\
\hline & & HSML-2 & 0.703 & 1.06 & 9.90 & 12.00 \\
\hline & 2.50 & HMML-1 & 0.682 & 1.42 & 8.74 & 11.30 \\
\hline
\end{tabular}




\begin{tabular}{llllll} 
& HMML-2 & 0.679 & 1.35 & 8.81 & 11.20 \\
\hline \multirow{2}{*}{5.00} & HLML-1 & 0.667 & 1.83 & 7.78 & 10.20 \\
\cline { 2 - 7 } & HLML-2 & 0.671 & 1.86 & 7.80 & 10.30 \\
\hline
\end{tabular}

Table 7

Experimental results of Q345B steel

\begin{tabular}{|c|c|c|c|c|c|c|}
\hline Position & $R / \mathrm{mm}$ & ID & $d_{f} / d_{0}$ & $\delta_{f} / \mathrm{mm}$ & $N_{\mathrm{f}} / \mathrm{kN}$ & $N_{\mathrm{u}} / \mathrm{kN}$ \\
\hline \multirow{6}{*}{ Base Metal } & \multirow{2}{*}{1.25} & BSMH-1 & 0.820 & 0.69 & 14.70 & 16.30 \\
\hline & & BSMH-2 & 0.760 & 0.80 & 14.40 & 15.90 \\
\hline & \multirow{2}{*}{2.50} & BMMH-1 & 0.730 & 1.15 & 11.20 & 13.20 \\
\hline & & BMMH-2 & 0.700 & 1.22 & 11.00 & 13.30 \\
\hline & \multirow{2}{*}{5.00} & BLMH-1 & 0.730 & 1.29 & 11.00 & 12.70 \\
\hline & & BLMH-2 & 0.730 & 1.79 & 9.67 & 12.60 \\
\hline \multirow{6}{*}{ Weld metal } & \multirow{2}{*}{1.25} & WSMH-1 & 0.756 & 0.89 & 12.10 & 14.20 \\
\hline & & WSMH-2 & 0.787 & 0.90 & 11.50 & 15.40 \\
\hline & \multirow{2}{*}{2.50} & WMMH-1 & 0.563 & 1.15 & 9.24 & 12.20 \\
\hline & & WMMH-2 & 0.548 & 1.42 & 9.98 & 13.30 \\
\hline & \multirow{2}{*}{5.00} & WLMH-1 & 0.578 & 2.08 & 8.53 & 12.40 \\
\hline & & WLMH-2 & 0.601 & 2.10 & 8.32 & 12.30 \\
\hline \multirow{6}{*}{ HAZ } & \multirow{2}{*}{1.25} & HSMH-1 & 0.769 & 0.75 & 15.00 & 16.60 \\
\hline & & HSMH-2 & 0.770 & 0.75 & 14.80 & 16.60 \\
\hline & \multirow{2}{*}{2.50} & НMМН-1 & 0.730 & 1.00 & 12.80 & 15.00 \\
\hline & & HMMH-2 & 0.740 & 0.94 & 12.80 & 14.60 \\
\hline & \multirow{2}{*}{5.00} & HLMH-1 & 0.674 & 1.50 & 10.90 & 13.50 \\
\hline & & HLMH-2 & 0.685 & 1.48 & 11.00 & 13.50 \\
\hline
\end{tabular}

The reduction in area was calculated from the test results. Together with the fracture displacement and ultimate load, the comparisons are summarised in Fig. 14, where the average value of each notch size is used. It can be seen

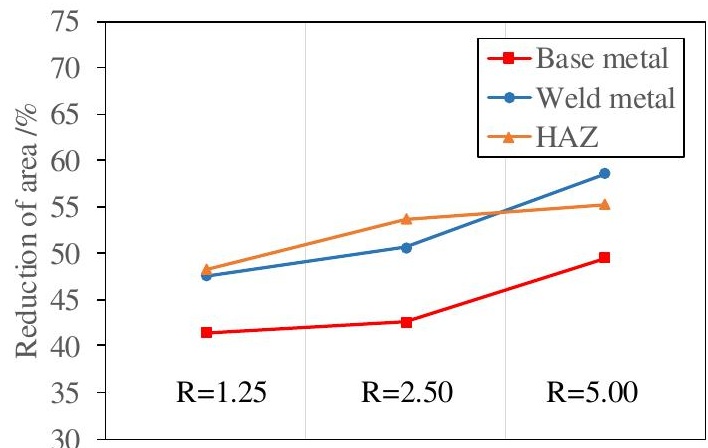

(a) Q235B reduction of area comparisons

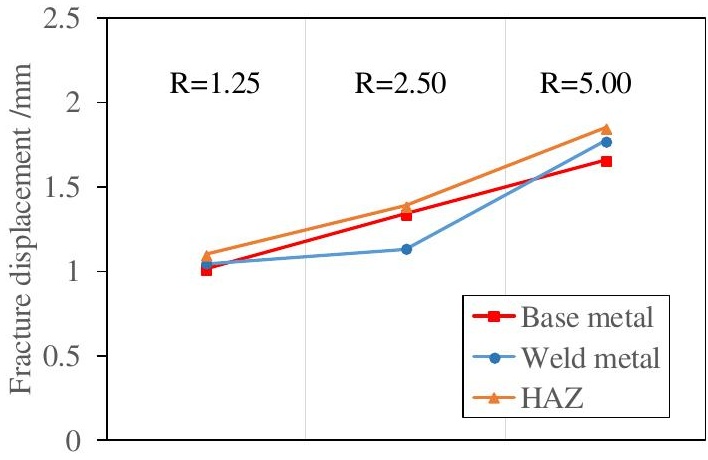

(c) Q235B displacement comparisons that for most specimens the reduction in area increases with increase notch size, while the percentage reduction in area for the weld metal of Q345B is generally higher, showing better ductility.

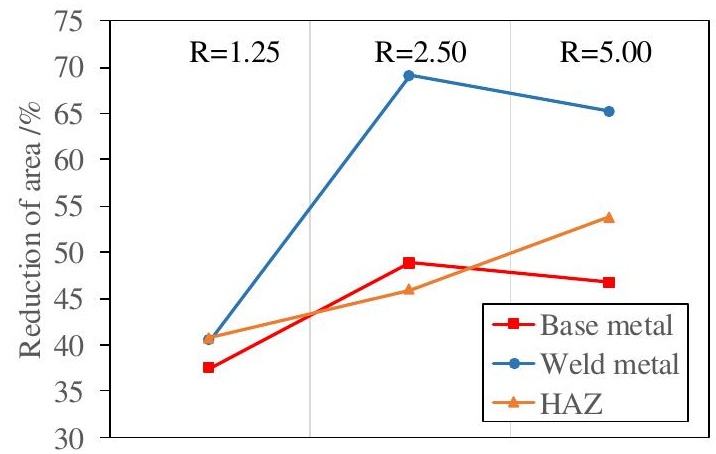

(b) Q345B reduction of area comparisons

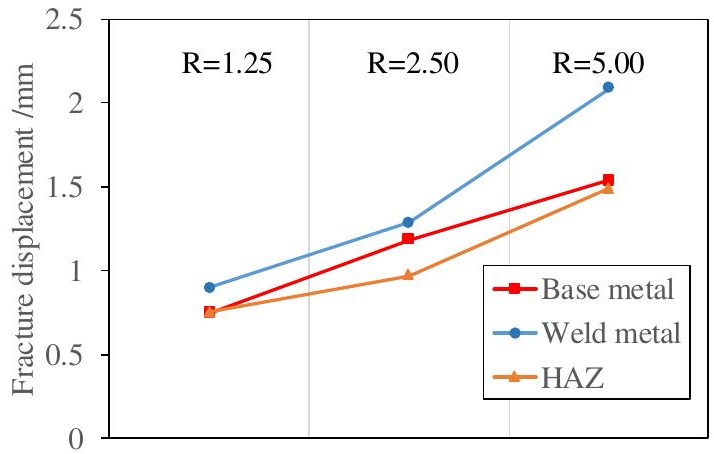

(d) Q345B displacement comparisons 


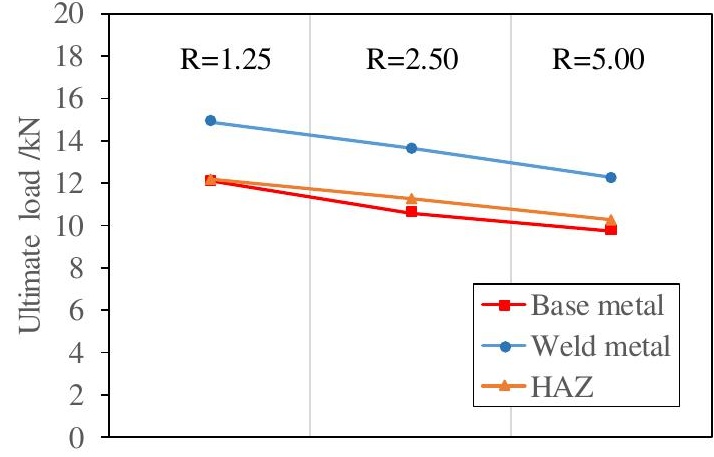

(e) Q235B load comparisons

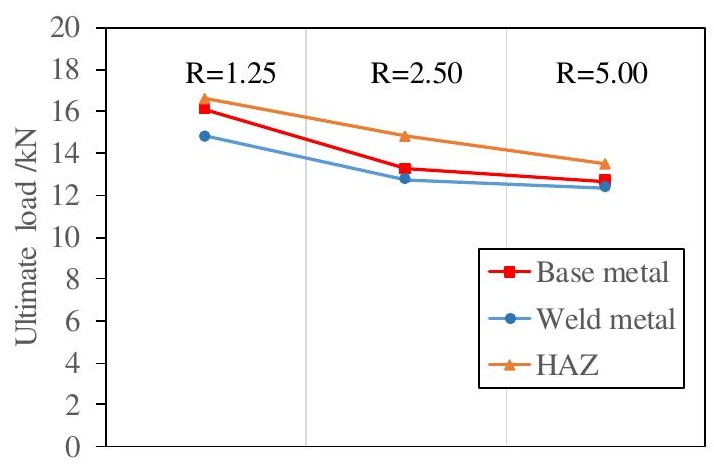

(f) Q345B load comparisons

Fig. 14 Test results comparisons

According to the results of the notch round bar tensile tests in Fig. 14, it can be seen that: (1) As the radius of the notch of the round bar increases, the ultimate load decreases, while the displacement at the time of failure increases, showing the equivalent plastic strain increases with the triaxiality decreases. (2) In general, the tensile strength and plasticity of weld region for Q235B steel are higher than that of base metal, showing good welding performance. (3) Sedimentary cladding metal of Q345B steel is more plastic than the base metal, while the tensile strength is slightly lower than that of the base metal, and the tensile strength of heat affected zone is enhanced. The properties of the deposited metal are slightly different from those of the Q235 B weld. The reason may be that the weld pool is wider. The fusion of Q345 B steel and weld seam is weaker than that of Q235 B weld. The heat affected zone of the heated edge is prone to hardening under the influence of thermal cycling.

\subsubsection{Macroscopic fracture analysis}

Same as in 3.3.1 scanning electron microscope (SEM) measurements were taken for all specimens. The upper and lower limits of the characteristic length $l^{*}$, a parameter of microscopic mechanism models, were obtained from the measurements.
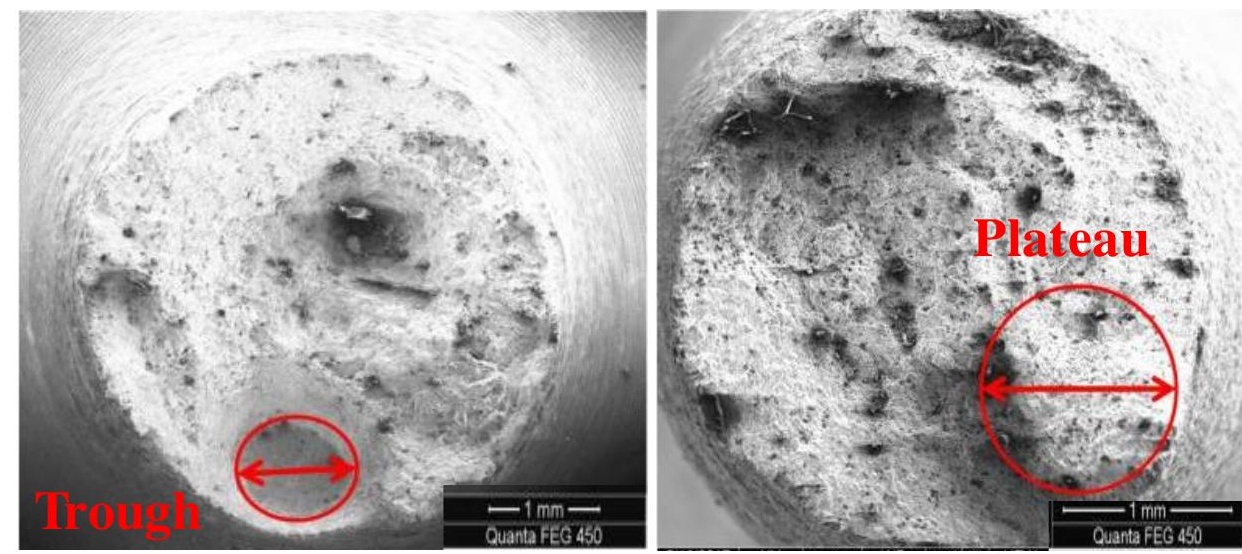

(a) Upper limit of characteristic length
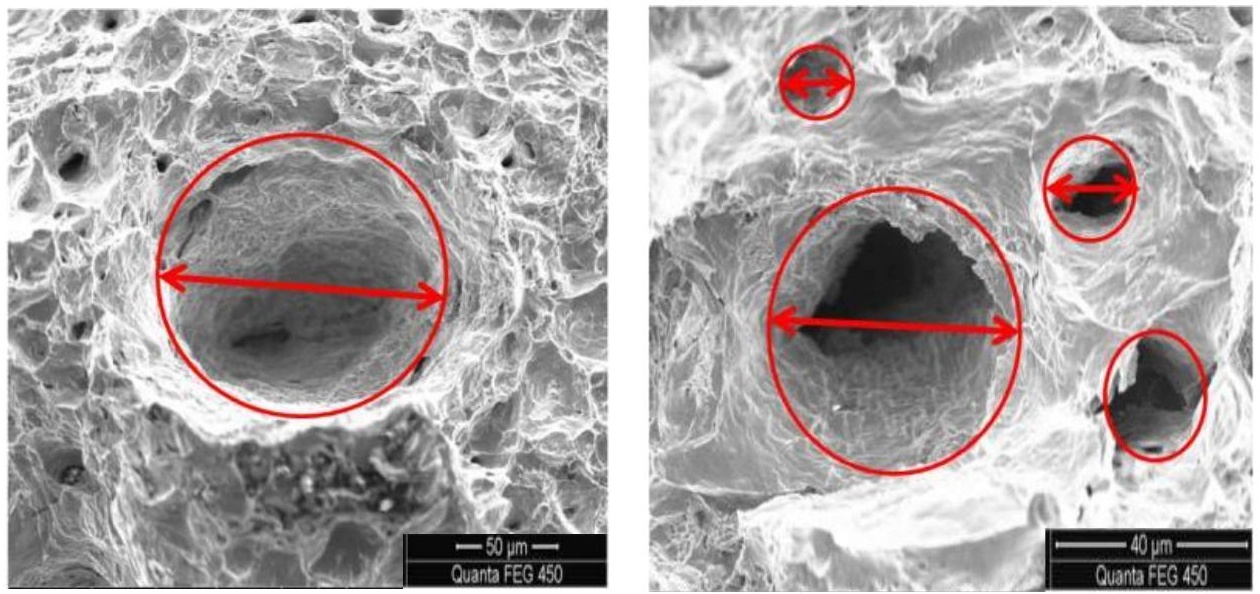

(b) Lower limit of characteristic length

Fig. 15 SEM measurements of typical fracture surfaces

Micromechanics-based model assumes crack initiation at coalescence of adjacent voids. The lower limit of the characteristic length is twice the diameter of the average dimple, while the upper limit is the size of the largest plateau or trough observed in the fractograph ${ }^{[23]}$. This method might bring scatters to the value of characteristic lengths, thus influencing the material toughness value. The mean value of the characteristic length is taken as the average of 10 measurements of the size of plateaus or troughs. The typical fracture surfaces are shown in Fig. 15. The upper limit, average value and lower limit of the characteristic length are tabulated in Table 8 . 
Table 8

Characteristic length obtained from SEM measurements ( $\mathrm{mm}$ )

\begin{tabular}{|c|c|c|c|c|}
\hline \multirow{2}{*}{ Material } & \multirow{2}{*}{ ID } & \multicolumn{3}{|c|}{ Characteristic length } \\
\hline & & Lower limit & Upper limit & Mean value \\
\hline \multirow{4}{*}{ Q235B base metal } & BSML-1 & 0.051 & 0.513 & 0.236 \\
\hline & BLML-2 & 0.075 & 0.886 & 0.230 \\
\hline & BMML-2 & 0.081 & 0.424 & 0.295 \\
\hline & Average & 0.069 & 0.608 & 0.254 \\
\hline \multirow{4}{*}{ Q235B weld metal } & WLML-2 & 0.054 & 0.325 & 0.187 \\
\hline & WLML-2 & 0.049 & 0.463 & 0.276 \\
\hline & WLML-2 & 0.035 & 0.428 & 0.228 \\
\hline & Average & 0.046 & 0.405 & 0.230 \\
\hline \multirow{4}{*}{ Q235B HAZ } & HSML-1 & 0.072 & 0.470 & 0.193 \\
\hline & HMML-1 & 0.027 & 0.215 & 0.191 \\
\hline & HMML-1 & 0.038 & 0.283 & 0.187 \\
\hline & Average & 0.046 & 0.323 & 0.190 \\
\hline \multirow{4}{*}{ Q345B base metal } & BLMH-2 & 0.041 & 0.804 & 0.590 \\
\hline & BMMH-1 & 0.034 & 0.585 & 0.160 \\
\hline & BSMH-2 & 0.052 & 0.753 & 0.482 \\
\hline & Average & 0.042 & 0.714 & 0.411 \\
\hline \multirow{4}{*}{ Q345B weld metal } & WSMH-2 & 0.068 & 0.385 & 0.297 \\
\hline & WMMH-2 & 0.042 & 0.519 & 0.222 \\
\hline & WLMH-1 & 0.075 & 0.397 & 0.174 \\
\hline & Average & 0.062 & 0.434 & 0.231 \\
\hline \multirow{4}{*}{ Q345B HAZ } & HMMH-1 & 0.045 & 0.502 & 0.148 \\
\hline & HLMH-2 & 0.047 & 0.452 & 0.241 \\
\hline & HSMH-1 & 0.036 & 0.428 & 0.122 \\
\hline & Average & 0.043 & 0.461 & 0.17 \\
\hline
\end{tabular}

\section{Calibration and validation of micromechanical fracture models}

\subsection{Finite element models}

Finite element models corresponding to the notched tensile test specimens were developed to calibrate the facture parameters. The general-propose finite element (FE) package ABAQUS was used. The gauge part of the specimen was simulated with axisymmetric 2-dimensional FE model with axisymmetry boundary conditions along the centre. One end of the gauge part was hinged while the other end was loaded with displacement control. The four-node axisymmetric element CAX4 from the ABAQUS element library was adopted. The geometries of the corresponding test specimens were employed, while the average material properties from the smooth round bar tensile coupon tests were used. Element size in the vicinity of the gap was taken around $0.2 \mathrm{~mm}$, with reference to the aforementioned average value of characteristic length $l^{*}$ obtained in the SEM measurements, as shown in Fig. 16. The fracture points obtained from the notched tensile tests, as shown in Fig. 13, were used for displacement control in the models. The load-displacement curves from the tests and FE models are compared in Figs. 17 and 18, for Q235B and Q345B respectively.

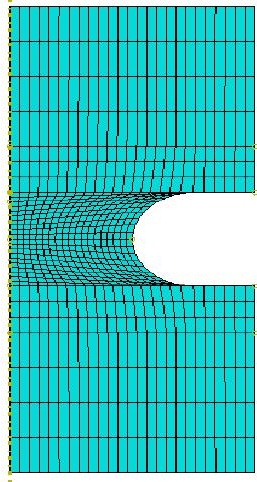

(a) $R=1.25 \mathrm{~mm}$

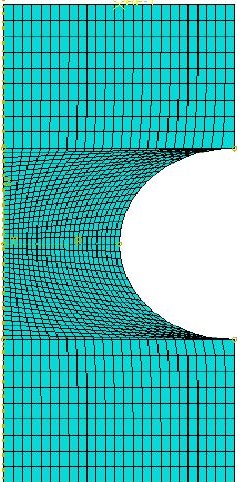

(b) $R=2.50 \mathrm{~mm}$

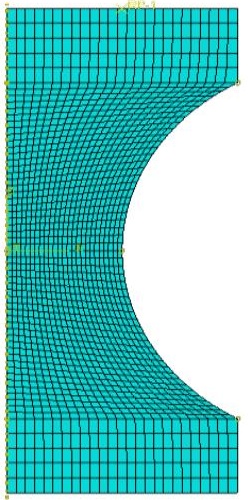

(c) $R=5.00 \mathrm{~mm}$

Fig. 16 Finite element model mesh 


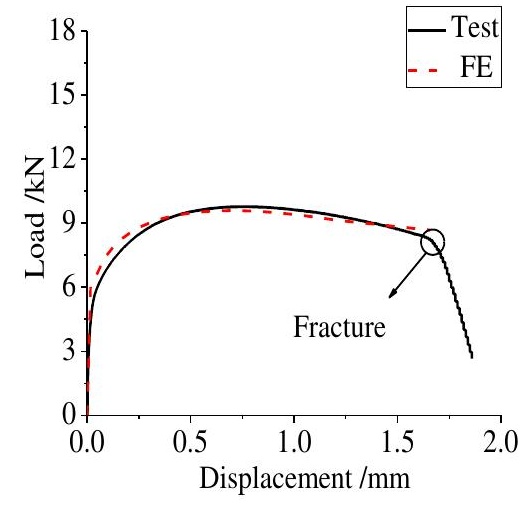

(a)BLML-1

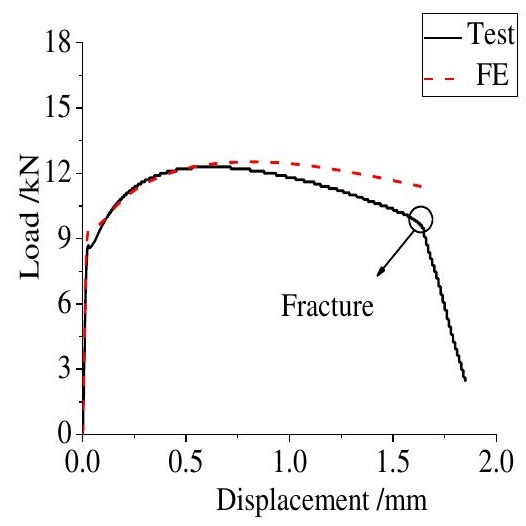

(d)WLML-1

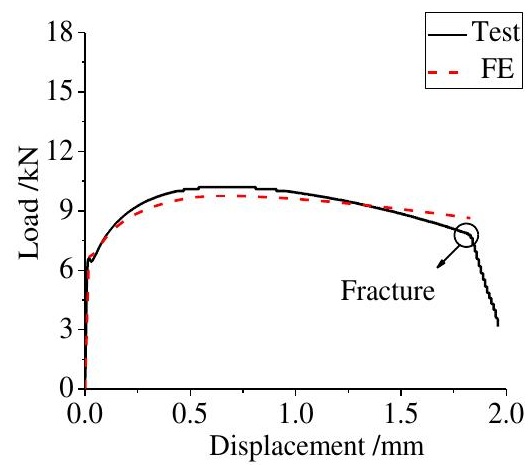

(g)HLML-1

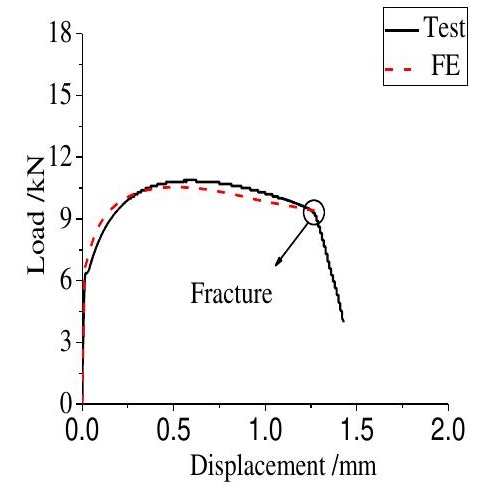

(b)BMML-1

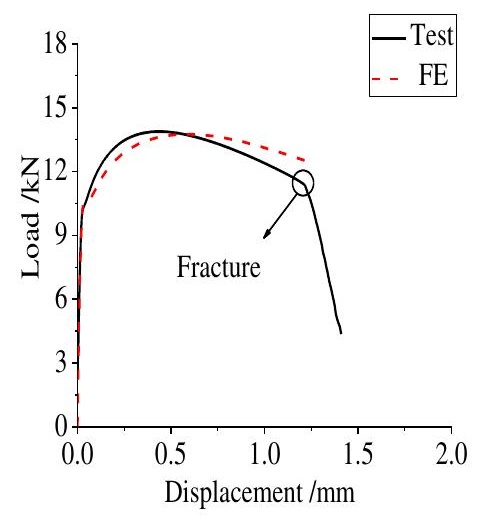

(e)WMML-1

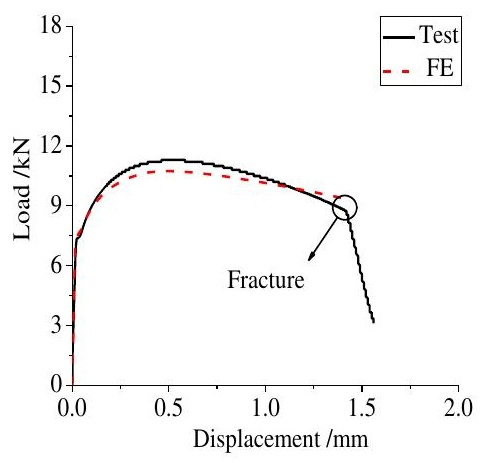

(h)HMML-1

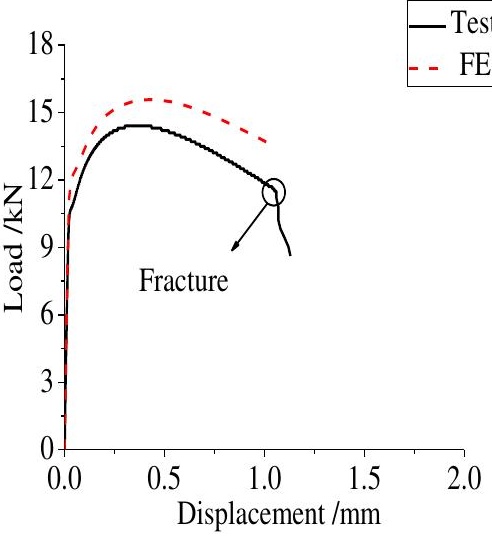

(f)WSML-1

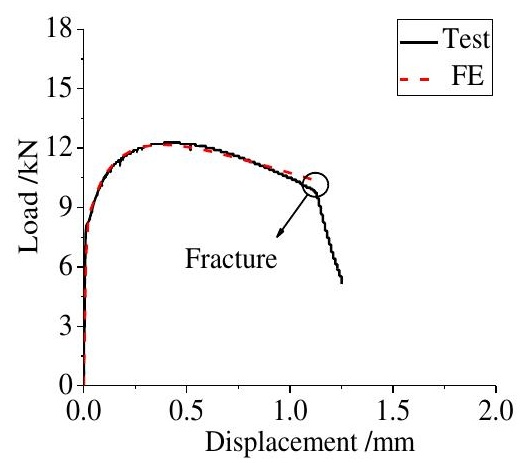

(i)HSML-1

Fig. 17 Load-displacement curves of Q235B

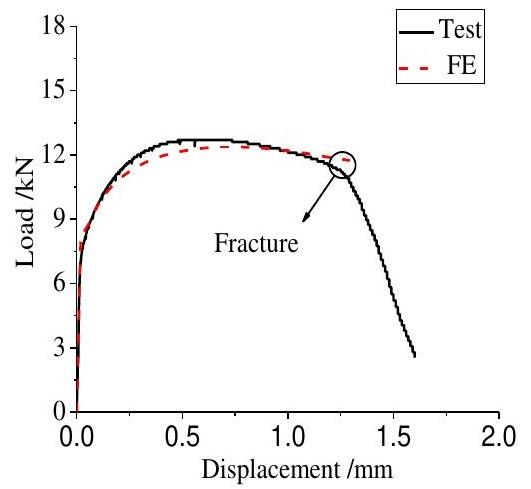

(a)BLMH-1

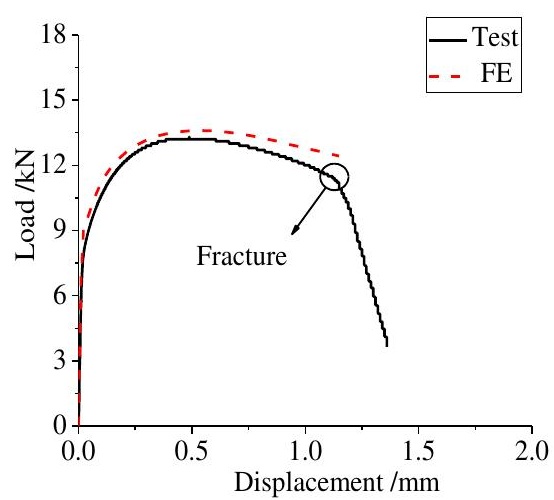

(b)BMMH-1

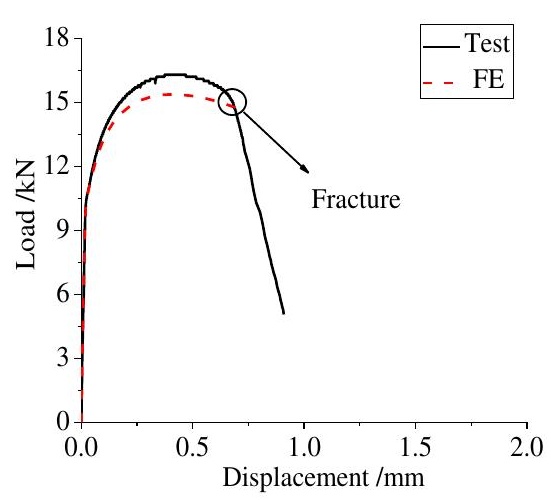

(c)BSMH-1 


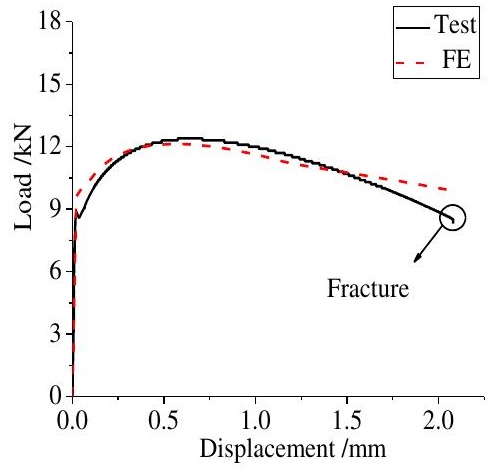

(c)WLMH-1

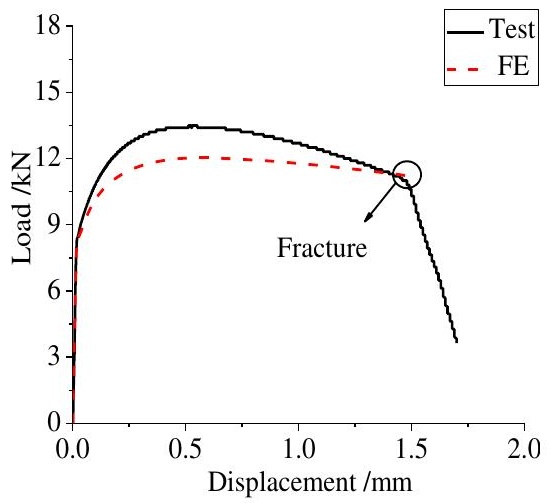

(f)HLMH-1

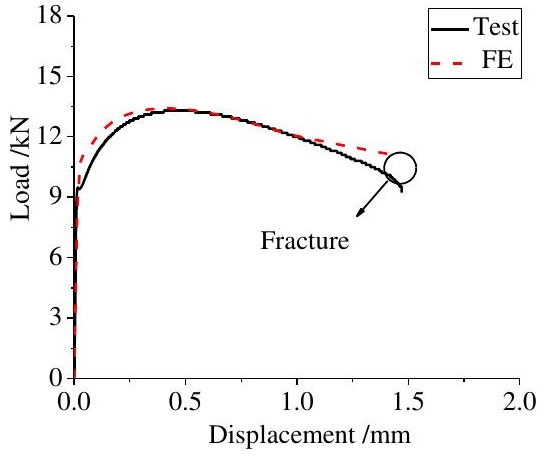

(d)WMMH-1

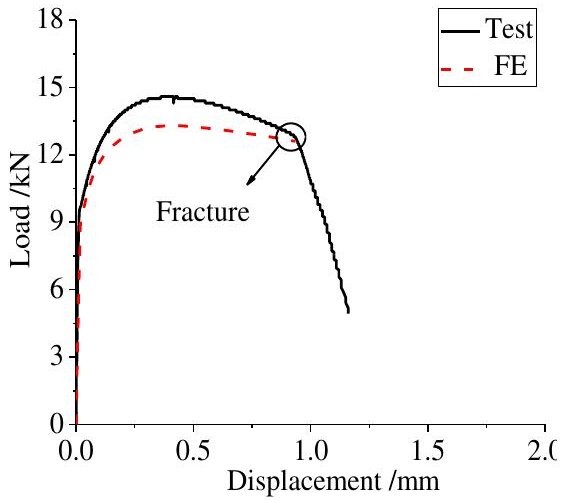

(g)HMMH-1

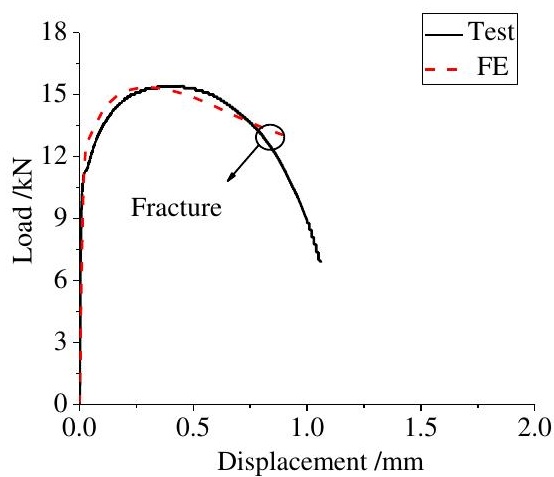

(e)WSMH-1

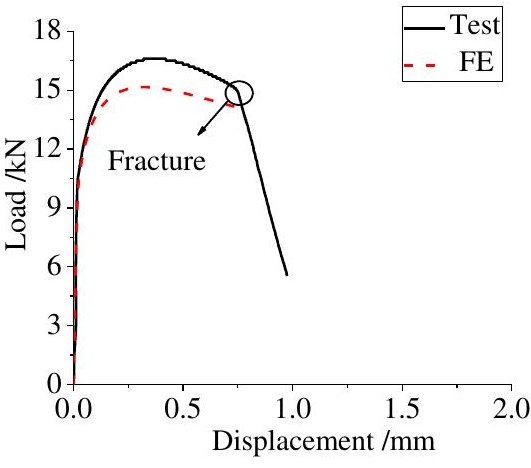

(h)HSMH-1

Fig. 18 Load-displacement curves of Q345B

\subsection{Toughness parameters calibration}

With fracture reaching the critical state, the toughness parameters $\eta_{\text {mon }}$ and $\gamma$, in VGM model and SMCS model respectively, were back-calculated through the UMAT subroutine in ABAQUS. The results at fracture displacement obtained from the finite element models are shown in Tables 9 and 10, where $\varepsilon_{\mathrm{p}, \mathrm{cr}}$ is plastic strain, ${ }^{\sigma_{m}}$ is von Mises stress, ${ }^{e}$ is equivalent stress, ${ }^{{ }_{f}}$ is fracture radius, $T$ is stress triaxiality. The results show that with increasing notch radius, the stress triaxiality $T$ decreases. It can be seen that the toughness parameters $\eta_{\text {mon }}$ and $\gamma$ of Q345B are less scatter than that of the Q235B. That may be caused by the better plasticity of Q235B than that of Q345B, and the equivalent plastic strain varies greatly with the stress triaxiality, showing higher level of microvoid expansion capacity. By comparing the toughness parameters of base material, weld metal and heat affected zone, the values of heat affected zone are relative small, while the average values of these three materials are close, which indicates that the calibrated parameters can be used to predict fracture initiation in welded steel components under different stress state.

Table 9

Calibrations for toughness parameters of Q235B

\begin{tabular}{|c|c|c|c|c|c|c|c|c|c|c|}
\hline Material & $R / \mathrm{mm}$ & ID & $\delta_{\mathrm{f}} / \mathrm{mm}$ & $\varepsilon_{\mathrm{p}, \mathrm{cr}}$ & $\sigma_{\mathrm{m}} / \mathrm{MPa}$ & $d_{\mathrm{f}} / d_{0}$ & $\sigma_{\mathrm{e}} / \mathrm{MPa}$ & $T$ & $\gamma$ & $\eta_{\text {mon }}$ \\
\hline \multirow{6}{*}{$\begin{array}{l}\text { Base } \\
\text { metal }\end{array}$} & \multirow{2}{*}{1.25} & BSML-1 & 1.08 & 0.783 & 680.6 & 0.768 & 768.1 & 0.886 & 2.665 & 2.712 \\
\hline & & BSML-2 & 0.94 & 0.673 & 687.4 & 0.762 & 708.5 & 0.970 & 2.531 & 2.637 \\
\hline & \multirow{2}{*}{2.50} & BMML-1 & 1.27 & 0.637 & 560.2 & 0.756 & 688.8 & 0.813 & 2.094 & 2.311 \\
\hline & & BMML-2 & 1.40 & 0.714 & 564.6 & 0.759 & 730.4 & 0.773 & 2.205 & 2.546 \\
\hline & \multirow{2}{*}{5.00} & BLML-1 & 1.66 & 0.658 & 473.7 & 0.699 & 699.7 & 0.677 & 1.815 & 1.911 \\
\hline & & BLML-2 & 1.65 & 0.653 & 473.0 & 0.722 & 697.3 & 0.678 & 1.807 & 1.899 \\
\hline \multicolumn{9}{|c|}{ Mean value } & 2.186 & 2.408 \\
\hline \multicolumn{9}{|c|}{$\mathrm{COV}$} & 0.16 & 0.15 \\
\hline \multirow{6}{*}{$\begin{array}{l}\text { Weld } \\
\text { metal }\end{array}$} & \multirow{2}{*}{1.25} & WSML-1 & 1.06 & 0.789 & 914.30 & 0.748 & 985.0 & 0.928 & 2.626 & 2.924 \\
\hline & & WSML-2 & 1.03 & 0.765 & 908.93 & 0.697 & 971.8 & 0.935 & 2.555 & 2.827 \\
\hline & \multirow{2}{*}{2.50} & WMML-1 & 1.22 & 0.600 & 741.77 & 0.694 & 881.8 & 0.841 & 1.966 & 1.981 \\
\hline & & WMML-2 & 1.04 & 0.503 & 700.47 & 0.711 & 829.5 & 0.844 & 1.631 & 1.648 \\
\hline & \multirow{2}{*}{5.00} & WLML-1 & 1.65 & 0.621 & 646.80 & 0.665 & 893.0 & 0.724 & 1.834 & 1.745 \\
\hline & & WLML-2 & 1.89 & 0.751 & 714.13 & 0.621 & 967.3 & 0.738 & 2.272 & 2.169 \\
\hline \multicolumn{9}{|c|}{ Mean value } & 2.147 & 2.216 \\
\hline \multicolumn{9}{|c|}{$\mathrm{COV}$} & 0.19 & 0.25 \\
\hline \multirow{2}{*}{ HAZ } & \multirow{2}{*}{1.25} & HSML-1 & 1.13 & 0.845 & 715.3 & 0.735 & 802.9 & 0.891 & 2.683 & 3.609 \\
\hline & & HSML-2 & 1.06 & 0.785 & 707.6 & 0.703 & 775.4 & 0.913 & 2.697 & 3.406 \\
\hline
\end{tabular}




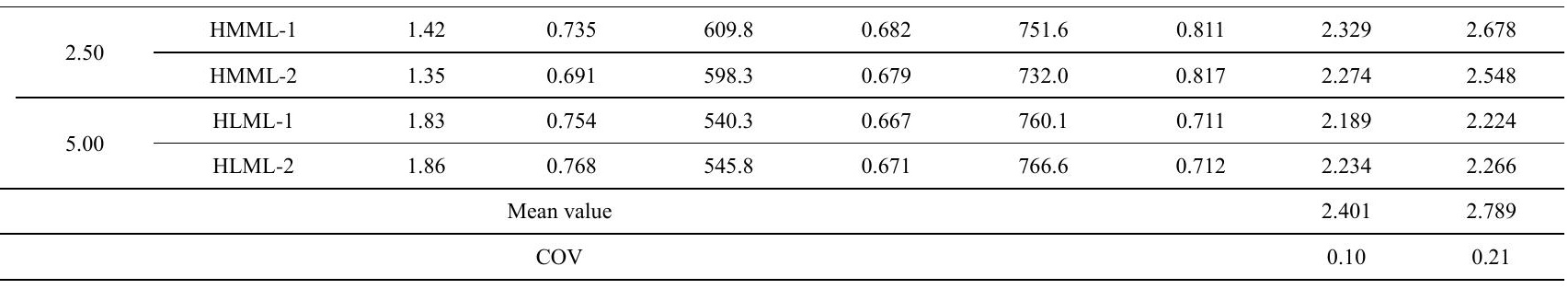

\section{Table 10}

Calibrations for toughness parameters of Q345B

\begin{tabular}{|c|c|c|c|c|c|c|c|c|c|c|}
\hline Material & $R / \mathrm{mm}$ & ID & $\delta_{\mathrm{f}} / \mathrm{mm}$ & $\varepsilon_{\mathrm{p}, \mathrm{cr}}$ & $\sigma_{\mathrm{m}} / \mathrm{MPa}$ & $d_{\mathrm{f}} / d_{0}$ & $\sigma_{\mathrm{e}} / \mathrm{MPa}$ & $T$ & $\gamma$ & $\eta_{\text {mon }}$ \\
\hline \multirow{8}{*}{$\begin{array}{l}\text { Base } \\
\text { metal }\end{array}$} & \multirow{2}{*}{1.25} & BSMH-1 & 0.69 & 0.491 & 850.7 & 0.820 & 761.1 & 1.118 & 2.039 & 2.070 \\
\hline & & BSMH-2 & 0.8 & 0.572 & 873.63 & 0.760 & 813.8 & 1.074 & 2.451 & 2.515 \\
\hline & \multirow{2}{*}{2.50} & BMMH-1 & 1.15 & 0.577 & 697.03 & 0.730 & 816.8 & 0.853 & 2.085 & 2.287 \\
\hline & & BMMH-2 & 1.22 & 0.618 & 708.37 & 0.700 & 843.4 & 0.84 & 2.138 & 2.427 \\
\hline & \multirow{2}{*}{5.00} & BLMH-1 & 1.29 & 0.520 & 583.33 & 0.730 & 779.4 & 0.748 & 1.597 & 1.581 \\
\hline & & BLMH-2 & 1.79 & 0.749 & 623.7 & 0.730 & 929.2 & 0.671 & 2.049 & 2.236 \\
\hline & \multicolumn{8}{|c|}{ Mean value } & 2.060 & 2.186 \\
\hline & \multicolumn{8}{|c|}{$\mathrm{COV}$} & 0.13 & 0.15 \\
\hline \multirow{8}{*}{ Weld metal } & \multirow{2}{*}{1.25} & WSMH-1 & 0.894 & 0.685 & 875.8 & 0.756 & 827.2 & 1.059 & 3.056 & 3.445 \\
\hline & & WSMH-2 & 0.895 & 0.686 & 875.67 & 0.787 & 827.7 & 1.058 & 3.057 & 3.309 \\
\hline & \multirow{2}{*}{2.50} & WMMH-1 & 1.152 & 0.600 & 714.67 & 0.563 & 780.3 & 0.916 & 2.343 & 2.520 \\
\hline & & WMMH-2 & 1.42 & 0.768 & 732.1 & 0.548 & 871.3 & 0.83 & 2.671 & 3.105 \\
\hline & \multirow{2}{*}{5.00} & WLMH-1 & 2.079 & 0.944 & 698.97 & 0.578 & 965.4 & 0.724 & 2.796 & 2.919 \\
\hline & & WLMH-2 & 2.100 & 0.955 & 703.87 & 0.601 & 971.3 & 0.725 & 2.831 & 2.951 \\
\hline & \multicolumn{8}{|c|}{ Mean value } & 2.792 & 3.042 \\
\hline & \multicolumn{8}{|c|}{$\mathrm{COV}$} & 0.10 & 0.11 \\
\hline \multirow{8}{*}{ HAZ } & \multirow{2}{*}{1.25} & HSMH-1 & 0.748 & 0.522 & 924.87 & 0.769 & 828.6 & 1.116 & 2.263 & 2.298 \\
\hline & & HSMH-2 & 0.745 & 0.520 & 924.27 & 0.770 & 827.3 & 1.117 & 2.251 & 2.284 \\
\hline & \multirow{2}{*}{2.50} & НММН-1 & 1.000 & 0.483 & 751.13 & 0.730 & 805.8 & 0.932 & 1.913 & 1.938 \\
\hline & & HMMH-2 & 0.936 & 0.447 & 748.1 & 0.740 & 785.1 & 0.953 & 1.812 & 1.785 \\
\hline & \multirow{2}{*}{5.00} & HLMH-1 & 1.500 & 0.62 & 648.33 & 0.674 & 884.3 & 0.733 & 1.860 & 1.898 \\
\hline & & HLMH-2 & 1.480 & 0.61 & 645.47 & 0.685 & 878.8 & 0.734 & 1.836 & 1.869 \\
\hline & \multicolumn{8}{|c|}{ Mean value } & 1.989 & 2.012 \\
\hline & \multicolumn{8}{|c|}{$\mathrm{COV}$} & 0.11 & 0.11 \\
\hline
\end{tabular}

\subsection{Discussions}

Having calibrated the toughness parameters of the two models, numerical results were compared and discussed.

The von Mises stress field, triaxiality stress field and the equivalent plastic strain field of a typical group of specimens (Q345B base metal specimens with different notch sizes) are shown in Fig. 19. Specimens with different notch sizes shows different stress and strain fields.

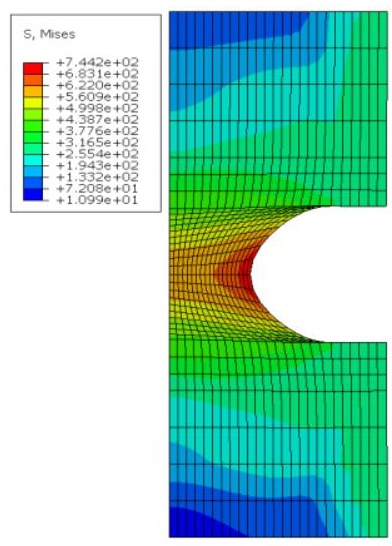

von Mises stress

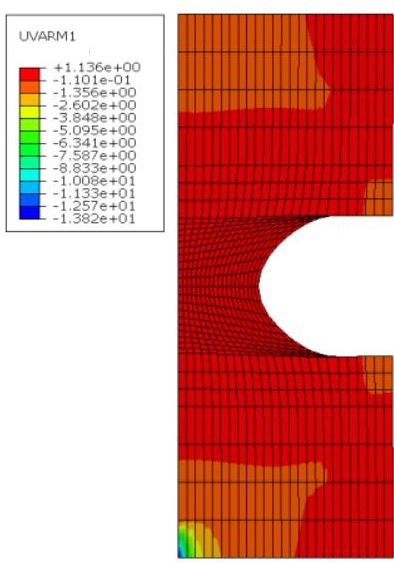

Stress triaxiality

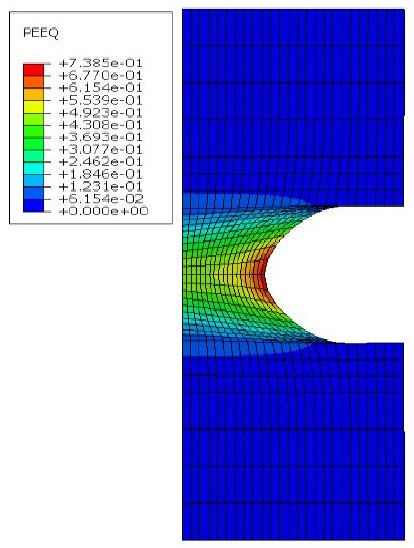

Equivalent plastic strain

(a) $R=1.25 \mathrm{~mm}$ 


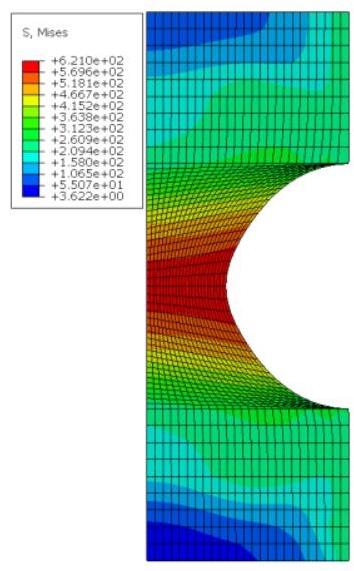

von Mises stress

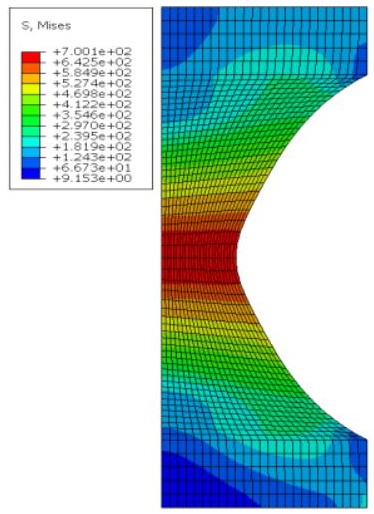

von Mises stress

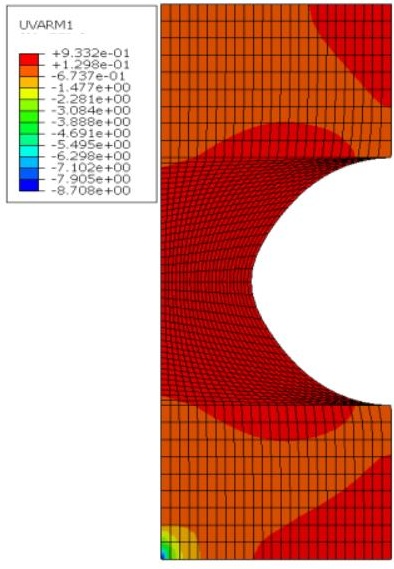

Stress triaxiality

(b) $R=2.50 \mathrm{~mm}$

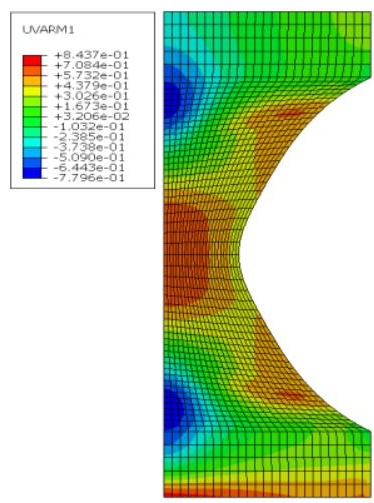

Stress triaxiality

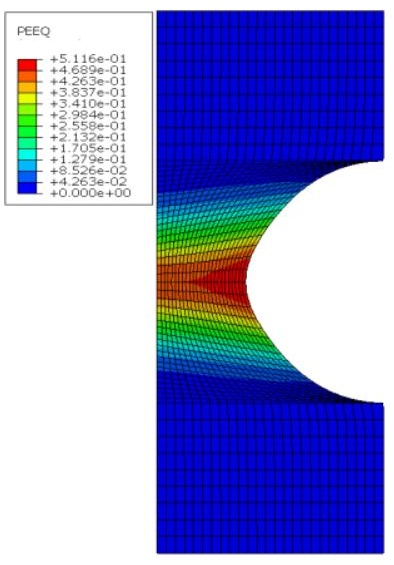

Equivalent plastic strain

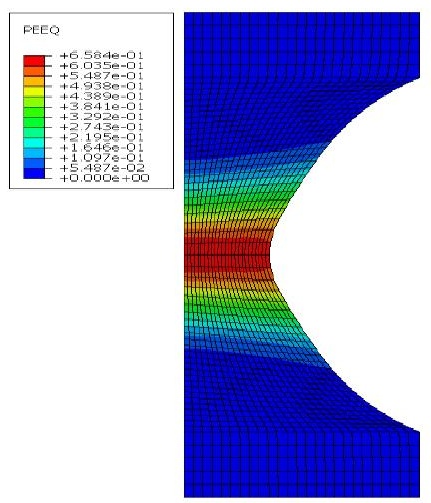

Equivalent plastic strain

(c) $R=5.00 \mathrm{~mm}$

Fig. 19 Distribution of stress and strain fields in notched area

The equivalent plastic strain and triaxial stress distribution along the notched cross-section at crack initiation is shown in Figs. 20 and 21, respectively. PEEQ is the value of equivalent plastic strain while UVARM1 is the stress triaxiality, output from the subroutine in ABAQUA. It can be observed that for round bars with a notch radius of $R=5.00 \mathrm{~mm}$, the equivalent plastic strain is distributed uniformly along the notched section. With smaller notch radius of $R=2.50 \mathrm{~mm}$ and $1.25 \mathrm{~mm}$, the equivalent plastic strain is high at the edge and low near the centre. The maximum UVARM1 value, namely stress triaxiality, appears at the centre of the test piece, unlike the equivalent plastic strain distribution. Therefore, the fracture of materials, especially those in triaxial stress state, cannot be predicted with only equivalent plastic strain. The micromechanical fracture models take into consideration of the influence of both stress triaxiality and equivalent plastic strain, thus giving better predictions.

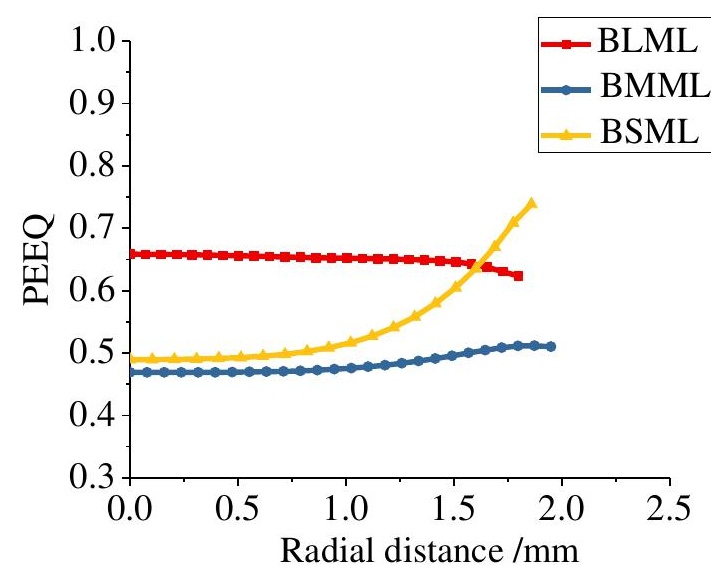

(a) Q235B base metal

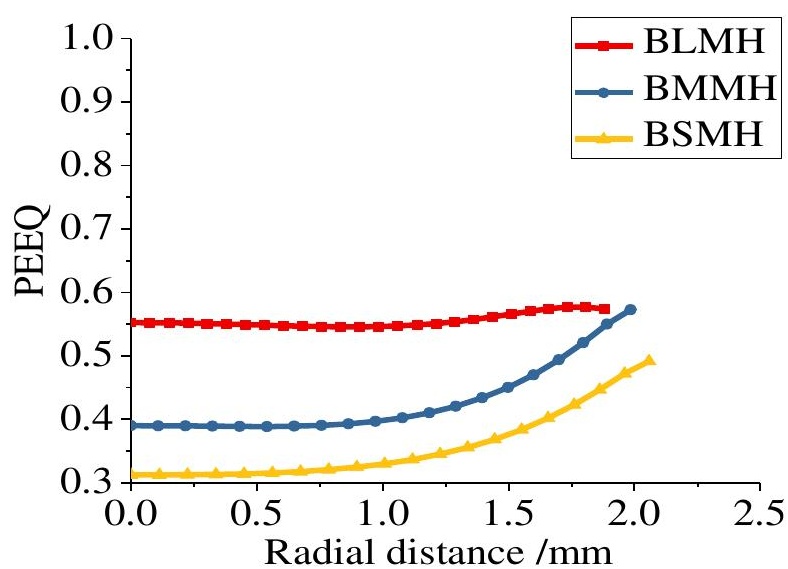

(b) Q345B base metal 


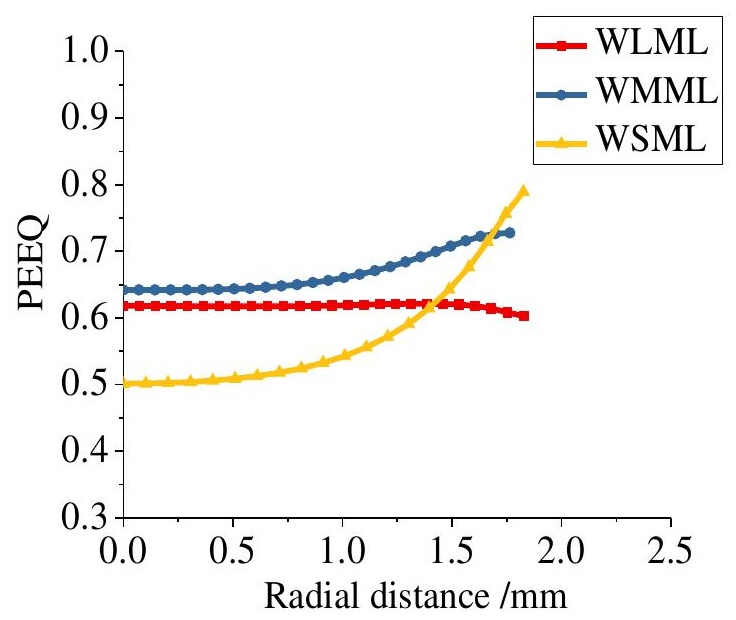

(c) Q235B weld metal

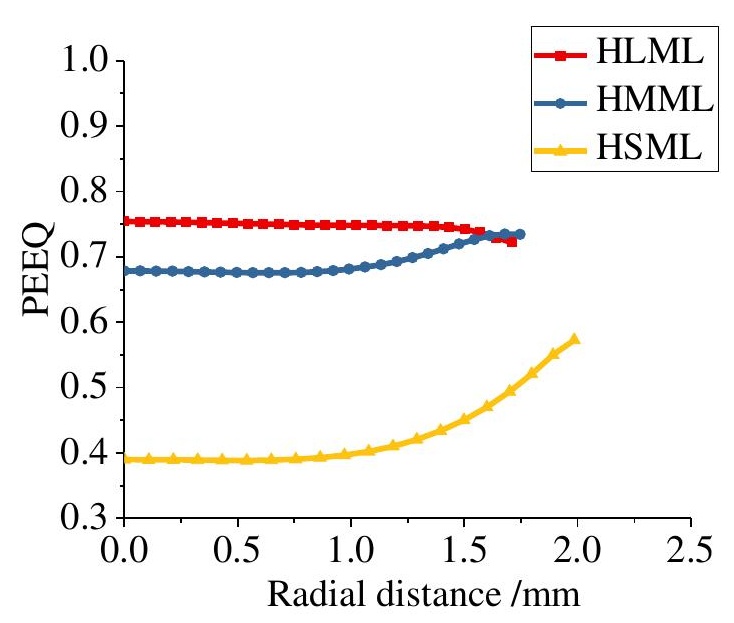

(e) Q235B HAZ

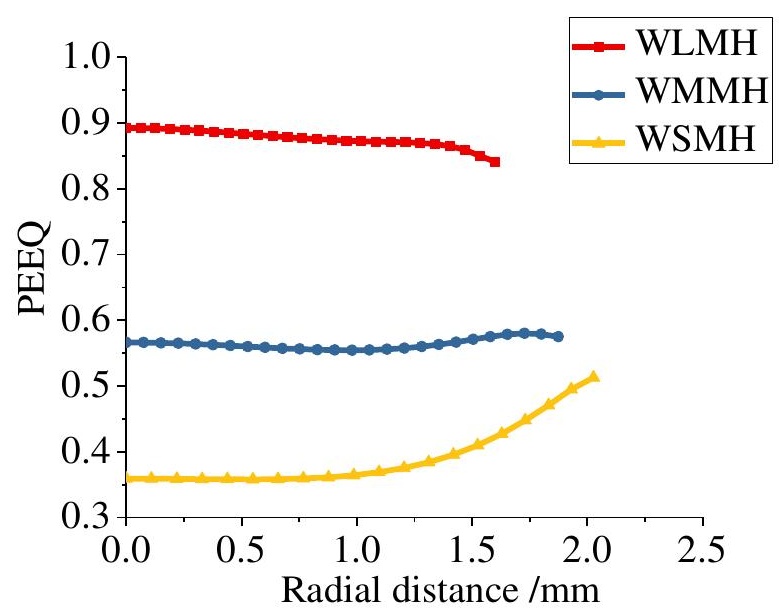

(d) Q345B weld metal

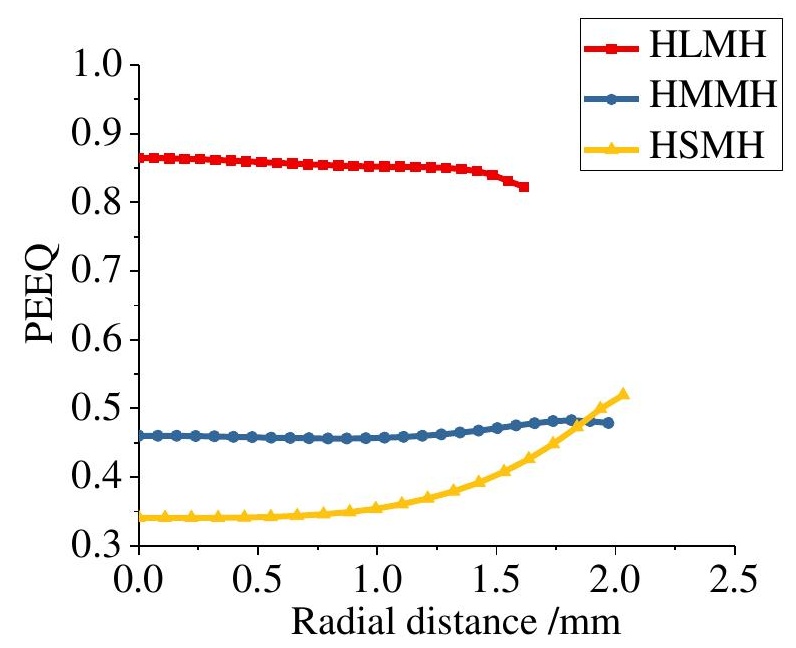

(f) Q345B HAZ

Fig. 20 Equivalent plastic strain of Q235B and Q345B

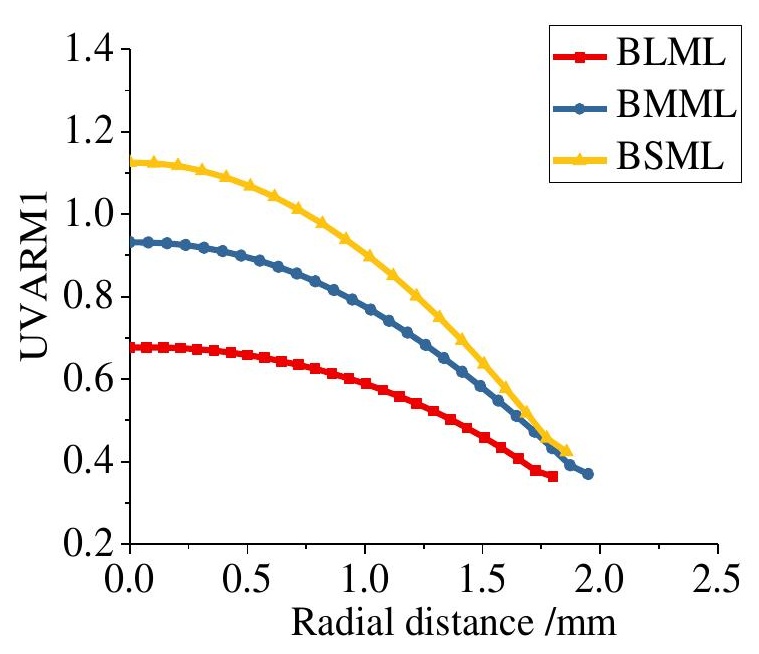

(a) Q235B base metal

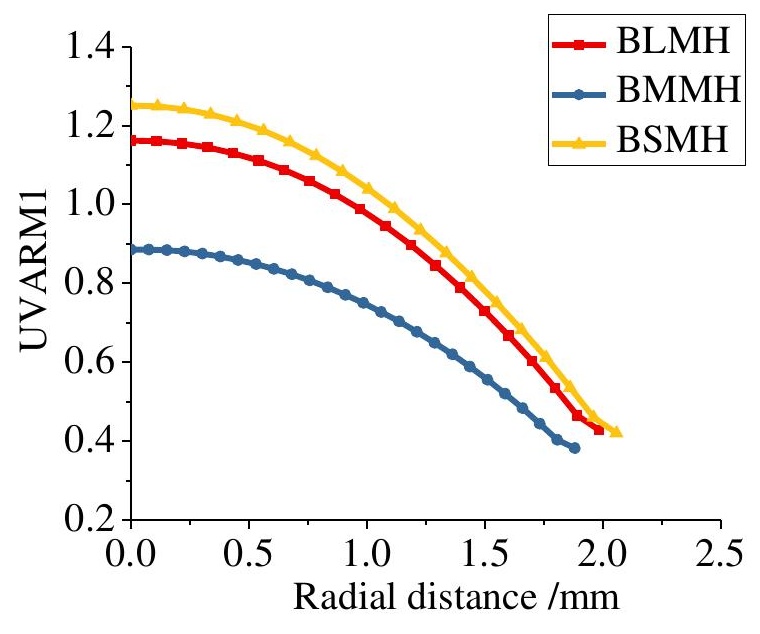

(b) Q345B base metal 


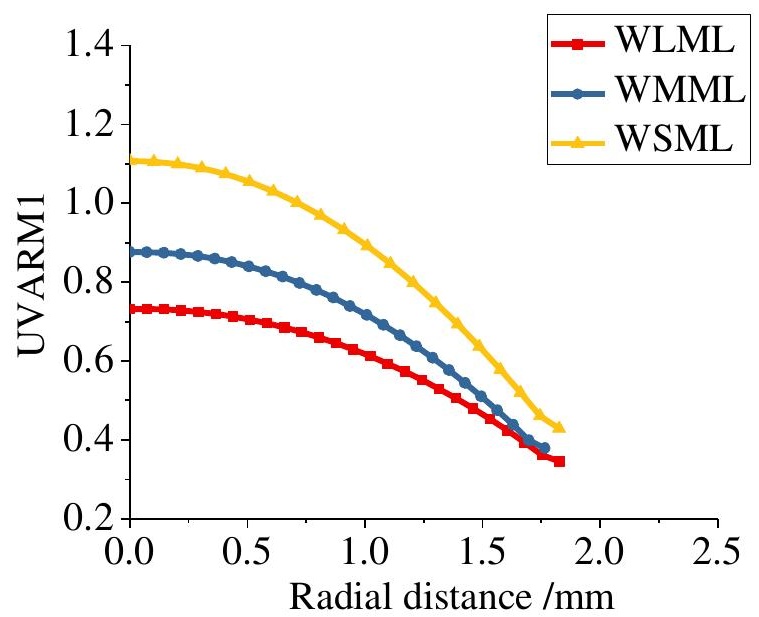

(c) Q235B weld metal

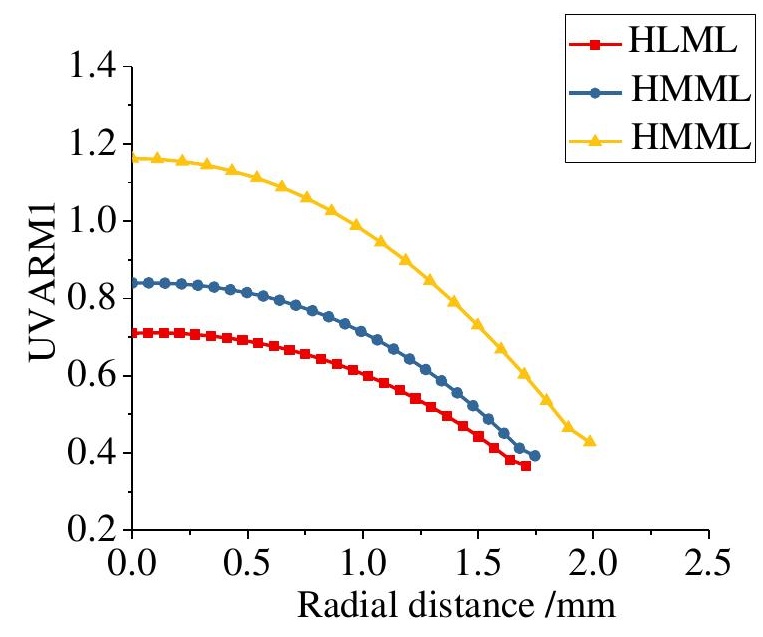

(e) Q235B HAZ

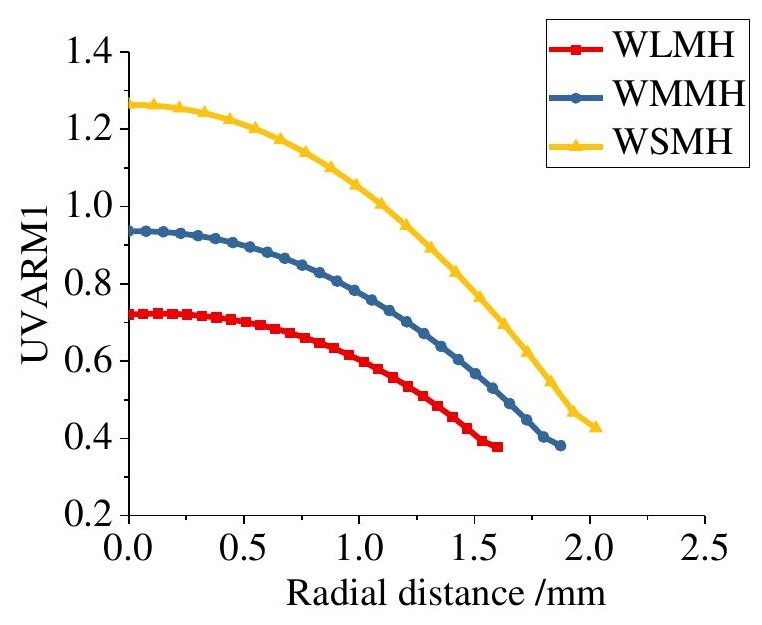

(d) Q345B weld metal

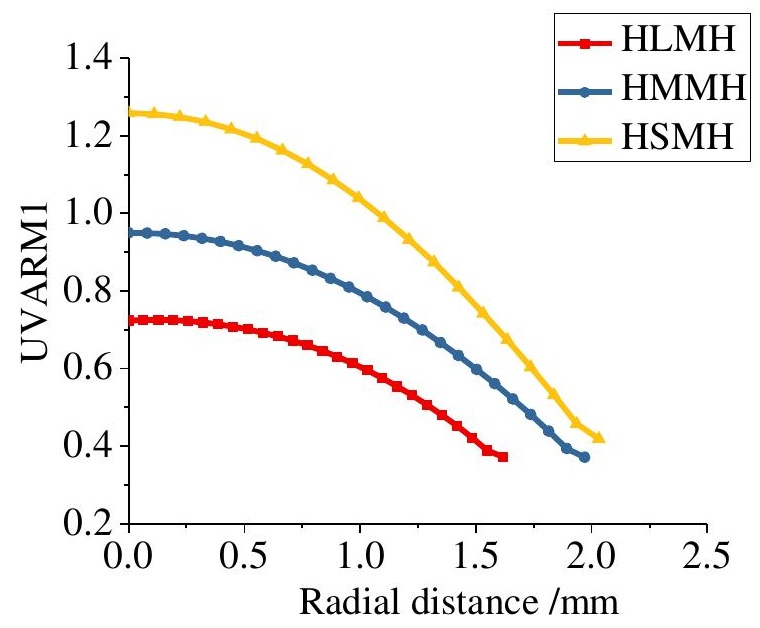

(f) Q345B HAZ

Fig. 21 UVARM1 of Q235B and Q345B

Figs. 22 and 23 show the VGM and SMCS fracture index, $\mathrm{FI}_{\mathrm{VGM}}$ and $\mathrm{FI}_{\mathrm{SMCS}}$ respectively, distribution along the notched cross-section at the fracture initiation (when fracture displacement is reached in the numerical model). It can be seen that the fracture index is biggest at the centre of the bar, indicating that the fracture initiates from the centre. This is consistent with the observations from the SEM measurements. For the three different stress states, the fracture parameters of the SMCS model and the VGM model show similar distributions along the notched cross-section: decreasing from the centre to the edge, having less change within a certain range. This also shows that for the notched round bar specimen, the value of the characteristic length based on the microstructure of the material has little effect on the fracture prediction, and there is no obvious correlation between the characteristic length and the value of the toughness parameters. The consistency in the distribution of fracture parameters in VGM and SMCS also shows that both models offer similar predictions under different stress states.

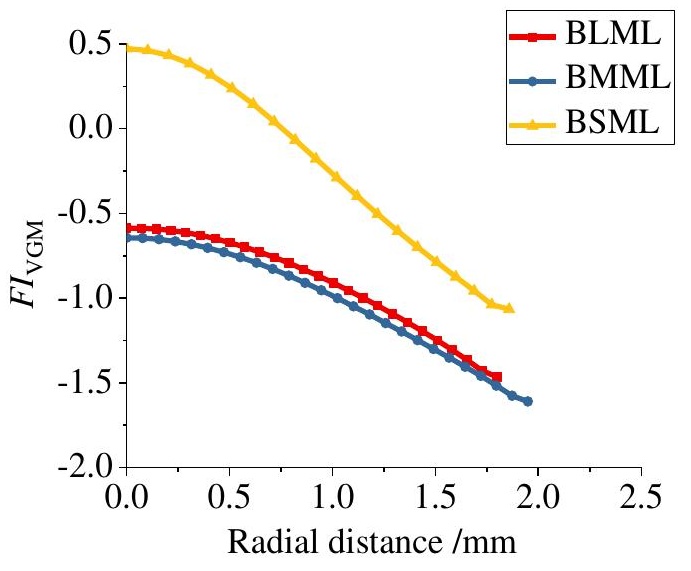

(a) Q235B base metal

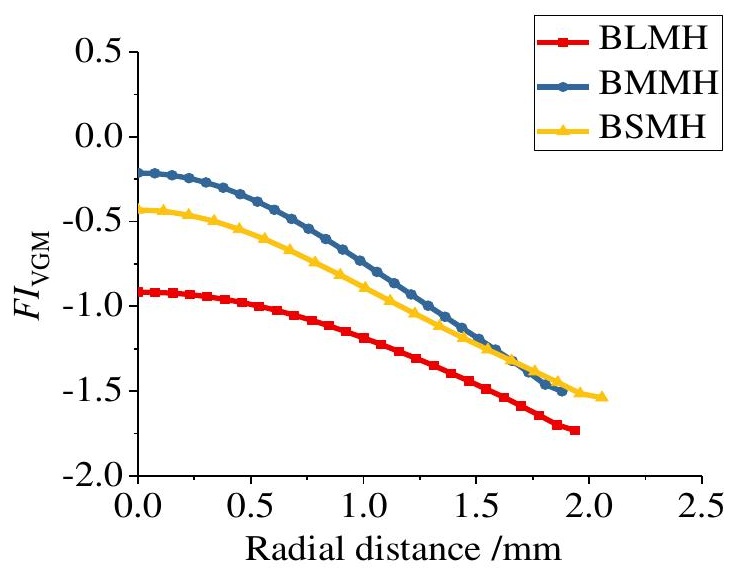

(b) Q345B base metal 


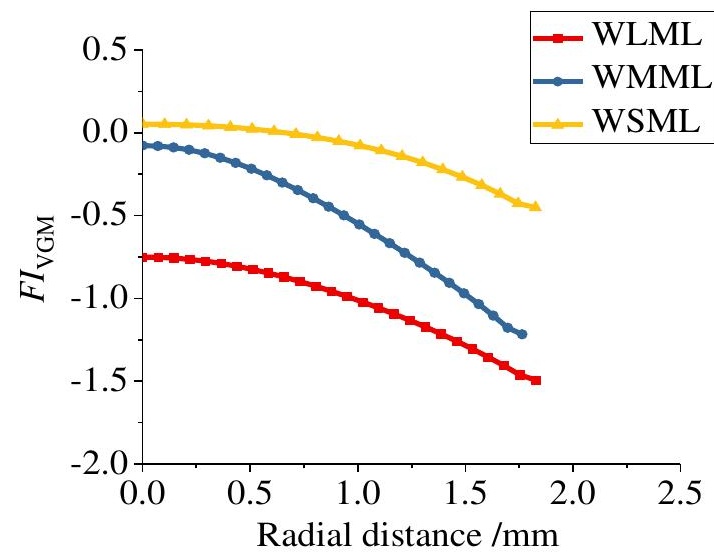

(c) Q235B weld metal

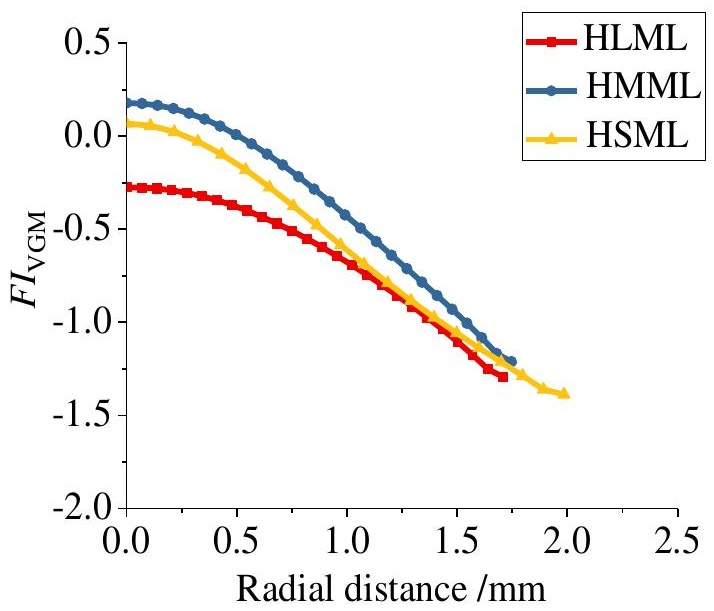

(e) Q235B HAZ

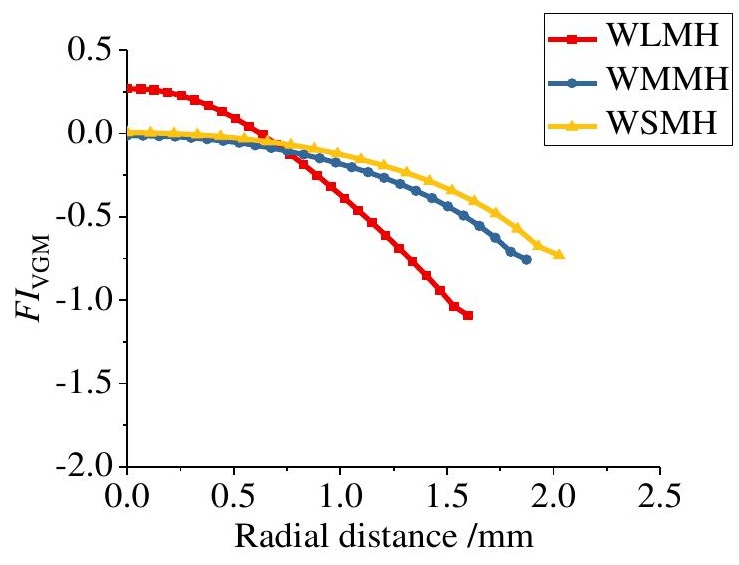

(d) Q345B weld metal

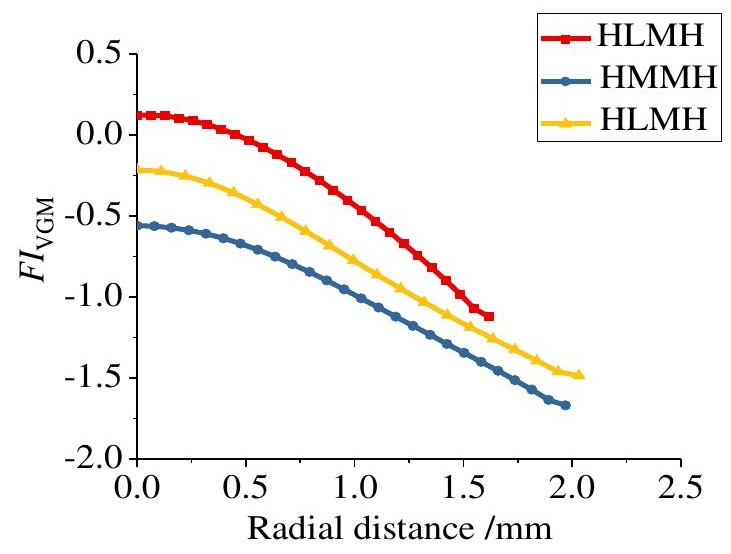

(f) Q235B HAZ

Fig. 22 Distribution of SMCS fracture index

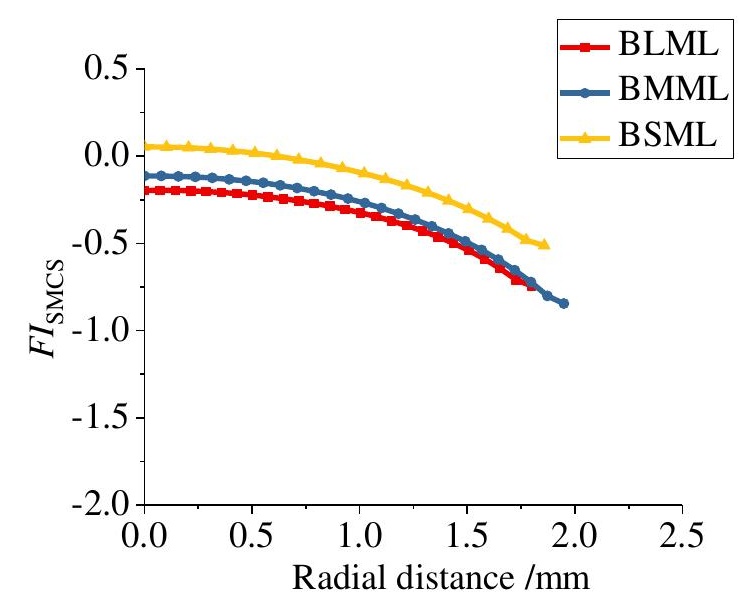

(a)Q235B base metal

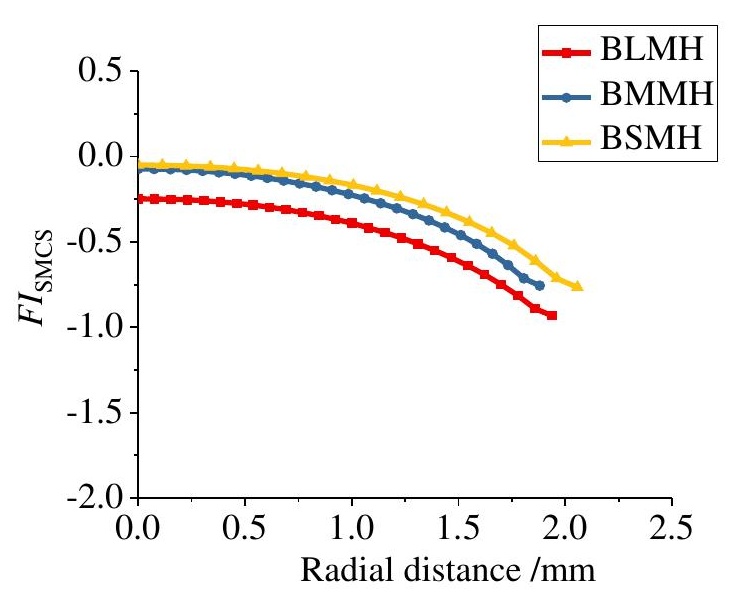

(b)Q345B base metal 


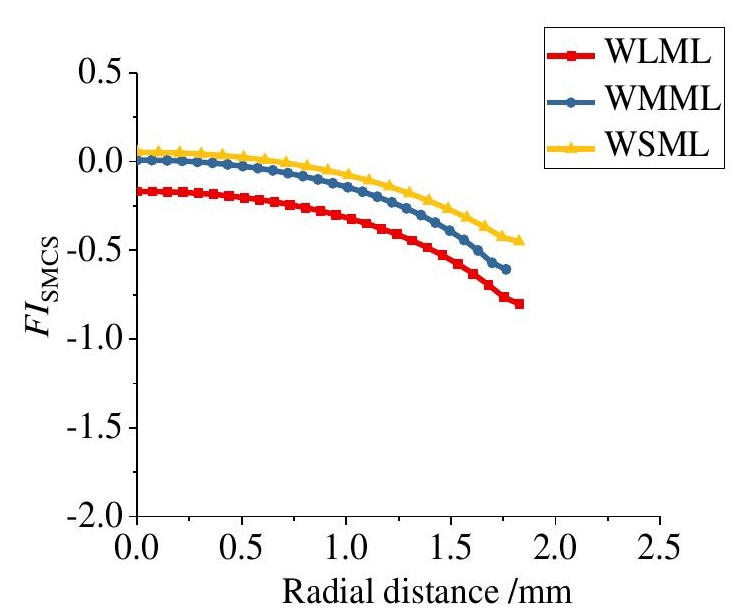

(c) Q235B weld metal

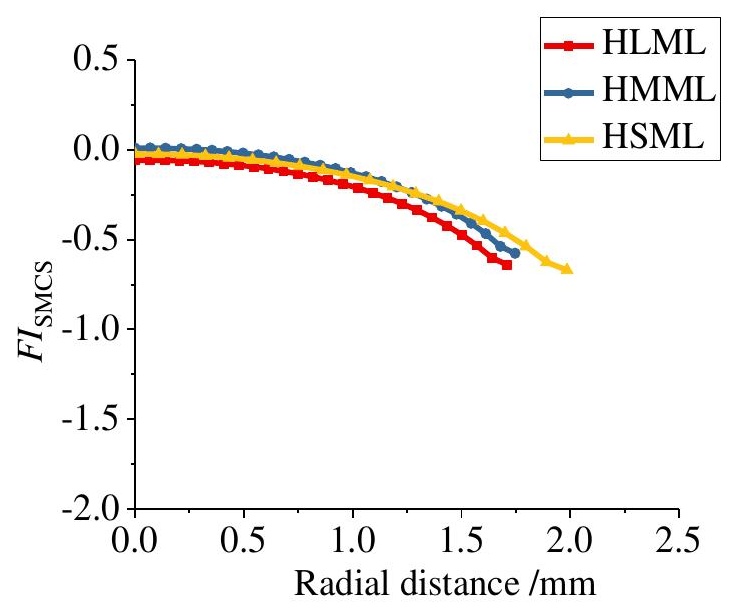

(e) Q235B HAZ

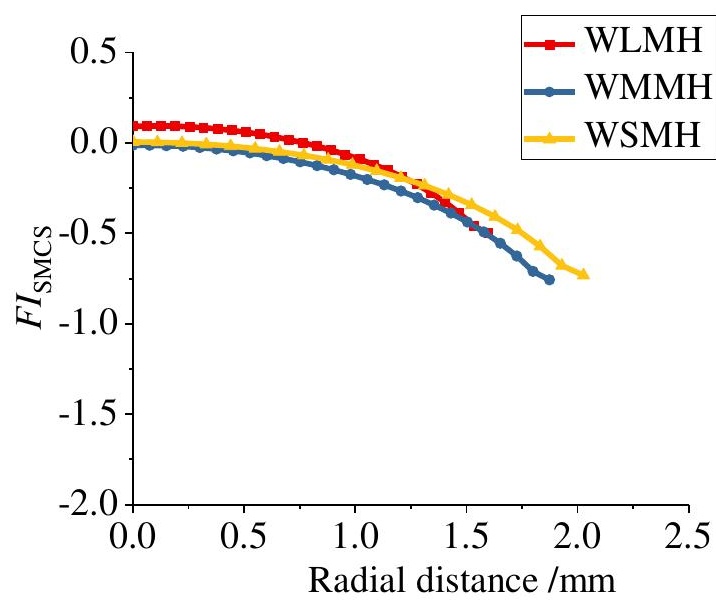

(d) Q345B weld metal

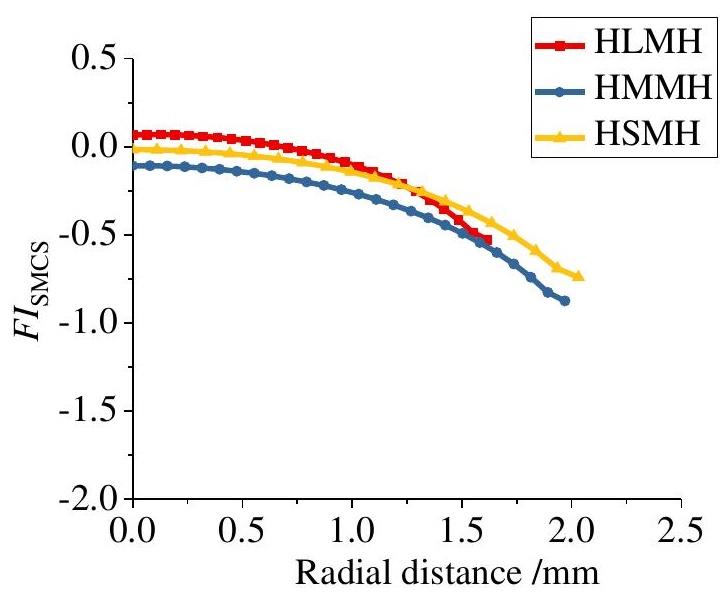

(f) Q345B HAZ

Fig. 23 Distribution of SMCS fracture index

\subsection{Fracture prediction}

With the calibrated toughness parameters, as listed in Tables 9 and 10 , the load-displacement response of monotonic experiments can be predicted with the VUMAT subroutine in ABAQUS. The comparisons of load-displacement curves are shown in Figs. 24 to 26 . Note that the FE curves are without subroutine and displacement controlled till the fracture displacement obtained in the tests. The fracture load and displacement obtained by tests are compared with the predictions in Tables 11 and 12, respectively. The fracture load and displacement predictions are compared with test results in Figs. 27 and 28, respectively. The typical test curves from each set of two repetitive specimens were employed.

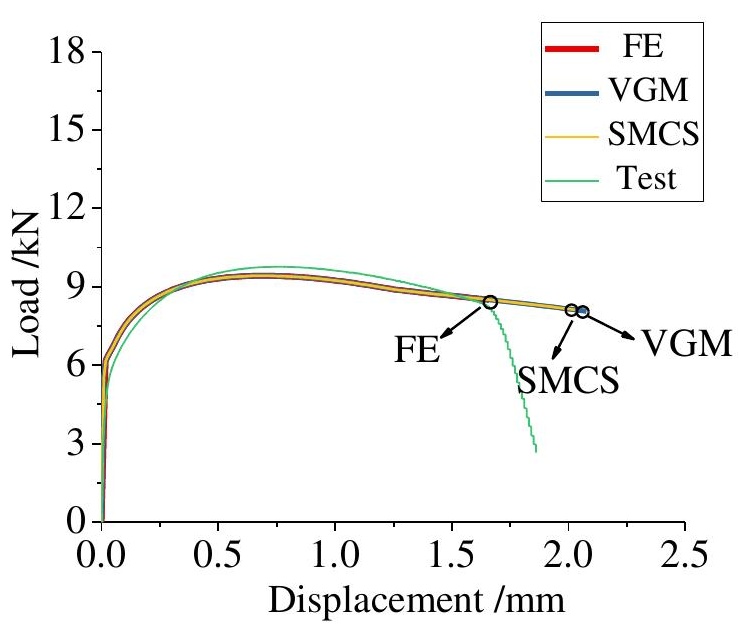

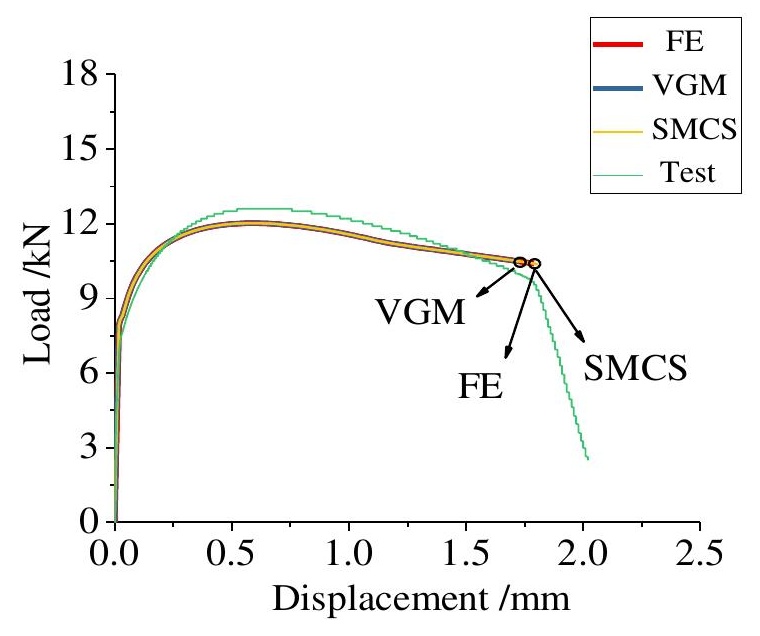

(b)BLMH 


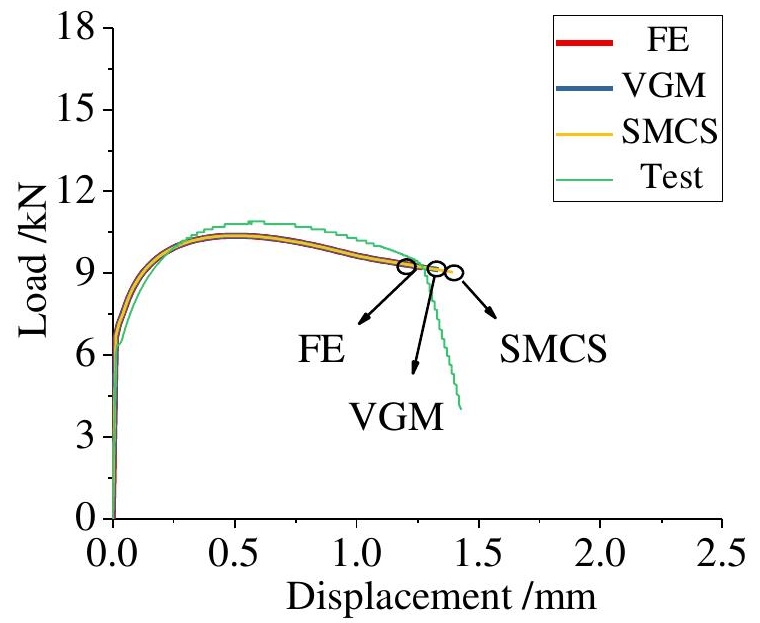

(c)BMML

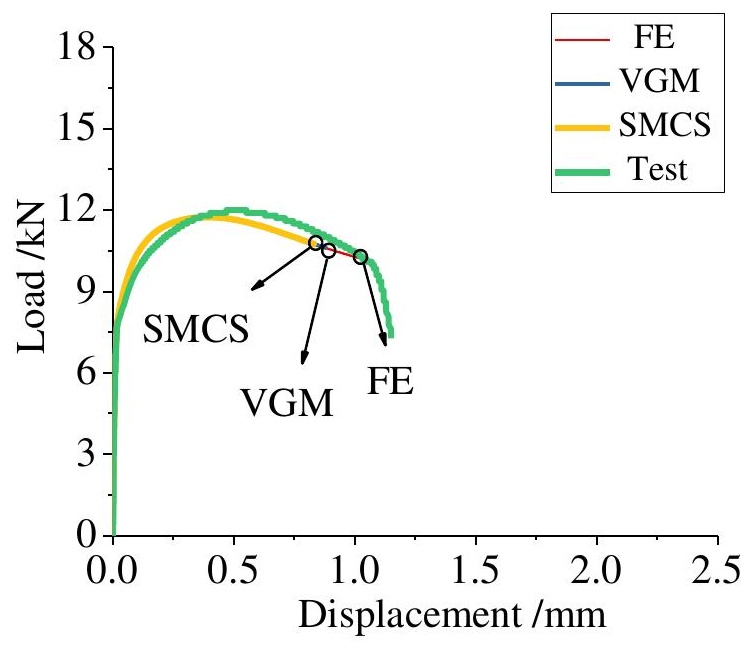

(e)BSML

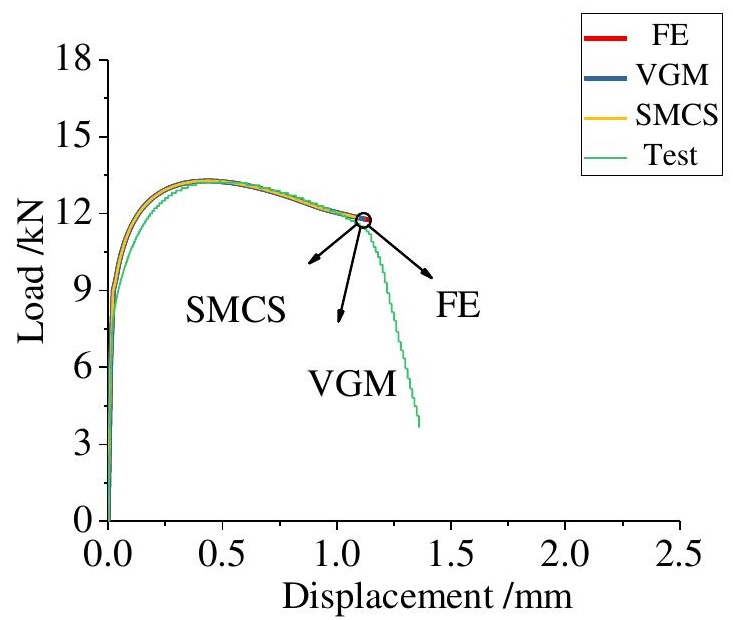

(d)BMMH

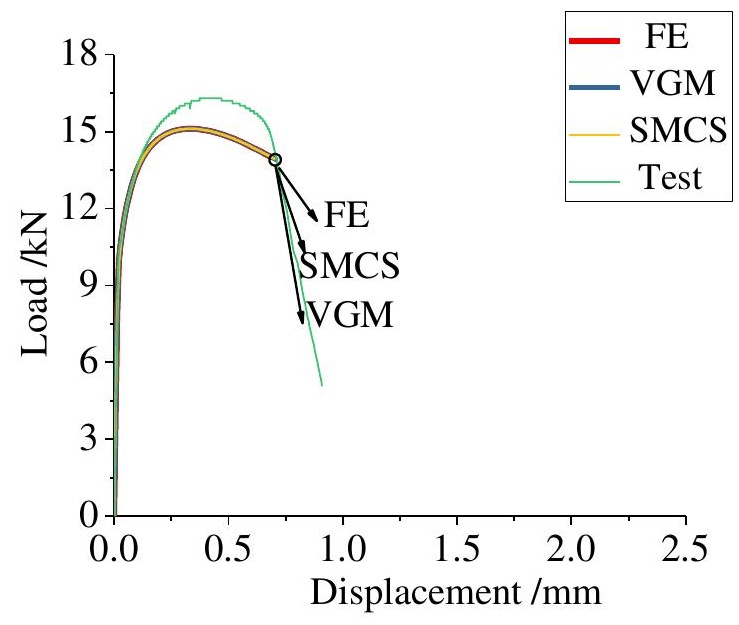

(f) $\mathrm{BSMH}$

Fig. 24 Base metal prediction

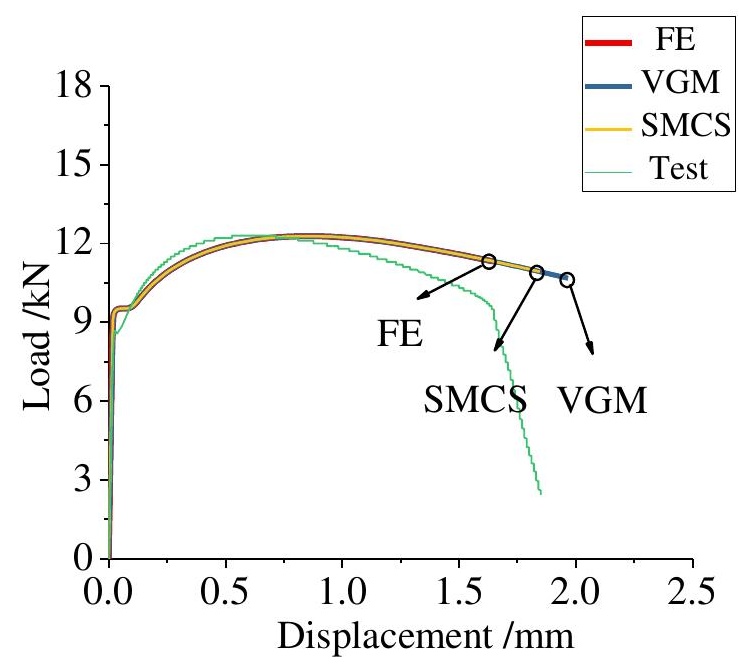

(a) WLML

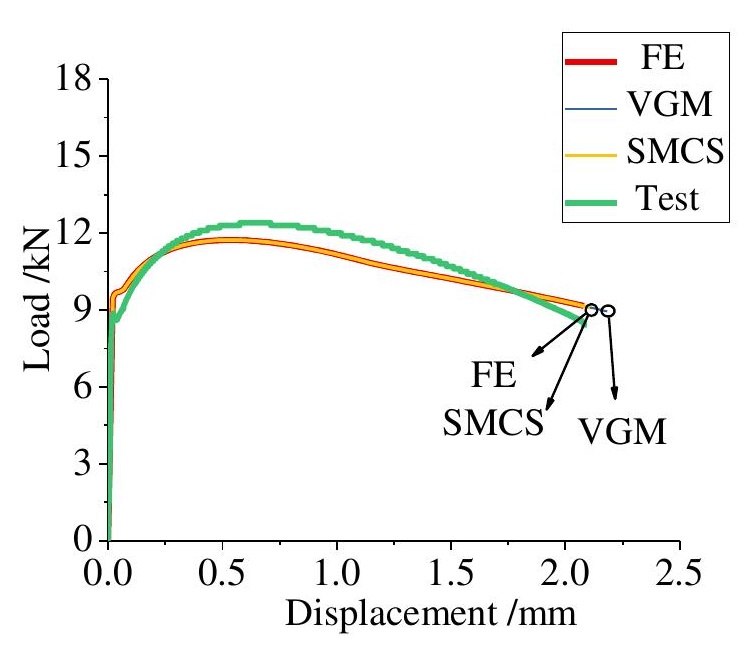

(b) WLMH 


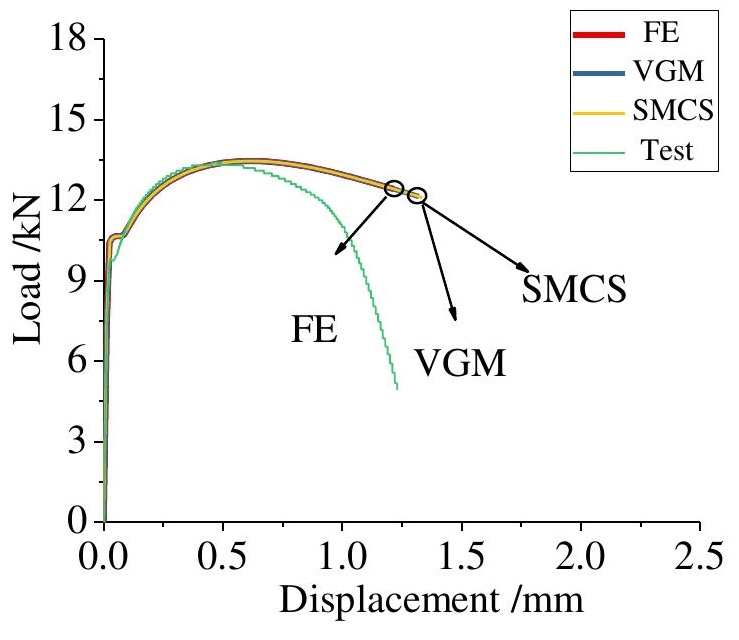

(c) WMML

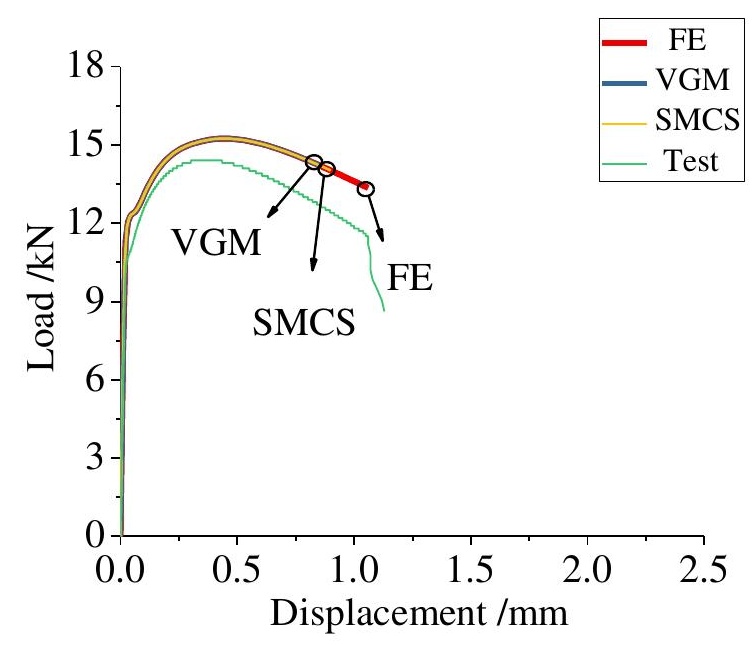

(e) WSML

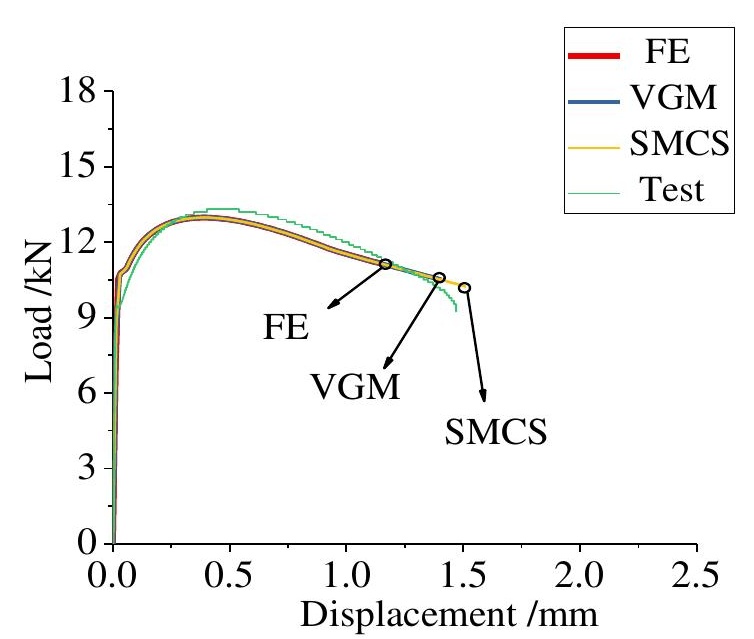

(d) WMMH

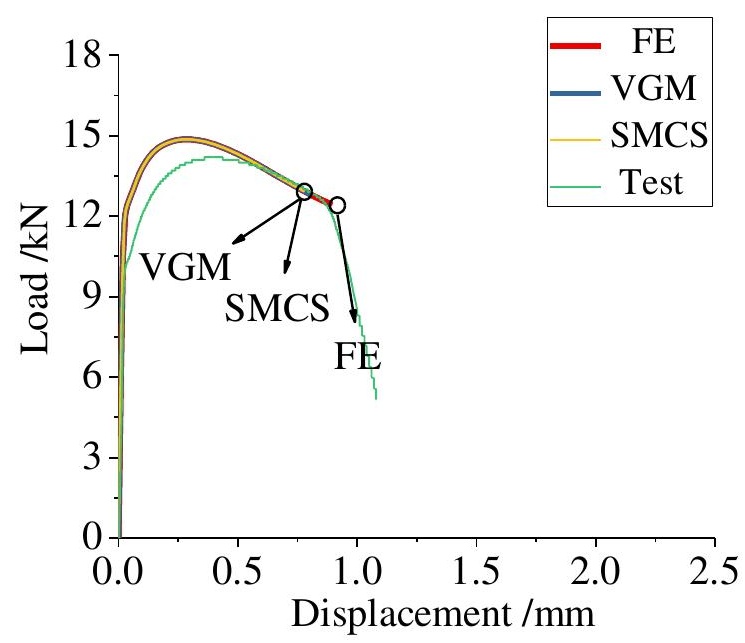

(f) WSMH

Fig. 25 Weld metal prediction

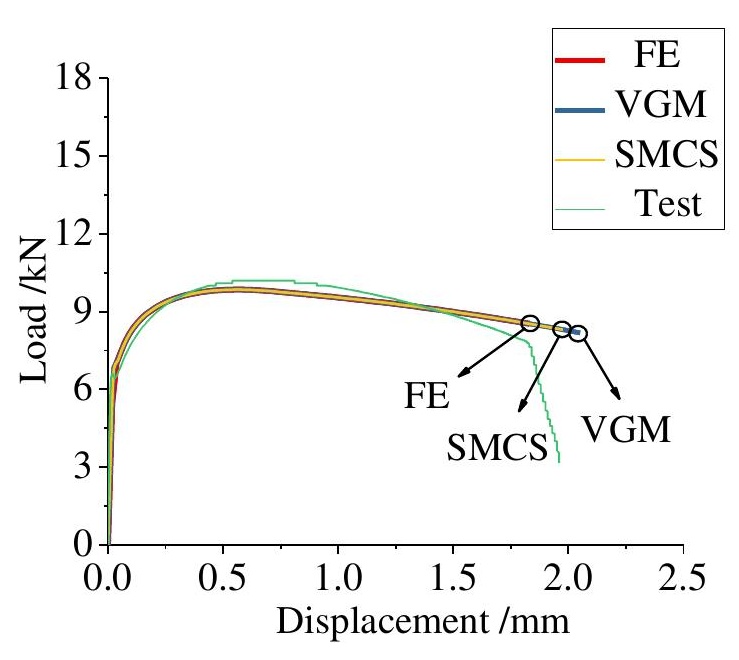

(a) HLML

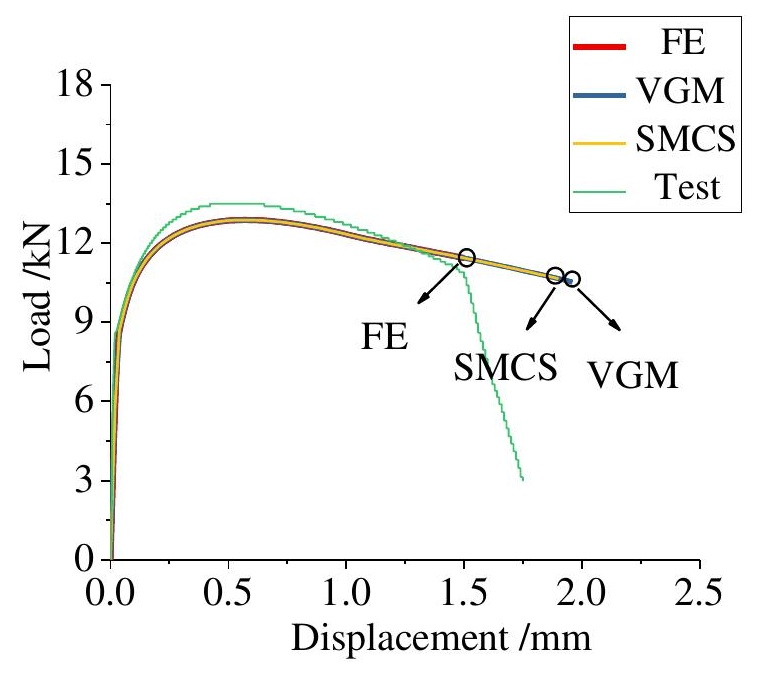

(b) HLMH 


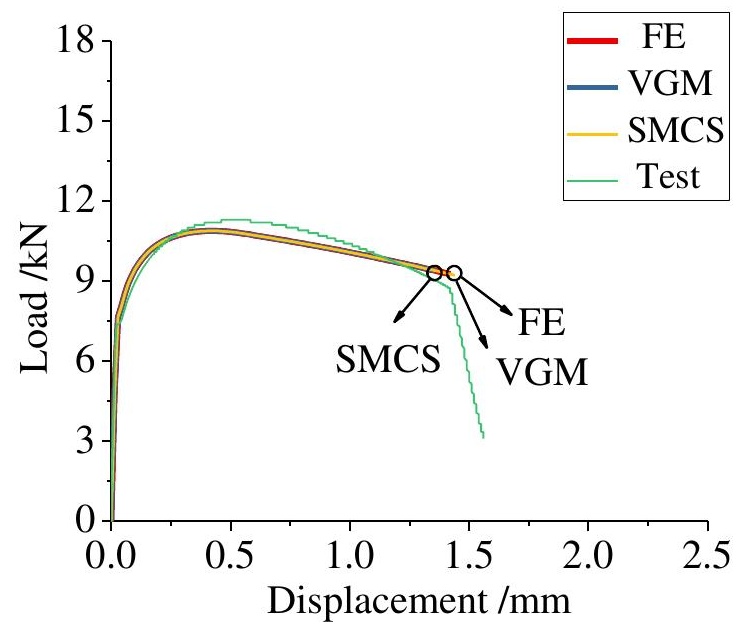

(c) HMML

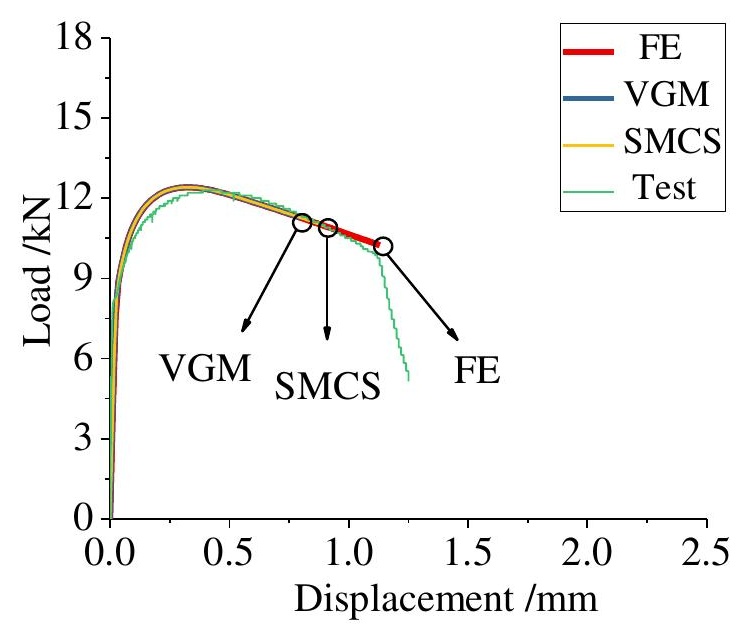

(e) HSML

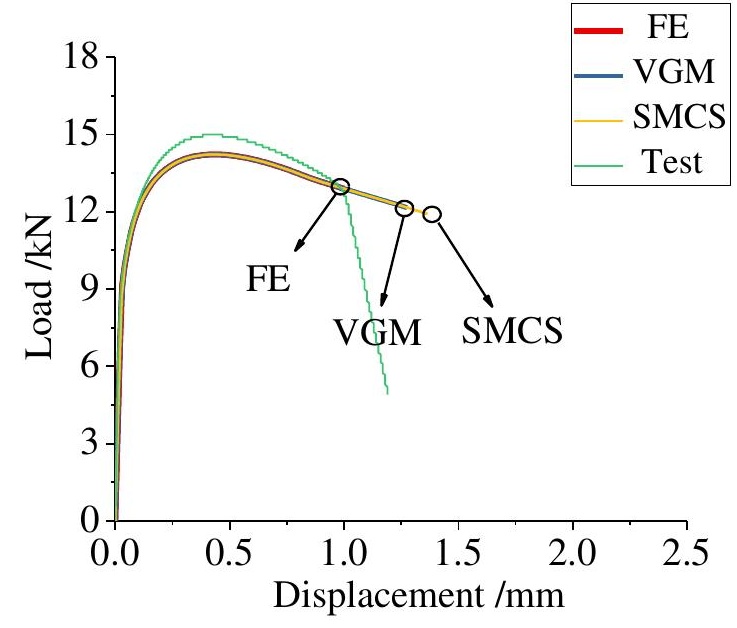

(d) HMMH

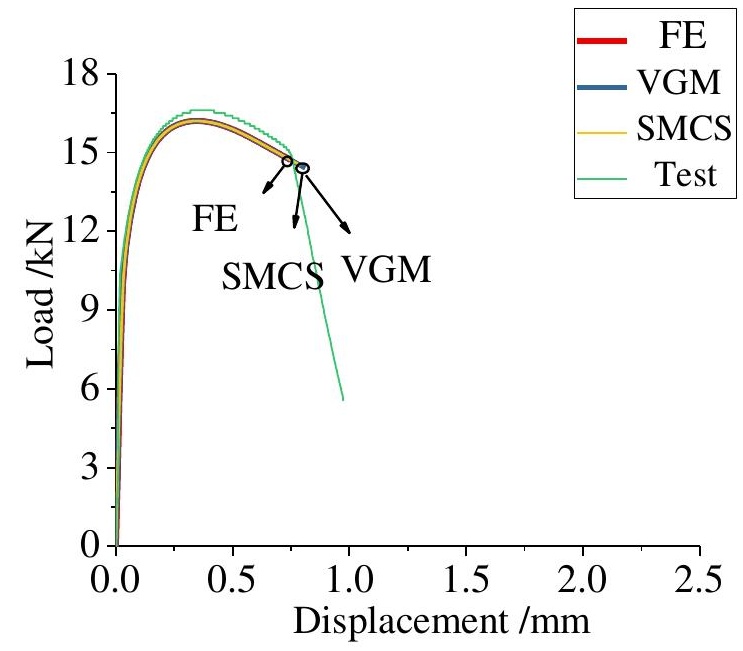

(f) $\mathrm{HSMH}$

Fig. $26 \mathrm{HAZ}$ prediction

Table 11

Fracture load comparisons $(\mathrm{kN})$

\begin{tabular}{|c|c|c|c|c|c|}
\hline Specimen ID & Test & SMCS Prediction & (SMCS-Test) $/$ Test $\%$ & VGM Prediction & (VGM-Test) $/$ Test $\%$ \\
\hline BLMH & 9670 & 10373.70 & 7.28 & 10486.60 & 8.44 \\
\hline BLML & 8250 & 8123.20 & -1.54 & 8064.87 & -2.24 \\
\hline BMMH & 11200 & 11838.10 & 5.70 & 11778.70 & 5.17 \\
\hline BMML & 9300 & 9123.40 & -1.90 & 9032.93 & -2.87 \\
\hline BSMH & 14700 & 13924.50 & -5.28 & 13888.10 & -5.52 \\
\hline BSML & 10400 & 10724.50 & 3.12 & 10590.50 & 1.83 \\
\hline WLMH & 8310 & 8946.89 & 7.66 & 9100.04 & 9.51 \\
\hline WLML & 9480 & 10926.50 & 15.26 & 10672.60 & 12.58 \\
\hline WMMH & 11400 & 10231.10 & -10.25 & 10504.80 & -7.85 \\
\hline WMML & 11344 & 12096.50 & 6.64 & 12137.90 & 7.00 \\
\hline WSMH & 12100 & 12925.20 & 6.82 & 12785.00 & 5.66 \\
\hline WSML & 11500 & 14019.80 & 21.91 & 14200.60 & 23.48 \\
\hline HLMH & 10900 & 10655.30 & -2.24 & 10527.90 & -3.41 \\
\hline HLML & 7780 & 8305.35 & 6.75 & 8182.78 & 5.18 \\
\hline НMМH & 12700 & 11914.70 & -6.18 & 12163.00 & -4.23 \\
\hline HMML & 8740 & 9219.70 & 5.49 & 9385.77 & 7.39 \\
\hline HSMH & 15000 & 14510.90 & -3.26 & 14417.50 & -3.88 \\
\hline HSML & 9750 & 10957.40 & 12.38 & 11262.40 & 15.51 \\
\hline
\end{tabular}




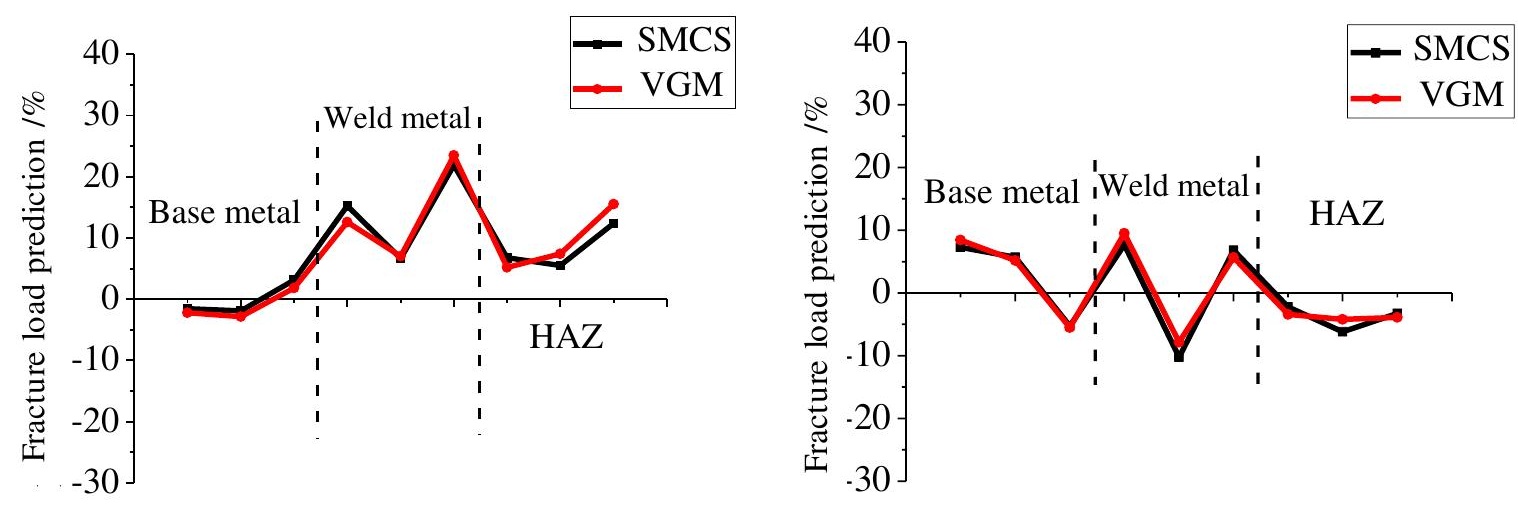

(a) Q235B

(b) Q345B

Fig. 27 Fracture load prediction

Table 12

Fracture displacement comparisons (mm)

\begin{tabular}{|c|c|c|c|c|c|}
\hline Specimen ID & Test & $\begin{array}{c}\text { VGM displacement of } \\
\text { prediction }\end{array}$ & (VGM-Test)/Test $\%$ & $\begin{array}{c}\text { SMCS displacement of } \\
\text { prediction }\end{array}$ & (SMCS-Test) $/$ Test $\%$ \\
\hline BLMH & 1.790 & 1.726 & -3.60 & 1.806 & 0.89 \\
\hline BLML & 1.660 & 2.076 & 25.06 & 2.026 & 22.05 \\
\hline BMMH & 1.150 & 1.125 & -2.17 & 1.095 & -4.78 \\
\hline BMML & 1.270 & 1.335 & 5.12 & 1.395 & 9.84 \\
\hline BSMH & 0.691 & 0.712 & 3.04 & 0.704 & 1.88 \\
\hline BSML & 1.020 & 0.885 & -13.24 & 0.840 & -17.65 \\
\hline WLMH & 2.079 & 2.182 & 4.95 & 2.107 & 1.35 \\
\hline WLML & 1.650 & 1.966 & 19.15 & 1.846 & 11.88 \\
\hline WMMH & 1.152 & 1.404 & 21.88 & 1.512 & 31.25 \\
\hline WMML & 1.216 & 1.320 & 8.55 & 1.335 & 9.77 \\
\hline WSMH & 0.894 & 0.810 & -23.38 & 0.780 & -12.75 \\
\hline WSML & 1.060 & 0.855 & -19.34 & 0.900 & -15.09 \\
\hline HLMH & 1.500 & 1.960 & 30.67 & 1.900 & 26.67 \\
\hline HLML & 1.830 & 2.051 & 12.08 & 1.976 & 8.00 \\
\hline HMMH & 1.000 & 1.275 & 27.50 & 1.365 & 36.50 \\
\hline HMML & 1.420 & 1.360 & -4.23 & 1.440 & 1.41 \\
\hline HSMH-1 & 0.748 & 0.81 & 8.29 & 0.790 & 5.61 \\
\hline HSML-1 & 1.130 & 0.80 & -29.20 & 0.900 & -20.35 \\
\hline
\end{tabular}

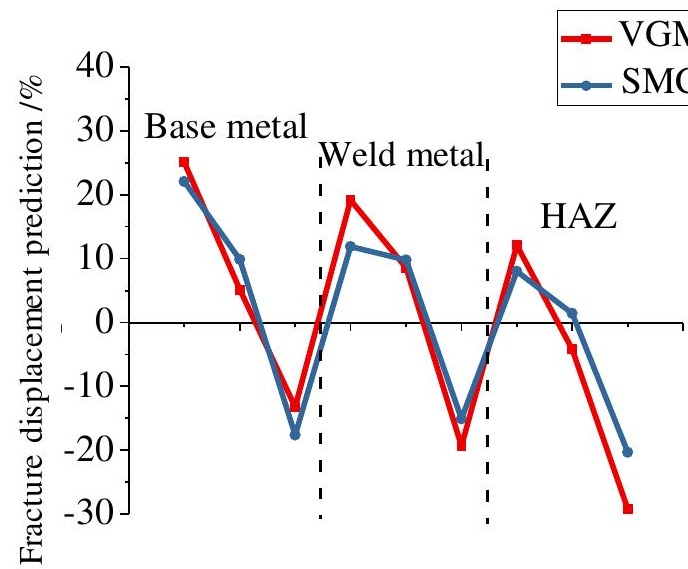

(a) Q235B

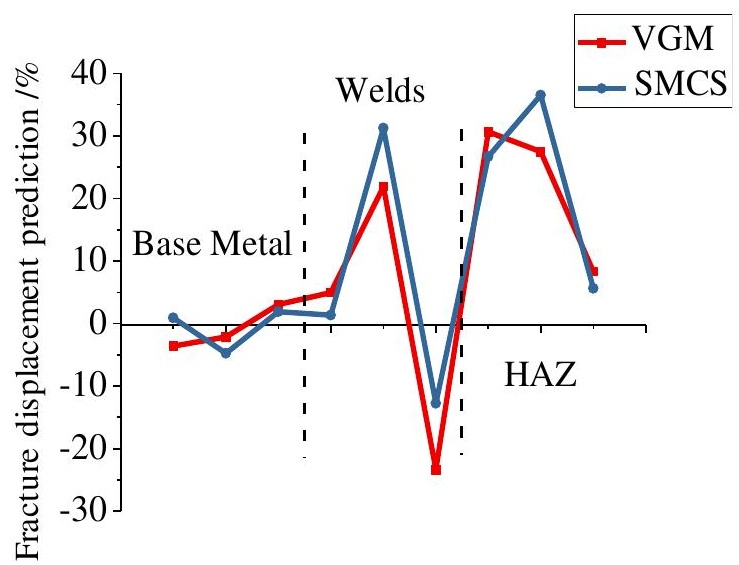

(b) Q345B 
From Fig. 27, it can be seen that both VGM and SMCS model offer good predictions of the failure loads for Q235B and Q345B, especially for the base metal. While the predictions of the weld metal and heat affected zone are more scattered, which might be attributed to the welding effect. Fig. 28 shows that both models offer the fracture displacement prediction within $25 \%$ for base metal, yet the weld metal and HAZ reveals larger level of scatter. In general, VGM model and SMCS model are shown to be applicable to predict the ductile fracture of ordinary steel under different stress states, while for welding seam and HAZ scatter should be expected.

\section{Conclusions}

In this paper 12 smooth round bars and 36 notched round bars were tested under axial tensile load. The fracture behaviour of the base material, the weld metal and the HAZ of welded structural steels Q235B and Q345B were investigated. Two micromechanical fracture models: void growth model (VGM) and stress modified critical strain model (SMCS) were investigated.

The material toughness parameters $\eta_{\text {mon }}$ and $\gamma$ of micromechanical fracture models VGM and SMCS for each material, including the base material, the weld metal and the HAZ of Q235B and Q345B structure steel were calibrated by the tests results. Finite element analysis integrated with the micromechanical models were carried out to simulate the fracture behaviour of these tested specimens. Fracture index distributions show that the fracture initiated from the centre of the specimens, which coincides with the SEM measurements. Upon calibrations, the two models were used to predict the fracture load and displacement and the predictions were compared with the test results. The comparisons show that VGM model and SMCS model offer accurate ductile fracture prediction for the base metal under different stress states, while for welding seam and HAZ scatter should be expected.

\section{Compliance with Ethical Standards:}

Funding: This study was funded by the National Natural Science Foundation of China (No. 51678339 and No.51708549).

Conflict of interest: The authors declared that they have no conflicts of interest to this work.

\section{Reference}

[1] F. A. McClintock, A criterion for ductile fracture by the growth of holes. Journal of Applied Mechanics. 35 (2) (1968) 363-371.

[2] J. R. Rice, D. M. Tracey, On the ductile enlargement of voids in triaxial stress fields. Journal of Mechanics and Physics of Solids. 17 (3) (1969) 201-217.

[3] J. W. Hancock, A. C. Mackenzie, On the mechanics of ductile failure in high-strength steel subjected to multi-axial stress states. Journal of the Mechanis and of Physics of Solids. 24 (3) (1976) $147-169$.

[4] J. W. Hancock, M. J. Cowling, Role of state of stress in crack-tip failure processes, Metal Science. 14 (8-9) (1980) 293-304.

[5] J. W. Hancock, D. K. Brown, On the role of strain and stress state in ductile failure. Journa of the Mechanics \& Physics of Solids, 31 (1) (1983) 1-24.

[6] G. R. Johnson, W. H. Cook, A constitutive model and data for metals subjected to large strains, high strain rates and high temperatures. Proceedings of the 7th International Symposium on Ballistics, The Hague. (1983) 541-547.

[7] B. Marini, F. Mudry, A. Pineau. Ductile rupture of A508 steel under nonradial loading. Engineering Fracture Mechanics. 22 (3) (1985) 375-386.

[8] T. L. Panontin, S. D. Sheppard. The relationship between constraint and ductile fracture initiation as defined by micromechanical analyses, Fracture Mechanics. (1995), 54-85.

[9] J. P. Bandstra, D. A. Koss. A simulation of growth and coalescence of voids during ductile fracture. Materials Science \& Engineering A. 387 (1) (2004) 399-403.

[10] A. M. Kanvinde, G. G. Deierlein. Void growth model and stress modified critical strain model to predict ductile fracture in structural steels. Journal of Structural Engineering. 132 (12) (2006) 1907-1918

[11] W. M. Chi, A. M. Kanvinde, G. G. Deierlein, Prediction of ductile fracture in steel connections using SMCS criterion. Journal of Structural Engineering. 132 (2) (2006) $171-181$.

[12] A. A. Benzerga, Micromechanical Models of Ductile Damage and Fracture. Springer New York. (2015) 939-962.

[13] A. T. Myers, G. G. Deierlein, A. M. Kanvinde, Testing and probabilistic simulation of ductile fracture initiation in structural steel components and weldments. Report No.170, the John A.Blume Earthquake Engineering Center, Stanford University, CA, 2009.

[14] Y. Q. Wang, H. Zhou, Y. J. Shi, J. Xiong, Fracture prediction of welded steel connections using traditional fracture mechanics and fracture mechanics and calibrated fracture mechanics and calibrated micromechanics-based model. International Journal of Steel Structures. 11 (3) (2011) 351-366.

[15] P. G. Kossakowski, Prediction of ductile fracture for S235JR steel using the stress modified critical strain and Gurson-Tvergaard-Needleman models. Journal of Materials in Civil Engineer. 24 (12) (2012) 1492-1500.

[16] F. F. Liao. Criterion of micro-cracking criterion of steel and its application in prediction of ductile fractures at nodes (in Chinese)..Shanghai, Tongji University, 2012.

[17] R. Kiran, K, Khandelwal, Experimental studies and models for ductile fracture in ASTM A992 steels at high triaxiality. Journal of Structural Engineering, ASCE. 140 (2) (2013) $1-48$.

[18] X. Y. Liu, Study on fracture property of high strength steel structure materials and joints based on microscopic mechanism. Beijing, Tsinghua University, 2015.

[19] L. Lu, Experiment and analysis of ductile fracture of steel based on microscopic mechanism.
Nanjing, Southeast University, 2015

[20] GB/T 228.1-2010. Metallic materials-Tensile testing -Part 1: Method of test at room temperature (in Chinese). Beijing: Standards Press of China, 2010.

[21] B. Xiao, L. Xu, L. Zhao, H. Jing, Y. Han, Z. Tang, Microstructure evolution and fracture mechanism of a novel $9 \mathrm{Cr}$ tempered martensite ferritic steel during short-term creep. Materials Science and Engineering. A. (2017) 466-477.

[22] A. M. Kanvinde, G. G. Deierlein, Micromechanical simulation of earthquake-induced fracture in steel structures. Report No.145, the John A. Blume Earthquake Engineering Center, Stanford University, CA, 2004. 


\title{
NUMERICAL STUDY AND DESIGN METHOD OF HIGH STRENGTH STEEL WELDED BOX COLUMNS
}

\author{
Yong-Jun Lin ${ }^{1}$, Kai-Qi Liu ${ }^{1}$, Tian-Ji Li ${ }^{2}$ and Yi Zhou*, \\ ${ }^{1}$ School of Civil Engineering, Southwest Jiaotong University, 999 Xi' an road, Chengdu, Sichuan Province, China \\ ${ }^{2}$ Shanghai Construction No.5 (Group) Co., Ltd., 1000 Cao yang road, Shanghai, China \\ *(Corresponding author: E-mail: suzhouzhouyi@switu.edu.cn)
}

\section{A B S T RA C T}

In this paper, the buckling strength of HSS welded box columns was studied by means of numerical study, and the results were used to verify the applicability of provisions of buckling design in the current design codes and provide design recommendations. Fiber models were established taking into account for the effects of residual stress and geometric imperfection. Through the validation against the experimental results, these fiber models showed excellent capability of replicating the key test results, including buckling strengths and load-lateral deflection histories. Then a comprehensive parametric analysis was conducted to reveal the effects of steel grade and width to thickness ratio on column curves. The fiber model results were then compared with the design buckling strength factors from the current designs such as GB50017-2017, Eurocode 3 and ANSI/AISC 360-10. The comparison showed that the design codes could provide satisfactory accuracy in predicting buckling strength of HSS welded box columns by properly selecting columns curves. Furthermore, by updating the coefficients in the three current design codes, new column curves were proposed, which take the effects of yield strength and width-thickness ratio into consideration. The new column curves were proved to be able to predict the buckling strength with better accuracy and could facilitate the design of HSS welded box columns with different steel grades and width to thickness ratios.

\section{A R T I C L E H I S T O R Y}

$\begin{array}{ll}\text { Received: } & \text { 19 April } 2020 \\ \text { Revised: } & \text { 29 December } 2020 \\ \text { Accepted: } & \text { 29 December } 2020\end{array}$

\section{K E Y W O R D S}

High strength steel;

Welded box columns;

Global buckling;

Fiber model;

Column curve

\section{Introduction}

High strength steels (HSS) have yield strength more than 460MPa, which are prevailed in China and abroad. The GJ steel, as a typical high performance HSS, is created in China and increasingly applied in constructions [1-5]. In civil engineering, the commonly used steel grades for HSS columns include S460, S550, S690, S800 and S960 [6-10]. However, the applicability of current design codes in many countries is limited in the scope of normal strength steel (NSS) structures. For example, the Chinese code GB50017-2017 is not suitable for steel grades higher than S420 (420MPa) [11]. Though Eurocode 3 and ANSI/AISC 360-10 (2010) allow the use of HSS up to S700 (700 MPa) and A514 (690 MPa), the column curves in the design codes are on the basis of experiments and theoretical derivations of NSS with nominal yield strength from $235 \mathrm{MPa}$ to $345 \mathrm{MPa}$ [12-13].

In recent years, a series of axial compression experiments on columns made of HSS and GJ steel had been reported, where the main results include buckling capacity, typical failure mode, global and local buckling behaviors. It was concluded that the overall buckling behavior of HSS columns may be characterized differently from NSS columns due to different material properties and manufacturing processes. Furthermore, several researchers conducted experiments on residual stress and investigated its influence on overall buckling of HSS columns. The results indicated that the effects of initial geometric imperfections and residual stresses on buckling strength become less significant with increasing yield strength [14-20].

However, it was found that the existing researches are limited in conducting experiments on few specimens with one or several steel grades and sectional dimensions. Thus the column curves and design recommendations based on the experiments are unable to take material steel grade and sectional width to thickness ratio into consideration. As a result, the current design codes, such as Chinese code GB50017-2017, Eurocode 3 and American code ANSI/AISC 360-10 have not included these experimental results into provisions, making them not applicable to the buckling design of HSS columns [11-13].

This paper presented a numerical study in order to investigate the effect of material properties and sectional dimensions on buckling strength of HSS welded box columns. The buckling strengths of 1105 HSS welded box columns were obtained by means of fiber model and compared against the predictions of GB50017-2017, Eurocode 3 and ANSI/AISC 360-10. Based on the comparison, several recommendations were proposed for the design of HSS welded box columns subject to axial compression using the current codes. Furthermore, by updating the coefficients in the provisions, new column curves were proposed, which are described as functions of width to thickness ratio and nominal yield strength. The newly proposed column curves were proved to have better accuracy in predicting buckling strength of HSS welded box columns and could provide a unified design method for HSS welded box columns with different sectional dimensions and yield strength from 460MPa to $960 \mathrm{MPa}$.

\section{Recent experimental results}

On the basis of the literature review on previous axial compression experiments, several databases were collected.

Wang et al. and Li et al. investigated the buckling performance of S460 and S690 welded box columns with different slenderness and width to thickness ratios and reported the corresponding load-deflection curves and load-strain curves [21-23].

Ban et al. tested a series of S960 welded box columns with the same sectional dimension but different slenderness to buckling and proposed design recommendations for buckling design using ANSI/AISC 360-10, Eurocode 3 and GB50017-2003 codes [17]. Furthermore, Ban et al. conducted experiments on welded box and I-shaped columns made of S460 steel, where the boundary condition of the specimens was not perfect pin-end support and the initial rotational stiffness of the hinges was measured [24].

Nie et al., Kang et al., Zhou and Xue et al. carried out experiments on GJ welded box columns, where the main results include buckling strengths, load-deflection curves and load-strain curves [1, 4, 5, 25]. According to the results, several supplements for ANSI/AISC 360-10, Eurocode 3 and GB50017-2003 codes were proposed.

Table 1 lists the dimensions and the buckling strengths of the specimens in the aforementioned experiments, where $B$ is the sectional dimension, $t$ is the plate thickness, $L$ is the length, $v_{e}$ is the initial loading eccentricity, $v_{0}$ is the initial bending, $f_{y}$ is the yield strength of steel, $E$ is the Elastic modules and $P_{u}$ is the buckling strength. 
Table 1

Specimens in collected database

\begin{tabular}{|c|c|c|c|c|c|c|c|c|c|c|}
\hline HSS type & Reference & Specimen & $\begin{array}{c}B \\
(\mathrm{~mm})\end{array}$ & $\begin{array}{c}t \\
(\mathrm{~mm})\end{array}$ & $\begin{array}{c}L \\
(\mathrm{~mm})\end{array}$ & $\begin{array}{c}v_{e} \\
(\mathrm{~mm})\end{array}$ & $\begin{array}{c}v_{0} \\
(\mathrm{~mm})\end{array}$ & $\begin{array}{c}f_{y} \\
(\mathrm{MPa})\end{array}$ & $\begin{array}{c}E \\
(\mathrm{GPa})\end{array}$ & $\begin{array}{c}P_{u} \\
(\mathrm{kN})\end{array}$ \\
\hline \multirow{14}{*}{ Conventional } & \multirow{6}{*}{ Wang et al. [21] } & B-8-80-1 & 110 & 11.40 & 3320 & 0.50 & -3.50 & 506 & 208 & 1122 \\
\hline & & B-8-80-2 & 112 & 11.49 & 3260 & -0.9 & 1.50 & 506 & 208 & 1473 \\
\hline & & B-12-55-1 & 156 & 11.43 & 3260 & 1.90 & 3.00 & 506 & 208 & 2591 \\
\hline & & B-12-55-2 & 156 & 11.42 & 3260 & -1.80 & -2.00 & 506 & 208 & 2436 \\
\hline & & B-18-38-1 & 220 & 11.46 & 3260 & -0.60 & 3.00 & 506 & 208 & 3774 \\
\hline & & B-18-38-2 & 221 & 11.46 & 3260 & 1.4 & 2.00 & 506 & 208 & 4010 \\
\hline & \multirow{5}{*}{ Li et al. [22-23] } & B-30-2 & 236 & 16.10 & 2812 & 2.40 & 2.50 & 772 & 233 & 9751 \\
\hline & & B-50-1 & 192 & 16.02 & 3610 & 0.10 & -1.00 & 772 & 233 & 6444 \\
\hline & & B-50-2 & 193 & 16.02 & 3612 & -0.80 & -1.50 & 772 & 233 & 7180 \\
\hline & & B-70-1 & 141 & 16.07 & 3610 & -0.80 & -2.00 & 772 & 233 & 3528 \\
\hline & & B-70-2 & 140 & 16.08 & 3609 & 0 & -1.50 & 772 & 233 & 2897 \\
\hline & \multirow{3}{*}{ Ban et al. [17] } & B1-960 & 143 & 13.99 & 1879 & 26.19 & -0.31 & 973 & 208 & 3779 \\
\hline & & B2-960 & 142 & 13.94 & 2880 & -1.97 & -1.16 & 973 & 208 & 4064 \\
\hline & & B3-960 & 142 & 13.92 & 4382 & 3.45 & -2.63 & 973 & 208 & 2193 \\
\hline \multirow{24}{*}{ GJ } & \multirow{9}{*}{ Xue et al. [25] } & $460 \mathrm{~B} 50-150 \times 12$ & 155 & 12.46 & 3118 & 0 & 4.31 & 492 & 210 & 2508 \\
\hline & & $460 \mathrm{~B} 70-100 \times 12$ & 105 & 12.35 & 2828 & 0 & 3.05 & 492 & 210 & 1245 \\
\hline & & $550 \mathrm{~B} 110-75 \times 12$ & 77 & 12.51 & 3170 & 0 & 4.43 & 635 & 208 & 451 \\
\hline & & $550 \mathrm{~B} 30-100 \times 12$ & 101 & 12.60 & 1378 & 0 & 2.42 & 635 & 208 & 2057 \\
\hline & & $550 \mathrm{~B} 30-150 \times 12$ & 153 & 12.82 & 1987 & 0 & 0.95 & 635 & 208 & 4117 \\
\hline & & $550 \mathrm{~B} 50-100 \times 12$ & 102 & 12.60 & 2103 & 0 & 2.01 & 635 & 208 & 1900 \\
\hline & & $550 \mathrm{~B} 50-150 \times 12$ & 153 & 12.82 & 3118 & 0 & 0.82 & 635 & 208 & 3560 \\
\hline & & $550 \mathrm{~B} 70-100 \times 12$ & 102 & 12.60 & 2828 & 0 & 4.47 & 635 & 208 & 1177 \\
\hline & & $690 \mathrm{~B} 50-100 \times 12$ & 106 & 12.61 & 2103 & 0 & 0.78 & 727 & 211 & 2514 \\
\hline & \multirow{4}{*}{ Kang et al. [4] } & B-120-12 & 120 & 12.23 & 3493 & 2.34 & -1.22 & 546 & 209 & 1635 \\
\hline & & B-168-12 & 168 & 12.45 & 4111 & 1.19 & -2.44 & 546 & 209 & 2740 \\
\hline & & B-264-12 & 264 & 12.21 & 3684 & 0.88 & -3.12 & 546 & 209 & 5852 \\
\hline & & B-175-25 & 176 & 21.53 & 5323 & 2.74 & -0.12 & 473 & 209 & 3453 \\
\hline & \multirow{3}{*}{ Zhou [5] } & B-200-25 & 201 & 25.42 & 5154 & 3.42 & -1.37 & 473 & 208 & 4511 \\
\hline & & B- $225-25$ & 226 & 25.33 & 4704 & 2.41 & -1.75 & 473 & 208 & 6710 \\
\hline & & B-250-25 & 251 & 25.32 & 3965 & 2.37 & -2.25 & 473 & 208 & 8105 \\
\hline & \multirow{8}{*}{ Nie et al. [1] } & B-120-45 & 121 & 12.54 & 3392 & 48.10 & -2.58 & 557 & 208 & 862 \\
\hline & & B-120-75 & 121 & 12.60 & 3391 & 79.40 & 1.16 & 557 & 208 & 643 \\
\hline & & B-168-30 & 169 & 12.61 & 4009 & 28.60 & -1.22 & 557 & 208 & 2004 \\
\hline & & B-168-60 & 168 & 12.63 & 4009 & 58.80 & 1.51 & 557 & 208 & 1470 \\
\hline & & B-216-45 & 217 & 12.57 & 4072 & 44.60 & -1.14 & 557 & 208 & 2881 \\
\hline & & B-216-75 & 217 & 12.55 & 4075 & 74.00 & -3.61 & 557 & 208 & 2241 \\
\hline & & B-264-30 & 264 & 12.59 & 3583 & 30.6 & -0.96 & 557 & 208 & 4749 \\
\hline & & B-264-60 & 265 & 12.63 & 3582 & 58.80 & 1.67 & 557 & 208 & 3900 \\
\hline
\end{tabular}

\section{Fiber model}

\subsection{Assumptions}

According to the previous researches, the following assumptions are made for the fiber model [26-27]:

(1) A plane cross section remains plane after deformation.

(2) The deformation of structure consists with half-sinusoid.

(3) All members are assumed to be fully compact and adequately braced, thus local buckling and lateral torsional buckling are not considered.

(4) The influence of shear deformation is not considered.

\subsection{Calculation method}

The whole mid-span cross section is meshed into rectangular fibers for the preparation of numerical calculation, as shown in Fig. 1, where $P$ is the load position of axial force and $e_{0}$ is the initial geometric imperfection to the mid-span section, which can be calculated by Eq. (1). Herein, each fiber is represented by its area and coordinate location corresponding to its centroid. The residual stresses are assigned directly to fibers as the initial stresses and the properties of the cross-section can be evaluated at each step of analysis [26]. 


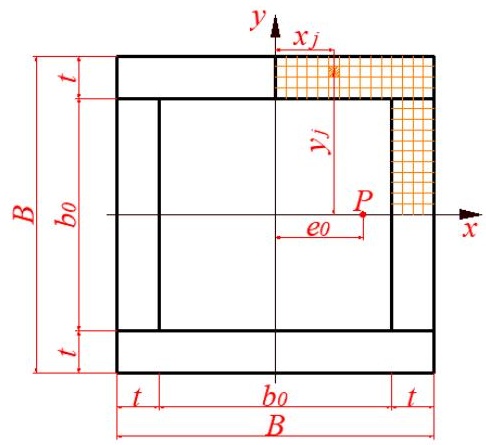

Fig. 1 Mesh fibers and sectional dimensions

$e_{0}=\left|v_{e}+v_{0}\right|$

According to the assumption 2, the lateral deflection of axial compression member can be calculated by:

$u_{i}=u_{m} \sin \frac{\pi}{L} z$

where, $u_{i}$ is the lateral displacement of section number $i, u_{m}$ is the lateral displacement of mid-span section and $z$ is the distance from the $i$ section to the top end of the column.

The curvature of the mid-span section, $\phi_{m}$, is:

$\phi_{m}=u_{m} \frac{\pi^{2}}{L^{2}}$

In the mid-span cross section, the coordinate of the fiber number $j$ can be expressed as $\left(x_{j}, y_{j}\right)$, and the strain $\varepsilon_{j}$ of the fiber is given by:

$\varepsilon_{j}=\varepsilon_{c}+\phi_{m} x_{j}+\sigma_{r s j} / E$

where, $\varepsilon_{c}$ is the centroid strain of the section, $\sigma_{r s j}$ is the residual stress of fiber number $j$ and $E$ is the elastic module.

Then the stress of the fiber number $j$ can be calculated according to the constitutive relation:

$\sigma_{j}=f\left(\varepsilon_{j}\right)$

where the symbol ' $f()$ ' represents the constitutive function of steel, as shown in Fig. 2 and defined by Eq. (6).

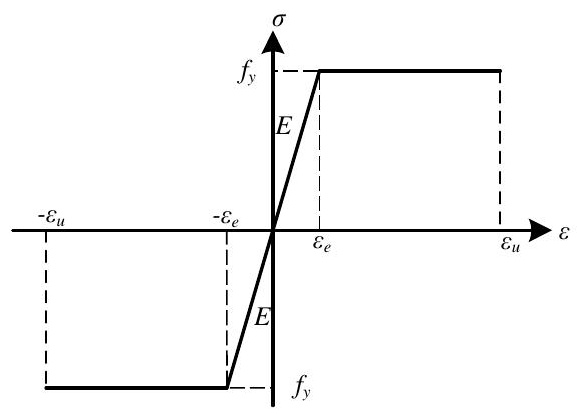

Fig. 2 Constitutive function of steel applied in fiber model

$\sigma=\left\{\begin{array}{cc}f_{y} & \varepsilon_{e} \leq \varepsilon<\varepsilon_{u} \\ E \varepsilon & -\varepsilon_{e} \leq \varepsilon<\varepsilon_{e} \\ -f_{y} & -\varepsilon_{u} \leq \varepsilon<-\varepsilon_{e}\end{array}\right.$

where, $\sigma$ is the stress, $\varepsilon_{e}$ is the elastic strain, $\varepsilon_{u}$ is the ultimate strain.

Then, the internal axial force $N_{i n}$ and bending moment $M_{i n}$ can be calculated as:
$M_{i n}=\sum_{j=1}^{k} \sigma_{j} A_{j} x_{j}$

$N_{i n}=\sum_{j=1}^{k} \sigma_{j} A_{j}$

where $k$ is the total number of fibers.

\subsection{Residual stres}

The residual stress has a strong influence on the buckling behavior of axial compression members, and the fiber models employing different residual models will result in different buckling strengths [17, 20, 28, 29]. A unified residual model suitable for HSS welded box columns of comprehensive steel grades and sectional dimensions was proposed by Ban et al., which could be further employed in the current numerical research $[17,20]$. The shape of the unified model is presented in Fig. 3 and the major parameters, such as width of tensile and compressive stress areas, magnitude of tensile stress and the self-balance conditions are listed in Tables 2-3.

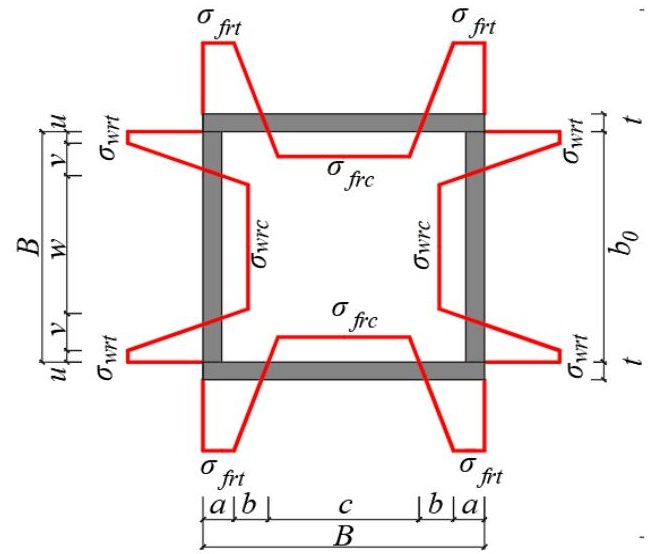

Fig. 3 Unified residual stress model

Table 2

Magnitude parameters of the unified residual stress model

\begin{tabular}{cc|c}
\hline \multicolumn{2}{c|}{$\sigma_{f r t,} \sigma_{w r t}$} & $\sigma_{f r c}, \sigma_{w r c}$ \\
\hline $460 \mathrm{MPa} \leq f_{y} \leq 690 \mathrm{MPa}$ & $460 \mathrm{MPa}$ & $\sigma_{r c}=-95-\frac{1450}{h_{0} / t}-\frac{270}{t}$ \\
$f_{y} \geq 690 \mathrm{MPa}$ & $690 \mathrm{MPa}$ & $-f_{y} \leq \sigma_{r c} \leq-0.1 f_{y}$ \\
\hline
\end{tabular}

Table 3

Location parameters of the unified residual stress model

\begin{tabular}{|c|c|c|c|}
\hline$a$ & $u$ & $b, c$ & $v, w$ \\
\hline \multirow[t]{2}{*}{$t+h_{0} / 10$} & $t$ & $\iint_{A_{f}} \sigma_{r s} \cdot d A=0$ & $\iint_{A_{w}} \sigma_{r s} \cdot d A=0$ \\
\hline & & $2(a+b)+c=D$ & $2(u+v)+w=b_{0}$ \\
\hline
\end{tabular}

In Table $3, A_{f}$ is the area of flange, $A_{w}$ is the area of web and $\sigma_{r s}$ is the residual stress.

\subsection{Equilibrium and calculation process}

According to the assumption 4, the equilibrium of the mid-span section subject to axial compression and bending moment can be defined as:

$M_{i n}-N_{i n}\left(e_{0}+u_{m}\right)=0$

where $u_{m}$ is the deflection in the mid-span section oriented from bending moment.

Since the axial force $N_{i n}$ is coupled with the bending moment $M_{i n}$, the mid-span deflection $u_{m}$ and the mid-span curvature $\phi_{m}$, an iterative method should be employed to find the solution of Eq. (9). Giving a specific mid-span curvature $\phi_{m}$, the processes of iteration aiming to find the axial force $N_{\text {in }}$ 
corresponding to the $\phi_{m}$ and satisfying the equilibrium is presented in Fig. 4 [27].

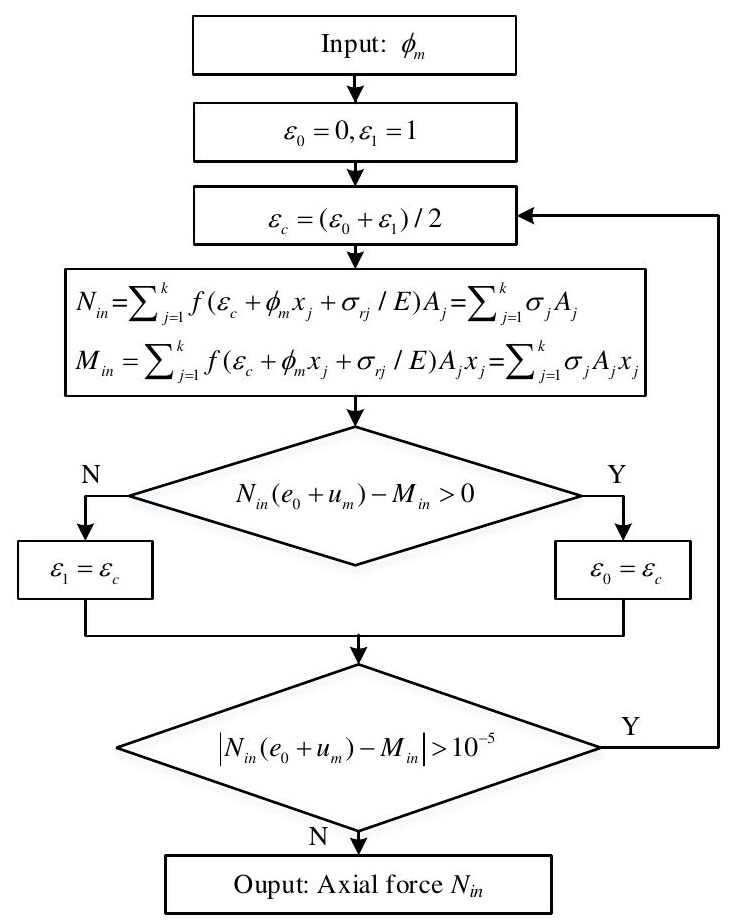

Fig. 4 Flowchart for iterative method

\subsection{Calculation process}

The calculation process includes the three steps:

a) Give a specific mid-span curvature $\phi$;

b) Calculate the deflection of the mid-span section $u_{m}$ subject to the given $\phi_{m}$ according to Eq. (10);

c) Calculate axial load using the iterative strategy presented in Fig. 4.

The steps are repeated until the curvature of the mid-span section reaches a preset value and the whole load-deflection curve can be obtained. Then, the buckling strength can be set as the peak load. The specific processes are shown in Fig. 5.

$u_{m}=\frac{L^{2}}{\pi^{2}} \phi_{m}$

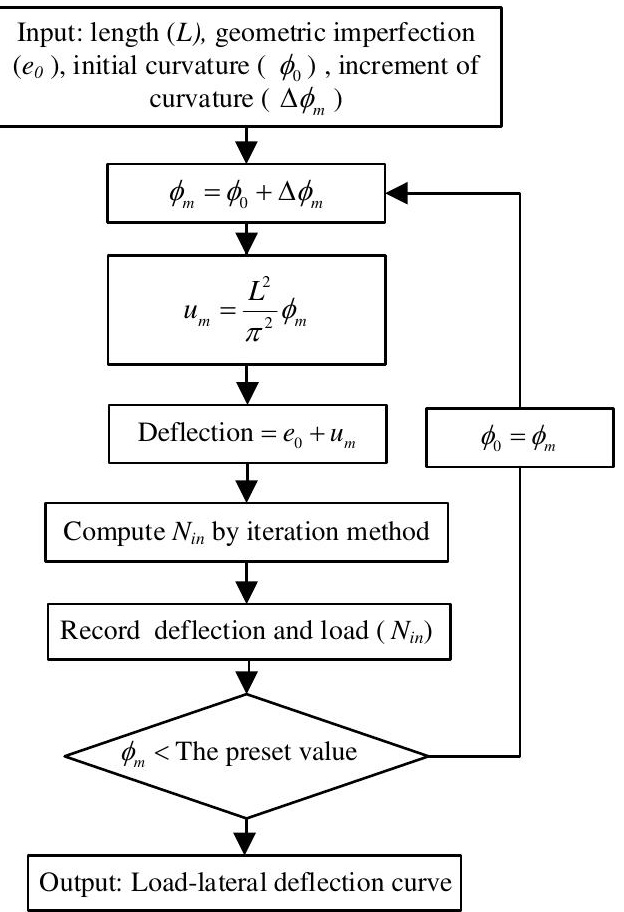

Fig. 5 Flowchart for calculation process

\section{Model validation}

To verify the accuracy, efficiency and versatility of the fiber model, HSS welded box columns under axial compression are analyzed and compared with the test data presented by several scholars. The buckling strengths of fiber models and the buckling strengths of test specimens are compared in Table 4 . It can be seen that the buckling strength ratios range from 0.89 to 1.31 with an average of 1.05. Thus, the fiber models with unified residual stress model are able to capture the buckling strength of HSS welded box columns. The load-deflection curves obtained from the fiber models and test results are shown in Fig. 8. The comparison suggests that the numerical results are in good agreement with test results. Overall, it is concluded that the fiber models are capable of replicating the key test results.

Table 4

Comparison on buckling strength between test results and fiber models

\begin{tabular}{|c|c|c|c|c|}
\hline Reference & Specimen & $\begin{array}{c}\text { Test buckling } \\
\text { strength } \\
(\mathrm{kN})\end{array}$ & $\begin{array}{c}\text { Fiber model } \\
\text { buckling strength } \\
(\mathrm{kN})\end{array}$ & Ratio \\
\hline \multirow{6}{*}{ Wang et al. [21] } & B-8-80-1 & 1122 & 987 & 1.14 \\
\hline & B-8-80-2 & 1473 & 1124 & 1.31 \\
\hline & B-12-55-1 & 2591 & 2220 & 1.17 \\
\hline & B-12-55-2 & 2436 & 2253 & 1.08 \\
\hline & B-18-38-1 & 3774 & 4178 & 0.90 \\
\hline & B-18-38-2 & 4010 & 4122 & 0.97 \\
\hline \multirow{5}{*}{ Li et al. [22-23] } & B-30-2 & 9751 & 8680 & 1.12 \\
\hline & B-50-1 & 6444 & 5675 & 1.14 \\
\hline & B-50-2 & 7180 & 5551 & 1.29 \\
\hline & B-70-1 & 3528 & 3132 & 1.13 \\
\hline & B-70-2 & 2897 & 2825 & 1.03 \\
\hline \multirow{3}{*}{ Ban et al. [17] } & B1-960 & 3779 & 3805 & 0.99 \\
\hline & B2-960 & 4064 & 3806 & 1.07 \\
\hline & B3-960 & 2193 & 2052 & 1.07 \\
\hline \multirow{9}{*}{ Xue et al. [25] } & $460 \mathrm{~B} 50-150 \times 12$ & 2508 & 2379 & 1.05 \\
\hline & $460 \mathrm{~B} 70-100 \times 12$ & 1245 & 1109 & 1.12 \\
\hline & $550 \mathrm{~B} 110-75 \times 12$ & 451 & 413 & 1.09 \\
\hline & $550 \mathrm{~B} 30-100 \times 12$ & 2057 & 2323 & 0.89 \\
\hline & $550 \mathrm{~B} 30-150 \times 12$ & 4117 & 4162 & 0.99 \\
\hline & $550 \mathrm{~B} 50-100 \times 12$ & 1900 & 1794 & 1.06 \\
\hline & $550 \mathrm{~B} 50-150 \times 12$ & 3560 & 3138 & 1.13 \\
\hline & $550 \mathrm{~B} 70-100 \times 12$ & 1177 & 1178 & 1.00 \\
\hline & $690 \mathrm{~B} 50-100 \times 12$ & 2514 & 2009 & 1.25 \\
\hline \multirow{4}{*}{ Kang et al. [4] } & B-120-12 & 1635 & 1384 & 1.18 \\
\hline & B-168-12 & 2740 & 2595 & 1.06 \\
\hline & B-264-12 & 5852 & 6089 & 0.96 \\
\hline & B-175-25 & 3453 & 3269 & 1.06 \\
\hline \multirow{3}{*}{ Zhou [5] } & B-200-25 & 4511 & 4550 & 0.99 \\
\hline & B-225-25 & 6710 & 6786 & 0.99 \\
\hline & B-250-25 & 8105 & 9427 & 0.86 \\
\hline \multirow{8}{*}{ Nie et al. [1] } & B-120-45 & 862 & 826 & 1.04 \\
\hline & B-120-75 & 643 & 659 & 0.98 \\
\hline & B-168-30 & 2004 & 1970 & 1.02 \\
\hline & B-168-60 & 1470 & 1514 & 0.97 \\
\hline & B-216-45 & 2881 & 2966 & 0.97 \\
\hline & B-216-75 & 2241 & 2482 & 0.90 \\
\hline & B-264-30 & 4749 & 4917 & 0.97 \\
\hline & B-264-60 & 3900 & 4084 & 0.96 \\
\hline
\end{tabular}


(a) $550 \mathrm{~B} 70-100 \times 12$

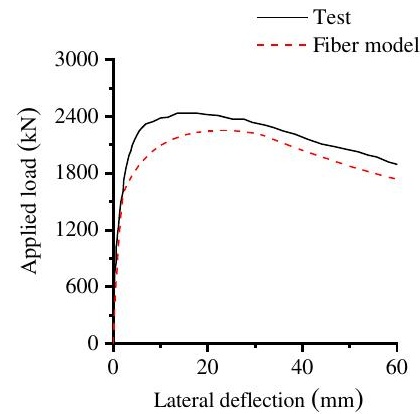

(c) B-12-55-2

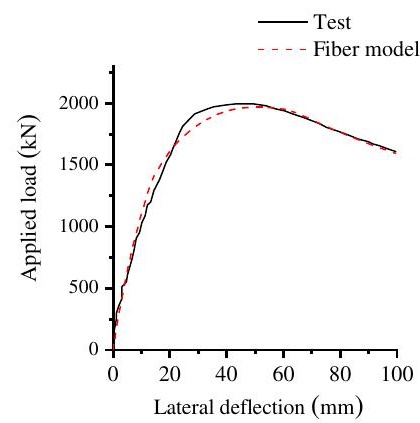

(e) B-168-30

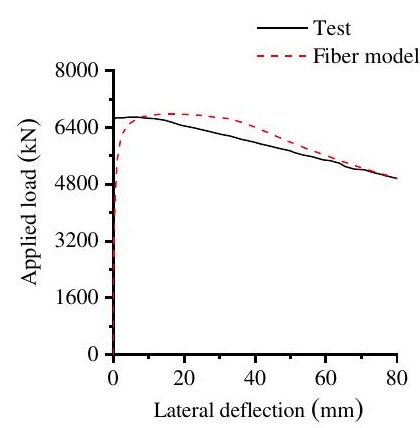

(g) B-225-25

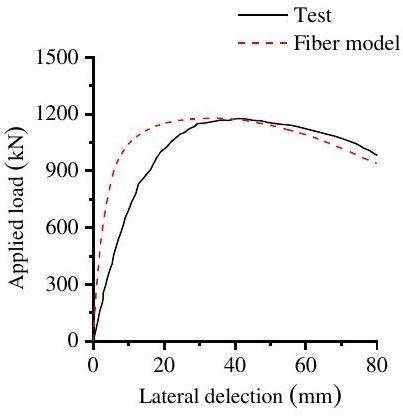

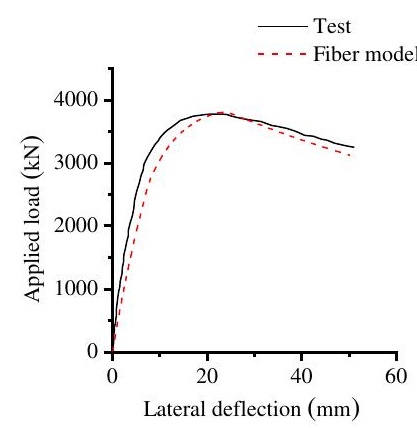

(b) B1-960

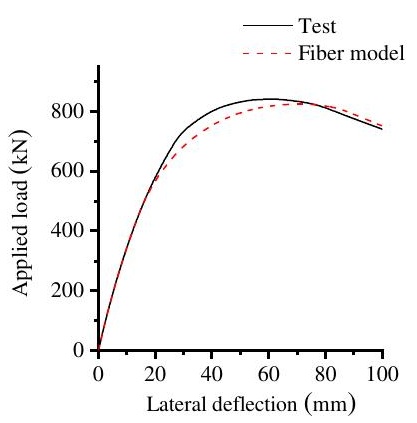

(d) B-120-45

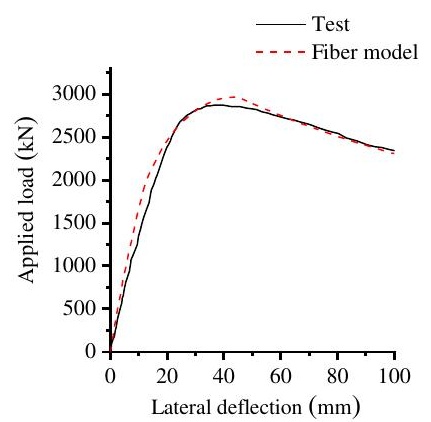

(f) B-216-45

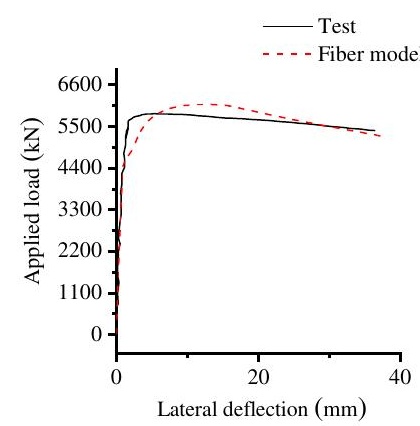

(h) B-264-12
Fig. 6 Comparison on load-deflection curves between test results and fiber model results

\section{Parametric studies and design recommendations}

\subsection{Parametric studies}

Having validated the fiber models against the test results, a series of parametric studies are performed, focusing on steel grades and sectional width to thickness ratios. The sectional dimensions of specimens in the parametric study are listed in Table 5. For each sectional dimension, the slenderness varies from 10 to 130 with an interval of 10 corresponding to non-dimensional slenderness ranging from 0.15 to 3.0. And for each combination of sectional dimension and slenderness, the steel grades include S460, S550, S690, S800 and S960. The initial geometric imperfection is set as $1 \%$ of the specimen length covering unintentional load eccentricities and initial bending [11-13].

The buckling strength factors for each specimen are calculated according to the column curves in the design codes GB50017-2017, Eurocode 3 and ANSI/AISC 360-10. According to GB50017-2017, the curve $\mathrm{c}$ is used to design welded box columns with width to thickness ratios lower than 20 and curve the $\mathrm{b}$ is used to design welded box columns with width to thickness ratios higher than 20. According to Eurocode 3, the curve b is used to design welded box columns with width to thickness ratios higher than 30 and the curve $\mathrm{c}$ is used to design welded box columns with width-thickness ratios lower than 30 . ANSI/AISC 360-10 code employs a single column curve to design all the welded box columns. The corresponding relations of sectional dimensions and design curves are listed in Table 5.

Table 5

Sectional dimensions of fiber models

\begin{tabular}{cccc|ccc}
\hline & & & & \multicolumn{3}{|c}{ Design curve } \\
\cline { 5 - 7 } Section & $B(\mathrm{~mm})$ & $t(\mathrm{~mm})$ & $b$ o/ & & & \\
& & & & GB50017-2017 & Eurocode 3 & ANSI/AISC \\
& & & & & & $360-10$ \\
\hline Sec-B1 & 77 & 13 & 3.92 & Curve b & Curve c & Curve a \\
Sec-B2 & 101 & 13 & 5.77 & Curve b & Curve c & Curve a \\
Sec-B3 & 201 & 25 & 6.04 & Curve b & Curve c & Curve a \\
Sec-B4 & 140 & 16 & 6.75 & Curve b & Curve c & Curve a \\
Sec-B5 & 120 & 12 & 8.00 & Curve b & Curve c & Curve a \\
Sec-B6 & 251 & 25 & 8.04 & Curve b & Curve c & Curve a \\
Sec-B7 & 192 & 16 & 10.00 & Curve b & Curve c & Curve a \\
Sec-B8 & 155 & 12 & 10.92 & Curve b & Curve c & Curve a \\
Sec-B9 & 168 & 12 & 12.00 & Curve b & Curve c & Curve a \\
Sec-B10 & 250 & 11 & 20.73 & Curve c & Curve c & Curve a \\
Sec-B11 & 220 & 10 & 20.00 & Curve c & Curve c & Curve a \\
Sec-B12 & 270 & 12 & 20.50 & Curve c & Curve c & Curve a \\
Sec-B13 & 380 & 14 & 25.14 & Curve c & Curve c & Curve a \\
Sec-B14 & 360 & 12 & 28.00 & Curve c & Curve c & Curve a \\
Sec-B15 & 390 & 12 & 30.50 & Curve c & Curve b & Curve a \\
Sec-B16 & 350 & 10 & 33.00 & Curve c & Curve b & Curve a \\
Sec-B17 & 211 & 6 & 33.17 & Curve c & Curve b & Curve a \\
\hline & & & & & &
\end{tabular}

\subsection{Applicability of current design codes}

In GB 50017-2017 the buckling strength $N_{d}$ of axial compression member is expressed as,

$N_{d}=\varphi A f_{y}$

where $\varphi$ is the buckling strength factor.

When $\lambda_{d} \leq 0.215$,

$\varphi=1-a_{1} \lambda_{d}^{2}$

When $\lambda_{d}>0.215$

$\varphi=\frac{\left(a_{2}+a_{3} \lambda_{d}+\lambda_{d}{ }^{2}\right)-\sqrt{\left(a_{2}+a_{3} \lambda_{d}+\lambda_{d}{ }^{2}\right)^{2}-4 \lambda_{d}^{2}}}{2 \lambda_{d}{ }^{2}}$

where $\lambda_{d}$ is the non-dimensional slenderness, $a_{1}, a_{2}$ and $a_{3}$ are the imperfection factors.

The buckling strength of column in Eurocode 3 is defined as,

$N_{d}=\varphi_{e} A f_{y}$

where $\varphi_{e}$ is the buckling strength factor

When $\lambda_{d} \leq 0.2$

$\varphi_{e}=1$

When $\lambda_{d}>0.2$, 


$$
\varphi_{e}=\frac{1}{0.5\left[1+a_{E}\left(\lambda_{d}-0.2\right)+\lambda_{d}{ }^{2}\right]+\sqrt{\left\{0.5\left[1+a_{E}\left(\lambda_{d}-0.2\right)+\lambda_{d}{ }^{2}\right]\right\}^{2}-\lambda_{d}{ }^{2}}}
$$

where, $a_{E}$ is the imperfection factor.

In ANSI/AISC 360-10, the buckling strength of axial compression member is calculated by Eq. (17).

$N_{d}=\varphi_{c} A f_{y}$

where $\varphi_{c}$ is the buckling strength factor.

When $\lambda_{d} \leq 1.5$,

$\varphi_{c}=a_{A N}^{\lambda_{n}^{2}}$

When $\lambda_{d}>1.5$

$\varphi_{c}=2.25 \frac{a_{A N}^{2.25}}{\lambda_{n}{ }^{2}}$

where $\alpha_{A N}$ is the imperfection factor.

\subsection{Comparison between fiber model and current design codes}

Figs.7-9 show the buckling strength ratios of fiber models together with design results using column curves in the three design codes, where the S460, S690 and S960 specimens are selected to present the deviations. It is found that the deviations of the two methods are clear and increase with yield strength, which means the buckling strength of HSS welded box columns are generally underestimated by the current design codes. This fact is in agreement with the existing researches and can be explained by that the influence of initial imperfection and residual stress is less severe in the HSS structures compared with the NSS structures [30-31]

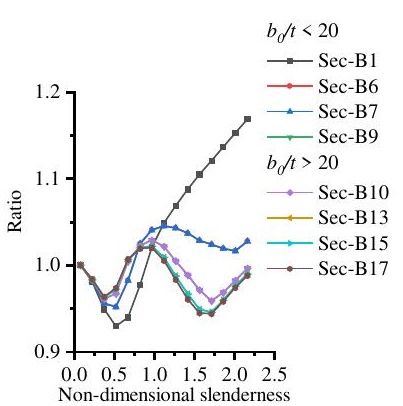

(a) GB50017-2017

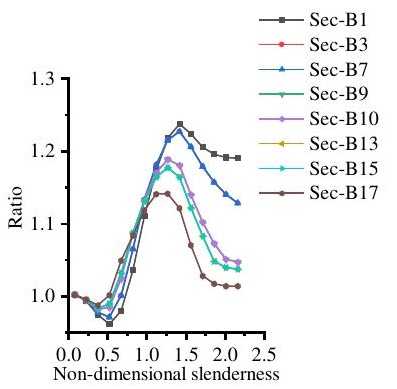

(c) ANSI/AISC 360-10

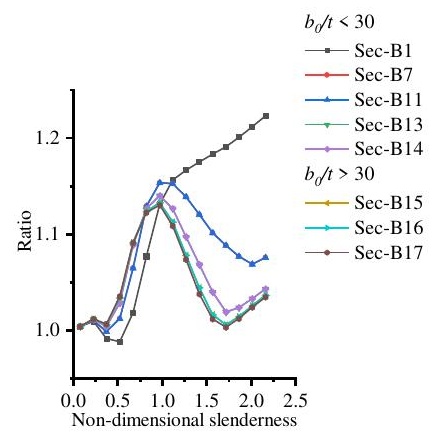

(b) Eurocode 3
Fig. 7 Comparison of fiber model results and design results for S460 specimens

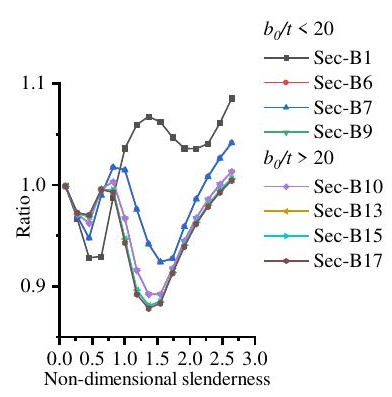

(a) GB50017-2017

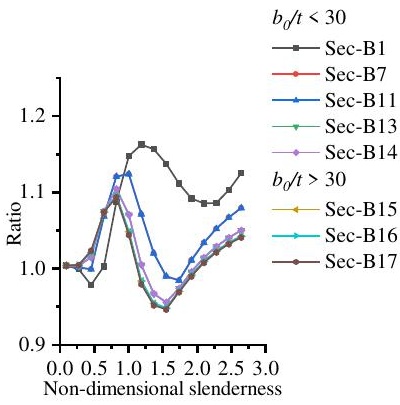

(b) Eurocode 3

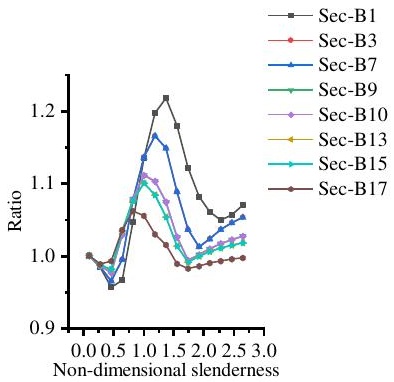

(c) ANSI/AISC 360-10

Fig. 8 Comparison of fiber model results and design results for S690 specimens

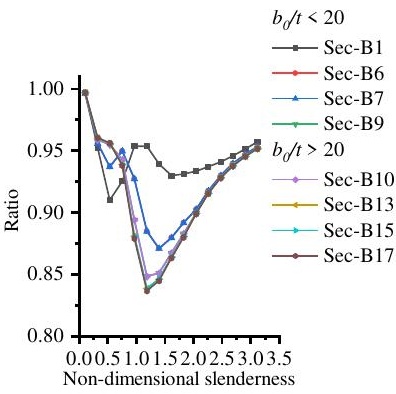

(a) GB50017-2017

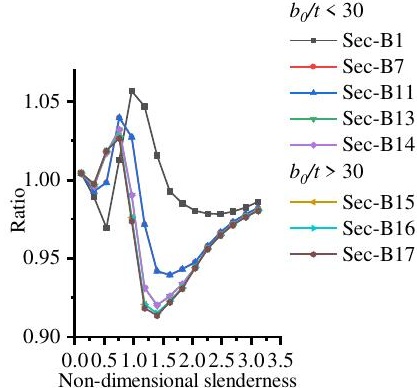

(b) Eurocode 3

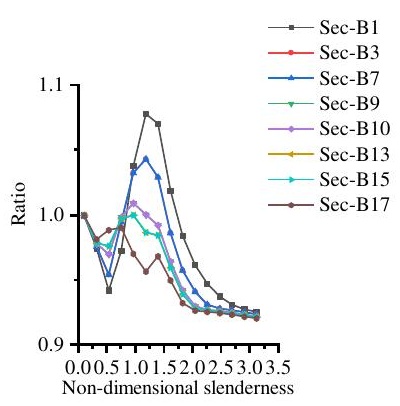

(c) ANSI/AISC 360-10
Fig. 9 Comparison of fiber model results and design results for S960 specimens

\subsection{Recommendation on column curves}

The errors between buckling strength factors using fiber models $\varphi_{F M}$ and column curves in the three design codes $\varphi_{D E}$ are calculated for all the parametric members by means of Eq. (20) and the mean errors of each steel grade are listed in Table 6.

$$
\text { Error }=\frac{\left|\varphi_{F M}-\varphi_{D E}\right|}{\varphi_{F M}} \times 100 \%
$$

It is suggested that GB50017-20017 using curve b for all the steel grades while Eurocode 3 using curve b for steel grades lower than S800 and using c for steel grades higher than S800 could make predictions with satisfactory 
accuracy to buckling strength of HSS welded box columns. Noting that if the column curve chosen according to the width to thickness ratio different from the column curve chosen according to the steel grade for one specimen, the buckling strength factor shall be the lower value obtained from the two column curves.

In the case of ANSI/AISC 360-10, it shows that most of the mean error values lie close to or lower than the recommended column curves in GB50017-2017 and Eurocode 3. And only the mean error of S460 specimens which is $7.55 \%$ lies between curve b and curve c in GB50017-2017 and slightly higher than curve $\mathrm{c}$ in Eurocode 3 . Therefore, the column curve in ANSI/AISC 360-10 is also recommended to design HSS welded box columns.

Table 6

Average errors of buckling strength between numerical results and design curves

\begin{tabular}{|c|c|c|c|c|c|c|c|}
\hline \multirow{2}{*}{ Steel grade } & \multicolumn{3}{|c|}{ GB50017-2017 } & \multicolumn{3}{|c|}{ Eurocode 3} & \multirow{2}{*}{ ANSI/AISC $360-10$} \\
\hline & Curve b & Curve $\mathrm{c}$ & Recommendation & Curve $\mathrm{b}$ & Curve $\mathrm{c}$ & Recommendation & \\
\hline S460 & $3.54 \%$ & $9.05 \%$ & Curve $b$ & $3.16 \%$ & $7.41 \%$ & Curve $b$ & $7.55 \%$ \\
\hline S550 & $3.53 \%$ & $11.84 \%$ & Curve $b$ & $3.79 \%$ & $3.61 \%$ & Curve b & $4.20 \%$ \\
\hline S690 & $3.84 \%$ & $10.52 \%$ & Curve $b$ & $3.88 \%$ & $4.61 \%$ & Curve b & $3.50 \%$ \\
\hline S800 & $5.43 \%$ & $12.80 \%$ & Curve b & $5.87 \%$ & $2.83 \%$ & Curve $\mathrm{c}$ & $3.41 \%$ \\
\hline S960 & $7.59 \%$ & $14.32 \%$ & Curve b & $8.07 \%$ & $3.36 \%$ & Curve $\mathrm{c}$ & $4.61 \%$ \\
\hline
\end{tabular}

\subsection{Proposed column curve}

In order to predict the buckling strength of HSS welded box columns with better accuracy for design, new column curves are proposed in this paper. The values of imperfection factors in the formula of column curves in Eurocode 3 $\left(a_{E}\right)$, ANSI/AISC 360-10 $\left(a_{A N}\right)$ and GB50017-2017 $\left(a_{2}, a_{3}\right)$ are obtained using non-linear regression analysis on the buckling strength factors from parametric studies. The results are demonstrated in Figs. 10-11. It is found that the imperfection factors have a significant correlation with the width to thickness ratio and the nominal yield strength. Therefore, an empirical equation related to width to thickness ratio and nominal yield strength is suggested to calculate the imperfection factors of the column curves, as shown in Eq. (21), where $a$ is the imperfection factor which is labeled as $a_{E}$ in Eurocode 3, $a_{A N}$ in ANSI/AISC 360-10 and $a_{3}$ in GB50017-2017 and $f_{y}$ is the nominal yield strength $(\mathrm{MPa})$.

$a=\left(\alpha_{1}+\alpha_{2} \frac{b_{0}}{t}\right) \times\left(\alpha_{3}+\alpha_{4} \frac{f_{y}}{460}\right)$

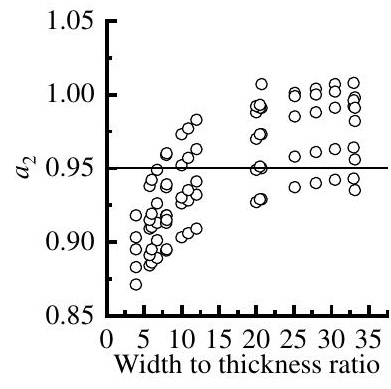

(a) $a_{2}$ of GB50017-2017

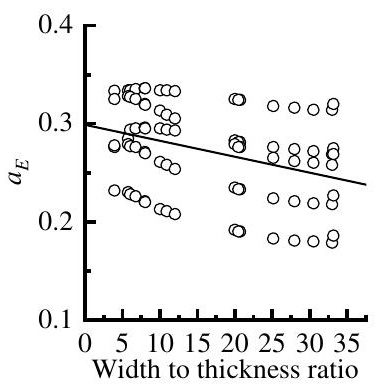

(c) $a_{E}$ of Eurocode 3

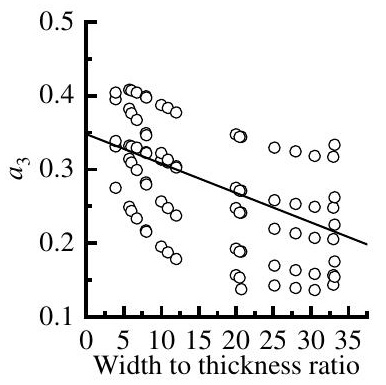

(b) $a_{3}$ of GB50017-2017

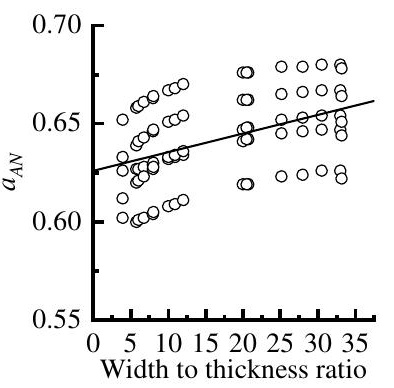

(d) $a_{A N}$ of ANSI/AISC $360-10$
Fig. 10 The relation between imperfection factor and with to thickness ratio

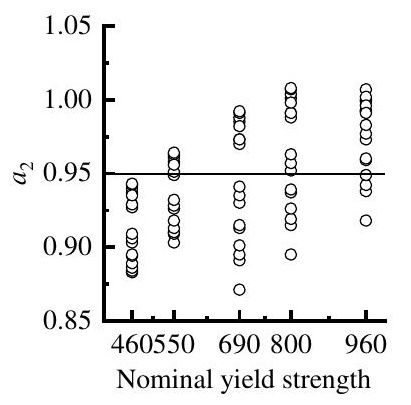

(a) $a_{2}$ of GB50017-2017

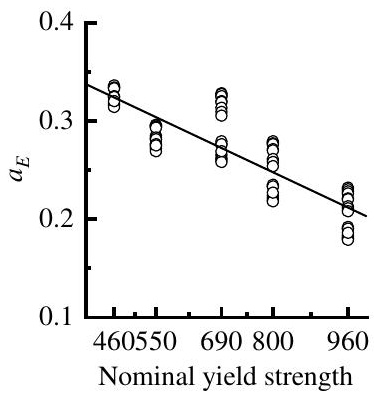

(c) $a_{E}$ of Eurocode 3

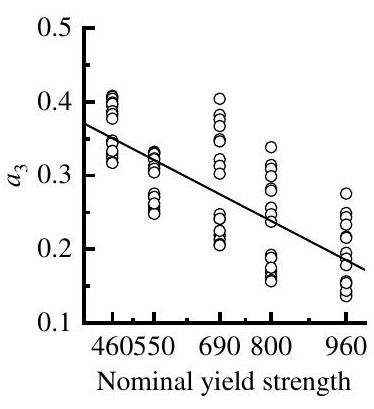

(b) $a_{3}$ of GB50017-2017

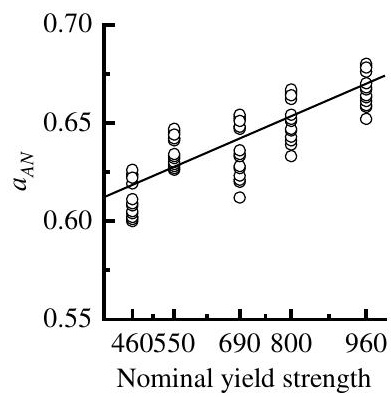

(d) $a_{A N}$ of ANSI/AISC 360-10
Fig. 11 The relation between imperfection factor and nominal yield strength

The values of regression coefficients $\alpha_{1}, \alpha_{2}, \alpha_{3}$ and $\alpha_{4}$ are listed in Table 7. For Eurocode 3 and ANSI/AISC 360-10, the imperfection factors $a_{E}$ and $a_{A N}$ can be calculated by Eq. (21). While for GB50017-2017, there are three coefficients to be determined, where the $a_{2}$ is settled as the average 0.95 , the $a_{3}$ is determined by Eq. (21) and the $a_{1}$ is computed according to the continuity condition as shown in Eq. (22).

$a_{1}=\frac{2 \times 0.215^{2}-\left(a_{2}+0.215 a_{3}+0.215^{2}\right)+\sqrt{\left(a_{2}+0.215 a_{3}+0.215^{2}\right)^{2}-4 \times 0.215^{2}}}{2 \times 0.215^{4}}$

Table 7

Values of regression coefficients

\begin{tabular}{cccccc}
\hline & & \multicolumn{5}{c}{ Regression coefficients } \\
Design code & Coefficient & $\alpha_{1}$ & $\alpha_{2}$ & $\alpha_{3}$ & $\alpha_{4}$ \\
\hline GB50017-2017 & $a_{3}$ & 2.590 & -0.032 & 0.240 & -0.071 \\
Eurocode 3 & $a_{E}$ & 1.780 & -0.009 & 0.261 & $-6.27 \times 10^{-2}$ \\
ANSI/AISC 360-10 & $a_{A N}$ & 2.820 & $4.27 \times 10^{-3}$ & 0.198 & 0.0164 \\
\hline
\end{tabular}

Fig. 12 depicts the comparison of mean errors of buckling strength factors using the recommended column curves and using the proposed column 
curves for all the parametric specimens. It can be seen that the mean error using proposed column curves are smaller than the mean error using recommended column curves given in GB50017-2017, Eurocode 3 and ANSI/AISC 360-10. Fig. 13 depicts the buckling strength factors of selected specimens obtained from fiber models together with design results obtained from proposed column curves. It can be seen that the results obtained from the proposed curves are in good agreement with the results obtained from the fiber models. Overall, it is concluded that the proposed column curves are able to make predictions with better accuracy to buckling strength factors of HSS welded box columns with different width to thickness ratios and steel grades.

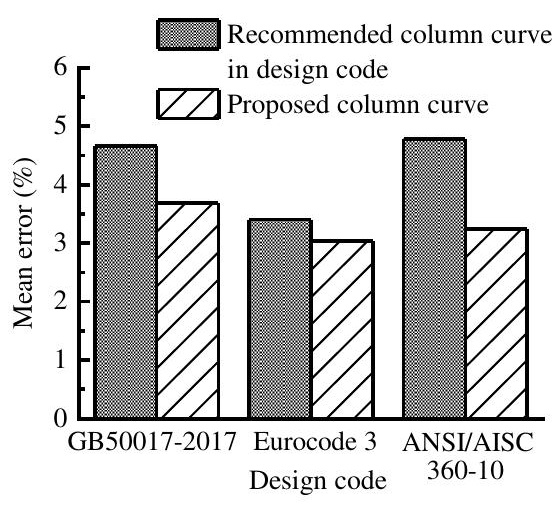

Fig. 12 Comparison of mean error between proposed column curves and design codes

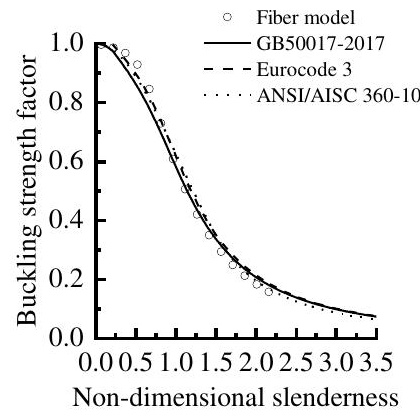

(a) S460 with Sec-B1

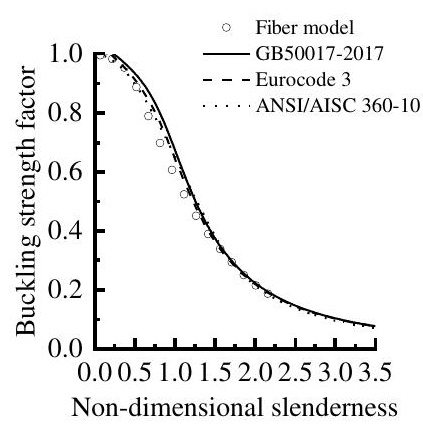

(c) S460 with Sec-B17

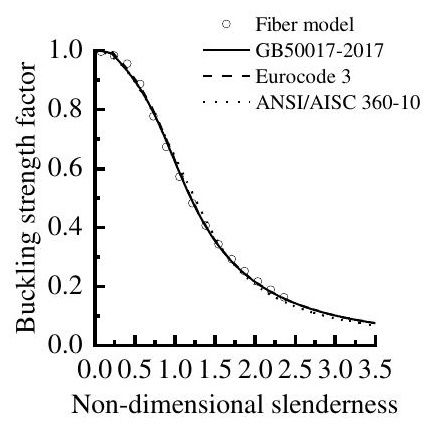

(e) S550 with Sec-B9

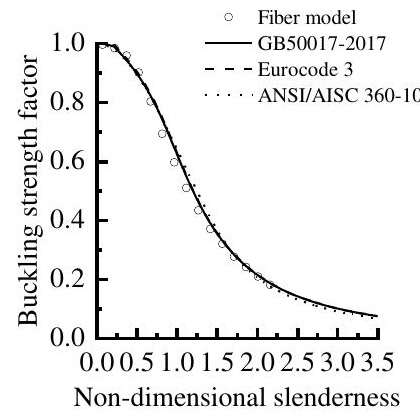

(b) S460 with Sec-B9

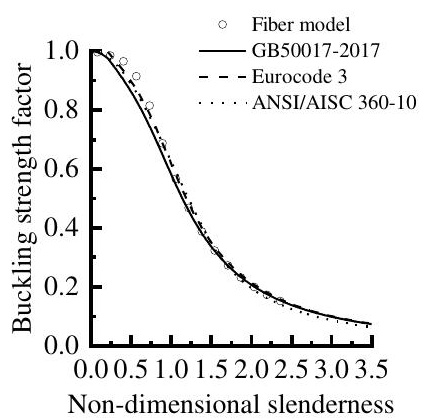

(d) S550 with Sec-B1

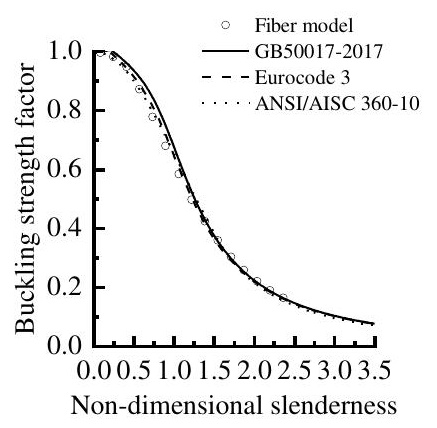

(f) S550 with Sec-B17
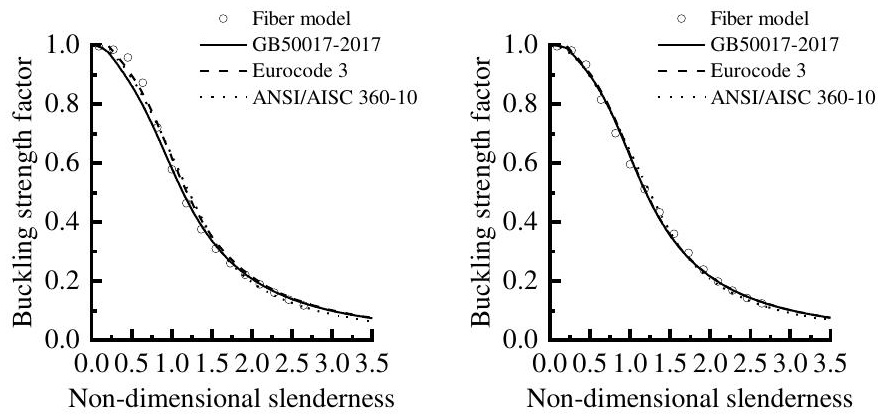

(g) S690 with Sec-B1

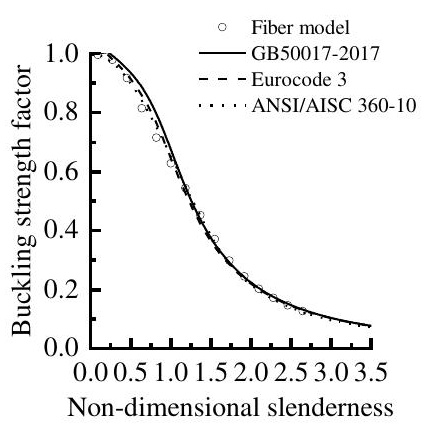

(h) S690 with Sec-B9

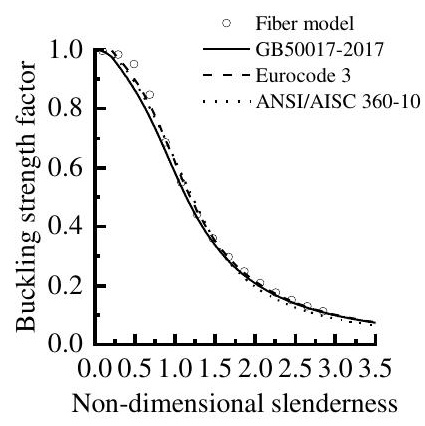

(j) S800 with Sec-B1
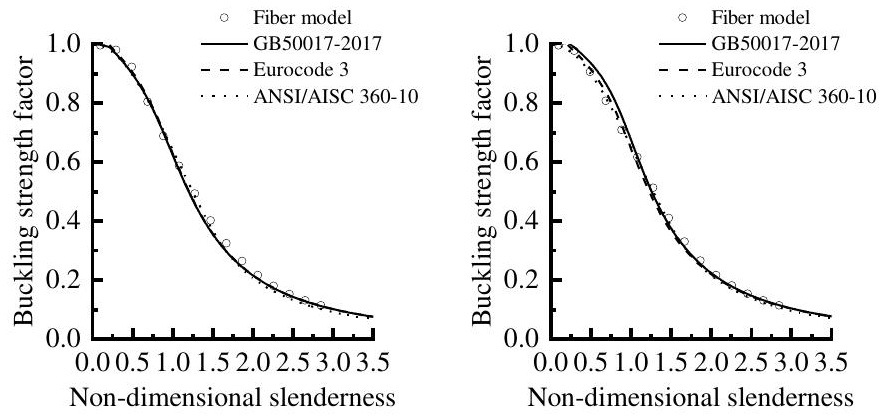

(k) S800 with Sec-B9

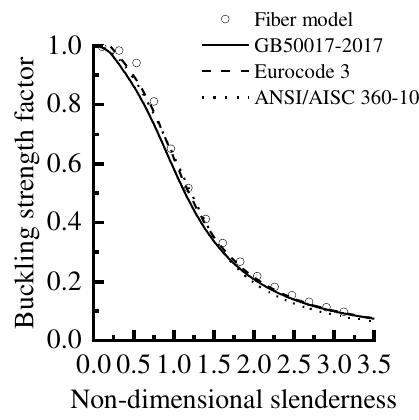

(1) S800 with Sec-B17

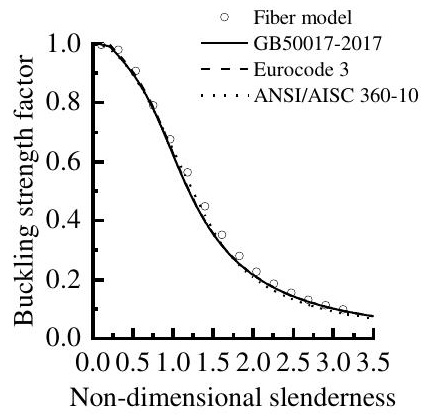

(n) S960 with Sec-B9

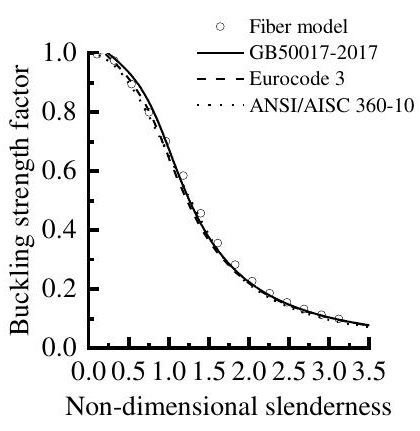

(o) S960 with Sec-B17

Fig. 13 Comparison of buckling strength factor between fiber model and proposed 


\section{Conclusion}

This paper conducted a numerical study on the buckling strength of HSS welded box columns with different steel grades under axial compression and to propose design recommendations for the current design codes. Fiber models employing unified residual stress model were established to replicate the experimental results of HSS welded box columns of different steel grades. Having the fiber models validated, parametric studies were carried out to investigate the effects of steel grade and width to thickness ratio on buckling strength of HSS welded box steel columns. The results are used to assess the applicability of current design codes including GB50017-2017, Eurocode 3 and ANSI/AISC 360-16 on buckling design of HSS welded box columns with different steel grades and sectional dimensions. The following conclusions have been made:

a)The fiber model employing unified residual stress model could accurately replicate the key test results.

b)The buckling strength factors of HSS welded box columns of different steel grades subject to axial compression from design codes GB50017-2017, Eurocode 3 and ANSI/AISC 360-10 are inconsistent with the buckling strength factors from fiber models. The average deviation of the whole parametric specimens is $8.37 \%, 4.7 \%$ and $4.6 \%$, respectively.

c)In determination of buckling strength factor of HSS welded box columns subject to axial compression, the design rules in GB50017-2017 using curve $\mathrm{b}$, the design rules in Eurocode 3 using curve $\mathrm{b}$ for steel grades lower than S800, the design rules in Eurocode 3 using curve $\mathrm{c}$ for steel grades higher than S800 and the design rules in ANSI/AISC 360-10 using single curve are recommended.

d) By updating the coefficients in the current design codes, new column curves are proposed, which takes the effects of material steel grade and sectional width to thickness ratio into consideration. The newly proposed column curves provide a unified method for the design of HSS welded box columns.

\section{Acknowledgments}

The authors are grateful to the financial support of the Natural Science Foundation of China (No.51608453)

\section{References}

[1] Nie S.D., Kang S.B., Shen L., Yang B., "Experimental and numerical study on global buckling of Q460GJ steel box columns under eccentric compression", Engineering Structures, 142, 211-222, 2017.

[2] Y B., Nie S.D., Xiong G., Hu Y., Bai J.B., Zhang W.F., Dai G.X., "Residual stresses in welded I-shaped sections fabricated from Q460GJ structural steel plates", Journal of Constructional Steel Research, 122, 261-273, 2016.

[3] Yang B., Xiong G., Ding K., Nie S.D,, Zhang W., Hu Y., and Dai G., "Experimental and numerical studies on lateral torsional buckling of welded Q460GJ structural steel beams", Engineering Structures, 126, 1-14, 2016

[4] Kang S.B., Yang B., Zhou X., Nie S.D., "Global buckling behaviour of welded Q460GJ steel box columns under axial compression", Journal of Constructional Steel Research, 140, 153-162, 2018.

[5] Zhou X, "Global Buckling Behaviour of Welded Q460GJ Steel Box Columns under Axial Compression", Licentiate Thesis, Chongqing University, Chongqing, China, 2017

[6] Ban H.Y., Shi G., Shi Y.J., "Overall buckling behavior and design method for axially compressed welded I-sectional columns constructed with different grades of high-strength steels", CHINA CIVIL ENGINEERING JOURNAL, Vol. 47 No.11, 2014

[7] Cao X., Gu L., Kong Z., Zhao G., Wang M., Kim S., Jia D. and Ma C., "Local buckling of $800 \mathrm{MPa}$ high strength steel welded T-section columns under axial compression", Engineering Structures, 194, 196-206, 2019.

[8] Yang H., Yang X.Q., Varma A.H. and Zhu Y., "Strain-Rate Effect and Constitutive Models for Q550 High-Strength Structural Steel", Journal of Materials Engineering and Performance, 28, 6626-6637, 2019.

[9] Mursi M., Uy B. "Behaviour and design of fabricated high strength steel columns subjected to biaxial bending. Part 1: Experiments", Advanced Steel Construction, 2(4), 286-313, 2006.

[10] Mursi M., Uy B., "Behaviour and design of fabricated high strength steel columns subjected to biaxial bending. Part 2: Analysis and design codes", Advanced Steel Construction, 2(4), 314-354, 2006

[11] GB 50017-2017 Code for design of steel structures, China Architecture \&Building Press, Beijing, China, 2018.

[12] BSI, Eurocode 3, Design of Steel Structures-Part 1-1: General Rules and Rules for Buildings, British Standards Institution, London, 2003.

[13] ANSI/AISC360-10, Specification for Structural Steel Buildings, American Institute of Steel Construction, Chicago, Illinois, 2010.

[14] Li D., Paradowska A., Uy B., Wang J. and Khan M., "Residual stresses of box and I-shaped columns fabricated from S960 ultra-high-strength steel", Journal of Constructional Steel Research, 166, 105904, 2020

[15] Hussain A., Liu Y.P. and Chan S.L., "Finite Element Modeling and Design of Single Angle Member Under Bi-axial Bending". Structures, 16, 373-389, 2018.

[16] Hussain A., Du Z.L., Liu Y.P. and Chan S.L., Stability design of single angle member using effective stress-strain method. Structures, 20, 298-308, 2019.

[17] Ban H.Y., Shi G., and Shi Y, "Experimental study on residual stress in 960MPa high strength steel welded box sections and unified model", CHINA CIVIL ENGINEERING JOURNAL, 46(11), 63-69, 2013
[18] Nie S.D., Zhu Q., Yang B., Li P.C., "Investigation of residual stresses in Q460GJ steel plate from medium-walled box sections" Journal of Constructional Steel Research, 148, 728-740, 2018

[19] Li T.J., Li G.Q., Wang Y.B., "Residual stress tests of welded Q690 high-strength steel boxand H-sections", Journal of Constructional Steel Research, 115, 283-289, 2015.

[20] Somodi B., Kövesdi B., "Residual stress measurements on welded square box sections using steel grades of S235-S960", Thin-Walled Structures, 123, 142-154, 2018.

[21] Wang Y.B., Li G.Q., Chen S.W., Sun F.F., "Experimental and numerical study on the behavior of axially compressed high strength steel box-columns", Engineering Structures, 58 , 79-91, 2014.

[22] Li T.J., Li G.Q., Chan S.L., Wang Y.B., "Behavior of Q690 high-strength steel columns: Part 1: Experimental investigation", Journal of Constructional Steel Research, 123, 18-30, 2016.

[23] Li T.J., Liu S.W., Li G.Q., Chan S.L., Wang Y.B., "Behavior of Q690 high-strength stee columns: Part 2: Parametric study and design recommendations", Journal of Constructional Steel Research, 122, 379-394, 2016.

[24] Ban H.Y., Shi G., Shi Y.J., Wang Y.Q., "Overall buckling behavior of 460 MPa high strengt steel columns: Experimental investigation and design method", Journal of Constructional Steel Research, 74, 140-150,2012.

[25] Xue, J.Y, "Experimental Research on the Overall Buckling Behavior of High Strength Steel Members under Compression", Licentiate Thesis, Southeast University, NanJing. China., 2014

[26] Cuong N.H., Kim S.E., Oh J.R., "Nonlinear analysis of space steel frames using fiber plastic hinge concept", Engineering Structures, 29, 649-657, 2007.

[27] $\mathrm{Li}, \mathrm{T}$., Liu, S. and Chan, S. "Cross-sectional analysis of arbitrary sections allowing for residual stresses", Steel and composite structures, 18(4), 985-1000, 2015

[28] Ban H.Y., Shi G., Shi Y.J., Wang Y.Q., "Residual stress of $460 \mathrm{MPa}$ high strength steet welded box section: Experimental investigation and modeling", 64, 73-82, 2013.

[29] Khan M., Paradowska A., Uy B., Mashiri F., Tao Z., "Residual stresses in high strength stee welded box sections", 116, 55-64, 2016.

[30] Fang H. and Chan T., "Buckling resistance of welded high-strength-steel box-section members under combined compression and bending", Journal of Constructional Steel Research, 162105711,2019

[31] Han H., Chan T.M., "Buckling resistance of welded high-strength-steel box-section member under combined compression and bending", Journal of Constructional Steel Research, 162, $150711,2019$. 


\title{
EXPERIMENTAL STUDY ON THE MECHANICAL BEHAVIOUR OF Q345 STEEL HIGH-STRENGTH BOLT BEARING-TYPE CONNECTIONS
}

\author{
Jing-Yao Li ${ }^{1,2}$, Shi-Dong Nie ${ }^{1,2, *}$, Jia Zeng ${ }^{2,3}$ and Bo Yang ${ }^{1,2}$ \\ ${ }^{1}$ Key Laboratory of New Technology for Construction of Cities in Mountain Area (Chongqing University), Ministry of Education, Chongqing, China. \\ ${ }^{2}$ School of Civil Engineering, Chongqing University, Chongqing, China. \\ ${ }^{3}$ China Southwest Architectural Design and Research Institute Corp., Ltd., Chengdu, China. \\ *(Corresponding author: E-mail: nieshidong@cqu.edu.cn)
}

\section{A B S T R A C T}

Static tensile tests were performed on 45 sets of Q345 steel high-strength bolt bearing-type connections, in which grade 10.9 and 12.9 high-strength bolts were used. In the tests, tearout failure, splitting failure, pure bearing failure, net cross section failure and bolt shear failure were observed. The effect of the thickness and geometrical dimensions of the test plates, and the property grade, diameter, pretension, layout of the bolts on the load-carrying capacity and deformation of the connections were investigated. Further, the experimental results were compared with the calculated values that employed the design methods in GB 50017-2017, Eurocode 3, and the AISC 360-10. And finally, the applicability of the calculation methods in various specifications to the connections with two bolts arranged parallelly to the load was discussed. It was found that bolt specifications controlled the occurrence of the shear failure mode, and the pretension of bolts improved the load-carrying capacity and peak displacement of the specimens with bolt shear failure. Meanwhile, the calculation methods in GB50017-2017 and Eurocode 3 were conservative for predicting the load-carrying capacity of connections, and the calculated resistance using method 2 in AISC360-10 was the closest to the experimental results. And for the shear connection with two bolts arranged parallelly to the load and with a relatively small end distance, the resistance calculated by the simple summation method in Eurocode 3 or AISC360-10 would be higher than the actual load-carrying capacity.

\section{A R T I C L E H I S T O R Y}

$\begin{array}{ll}\text { Received: } & \text { 19 April 2020 } \\ \text { Revised: } & \text { 29 December } 2020 \\ \text { Accepted: } & \text { 29 December 2020 }\end{array}$

\section{KEYWOR D S}

Q345;

Bolted connection;

Shear connection;

High-strength bolts

Experimental study

\section{Introduction}

With the development of architectural concepts and construction technology, steel structures play an important role in modern engineering constructions. And bolted connections are prevalent in steel constructions and the relevant studies started early ${ }^{[1-4]}$. Recently, the studies on the shear connection with high-strength bolts were primarily focused on the bearing performance test of single-bolt ${ }^{[5-9]}$, two bolts ${ }^{[8,10]}$ and multiple bolts ${ }^{[11,12]}$ shear connections. Moreover, the effect of the geometrical dimensions of the plate, the layout properties of the bolt holes ${ }^{[13,14]}$ and the material properties ${ }^{[15]}$ on the resistance and deformation of the specimen were discussed. In the past decades, high strength bolts with nominal tensile strengths of over $800 \mathrm{MPa}$ were widely used in building engineering and the behaviour was investigated ${ }^{[16]}$. Pretension was required for the high-strength bolts in most cases, while it was not taken into consideration in most investigations.

On the other hand, the discussion on the accuracy of the calculation methods in codes or specifications is also an important topic, which was involved in many previous papers about the performance of high-strength steel members ${ }^{[17-19]}$. And for the Chinese Code for Steel Structure Design, some previous studies ${ }^{[20-23]}$ showed that the calculation methods of load-carrying capacity and bolt shear capacity in the GBJ $17-88^{[24]}$ (an earlier vision of the Chinese Code for Steel Structure Design published in 1988) were conservative. And From the GBJ 17-88 to the current standard for steel structure design (GB50017-2017) ${ }^{[25]}$, the calculation methods of the bearing capacity, the net section carrying capacity, and the bolt shear capacity of the bearing-type connection remain they were. Meanwhile, the relationship between the design value of bearing strength of steel and their ultimate strength, and the relationship between the design value of shear strength of high-strength bolts and their ultimate strength have not changed. Accordingly, the relevant study results of the GBJ 17-88 can be used to indicate the current one. While there were few discussions on the accuracy of calculation methods in the European code ${ }^{[26]}$ and the US specification ${ }^{[27]}$. Therefore, it is necessary to conduct the study through experiments.

In the current study of this paper, static tensile tests were conducted on 45 sets of Q345 steel high-strength bolted bearing-type connections. Based on the test results, the influence of bolt pretension on the load-carrying capacity and deformation of the connection was primarily studied. Further, the strength and the diameters of bolts, geometric dimensions of the test plates, such as end distances and edge distances, were discussed. And finally, the experimental results were compared with the calculated values that using the methods in the Chinese Standard for Steel Structure Design, European code, and the US specification

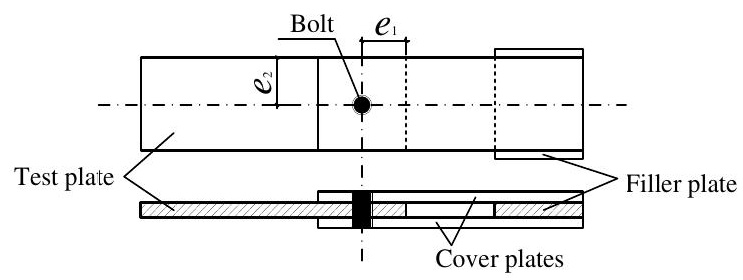

(a) A-series specimens: connection with a single bolt

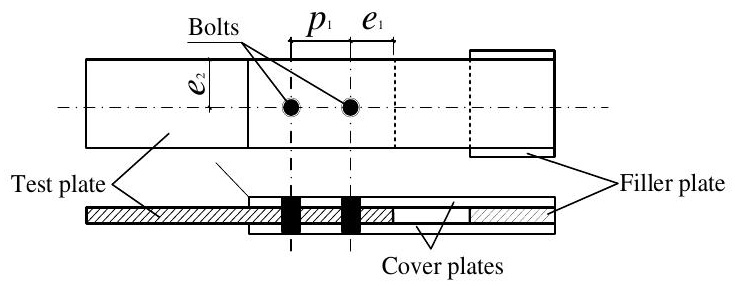

(b) B-series specimens: connection with two bolts arranged parallelly to the load

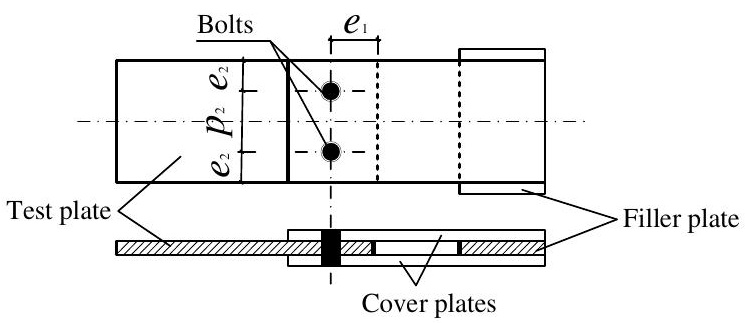

(c) C-series specimens: connection with two bolts arranged perpendicularly to the load

Fig. 1 Three series of specimens 

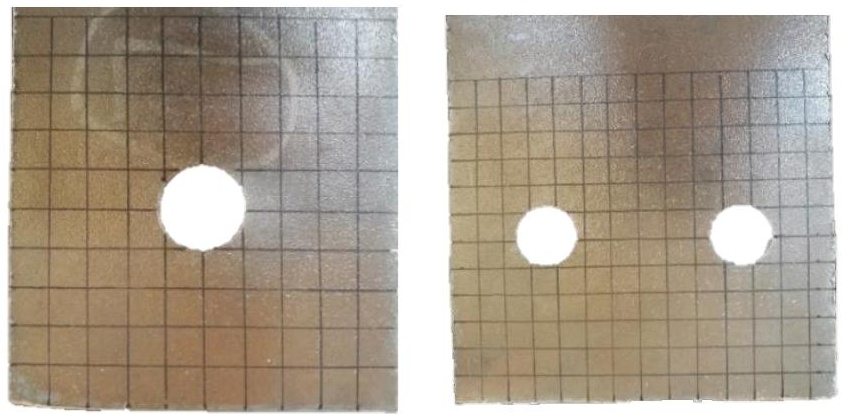

Fig. 2 The grid drawn on the test plate contact surface
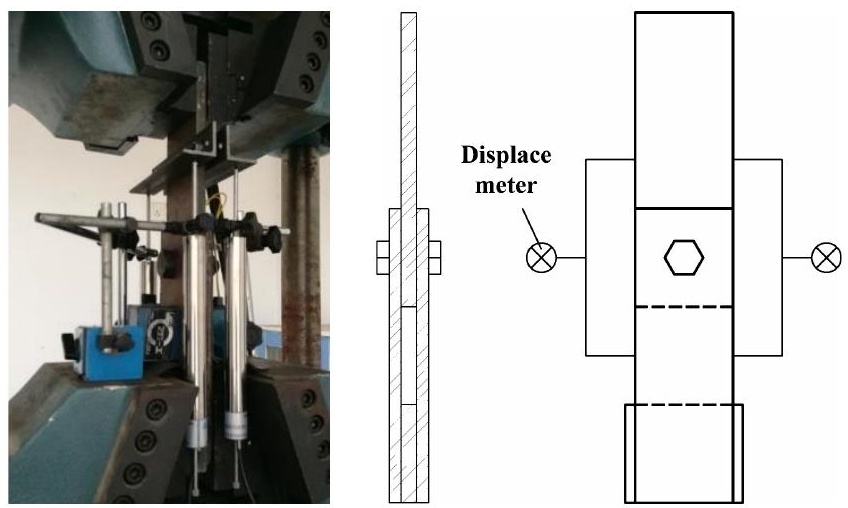

Fig. 3 Loading device and measuring point layout

\section{Test overview}

\subsection{Specimens design and processing}

The experimental test objects were the bearing-type shear connections of Q345 steel combined high-strength bolts with grade 10.9 or 12.9. Each specimen consists of a test plate, cover plates, high-strength bolts, and a filler plate. When designing the test plate, the effect of the thickness and geometrical dimensions of the test plates, and the property grade, diameter, pretension, layout of the bolts were considered and be set as variables, in which the layout includes the end distance, edge distance and pitch. According to the above concern, the designed specimens can be divided into three kinds according to the number of bolts and their layout: single bolt, two bolts arranged parallelly to the load, and two bolts arranged perpendicularly to the load. And the three kinds of specimens can be named as the "A", "B" and "C" series, where "A" represents the layout of a single bolt, "B" and "C" represent two bolts arranged parallelly or perpendicularly to the load, which are shown in Fig. 1.

45 groups of double-shear high-strength bolt bearing-type connections were designed, including 29 groups of Q345+12.9M20 specimens, 8 groups of Q345+10.9M20 specimens, and 8 groups of Q345+10.9M16 specimens. While if classifying according to the bolt layout, there were 19 groups of A-series specimens, 6 groups of B-series specimens and 20 groups of $\mathrm{C}$-series specimens All the plates of the specimens in this study were manufactured with the same grade of steel, that is Q345 specifically. The geometrical dimensions (end distance, edge distance, and pitch) of the test plates and cover plates remain the same. And the nominal diameter of the high-strength bolts used in this current study was $16 \mathrm{~mm}$ or $20 \mathrm{~mm}$.

The specimens processing in this test includes the following steps: steel plate surface treatment, blanking, drilling, descaling, assembling and splint welding, etc. The surface treatment process of the steel plate was done before the blanking and drilling of the steel plate due to the small size of the steel plates, which caused less workload than the treatment process done after the blanking and drilling. After drilling, the steel plates were exposed to indoor air for 30 days. Before assembling, the rust was removed with a wire brush; subsequently, the actual size of the plate was measured.

The actual dimensions of the specimens are measured and listed in Table 1. The naming of the specimens contains the information of bolts layout type, strength grade of bolts and serial number, and there is a sign $n$ to show if the bolts pretension is applied: the appearance of the $n$ represents the specimen without bolt pretension. The width of the test plates is the width of the crosssection at the bolt hole, and the thickness of the test plates is the average of the thickness at the bolt holes and the thickness at the edge of the weakened crosssection. When the bolt hole diameter $d_{0}$, the end distance $e_{1}$, the edge distance $e_{2}$, the pitch $p_{1}$ and the lateral pitch $p_{2}$ have multiple values, the average value is taken. To facilitate the local deformation observation of the test plates after the test piece failed, grids with a geometry of $1 \mathrm{~cm} \times 1 \mathrm{~cm}$ was drawn on the contact surface of the test plate and cover plate, as shown in Fig. 2.

\subsection{Loading device and loading system}

The loading device of the shear-connection tensile tests is shown in Fig. 3 . Two displacement meters (DM) with a measuring range of $50 \mathrm{~mm}$ were equipped on both sides of the specimen, and another displacement meter was equipped at the position between the fixture and the measuring point at the top of the specimen to monitor the slipping between the fixture and the plate.

During the test, it was preloaded to $5 \mathrm{kN}$ and subsequently unloaded to ensure that the loading device function well and reliable. Thereafter, the tensile test was subsequently started. Monotonic loading was performed at a loading rate of $1.0 \mathrm{kN} / \mathrm{s}$ until the load-carrying capacity of the specimen reduced to $85 \%$ of its peak, at which the loading was then stopped. During this period, the force exerted by the tension tester was recorded by the force sensor of the machine, and the displacement meter was recorded by the DH3816N acquisition instrument.

Table 1

Actual dimensions of the test plates

\begin{tabular}{|c|c|c|c|c|c|c|c|}
\hline Specimen & $\begin{array}{l}\text { Width of test plates } \\
\qquad b(\mathrm{~mm})\end{array}$ & $\begin{array}{l}\text { Thickness of test plates } \\
\qquad t(\mathrm{~mm})\end{array}$ & $\begin{array}{l}\text { Bolt hole diameter } \\
\qquad d_{0}(\mathrm{~mm})\end{array}$ & $\begin{array}{l}\text { End distance } \\
\qquad e_{1}(\mathrm{~mm})\end{array}$ & $\begin{array}{l}\text { Edge distance } \\
\qquad e_{2}(\mathrm{~mm})\end{array}$ & $\begin{array}{c}\text { Pitch } \\
p_{1}(\mathrm{~mm})\end{array}$ & $\begin{array}{l}\text { Lateral pitch } \\
p_{2}(\mathrm{~mm})\end{array}$ \\
\hline A-12.9-1 & 99.97 & 14.53 & 22.48 & 47.61 & 50.08 & - & - \\
\hline A-12.9-1n & 99.26 & 13.90 & 22.35 & 50.66 & 49.58 & - & - \\
\hline A-12.9-2 & 101.20 & 13.86 & 22.38 & 51.68 & 50.72 & - & - \\
\hline A-12.9-3 & 100.82 & 9.76 & 22.58 & 50.24 & 50.69 & - & - \\
\hline A-12.9-4 & 100.28 & 16.01 & 22.63 & 49.37 & 51.02 & - & - \\
\hline A-12.9-5 & 79.42 & 13.88 & 22.65 & 48.76 & 39.93 & - & - \\
\hline A-12.9-5n & 80.26 & 13.68 & 22.74 & 47.25 & 40.25 & - & - \\
\hline A-12.9-6 & 122.64 & 13.75 & 21.98 & 49.04 & 61.12 & - & - \\
\hline A-12.9-6n & 122.15 & 13.64 & 22.17 & 48.87 & 60.78 & - & - \\
\hline A-12.9-7 & 100.49 & 13.97 & 22.53 & 30.49 & 50.11 & - & - \\
\hline A-12.9-7n & 101.55 & 13.92 & 22.53 & 31.17 & 50.63 & - & - \\
\hline A-12.9-8 & 102.83 & 14.32 & 22.30 & 40.65 & 51.34 & - & - \\
\hline A-12.9-8n & 102.73 & 14.29 & 22.36 & 40.10 & 51.54 & - & - \\
\hline A-12.9-9 & 103.56 & 13.80 & 22.26 & 59.48 & 51.34 & - & - \\
\hline
\end{tabular}




\begin{tabular}{|c|c|c|c|c|c|c|c|}
\hline Specimen & $\begin{array}{l}\text { Width of test plates } \\
\qquad b(\mathrm{~mm})\end{array}$ & $\begin{array}{c}\text { Thickness of test plates } \\
t \quad(\mathrm{~mm})\end{array}$ & $\begin{array}{l}\text { Bolt hole diameter } \\
\qquad d_{0}(\mathrm{~mm})\end{array}$ & $\begin{array}{l}\text { End distance } \\
\qquad e_{1}(\mathrm{~mm})\end{array}$ & $\begin{array}{l}\text { Edge distance } \\
\qquad e_{2}(\mathrm{~mm})\end{array}$ & $\begin{array}{c}\text { Pitch } \\
p_{1}(\mathrm{~mm})\end{array}$ & $\begin{array}{l}\text { Lateral pitch } \\
\qquad p_{2}(\mathrm{~mm})\end{array}$ \\
\hline A-12.9-9n & 100.28 & 13.81 & 22.45 & 59.30 & 50.20 & - & - \\
\hline B-12.9-3 & 121.39 & 13.68 & 22.39 & 51.35 & 60.87 & 70.18 & - \\
\hline B-12.9-3n & 121.03 & 13.94 & 22.49 & 50.98 & 60.58 & 69.78 & - \\
\hline C-12.9-1 & 102.60 & 13.96 & 22.46 & 50.78 & 26.46 & - & 49.75 \\
\hline C-12.9-1n & 101.70 & 13.90 & 22.05 & 50.15 & 25.86 & - & 49.68 \\
\hline C-12.9-2 & 120.65 & 13.68 & 22.24 & 51.39 & 30.51 & - & 60.01 \\
\hline C-12.9-2n & 121.26 & 13.74 & 22.22 & 51.36 & 30.66 & - & 59.96 \\
\hline C-12.9-3 & 142.48 & 13.74 & 22.54 & 50.08 & 36.36 & - & 70.26 \\
\hline C-12.9-3n & 141.87 & 13.68 & 22.35 & 49.00 & 35.79 & - & 70.04 \\
\hline C-12.9-4 & 142.78 & 13.94 & 22.48 & 29.97 & 36.55 & - & 70.09 \\
\hline C-12.9-4n & 142.85 & 13.70 & 22.55 & 30.88 & 36.42 & - & 70.08 \\
\hline C-12.9-5 & 142.13 & 13.86 & 22.42 & 39.12 & 36.33 & - & 69.79 \\
\hline C-12.9-5n & 142.71 & 13.86 & 22.52 & 39.26 & 36.63 & - & 69.99 \\
\hline C-12.9-6 & 142.65 & 13.70 & 22.36 & 60.43 & 36.28 & - & 70.03 \\
\hline C-12.9-6n & 143.09 & 13.61 & 22.42 & 61.04 & 36.73 & - & 69.97 \\
\hline A-10.9-1 & 101.01 & 13.80 & 18.06 & 38.85 & 50.64 & - & - \\
\hline A-10.9-1n & 100.68 & 14.03 & 18.05 & 38.58 & 50.32 & - & - \\
\hline A-10.9-2 & 101.20 & 13.81 & 22.31 & 48.64 & 50.68 & - & - \\
\hline A-10.9-2n & 100.27 & 13.63 & 22.30 & 45.37 & 50.18 & - & - \\
\hline B-10.9-1 & 121.39 & 13.81 & 18.09 & 40.97 & 60.57 & 60.02 & - \\
\hline B-10.9-1n & 121.21 & 13.95 & 18.25 & 41.23 & 60.68 & 59.91 & - \\
\hline B-10.9-2 & 121.81 & 14.33 & 22.50 & 51.60 & 61.13 & 69.95 & - \\
\hline B-10.9-2n & 121.43 & 13.76 & 22.45 & 51.98 & 60.64 & 70.03 & - \\
\hline C-10.9-1 & 120.82 & 13.67 & 18.39 & 40.64 & 30.40 & - & 59.98 \\
\hline C-10.9-1n & 121.04 & 13.77 & 18.25 & 40.92 & 30.60 & - & 59.90 \\
\hline C-10.9-2 & 142.41 & 13.88 & 18.18 & 38.38 & 36.41 & - & 69.76 \\
\hline C-10.9-2n & 144.73 & 14.38 & 18.09 & 38.49 & 37.57 & - & 69.63 \\
\hline C-10.9-3 & 121.54 & 13.85 & 22.27 & 51.10 & 30.88 & - & 60.07 \\
\hline C-10.9-3n & 120.17 & 13.67 & 22.28 & 51.33 & 30.25 & - & 60.02 \\
\hline C-10.9-4 & 142.04 & 13.64 & 22.54 & 48.99 & 36.01 & - & 70.19 \\
\hline C-10.9-4n & 142.51 & 13.83 & 22.53 & 49.32 & 36.30 & - & 70.20 \\
\hline
\end{tabular}

\subsection{Material properties and torque coefficients of high-strength bolts}

The material properties of steel and the high-strength bolts used in the tests are listed in Table 2 and Table 3 respectively.

The tests of the torque coefficients of the high-strength bolt were performed to apply the pretension accurately to the specimens. These tests were following the requirement in "Specifications of high strength bolts with large hexagon head, large hexagon nuts, plain washers for steel structures (GB/T 1231-2006) [28]". Seven sets, and there were eight high-strength bolts in each set, of the torque coefficient measurement test were carried out. The average value and standard deviation of the torque coefficients of the high-strength bolt are shown in Table 4. The average torque coefficient of each batch is between 0.110 and 0.150 , and its standard deviation of the torque coefficient is less than 0.01 , which meets the requirements in GB/T 1231-2006 ${ }^{[28]}$.

In this test, a torque wrench was employed to apply pretension to bolts. According to the "Technical specifications for high-strength bolt connection of steel structures (JGJ 82-2011) [29]", the tightening of high-strength bolts is divided into two steps, which were initial tightening and final tightening respectively. The final construction tightening torque $T_{\mathrm{c}}$ shall be calculated by Eq. (1).

$T_{\mathrm{c}}=k P_{\mathrm{c}} d$

where, $T_{\mathrm{c}}$ is the final construction tightening torque, $k$ is the torque coefficient of the high-strength bolts, $P_{c}$ is the construction pretension value of high strength bolts, and $d$ is the nominal diameter of high strength bolts.
The initial tightening torque shall be half of the final construction tightening torque, i.e. $0.5 T_{\mathrm{c}}$. And the screwing sequence shall be performed from the middle bolts to both ends. The measured torque coefficients of the high-strength bolts and the final tightening torque, as well as the construction pretension in the test are listed in Table 5. The pretension value of the grade 10.9 high-strength bolt is specified in the "Technical specifications for high strength bolt

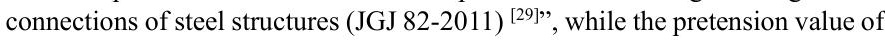
the grade 12.9 high-strength bolt is beyond the specification. According to the corresponding calculation rules, the construction pretension of the grade 12.9 high-strength bolt was determined, which is $205 \mathrm{kN}$. Considering the accuracy of the torque wrench, the construction torque is represented as an integral multiple of 25 , and the corresponding pretension value of the construction is obtained in the actual construction.

Table 2

Material properties of Q345 steel plates

\begin{tabular}{cccccc}
\hline Thickness of & Yield & Tensile & Peak & Yield & Elongation \\
steel plates & strength & strength & strain & ratio & $\%$ \\
$t(\mathrm{~mm})$ & $f_{\mathrm{y}}(\mathrm{MPa})$ & $f_{\mathrm{u}}(\mathrm{MPa})$ & $\%$ & & \\
\hline 10 & 356.87 & 494.81 & 16.86 & 0.72 & 36.31 \\
14 & 431.19 & 526.73 & 12.87 & 0.82 & 26.35 \\
16 & 430.77 & 586.54 & 13.74 & 0.73 & 30.73 \\
\hline
\end{tabular}


Table 3

Material properties of High-strength bolts

\begin{tabular}{|c|c|c|c|c|c|}
\hline \multirow{3}{*}{ Bolt specification } & Yield strength & Tensile strength & Peak strain & \multirow{3}{*}{ Yield ratio } & \multirow{3}{*}{$\begin{array}{c}\text { Elongation } \\
\%\end{array}$} \\
\hline & & & & & \\
\hline & $f_{\mathrm{y}}^{\mathrm{b}}(\mathrm{MPa})$ & $f_{\mathrm{u}}^{\mathrm{b}}(\mathrm{MPa})$ & $\%$ & & \\
\hline $10.9 \mathrm{M} 16 \times 70$ & 1066.9 & 1136.2 & 3.80 & 0.939 & 15.7 \\
\hline $10.9 \mathrm{M} 16 \times 75$ & 1054.5 & 1113.4 & 4.07 & 0.947 & 15.3 \\
\hline $10.9 \mathrm{M} 20 \times 70$ & 1152.6 & 1188.3 & 4.08 & 0.970 & 13.0 \\
\hline $10.9 \mathrm{M} 20 \times 80$ & 1152.2 & 1183.2 & 3.42 & 0.974 & 14.0 \\
\hline $10.9 \mathrm{M} 20 \times 85$ & 1198.3 & 1289.3 & 4.44 & 0.929 & 13.2 \\
\hline $12.9 \mathrm{M} 20 \times 70$ & 1347.6 & 1450.2 & 4.51 & 0.929 & 12.0 \\
\hline $12.9 \mathrm{M} 20 \times 75$ & 1355.3 & 1455.9 & 4.86 & 0.931 & 12.6 \\
\hline
\end{tabular}

Table 4

Pretension of high-strength bolt in the torque coefficient test

\begin{tabular}{ccccc}
\hline Bolt specification & & $10.9 \mathrm{M} 16$ & $10.9 \mathrm{M} 20$ & $12.9 \mathrm{M} 20$ \\
\hline Pretension $P(\mathrm{kN})$ & Max & 121 & 187 \\
\cline { 2 - 4 } & Min & 99 & 153 \\
\hline
\end{tabular}

Table 5

Measured torque coefficient and construction pretension of high-strength bolts

\begin{tabular}{|c|c|c|c|c|c|}
\hline Bolt & Torque coefficient & $\begin{array}{r}\text { Standard } \\
\text { deviation }\end{array}$ & $\begin{array}{l}\text { Pretension } \\
\qquad(\mathrm{kN})\end{array}$ & $\begin{array}{l}\text { Construction pretension } \\
\qquad(\mathrm{kN})\end{array}$ & $\begin{array}{c}\text { Construction tightening torque } \\
\qquad \mathrm{N} \cdot \mathrm{m}\end{array}$ \\
\hline $12.9-\mathrm{M} 20 \times 70$ & 0.1325 & 0.0032 & 185 & 208 & 550 \\
\hline 12.9-M20×75 & 0.1292 & 0.0026 & 185 & 203 & 525 \\
\hline $10.9-\mathrm{M} 20 \times 70$ & 0.1415 & 0.0047 & 155 & 168 & 475 \\
\hline 10.9-M20×80 & 0.1283 & 0.0076 & 155 & 175 & 450 \\
\hline 10.9-M20×85 & 0.1300 & 0.0030 & 155 & 173 & 450 \\
\hline 10.9-M16×70 & 0.1487 & 0.0093 & 100 & 116 & 275 \\
\hline 10.9-M16×75 & 0.1418 & 0.0085 & 100 & 110 & 250 \\
\hline
\end{tabular}

\section{Test Results}

\subsection{Failure mode}

Five failure modes were observed in the test: tearout failure, splitting failure, pure bearing failure, net cross-section failure, and bolt shear failure.

The tearout failure of a specimen was shown as Fig. 4, which occurred when the end distance was small while the edge distance was relatively large (net cross-section failure would not occur). The bolt extruded the steel plate forward, and the bolt hole was been lengthened until the damage occurred. When failed, there were clear shear lines and the "tearout block" at front of the bolt hole. When the end distance increased, the edge distance remains unchanged or increased with a rate that slower than the end distance, the failure mode of the specimen transformed to the splitting failure, as shown in Fig. 5. The front edge of the bolt hole was split, and the crack developed obliquely to the side of the elongated bolt hole. When the bolt hole was under pressure, the edge of the plate was in the high tensile stress area, which is shown in Fig. 6. The edges of the plate were tensioned causing the splitting in the edge of the plate. After the splitting occurred, the crack entered the high shear stress zone in a curved shape and ends at the high shear stress zone on the side of the elongated bolt hole, thus forming the splitting failure mode. In this test, only one specimen, A-10.9-2n, experienced pure bearing failure, as shown in Fig. 7. The specimen only appeared as a phenomenon of the elongation of the bolt hole. No obvious shear line appeared for this specimen, while a split appeared at the end of the test plate, which may be the bud of splitting failure, and if the load continued to be applied, it was very likely that splitting failure would occur. Another test piece, A-10.9-2, with the same dimensions as A-10.9-2n but a pretension of the bolt, was subjected to splitting failure, as shown in Fig. 8. Kim ${ }^{[15]}$, Rex ${ }^{[7]}$, Wang ${ }^{[6]}$, and Može ${ }^{[12]}$ have also observed splitting failure in their studies, and that pure bearing failure rarely occurred. Wang and Može have not observed pure bearing failure in their experimental studies. Accordingly, considering the small number of pure bearing failures in the experiment, and the impact on the ultimate load-carrying capacity of the connection is not obvious (A-10.9-2n is $5 \%$ higher than the ultimate load-carrying capacity of A-10.9-2), pure bearing failure is fallen into to splitting failure in the following discussion. Net cross-section failure occurs when the end distance of the test plate is large enough while the edge distance or pitch $p_{2}$ is relatively small. The net section of the weakened area is necked and even fractured, as shown in Fig. 9. Moreover, the failure was accompanied by obvious elongation of bolt holes in some tests. Bolt shear failure occurs when the bolts are weaker relatively than the plate. The bolts were damaged along the shear face of the bolt shank. The failure surface is smooth, as shown in Fig. 10. The bolt shear failure occurred in specimen B10.9-1, the bolt hole of the test plate was significantly deformed and even the edge of the plate was split.

In this study, mixed failure modes occurred, but the statistical failure mode was incorporated in the final failure mode. For example, the final failure mode of the specimen shown as Fig. 10 was regarded as bolt shear failure due to that the shearing happened first, although the edge of the plate in the force direction has been split. Table 6 lists the number of failure modes for different test specimen groups, where "TF", "SPF", "BF", "NF" and "SF" represent tearout failure, splitting failure, pure bearing failure, net cross-section failure and bolt shear failure respectively.

\section{Table 6}

Failure modes statistics

\begin{tabular}{ccc|ccccc|c}
\hline \multicolumn{3}{c|}{ Specimen information } & \multirow{2}{*}{ TF } & SPF & BF & NF & SF & Total \\
\hline \multirow{2}{*}{ Steel } & Bolt & Bolt & & & & & & \\
\hline \multirow{3}{*}{ Q345 } & 12.9 & M20 & 3 & 20 & 0 & 6 & 0 & 29 \\
\cline { 2 - 6 } & \multirow{2}{*}{10.9} & M20 & 0 & 5 & 1 & 2 & 0 & 8 \\
& & M16 & 0 & 0 & 0 & 0 & 8 & 8 \\
\hline
\end{tabular}




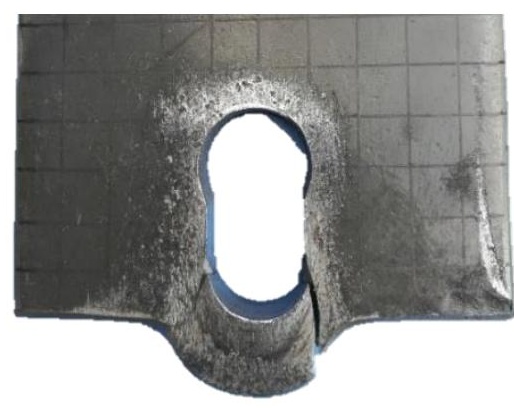

Fig. 4 Tearout failure
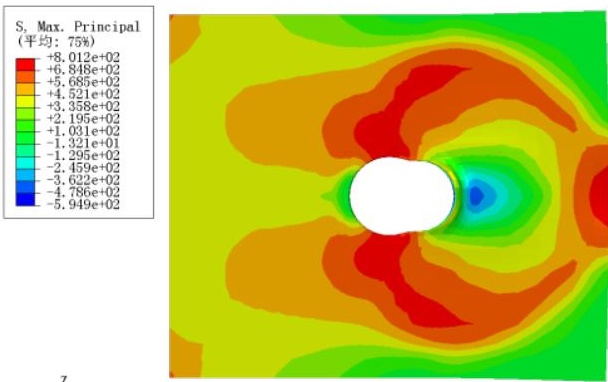

(a) Principal stress

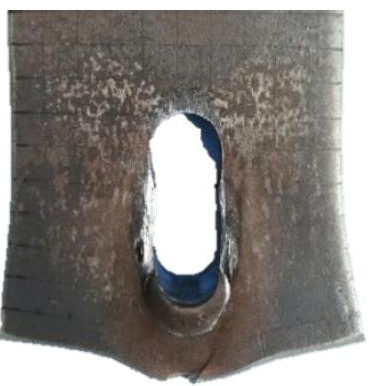

Fig. 5 Splitting failure

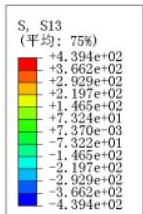

Fig. 6 The stress of test plate of the connection with a single bolt in tension

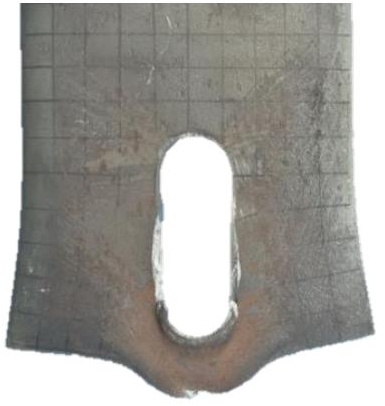

Fig. 7 Pure bearing failure

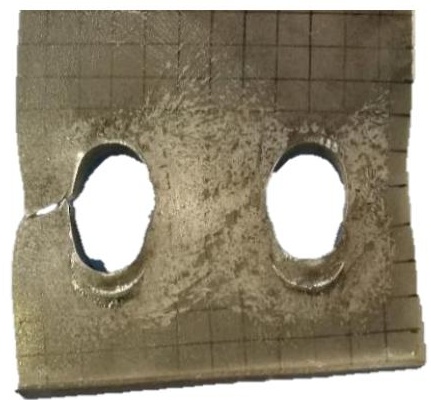

Fig. 9 Net cross-section failure

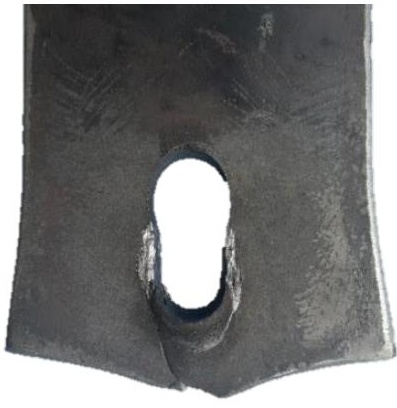

Fig. 8 A-10.9-2
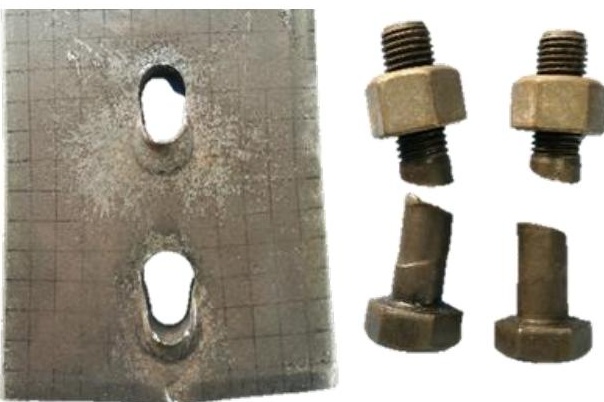

Fig. 10 Bolt shear failure

\subsection{Ultimate load-carrying capacity and deformation}

The ultimate load-carrying capacity and deformation of each specimen are shown in Table 7. In the table, $P_{\mathrm{c}}, F_{\mathrm{s}}, \Delta_{\mathrm{s}}, F_{\mathrm{u}}, \Delta_{\mathrm{p}}$ and $\Delta_{\mathrm{u}}$ is respectively the construction pretension, the slip load, the slip displacement, ultimate loadcarrying capacity, the peak displacement and the ultimate displacement. The slip displacement is defined as follows: for the specimen with bolt pretension, the displacement difference between before and after the specimen slips is regarded as the slip displacement; while for the specimen without pretension, take the displacement corresponding to the load of $10 \mathrm{kN}$. Herein, the peak displacement and the ultimate displacement do not contain the slip displacement. For the bolt shear failure specimens, the ultimate displacement is the same as the peak displacement.

\subsection{Analysis of test results}

\subsubsection{Influence of steel thickness}

In this test, the specimens of A-12.9-3, A-12.9-1, and A-12.9-4 were manufactured by Q345 steel with nominal thicknesses of $10 \mathrm{~mm}, 14 \mathrm{~mm}$ and 16 $\mathrm{mm}$ respectively. Splitting failure occurred in all the three specimens, and their load-carrying capacity and deformation are listed in Table 8 . The load-carrying capacity of the specimens increases as the thickness of the test plate increases, while the ratio of the load-carrying capacity to the product of thickness and the ultimate strength of the test plate remain constant, i.e. the load-carrying capacity of the specimens is proportional to the product of the thickness and the steel tensile strength of the test plate. 
Table 7

Test results

\begin{tabular}{|c|c|c|c|c|c|c|c|}
\hline Specimen & $P_{\mathrm{c}}(\mathrm{kN})$ & $F_{\mathrm{S}}(\mathrm{kN})$ & $\Delta_{\mathrm{S}}(\mathrm{mm})$ & $F_{\mathrm{u}}(\mathrm{kN})$ & Failure mode & $\Delta_{\mathrm{p}}(\mathrm{mm})$ & $\Delta_{\mathrm{u}}(\mathrm{mm})$ \\
\hline A-12.9-1 & 203 & 140.8 & 2.63 & 348.0 & SPF & 16.44 & 28.02 \\
\hline A-12.9-1n & 0 & - & 4.20 & 342.4 & SPF & 18.54 & 31.00 \\
\hline A-12.9-2 & 203 & 185.8 & 2.55 & 392.0 & SPF & 13.67 & 32.39 \\
\hline A-12.9-3 & 208 & 155.7 & 3.59 & 221.4 & SPF & 21.10 & 36.15 \\
\hline A-12.9-4 & 203 & 154.1 & 1.54 & 426.0 & SPF & 18.25 & 30.99 \\
\hline A-12.9-5 & 203 & 171.3 & 1.06 & 369.5 & SPF & 14.83 & 24.40 \\
\hline A-12.9-5n & 0 & - & 3.30 & 342.4 & SPF & 21.30 & 31.68 \\
\hline A-12.9-6 & 203 & 162.5 & 1.97 & 362.8 & SPF & 17.06 & 27.24 \\
\hline A-12.9-6n & 0 & - & 2.98 & 365.8 & SPF & 21.71 & 29.31 \\
\hline A-12.9-7 & 203 & 151.6 & 3.95 & 249.0 & $\mathrm{TF}$ & 12.42 & 23.16 \\
\hline A-12.9-7n & 0 & - & 2.10 & 250.4 & $\mathrm{TF}$ & 14.70 & 24.58 \\
\hline A-12.9-8 & 203 & 169.2 & 3.42 & 303.4 & SPF & 15.89 & 25.29 \\
\hline A-12.9-8n & 0 & - & 4.26 & 304.6 & SPF & 17.44 & 29.07 \\
\hline A-12.9-9 & 203 & 163.8 & 3.46 & 457.0 & SPF & 29.34 & 42.13 \\
\hline A-12.9-9n & 0 & - & 3.16 & 456.5 & SPF & 29.56 & 35.40 \\
\hline B-12.9-3 & 203 & 298.8 & 2.77 & 670.0 & SPF & 20.14 & 28.77 \\
\hline B-12.9-3n & 0 & - & 4.08 & 682.5 & SPF & 23.82 & 32.81 \\
\hline C-12.9-1 & 203 & 271.8 & 1.86 & 438.0 & NF & 8.74 & 12.68 \\
\hline C-12.9-1n & 0 & - & 3.81 & 447.0 & NF & 14.12 & 17.95 \\
\hline C-12.9-2 & 203 & 308.0 & 2.59 & 585.0 & NF & 10.60 & 14.92 \\
\hline C-12.9-2n & 0 & - & 3.44 & 606.0 & NF & 18.59 & 21.78 \\
\hline C-12.9-3 & 203 & 417.5 & 2.39 & 684.5 & SPF & 17.08 & 28.42 \\
\hline C-12.9-3n & 0 & - & 3.29 & 674.0 & SPF & 22.91 & 29.96 \\
\hline C-12.9-4 & 203 & 320.0 & 2.29 & 483.5 & $\mathrm{TF}$ & 9.18 & 17.73 \\
\hline C-12.9-4n & 0 & - & 3.69 & 418.2 & SPF & 12.84 & 22.15 \\
\hline C-12.9-5 & 201 & 348.2 & 2.92 & 557.5 & SPF & 12.63 & 21.39 \\
\hline C-12.9-5n & 0 & - & 3.84 & 560.5 & SPF & 13.39 & 21.37 \\
\hline C-12.9-6 & 203 & 290.0 & 2.17 & 720.0 & NF & 24.62 & 27.12 \\
\hline C-12.9-6n & 0 & - & 3.48 & 714.5 & NF & 24.74 & 27.28 \\
\hline A-10.9-1 & 110 & 97.0 & 1.74 & 278.4 & $\mathrm{SF}$ & 10.84 & 10.84 \\
\hline A-10.9-1n & 0 & - & 2.26 & 264.4 & $\mathrm{SF}$ & 9.77 & 9.77 \\
\hline A-10.9-2 & 168 & 135.4 & 1.50 & 369.2 & SPF & 17.80 & 31.75 \\
\hline A-10.9-2n & 0 & - & 3.76 & 388.8 & $\mathrm{BF}$ & 20.45 & 33.29 \\
\hline B-10.9-1 & 110 & 184.0 & 1.64 & 544.5 & $\mathrm{SF}$ & 14.18 & 14.18 \\
\hline B-10.9-1n & 0 & - & 4.05 & 526.5 & $\mathrm{SF}$ & 14.09 & 14.09 \\
\hline B-10.9-2 & 168 & 229.0 & 2.78 & 683.0 & SPF & 22.20 & 31.76 \\
\hline B-10.9-2n & 0 & - & 3.80 & 665.0 & SPF & 24.04 & 39.10 \\
\hline C-10.9-1 & 105 & 274.4 & 2.53 & 593.0 & SF & 15.71 & 15.71 \\
\hline C-10.9-1n & 0 & - & 2.70 & 516.0 & $\mathrm{SF}$ & 9.91 & 9.91 \\
\hline C-10.9-2 & 105 & 197.2 & 1.77 & 558.0 & $\mathrm{SF}$ & 11.99 & 12.36 \\
\hline C-10.9-2n & 0 & - & 3.90 & 497.5 & $\mathrm{SF}$ & 6.64 & 6.64 \\
\hline C-10.9-3 & 168 & 335.6 & 1.58 & 613.5 & NF & 14.89 & 19.48 \\
\hline C-10.9-3n & 0 & - & 3.29 & 587.5 & NF & 22.91 & 27.29 \\
\hline C-10.9-4 & 168 & 315.0 & 2.59 & 682.5 & SPF & 17.99 & 27.89 \\
\hline C-10.9-4n & 0 & - & 3.71 & 715.0 & SPF & 23.76 & 29.33 \\
\hline
\end{tabular}

\subsubsection{Influence of bolt specifications}

12.9 M20, 10.9 M20 and 10.9 M16 high-strength bolts were used in this test. The statistical data in Table 6 shows that the failure modes of the specimens set with different bolts are different. The bolts specifications significantly affect the failure mode of the specimens, primarily controlling the occurrence of the shear failure modes of the bolts. All specimens with bolts of 10.9 M16 failed resulted in bolt shear in this test.

Table 9 shows the comparison of the load-carrying capacity and deformation of specimens with different high-strength bolts. The difference in load-carrying capacity $\left|\Delta F_{\mathrm{u}}\right|$ shown in Table 9 is small, and the maximum ratio $\left|\Delta F_{\mathrm{u}}\right|$ to the load-carrying capacity $F_{\mathrm{u}}$ is $6.1 \%$. The grade of bolt shows an unobvious influence on the load-carrying capacity and deformation of the specimen with splitting failure and net cross-section failure. 
Table 8

Effect of plate thickness on bearing capacity and deformation of the specimens

\begin{tabular}{cccccc}
\hline Specimen & $t(\mathrm{~mm})$ & $f_{\mathrm{u}}(\mathrm{MPa})$ & $F_{\mathrm{u}}(\mathrm{kN})$ & $F_{\mathrm{u}} / f_{\mathrm{u}} t$ & $\Delta_{\mathrm{p}}(\mathrm{mm})$ \\
\hline A-12.9-3 & 9.76 & 484.81 & 221.4 & 0.0468 & 21.10 \\
A-12.9-1 & 14.53 & 526.73 & 348.0 & 0.0455 & 16.44 \\
A-12.9-4 & 16.01 & 586.54 & 426.0 & 0.0454 & 18.25 \\
\hline
\end{tabular}

Table 9

Bearing capacity and deformation of different bolt specimens

\begin{tabular}{|c|c|c|c|c|c|}
\hline Specimen & Bolt & Failure mode & $F_{\mathrm{u}}(\mathrm{kN})$ & $\left|\Delta F_{\mathrm{u}}\right|(\mathrm{kN})$ & $\Delta_{\mathrm{p}}(\mathrm{mm})$ \\
\hline A-12.9-1 & $12.9 \mathrm{M} 20$ & \multirow{2}{*}{ SPF } & 348.0 & \multirow{2}{*}{21.2} & 16.44 \\
\hline A-10.9-2 & $10.9 \mathrm{M} 20$ & & 369.2 & & 17.80 \\
\hline B-12.9-3 & $12.9 \mathrm{M} 20$ & \multirow{2}{*}{ SPF } & 670.0 & \multirow{2}{*}{13.0} & 20.14 \\
\hline B-10.9-2 & $10.9 \mathrm{M} 20$ & & 683.0 & & 22.20 \\
\hline C-12.9-3 & $12.9 \mathrm{M} 20$ & \multirow{2}{*}{ SPF } & 684.5 & \multirow{2}{*}{2.0} & 17.08 \\
\hline C-10.9-4 & $10.9 \mathrm{M} 20$ & & 682.5 & & 17.99 \\
\hline C-12.9-2 & $12.9 \mathrm{M} 20$ & \multirow[t]{2}{*}{$\mathrm{NF}$} & 585.0 & \multirow{2}{*}{28.5} & 7.60 \\
\hline C-10.9-3 & $10.9 \mathrm{M} 20$ & & 613.5 & & 14.89 \\
\hline
\end{tabular}

\subsubsection{Influence of bolt pretension}

In this test, the influence of bolt pretension on the load-carrying capacity, stiffness and deformation of specimens with various failure modes was primarily studied. Fig. 11 shows the effect of pretension on the load-carrying capacity of the specimens with tearout failure, splitting failure, net cross-section failure and bolt shear failure. Two specimens with the same geometric dimensions but differ in whether pretension was applied or not are defined as one pair. The naming of the specimen pair adopted the name of the specimen with bolt pretension in this pair. For example, the two specimens C-10.9-4 and C-345-10.9-4n were identified as a pair of C-10.9-4. As shown in Fig. 11, the pretension has no significant effect on the load-carrying capacity of the specimens with tearout failure, splitting failure and net cross-section failure. The maximum deviation of the ultimate load-carrying capacity of the two specimens in the same pair is only $5.18 \%$. When the specimens with the above three failure modes close to failing, the slippage of the specimen had been completed already and the surface of each plate became smoother, meanwhile, the pretension decreased due to the deformation. Accordingly, the friction between the cover plates and the test plate of the specimens with pretension was relatively small and the influence of the pretension on the ultimate load-carrying capacity of the specimens is insignificant. In another word, the influence of the bolt pretension on the ultimate load-carrying capacity of the specimens that failed with tearout failure, splitting failure and net cross-section failure can be neglected. However, the pretension shows a significant effect on the loadcarrying capacities of the specimens subjected to bolt shear failure. The loadcarrying capacities of the specimens with pretension are higher than that of the specimens without it. The pretension improved the load-carrying capacity of the specimens with bolt shear failure. Table 10 lists the relationship between the load-carrying capacity and the slip load of the specimen pairs in which the bolt shear failure occurred, where the $F_{\mathrm{u}, \mathrm{Y}}$ and $F_{\mathrm{u}, \mathrm{N}}$ is the ultimate load-carrying capacity of the specimen with or without preload respectively. The pretension could increase the load-carrying capacity of the connections, and the improvement is approximately $9.8 \% \sim 30.7 \%$ of the slip load but with a relatively large deviation range.

\section{Table 10}

Increases of load-bearing capacity and slip load of specimens with bolt shear failure

\begin{tabular}{cccccc}
\hline \multicolumn{2}{c}{ Specimen } & $F_{\mathrm{u}, \mathrm{Y}}(\mathrm{kN})$ & $F_{\mathrm{u}, \mathrm{N}}(\mathrm{kN})$ & $F_{\mathrm{S}}(\mathrm{kN})$ & $\left(F_{\mathrm{u}, \mathrm{Y}}-F_{\mathrm{u}, \mathrm{N}}\right) / F_{\mathrm{s}}$ \\
\hline A-10.9-1 & A-10.9-1n & 278.4 & 264.4 & 97.0 & 0.144 \\
B-10.9-1 & B-10.9-1n & 544.5 & 526.5 & 184.0 & 0.098 \\
C-10.9-1 & C-10.9-1n & 593.0 & 516.0 & 274.4 & 0.281 \\
C-10.9-2 & C-10.9-2n & 558.0 & 497.5 & 197.2 & 0.307 \\
\hline
\end{tabular}

Fig. 12 shows the load-displacement curves of some specimens with different failure modes. For the specimens in the same pair, the two specimens have similar geometric dimensions but differ in the presence or absence of bolt pretension. To facilitate the comparison, the load-displacement curves of the specimens with the tearout failure, splitting failure and net cross-section failure specimens were plotted on the principle that the peak displacements of the two specimens are equal. While since the pretension affects the load-carrying capacity of the bolt shear failure specimens, the load-displacement curves of the bolt shear failure specimens were drawn according to the rule that make the displacement corresponding to the load-bearing capacity of the specimen with pretension equal to that of the specimen without pretension.

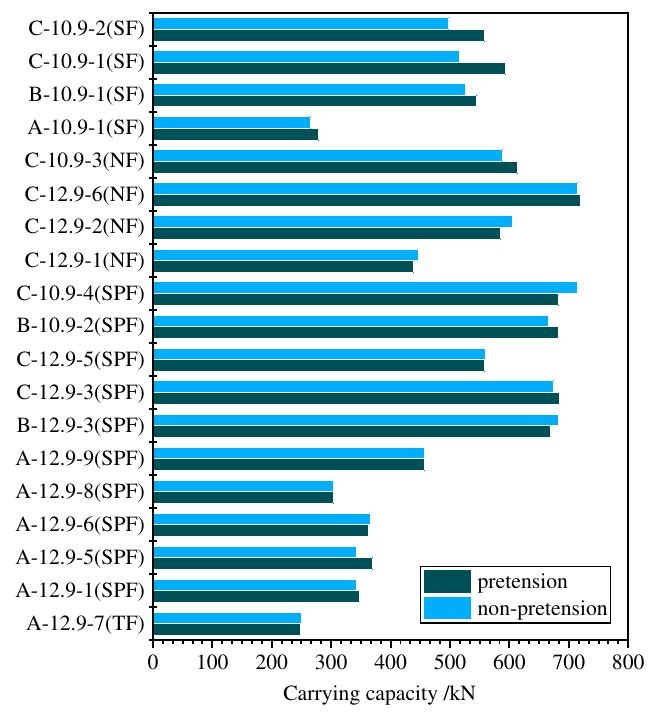

Fig. 11 Effect of pretension on bearing capacity of specimens with different failure modes

As shown in Fig. 12 (a) to Fig. 12 (c), the stiffnesses of specimens with pretension were larger than that of the non-pretension specimens at the friction stage and the initial stage of the bolt bar extrusion. However, as the load increased, the bearing stress of the bolt increased, the bolt hole deformation increased also, and the stiffness of the pretension specimens became gradually smaller. The stiffness change segment was identified in the diagram, the descending was rapid; and in the segment, the stiffness was less than that of the non-pretension specimen. This phenomenon can be explained as follows: in the initial stage of loading the bolt pretension specimens, there was little pretension loss, and the friction causes the stiffness of the specimen to be larger than that of the non-pretension specimen. With load increased, the bolt hole extrusion deformation and the bending deformation of the bolt bar were increased also, and the bolt pretension loss was accumulated. Meanwhile, the contact surface became smoother because of slippage. Owing to the above two reasons, the friction of the pretension specimens was decreasing in the period, the bolt hole bearing load was increased, the deformation of the bolt hole was aggravated, the displacement of specimens was increased, and the stiffness of the specimens was decreased. The bolt pretension has a certain influence on the shear connections with bolt shear failure before the failure, as shown in Fig. 12(d). When the load reaches the ultimate load-carrying capacity of the non-pretension specimens, there is no obvious stiffness change segment in the bolt pretension specimens. The stiffness tended to be stable when approaching failure and is lower than that of specimens without bolt pretension.

\subsubsection{Influence of geometrical dimensions}

The geometrical limitations for shear connections are specified in the European steel structure design code (Eurocode 3) and the American steel structure specification (AISC360-10). Moreover, geometrical dimension parameters are also involved in the bearing capacity formulas in the above code or specification. The above two aspects reflect the important role of geometrical dimensions in the behaviour of the shear connection.

Fig. 13 and Fig. 14 show the relationship between load-carrying capacity and end distance and that between load-carrying capacity and edge distance respectively. To facilitate the analysis, dimensionless coordinate systems were adopted. For the vertical axis, the load-carrying capacity of the specimen was nondimensionalized according to the corresponding failure modes. In the dimensionless method, define the bearing stress ratio $\alpha_{\mathrm{b}}$, the net cross-section stress ratio $\alpha_{\mathrm{n}}$ and the bolt shear stress ratio $\alpha_{\mathrm{s}}$, which can be calculated by Eq (2) to (4). While the abscissa was nondimensionalized by using the index of the ratio of the end distance to the bolt hole diameter. 
$\alpha_{\mathrm{b}}=\frac{F_{\mathrm{u}}}{f_{\mathrm{u}} d t}$

$\alpha_{\mathrm{n}}=\frac{F_{\mathrm{u}}}{A_{\mathrm{n}} f_{\mathrm{u}}}$

$\alpha_{\mathrm{s}}=\frac{F_{\mathrm{u}}}{A f_{\mathrm{u}}^{\mathrm{b}}}$

where $A_{\mathrm{n}}$ is the net sectional area of the test plate, and $A$ is the shear crosssectional area of the bolt (when the threaded section is in shearing, it shall be calculated based on the effective area of the threaded section $A_{\mathrm{e}}$ )

For the tearout failure and splitting failure specimens, as shown in Fig. 13(a) and Fig. 13(b), in the range of the end distance $\left(1.35 d_{0}-2.67 d_{0}\right)$ in this test, as the end distance increases, the failure mode of the specimens transformed from tearout failure to splitting failure. For the A-series specimens with splitting failure, the bearing stress ratio increased substantially in a linear manner. For the net cross-section failure and the bolt shear failure specimens, as shown in Fig. 13(c) and (d), the load-carrying capacity of the specimens shows little relation with the change in the end distance. The net cross-section stress ratio of the specimen with the net cross-section failure is between 1.00 and 1.10 , and the bolt shear stress ratio of the bolt shear failure specimen is almost greater than $1 / \sqrt{3}$, i.e. 0.577 .

As shown in Fig. 14(a) and Fig. 14(b), in the edge distance range $\left(1.77 d_{0^{-}}\right.$ $2.78 d_{0}$ ) in this test, the bearing stress ratio of the tearout failure and splitting failure specimens did not change significantly. There is no obvious correlation between the bearing stress ratio and edge distance. For the net cross-section failure specimens, the net cross-section stress ratio is distributed between 1.00 and 1.10. As shown in Fig. 14(c), the net section stress ratio has little relationship with the edge distance. In fact, when using Eq. (3) to calculate the net cross-section stress ratio, the influence of the edge distance had already been considered, indicating that the load-carrying capacity has a significant positive correlation with the edge distance. As shown in Fig. 14(d), the bolt shear stress of the bolt shear failure specimen is greater than $1 / \sqrt{3}$, i.e. 0.577 , which shows an unobvious correlation with the edge distance.

\section{Comparison with specification calculation results}

\subsection{Specification calculation results}

There are different geometric requirements for bolted shear connections in different codes, standards and specifications ${ }^{[25-27]}$. The following analysis of different specifications was based on the test data of the specimens that meet the geometric requirements of the corresponding specifications. The number of specimens that meet the geometric requirements of different specifications was counted according to failure mode, as shown in Table 11. Instead of dividing the failure modes into tearout failure, splitting failure, and pure bearing failure, Eurocode 3 and AISC360-10 put these three failure modes into one category, i.e. bearing failure. Besides, GB50017-2017 sets strict geometric requirements to avoid the occurrence of tearout failure and holds that splitting failure and pure bearing failure are included in bearing failure. Therefore, to facilitate the comparison among various calculation methods in various specifications, tearout failure, splitting failure and pure bearing failure of the specimens were collectively referred to as bearing failure in the following discussion.

Table 11

The quantity of specimens meets the requirements for various specifications

\begin{tabular}{cccc}
\hline Failure mode & GB50017-2017 & Eurocode 3 & AISC360-10 \\
\hline BF & 21 & 29 & 29 \\
NF & 2 & 6 & 6 \\
SF & 8 & 8 & 8 \\
Total & 31 & 43 & 43 \\
\hline
\end{tabular}

The calculation methods in the GB 50017-2017, EC3 and AISC 360-10 are listed in Table 12. The calculated resistances and the predicted failure modes according to the three specifications are listed in Table 13. All parameters used for calculation are the actual, and the partial safety factor is not included. In Table 13, the calculation result with the symbol "**" indicates that the specimen does not meet the geometric requirements of the corresponding specification. $F_{\mathrm{u}, \mathrm{CH}}, F_{\mathrm{u}, \mathrm{EC}}, F_{\mathrm{u}, \mathrm{AISC}, 1}$ and $F_{\mathrm{u}, \mathrm{AISC}, 2}$ represent the resistance calculated according to GB50017-2017, Eurocode 3, AISC360-10 method 1 and AISC36010 method 2 respectively. And the calculation resistance took the minimum of calculated resistance of bolts against shear force, bearing capacity and resistance of net cross-section against tension. Meanwhile, the failure mode refers to the mode corresponding to the calculation resistance.

The shear capacity of the connection is based on the load-carrying capacity of a single bolt. But the calculation principles for the resistance of bolts against shear force are different among the three specifications. The shear capacity of the connection is defined as the sum of the load-carrying capacity of a single bolt in GB50017-2017 and AISC360-10. While in Eurocode 3, if the shear capacity of each bolt in the connection is greater than its corresponding bearing capacity, the shear capacity of the connection is the sum of the bearing capacity of each bolt, otherwise it should be represented as the value obtained by multiplying the minimum load-carrying capacity of any single bolt by the number of bolts.

\subsection{Comparison of load-carrying capacity}

The comparison of the experimental resistance with its corresponding calculated value according to the three specifications were drawn in Fig. 15 and the quantitative comparison was presented in Table 14. In Table 14, the average values of the ratio of the test load-carrying capacity to the calculated value of each specification were listed according to the actual failure mode of the specimens, and the standard deviation of the average values was also calculated.

As shown in Table 14, the ratio of test load-carrying capacity to the calculated value of each specification was averaged and found all of that were not less than 1.0, with GB50017-2017 and Eurocode 3 being conservative and AISC360-10 method 2 being the closest to the experimental results. Except for the calculated resistances using AISC360-10 method 2 for the specimens with bearing failure are slightly higher than the experimental results, the calculated resistances using the methods in other specifications for all failure modes are less than the experimental results.

For the specimens with bearing failure, Eurocode 3 is the most conservative specification and GB50017-2017 is second to it. On the contrary, AISC360-10 method 2 overestimates the resistance. For the specimens with net cross-section failure, the principles in the three different specifications are different. The failure criteria adopted by GB GB50017-2017 is the yield of the net crosssection, which makes it the most conservative specification of the three. While Eurocode 3 and AISC360-10 take the minimum of the resistances of gross section yield and net section fracture as failure criteria. Besides, a safety factor of 0.9 is adopted for net section fracture in Eurocode 3, while the net crosssection fracture is directly adopted in AISC360-10 without a safety factor, which results in AISC360-10 being most close to the capacity obtained by experiment. For the specimens with bolt shear failure, GB50017-2017 is the most conservative, followed by Eurocode 3 and AISC360-10.

\subsection{Failure mode comparison}

The gap between the load-carrying capacity obtained by the experiment and the calculation according to specifications reflects the degree of "safety reserve" of each specification for different failure modes. But it is at the cost of the accuracy of the prediction of the failure mode.

Table 15 lists the accuracy of the failure mode prediction of each specification. The failure mode in the table refers to the actual failure mode of the specimens. In general, the prediction using the AISC360-10 method 1 is the most accurate, and the prediction accuracy of the failure mode of the specimens in this test reaches $95.4 \%$.

As to each failure mode, for the specimens with bearing failure, except for AISC360-10 method 2, the other three methods can predict the failure mode well. For the specimens with net cross-section failure, AISC360-10 method 2 shows better prediction accuracy among the four methods. And for the specimens with bolt shear failure, AISC360-10 method 1 can predict the failure mode well.

The large difference in the prediction accuracy of each specification for different failure modes is caused by the difference in the "safety reserve" among the bearing capacity, bolt shear capacity and net cross-section capacity.

As shown in Table 14, GB50017-2017 has the highest safety factor for bolt shear failure, but correspondingly, it cannot output an accurate prediction for bolt shear failure, which is also presented zero accuracies in Table 15. Similarly, Eurocode 3 owns the best prediction for bearing failure. AISC360-10 method 1 has a good prediction for bearing failure and bolt shear failure, and method 2 has a good prediction for the net section failure and bolt shear failure. In general, the prediction accuracy of the failure mode of AISC360-10 method 1 shows the best in the four. Generically, the safety reserve of bearing capacity, bolt shear capacity and net cross-section capacity in the code formula has a decisive influence on the accuracy of the code formula for predicting the failure mode. 


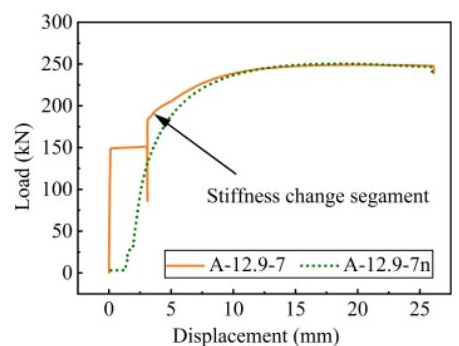

(a) Tearout failure

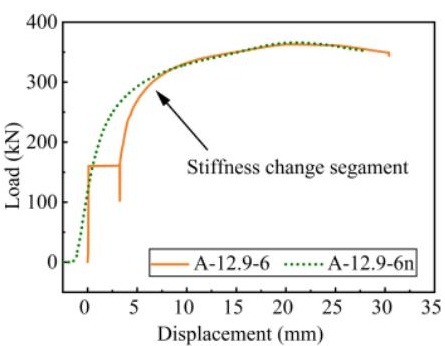

(b) Splitting failure

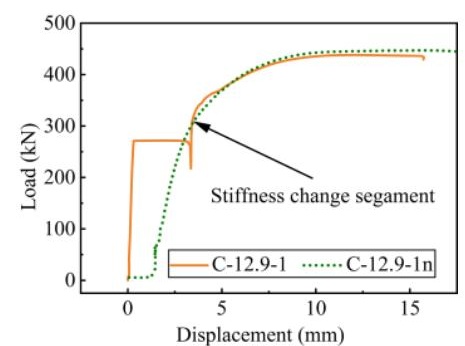

(c) Net cross-section failure

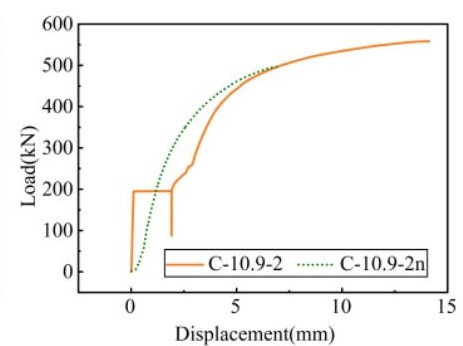

(d) Bolt shear failure

Fig. 12 Effect of pretension on the stiffness of specimens with different failure modes

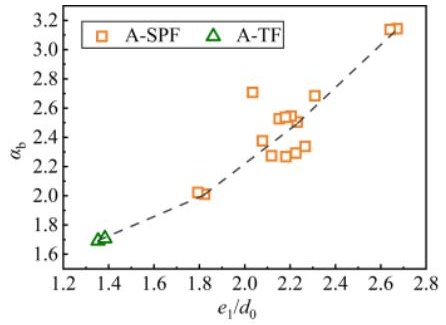

(a) A-series tearout and splitting specimens

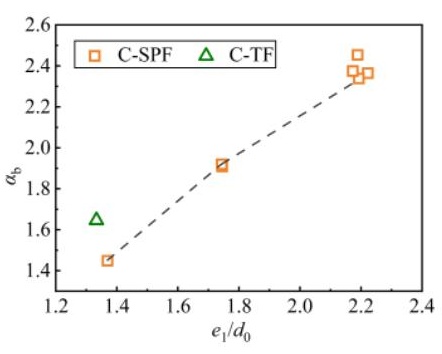

(b) C-series tearout and splitting specimens

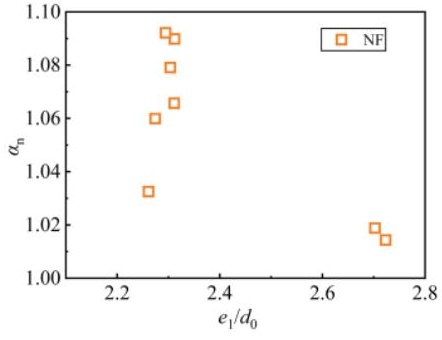

(c) Net cross-section failure

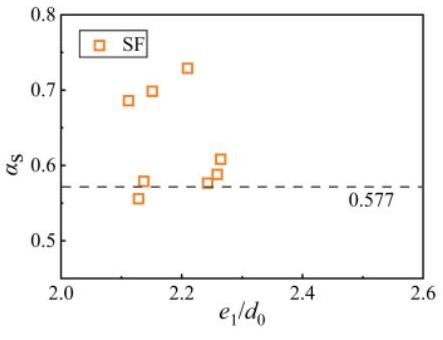

(d) Bolt shear failure

Fig. 13 Effect of end distance on bearing capacity of specimens

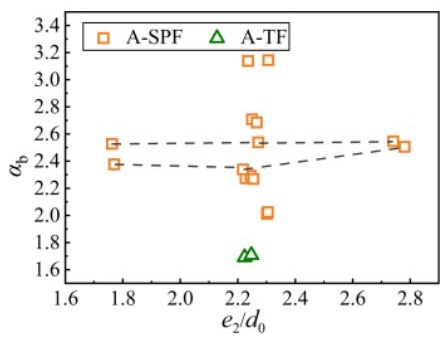

(a) A-series tearout and splitting specimens

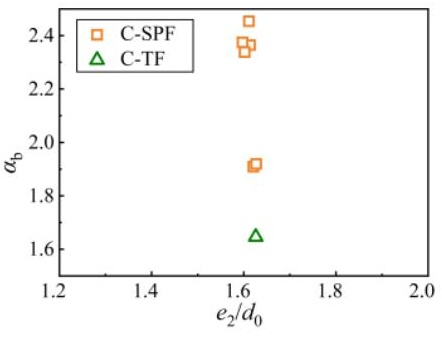

(b) C-series tearout and splitting specimens

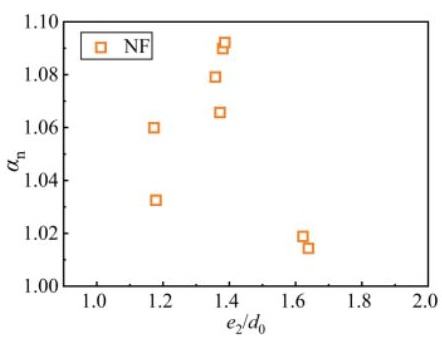

(c) Net cross-section failure

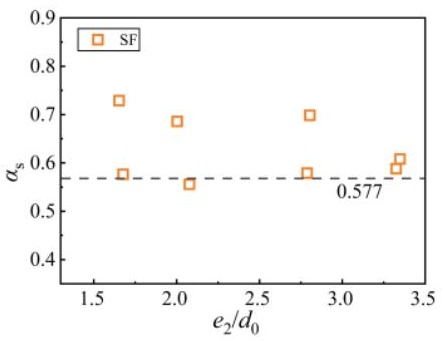

(d) Bolt shear failure

Fig. 14 Effect of edge distance on bearing capacity of specimens

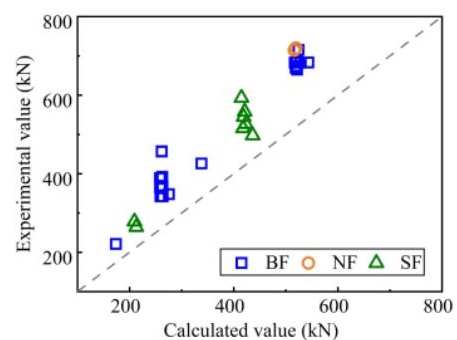

(a) GB50017-2017

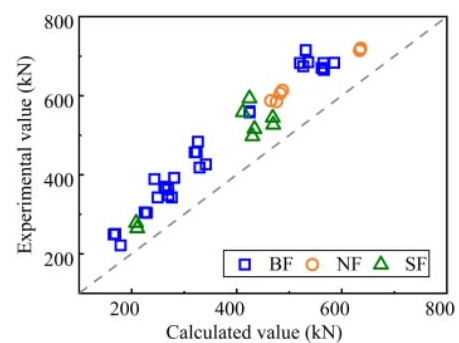

(b) EC 3

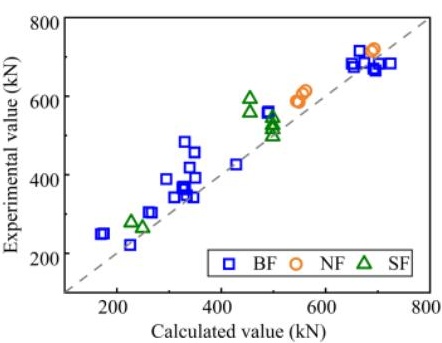

(c) AISC 360-10 method 1

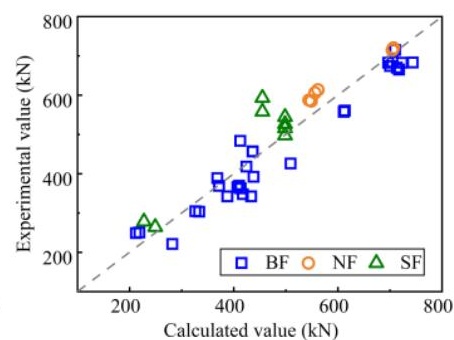

(d) AISC 360-10 method 2

Fig. 15 Comparison between experimental resistance and calculated value

\section{Discussion on the applicability of the code formula for B-series specimens}

For the B-series specimens, the bearing resistances for the two bolts with different end distances were calculated and summed when calculating the bearing resistance according to Eurocode 3 and AISC360-10, which means the deformation at the bolt hole was not taken into consideration. However, the peak displacements of the specimens with different end distances are different when the ultimate bearing capacity is achieved, which means there are different displacement requirements for specimens with different end distances to get their ultimate bearing capacities.

As to the specimen with two bolts parallel to the force, shown as Fig.16, whether the bearing resistance of the specimen (assuming that net section failure and bolt shear failure do not occur) is a simple summation of the bearing resistance of the inner bolt and outer bolt is worth discussing.

If the inner bolt and outer bolt reached their respective ultimate bearing capacity simultaneously or if the outer bolt had sufficient ductility to maintain the ultimate bearing capacity and the inner bolt reaching its ultimate bearing capacity before the outer bolt fails, the connection bearing resistance could be obtained by simply summing the bearing resistance of the two bolts. However, this is not the case in reality. The end distances of the four A-series specimens in Fig. 17 vary from 31.17 to $59.30 \mathrm{~mm}$, and the peak displacements of the three specimens that failed with splitting are significantly different. The bearing capacity of the specimens with a large end distance is significantly lower than its ultimate bearing capacity at the deformation that corresponds to the specimen with a small end distance reaches its ultimate bearing capacity. Vice versa, the bearing capacity of the specimens with a small end distance has started to decline or already failed at the deformation that corresponds to the specimens with a large end distance achieves its ultimate bearing capacity. The loaddisplacement curve of specimen B-12.9-3n is drawn in Fig. 17, which indicates the peak displacement is between the peak displacement of specimen A-12.9$6 \mathrm{n}$ and the peak displacement of A-12.9-9n.

Table 16 lists the experimental bearing capacity and the corresponding calculated values of a B-series specimen with bearing failure. For individual bolts in the B-series specimen, the calculated capacities of the two bolts are different using the methods in Eurocode 3 and AISC360-10. The experimental bearing capacity of the $\mathrm{B}$-series specimens is approximately twice that of the Aseries specimens with similar end distances. For B-series specimens in this 
paper, when the outer bolt is approaching failure, the resistance of the two bolts in the B-series specimens can be considered evenly distributed. In another word, the bearing capacities of the inner bolt and the outer bolt are almost equal, and the bearing capacity of the connection can be considered as twice that of the outer bolt. However, for the shear connection of two bolts with a small end distance and a binger pitch parallel to the force direction, the displacement requirement to achieve the ultimate bearing capacity is different for two bolts, so that the ultimate bearing capacity cannot be reached simultaneously. Further, the connection bearing capacity obtained by the simple summation method according to Eurocode 3 and AISC360-10 will be significantly higher than the actual bearing capacity of the connection. Therefore, for the shear connection with two bolts parallel to the force, when there is a large difference between the end distance and pitch, the safety of the bearing capacity calculated by the methods in Eurocode 3 and AISC360-10 will be significantly lower than the shear connection with a single bolt. And when the difference between the end distance and pitch is larger, an unsafe situation may occur. GB 50017-2017 sets stricter geometric requirements for shear connections. The influence of geometrical dimensions on the bearing capacity of bolts is not a design consideration and assumes that the bolts are evenly stressed, which agrees with the performance of the B-series specimens in this test.

Table 12

Calculation methods in various specifications

\begin{tabular}{|c|c|c|c|}
\hline Specification & Bearing resistance & Net cross-section resistance & Bolt shear resistance \\
\hline $\begin{array}{l}\text { GB50017- } \\
2017\end{array}$ & where, $\quad N_{c}^{b}=d \sum t \cdot f_{c}^{b}$ & $N=A_{\mathrm{n}} f_{\mathrm{y}}$ & $N_{v}^{b}=n_{v} \frac{\pi d^{2}}{4} f_{v}^{b}$ \\
\hline \multirow{8}{*}{2017} & $d$ is bolt shank diameter; & $A_{\mathrm{n}}$ is the net sectional area; & where, \\
\hline & $\sum t$ is the lesser sum of thickness of the connected plies bearing in & $f_{\mathrm{y}}$ is the yield strength of steel. & $n_{v}$ is the number of shear plane; \\
\hline & the same direction; & & $d$ is bolt shank diameter, and when the threaded \\
\hline & $f_{c}^{b}$ is the design value of bearing strength of the bolt; & & section is in shearing, the design value of shear \\
\hline & And $f_{c}^{b}=1.26 f_{u}$, where $f_{u}$ is the ultimate strength of steel. & & capacity shall be calculated based on the effective \\
\hline & & & area of the threaded section. \\
\hline & & & $f_{c}^{b}$ is the design value of shear strength of the bolt; \\
\hline & & & And $f_{v}^{b}=0.3 f_{u}^{b}$, where $f_{u}^{b}$ is the ultimate \\
\hline
\end{tabular}

EC3 $F_{b, R d}=\frac{k_{1} \alpha_{b} f_{u} d t}{\gamma_{M 2}}$

where,

$\alpha_{b}$ is the smallest of $\alpha_{d}, \frac{f_{u b}}{f_{u}}$ or 1.0 ;

in the direction of load transfer:

for end bolts: $\alpha_{d}=\frac{p_{1}}{3 d_{0}}$; for the inner bolts: $\alpha_{d}=\frac{p_{1}}{3 d_{0}}-\frac{1}{4}$.

perpendicular to the direction of load transfer:

for the edge bolts: $k_{1}=\min \left(2.8 \frac{e_{2}}{d_{0}}-1.7,2.5\right)$; for inner bolts:

$k_{1}=\min \left(1.4 \frac{p_{2}}{d_{0}}-1.7,2.5\right)$.

and where $f_{u}$ is the ultimate strength of steel; $\gamma_{M 2}$ is the safety

factor, which is $1.25 ; d$ and $d_{0}$ are the diameter of bolt and bolt

hole respectively.

AISC 360- Method 1: When deformation at the bolt hole at service load is a

10

design consideration.

$$
R_{n 1}=1.2 \phi l_{c} t F_{u} \leq 2.4 \phi d t F_{u}
$$

Method 2: When deformation at the bolt hole at service load is not a design consideration.

$$
R_{n 2}=1.5 \phi l_{c} t F_{u} \leq 3.0 \phi d t F_{u}
$$

where,

$l_{c}$ is the clear distance;

$t$ is the thickness of connected material.

$\phi$ is the safety factor;

$F_{u}$ is the specified minimum tensile strength of the connected

material;

$d$ is the nominal fastener diameter
$N=\min \left(0.9 A_{\mathrm{n}} f_{\mathrm{u}}, A f_{\mathrm{y}}\right)$

where,

$A_{\mathrm{n}}$ is the net sectional area;

$A$ is the gross sectional area;

$f_{\mathrm{y}}$ is the yield strength of steel;

$f_{u}$ is the ultimate strength of steel.

$$
F_{v, R d}=\frac{\alpha_{v} f_{u b} A}{\gamma_{M 2}}
$$

where the shear plane passes through the threaded portion of the bolt ( $A$ is the tensile stress area of the bolt $A_{\mathrm{s}}$ ):

for classes 4.6, 5.6 and 8.8: $\alpha_{v}=0.6$;

for classes 4.8, 5.8, 6.8 and 10.9: $\alpha_{v}=0.5$;

while where the shear plane passes through the unthreaded portion of the bolt (A is the gross crosssection of the bolt): $\alpha_{v}=0.6$.

and $\gamma_{M 2}$ is the safety factor, $f_{u b}$ is the ultimate tensile strength.

$$
N=\min \left(A_{\mathrm{n}} f_{\mathrm{u}}, A f_{\mathrm{y}}\right)
$$

$$
R_{n 1}=\phi F_{n v} A_{b}
$$

where,

$A_{\mathrm{n}}$ is the net sectional area;

$A$ is the gross sectional area;

$f_{\mathrm{y}}$ is the yield strength of steel;

$f_{u}$ is the ultimate strength of steel. where,

$\phi$ is the safety factor;

$F_{n v}$ is the nominal shear stress;

$A_{b}$ is the nominal unthreaded body area of bolt or threaded part. 
Table 13

Comparison between test results and calculated values

\begin{tabular}{|c|c|c|c|c|c|c|c|c|c|c|c|c|c|c|}
\hline \multirow[b]{2}{*}{ Specimen } & \multirow{2}{*}{$\begin{array}{l}\text { Actual } \\
\text { failure } \\
\text { mode }\end{array}$} & \multirow{2}{*}{$\begin{array}{l}F_{\mathrm{u}} \\
\mathrm{kN}\end{array}$} & \multicolumn{3}{|c|}{ GB 50017-2017 } & \multicolumn{3}{|c|}{ Eurocode 3} & \multicolumn{3}{|c|}{ AISC $360-10$ method 1} & \multicolumn{3}{|c|}{ AISC $360-10$ method 2} \\
\hline & & & $\begin{array}{l}\text { Failure } \\
\text { mode }\end{array}$ & $\begin{array}{l}F_{\mathrm{u}, \mathrm{CH}} \\
(\mathrm{kN})\end{array}$ & $\frac{F_{\mathrm{u}}}{F_{\mathrm{u}, \mathrm{CH}}}$ & $\begin{array}{l}\text { Failure } \\
\text { mode }\end{array}$ & $\begin{array}{l}F_{\mathrm{u}, \mathrm{EC}} \\
(\mathrm{kN})\end{array}$ & $\frac{F_{\mathrm{u}}}{F_{\mathrm{u}, \mathrm{EC}}}$ & $\begin{array}{l}\text { Failure } \\
\text { mode }\end{array}$ & $\begin{array}{c}F_{\mathrm{u}, \mathrm{AISC}, 1} \\
(\mathrm{kN})\end{array}$ & $\frac{F_{\mathrm{u}}}{F_{\mathrm{u}, \mathrm{AISC}, 1}}$ & $\begin{array}{l}\text { Failure } \\
\text { mode }\end{array}$ & $\begin{array}{c}F_{\mathrm{u}, \mathrm{AISC}, 2} \\
(\mathrm{kN})\end{array}$ & $\frac{F_{\mathrm{u}}}{F_{\mathrm{u}, \mathrm{AISC}, 2}}$ \\
\hline A-12.9-1 & $\mathrm{BF}$ & 348.0 & $\mathrm{BF}$ & 275.52 & 1.26 & $\mathrm{BF}$ & 270.15 & 1.29 & $\mathrm{BF}$ & 334.02 & 1.04 & $\mathrm{BF}$ & 417.53 & 0.83 \\
\hline A-12.9-1n & $\mathrm{BF}$ & 342.4 & $\mathrm{BF}$ & 263.58 & 1.30 & $\mathrm{BF}$ & 276.56 & 1.24 & $\mathrm{BF}$ & 346.87 & 0.99 & $\mathrm{BF}$ & 433.58 & 0.79 \\
\hline A-12.9-2 & $\mathrm{BF}$ & 392.0 & $\mathrm{BF}$ & 262.82 & 1.49 & $\mathrm{BF}$ & 280.97 & 1.40 & $\mathrm{BF}$ & 350.42 & 1.12 & $\mathrm{BF}$ & 438.03 & 0.89 \\
\hline A-12.9-3 & $\mathrm{BF}$ & 221.4 & $\mathrm{BF}$ & 173.86 & 1.27 & $\mathrm{BF}$ & 179.09 & 1.24 & $\mathrm{BF}$ & 225.72 & 0.98 & $\mathrm{BF}$ & 282.15 & 0.78 \\
\hline A-12.9-4 & $\mathrm{BF}$ & 426.0 & $\mathrm{BF}$ & 338.06 & 1.26 & $\mathrm{BF}$ & 341.41 & 1.25 & $\mathrm{BF}$ & 428.77 & 0.99 & SF & 509.28 & 0.84 \\
\hline A-12.9-5 & $\mathrm{BF}$ & 369.5 & $\mathrm{BF}$ & 263.20 & 1.40 & $\mathrm{BF}$ & 262.29 & 1.41 & $\mathrm{BF}$ & 328.38 & 1.13 & $\mathrm{BF}$ & 410.48 & 0.90 \\
\hline A-12.9-5n & $\mathrm{BF}$ & 342.4 & $\mathrm{BF}$ & 259.40 & 1.32 & $\mathrm{BF}$ & 249.54 & 1.37 & $\mathrm{BF}$ & 310.25 & 1.10 & $\mathrm{BF}$ & 387.81 & 0.88 \\
\hline A-12.9-6 & $\mathrm{BF}$ & 362.8 & $\mathrm{BF}$ & 260.73 & 1.39 & $\mathrm{BF}$ & 269.32 & 1.35 & $\mathrm{BF}$ & 330.69 & 1.10 & $\mathrm{BF}$ & 413.37 & 0.88 \\
\hline A-12.9-6n & $\mathrm{BF}$ & 365.8 & $\mathrm{BF}$ & 258.65 & 1.41 & $\mathrm{BF}$ & 263.93 & 1.39 & $\mathrm{BF}$ & 325.72 & 1.12 & $\mathrm{BF}$ & 407.15 & 0.90 \\
\hline A-12.9-7 & $\mathrm{BF}$ & 249.0 & $\mathrm{BF}^{*}$ & $264.90 *$ & $0.94 *$ & $\mathrm{BF}$ & 165.94 & 1.50 & $\mathrm{BF}$ & 169.71 & 1.47 & $\mathrm{BF}$ & 212.14 & 1.17 \\
\hline A-12.9-7n & $\mathrm{BF}$ & 250.4 & $\mathrm{BF}^{*}$ & $263.95 *$ & $0.95^{*}$ & $\mathrm{BF}$ & 169.04 & 1.48 & $\mathrm{BF}$ & 175.09 & 1.43 & $\mathrm{BF}$ & 218.86 & 1.14 \\
\hline A-12.9-8 & $\mathrm{BF}$ & 303.4 & $\mathrm{BF}^{*}$ & $271.54 *$ & $1.12 *$ & $\mathrm{BF}$ & 229.16 & 1.32 & $\mathrm{BF}$ & 267.01 & 1.14 & $\mathrm{BF}$ & 333.77 & 0.91 \\
\hline A-12.9-8n & $\mathrm{BF}$ & 304.6 & $\mathrm{BF}^{*}$ & $270.97^{*}$ & $1.12 *$ & $\mathrm{BF}$ & 224.98 & 1.35 & $\mathrm{BF}$ & 261.22 & 1.17 & $\mathrm{BF}$ & 326.52 & 0.93 \\
\hline A-12.9-9 & $\mathrm{BF}$ & 457.0 & $\mathrm{BF}$ & 261.68 & 1.75 & $\mathrm{BF}$ & 323.71 & 1.41 & $\mathrm{BF}$ & 348.91 & 1.31 & $\mathrm{BF}$ & 436.13 & 1.05 \\
\hline A-12.9-9n & $\mathrm{BF}$ & 456.5 & $\mathrm{BF}$ & 261.87 & 1.74 & $\mathrm{BF}$ & 320.21 & 1.43 & $\mathrm{BF}$ & 349.16 & 1.31 & $\mathrm{BF}$ & 436.45 & 1.05 \\
\hline B-12.9-3 & $\mathrm{BF}$ & 670.0 & $\mathrm{BF}$ & 518.81 & 1.29 & $\mathrm{BF}$ & 561.76 & 1.19 & $\mathrm{BF}$ & 691.74 & 0.97 & $\mathrm{NF}$ & 713.36 & 0.94 \\
\hline B-12.9-3n & $\mathrm{BF}$ & 682.5 & $\mathrm{BF}$ & 528.67 & 1.29 & $\mathrm{BF}$ & 565.29 & 1.21 & $\mathrm{BF}$ & 702.51 & 0.97 & $\mathrm{NF}$ & 723.54 & 0.94 \\
\hline C-12.9-1 & $\mathrm{NF}$ & 438.0 & $\mathrm{NF}^{*}$ & $347.69 *$ & $1.26^{*}$ & $\mathrm{BF}^{*}$ & $354.66^{*}$ & $1.23^{*}$ & $\mathrm{NF}^{*}$ & $424.20^{*}$ & $1.03^{*}$ & $\mathrm{NF}^{*}$ & $424.20 *$ & $1.03 *$ \\
\hline C-12.9-1n & $\mathrm{NF}$ & 447.0 & $\mathrm{NF}^{*}$ & $345.66^{*}$ & $1.29 *$ & $\mathrm{BF}^{*}$ & $351.47 *$ & $1.27^{*}$ & $\mathrm{NF}^{*}$ & $421.72 *$ & $1.06^{*}$ & $\mathrm{NF}^{*}$ & $421.72 *$ & $1.06^{*}$ \\
\hline C-12.9-2 & $\mathrm{NF}$ & 585.0 & NF* & $449.92 *$ & $1.30 *$ & $\mathrm{BF}$ & 475.55 & 1.23 & NF & 548.93 & 1.07 & $\mathrm{NF}$ & 548.93 & 1.07 \\
\hline C-12.9-2n & $\mathrm{NF}$ & 606.0 & $\mathrm{NF}^{*}$ & $455.75^{*}$ & $1.33^{*}$ & $\mathrm{BF}$ & 482.92 & 1.25 & $\mathrm{NF}$ & 556.04 & 1.09 & NF & 556.04 & 1.09 \\
\hline C-12.9-3 & $\mathrm{BF}$ & 684.5 & $\mathrm{BF}$ & 521.08 & 1.31 & $\mathrm{BF}$ & 536.14 & 1.28 & $\mathrm{BF}$ & 674.20 & 1.02 & $\mathrm{NF}$ & 704.98 & 0.97 \\
\hline C-12.9-3n & $\mathrm{BF}$ & 674.0 & $\mathrm{BF}$ & 518.81 & 1.30 & $\mathrm{BF}$ & 526.73 & 1.28 & $\mathrm{BF}$ & 654.22 & 1.03 & $\mathrm{NF}$ & 700.25 & 0.96 \\
\hline C-12.9-4 & $\mathrm{BF}$ & 483.5 & $\mathrm{BF}$ & $528.67^{*}$ & $0.91 *$ & $\mathrm{BF}$ & 326.30 & 1.48 & $\mathrm{BF}$ & 330.07 & 1.46 & $\mathrm{BF}$ & 412.58 & 1.17 \\
\hline C-12.9-4n & $\mathrm{BF}$ & 418.2 & $\mathrm{BF}$ & $519.57^{*}$ & $0.80^{*}$ & $\mathrm{BF}$ & 329.44 & 1.27 & $\mathrm{BF}$ & 339.54 & 1.23 & $\mathrm{BF}$ & 424.42 & 0.99 \\
\hline C-12.9-5 & $\mathrm{BF}$ & 557.5 & $\mathrm{BF}$ & $525.63 *$ & $1.06^{*}$ & $\mathrm{BF}$ & 424.68 & 1.31 & $\mathrm{BF}$ & 489.02 & 1.14 & $\mathrm{BF}$ & 611.27 & 0.91 \\
\hline C-12.9-5n & $\mathrm{BF}$ & 560.5 & $\mathrm{BF}$ & $525.63 *$ & $1.07^{*}$ & $\mathrm{BF}$ & 424.36 & 1.32 & $\mathrm{BF}$ & 490.68 & 1.14 & $\mathrm{BF}$ & 613.35 & 0.91 \\
\hline C-12.9-6 & $\mathrm{NF}$ & 720.0 & $\mathrm{BF}$ & 519.57 & 1.39 & $\mathrm{NF}$ & 636.01 & 1.13 & $\mathrm{BF}$ & 692.76 & 1.04 & $\mathrm{NF}$ & 706.68 & 1.02 \\
\hline C-12.9-6n & $\mathrm{NF}$ & 714.5 & $\mathrm{BF}$ & 516.15 & 1.38 & $\mathrm{NF}$ & 633.97 & 1.13 & $\mathrm{BF}$ & 688.20 & 1.04 & $\mathrm{NF}$ & 704.41 & 1.01 \\
\hline A-10.9-1 & $\mathrm{SF}$ & 278.4 & $\mathrm{BF}$ & 209.34 & 1.33 & $\mathrm{BF}$ & 208.49 & 1.34 & $\mathrm{SF}$ & 227.58 & 1.22 & $\mathrm{SF}$ & 227.58 & 1.22 \\
\hline A-10.9-1n & SF & 264.4 & $\mathrm{BF}$ & 212.83 & 1.24 & $\mathrm{BF}$ & 210.58 & 1.26 & $\mathrm{SF}$ & 249.27 & 1.06 & $\mathrm{SF}$ & 249.27 & 1.06 \\
\hline A-10.9-2 & $\mathrm{BF}$ & 369.2 & $\mathrm{BF}$ & 261.87 & 1.41 & $\mathrm{BF}$ & 264.29 & 1.40 & $\mathrm{BF}$ & 327.16 & 1.13 & $\mathrm{SF}$ & 371.88 & 0.99 \\
\hline A-10.9-2n & $\mathrm{BF}$ & 388.8 & $\mathrm{BF}$ & 258.46 & 1.50 & $\mathrm{BF}$ & 243.44 & 1.60 & $\mathrm{BF}$ & 294.81 & 1.32 & $\mathrm{BF}$ & 368.52 & 1.06 \\
\hline B-10.9-1 & SF & 544.5 & $\mathrm{BF}$ & 418.99 & 1.30 & $\mathrm{BF}$ & 468.68 & 1.16 & SF & 498.54 & 1.09 & SF & 498.54 & 1.09 \\
\hline B-10.9-1n & SF & 526.5 & $\mathrm{BF}$ & 423.24 & 1.24 & $\mathrm{BF}$ & 469.45 & 1.12 & SF & 498.54 & 1.06 & $\mathrm{SF}$ & 498.54 & 1.06 \\
\hline B-10.9-2 & $\mathrm{BF}$ & 683.0 & $\mathrm{BF}$ & 543.46 & 1.26 & $\mathrm{BF}$ & 585.36 & 1.17 & $\mathrm{BF}$ & 724.61 & 0.94 & $\mathrm{SF}$ & 743.76 & 0.92 \\
\hline B- $10.9-2 n$ & $\mathrm{BF}$ & 665.0 & $\mathrm{BF}$ & 521.84 & 1.27 & $\mathrm{BF}$ & 566.03 & 1.17 & $\mathrm{BF}$ & 695.79 & 0.96 & $\mathrm{NF}$ & 717.42 & 0.93 \\
\hline C-10.9-1 & SF & 593.0 & $\mathrm{BF}$ & 414.74 & 1.43 & $\mathrm{BF}$ & 424.27 & 1.40 & SF & 455.15 & 1.30 & SF & 455.15 & 1.30 \\
\hline C-10.9-1n & SF & 516.0 & $\mathrm{BF}$ & 417.78 & 1.24 & $\mathrm{BF}$ & 433.82 & 1.19 & $\mathrm{SF}$ & 498.54 & 1.04 & SF & 498.54 & 1.04 \\
\hline C-10.9-2 & SF & 558.0 & $\mathrm{BF}$ & 421.11 & 1.33 & $\mathrm{BF}$ & 411.72 & 1.36 & SF & 455.15 & 1.23 & SF & 455.15 & 1.23 \\
\hline C-10.9-2n & SF & 497.5 & $\mathrm{BF}$ & 436.28 & 1.14 & $\mathrm{BF}$ & 429.91 & 1.16 & SF & 498.54 & 1.00 & $\mathrm{SF}$ & 498.54 & 1.00 \\
\hline C-10.9-3 & $\mathrm{NF}$ & 613.5 & $\mathrm{NF}^{*}$ & $460.42 *$ & $1.33^{*}$ & $\mathrm{BF}$ & 486.93 & 1.26 & NF & 561.73 & 1.09 & $\mathrm{NF}$ & 561.73 & 1.09 \\
\hline C-10.9-3n & $\mathrm{NF}$ & 587.5 & $\mathrm{NF}^{*}$ & $446.23 *$ & $1.32 *$ & $\mathrm{BF}$ & 464.80 & 1.26 & $\mathrm{NF}$ & 544.42 & 1.08 & $\mathrm{NF}$ & 544.42 & 1.08 \\
\hline C-10.9-4 & $\mathrm{BF}$ & 682.5 & $\mathrm{BF}$ & 517.29 & 1.32 & $\mathrm{BF}$ & 520.46 & 1.31 & $\mathrm{BF}$ & 650.32 & 1.05 & $\mathrm{NF}$ & 696.62 & 0.98 \\
\hline C- $10.9-4 n$ & $\mathrm{BF}$ & 715.0 & $\mathrm{BF}$ & 524.50 & 1.36 & $\mathrm{BF}$ & 531.50 & 1.35 & $\mathrm{BF}$ & 665.24 & 1.07 & NF & 709.89 & 1.01 \\
\hline
\end{tabular}


Table 14

The average value of the ratio of experimental results and standard calculated values with different failure modes

\begin{tabular}{|c|c|c|c|c|}
\hline Failure mode & GB50017-2017 & Eurocode 3 & $\begin{array}{l}\text { AISC360-10 } \\
\text { method } 1\end{array}$ & $\begin{array}{c}\text { AISC360-10 } \\
\text { method } 2\end{array}$ \\
\hline $\mathrm{BF}$ & 1.28 & 1.34 & 1.14 & 0.95 \\
\hline NF & 1.29 & 1.21 & 1.06 & 1.05 \\
\hline SF & 1.36 & 1.25 & 1.12 & 1.12 \\
\hline Average & 1.30 & 1.31 & 1.12 & 1.00 \\
\hline Standard deviation & 0.127 & 0.108 & 0.132 & 0.115 \\
\hline
\end{tabular}

Table 15

The accuracy of the predicted failure mode for different failure modes specimens

\begin{tabular}{|c|c|c|c|c|}
\hline Failure mode & GB50017-2017 & Eurocode 3 & AISC360-10 method 1 & AISC360-10 method 2 \\
\hline $\mathrm{BF}$ & $100 \%$ & $100 \%$ & $100 \%$ & $65.5 \%$ \\
\hline NF & $0 \%$ & $33.3 \%$ & $66.7 \%$ & $100 \%$ \\
\hline SF & $0 \%$ & $0 \%$ & $100 \%$ & $100 \%$ \\
\hline Total & $67.7 \%$ & $72.1 \%$ & $95.4 \%$ & $76.7 \%$ \\
\hline
\end{tabular}

\section{Table 16}

Comparison between experimental results and the calculated values of B-12.9-3n

\begin{tabular}{|c|c|c|c|c|c|c|c|c|c|c|c|c|c|}
\hline \multirow{3}{*}{$\begin{array}{c}e_{1} \\
/ \mathrm{mm}\end{array}$} & \multirow{3}{*}{$\begin{array}{c}p_{1} \\
/ \mathrm{mm}\end{array}$} & \multirow{3}{*}{$\begin{array}{l}F_{\mathrm{U}, \mathrm{B}} \\
/ \mathrm{kN}\end{array}$} & \multirow{3}{*}{$\begin{array}{l}F_{\mathrm{U}, \mathrm{A}} \\
/ \mathrm{kN}\end{array}$} & \multirow{3}{*}{$F_{\mathrm{u}, \mathrm{B}} / F_{\mathrm{u}, \mathrm{A}}$} & \multicolumn{9}{|c|}{ Calculated value $(\mathrm{kN})$} \\
\hline & & & & & \multicolumn{3}{|c|}{ GB50017-2017 } & \multicolumn{3}{|c|}{ Eurocode 3} & \multicolumn{3}{|c|}{ AISC360-10 method 1} \\
\hline & & & & & Outer bolt & Inner bolt & Connection & Outer bolt & Inner bolt & Connection & Outer bolt & Inner bolt & Connection \\
\hline 51.35 & 70.18 & 682.5 & 342.5 & $199 \%$ & 284.58 & 284.58 & 569.16 & 277.38 & 287.92 & 565.29 & 350.07 & 352.45 & 702.51 \\
\hline
\end{tabular}

$F_{\mathrm{U}, \mathrm{B}}$ is the test load-carrying capacity of the specimen B-12.9-3n, $F_{\mathrm{U}, \mathrm{A}}$ is the test load-carrying capacity of A-series specimen with a similar end distance.

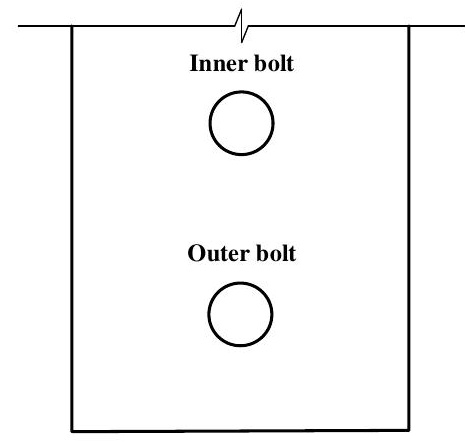

Fig. 16 B-series specimen schematic

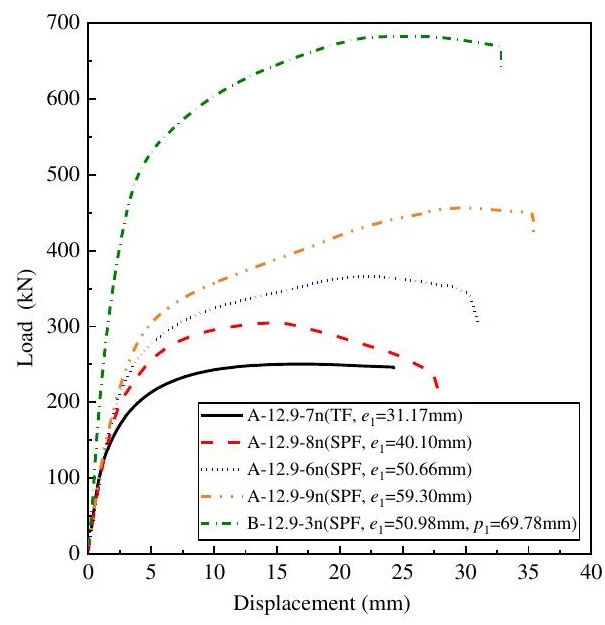

Fig. 17 Load displacement curves of specimens with different end distance

\section{Conclusion}

In this study, static tensile tests were performed on 45 sets of bearing-type connections that combine with Q345 steel and high-strength bolt, and five failure modes were observed. Based on the test results, the influence of the thickness and geometrical dimensions of the test plates, and the property grade, diameter, pretension, layout of the bolts were studied. Moreover, the experimental resistances were compared with the calculated values employed the design methods in GB50017-2017, Eurocode 3 and AISC360-10. And finally, the applicability of the code formula to the B-series specimens was discussed. The conclusions can be drawn as follows:

(1)There are five failure modes that the bearing-type shear connection may occur with: Tearout failure, splitting failure, pure bearing failure, net crosssection failure and bolt shear failure.

(2)Bolt specifications significantly affected the failure mode, primarily controlling the occurrence of the bolt shear failure modes. The bearing capacity of splitting failure specimens in this test was positively correlated with the thickness of the steel.

(3) The pretension of bolts affects little on the load-carrying capacity of specimens with the tearout failure, splitting failure and net cross-section failure, while it improved the load-carrying capacity and peak displacement of the specimen with bolt shear failure, and the increase in value was approximately $9.8 \% \sim 30.7 \%$ of the slip load. Meanwhile, the bolt pretension improved the stiffness of the connection at the friction stage and the bolt bar extrusion stage; however, the stiffness decreased rapidly when the specimen was approaching failing.

(4)The influence of geometrical dimensions on the load-carrying capacity and failure mode of the connections can be concluded as: when the end distance was in the range from $1.35 d_{0}$ to $2.67 d_{0}$, the carrying capacities of the specimens with tearout failure and splitting failure were positively correlated with the end distance. And when the edge distance was in the range from $1.77 d_{0}$ to $2.78 d_{0}$, the edge distance affected little on the carrying capacities of the specimens with splitting failure, and the load-carrying capacities of the specimens with net cross-section failure were positively correlated with the edge distance.

(5)The calculation methods in GB50017-2017 and Eurocode 3 were conservative for predicting the load-carrying capacity of connections that combine with Q345 steel and 10.9S or 12.9S bolts, and the calculated values that using AISC360-10 method 2 was the closest to the experimental results. The safety reserve of the bearing capacity, bolt shear capacity, and net crosssection capacity in the code formula had a decisive influence on the accuracy for predicting the failure mode. 
(6)For the shear connection with two bolts arranged parallelly to the load, the resistance calculated by the simple summation method in Eurocode 3 or AISC360-10 may be significantly higher than the actual load-carrying capacity.

\section{References}

[1] Fisher J.W., Ramseier P.O. and Beedle L.S., "Strength of a440 steel joints connected with a325 bolts", Publication IABSE, Vol. 23, Reprint 245 (63-24), 1963.

[2] Fisher J.W. and Rumpf J.L., "Analysis of bolted butt joints", Journal of the Structural Division, 91, 181-203, 1964

[3] Sterling G.H., "A440 steel butt join ts connected with high strength bolts or rivets", LehighUniversity, 1965 .

[4] Sterling G.H. and Fisher J.W., "A440 Steel Joints Connected by A490 Bolts", Journal of the Structural Division, 92, 101-118, 1965.

[5] Može P. and Beg D., "A complete study of bearing stress in single bolt connections", Journal of Constructional Steel Research, 95, 126-140, 2014

[6] Wang Y.B., Lyu Y.F., Li G.Q. and Liew J.Y. R., "Behavior of single bolt bearing on high strength steel plate", Journal of Constructional Steel Research, 137, 19-30, 2017.

[7] Rex C.O. and Easterling W.S., "Behavior and modeling of a bolt bearing on a single plate", Journal of Structural Engineering, 129(6), 792-800, 2003.

[8] Može P. and Beg D., "High strength steel tension splices with one or two bolts", Journal of Constructional Steel Research, 66(8-9), 1000-1010, 2010.

[9] Lyu Y.F., Wang Y.B., Li G.Q. and Jiang J., "Numerical analysis on the ultimate bearing resistance of single-bolt connection with high strength steels", Journal of Constructional Steel Research, 153, 118-129, 2019

[10] Wang Y.B., Lyu Y.F., Li G.Q. and Liew J.Y. R., "Bearing-strength of high strength steel plates in two-bolt connections", Journal of Constructional Steel Research, 155, 205-218, 2019.

[11] Lyu Y.F., Li G.Q., Wang Y.B., Li H. and Wang Y.Z., "Bearing behavior of multi-bolt high strength steel connections", Engineering Structures, 212, 110510, 2020.

[12] Može P., and Beg D., "Investigation of high strength steel connections with several bolts in double shear", Journal of constructional steel research, 67(3), 333-347, 2011.

[13] Može P., "Bearing strength at bolt holes in connections with large end distance and bolt pitch", Journal of Constructional Steel Research, 147, 132-144, 2018.

[14] Jiang K., Zhao O. and Tan K.H., "Experimental and numerical study of S700 high strength steel double shear bolted connections in tension", Engineering Structures, 225: 111175, 2020.

[15] Kim H.J. and Yura J.A. "The effect of ultimate-to-yield ratio on the bearing strength of bolted connections", Journal of Constructional Steel Research, 49(3), 255-269, 1999.

[16] Li D, Brian Uy., Wang J. and Song Y., "Behaviour and design of high-strength Grade 12.9 bolts under combined tension and shear", Journal of Constructional Steel Research, 174,

\section{Acknowledgments}

This research is supported by the National Natural Science Foundation of China (NSFC-51578089) and 111 Project (Grant No. B18062)

$106305,2020$.

[17] Nie S.D., Kang S.B, Shen L. and Yang B., "Experimental and numerical study on global buckling of Q460GJ steel box columns under eccentric compression", Engineering Structures, $142,211-222,2017$.

18] Nie S.D, Wu D., Yu X., Liu P. and Zhang W.F., "Global Buckling Behavior of Welded Thick H-Shaped Axial Compression Columns of Q460GJ Steel", Journal of Materials in Civil Engineering, 33(1), 04020398, 2021

[19] Yang B., Kang S.B, Xiong G., Nie S.D., Hu Y., Wang S.B., Bai J.B. and Dai G.X., "Experimental and numerical study on lateral-torsional buckling of singly symmetric Q460GJ steel I-shaped beams", Thin-Walled Structures, 113, 205-216, 2017.

[20] Zeng B., Dai G.X. and Xia Z.Z., "Reliability evaluation of high strength bolt connections", Industrial Construction, 27(6), 44-49, 1997. (in Chinese)

[21] Zeng B. and Xia Z.Z., "Pattern Classification Analysis Based on Fuzzy Relation of UncertainInfluence-Factors in High-Strength-Bolt Connections", Journal of Civil, Architectural and Environmental Engineering, S1, 52-58, 1992. (in Chinese)

[22] Dai G.X., "Research and evaluation of reliability of building steel structure", Chongqing university, 2004. (in Chinese)

[23] Hou Z.X. "Study on performance of bearing-type high-strength bolt connection", Industrial Construction, 9, 24-27, 1992. (in Chinese)

[24] GBJ17-88, Code for design of steel structures., Ministry of metallurgical industry of China, Beijing, China, 1988. (in Chinese)

[25] GB 50017-2017, Standard for design of steel structures., Ministry of Housing and UrbanRural Development of the People's Republic of China \& General Administration of Quality Supervision, Inspection and Quarantine of the People's Republic of China, Beijing, China, 2017. (in Chinese)

[26] EN 1993-1-8, Eurocode 3: Design of Steel Structures - Part 1-8: Design of Joints., European Committee for Standardisation, Brussels, Belgium, 2005.

[27] ANSI/AISC 360-10, Specification for Structural Steel Buildings., American Institute of Stee Construction, Chicago, America, 2010.

[28] GB/T 1231-2006, High strength bolts with large hexagon head, large hexagon nuts, plain washers and specification for steel structures., General Administration of Quality Supervision, Inspection and Quarantine of the People's Republic of China \& China National Standardization Administration Committee, Beijing, China, 2006. (in Chinese)

[29] JGJ 82-2011, Technical specification for high strength bolt connection of Steel Structures. Ministry of Housing and Urban-Rural Development of the People's Republic of China, Beijing, China, 2011. (in Chinese) 


\title{
EXPERIMENT OF HYSTERETIC BEHAVIOR AND STABILITY PERFORMANCE OF BUCKLING-RESTRAINED BRACED COMPOSITE FRAME
}

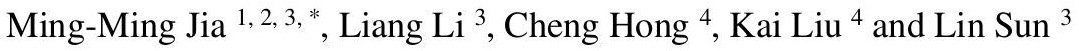 \\ ${ }^{1}$ Institute of Engineering Mechanics, China Earthquake Administration, Harbin 150080, P. R. China; \\ ${ }^{2}$ Key Laboratory of Earthquake Engineering and Engineering Vibration of China Earthquake Administration, Harbin 150080, P. R. China \\ ${ }^{3}$ School of Civil Engineering, Harbin Institute of Technology, Harbin 150090, P. R. China \\ ${ }^{4}$ School of Civil Engineering and Architecture, Nanchang Institute of Technology, Nanchang 330099, P. R. China \\ (Corresponding author: E-mail: jiamingming@hit.edu.cn)
}

\section{A B S T R A C T}

One large-scale 2-story 1-bay buckling-restrained braced (BRBed) concrete-filled steel tube column composite frame (BRBCF) was tested, and the quasi-static cyclic test of the outer composite frame (CF) of BRBCF for comparison. The lateral stiffness, ultimate load bearing capacity and energy dissipation capability of the composite frame were significantly improved when installed with the BRBs. BRBCF exhibited good hysteretic behaviour and sustained story drifts of nearly $2 \%$ with large BRB maximum ductility demands, which was a double lateral-resistance structure system with high efficiency. The bolt splices connections of BRBs with CF frame played the intended function perfectly, but the test also indicated that the large flexural demand occurred on the typical beam-column-brace connection that caused the failure of $\mathrm{BRB}$ connection segments. In the test, in addition to the axial force, the buckling-restrained braces in the BRBCF were also affected by the bending moment, which led to the out-of-plane buckling of BRB bolt splices connection and significant decrease of bearing capacity and stiffness of the frame system. According to the failure modes of BRBCF, the reasons of joint failure were analyzed, and the design suggestions of improving the stability performance of BRB unrestrained connection segments were proposed.
ART I CLE H I S T O RY

$\begin{array}{ll}\text { Received: } & \text { 4 June } 2020 \\ \text { Revised: } & \text { 6 February } 2021 \\ \text { Accepted: } & \text { 6 February } 2021\end{array}$

\section{K E Y W O R D S}

Buckling-restrained brace;

Hysteretic behaviour;

Stability performance

Maximum ductility;

Energy dissipation;

Composite frame

\section{Introduction}

The Buckling restrained brace (BRB) resists the axial force with a full tension or compression yielding capacity without the local or global flexural buckling failure. The BRB exhibits nearly identical properties in tension and compression, which has the ability to undergo numerous cycles of inelastic deformations without strength and stiffness degradation or fracture. As a part of buckling- restrained braced frames (BRBFs), BRBs are usually installed concentrically in the frames, and provide evidently good seismic performance as braced frame systems. The superior performance of BRBFs results from the robust cyclic behavior exhibited by BRBs with significant stiffness, energy dissipation capacity and ductility. The frames installed with BRBs have been used widely in building constructions in the real world, such as U.S. Salt Lake City state building, Japan Toyota Stadium and China Tianjin 101 building.

Aiken et al. [1] conducted three cyclic tests on a 0.7 -scale one-bay one-story BRBF. The columns exhibited flexural and shear yielding, and the gusset plates, beam-column-brace connections, column, beam initiate cracks. Iwata et al [2-3] evaluated the performance of a ten-story dual system combining MRFs and BRBFs through time-history analyses. The response of BRB separated from the global system during time-history analyses was evaluated on the basis of the $\mathrm{BRB}$ performance criteria with respect to the maximum and cumulative ductility capacities. This fracture led to large torsional rotations of the beam and out-ofplane deformation of the BRB. Two big-scale BRBFs tested by Tsai et al. [4], which developed distortion in BRB gussets at story of $0.01 \mathrm{rad}$, and the instability was attributed to the long brace-gusset plate connection Regions. Christopulos [5] tested five full-scale one-bay one-story BRBFs under cyclic displacement histories. The BRB gusset connections were bolted and the connections of beams and columns were via of single-plate shear tabs. BRB failure was typically preceded by yielding and buckling of the gusset plates at the beam-column joints. Roeder et al. [6] tested five full-scale one-story onebay BRBFs. The effects of gusset plate geometry, type of bolted brace-gusset plate connections were investigated, and the variations between test specimens had minimal influence on performance. Four of the five BRBFs failed due to out-of-plane deformation of the BRB at 0.022 to $0.024 \mathrm{rad}$ story drift. Chou and Liou et al. [7, 8] proposed a new BRB that the dual gusset plates sandwiching an inner core to reduce gusset plate size and eliminate the need for splice plates, and the connection stability under compression was enhanced. Use of dual corner gusset plate can eliminate buckling of single-angle gusset plate without free edge. The large-scale shaking table simulation test method was used to perform stability tests on the single-bay and single-story steel frames, and the out-of-plane stability of steel frames under the chevron arrangement of BRBs was studied. When the force of the steel core is less than its yield strength, the BRBs with a flexible section at each end of the steel core will fail due to out-of- plane buckling. Tsuyoshi Hikino et al. [9] proposed a simple stability model that predicted the mechanism of BRBs. In this study of Chuang [10], 581 BRBF design examples were studied, and the effectiveness of the proposed design procedures to meet all design requirements was analyzed. It was found that the most critical limit states for an initial design are joint region buckling, gusset plate buckling, gusset-to-beam and gusset-to-column interface strength. Recommendations on initial selections including the BRB joint size and gusset plate thickness were given. Four BRB end deformation modes for quick determination of end rotational demand were proposed for non-moment BRBF, and key factors affecting BRB end rotation and flexural moments were examined theoretically by parametric analysis by Zhao et al. [11, 12]. Zhao et al. [13] found that the triggering moment induced by rigid-body rotation of BRB ends and the amplified moment resulted from bending and semi-rigid effects of the connections were responsible for premature in-plane buckling of the BRB end connections, and an equivalent rigidity concept was proposed to combine the contributions of both flexural and rotational rigidities of the entire connection. Because the BRBs have a higher ductility coefficient, Jamkhaneh et al. [14] found that the structural response modification coefficients of steel frame with the regular cross convergent BRBs were 44 and $41 \%$ bigger than those of the frame system. The effects of diagonal angles of BRBs on the structural seismic performance characteristics were evaluated by Sadeghi et al. [15]. BRBs can be used to partially replace the diagonal elements and improve the seismic performance of diagrid structures by efficiently accumulating the plastic damages in BRBs.

Although the afore-mentioned studies have been conducted, there are still some problems under research, especially the joint of concrete filled steel tube column, steel beams and buckling-restrained brace is complicated, the failure mode and mechanics properties of which should be studied.

In this paper, the boundary members of the structure are mainly concentrated on concrete-filled steel tubular columns and steel beams, and the energy dissipation capacity, hysteretic behavior, bearing capacity, maximum ductility and failure mode were investigated on BRBCF system. This paper describes the details of the design procedure and the results of the BRBCF using the bolted BRB gusset connection from quasi-static cyclic testing. The failure modes of BRBCF on system-level were researched. The out-of-plane buckling of unrestrained connection segments of buckling-restrained braces were investigated and the effect on structural performance was studied. The behavior and failure mode of the BRBCF joints were fully investigated. The reasons of joint failure were analyzed, some suggestions for improving the connection performance were proposed. Compared with composite frame system, the research indicated that the performance of BRBCF system increased evidently due to the contribution of the BRBs. 


\section{Design and fabrication of test specimens}

BRB's load-carrying core elements is divided into a restrained yielding part, two restrained non-yielding parts and two unrestrained non-yielding parts, as shown in Fig. 1. We welded two steel plates at both ends of the inner core on both sides of the original steel plate, so changed the cross section to crisscross section. The end enlarged section can provide space for connection and extra flexural rigidity for buckling strength. To ensure the first yielding and full development of energy dissipation capacity of the restrained yielding part, the elastic tension and compression strength of unyielding segment were 2.54 times of the ultimate strength of yielding part, because the cross section area of unyielding segment were 3.12 times of yielding part, while the yielding strength of inner core steel is 0.814 times of the ultimate strength. Four stories of plastic film $(0.2 \mathrm{~mm}$ in thickness) were adopted as unbounding material between steel inner core and concrete. We precisely positioned the load-bearing component in the center of the steel tubes, welded a seal plate at one end of the steel tube, and then casted the concrete into a steel tubes, as shown in Fig. 2. After the concrete is cured, another seal plate was welded on the other end of the steel tube.
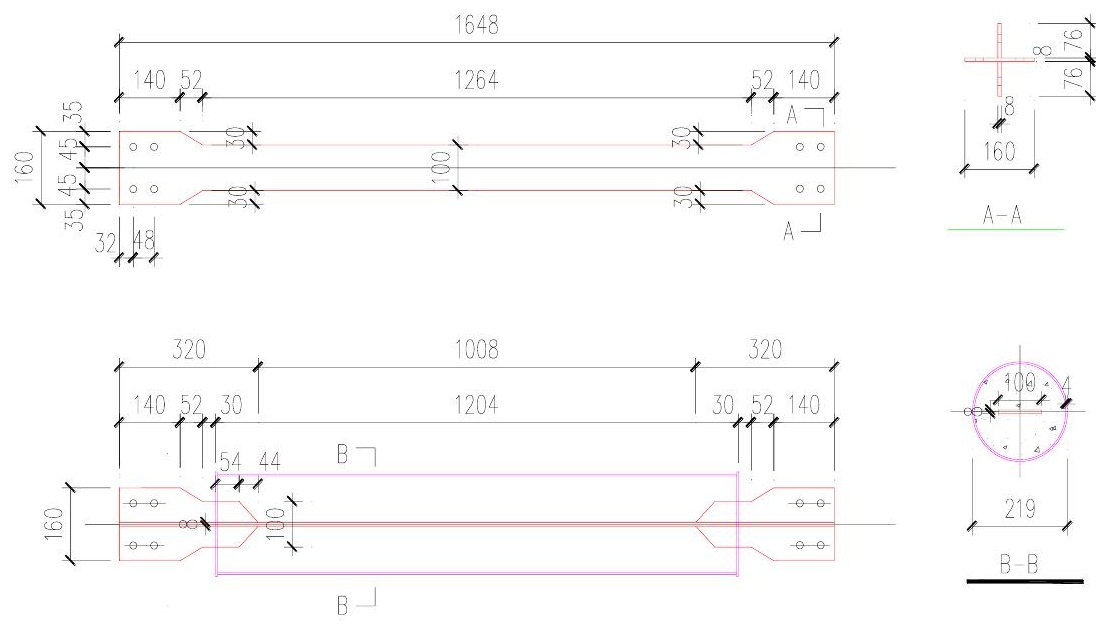

Fig. 1 Dimensions of BRB specimens

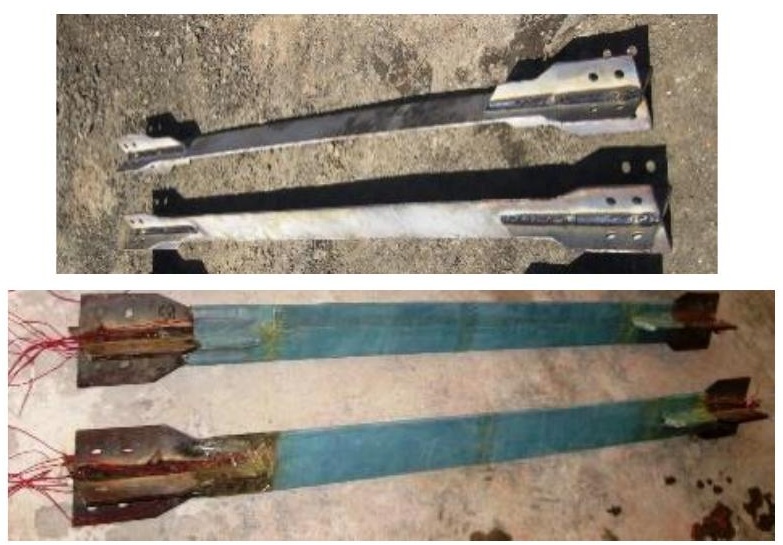

(a) The inner cores of BRBs

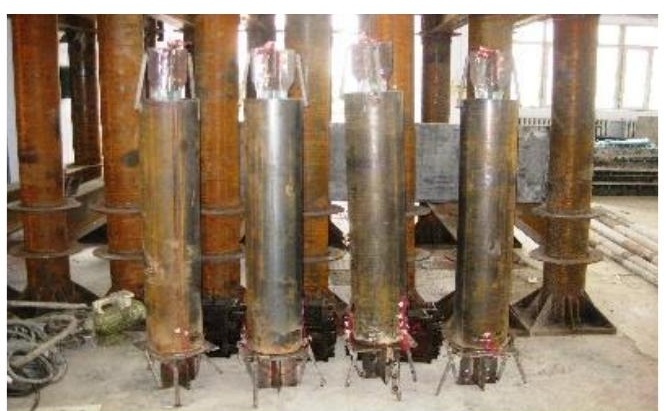

(b) The BRB specimens

Fig. 2 Fabrication process of BRB specimens

The specimen frame consisted of concrete-filled circular hollow section (CHS) steel columns and steel beams, and the composite moment frame was installed with BRBs. In this study, a one-bay, two-and-half- story specimen was designed acting as a lateral load-bearing system. The prototype structure of test specimen was used as the middle two floor sub-assemblies of a building, and the structure was designed with Chinese codes including Chinese code for seismic design of buildings (GB50011-2010) [16], Chinese code for design of steelconcrete composite structure (DL/T5085-1999) [17], Chinese code for design of steel structure (GB50017-2003) [18]. The buckling-restrained braces were designed with checking of global and local stability performance [19]. The 1/2 scaled story height was $1500 \mathrm{~mm}$, and the scaled span length was $2000 \mathrm{~mm}$, as shown in Fig. 3. The dimension of circular steel tubes was $219 \mathrm{~mm} \times 4 \mathrm{~mm}$ (Diameter $x$ steel tube wall thickness). The dimensions of middle beam, top and bottom beams were $H 194 \times 150 \times 6 \times 9(\mathrm{~mm}$, web height $\times$ flange width $\times$ web thickness $\times$ flange thickness), $\mathrm{H} 300 \times 150 \times 6.5 \times 9(\mathrm{~mm}$, web height $\times$ flange width $\times$ web thickness $\times$ flange thickness). The rectangular cross-sectional area of the inner core of BRB was $100 \mathrm{~mm} \times 8 \mathrm{~mm}$ (width $\times$ thickness). The specimen had a half story at the bottom, and the height of it was $600 \mathrm{~mm}$. The construction of half story was used to adapt the position of test specimen to suit the load actuators on the reaction wall. The specimen was connected to the rigid base beam by bolts and stiffeners capable of transmitting plastic moments, and then the rigid base beam was pretensioned to the strong floor according to the uplift check of the specimen during testing. Chinese Q235B steel was adopted with nominal yielding stress of $235 \mathrm{MPa}$, elastic modulus $E_{s}=2.0 \times 10^{5} \mathrm{~N} / \mathrm{mm}^{2}$, poisson ratio $v=0.287$. Test characteristics of steel such as the yielding strength $f_{y}$, ultimate tensile strength $f_{u}$, the ratio $\gamma$ of ultimate tensile strength and the yielding strength, ultimate strain $\varepsilon_{\max }$ are listed in Table 1 . The test compressive stress of filled C30 concrete is $28.92 \mathrm{MPa}$. 

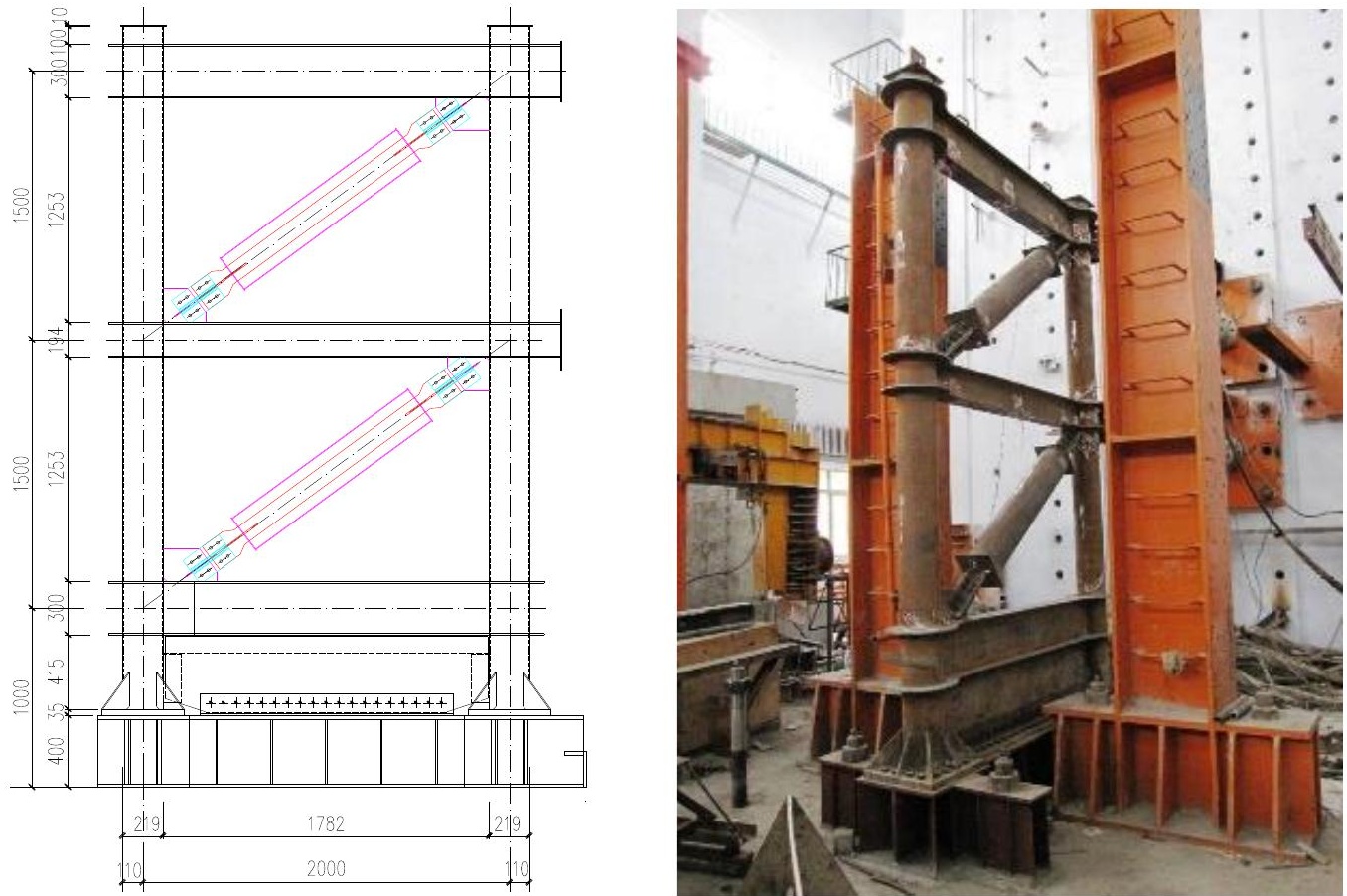

Fig. 3 The BRBCF specimen

Table 1

Characteristics of steel

\begin{tabular}{cccc}
\hline & Stell inner core & Outer circle steel tubes & H steel \\
\hline$f_{y}\left(\mathrm{~N} / \mathrm{mm}^{2}\right)$ & 263 & 298 & 261 \\
$f_{u}\left(\mathrm{~N} / \mathrm{mm}^{2}\right)$ & 379 & 366 & 413 \\
$\gamma$ & 1.44 & 1.23 & 1.58 \\
$\varepsilon_{\max }$ & $25 \%$ & $31.7 \%$ & $26.94 \%$
\end{tabular}

The joints of BRBCF are always in the complicated stress conditions under moment, shear and torsion combination actions. When the ultimate load-bearing capacity of joints were reached, the joints would buckle and fracture. The failure of the joints of BRBCF will result the collapse of structure, and the casualties are unavoidable. So the design and construction of joints are very important for structural performance and personnel safety. The moment connections were adopted in the composite frame, the composite column and steel beam were connected with the enforced loops. The internal diaphragms of enforced loops have are shown in Fig. 4, and the thickness of enforced loops is as same as beam flange thickness, the enforced loops can transfer the stress of beam flanges uniformly to the columns. So the failure of connections can be avoided effectively based on the above joint configuration.

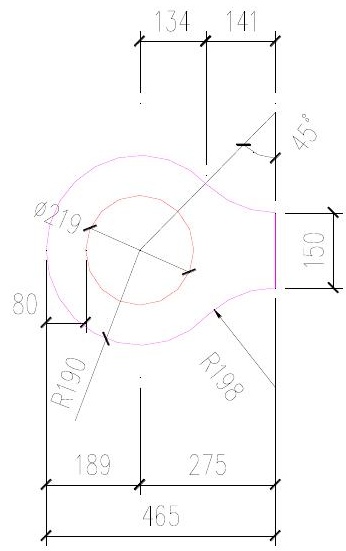

(a) The left side

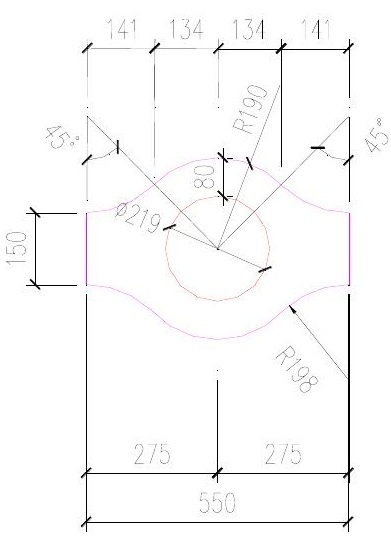

(b) The right side
Fig. 4 The internal diaphragms of the enforced loops
As shown in Fig. 5, one BRB was installed diagonally in one story, and each BRB end gusset connection employed 8 unconstrained splice plates and $16 \mathrm{~mm}$ diameter M16 bolts. Typical BRB gusset plates located at the beamcolumn joints, and the centrelines of column, beam and the BRB intersected at the same point.
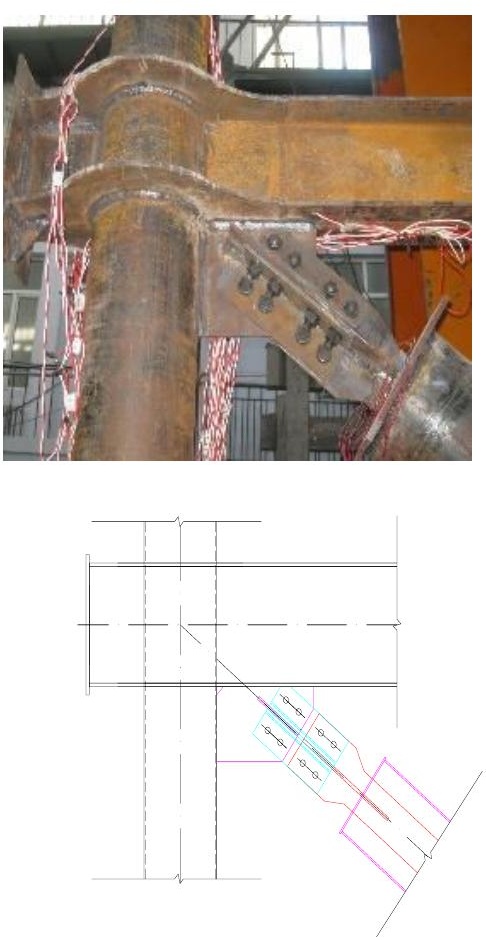

Fig. 5 The details of the frame joint and BRB connection

There are three reaction points and one load point (two column bases and one ground-level link) used as four in-plane attachments for the test planar frame structure, and the experimental setup is shown in Fig. 6. 

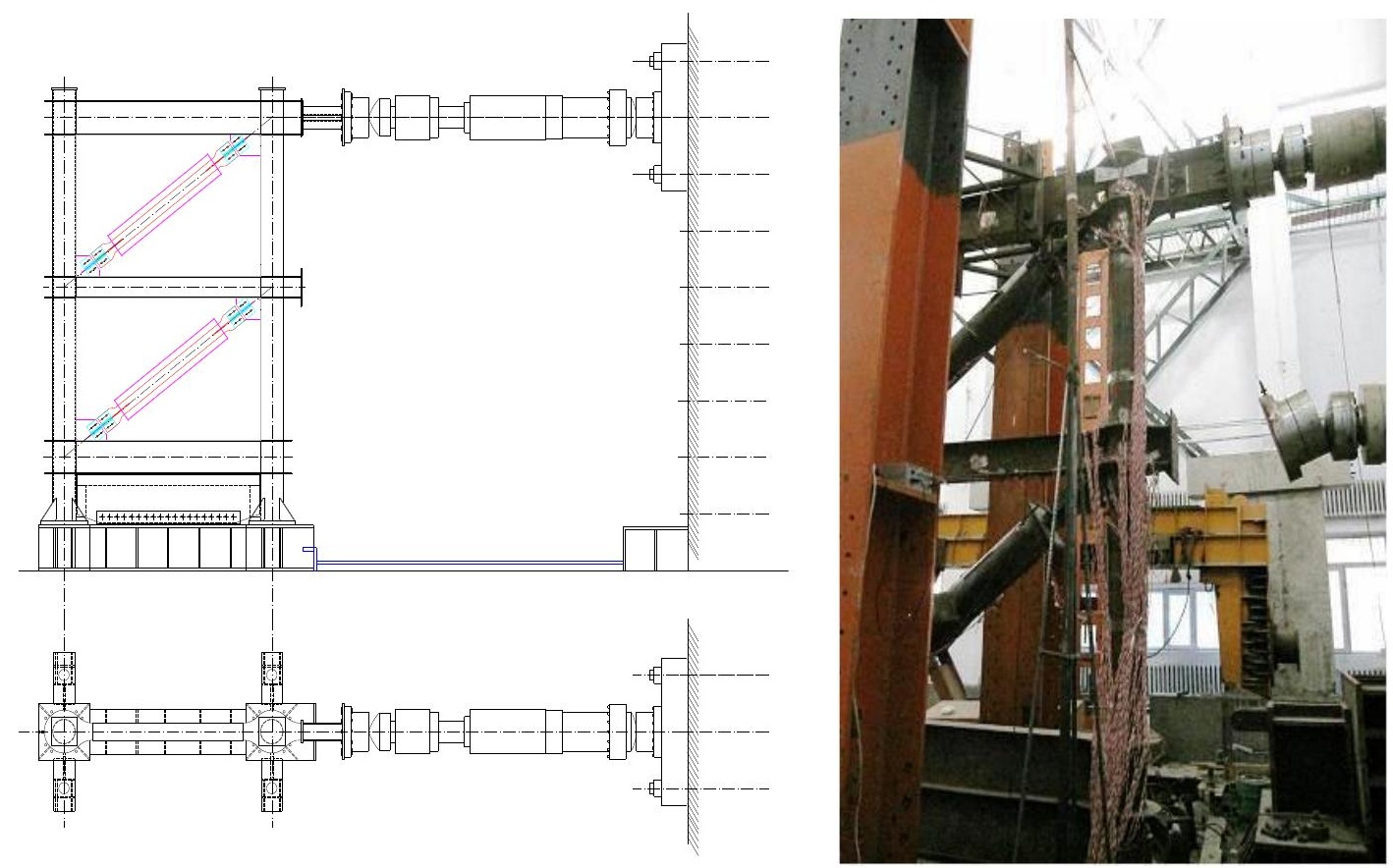

Fig. 6 The experimental setup of BRBCF

The ground-level link was anchored at the reaction wall, and the rigid base beam was fixed on the rigid floor to prevent the overturn of test specimen. One electro-hydraulic servo actuator was attached to the reaction wall, and the electro-hydraulic servo actuator was employed to apply in-plane loading on the specimen at the top story. The actuator with individual loading capacity of $630 \mathrm{kN}$ applied the loads through loading beam to the top beam midpoints of test frame. The applied actuator force was measured by the load cell. The top beam was restrained with dual lateral bracing frames, which were used to avoid outof-plane buckling of the specimen frame, and almost no planar resistance was provided by four rollers.

Strain gauges were stuck on vital positions of beams, columns and the inner core of BRBs. Linear Variable Displacement Transducers (LVDTs) were used to measure the absolute horizontal displacement of each story and the relative displacement between the column base and the strong floor. Through the LVDTs at the top beam we could measure the out-of-plane deformation of the entire frame. The loading scheme in Chinese specification of testing methods for earthquake resistant building (JGJ 101-2015) [15] was adopted. Firstly, the incremental elastic load was $50 \mathrm{kN}$ from $0 \mathrm{kN}$, and each load amplitude was applied as a load cycle. In the plastic range, the increasing frame roof displacements were taken as control quantity, which were integral multiples of $10 \mathrm{~mm}$, and three cycles of the same displacement amplitude were applied for the test frame at each load amplitude.

\section{Experimental phenomena}

As shown in Fig. 7, circle points are used to indicate the yielding locations of components, the yielding sequence numbers are also presented in Fig. 7. The frame remained elastic within the range of lateral load of $200 \mathrm{kN}$. At this stage, the load increased linearly with the increment of story drift. At the lateral load of $250 \mathrm{kN}$, the principal strain indicated that the BRB cores began to yield, while the main frame remained resilient. During the cycles of sequence at approximately $1 / 300$ frame roof drift (10mm roof displacement), due to the yielding of BRBs at 1,2 points, the stiffness of BRBF began to decrease. Note that the BRB was connected to the beam flange. At the top drift of $1 / 150(20 \mathrm{~mm}$ roof displacement), 3, 4 points at the middle beam flange yielded near the beamcolumn-brace connection. At the loading cycles of approximate 1/100 frame roof drift ( $30 \mathrm{~mm}$ roof displacement), 5, 6 points opposite to 3,4 points yielded at the middle beam's flange. When the top story displacement was $40 \mathrm{~mm}$, the 7,8 points of the beam web yielded, and plastic hinges were formed at both ends of the web beam. At the top story drift of $1 / 50$ (about $60 \mathrm{~mm}$ roof displacement), flexural and shear yielding occurred on the columns, 9, 10 points at the column bases of the first story began to yield. The frame action force was resulted from the BRB axial force on the frame, which had an influence on the yielding of the beam-column-brace connection regions. 11, 12 points at the column base and 13,14 points at the column top yielded sequentially, especially close to the enforced loop regions. BRBs and main frame yielded in proper order, and BRBs acted as the structural fuse and yielded before the main frame.

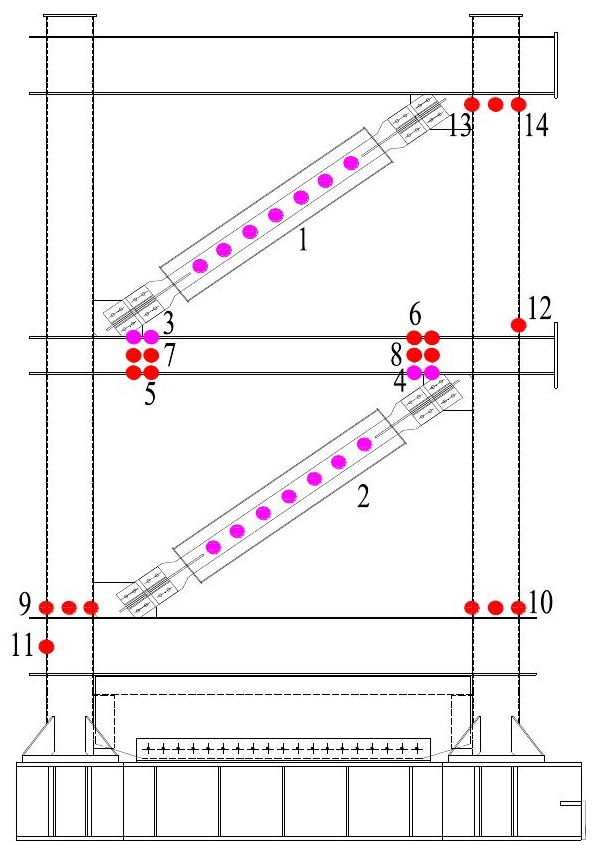

Fig. 7 Yielding locations and sequence

As shown in Fig. 8, the unrestrained connection segments of BRBs buckled at the approximate frame roof displacement of $60 \mathrm{~mm}$, which resulted the large out-of-plane rotational deformation of the unrestrained connection segments of BRBs in two stories, but the rotational direction is opposite. Therefore, the bearing capacity and stiffness of BRBCF are significantly reduced, so the test is completed at this load level.

The BRBCF specimens showed good ductility, and there was evident plastic deformation development on BRBs, beams and columns. The BRBs, acting as fuses, yielded at a fairly low drift of $1 / 300$, and dissipated almost all energy before the frame yielded. The requirement that BRBs should begin to yield at less than $1 \%$ drift was indeed satisfied. So the main frame was protected due to the plastic deformation and energy dissipation of BRBs, and beams and columns yielded and absorbed energy only in the subsequent larger displacement stage. 


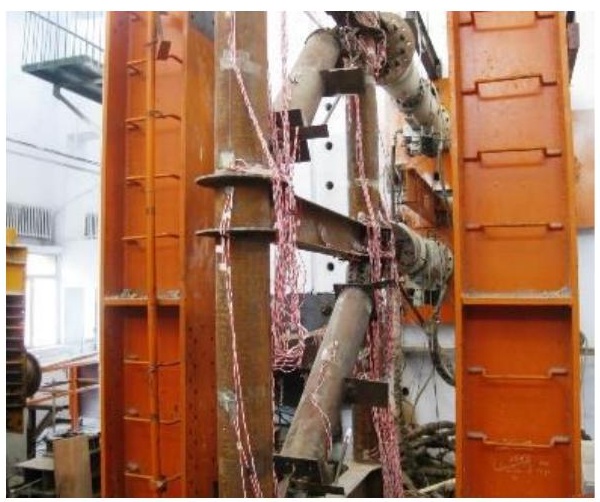

(a) Buckling of BRBs in two stories

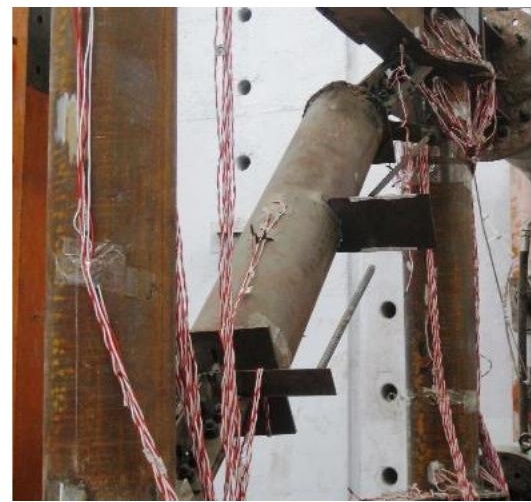

(b) Buckling of BRB

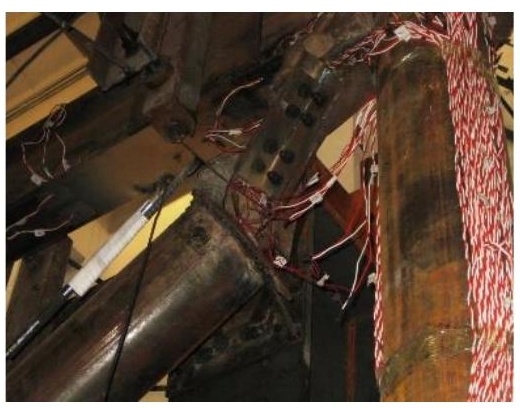

(c) Buckling of unrestrained connection

Fig. 8 Buckling of unrestrained connection segment of BRBs, (a), (b), (c) segment

After the test, BRBs were removed from the frame, steel tubes were stripped from BRBs. Due to the buckling and rotation of the unrestrained connection segments of BRBs, the concrete were crushed and cracked at the buckling position. As shown in Fig. 9, the length of restrained unyielding segment is not enough, the junction of restrained unyielding segment and restrained yielding segment became a central point of rotation, and the concrete suffered further crush due to the buckling of unrestrained connection segment.

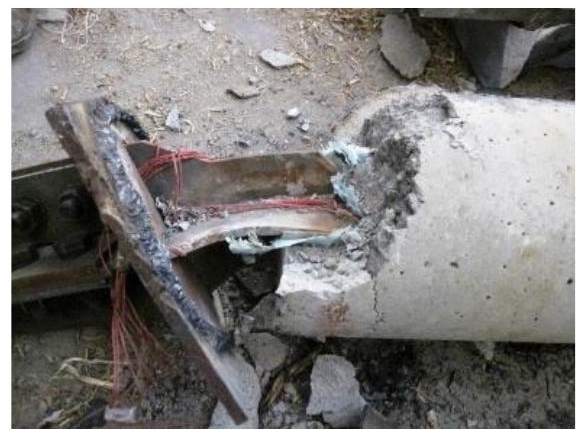

(a) Buckling of unrestrained connection segment and cracked concrete

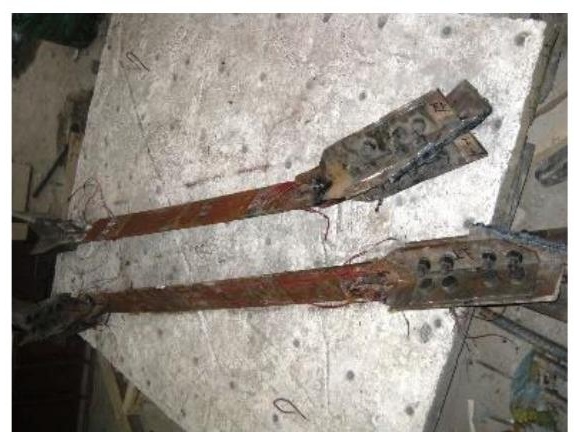

(b) Buckling of inner core of BRBs after disassemble

Fig. 9 Situations of concrete and inner cores of BRBs

Out-of-plane buckling may occur at the angle between the column and the beam during the beam-to-column joint "closes" due to frame sway, causing an out-of-plane moment on the BRB and the BRB connection. Although the system met the performance objectives for the design seismic demands, However, test also confirmed that the maximum ductility and cumulative plastic deformation (CPD) capacity of the BRBs adopted in the BRBCF was lower than that found in typical component test, and the drift levels achieved during the test were relatively small, albeit large enough to cause BRB yielding.

The large plastic deformation occurred at the inner core of $\mathrm{BRB}$, if the global stiffness of BRB is not large enough, BRB may buckle as a whole, or only buckle at the unrestrained connection segment due to relatively small stiffness compared to restrained segment. The root of unrestrained connection segment is a section of least area and least stiffness. Under axis compression and additive moment, if the stiffness of BRB connection joint is not enough, the outermost fiber of the root of unstrained segment yields firstly, and the unrestrained connection segment begins to buckle and rotates at the junction of unrestrained segment and restrained segment.

The performed test suggests that the reduction in the BRB maximum ductility and CPD capacities observed in this $1 / 3$ scale frame specimen could be due to the significant rotational demands imposed on the BRB unrestrained connection segments. The moment was amplified because the flexure of BRB end parts and became prominent especially for small flexural rigidity of BRB unrestrained connection segments. It shows that BRB end rotation subjected BRB unrestrained connection segments to large flexural moments, leading to premature yielding or even buckling tendency of BRB unrestrained connection segments. It is necessary to evaluate the stability of the BRB unrestrained connection segments as a separated segment. If the stability can't be satisfied, the stiffeners should be welded on the gusset plate edges in the direction perpendicular to the steel plate, and the cross section of unrestrained connection segment should be strengthened or connection collar can be added to BRB unrestrained connection segment for improving the load bearing and deformation capacity of gusset connections.

\section{Hysteretic curves and backbone curves}

The LVDT at top, middle and bottom beam indicated the displacements of specific location. The frame roof displacement, the second story and the first story displacement can be obtained via of the relationship of the displacements of different location, and the story drift can be calculated with the equation that the story displacement divided by the height of each story. The hysteretic curve of the base shear force versus the displacement of the roof is shown in Fig. 10. (a). Elastic behavior of specimen was displayed with a small hysteretic area in the first two cycles although there was some friction in the system. The story shear-displacement plots are presented in Fig. 10(c), (e), and Fig. 10(b), (d), (f) also presented the tri-linear backbone curves of overall structure and the separate stories within nearly $1 / 50$ drift. 


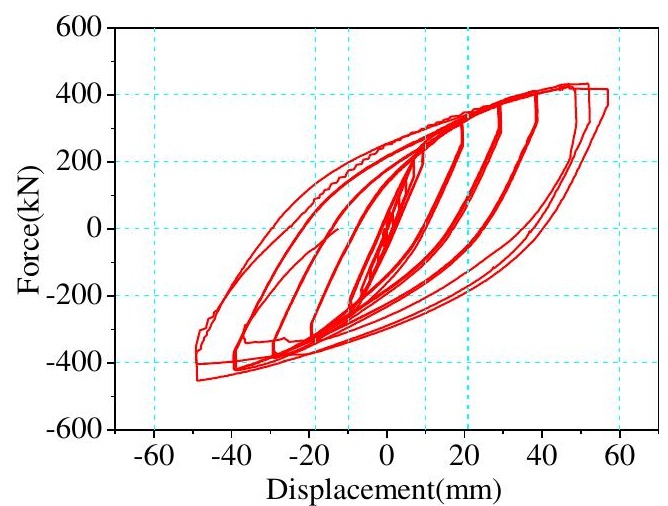

(a) Hysteretic curves of BRBCF

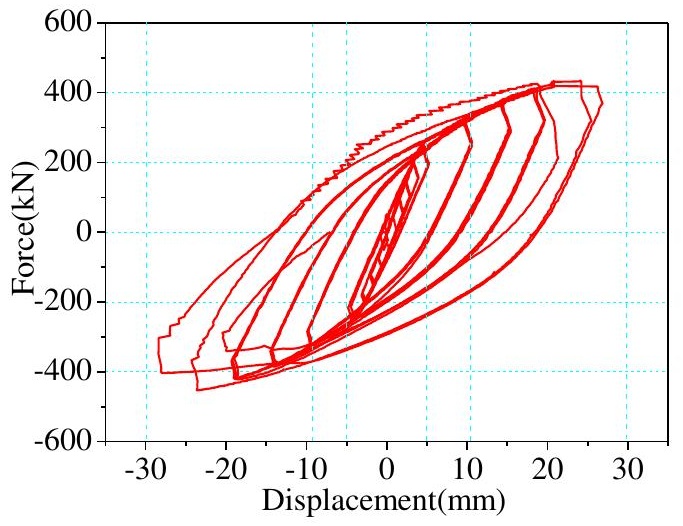

(c) Hysteretic curves of the first story

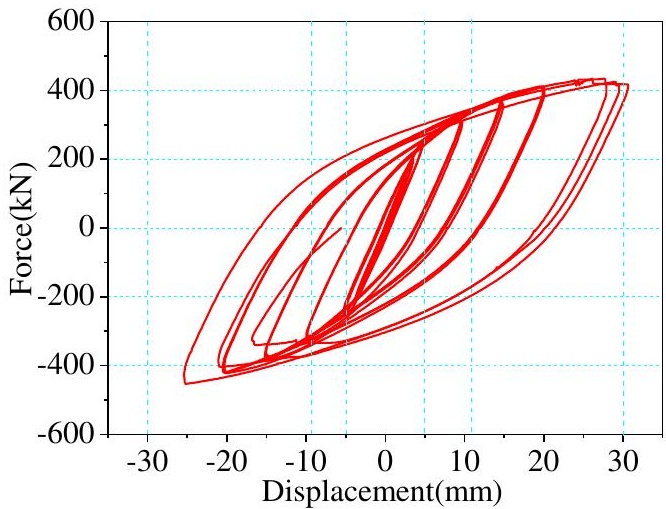

(e) Hysteretic curves of the second story

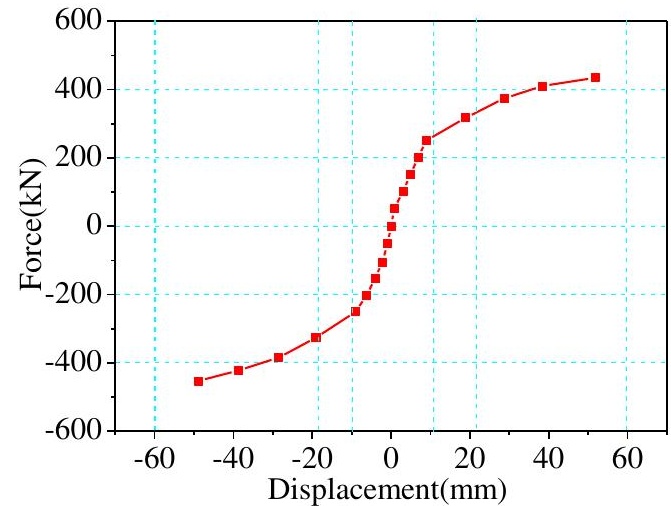

(b) Back-bone curve of BRBCF

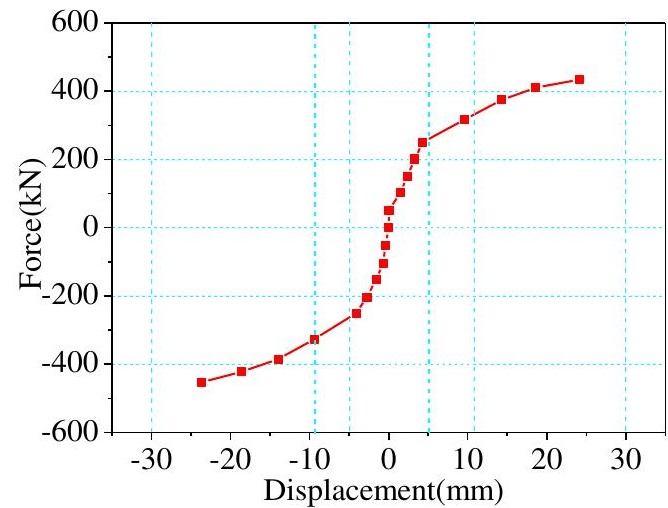

(d) Back-bone curve of the first story

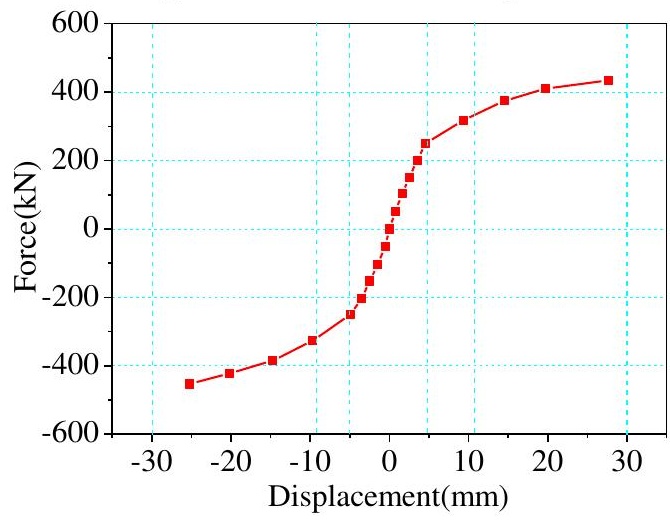

(f) Back-bone curve of the second story

Fig. 10 Force-Displacement hysteretic curves and back-bone curves

An electro-hydraulic servo actuator was attached to the reaction wall to apply an in-plane load to the specimen at the top story, so the lateral shear forces of two stories are the same as the applied actuator force. Two stories exhibited similar stiffness and sustained alike lateral shear force at the approximately same displacement amplitude. The BRBCF exhibited symmetrical mechanical behavior, except slightly larger stiffness and strength in compression stage relative to tension stiffness and strength, which was the result of the confinement effect of the lateral restraining mechanics to inner cores of BRBs and the friction between inner core and lateral restraining mechanics of BRBs. The positive and negative yielding displacements of BRBCF are $21.56 \mathrm{~mm}$ and $18.53 \mathrm{~mm}$, and the positive and negative yielding forces are $332 \mathrm{kN}$ and $323 \mathrm{kN}$. The maximum drift of BRBCF is close to $1 / 50$, ultimate positive and negative forces of BRBCF are $434 \mathrm{kN}$ and $453 \mathrm{kN}$. Although the buckling occurred on the BRB unrestrained connection segment, the stiffness of the BRBCF did not decrease significantly.

The energy dissipation coefficient $h_{e}$ can be calculated based on the hysteretic curves, which is equal to the sum of area $S_{\mathrm{ABC}}$ and $S_{\mathrm{CDA}}$ divided by the sum of area $S_{\mathrm{OBE}}$ and $S_{\mathrm{ODF}}$, and then divided by $2 \pi$, as shown in Fig. 11 and Equation 1.

$h_{e}=\frac{1}{2 \pi} \frac{S_{\mathrm{ABC}}+S_{\mathrm{CDA}}}{S_{\mathrm{OBE}}+S_{\mathrm{ODF}}}$

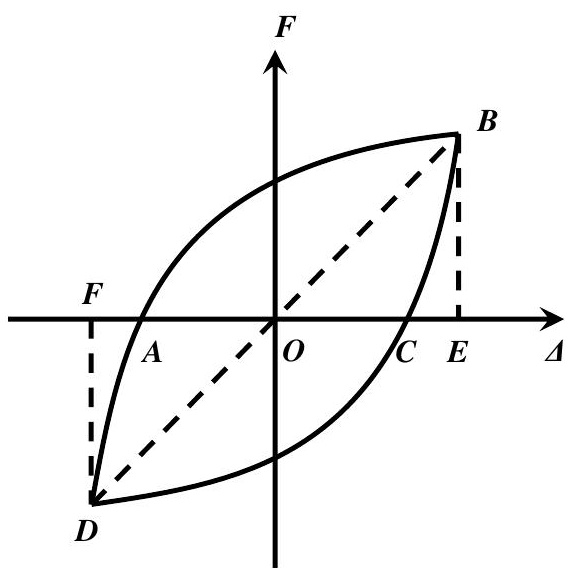

Fig. 11 Calculation of energy dissipation coefficient

Fig. 12 (a) shows the relationship of the area of hysteretic curves versus frame roof displacement, and Fig. 12 (b) showed the relationship between energy dissipation coefficient and frame roof displacement. The area of the 
hysteresis curve is the energy dissipated by the BRBCF, while the energy dissipation coefficient is used to evaluate the energy consumption capacity. As the plastic displacement of frame roof increases, structural energy dissipation

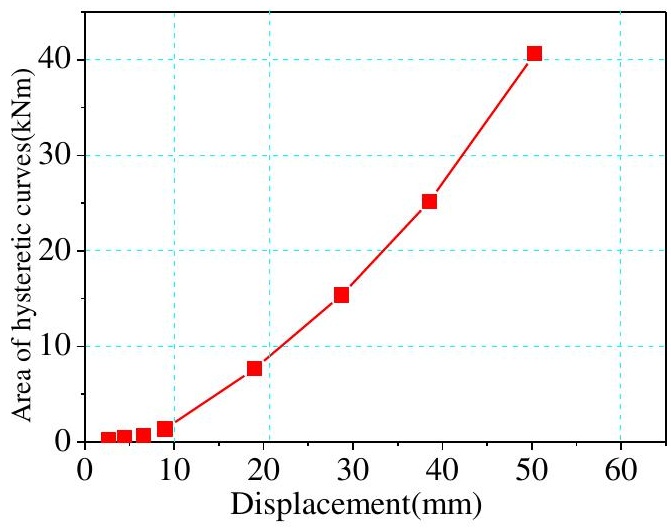

(a) The relationship of area of hysteretic curves and frame roof displacement capacity and energy dissipation coefficient increase, and the final energy dissipation coefficient reaches 0.885 , indicating that $\mathrm{BRBCF}$ has good hysteretic performance and energy dissipation capacity.

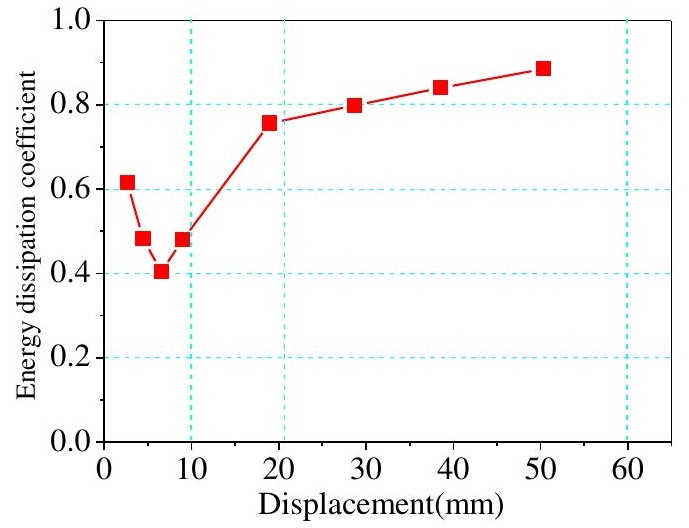

(b) The relationship of energy dissipation coefficient and frame roof displacement

Fig. 12 The energy dissipation capacity of BRBCF

\section{Comparison with experimental results of composite frame}

Comparative testing using the outer composite framework (CF) of BRBCF was conducted, and the components, joints and boundary conditions of both structures were the same. The hysteretic curve of the base shear force with the roof displacement of the CF frame and the corresponding backbone curve are shown in Fig. 13. When the displacement amplitude increased to $60 \mathrm{~mm}, \mathrm{CF}$ showed a decrease in strength and stiffness.

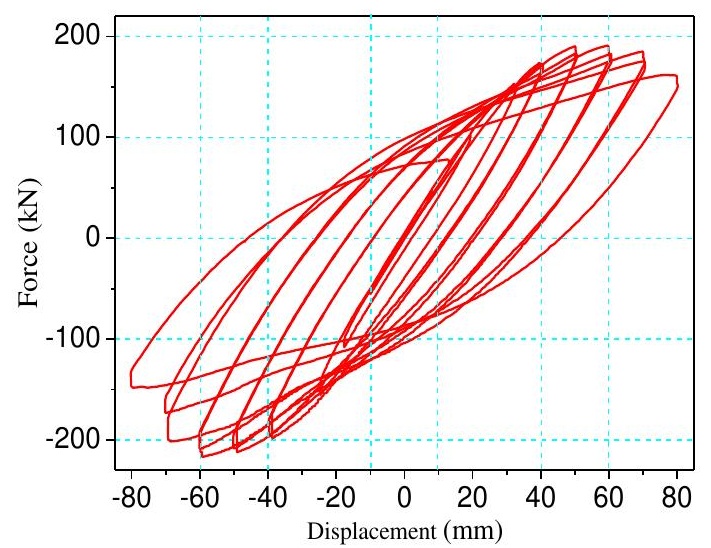

(a) Hysteretic curve

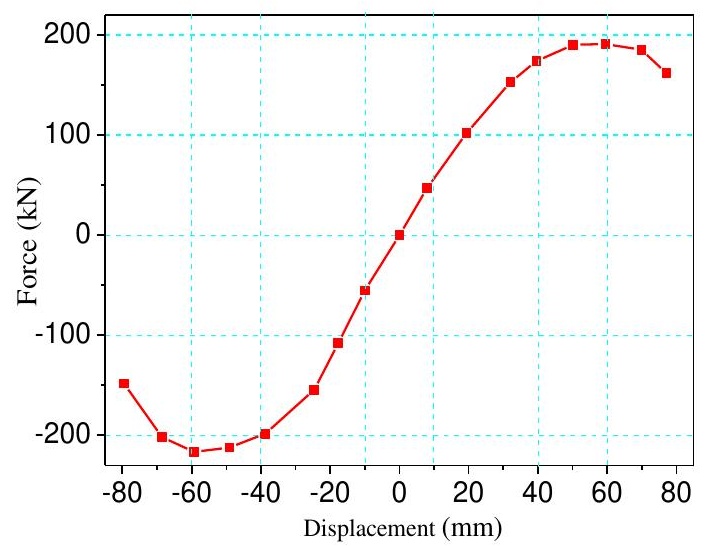

(b) Back-bone curve

Fig. 13 Hysteretic curves and back-bone curves of $\mathrm{CF}$

The backbone curves and tangent stiffness of BRBCF and CF were compared. Fig. 14 shows the backbone curves of two structures, which indicates the stiffness and load bearing capacity of BRBCF are larger than those of CF.
As shown in Fig. 15, BRBCF's tangent stiffness is 4.5 times of that of CF, and the stiffness of BRBCF after structural yielding is also larger than that of $\mathrm{CF}$ respectively. The curve shows that before the BRB buckling, the stiffness of the BRBCF did not decrease during the plastic development of the components. CF showed a decrease in strength and stiffness when displacement amplitude increased to $60 \mathrm{~mm}$, which also indicated good ductility of CF. With the help of $\mathrm{BRB}$, the lateral bearing capacity and stiffness of the CF have been significantly improved.

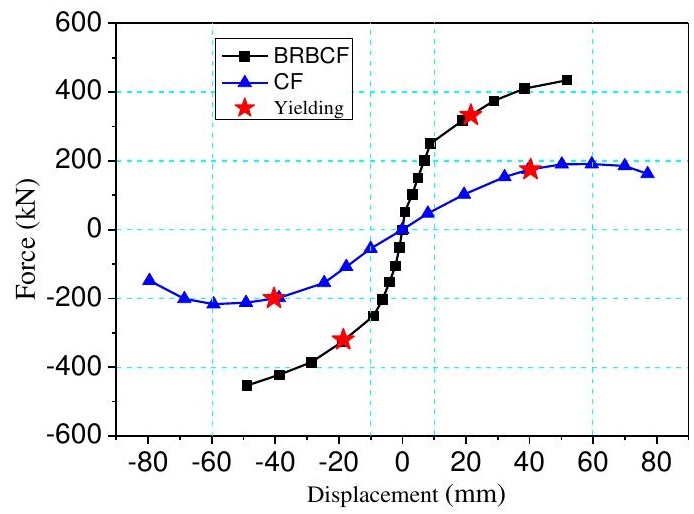

Fig. 14 Comparison of backbone curves

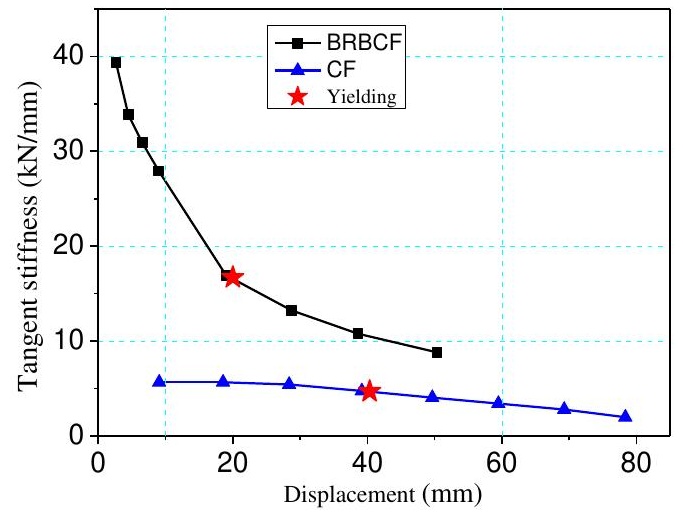

Fig. 15 Comparison of secant stiffness

When the lateral stiffness is insufficient to comply with the code drift requirements imposed for moment resisting frame systems in earthquake-prone regions, the frame can be retrofitted with BRBs for larger structural stiffness and smaller structural displacement. Although it could also be noted that the seismic 
demand of BFBCF is also greater than CF due to the larger lateral stiffness of structures, and the larger load bearing capacity should be required for BRBCF to resist the horizontal force and control the lateral displacement. The large lateral stiffness and load bearing capacity of BRBCF will also result in the bigger and fuller hysteretic loops, BRBs are usually used as energy dissipation components in structural system, so the CF retrofitted with BRBs can dissipate more energy and mitigate the damage of main structural components.

As shown in Table 2, the loads of BRBCF at maximum negative and positive displacement are 1.40 times and 1.31 times of yielding load, and the loads of $\mathrm{CF}$ at maximum negative and positive displacement are 1.08 times and 1.09 times of yielding load. The ratios of negative and positive yielding load $V$ of $\mathrm{BRBCF}$ and $\mathrm{CF}$ are 1.61 and 1.90; the ratios of negative and positive maximum load $V_{\max }$ of BRBCF and $\mathrm{CF}$ are 2.09 and 2.27; the ratios of negative and positive ultimate load $V_{u}$ of BRBCF and $\mathrm{CF}$ are 3.06 and 2.68. When the CF frame is equipped with BRBs, the stiffness and load bearing capacity are significantly improved.

Table 2

Comparison of load bearing capacity of BRBCF and CF

\begin{tabular}{|c|c|c|c|c|c|c|c|c|}
\hline \multirow{2}{*}{ Specimens } & \multirow{2}{*}{$\begin{array}{c}\text { Load } \\
\text { Direction }\end{array}$} & \multicolumn{2}{|c|}{$\begin{array}{l}\text { Yielding load and } \\
\text { dispalcement }\end{array}$} & \multicolumn{2}{|c|}{$\begin{array}{l}\text { Maximum load and } \\
\text { dispalcement }\end{array}$} & \multicolumn{2}{|c|}{$\begin{array}{l}\text { Ultimate displacement } \\
\text { and corresponding load }\end{array}$} & \multirow{2}{*}{$V_{\max } / V_{y}$} \\
\hline & & $\begin{array}{r}V_{y} \\
(\mathrm{kN})\end{array}$ & $\begin{array}{c}\Delta_{y} \\
(\mathrm{~mm}) \\
\end{array}$ & $\begin{array}{r}V_{\max } \\
(\mathrm{kN}) \\
\end{array}$ & $\begin{array}{c}\Delta_{\max } \\
(\mathrm{mm}) \\
\end{array}$ & $\begin{array}{r}V_{u} \\
(\mathrm{kN}) \\
\end{array}$ & $\begin{array}{c}\Delta_{u} \\
(\mathrm{~mm})\end{array}$ & \\
\hline \multirow{2}{*}{ BRBCF } & Positive & 332.17 & 21.56 & 434.04 & 51.77 & 434.04 & 51.77 & 1.31 \\
\hline & Negative & -322.84 & -18.53 & -453.39 & -48.87 & -453.39 & -48.87 & 1.40 \\
\hline \multirow{2}{*}{$\mathrm{CF}$} & Positive & 175.02 & 40.37 & 190.97 & 59.58 & 161.87 & 77.13 & 1.09 \\
\hline & Negative & -200.46 & -40.35 & -216.67 & -59.38 & -148.07 & -79.59 & 1.08 \\
\hline \multirow{2}{*}{ Ratio } & Positive & 1.90 & 0.53 & 2.27 & 0.87 & 2.68 & 0.67 & \\
\hline & Negative & 1.61 & 0.46 & 2.09 & 0.82 & 3.06 & 0.61 & \\
\hline
\end{tabular}

The hysteresis loops of the displacement amplitude of 50mm of BRBCF and $\mathrm{CF}$ are selected and compared, as shown in Fig. 16 (a), the hysteretic loop of BRBCF is much bigger than that of CF. The area of hysteretic curves and energy dissipation coefficient of BRBCF are compared to those of CF as shown in Fig. 16 (b) and Fig. 16 (c).

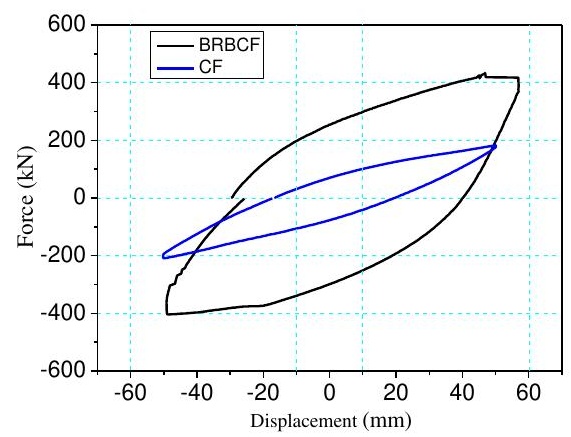

(a) Hysteretic loops of BRBCF and $\mathrm{CF}$ at the roof displacement of $50 \mathrm{~mm}$

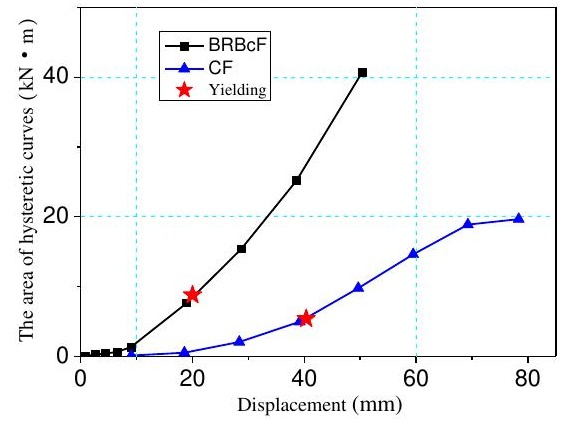

(b) The area of total hysteretic curves

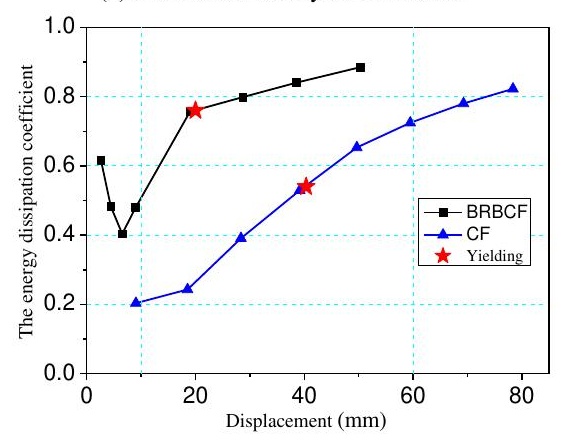

(c) The energy dissipation coefficients

Fig. 16 Comparison of energy dissipation capacity of $\mathrm{BRBCF}$ and $\mathrm{CF}$
Total hysteresis loops area of BRBCF is $40.65 \mathrm{kN} \cdot \mathrm{m}$ that is 2.15 times of that of CF of $18.88 \mathrm{kN} \cdot \mathrm{m}$ at the frame roof displacement of $50 \mathrm{~mm}$. The energy dissipation coefficient of BRBCF is 0.89 that is 1.14 times of that of CF of 0.78 at the frame roof displacement of $50 \mathrm{~mm}$, and the ratio is 2.68 at the frame roof displacement of $20 \mathrm{~mm}$. BRBs play the important role of improving the structural system's energy dissipation capacity.

\section{Summary and conclusions}

The buckling-restrained braced composite frame (BRBCF) system was researched in this paper, which consisted of concrete-filled circular hollow section (CHS) steel columns, steel beams, and BRBs. The quasi-static cyclic test of one 1/3 scale 1-bay 2-story BRBCF was conducted, which was compared with the same outer composite frame. After installed with the BRBs, the lateral stiffness, ultimate load bearing capacity and energy dissipation capability of the composite frame were improved evidently. Under the significant drift requirements of the subsequent quasi-static cycle test, BRBCF showed excellent performance without strength or stiffness degradation, and had good ductility and energy dissipation capacity.

The ratios of yield load, maximum load and ultimate load of BRBCF to CF at positive displacement are 1.9, 2.27 and 2.68, respectively, and they are 1.61, 2.09 and 3.06 at negative displacement, respectively. The stiffness of BRBCF before and after yielding are 4.5 and 2.5 times of those of $\mathrm{CF}$, respectively. The maximum hysteresis loop area of BRBCF is 2.15 times of that of CF. The energy dissipation coefficient of $\mathrm{BRBCF}$ is 2.68 times of that of $\mathrm{CF}$ when the frame roof displacement is $20 \mathrm{~mm}$, and 1.14 times of that of $\mathrm{CF}$ when the frame roof displacement is $50 \mathrm{~mm}$. The stiffness of unrestrained connection segment of BRBs is very important, under axis compression and additive moment, the unstrained segments buckled and rotated at the junction of unrestrained segment and restrained segment.

According to Chinese code, the frame system met the performance objectives for the design seismic demands. The better performance should be achieved on condition that the stability performance of BRB joint was ensured. The test suggests that the reduction in the BRB maximum ductility and energy dissipation capacity observed in this $1 / 3$ scale frame specimen compared to typical BRB component tests could be due to the significant flexural demands imposed on the BRB unrestrained connection segments. It is necessary to evaluate the stability design of the BRB joints and consider the effects of the added stiffeners or connection collar in improving the load bearing and deformation capacity of gusset connections.

\section{Acknowledgements}

The support of Scientific Research Fund of Institute of Engineering Mechanics, China Earthquake Administration (Grant No. 2018D04), National Science Foundation of China through projects (Grant No. 51978220). All the opinions, findings, and conclusions or recommendations expressed in this material are those of the authors and do not necessarily reflect those of the Foundations. 


\section{References}

[1] Aiken I. D., Mahin S. A. and Uriz P., "Large-scale testing of buckling restrained braced frames", Japan Passive Control Symposium, Tokyo Institute of Technology, Yokohama, Japan, 2002.

[2] Iwata M., Kato T. and Wada A., "Buckling-restrained braces as hysteretic dampers", Behavior of Steel Structures in Seismic Areas, 33-38, 2000.

[3] Iwata M., Kato T. and Wada A., "Performance evaluation of buckling-restrained braces in damage- controlled structures", STESSA 2003-Behaviour of Steel Structures in Seismic Areas. Routledge, 37-43, 2003.

[4] Tsai K. C., Hsiao P. C., et al., "Pseudo-dynamic test of a full-scale CFT/BRB frame-part ii: seismic performance of buckling-restrained braces and connections", Earthquake Engineering and Structural Dynamics, 37, 1099-1115, 2008.

[5] Christopulos A. S., "Improved seismic performance of BRBFs", M.S. thesis of University of Washington, Seattle, USA, 2005.

[6] Roeder C. W., Lehman D. E. and Christopulos A, "Seismic performance of special concentrically braced frames with buckling restrained braces", 8th U.S. National Conference on Earthquake Engineering, Earthquake Engineering Research Institute, Oakland, California, USA, Paper No. 1503, 2006

[7] Chou C. C., Liou G. S. and Yu J. C., "Compressive behavior of dual-gusset-plate connections for buckling- restrained braced frames", Journal of Constructional Steel Research, 76, 54-67, 2012

[8] Chou C. C., Liu J. H. and Pham D. H., "Steel buckling-restrained braced frames with single and dual corner gusset connections: seismic tests and analyses", Earthquake Engineering and Structural Dynamics, 41, 1137-1156, 2012.

[9] Tsuyoshi H., Taichiro O., Kouichi K. and Masayoshi N., "Out-of-plane stability of bucklingrestrained braces", ASCE Structures Congress, Orlando, Florida, USA, 939-949, 2010.

[10] Chuang M. C., Tsai, K. C. et al, "Critical limit states in seismic buckling-restrained brace and connection designs”, Earthquake Engineering and Structural Dynamics, 44, 1559-1579, 2015.
[11] Zhao J. X., Lin F. X. and Wang Z., "Effect of non-moment braced frame seismic deformations on buckling-restrained brace end connection behavior: Theoretical analysis an subassemblage tests", Earthquake engineering and structural dynamics, 45, 359-381, 2016.

[12] Zhao J. X., Chen R. B., Wang Z. and Pan Y. "Sliding corner gusset connections for improved buckling-restrained braced steel frame seismic performance: Subassemblage tests", Engineering Structures, 172, 644-662, 2018

[13] Zhao J. X., Lin F. X. and Wang Z., "Seismic design of buckling-restrained brace welded end connection considering frame action effects: Theoretical, numerical and practical approaches", Engineering Structures, 132, 761-777, 2017.

[14] Jamkhaneh M. E., Ebrahimi A. H. and Amiri M. S., "Seismic Performance of Steel-Braced Frames with an All-Steel Buckling Restrained Brace", Practice periodical on structural design and construction, 23, 3, 04018016.1-16, 2018.

[15] Sadeghi S. and Rofooei F. R., "Improving the seismic performance of diagrid structures using buckling restrained braces" Journal of Constructional Steel Research, 166, 105905, 2020

[16] National Standard of the People's Republic of China, "Code for seismic design of buildings. National Standards of the People's Republic of China (GB50011-2010)" China Architecture $\&$ Building Press, Beijing, China, 2010. (in Chinese)

[17] Industrial Standard of the People's Republic of China, "Code for design of steel-concrete composite structure (DL/T5085-1999)”, China Electric Power Press, Beijing, China, 1999. (in Chinese)

[18] National Standard of the People's Republic of China, "Code for design of steel structure (GB50017-2003)", China Planning Press, Beijing, China, 2003. (in Chinese)

[19] Cameron J. B., et al. "Component Testing, Seismic Evaluation and Characterization of Buckling- Restrained Braces", Journal of structural engineering (ASCE), 130, 6, 880-894, 2004.

[20] Industrial Standards of the People's Republic of China, "Specification of testing methods for earthquake resistant building (JGJ 101-2015)", China Architecture \& Building Press, Beijing, China, 2015. (in Chinese) 


\title{
AXIAL BEHAVIOR OF HIGH-STRENGTH CONCRETE-FILLEDHIGH-STRENGTH SQUARE STEEL TUBULAR STUB COLUMNS
}

\author{
Guo-Chang $\mathrm{Li}^{1}$, Bo-Wen Chen ${ }^{1}$, Zhi-Jian Yang ${ }^{1,}{ }^{*}, \mathrm{Han}-\mathrm{bin}$ Ge ${ }^{2}$ and Xiao Li ${ }^{1}$ \\ ${ }^{1}$ School of Civil Engineering, Shenyang Jianzhu University, Shenyang, China \\ ${ }^{2}$ Department of Civil Engineering, Meijo University, Nagoya, Japan \\ *(Corresponding author: E-mail: faemail@163.com)
}

\section{A B S T RA C T}

To investigate the fundamental behavior of concrete-filled steel tubes (CFSTs) consisting of high-strength materials, this study experimentally explored the axial performance of eight high-strength concrete-filled high-strength square steel tube (HCFHSST) stub columns considering various yield strengths of steel ( $f_{\mathrm{y}}$ from $566.90 \mathrm{MPa}$ to $\left.889.87 \mathrm{MPa}\right)$. Thereafter, the compatibility between the strengths of steel and concrete was discussed. Simulations were also performed to evaluate the structural responses of the column, incorporating the crushing failure and load-carrying performance of concrete, the local and post-local buckling behaviors of the column, and the steel tubular confinement effect.Based on existing literatures, a test database including data on 170 CFST stub columns with high-strength materials was established. The calculations from various design codes were compared with the peak-loads of these 170 samples, which identified that Eurocode 4 afforded the closest predictions on average, while it was unsafe for columns incorporating conventional-strength steel and high-strength concrete. As for columns with compact sections, AISC 360 can be safely utilized for predicting the peak-loads.

\section{ARTICLE HISTORY}

\begin{tabular}{|c|c|}
\hline Received: & 29 April 2020 \\
\hline Revised: & ber 2020 \\
\hline Accepted: & 12 December 2020 \\
\hline
\end{tabular}

\section{KE Y W O R D S}

Concrete-filled steel tube (CFST); High-strength material; Failure mechanism; Composite action

\section{Introduction}

Concrete-filled steel tubes (CFSTs) are extensively adopted in engineering applications owing to the beneficial composite action. Through the use of high-strength materials for CFST columns, an innovative structural member can be produced. This helps to achieve better mechanical behavior and reduce the cross-section of the column, which can improve building space usage. Using the current technology, the production of high-strength materials has become possible [1], and the use of these materials is promising as they afford significant advantages [2]. However, current design codes, such as Eurocode 4 [3], AISC 360 [4], and GB 50936 [5], set several limitations on the application of high-strength steel tube and concrete, as reported by several previous studies [6-8]. Given this background, further explorations regarding the fundamental behavior of CFSTs and database enrichment remain necessary.

Thai et al. [9] collected 3103 test samples, including stub and long CFSTs subjected to axial and eccentric loads. Then, a comprehensive database of circular, square, and rectangular CFSTs was established; the material strengths, namely $f_{\mathrm{y}}$ and $f_{\mathrm{c}}^{\prime}$, were $115.0 \mathrm{MPa}$ to $853.0 \mathrm{MPa}$ and 7.6 $\mathrm{MPa}$ to $186.0 \mathrm{MPa}$, respectively. According to Ref. [9], among existing tests,only $13.6 \%$ and $12.5 \%$ of the tested specimens adopted high-strength steel (HSS) with $f_{\mathrm{y}}>460 \mathrm{MPa}$ and high-strength concrete (HSC) with $f_{\mathrm{c}}^{\prime}>90 \mathrm{MPa}$, respectively; moreover, the highest $f_{\mathrm{y}}$ value employed for the CFST test specimens with square or rectangular cross-sections was $835 \mathrm{MPa}$. In existing literatures, only a few reports focus on the axial behavior of CFSTs with HSS whose $f_{\mathrm{y}}$ reached 800 $\mathrm{MPa}$.

Yan et al. [10] performed experimental investigations on 32 stub columns with HSS and high-performance concrete under axial compression, where $f_{\mathrm{y}}$ and $f_{\text {cu-100 }}$ (obtained from tests on 100-mm-wide cubic blocks) were from 444.6 $\mathrm{MPa}$ to $668.8 \mathrm{MPa}$ and 102.4 MPa to $141.0 \mathrm{MPa}$, respectively. It was observed that the ductility of such columns increased with the confinement coefficient. Lee et al. [11] experimentally investigated the axial response of five rectangular CFSTs made of high-strength materials, where $f_{\mathrm{y}}$ and $f_{\mathrm{c}}^{\prime}$ were from $301 \mathrm{MPa}$ to $746 \mathrm{MPa}$ and $70.5 \mathrm{MPa}$ to $83.6 \mathrm{MPa}$, respectively. Furthermore, it was numerically demonstrated that the peak-loads sustained by steel tube and concrete components were mainly influenced by the material strength and width-to-wall-thickness ratio. This finding was also reported by Lai and Varma [12].

Lam and Williams [13] experimentally confirmed that the steel-concrete bonding strength was critical to the axial behavior of stub columns filled with 100-MPa-HSC.Guler et al. [14] experimentally observed that high-strength CFST stub columns with circular sections exhibited greater steel-concrete bonding strengths than those with square sections. Additionally, new concrete constitutive models that considered the confinement effect were recommended by Aslani et al. [15] and Liang et al. [16] through investigations on the behaviors of axially loaded CFSTs made of high-strength materials.
Patel et al. [17] numerically confirmed that AISC 360 [4] was conservative in estimating the peak-loads of circular cases employing ultra-high-strength concrete $\left(f_{\mathrm{c}}^{\prime}\right.$ up to $\left.193.3 \mathrm{MPa}\right)$. In contrast, GB 50936 [5] was demonstrated to be unconservative [17]. Wei et al. [18] tested 20 circular CFST stub columns with $f_{\mathrm{y}}$ up to $1153 \mathrm{MPa}$ and $f_{\mathrm{c}}^{\prime}$ up to $125 \mathrm{MPa}$, and found that the calculations of AIJ [19] were close to the test results.For square or rectangular columns using high-strength materials, Aslani et al. [15] and Kang et al. [20] found that AS 5100 [21] offered a satisfactory prediction. Lai et al. [22] reported that Eurocode 4 [3] could be conservatively adopted to predict the peak-loads of CFST stub columns with $f_{\mathrm{y}}$ up to $780 \mathrm{MPa}$ and $f_{\mathrm{c}}^{\prime}$ from $150 \mathrm{MPa}$ to $190 \mathrm{MPa}$.

Based on foregoing research on the axial behavior of CFSTs fabricated using high-strength materials, numerous studies have been performed to explore the ductility, load sustained by each component, steel-concrete bonding behavior, and confined concrete model in CFSTs. Moreover, the peak-loads of CFSTs were predicted by using current design codes. These previous investigations have provided significant contributions toward the engineering applications of CFSTs.

Thus far, studies on the failure mechanism of CFSTs are limited. It should be noted that the typical failure mode of an axially loaded high-strength CFST stub column is characterized by bulging near the ends or at the middle of the steel tube, along with concrete crushing. This finding was also observed in many available tests $[8,11,23,24]$. However, investigations on the crushing mechanism of HSC are rare.Simultaneously, although the confinement action in composite columns has been analyzed using various methods [25-27],studies on the contact stress variation along the height of the high-strength CFST stub column are limited.Moreover, the variation of the longitudinal stress in the concrete elements along the column height can also be adopted to reflect the steel tubular constraint action, while therelated investigations remain unclear. Hence, further studies are necessary.

To address these research gaps, this work mainly focuses on factors such as (a) steel-concrete strength compatibility, (b) crushing failure of concrete, (c) local and post-local buckling behaviors, (d) steel tubular confinement, and (e) applicability of the current design codes. A more detailed outline is presented as follows.

In this study, tests were performed on eight concentrically compressed high-strength concrete-filled high-strength square steel tubular (HCFHSST) stub columns with $f_{\mathrm{y}}$ from $566.90 \mathrm{MPa}$ to $889.87 \mathrm{MPa}$. Numerical studies were also conducted to further analyze the failure mechanism of HCFHSST columns and the steel-concrete composite action. Moreover, a test database including data on 170 high-strength CFST samples was established. The feasibilities of utilizing current design codes to predict the peak-loads of axially compressed CFST stub columns incorporating high-strength materialswere alsodiscussed.The results of this research are anticipated to provide useful insights for engineering practices. 


\section{Experimental study}

\subsection{Design of specimens}

In the experiments, eight HCFHSST stub columns were subjected to axial compression using a $10000 \mathrm{kN}$ testing machine. The column parameters are summarized in Table 1 . The sectional dimension of each specimen was 150 $\mathrm{mm} \times 150 \mathrm{~mm}$, and column height was $450 \mathrm{~mm}$. Seamless square steel tubes with $f_{\mathrm{y}}$ from $566.90 \mathrm{MPa}$ to $889.87 \mathrm{MPa}$ (actual measured values) and HSC provided by a commercial concrete corporationwere employed.Mixture proportions of the concrete are tabulated in Table 2. Before the HCFHSST column tests, the cubic concrete blocks (width of $150 \mathrm{~mm}$ ) were tested under axial loading, and the average strength was $90 \mathrm{MPa}$

Table 1

Parameters and test results of specimens

\begin{tabular}{|c|c|c|c|c|c|c|c|c|c|}
\hline No. & $B(\mathrm{~mm})$ & $t(\mathrm{~mm})$ & $L(\mathrm{~mm})$ & $L / B$ & $f_{\mathrm{y}}(\mathrm{MPa})$ & $f_{\mathrm{u}}(\mathrm{MPa})$ & $f_{\text {cu }}(\mathrm{MPa})$ & $P_{\mathrm{u}}(\mathrm{kN})$ & $\Delta_{\mathrm{u}}(\mathrm{mm})$ \\
\hline HSSA1-1 & 150 & 5 & 450 & 3 & 566.90 & 644.00 & 90 & 3510.5 & 1.66 \\
\hline HSSA $1-2$ & 150 & 5 & 450 & 3 & 566.90 & 644.00 & 90 & 3363.5 & 1.50 \\
\hline HSSA2-1 & 150 & 5 & 450 & 3 & 780.75 & 830.19 & 90 & 4006.5 & 1.78 \\
\hline HSSA2-2 & 150 & 5 & 450 & 3 & 780.75 & 830.19 & 90 & 3975.0 & 2.26 \\
\hline HSSA3-1 & 150 & 5 & 450 & 3 & 838.00 & 880.00 & 90 & 4124.5 & 1.98 \\
\hline HSSA3-2 & 150 & 5 & 450 & 3 & 838.00 & 880.00 & 90 & 4197.5 & 1.86 \\
\hline HSSA4-1 & 150 & 5 & 450 & 3 & 889.87 & 947.09 & 90 & 4257.5 & 2.12 \\
\hline HSSA4-2 & 150 & 5 & 450 & 3 & 889.87 & 947.09 & 90 & 4248.5 & 1.79 \\
\hline
\end{tabular}

Note: In HSSA1-2, HSSA denotes the high-strength square CFST specimen under axial compression; 1 and 2 indicate the first group of specimens and the identical specimen, respectively; $B$ and $L$ are the cross-sectional outer width and column length, respectively; $t$ is the steel tubular wall-thickness; $f_{\mathrm{y}}$ and $f_{\mathrm{u}}$ are the measured steel yield and ultimate tensile strengths, respectively; $f_{\mathrm{cu}}$ is the measured concrete strength using 150 -mm cubic blocks; $P_{\mathrm{u}}$ is the measured peak-load; $\Delta_{\mathrm{u}}$ is the corresponding longitudinal deformation.

Table 2

Mixture proportions of high-strength concrete (unit: $\mathrm{kg} / \mathrm{m}^{3}$ )

\begin{tabular}{cccccc}
\hline Mixture & Cement & Admixture & Sand & Coarse aggregate & Superplasticizer \\
\hline Proportion & 500 & 100 & 660 & 1150 & 130 \\
\hline
\end{tabular}

\subsection{Data acquisition}

As shown in Fig. 1, flat plate loading was adopted in the tests, and the axial deformation values of the specimens were measured using displacement transducers (i.e., LVDTs) located on both sides of the specimens. Longitudinal and transverse strain gauges were attached to the midpoints of surfaces 1-4 (S1-S4). All test data were collected by the IMP automatic acquisition system. The applied load in each loading stage was $11_{10}-1 / 15$ of the predicted ultimate load, and each stage lasted for approximately 3 to 4 min. When the specimen load approximately approached the ultimate load, gradual and continuous loading was implemented. The loading rate during the post-peak stage was around $1.5 \mathrm{~mm} / \mathrm{min}$.

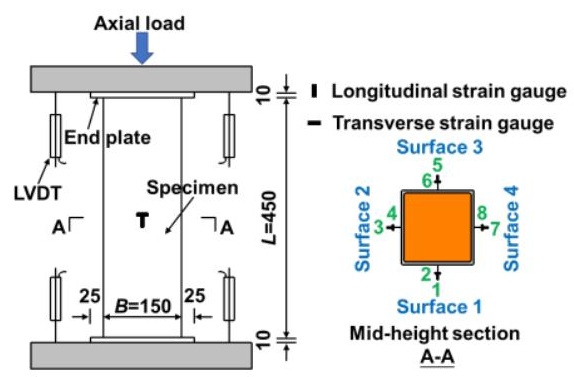

Fig. 1 Test set-up

\subsection{Failure modeand process}

The failure modes of the HCFHSST columns under axial compression are presented in Fig. 2. Outward buckling deformations were observed at the ends and mid-heights of the steel tubes. As illustrated in Fig. 2(b), when the steel tubes of the specimens were removed, the concrete was visibly crushed, particularly at the positions where the steel tubes bulged.

As presented in Fig. 3, the HSSA1-2 specimen was employed as an example to further illustrate the failure process of the columns. At the peak-load, outward buckling deformations initially occurred at the top end of the column and the bulges were insignificant. During the descending stage of loading, as the applied load reduced to $-75 \% P_{\mathrm{u}}$ (“--" indicates post-peak stage), bulges were distinctly observed at the mid-height section. Simultaneously, the outward deformation that appeared near the column end gradually increased at this stage. Further explanations of the failure process based on numerical investigations are provided in Section 3.

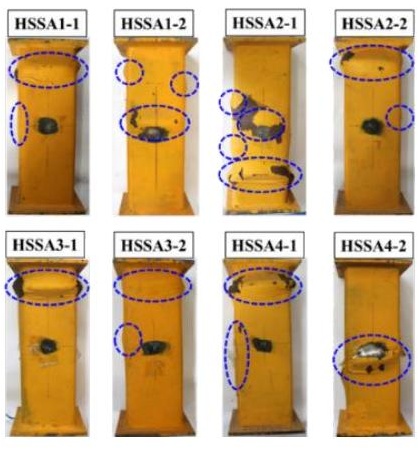

(a) Failure modes of specimens

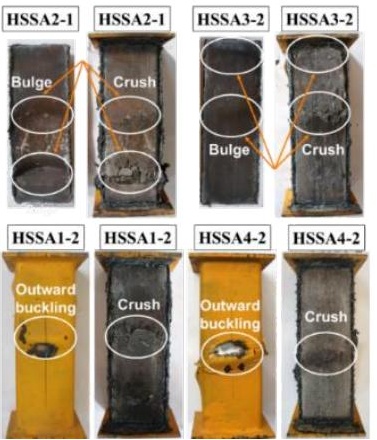

(b) Failure patterns in concrete
Fig. 2 Failure modes of HCFHSST columns

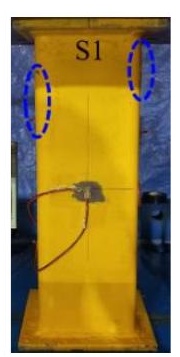

(a) Peak-load

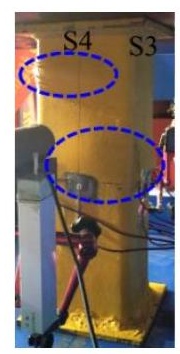

(b) $-75 \% P_{\mathrm{u}}$
Fig. 3 Failure process of HSSA1-2 specimen

\subsection{Load-longitudinal displacement curves}

As presented in Fig. 4, the change trends of the load-displacement curves for HSSA1-2, HSSA2-1, and HSSA2-2 specimens were similar. Among these, the HSSA1-2 was used to describe the loading process of HCFHSST specimens.During the pre-peak loading phase of HSSA1-2, the stiffness of the load-displacement curve was high, and the nonlinear trend was not visibly observed in this curve.During the post-peak loading stage, the load abruptly decreased from $3304.5 \mathrm{kN}$ to $2532.0 \mathrm{kN}$ (a $23.4 \%$ reduction) with increasing the longitudinal displacement, because the brittle failure of concrete occurred 
during the test. This phenomenon of "sudden descent" (Fig. 4) was also observed in Refs. [8, 28]. Meanwhile, the longitudinal displacement increased from 1.63 to $1.78 \mathrm{~mm}$ (i.e., $9.2 \%$ ). Thereafter, the load slightly declined from $2532.0 \mathrm{kN}$ to $2525.0 \mathrm{kN}$ (i.e., $0.3 \%$ ), whereas the longitudinal displacement evidently increased from $1.78 \mathrm{~mm}$ to $2.37 \mathrm{~mm}$ (i.e., $33.1 \%$ ).

Overall, the loads of the HSSA1-2, HSSA2-1, and HSSA2-2 specimens abruptly declined at $-98.2 \% P_{\mathrm{u}}--99.7 \% P_{\mathrm{u}}$. However, the load of the HSSA3-2 specimen started to decrease rapidly at a lower load level $\left(-91.9 \% P_{\mathrm{u}}\right)$, and the load reduction was relatively small. In addition, this phenomenon was not observed in the HSSA4-1 and HSSA4-2 specimens because the steel tubular confinement effect increased with $f_{\mathrm{y}}$. Hence, HSS with $f_{\mathrm{y}}=838.00 \mathrm{MPa}$ and 889.87 $\mathrm{MPa}$ could provide sufficient restraints to delay and prevent the concrete from significant split after reaching the peak-loads, ensuring that the axially loaded stub columns had adequate residual mechanical behaviors. Another reason is that the concrete in the column with a lower $f_{\mathrm{y}}$ value sustained more axial load.

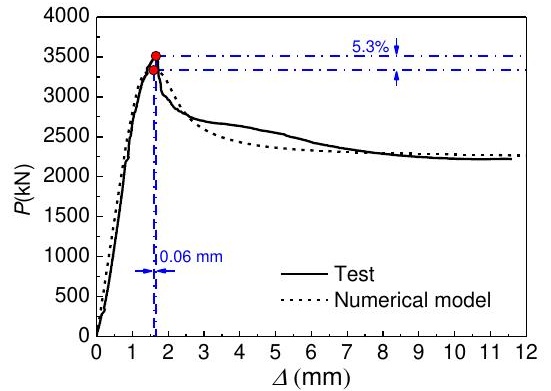

(a) HSSA1-1

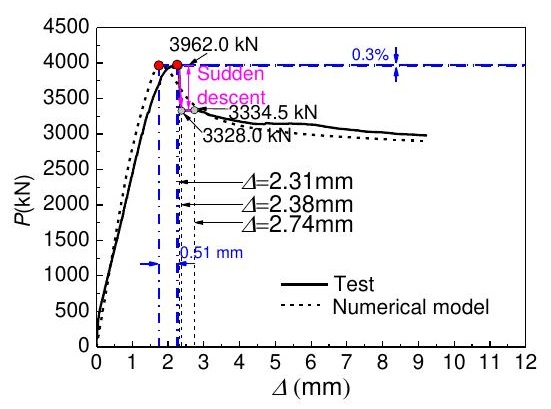

(d) HSSA2-2

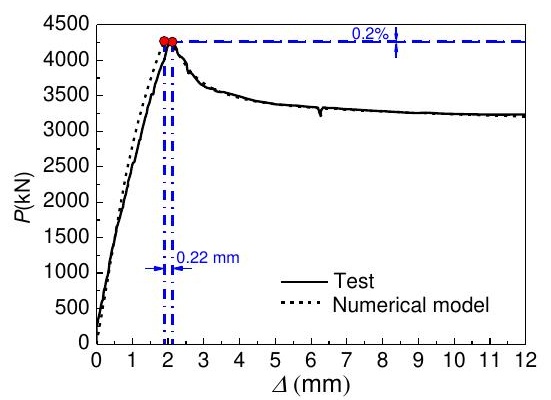

(g) HSSA4-1

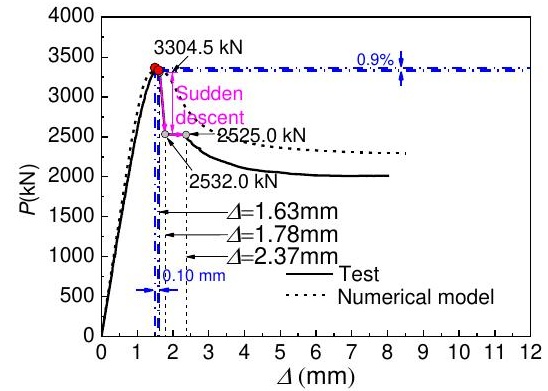

(b) HSSA1-2

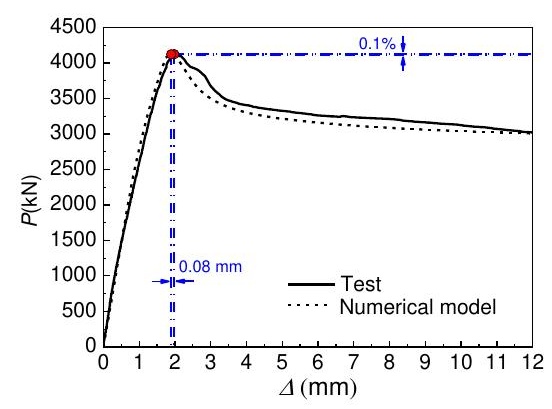

(e) HSSA3-1

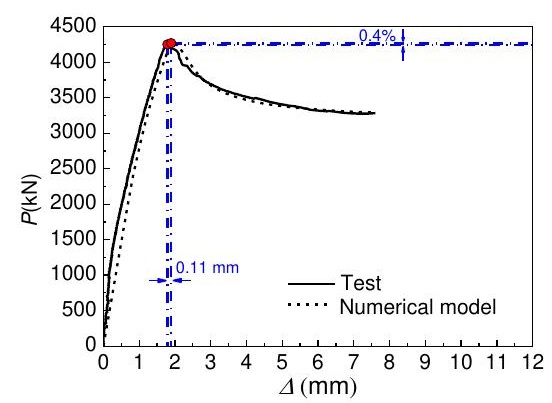

(h) HSSA4-2

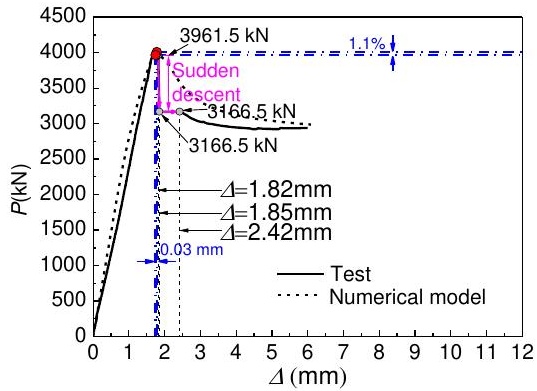

(c) HSSA2-1

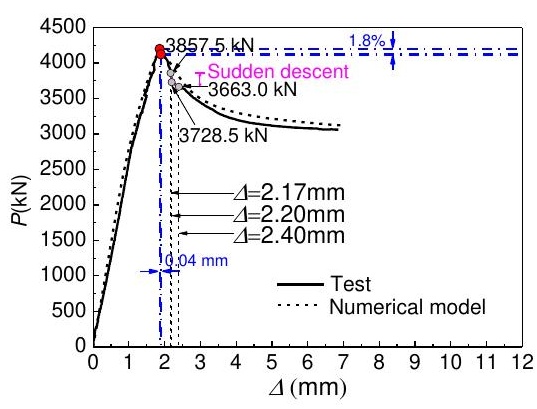

(f) HSSA3-2

Fig. 4 Comparative results of load-longitudinal displacement curves

\subsection{Strain and stress variations}

As expected, outward buckling was observed in the HCFHSST specimens. This occurred at $1 / 2 L$ of the HSSA4- 2 specimen, in which the HSS of $f_{\mathrm{y}}=889.87$ MPa effectively prevented the brittle failure mode. Accordingly, as illustrated in Fig. 5, eight strain gauge (SG) values in the HSSA4-2 specimen are obtained to determine the strain variation trend, and the locations of "1-8" and four surfaces of "S1-S4" are indicated in Fig. 1.

Based on Fig. 5, the SG1, SG3, and SG7 values were similar during the initial loading period, and the strain values increased with the axial load. After the load approximately achieved $2500 \mathrm{kN}\left(58.8 \% P_{\mathrm{u}}\right)$, the increase in the SG7 value was smaller than that in the SG1 value. Compared with other transverse strain values, the enhancement in the SG8 value was more pronounced. The abovementioned analysis demonstrated that the deformation at $1 / 2 L$ of S4 mainly concentrated in the transverse direction, and the extent of outward buckling was also evident. After the load approximately reached $3500 \mathrm{kN}(82.4 \%$ $P_{\mathrm{u}}$ ), strain reversal gradually occurred because of local buckling. Moreover, two bulges were observed in S3 of the steel tube. It was found that before the peak-load, the SG5 value increased greater than other longitudinal strain values, and the development trends of the SG2, SG4, and SG6 values were similar. This indicated that the deformation at ${ }^{1} / 2 L$ of S3 mainly concentrated in the longitudinal direction, and the degree of outward buckling was relatively small.

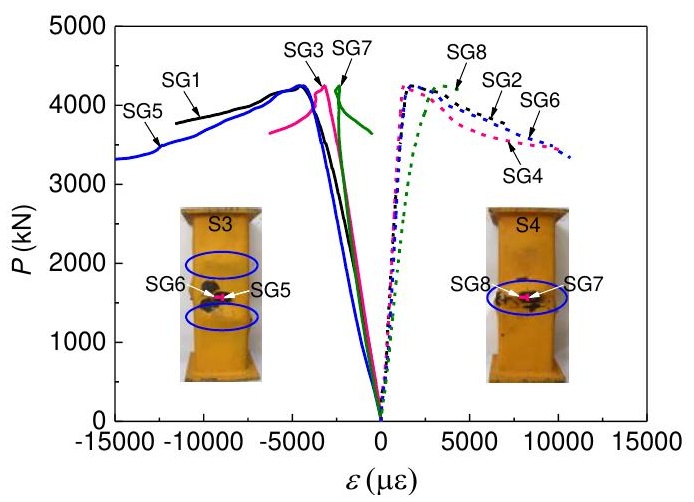

Fig. 5 Load-strain curves

The transverse stress $\left(\sigma_{\mathrm{h}}\right)$, longitudinal stress $\left(\sigma_{\mathrm{v}}\right)$, and equivalent stress $\left(\sigma_{\mathrm{z}}\right)$ variations at the mid-height of S1 in the HSSA4-2 column are exerted as an example to present the stress developments, asplotted in Fig. 6. Other specimens exhibit similar trends. The stresses were computed according to the SG1 and SG2 values, and the detailed assumption and computations can be found in Refs. [29,30]. The calculated stresses are sensitive to the strain variations. As depicted in Fig. 6 , in the initial loading process, $\sigma_{\mathrm{h}}$ apparently 
increased, owing to the temporary and minor fluctuations in the transverse strain. In general, $\sigma_{\mathrm{h}}$ was considerably lower than $\sigma_{\mathrm{v}}$ and $\sigma_{\mathrm{z}}$ during the entire loading process and mainly enhanced after $P_{\mathrm{u}}$. The steel tube practically yielded when the peak-load was attained. After yielding, both $\sigma_{\mathrm{v}}$ and $\sigma_{\mathrm{z}}$ gradually reduced although the steel underwent the strain hardening stage.

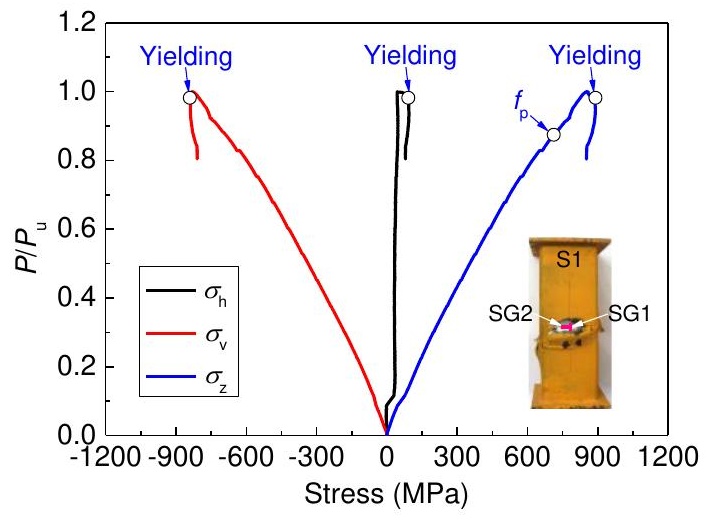

Fig. 6 Stress variations

\section{Numerical study}

\subsection{Modeling}

ABAQUS was adopted for the numerical simulation of HCFHSST columns under axial compressive loads. The C3D8R element was selected to model each part, as described in Fig. 7. The end-plates completely transferred the axial load to the columns. Accordingly, these plates were assumed to be rigid in the modeling process based on a previous study of the authors [31]. The end-plates were attached to the ends of the columns, and the "Tie" option in ABAQUS was selected to simulate the connections between two end-plates and a steel tube. The interaction between concrete and an end-plate was set as "Hard contact". Moreover, the "hard contact" and "friction contact" were defined between a steel tube and concrete, and a friction coefficient of 0.6 was used in this study.

The boundary conditions of the model are depicted in Fig. 7. The displacement in z-direction at the top of the column was released, whereas the remaining displacement and rotation at the top and bottom of the model were constrained. This method was also suggested by Patel et al. [17]. Additionally, the mesh size of $B / 15$ was selected for the concrete and steel tube in the current study based on the proposal of Taoet al. [32].

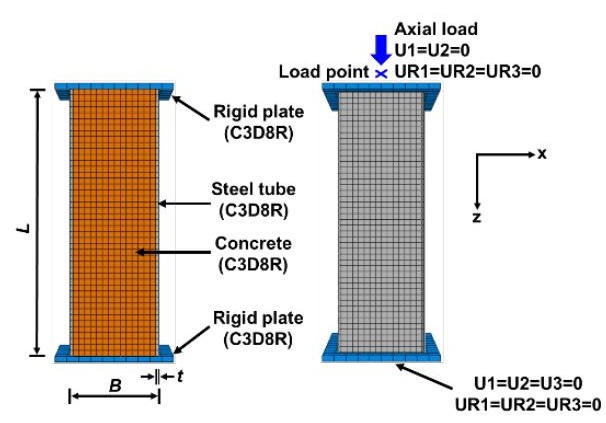

Fig. 7 Finite element modeling

\subsection{Constitutive model}

The bi-linear constitutive model was utilized for simulating the property of the HSS, as expressed in Eq. (1), where the elastic modulus $\left(E_{\mathrm{s}}\right)$ and Poisson's ratio wereset as $206 \mathrm{GPa}$ [5] and 0.3 [32], respectively. Furthermore, in the parametric studies, $f_{\mathrm{u}}$ was computed according to Eqs. (2) [32] and (3) [33] for steels with $f_{\mathrm{y}} \leq 800 \mathrm{MPa}$ and $f_{\mathrm{y}}>800 \mathrm{MPa}$, respectively.

$$
\sigma= \begin{cases}E_{\mathrm{s}} \cdot \varepsilon & \left(\sigma \leq f_{\mathrm{y}}\right) \\ f_{\mathrm{y}}+0.01 E_{\mathrm{s}}\left(\varepsilon-\varepsilon_{\mathrm{y}}\right) & \left(\sigma>f_{\mathrm{y}}\right)\end{cases}
$$

$f_{\mathrm{u}}= \begin{cases}{\left[1.6-2 \times 10^{-3}\left(f_{\mathrm{y}}-200\right)\right] f_{\mathrm{y}}} & \left(200 \mathrm{MPa} \leq f_{\mathrm{y}} \leq 400 \mathrm{MPa}\right) \\ {\left[1.2-3.75 \times 10^{-4}\left(f_{\mathrm{y}}-400\right)\right] f_{\mathrm{y}}} & \left(400 \mathrm{MPa} \leq f_{\mathrm{y}} \leq 800 \mathrm{MPa}\right)\end{cases}$ $f_{\mathrm{u}}=0.96 f_{\mathrm{y}}+\frac{650}{f_{\mathrm{y}}^{0.3}} \quad\left(f_{\mathrm{y}}>800 \mathrm{MPa}\right)$

The constitutive equations of confined concrete proposed by Han et al. [34] were chosen to describe the compressive property of HSC, which are feasible for $f_{\text {cu }}$ values in the range of $30 \mathrm{MPa}-120 \mathrm{MPa}$, and the specific expressions are provided in Eq. (4).Furthermore, the Elastic modulus was determined as $E_{\mathrm{c}}=3320\left(f_{\mathrm{c}}^{\prime}\right)^{1 / 2}+6900(\mathrm{MPa})$ [35] and Poisson's ratio was set as 0.2 [36]. The dilation angle and other parameters were consistent with those determined in a previous study of the authors [31].

$y= \begin{cases}2 x-x^{2} & (x \leq 1) \\ \frac{x}{\beta_{0}(x-1)^{\eta}+x} & (x>1)\end{cases}$

where $\quad x=\varepsilon \quad \varepsilon_{0}, \quad \mathrm{y}=\sigma / f_{\mathrm{c}}^{\prime}, \varepsilon_{\mathrm{c}}=\left(1300+12.5 f_{\mathrm{c}}^{\prime}\right) \times 10^{-6}, \quad \varepsilon_{0}=\varepsilon_{\mathrm{c}}+800 \xi^{0.2} \times 10^{-6}$, $\beta_{0}=\left(f_{\mathrm{c}}^{\prime}\right)^{0.1} /\left(1.2(1+\xi)^{1 / 2}\right)$, and $\eta=1.6+1.5 / x$. The confinement coefficient is computed as $\xi=f_{\mathrm{y}} A_{\mathrm{s}} /\left(f_{\mathrm{ck}} A_{\mathrm{c}}\right) ; f_{\mathrm{ck}}$ is the prismatic concrete characteristic strength; $A$ is the cross-sectional area of the component; and subscripts "s and c" represent steel and concrete, respectively.

In addition, the tensile properties of concrete were calculated using the GFI energy method illustrated in Refs. [31,37], and the specific expressions are as follows:

$G_{\mathrm{f}}=a \cdot\left(f_{\mathrm{c}}^{\prime} / 10\right)^{0.7} \times 10^{-3} \quad(\mathrm{~N} / \mathrm{mm})$

where $a=1.25 d_{\max }+10, d_{\max }$ denotes the maximum coarse aggregate size, and $f_{\mathrm{c}}^{\prime}$ is the cylindrical concrete strength. Additionally, the concrete cracking stress can be computed as $\sigma_{\mathrm{t} 0}=0.26 \times\left(1.25 f_{\mathrm{c}}^{\prime}\right)^{2 / 3}$. The strength conversion relationship of $f_{\mathrm{cu}}, f_{\mathrm{c}}^{\prime}$, and $f_{\mathrm{ck}}$ in the current study was determined according to Ref. [31].

\subsection{Validation of numerical model}

The simulation results were compared against the test results, as plotted in Fig. 4, where the blue lines illustrate their differences. The figure indicates that the load-longitudinal displacement curves predicted by the numerical studies exhibit satisfactory agreement with the test results, confirming the accuracy of the finite element models. It should be noted that, for the HSSA1-2, HSSA2-1, and HSSA2-2 specimens (Fig. 4), the applied load suddenly reduced and the corresponding longitudinal deformation rapidly enhanced after achieving the peak-loads. Therefore, for these specimens, some deviations exist in the post-peak stages of the load-longitudinal deformation curves, which is a reasonable phenomenon.

\subsection{Load-longitudinal displacement curve analysis}

A numerical model that matched the HSSA1-1 (as well as HSSA1-2) experimental specimen was extracted as a representative model to further analyze the axial behavior of HCFHSST columns. The load-longitudinal displacement curve of this model and the definitions of several events are shown in Fig. 8. The initial stiffness of the load-longitudinal displacement curve was relatively large during the elastic stage (OA stage). As the load reached $84.2 \%$ and $98.5 \%$ of the peak-load, the steel tubular stress at the column mid-height reached the proportional limit and yield strength of steel, respectively. The HCFHSST column gradually developed plasticity after event A, and a minor nonlinear development trend was observed in the load-longitudinal displacement curve. The sufficient plasticity development could be found in the HCFHSST column after event B. With increasing the longitudinal displacement, the load slowly increased, and the yielding load was found to considerably approximate the peak-load of the HCFHSST stub column.

At event $\mathrm{C}\left(P=99.6 \% P_{\mathrm{F}}\right)$, the ultimate compressive strain was achieved for concrete along the longitudinal direction. At event $\mathrm{D}$, the peak-load of the column was reached, and the longitudinal displacement was $1.60 \mathrm{~mm}$, which increased by $23.1 \%$ compared with that at event B. After event D, due to the yielding of steel tube and the crushing of concrete, the load began to decrease as longitudinal deformation increased. After event $\mathrm{F}\left(P=-70 \% P_{\mathrm{F}}\right)$, the load bearing capacity of the model tended to be stable with an increase in deformation. This indicates that the HCFHSST columns have satisfactory residual mechanical behaviors, that is, the load bearing capacity can still reach approximately $70 \%$ of the peak-load before unloading (event G). 


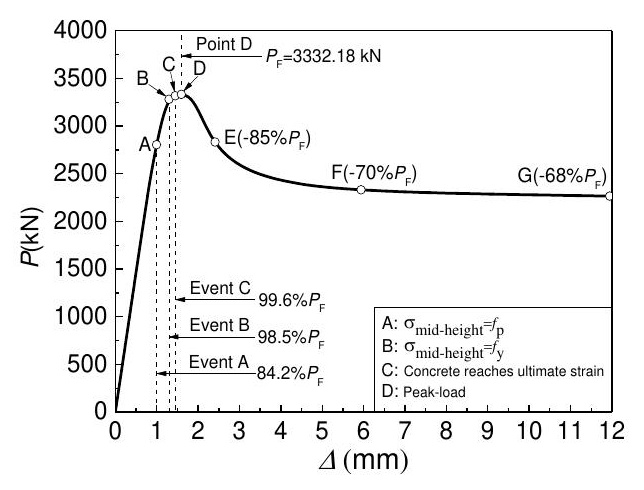

Fig. 8 Load-longitudinal displacement curve of the representative model

\subsection{Longitudinal stress of concrete}

Fig. 2 showed that the crushed positions of the core concrete coincided with the positions where the outward buckling of steel tubes occurred, indicating that these positions along the column height were greatly related to the stress states of the core concrete. Therefore, it is particularly important to examine the longitudinal stress $\left(\sigma_{1}\right)$ distribution in concrete.

The $\sigma_{1}$ distribution in the concrete corresponding to each event of the typical model is presented in Fig. 9. At event A, $\sigma_{1}$ was concentrated in the corner region at the concrete ends, and the magnitude of $\sigma_{1}$ at this location was larger than that at mid-height of the concrete length $(1 / 2 L)$. After event $\mathrm{A}$, the development of plasticity in the concrete caused lateral expansion, which was gradually restricted by the steel tube. Consequently, the independent actions of the steel tube and concrete were halted; instead, the two materials interacted. Moreover, for a square cross-section, stress concentration tends to be induced at the corner region. At event $\mathrm{B}$, the magnitude of $\sigma_{1}$ near the corner was greater than that in the mid-point at $1 / 2 L$.

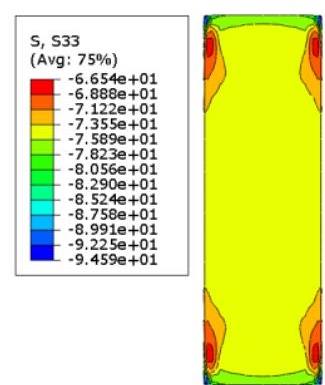

(a) Event $\mathrm{A}$

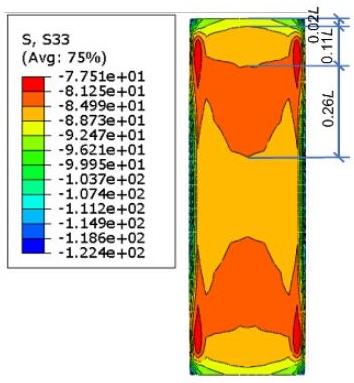

(c) Event C

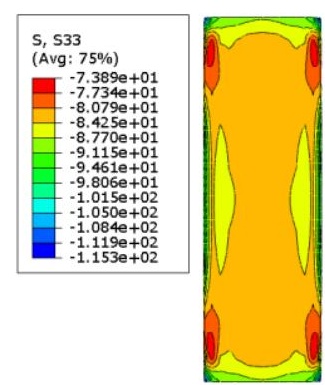

(b) Event B

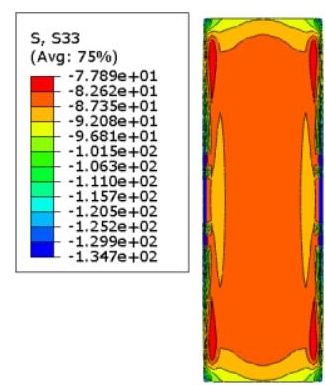

(d) Event D
Fig. 9 Longitudinal stress $\left(\sigma_{1}\right)$ distribution in concrete

At event $\mathrm{C}, \sigma_{1}$ still concentrated at the corner of $1 /{ }_{2} L$. Additionally, as shown in Fig. 9(c), the magnitudes of $\sigma_{1}$ in concrete at $h=1 /{ }_{2} L$ and at $h=0.02$ $L-0.13 L(0.02 L+0.11 L)$ were practically the same. Moreover, the $\sigma_{1}$ value of concrete from the end to $h=0.02 L$ was larger than the $\sigma_{1}$ at other heights. In this event, the $\sigma_{\mathrm{l}}$ value at ${ }^{1} / 2 L$ varied from $-84.99 \mathrm{MPa}\left(-1.04 f_{\mathrm{c}}^{\prime}\right)$ to $-88.73 \mathrm{MPa}$ $\left(-1.08 f_{\mathrm{c}}^{\prime}\right)$ at event $\mathrm{C}("-"$ represents the compressive state). Thereafter, because of the achievement of the ultimate concrete compression strain at event $\mathrm{C}$, $\sigma_{1}$ decreased to the range from $-82.62 \mathrm{MPa}\left(-1.01 f_{\mathrm{c}}^{\prime}\right)$ to $-87.35 \mathrm{MPa}\left(-1.07 f_{\mathrm{c}}^{\prime}\right)$ at event $\mathrm{D}$. Further findings are presented in the following Section.

3.6. Development of contact stress
The steel tube-concrete contact stress at $1 / 2 L$ cross-section of the typicalmodel is given in Fig. 10. The contact stress mainly concentrated at the corner region, whereas there was no contact stress in the flat-plate region. From events $\mathrm{B}$ to $\mathrm{C}, \mathrm{C}$ to $\mathrm{D}$, and $\mathrm{D}$ to $\mathrm{E}$, the maximum contact stresses at the corner increased by $48.4 \%, 53.4 \%$, and $226.8 \%$, respectively. This demonstrates that the contact stress is relatively low before the typical model reaches the peak-load and then develops rapidly after the peak-load. In addition, the numerical results demonstrated that the contact stress gradually propagated from the corners to the flat regions after event E, implying that the flat regions of the square steel tube began to restrain the lateral dilation of concrete at the post-peak stage.

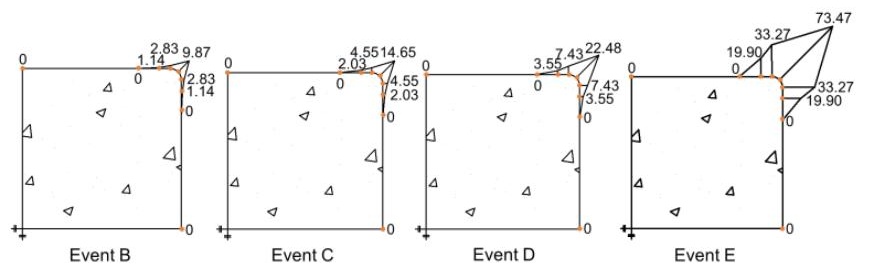

Fig. 10 Steel-concretecontact stress at middle height of typical model (unit: MPa)

As depicted in Fig. 10, the steel tube-concrete contact stress was relatively large at the corner region. To further illustrate the development of the contact stress before the peak-load and analyze its distribution along the column height, the contact stresses in the corner position along the height of the typical column at events $\mathrm{C}$ and $\mathrm{D}$ are provided in Fig. 11.

Based on Fig. 11, at event C, the contact stress at $h=0.31 L(p=16.22$ $\mathrm{MPa})$ was larger than that at $h={ }^{1}{ }_{2} L(p=14.65 \mathrm{MPa})$. This was because the lateral expansion deformation at the corner of the concrete exceeded that of the steel tube, leading to the generation of contact stress, and this phenomenon was more evident at $h=0.31 \mathrm{~L}$. However, at event D, the contact stress at $h=1 / 2 L$ was similar to that at $h=0.31 L$. From events $C$ to $D$, the contact stress at each height gradually increased. It enhanced by $53.4 \%$ at $h=1 / 2 L$, indicating that the steel-concrete coaction performed suitably.

Based on Fig. 9, the $\sigma_{1}$ values of concrete at $h=1 / 2 L$ and $h=0-0.13 L$ were considerably large corresponding to event $\mathrm{C}$, resulting in a large lateral expansion deformation of concrete. Meanwhile, as shown in Fig. 11, the contact stress values at $h=1 / 2 L$ and $h=0-0.13 L$ were also very large, especially, the contact stress was maximum at $h=0.07 L$ at event $\mathrm{C}$. At these positions, the steel tube tended to exhibit outward buckling due to the large contact stress (steel-concrete extrusion stress). Meanwhile, the numerical results confirmed that the outward buckling deformation near the column end $(h=0.07 L)$ was higher than that at $h=1 / 2 L$ before event $\mathrm{D}$, and the outward deformation at $h=1 / 2 L$ evidently enhanced during the descending stage of loading. This is basically consistent with the experimental observation presented in Fig. 3.Consequently, in the tests described in the current study, the outward buckling phenomena occurring in the steel tubes at $1 / 2 L$ and near the column ends (Figs. 2 and 3) can be further explained. The abovementioned findings are obtained within the limited parameter scopes of the columns. Further investigations on the influence of various parameters on the failure modes of the columns remain necessary.

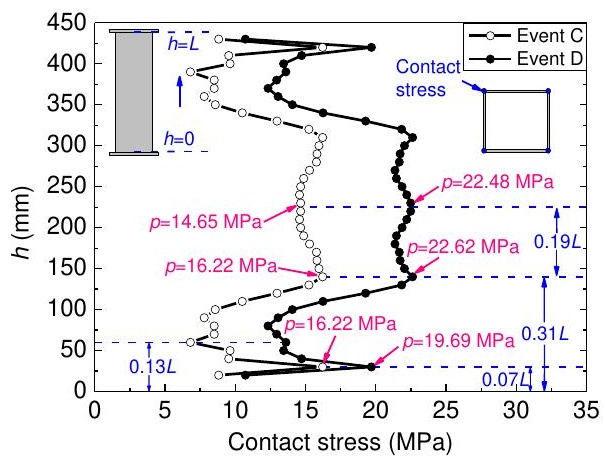

Fig. 11 Contact stress values along the height of the representative model

\subsection{Longitudinal stress distribution of concrete elements in different locations}

The ratios of $\sigma_{\mathrm{lc}-\mathrm{center}}$ and $\sigma_{\mathrm{lc}-\mathrm{outer}}$ to $f_{\mathrm{c}}$ corresponding to various heights of the typical model at its peak-load are presented in Fig. 12, where the values of $\sigma_{\mathrm{lc}-\mathrm{center}}$ and $\sigma_{\mathrm{lc}-\text { outer }}$ are derived from the longitudinal stresses in the concrete 
elements at the center of the effectively confined zone (location a) and at the outer surfacemid-point of the ineffectively confined region (location b), respectively. These ratios reflect the increase in the concrete strength $\left(\triangle f_{\mathrm{c}}^{\prime}\right)$ because of the overall constraint action provided by the steel tube.

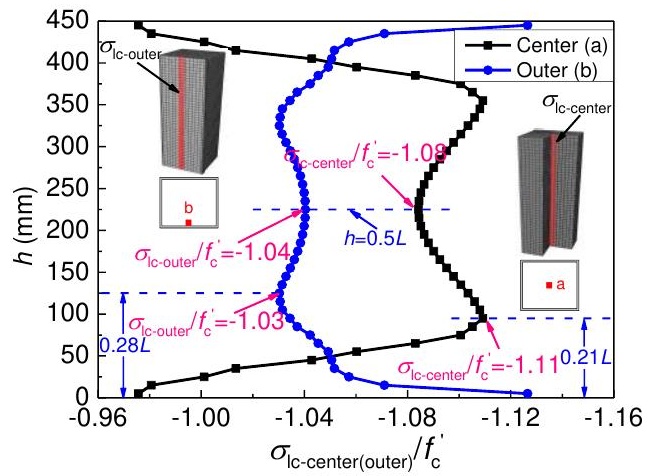

Fig. $12 \sigma_{\text {lc-center(outer) }} / f_{\mathrm{c}}^{\prime}$ values along the height of the typical model

As depicted in Fig. 12, the distributions of these ratios (i.e., $\sigma_{\mathrm{lc}-\mathrm{center}} f_{\mathrm{c}}$ ' and $\left.\sigma_{\mathrm{lc}-\text { outer }} / f_{\mathrm{c}}^{\prime}\right)$ along the height of the column were significantly different. At location a, the longitudinal stresses in concrete elements near the ends of the column were less than those at other heights along the column, whereas an opposite trend was observed at location b. This implies that, at the peak-load, the longitudinal stresses in concrete near the ends of the axially loaded stub column are mainly sustained by the outer surface of concrete. Therefore, the outer surfaces of concrete near the end regions are inclined to be crushed, as shown in Fig. 2.

Additionally, the contact stress at $h=0.5 L$ was practically the maximum at event D (Fig. 11). However, at location a (Fig. 12), $\sigma_{\text {lc-center }} f f_{c}^{\prime}(-1.11)$ at $h=0.21 L$ was slightly higher than that(-1.08) at $h=0.5 L$ ("-" represents compressive state). This is because the steel tube buckles outward at mid-height and near the ends of the column. The steel tubular buckling regions cannot sufficiently confine the concrete, whereas the steel tube regions around the buckling locations continue to effectively constrain the dilation of concrete. Additionally, at location $\mathrm{b}$, the $\sigma_{\mathrm{lc}-\text { outer }} f_{\mathrm{c}}^{\prime}$ values within the range of $0.44 L(1-0.28 L \times 2)$ in the middle of column height were similar (i.e., from -1.03 to -1.04), demonstrating that $\triangle f_{\mathrm{c}}^{\prime}$ in this region was similar.

\section{Parametric study}

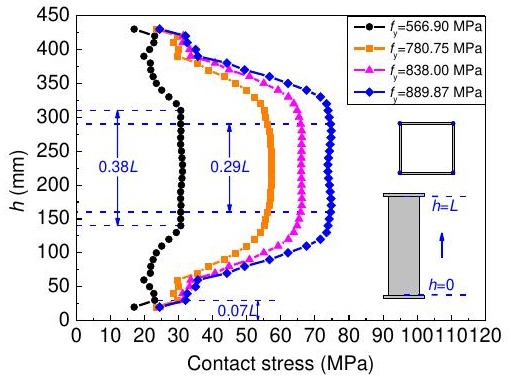

(a) $f_{\mathrm{cu}}=70 \mathrm{MPa}$

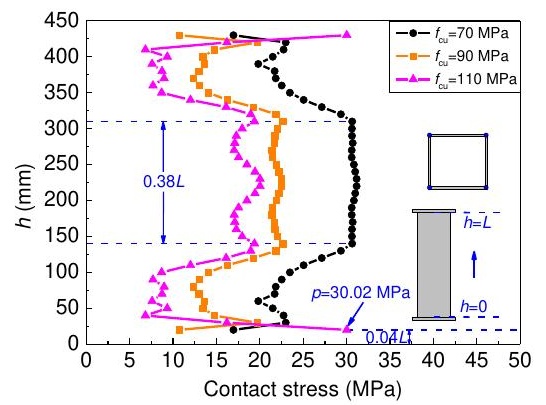

(a) $f_{\mathrm{y}}=566.90 \mathrm{MPa}$

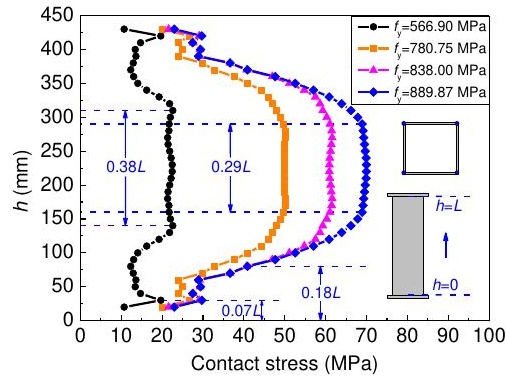

(b) $f_{\mathrm{cu}}=90 \mathrm{MPa}$

Fig. 13 Effect of $f_{\mathrm{y}}$ on contact stress

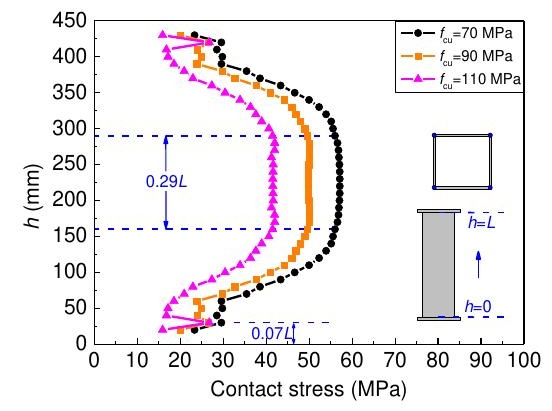

(b) $f_{\mathrm{y}}=780.75 \mathrm{MPa}$
The higher contact stress values indicate that the steel-concrete extrusion forces and confinements that exist in columns are greater. The confinement effect is important to improve the performance of composite columns. Thus, the steel tube-concrete contact stresses at the corners at various heights along the columns matching the peak-loads are presented in Section 4.1.Moreover, Section 4.2 illustrates the $\sigma_{\mathrm{lc}-\mathrm{center}} / f_{\mathrm{c}}^{\prime}$ variation, which helps to understand $\Delta f_{\mathrm{c}}^{\prime}$ caused by the overall restraining effect of the steel tube on concrete.

\subsection{Contact stress along column height}

\subsubsection{Effect of yield strength of steel}

The influence of $f_{\mathrm{y}}(566.90 \mathrm{MPa}$ to $889.87 \mathrm{MPa})$ on the contact stress of HCFHSST columns with $B=150 \mathrm{~mm}, \alpha=0.148, L=450 \mathrm{~mm}$, and $f_{\mathrm{cu}}=70$ $\mathrm{MPa}-110 \mathrm{MPa}$ is shown in Fig. 13. Although it is observed in Fig. 13(b) and (c) that the contact stresses practically remain unchanged within the range $h=0-0.18 L$ as $f_{\mathrm{y}}$ increases from 838.00 to $889.87 \mathrm{MPa}$, those at various heights generally increase with $f_{\mathrm{y}}$. In addition, as presented in Fig. 13(b), for the models with $f_{\mathrm{y}}=566.90 \mathrm{MPa}$, the contact stress slightly changes within the range of $0.38 \mathrm{~L}$ in the middle of the column, indicating that the constraint action is similar in this range. However, as $f_{\mathrm{y}}$ increases, the range decreases from $0.38 L$ to $0.29 L$, illustrating that the constraint afforded by the steel tube on concrete accumulates toward the mid-height section with an increase in $f_{\mathrm{y}}$.

\subsubsection{Effect of concrete strength}

The influence of $f_{\text {cu }}$ (70 MPa to $110 \mathrm{MPa}$ ) on the contact stress of models with $B=150 \mathrm{~mm}, \alpha=0.148, L=450 \mathrm{~mm}$, and $f_{\mathrm{y}}=566.90 \mathrm{MPa}-889.87 \mathrm{MPa}$ is shown in Fig. 14. Overall, the contact stress along the column height gradually decreases as $f_{\mathrm{cu}}$ increases, demonstrating that the constraint action reduces with increasing $f_{\text {cu. }}$. Additionally, as $f_{\text {cu }}$ increases from 70 to $110 \mathrm{MPa}$, the contact stress mainly concentrates within the range of $0.38 \mathrm{~L}$ in the middle of the column for the models with $f_{\mathrm{y}}=566.90 \mathrm{MPa}$, while it mainly concentrates within the range of $0.29 L$ for the models with $f_{\mathrm{y}}=780.75$ MPa-889.87 MPa. The results show that, compared with the effect of $f_{\mathrm{y}}$ on the concentration range of contact stress in the middle of the column, the influence of $f_{\text {cu }}$ is relatively insignificant.

It should be noted that the contact stress near the end of column is relatively high under the two following conditions.

As shown in Figs. 13 and 14, at peak-loads, the contact stress in the middle of the column is greater than that at the end region (except for the model with $\alpha=0.148, f_{\mathrm{y}}=566.90 \mathrm{MPa}$, and $f_{\mathrm{cu}}=110 \mathrm{MPa}$ ). However, based on the numerical results, the contact stress at $h=0.07 \mathrm{~L}$ remains close to that at the middle of the column before each column reaches the peak-load despite the variations in material strengths. This phenomenon is similar to that at event $\mathrm{C}$ (Fig. 11). 
The data in Fig. 14 were employed to investigate the ratio of the contact stress at $h=0.07 L\left(p_{1}\right)$ to that at the mid-height of the column $\left(p_{2}\right)$. For the models $w i t h f_{\mathrm{y}}=889.87,780.75$, and $566.90 \mathrm{MPa}$, at the peak-loads, the ratios of $p_{1}$ to $p_{2}$ were $0.43,0.52$, and 0.74 , respectively, when $f_{\mathrm{cu}}=70 \mathrm{MPa}$, and they were $0.51,0.64$, and 0.81 , respectively, when $f_{\mathrm{cu}}=110 \mathrm{MPa}$. It is found that, the ratio of $p_{1}$ to $p_{2}$ increases with $f_{\text {cu }}$ when $f_{\mathrm{y}}$ is constant, whereas it increases with the decrease of $f_{\mathrm{y}}$ when $f_{\text {cu }}$ is constant. Furthermore, as mentioned above, the confinement coefficient [34] decreases as $f_{\mathrm{y}}$ decreases and as $f_{\mathrm{cu}}$ increases.

\subsubsection{Effect of steel ratio}

The steel tubular wall-thickness $(t=5,6$, and $7 \mathrm{~mm})$ was varied to obtain several steel ratios $(\alpha=0.148,0.182$, and 0.217). The influence of $\alpha$ (0.148-0.217) on the contact stress of models with $B=150 \mathrm{~mm}, L=450 \mathrm{~mm}$, $f_{\mathrm{y}}=566.90 \mathrm{MPa}-889.87 \mathrm{MPa}$, and $f_{\mathrm{cu}}=90 \mathrm{MPa}$ is shown in Fig. 15. It can be observed that the contact stress increases when $\alpha$ increases from 0.148 to 0.182 . However, the increase in contact stress is small when $\alpha$ increases from 0.182 to 0.217 , as shown in Fig. 15 (b). In particular, the decrease in the contact stress at $h=1 / 2 L$ is presented in Fig. 15 (a) and (c). This may be attributed to the fact that the $\alpha$ value of 0.217 exceeds the normal steel ratio range (4\%-20\%), according to Ref. [38] and provisions of GB 50936 [5]. Hence, although the column confinement factor $(\xi)$ increases with $\alpha$, the improvement in the contact stress (confinement effect) is less effectivewhen $\alpha$ exceeds the normal range. Additionally, the influence of $\alpha$ on contact stress is smaller than that of material strengths.

4.2. Longitudinal stress distribution of concrete in the center of strongly confined zone

To further investigate the concrete stress variation at the center of the strongly confined zone. The influences of several key parameters on the values of $\sigma_{\text {lc-center }} / f_{\mathrm{c}}^{\prime}$ at the peak-loads are depicted in Fig. 16. Fig. 16(a) shows the effect of $f_{\mathrm{y}}$ on $\sigma_{\mathrm{lc}-\mathrm{center}} / f_{\mathrm{c}}^{\prime}$. The $\sigma_{\mathrm{lc}-\mathrm{center}} / f_{\mathrm{c}}^{\prime}$ value at $h=0.5 \mathrm{~L}$ increases by $6.3 \%$ when $f_{\mathrm{y}}$ increases from $566.90 \mathrm{MPa}$ to $838.00 \mathrm{MPa}$, whereas it slightly decreases by $0.4 \%$ when $f_{\mathrm{y}}$ increases from $838.00 \mathrm{MPa}$ to $889.87 \mathrm{MPa}$. The main reason is that the steel tubular buckling tends to occur in the axially loaded column with a relatively high $f_{\mathrm{y}}$ value when the values of $B$ and $t$ are constant, as per AISC 360 [4]. Consequently, the enhancement in $\sigma_{\text {lc-center }} / f_{\mathrm{c}}^{\prime}$ becomes less efficient. From the perspective of increasing $\sigma_{\text {lc-center }} / f_{\mathrm{c}}^{\prime}$, the steel with $f_{\mathrm{y}}=838.00 \mathrm{MPa}$ is a separation point within the limited parameter scopes.

The influence of $f_{\text {cu }}$ on $\sigma_{\text {lc-center }} / f_{\mathrm{c}}^{\prime}$ is illustrated in Fig. $16(\mathrm{~b})$. The $\sigma_{\text {lc-center }} / f_{\mathrm{c}}^{\prime}$ values decrease as $f_{\text {cu }}$ increases because of the reduction in the constraint factor $(\xi)$. As $f_{\text {cu }}$ increases from 70 to $90 \mathrm{MPa}$, and from 90 to $110 \mathrm{MPa}$, the $\sigma_{\text {lc-center }} / f_{\mathrm{c}}^{\prime}$ values at $h=0.5 \mathrm{~L}$ decrease by $4.2 \%$ and $1.4 \%$, respectively. This indicates that the reduction becomes limited as $f_{\text {cu }}$ increases.

The effect of $\alpha$ on $\sigma_{\text {lc-center }} / f_{\mathrm{c}}^{\prime}$ is provided in Fig. 16(c). It can be observed that the values of $\sigma_{\mathrm{lc}-\mathrm{center}} / f_{\mathrm{c}}^{\prime}$ within the range of $h=0-0.21 \mathrm{~L}$ are similar as $\alpha$ increases. The $\sigma_{\mathrm{lc}-\mathrm{center}} / f_{\mathrm{c}}^{\prime}$ value at $h=0.5 \mathrm{~L}$ increases by $1.2 \%$ as $\alpha$ increases from 0.148 to 0.182 , while it decreases by $0.2 \%$ as $\alpha$ increases from 0.182 to 0.217 . Although it is widely known that the confined effect increases with the steel ratio, it can be found that, when the normal steel ratio $(20 \%)$ specified in GB 50936 [5] and reported in Ref. [38] is exceeded, the enhancement in $\sigma_{\text {lc-center }} / f_{\mathrm{c}}^{\prime}$ is less effective, which is similarly observed in Fig. 15.

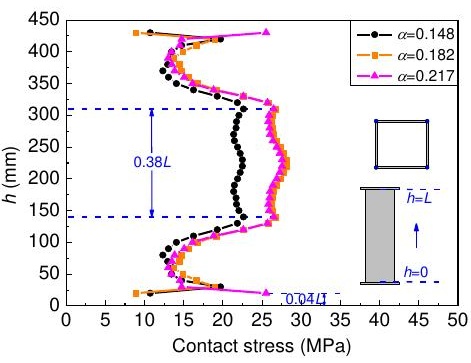

(a) $f_{\mathrm{y}}=566.90 \mathrm{MPa}$

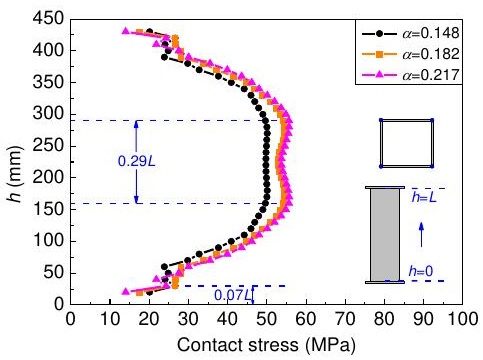

(b) $f_{\mathrm{y}}=780.75 \mathrm{MPa}$

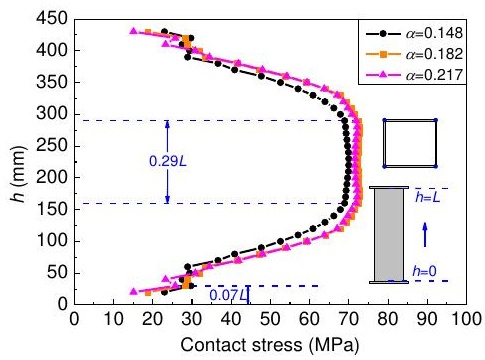

(c) $f_{\mathrm{y}}=889.87 \mathrm{MPa}$

Fig. 15 Effect of $\alpha$ on contact stress

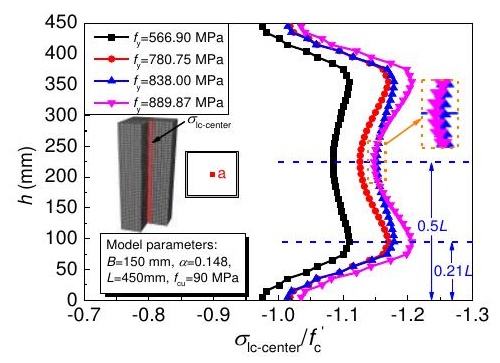

(a) Effect of $f_{\mathrm{y}}$ on $\sigma_{\mathrm{lc}-\mathrm{center}} / f_{\mathrm{c}}$

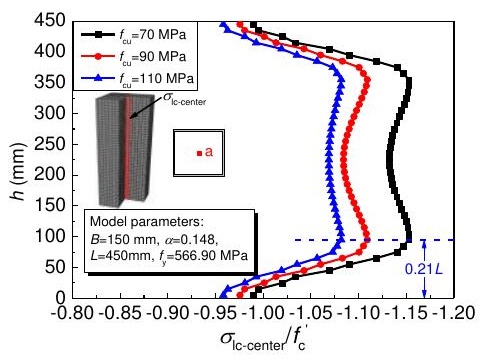

(b) Effect of $f_{\text {cu }}$ on $\sigma_{\text {lc-center }} / f_{\mathrm{c}}$

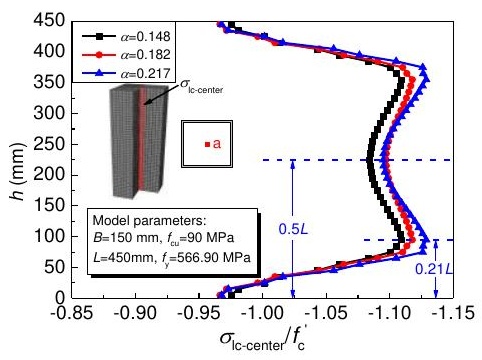

(c) Effect of $\alpha$ on $\sigma_{\mathrm{lc}-\mathrm{center}} / f_{\mathrm{c}}$

Fig. 16 Effects of $f_{\mathrm{y}} f_{\mathrm{cu}}$, and $\alpha$ on $\sigma_{\mathrm{lc}-\mathrm{center}} / f_{\mathrm{c}}$

\section{Calculation of peak-loads}

\subsection{Establishment of high-strength CFST database}

The data on the available 162 test samples and 8 experimental specimens tested in the current study were collected to establish a database of high-strength CFST stub columns. The material strength distributions of the collected CFST samples are shown in Fig. 17.The database (Table 3) consists of information on 48 axially loaded CFST stub columns using conventional-strength steel and high-strength concrete (CSS-HSC), 39 CFSTs adopting high-strength steel and conventional-strength concrete (HSS-CSC), and 83 columns using high-strength steel and high-strength concrete (HSS-HSC). The characteristics of the selected sample data are similar to those of the current investigation and a previous study of the authors [31]. Data on some CFSTs with noncompact or slender sections were also included in this database. As listed in Table 3, both square and rectangular samples were collected, where $B=60 \mathrm{~mm}-300 \mathrm{~mm}, H=60 \mathrm{~mm}-300 \mathrm{~mm}, B / H=1-2$, $t=1.87 \mathrm{~mm}-9.45 \mathrm{~mm}$, slenderness coefficient [4] $\left(\lambda_{\text {coeff }}=b / t\left(f_{\mathrm{y}} / E_{\mathrm{s}}\right)^{1 / 2}\right)=$
0.5-4.9, $\quad b=B-2 t, \quad L / H=2.4-6.1, \quad f_{\mathrm{y}}=250^{\mathrm{d}} \quad \mathrm{MPa}-889.87 \quad \mathrm{MPa}, \quad$ and $f_{\mathrm{c}}$ $\left(f_{\mathrm{cu}}\right)=21^{\mathrm{b}}-121.6^{\mathrm{c}} \mathrm{MPa}$.

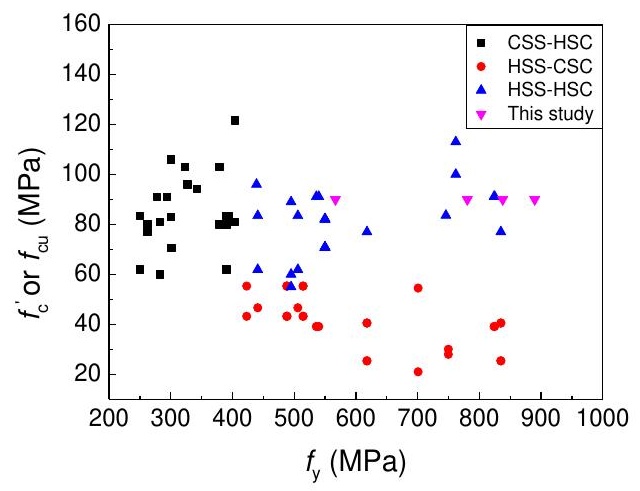

Fig. 17 Strength distributions of materials used in collected test samples 
Table 3

Test database of CFST stub columns using high-strength materials

\begin{tabular}{|c|c|c|c|c|c|c|c|c|}
\hline Source & NS & Type & $B(\mathrm{~mm})$ & $H(\mathrm{~mm})$ & $\lambda_{\text {coeff }}$ & $L / H$ & $f_{\mathrm{y}}(\mathrm{MPa})$ & $f_{\mathrm{c}}^{\prime}$ or $f_{\mathrm{cu}}(\mathrm{MPa})$ \\
\hline Lee et al.[11] & 1 & \multirow{9}{*}{ CSS-HSC } & 300 & 300 & 2.3 & 3 & 301 & $70.5^{\mathrm{a}}$ \\
\hline Sakino et al. [39] & 4 & & $148-215$ & $148-215$ & $1.2-1.7$ & 3 & $262-294$ & $77-91.1^{\mathrm{b}}$ \\
\hline Ibañez et al. [24] & 1 & & 125 & 125 & 1.2 & 2.4 & 342.6 & $94.3^{\mathrm{b}}$ \\
\hline Liu and Gho[40] & 14 & & $120-220$ & $100-200$ & $0.7-1.4$ & $3-5.4$ & 300 & $83-106^{\mathrm{b}}$ \\
\hline Young and Ellobody[41] & 5 & & $150.5-197.6$ & $80.4-150.6$ & $1.8-2.4$ & $3.0-6.0$ & $250-394^{d}$ & $61.9-83.5^{\mathrm{b}}$ \\
\hline Yu et al. [42] & 4 & & 100 & 100 & 2.3 & 3 & 404 & $121.6^{\mathrm{c}}$ \\
\hline Cederwall et al.[43] & 5 & & 120 & 120 & $0.5-0.6$ & 4.2 & $323-390$ & $80-103^{b}$ \\
\hline Han et al. [44] & 14 & & $60-250$ & $60-250$ & $1.1-4.9$ & 3 & $282-404$ & $60-81^{\mathrm{c}}$ \\
\hline Uy [45] & 4 & & $110-160$ & $110-160$ & $1.2-1.8$ & 3 & 750 & $28-30^{\mathrm{b}}$ \\
\hline Sakino et al. [39] & 16 & \multirow{4}{*}{ HSS-CSC } & $120-211$ & $120-211$ & $1.1-1.7$ & 3 & $536-835$ & $25.4-40.5^{b}$ \\
\hline Aslani et al. [15] & 5 & & $110-160$ & $110-160$ & $1.2-1.8$ & $2.7-2.8$ & 701 & $21-54.5^{\mathrm{b}}$ \\
\hline Du et al. [6] & 6 & & $150-203$ & $101-150$ & $0.8-1.3$ & $3.0-6.0$ & 488.38 & $43.2-55.3^{\mathrm{c}}$ \\
\hline Young and Ellobody [41] & 2 & & $140.2-150.5$ & $80.1-150.5$ & $1.2-2.0$ & $3.0-5.2$ & $441-506^{d}$ & $46.6^{\mathrm{b}}$ \\
\hline Du et al. [46] & 6 & \multirow{11}{*}{ HSS-HSC } & $120-182$ & $100-122$ & $1.0-1.5$ & $3.6-4.6$ & $423.2-514.5$ & $43.2-55.3^{\mathrm{c}}$ \\
\hline Lee et al. [11] & 1 & & 300 & 150 & 3.5 & 6 & 746 & $83.6^{\mathrm{a}}$ \\
\hline Sakino et al. [39] & 8 & & $119-211$ & $119-211$ & $1.1-1.7$ & 3 & $536-835$ & $77-91.1^{\mathrm{b}}$ \\
\hline Liu [47] & 22 & & $106-190$ & $80-140$ & $1.2-2.3$ & $3-6$ & 495 & $60-89^{\mathrm{b}}$ \\
\hline Khan et al. [7] & 6 & & $124.4-199.0$ & $124.4-199.0$ & $1.4-2.4$ & $3.4-5.3$ & 762 & $100-113^{\mathrm{b}}$ \\
\hline Liu and Gho[40] & 12 & & $120-190$ & $90-130$ & $1.4-2.3$ & $3-6$ & 495 & $55^{\mathrm{b}}$ \\
\hline Young and Ellobody [41] & 4 & & $140.2-150.6$ & $80.0-150.6$ & $1.2-2.0$ & $3.0-5.3$ & $441-506^{\mathrm{d}}$ & $61.9-83.5^{\mathrm{b}}$ \\
\hline Cederwallet al.[43] & 1 & & 120 & 120 & 0.6 & 4.2 & 439 & $96^{\mathrm{b}}$ \\
\hline Liu et al. [48] & 21 & & $100.3-200.2$ & $80.1-181.2$ & $1.2-2.4$ & $3.0-6.1$ & 550 & $70.8-82.1^{\mathrm{c}}$ \\
\hline This study & 8 & & 150 & 150 & $1.5-1.9$ & 3 & $566.9-889.87$ & $90^{c}$ \\
\hline Total & 170 & & $60-300$ & $60-300$ & $0.5-4.9$ & $2.4-6.1$ & $250^{\mathrm{d}}-889.87$ & $21^{\mathrm{b}}-121.6^{\mathrm{c}}$ \\
\hline
\end{tabular}

Note: NS $=$ number of the collected samples; $B \geq H$; for concrete strength, ${ }^{\text {a }}$ indicates the 100 -mm diameter concrete cylinder strength; ${ }^{\mathrm{b}}$ represents the standard cylinder strength; ${ }^{\mathrm{c}}$ denotes the concrete cube strength obtained from tests on $150 \times 150 \times 150-\mathrm{mm}^{3}$ blocks; ${ }^{\mathrm{d}}$ indicates the yield strength obtained from the hollow stub column tests.

\subsection{Comparisons among various design codes}

Eurocode 4 [3] regulates that the peak-load $\left(N_{\mathrm{pl}, \mathrm{Rk}}\right)$ of the concentrically compressed square CFST stub column can be computed according to Eq. (6), which is presented as follows based on the superposition method:

$N_{\mathrm{pl}, \mathrm{Rk}}=f_{\mathrm{y}} A_{\mathrm{s}}+f_{\mathrm{c}}^{\prime} A_{\mathrm{c}}$

According to the tube slenderness (width-to-thickness ratio, i.e., b/t) classifications listed in Table I1.1a of AISC 360 [4], the ultimate capacities $\left(P_{\mathrm{n} 0}\right)$ of CFST stub columns with various sections are determined using Eqs. (7)-(10).In these equations, at the peak-load, the strengths of steel $\left(f_{\mathrm{y}}\right)$ and concrete $\left(f_{\mathrm{c}}^{\prime}\right)$ are not exerted simultaneously, which is different from Eurocode 4 [3]. A coefficient of 0.85 is adopted in AISC 360 [4] to consider the reduction in the concrete strength of rectangular CFSTs with compact sections, becausethe strength of core concrete in CFSTs differs from the standard concrete strength, and the initial load eccentricity exists in the columns [12]. As provided in Eq. (7), for noncompact columns with $\lambda=\lambda_{\mathrm{r}}$, the ultimate capacityis $P_{\mathrm{n} 0}=P_{\mathrm{y}}$, and $P_{\mathrm{y}}$ is given in Eq. (9), indicating that although steel experiences local buckling, the steel stress can also attain $f_{\mathrm{y}}$. However, the concrete stress $\left(0.70 f_{\mathrm{c}}^{\prime}\right)$ is less than that in Eq. (8), because the confinement generated by the noncompact sectional steel tube is inadequate. Moreover, when calculating the peak-loads of slender columns, the critical buckling stress $\left(F_{\text {cr }}\right)$ is used instead of $f_{\mathrm{y}}$ in AISC 360 [4] due to the elastic buckling of the steel tube, and the concrete stress can reach $0.7 f_{\mathrm{c}}^{\prime}$, as expressed in Eq. (7).

$P_{\mathrm{n} 0}=\left\{\begin{array}{lr}P_{\mathrm{p}} & \text { Compact sections }\left(\lambda \leq \lambda_{\mathrm{p}}\right) \\ P_{\mathrm{p}}-\frac{P_{\mathrm{p}}-P_{\mathrm{y}}}{\left(\lambda_{\mathrm{r}}-\lambda_{\mathrm{p}}\right)^{2}}\left(\lambda-\lambda_{\mathrm{p}}\right)^{2} & \text { Noncompact sections }\left(\lambda_{\mathrm{p}}<\lambda \leq \lambda_{\mathrm{r}}\right) \\ F_{\mathrm{cr}} A_{\mathrm{s}}+0.7 f_{\mathrm{c}}^{\prime} A_{\mathrm{c}} & \text { Slender sections }\left(\lambda>\lambda_{\mathrm{r}}\right)\end{array}\right.$

$P_{\mathrm{p}}=f_{\mathrm{y}} A_{\mathrm{s}}+0.85 f_{\mathrm{c}}^{\prime} A_{\mathrm{c}}$

$P_{\mathrm{y}}=f_{\mathrm{y}} A_{\mathrm{s}}+0.70 f_{\mathrm{c}}^{\prime} A_{\mathrm{c}}$

$F_{\mathrm{cr}}=9 E_{\mathrm{s}} /(b / t)^{2}$ where $\lambda$ is the tube slenderness ratio, $\lambda=b / t, \lambda_{\mathrm{p}}=2.26 \cdot\left(E_{\mathrm{s}} / f_{\mathrm{y}}\right)^{1 / 2}$, and $\lambda_{\mathrm{l}}=3.00 \cdot\left(E_{\mathrm{s}} f_{\mathrm{y}}\right)^{1 / 2}$.

Compared with Eurocode 4 [3] and AISC 360 [4], the confined action of the steel tube is considered in GB 50936 [5] on the basis of the unified theory. The peak-load $\left(N_{0}\right)$ calculation equation is given as follows:

$N_{0}=A_{\mathrm{sc}} f_{\text {scy }}$

$f_{\text {scy }}=\left(1.212+B \theta+C \theta^{2}\right) f_{\mathrm{ck}}$

$\theta=\frac{A_{\mathrm{s}} f_{\mathrm{y}}}{A_{\mathrm{c}} f_{\mathrm{ck}}}$

$B=0.131 f_{\mathrm{y}} / 235+0.723$

$C=-0.070 f_{\mathrm{ck}} / 20+0.026$

where $f_{\text {scy }}$ is the compressive strength of the composite section; $A_{\text {sc }}$ is the area of the cross-section; and $\theta$ is the confined factor.

The peak-loads of the axially loaded CFST stub columns were calculated by utilizing the formulas provided in Eurocode 4 [3], AISC 360 [4], and GB 50936 [5]. The results are summarized in Table 4 and shown in Figs. 18-21. The concrete strengths specified in these design codes were determined based on the respective regulation and Ref. [31].

Table 4

Peak-load calculations

\begin{tabular}{|c|c|c|c|c|c|c|c|}
\hline \multirow{2}{*}{ Type } & \multirow{2}{*}{ NS } & \multicolumn{2}{|c|}{ Eurocode 4} & \multicolumn{2}{|c|}{ AISC 360} & \multicolumn{2}{|c|}{ GB 50936} \\
\hline & & Average & $\mathrm{COV}$ & Average & $\mathrm{COV}$ & Average & $\mathrm{COV}$ \\
\hline CSS-HSC & 48 & 1.04 & 0.07 & 0.91 & 0.12 & 1.00 & 0.06 \\
\hline HSS-CSC & 39 & 0.96 & 0.09 & 0.93 & 0.09 & 0.92 & 0.11 \\
\hline HSS-HSC & 83 & 0.97 & 0.07 & 0.91 & 0.07 & 0.94 & 0.06 \\
\hline All test samples & 170 & 0.99 & 0.08 & 0.91 & 0.09 & 0.95 & 0.08 \\
\hline
\end{tabular}

Note: NS = number of collected samples; Average $=$ mean ratio value of calculation to test results; and $\mathrm{COV}=$ Coefficientof Variation. 


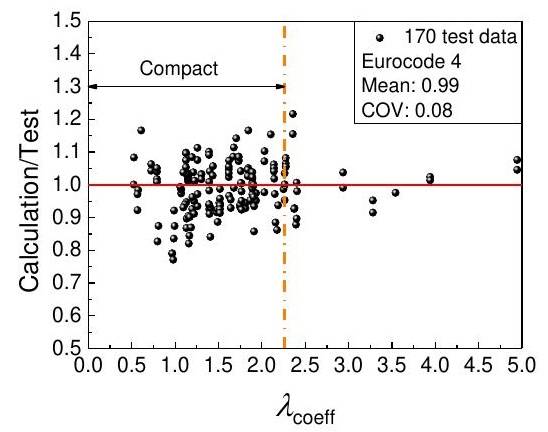

(a) Eurocode 4

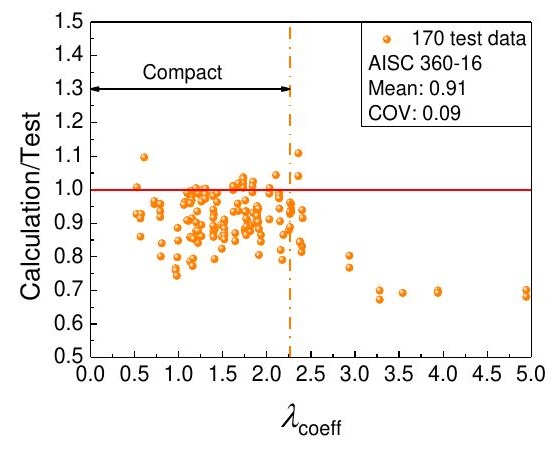

(b) AISC 360

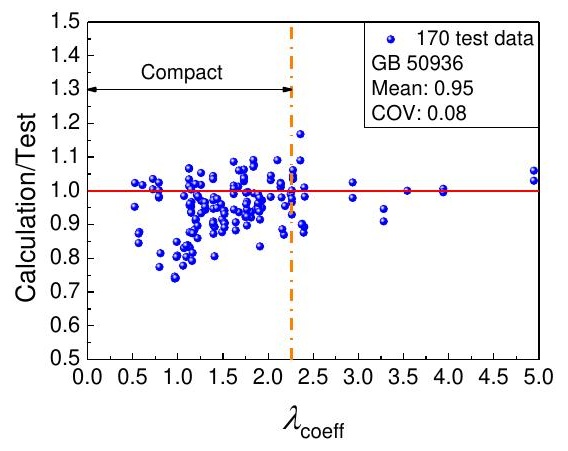

(c) GB 50936

Fig. 18 Ultimate bearing capacity evaluations of collected 170 test samples

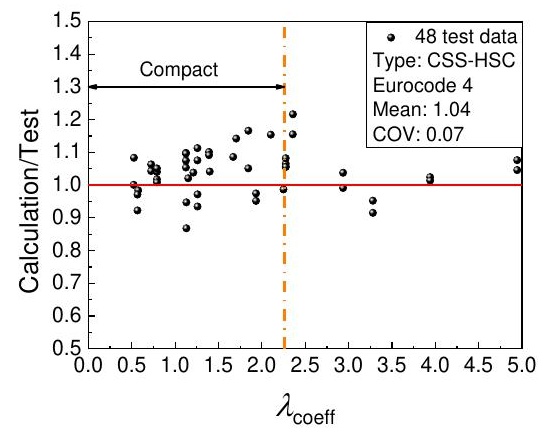

(a) Eurocode 4

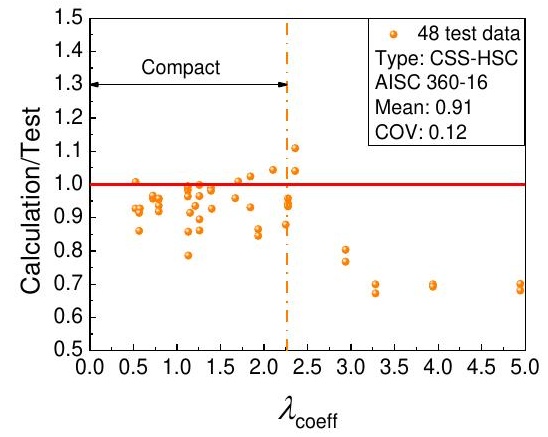

(b) AISC 360

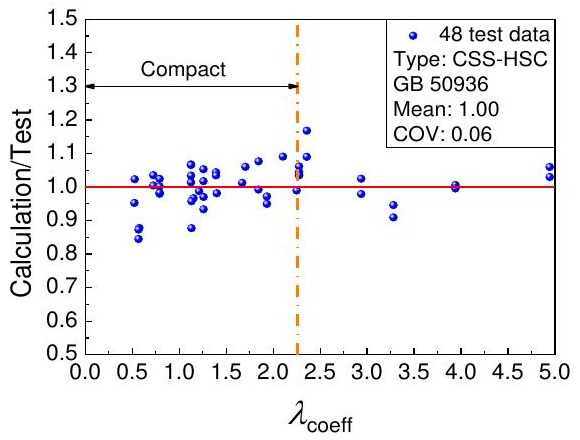

(c) GB 50936

Fig. 19 Ultimate bearing capacity evaluations of CSS-HSC columns

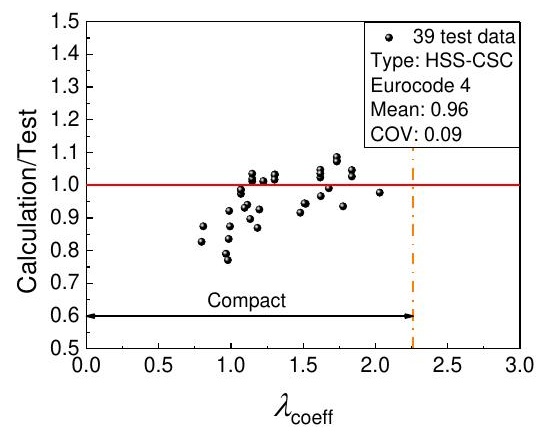

(a) Eurocode 4

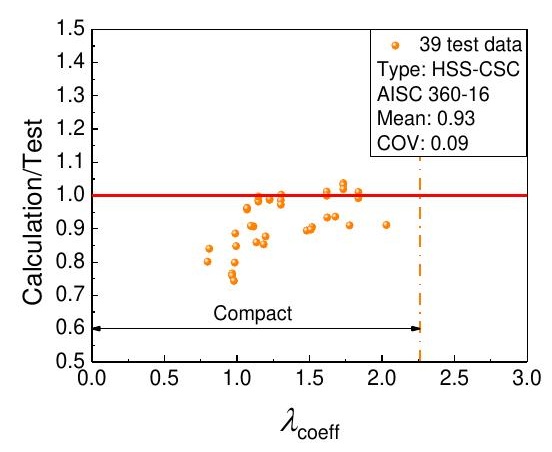

(b) AISC 360

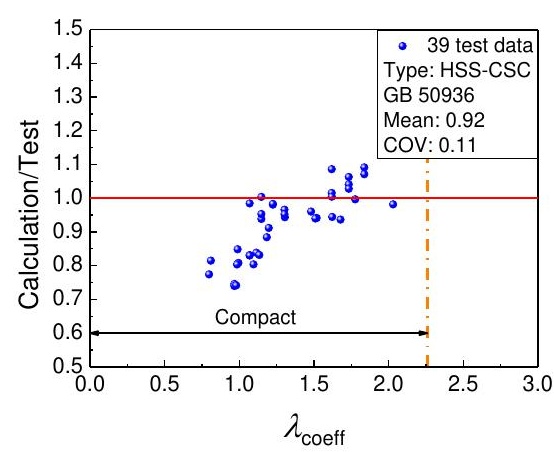

(c) GB 50936

Fig. 20 Ultimate bearing capacity evaluations of HSS-CSC columns

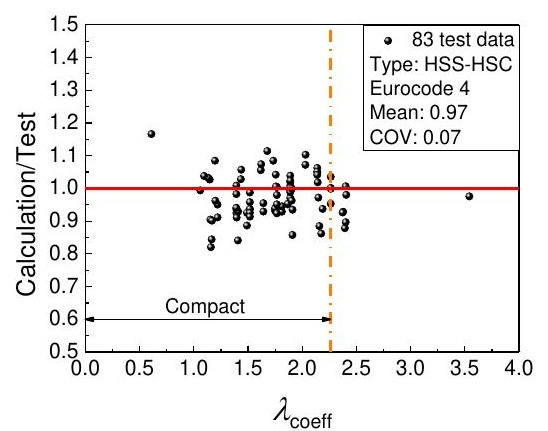

(a) Eurocode 4

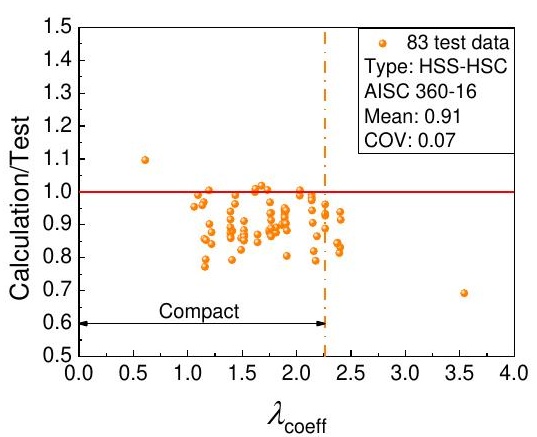

(b) AISC 360

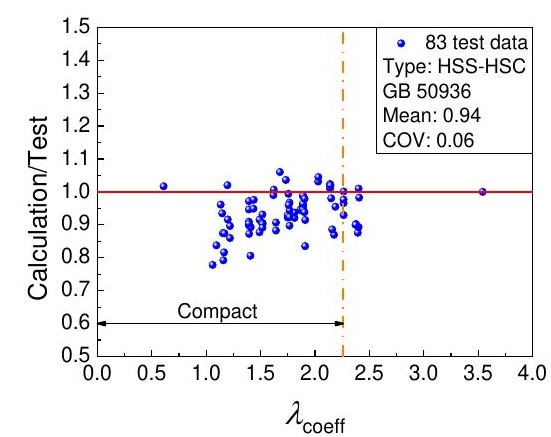

(c) GB 50936

Fig. 21 Ultimate bearing capacity evaluations of HSS-HSC columns

According to Table 4 and Fig. 18, the calculations of Eurocode 4 [3] are overall closer to the test results (average ratio of calculation to test equals to 0.99) than those of other codes.Compared with Eurocode 4 [3], the predictions of AISC 360 [4] are conservative. In particular, for columns with slender cross-sections, AISC 360 [4] presents the most conservative trend (Fig. 18) compared with other design codes, due to the consideration of material strength reductions.Additionally, compared with AISC 360 [4], GB 50936 [5] provides better predictions on average, with a smaller scatter, due to the consideration of confined action. 


\subsection{Further discussions on utilization efficiency of material strengths}

The utilization efficiency of material strengths is discussed in this Section based on further data analyses (Figs. 19 to 21). The calculation results of Eurocode 4 [3] are mainly used for comparison to clarify the corresponding findings, because Eurocode 4 [3] considers that the strengths of steel $\left(f_{\mathrm{y}}\right)$ and concrete $\left(f_{c}^{\prime}\right)$ can be simultaneously exerted when the columns achieve the peak-loads.

As demonstrated in Table 4 and Fig. 19, when calculating the peak-loads of CFST stub columns with CSS-HSC, the calculations of Eurocode 4 [3] are unsafe because of the following reasons. For the CSS-HSC cases, the CSS provides insufficient confinements on the HSC; consequently, steel tubular buckling may occur before yielding, and the load sustained by the steel tube decreases. Finally, the CFST column and concrete achieve their ultimate strengths simultaneously; hence, at the ultimate load, the longitudinal stress in the steel tube is lower than $f_{\mathrm{y}}$. Additionally, since the HSC is a more brittle material compared with CSC, its premature crushing may prevent the complete development of the concrete strength.

When evaluating the peak-loads of CFSTs with HSS-CSC, although Eurocode 4 [3] presents conservative predictions (Table 4 and Fig. 20) on average, more numbers of unsafe sample data points can be found in its calculations [3] than in the predictions of other design codes (Fig. 20). This is because the CSC tends to be crushed before the peak-load of the column is reached. Then, the concrete dilates rapidly, resulting in steel tubular premature buckling. Thereafter, steel strength may not be adequately exerted.

Although the columns using HSS can provide more sufficient confinement to the inner HSC than columns utilizing CSS, numerous unconservative sample data points are also found in the predictions of Eurocode 4 [3], as shown in Fig. 21. This is because steel tubular buckling tends to occur in the CFST column with a higher $f_{\mathrm{y}}$, thereby reducing the steel strength. Additionally, the size effect influences the property of HSC, which means that the maximum stress in the HSC is lower than that obtained by thecylindrical concrete test (i.e., $f_{\mathrm{c}}^{\prime}$ ).

\subsection{Further discussions on peak-load predictions of compact CFSTs}

As specified in AISC 360 [4], the steel yield strength $\left(f_{\mathrm{y}}\right)$ can be fully exerted in the CFST stub columns with compact sections $\left(b / t \leq 2.26 \cdot\left(E_{\mathrm{s}} / f_{\mathrm{y}}\right)^{1 / 2}\right)$. However, the local buckling effect is more pronounced in columns with noncompact and slender sections [4]. Given this background, the peak-loads of compact sectional CFSTs should be further assessed to derive useful insights for engineering applications. The detailed results are tabulated in Table 5 .

Based on Table 5, for predicting the peak-loads of compact CFST stub columns, Eurocode 4 [3] overall presents better results followed by codes GB 50936 [5] and AISC 360 [4], respectively. However, in the CSS-HSC cases, the predictions of Eurocode 4 [3] are unconservative, as similarly evidenced by the results listed in Table 4.In general, it is worth noting that the predictions of AISC 360 [4] and GB 50936 [5] are similar. Both codes yield conservative calculations, and the overall errors between the two are within 4\%. Although GB 50936 [5] conforms better with the test results than AISC 360 [4], the former yields more unconservative calculations for compact CFST stub columns, as presented in Figs. 18-21. In terms of safety, AISC 360 [4] can be utilized in the field applications of compact CFST stub columns using high-strength materials.

\section{Table 5}

Peak-load calculations of compact CFSTs

\begin{tabular}{|c|c|c|c|c|c|c|c|}
\hline \multirow{2}{*}{ Type } & \multirow{2}{*}{ NS } & \multicolumn{2}{|c|}{ Eurocode 4} & \multicolumn{2}{|c|}{ AISC 360} & \multicolumn{2}{|c|}{ GB 50936} \\
\hline & & Average & $\mathrm{COV}$ & Average & $\mathrm{COV}$ & Average & $\mathrm{COV}$ \\
\hline CSS-HSC & 34 & 1.04 & 0.07 & 0.94 & 0.06 & 0.99 & 0.06 \\
\hline HSS-CSC & 39 & 0.96 & 0.09 & 0.93 & 0.09 & 0.92 & 0.11 \\
\hline HSS-HSC & 72 & 0.98 & 0.07 & 0.91 & 0.07 & 0.94 & 0.07 \\
\hline All test samples & 145 & 0.99 & 0.08 & 0.92 & 0.07 & 0.95 & 0.08 \\
\hline
\end{tabular}

Note: NS = number of the collected samples; Average = mean ratio value of calculation to test results; $\mathrm{COV}=$ Coefficientof Variation .

\section{Conclusions}

The use of high-strength materials in CFST columns has promising prospects. High-strength square CFST columns generally exhibit complex performances including local and post-local buckling behaviors, brittle concrete crushing, and inhomogeneous steel-concrete interaction. To systematically reveal these mechanical responses, an experimental study was performed on eight specimens considering variations in the yield strength of steel. Numerical investigations were also conducted to explore the structural performance of the columns. An experimental database of high-strength CFST stub columns consisting of 170 group test data was established, and the applicability of current design codes was assessed based on this database. The conclusions derived within the parameter scope of the current study are summarized as follows:

(1) Axially compressed HCFHSST stub columnsexperienced failure modes incorporating steel tubular buckling and concrete crushing. The experimental results demonstrated that the CFST columns fabricated using steels with $f_{\mathrm{y}}=838.00 \mathrm{MPa}$ and $889.87 \mathrm{MPa}$ exhibited more adequate residual mechanical behaviors than those with steels of $f_{\mathrm{y}}=566.90 \mathrm{MPa}$ and 780.75 $\mathrm{MPa}$.

(2) After the steel tube buckles, itcontinues to confine the concrete around the buckled positions, resulting in an increase in the longitudinal concrete stress in those regions. The steel tube-concrete contact stress primarily exists at the corner region, which concentrates $0.29 \mathrm{~L}$ or $0.38 \mathrm{~L}$ inthe middle of the column. Before the peak-load is reached or when the constraint factor is relatively small, the contact stress near the column end is relatively high.

(3) Based on the parametric results, the $f_{\mathrm{y}}$ value of $838.00 \mathrm{MPa}$ can be regarded as a separation point for the improvement in the concrete strength $\left(\triangle f_{\mathrm{c}}^{\prime}\right)$ generated by the confinement action. Moreover, to achieve effective confinement effects and $\triangle f_{\mathrm{c}}^{\prime}$, the steel ratio of the column is suggested to be less than $20 \%$.

(4) The formulas provided in Eurocode 4, AISC 360, and GB 50936 are overall conservative to predict the peak-loads of axially loaded CFST stub columns fabricated using high-strength materials. Eurocode 4 is more accurate (calculation/test $=0.99$ and $\mathrm{COV}=0.08$ ) on average but unconservative for columns with CSS-HSC. The AISC 360 equations can be safely utilized for predicting the peak-loads of axially loaded high-strength CFST stub columns with compact sections.

\section{Acknowledgments}

This work was supported by the Key Project of National Natural ScienceFoundation of China, China (51938009), National Natural Science Foundation of China, China (51878419), and Liaoning Climbing Scholar Support Program, China (2018-0101).

\section{References}

[1] Xiong M.X., Xiong D.X. and Liew J.Y.R., "Behaviour of steel tubular members infilled with ultra high strength concrete", Journal of Constructional Steel Research, 138, 168-183, 2017.

[2] Xiang P., Ge H.B. and Jia L.J., "Advancement and applications of Japanese high performance steel in structural engineering", Advanced Steel Construction, 12(3): 245-262, 2016.

[3] Eurocode 4, Design of Composite Steel and Concrete Structures-Part 1-1: General Rules and Rules for Buildings, European Committee for Standardization, Brussels, 2004.

[4] ANSI/AISC360-16, Specification for Structural Steel Buildings, American Institute of Steel Construction, U.S., Chicago, 2016.

[5] GB50936-2014, Technical Code for Concrete filled Steel Tubular Structures, Ministry of Housing and Urban-Rural Development of the People's Republic of China, China Architecture \& Building Press, Beijing, 2014 (in Chinese).

[6] Du Y.S., Chen Z.H. and Xiong M.X., "Experimental behavior and design method of rectangular concrete-filled tubular columns using Q460 high-strength steel", Construction and Building Materials, 125, 856-872, 2016.

[7] Khan M., Uy B., Tao Z. and Mashiri F., "Behaviour and design of short high-strength steel welded box and concrete-filled tube (CFT) sections", Engineering Structures. 147, 458-472, 2017.

[8] Xiong M.X., Xiong D.X. and Liew J.Y.R., "Axial performance of short concrete filled stee tubes with high-and ultra-high-strength materials", Engineering Structures, 136, 494-510, 2017.

[9] Thai S., Thai H.T., Uy B. and Ngo T., "Concrete-filled steel tubular columns: Test database, design and calibration", Journal of Constructional Steel Research, 157, 161-181, 2019.

[10] Yan Y.X., Xu L.H., Li B., Chi Y., Yu M., Zhou K.K. and Song Y., "Axial behavior of ultra-high performance concrete (UHPC) filled stocky steel tubes with square sections", Journal of Constructional Steel Research, 158, 417-428, 2019.

[11] Lee H.J., Park H.G. and Choi I.R., "Compression loading test for concrete-filled tubula columns with high-strength steel slender section", Journal of Constructional Steel Research, 159, 507-520, 2019.

[12] Lai Z.C. and Varma A.H., "High-strength rectangular CFT members: Database, modeling, and design of short columns", Journal of Structural Engineering, 144(5), 04018036, 2018.

[13] Lam D. and Williams C.A., "Experimental study on concrete filled square hollow sections", Steel and Composite Structures, 4(2), 95-112, 2004.

[14] Guler S., Çopur A. and Aydogan M., "A comparative study on square and circular high strength concrete-filled steel tube columns", Advanced Steel Construction, 10(2), 234-247, 2014.

[15] Aslani F., Uy B., Tao Z. and Mashiri F., "Behaviour and design of composite columns incorporating compact high-strength steel plates", Journal of Constructional Steel Research, $107,94-110,2015$

[16] Liang Q.Q. and Fragomeni S., "Nonlinear analysis of circular concrete-filled steel tubula short columns under axial loading", Journal of Constructional Steel Research, 65(12), 
2186-2196, 2009.

[17] Patel V.I., Hassanein M.F., Thai H.T., Al Abadi H., Elchalakani M. and Bai Y., "Ultra-high strength circular short CFST columns: Axisymmetric analysis, behaviour and design", Engineering Structures, 179, 268-283, 2019.

[18] Wei J.G., Luo X., Lai Z.C. and Varma A.H., "Experimental behavior and design of high-strengthcircular concrete-filled steel tube short columns", Journal of StructuralEngineering, 146(1): 04019184, 2020.

[19] Architectural Institute of Japan (AIJ). Recommendations for design and construction of concrete-filled steel tubular structures. Tokyo, 333, 1997.

[20] Kang W.H., Uy B., Tao Z. and Hicks S., "Design strength of concrete-filled steel columns", Advanced Steel Construction, 11(2), 165-184, 2015.

[21] AS 5100.6 - 2004, Bridge Design - Part 6: Steel and Composite Construction, Standards Australia, Sydney, 2004

[22] Lai B.L., Liew J.Y.R. and Xiong M.X, "Experimental and analytical investigation of composite columns made of high strength steel and high strength concrete", Steel and Composite Structures, 33(1), 67-79, 2019.

[23] Yang C., Yu Z.X., Sun Y.P., Zhao L. and Zhao H., "Axial residual capacity of circular concrete-filled steel tube stub columns considering local buckling", Advanced Steel Construction, 14(3), 496-513, 2018

[24] Ibañez C., Hernández-Figueirido D. and Piquer A., "Shape effect on axially loaded high strength CFST stub columns", Journal of Constructional Steel Research, 147, 247-256, 2018

[25] Zhou X.H., Gan D., Liu J.P. and Chen Y.F., "Composite effect of stub square steel tubed columns under axial compression", Advanced Steel Construction, 14(2), 274-290, 2018.

[26] Xu J.J., Chen Z.P., Xiao Y., Demartino C. and Wang J.H., "Recycled aggregate concrete in FRP-confined columns: a review of experimental results", Composite Structures, 174, 277-291, 2017.

[27] Wang H.Y. and Zha X.X., "Axial strength of CFST columns considering concrete age", Advanced Steel Construction, 10(2), 139-150, 2014.

[28] Wang Y.B. and Liew J.Y.R., "Constitutive model for confined ultra-high strength concrete in steel tube", Construction and Building Materials, 126, 812-822, 2016.

29] Zhang S.M., Guo L.H., Ye Z.L. and Wang Y.Y., "Behavior of steel tube and confined high strength concrete for concrete-filled RHS tubes", Advances in Structural Engineering, 8(2), $101-116,2005$

[30] Wang Q.W., Shi Q.X., Lui E.M. and Xu Z.D., "Axial compressive behavior of reactive powder concrete-filled circular steel tube stub columns", Journal of Constructional Steel Research, 153, 42-54, 2019.

[31] Li G.C., Chen B.W., Yang Z.J. and Feng Y.H., "Experimental and numerical behaviour of eccentrically loaded high strength concrete filled high strength square steel tube stub columns", Thin-Walled Structures. 127, 483-499, 2018.

[32] Tao Z., Wang Z.B. and Yu Q., "Finite element modelling of concrete-filled steel stub columns under axial compression”, Journal of Constructional Steel Research, 89, 121-131, 2013.

[33] Lin S.Q. and Zhao Y.G., "Numerical study of the behaviors of axially loaded large-diameter CFT stub columns", Journal of Constructional Steel Research, 160, 54-66, 2019.

[34] Han L.H., Yao G.H. and Tao Z., "Performance of concrete-filled thin-walled steel tubes under pure torsion", Thin-Walled Structures, 45(1), 24-36, 2007.

[35] ACI 363R-92 (1997), State-of-the-Art Report on High-Strength Concrete, ACI Committee 363 ; Detroit.

[36] Logan, A., Choi, W., Mirmiran, A., Rizkalla, S. and Zia, P., "Short-term mechanical properties of high-strength concrete", ACI Materials Journal, 106(5), 1-7, 2009.

[37] Li G.C., Yang Z.J. and Lang Y., "Experimental behavior of high strength concrete-filled square steel tube under bi-axial eccentric loading", Advanced Steel Construction, 6(4): 963-975, 2010.

[38] Yang Y.L., Wang Y.Y. and Fu F., "Effect of reinforcement stiffeners on square concrete-filled steel tubular columns subjected to axial compressive load", Thin-Walled Structures, 82, 132-144, 2014

[39] Sakino K., Nakahara H., Morino S. and Nishiyama I., "Behavior of centrally loaded concrete filled steel-tube short columns", Journal of Structural Engineering, 130(2), 180-188, 2004.

[40] Liu D.L. and Gho W.M., "Axial load behaviour of high-strength rectangular concrete-filled steel tubular stub columns", Thin-Walled Structures, 43(8), 1131-1142, 2005.

[41] Young B. and Ellobody E., "Experimental investigation of concrete-filled cold-formed high strength stainless steel tube columns", Journal of Constructional Steel Research, 62, 484-492, 2006.

[42] Yu Q., Tao Z. and Wu Y.X., "Experimental behaviour of high performance concrete-filled steel tubular columns", Thin-Walled Structures, 46, 362-370, 2008.

[43] Cederwall K., Engstrom B. and Grauers M., "High-strength concrete used in composite columns", Special Publication, 121, 195-214, 1990.

[44] Han L.H., Yao G.H. and Zhao X.L., "Tests and calculations for hollow structural steel (HSS) stub columns filled with self-consolidating concrete (SCC)", Journal of Constructional Steel Research, 61, 1241-1269, 2005.

[45] Uy B., "Strength of short concrete filled high strength steel box columns", Journal of Constructional Steel Research, 57(2), 113-134, 2001

[46] Du Y.S., Chen Z.H. and Yu Y.J., "Behavior of rectangular concrete-filled high-strength steel tubular columns with different aspect ratio", Thin-Walled Structures, 109, 304-318, 2016.

[47] Liu D.L., "Tests on high-strength rectangular concrete-filled steel hollow section stub columns", Journal of Constructional Steel Research, 61(7), 902-911, 2005.

[48] Liu D.L., Gho W.M. and Yuan J., "Ultimate capacity of high-strength rectangular concrete-filled steel hollow section stub columns", Journal of Constructional Steel Research, 59(12), 1499-1515, 2003. 


\title{
DAMPING PERFORMANCE EXPERIMENT AND DAMAGE ANALYSIS OF REPLACEMENT CONNECTION WITH LOW-YIELD-POINT STEEL
}

\author{
Hao-Xiang He ", Li-Can Liao and Shi-Tao Cheng
}

Beijing Key Laboratory of Earthquake Engineering and Structural Retrofit, Beijing University of Technology of Technology, Beijing, China.

*(Corresponding author: E-mail: hhx7856@163.com)

\section{A B S T R A C T}

The performance design for traditional steel rigid connection cannot fulfill the desired seismic requirements. Though beam column connection with weaken beam end can approximately realize the concept about "strong column-weak beam", the local buckling and the distortion buckling in the weaken zone and the total lateral damage maybe occur in rare earthquake and the capacity is not enough. The replacement connection with low-yield-point steel (LYPS) is proposed base on the idea of resilient structure, and its weakened parts in the flange slab and web plate are filled with LYPS. During earthquake, the LYPS primarily yields and fully dissipates energy. The damage of the main parts in the connection is minor and the LYPS can be replaced after the earthquake. According to the insufficiency of the traditional damage models, the damage model based on differential ratio of elastic plastic dissipated energy is proposed. Low cycle loading experimental research is carried out on three kinds of beam-column connections, which involve the classic connection, the beam end weaken connection and the replacement connection. Comprehensive assessments of damping performance are proposed through a variety of performance evaluation parameters. It is approved that the replacement connection has much more excellent bearing capacity, ductility and energy consumption ability. In addition, the proposed energy damage index can represent damage evolution process and damage law.

\section{A R T I C LE H I S T O RY}

$\begin{array}{ll}\text { Received: } & \text { 24 June } 2020 \\ \text { Revised: } & \text { 2 February 2021 } \\ \text { Accepted: } & \text { 6 February 2021 }\end{array}$

\section{K E Y W O R D S}

Low-yield-point steel;

Beam-column connection

Seismic damage model;

Damage index;

Energy dissipation;

Resilient structure;

Damping performance

\section{Introduction}

For seismic design of high-rise steel structures, the design pattern and the energy-dissipating ability of beam-column connection play a significant role, which markedly affect the stability and safety of the whole steel frame. The current common forms of beam-column connection include the column-through type, the type that beam flange is welded with the column and the type that web plate is welded with column or fixed by high-strength bolts.

In the initial study of the steel connection design, the steel flanges is assumed to resist all the bending moments while the web in the beam merely resist all the shear forces. In fact, the bending capacity of the connection occupies up to $80 \%$ of the capacity of the beam, which derogates from the fundamental principle of strong connection and weak beam in earthquake design philosophy [1-3]. During the earthquake occurred in Northridge and Kobe, the phenomenon that the brittle fractures occurred on the rigid connection in many steel structures has urged many researchers to proposed a range of solutions to deal with this adverse situation. Among them, the plastic hinge offset method has become a hot topic in many fields of research, which advocates the shift of stress concentration zone of beams from the vicinity of the connection to the exterior zone [4]. In actual engineering processing mode, the beam end weaken type and the beam end strengthen type are mainly adopted $[5,6]$.

The typical representatives of the beam end weakening connection include the dog-bone connection and the web opening connection [7-10]. However, the beam weaken connection still has the deficiencies as follows. First, when the flange or web is weakened, it is easy to produce large yield deformation at the weakened position. Secondly, due to the weakening of the structure, the bearing capacity and stiffness of the structure are reduced, which is easy to damage and difficult to repair after earthquake. Thirdly, local buckling and global lateral displacement may occur in the weakened zone under strong earthquake, and the safety reserve capacity is insufficient. If subjected to strong earthquake or multiple aftershocks, severe buckling or even fracture may occur in the weakened zone.

On the other hand, the flange or web near the end of the beam will still yield first, although it can dissipate energy, but it is easy to appear irrecoverable damage, which makes the repair of the structure very difficult after the earthquake. Hence, it indicates that there is still something to be improved in the constructional measures and material of the beam-column connection.

In recent studies, the idea about resilient structures has been proposed and developed gradually. The resilient structure has various ways to be achieved in the structural form [11-13]. However, due to the extreme complicacy of construction technology and seismic design, the researches on the replaceability and resilience of steel structure members after serious damage need to be strengthened, and the engineering applications are still less [14-17].

In view of this, a replaceable steel beam-column connection with low-yield- point steel (LYPS) is proposed in order to resolve the existing deficiencies of the beam end weaken connection. For the new connection, the weakened areas in beam are filled with LYPS, which can primarily deform and consume energy fully in earthquake, thus the overall energy dissipation performance is improved. Moreover, the accumulated plastic strain is basically confined to the low-yield-point steel by reasonably setting the weaken size and filling zone, so as to avoid large deformation of beams, therefore, the repair work of the connection after the earthquake can be completed quickly and easily, which represents the idea of structural resilience.

From the perspective of structural seismic evaluation, the structural seismic performance can be represented by means of the damage model or the damage index. Researchers have proposed a variety of types of damage models, including the model based on maximum deformation and relevant improved models [18], the models based on stiffness variation [19], the models based on energy [20], the models based on deformation-energy double criterion and improve the models [21-23], etc. However, most damage models lack explicit mechanisms and sufficient accuracies. Hence, it is significant to develop an accurate, convenient and adaptable dynamic damage model or damage index.

In summary, the traditional connections, the weakened steel connections and the replacement steel connections with LYPS are simulated by finite element method and the experimental specimens are manufactured, and the different types of connections are tested and compared, which proves that the replacement steel connections are more capable of energy dissipation. Besides above study, a seismic damage model based on elastic-plastic energy dissipation different ratio are put forward on the basis of existing research so that we can characterize the damage evolution process and performance level of steel components.

\section{Construction of replacement steel connection}

The main types of weakened connections mainly include flange weaken type and web opening type. The design parameters of weaken part of flange can be calculated according to reference [24]. As shown in Fig. $1, b_{f}$ and $h_{b}$ is the flange width and section height of the beam, respectively. $a$ is the length from the weakening initiation point to the column surface, and it can be taken as $0.50 b_{f}$ $\sim 0.75 b_{f}$. The weakening length $b$ can be taken as $0.65 h_{b} \sim 0.85 h_{b}$, the weakening depth $c$ can be taken as $0.20 b_{f} \sim 0.25 b_{f}$, and the radius of round hole $R$ can be set as $0.25 h_{b} \sim 0.375 h_{b}$

In view of the fact that the beam-end weakening connection may have severe buckling and obvious lateral displacement of the beam under rare earthquakes, a beam-filled connection with LYPS is presented, and the corresponding constructional detail is shown in Fig. 1. The connection is weakened and the part of the original steel of the flange and the web of the steel beam are removed, and then replaced by the weakened part of the LYPS by welding technology to ensure the bearing capacity of the components. During 
the earthquake, the LYPS firstly yield, the elastic-plastic deformation occur and the dynamic energy is dissipated, then the main part of the connection begin to dissipate energy. The LYPS could be replaced after the earthquake. For the sake of making fullest use of the energy consumption capacity of LYPS, it is more advisable that the corresponding weakening parameters should be larger values in the range of traditional weakened connections.

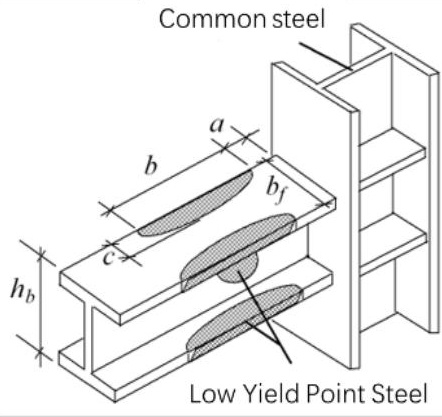

(a) Side looking

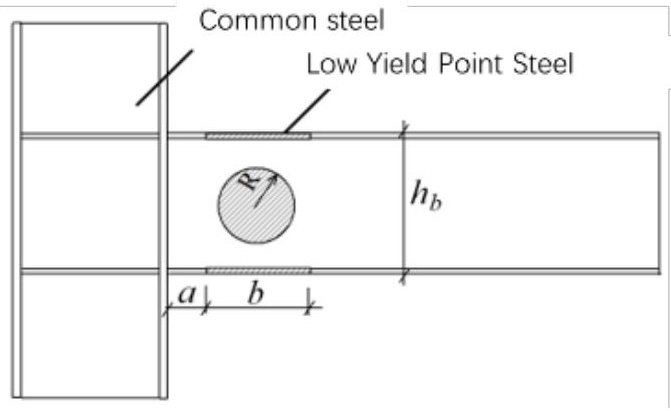

(b) facade

Fig. 1 Beam end weaken and replacement connection

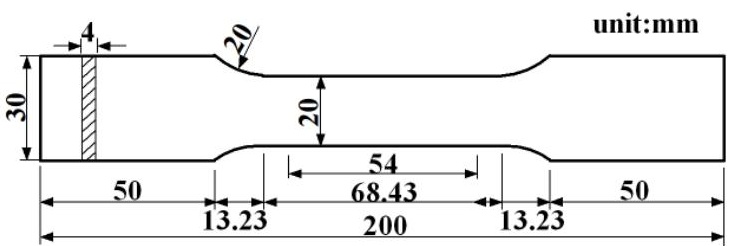

(a) Specimen type and size

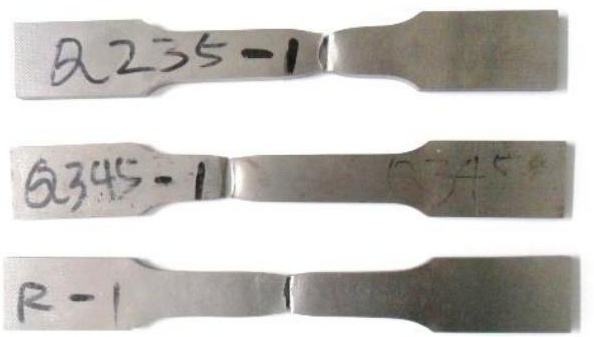

(b) Fracture morphology of specimens

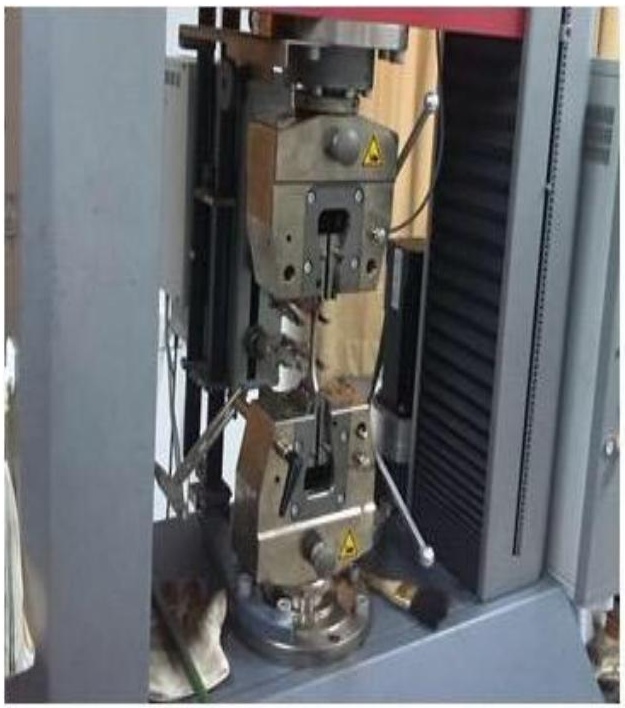

(c) Tensile Testing Device

Fig. 2 Specimen size, tensile test and fracture morphology

\section{Material performance experiment of low-yield-point steel}

There are lots of theoretical studies on damping performance about lowyield-point metal, but the actual low-yield-point materials which meet the requirements of engineering application is very few [25-28]. By comparison, the LY160 steel (the yield strength is about $160.0 \mathrm{Mpa}$ ) is selected as low-yield- point energy dissipation material. To verify the practical material performance of different kinds of steel, three groups of specimens with the same size were fabricated by Q345 steel (the yield strength is about 345.0 Mpa), Q235 steel (the yield strength is about $235.0 \mathrm{Mpa}$ ) and LY160 steel, respectively. The tensile test was carried out in a hydraulic testing machine with the loading stress rate in the elastic stage $16 \mathrm{MPa} / \mathrm{s}$ and the loading strain rate in yield stage $0.0025 / \mathrm{s}$. The average value of each group of material is calculated and taken as the final typical result.

The dimensions of the standard test piece, the tensile test and the fractures of the different material specimens are illustrated in Fig. 2. The corresponding average stress-strain curves for the three types of steel are illustrated in Fig. 3. According to the strain-stress curves obtained from the tensile test, the measured yield strength of Q345 steel, Q235 steel and LY160 steel is 385.2 MPa, 275.3 $\mathrm{MPa}$ and $160.1 \mathrm{MPa}$, respectively, and the measured elongations is $23.2 \%, 27.3 \%$ and $31.3 \%$, respectively. Based on the experimental data, it is evident that LY160 steel has the expected low yield strength and outstanding ductility and toughness, so it could be selected as an energy dissipation material for the replacement steel connections. However, it is still necessary to further verify the damping performance of the replacement steel connections with LYPS through the elastoplastic test of connections.

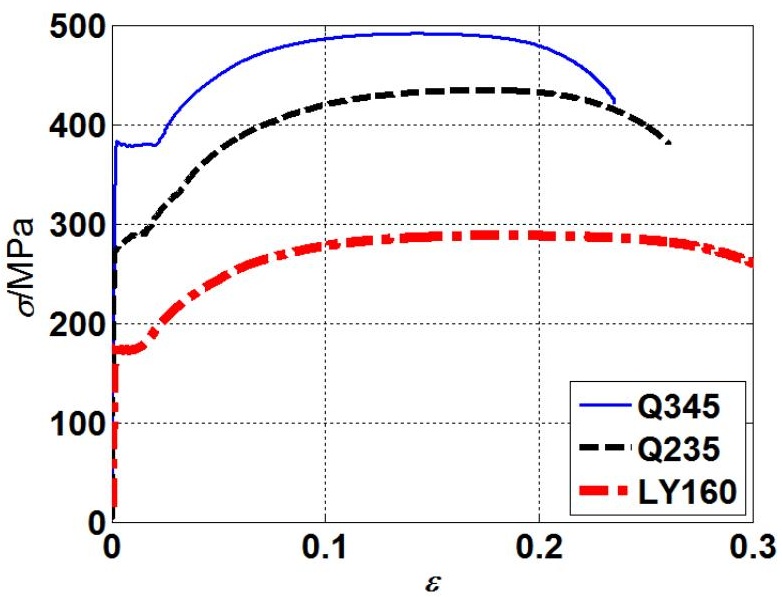

Fig. 3 Constitutive curves of different steels

\section{Design method for replacement connection}

According to the introduction of the beam flange arc weakening connection in reference [29] and the design process of the connection, combined with the concept of the new replaceable connection proposed in this paper, the design steps of the beam-filled connection with LYPS are presented, as shown in Fig. 4.

Assuming $b_{f}, h_{b}, t_{f}$ and $t_{w}$ is the flange width, the section height, the flange thickness and the web thickness of the beam, respectively. $V_{p}$ is the shear force at the plastic hinge, $C_{p r}$ is the coefficient considering the peak bearing capacity, stress-strain strengthening and other conditions, taking as $1.15 . R_{y}$ is the partial coefficient of the material, taking as $1.1, F_{y}$ is the yield strength of metal, $C_{y}$ is a proportional adjustment coefficient, $S_{b}$ is the elastic modulus at the weakening 
point, $V_{g}$ is the beam's yield strength Shear force, $x$ is the distance from plastic hinge to critical section of beam column, $L$ is the distance to column axis, and $d_{c}$ is the section height of column. $Q$ is the uniform load acting on beam.

In the specific design flow, the plastic section modulus of the beam is given

$$
W_{b}=t_{f} b_{f} \frac{h_{b}-t_{f}}{2}+\frac{\left(h_{b}-2 t_{f}\right)^{2}}{8}
$$

The plastic modulus of the weakened part of traditional weaken connection is

$W_{R B S}=t_{f}\left(b_{f}-2 c\right) \frac{h_{b}-t_{f}}{2}+t_{w} \frac{\left(h_{b}-2 t_{f}\right)^{2}}{8}$
Combining Eq. (1) and Eq. (2), it can be deduced that the plastic section modulus of beam-filled beam-column connection with LYPS is

$$
W_{F B S}=t_{f}\left[b_{f}-2(1-\eta) c\right] \frac{h_{b}-t_{f}}{2}+t_{w} \frac{\left[h_{b}-2 t_{f}-2(1-\eta) R\right]^{2}}{8}
$$

where $\eta$ is the coefficient related to the ratio of the elastic modulus of the LYPS to the elastic modulus of the ordinary steel. Since the section modulus of the filling LYPS is between the full section and the weakened section, $\eta$ can be taken according to the following principles: when $\eta$ is 0 , it is the weakened section type; when $\eta$ is 1 , it is the full section type, so the selected $\eta$ value must be between 0 and 1 .

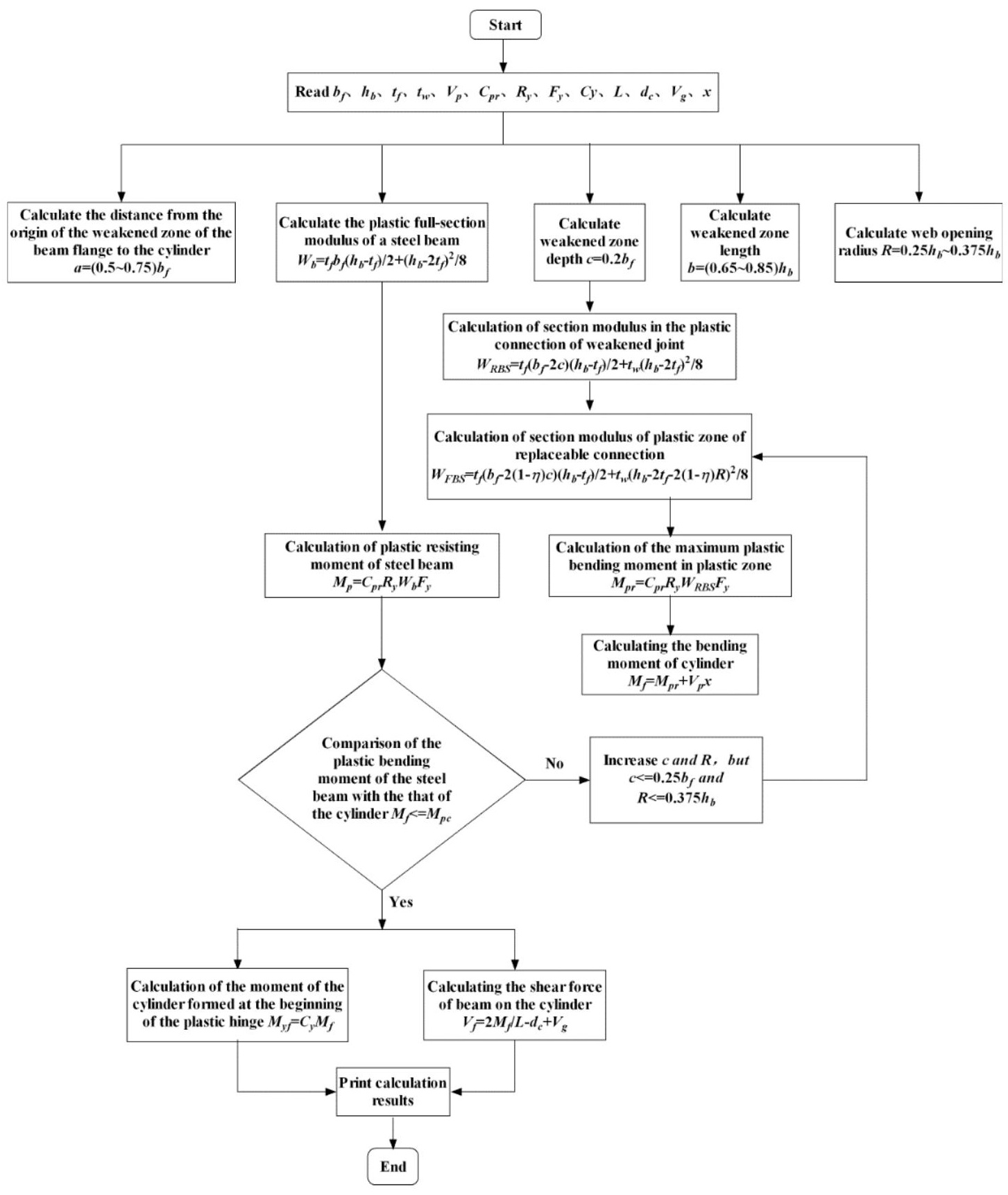

Fig. 4 Design flow chart of replaceable connection

The maximum bending moment in plastic zone is

$M_{p r}=C_{p r} R_{y} W_{F B S} F_{y}$

The bending moment in plastic zone is

$$
M_{p}=C_{p r} R_{y} W_{b} F_{y}
$$

The shear in plastic zone is 
$V_{p}=\frac{2 M_{p r}+P a+Q L^{2} / 2}{a}$

The bending moment of the column is

$M_{f}=M_{p r}+V_{p} x$

The moment of the column when plastic hinge appears is

$$
M_{y f}=\frac{S_{b}}{C_{p r} W_{F B S}} M_{f}
$$

The shear force of beam when the plastic hinge appears is

$$
V_{f}=2 \frac{M_{f}}{L-d_{c}}+V_{g}
$$

\section{Damage model based on elastic-plastic energy dissipation difference ratio}

Besides the design process and the test for the seismic capacity of steel connections, the theoretical analysis and evaluation of the member performance and damage evolution characteristics are also needed. Damage index is an important parameter quantitatively indicate the characteristics of the structural earthquake damage model. The traditional structural damage models include various types, such as strength-based model, displacement-based model, stiffness-based model, period (frequency)-based model, energy-based model, and deformation and energy-based model, etc. It is generally considered that structural displacement and the damage of the cumulative energy interacts each other. Hence, among these models, the Park-Ang damage model, which is a superposition of the maximum displacement and cumulative hysteretic energy, is widely recognized and applied. The damage index $D_{P}$ can be determined as the following method:

$$
D_{P}=\frac{x_{m}}{x_{c u}}+\beta \frac{E_{h}}{F_{y} x_{c u}}
$$

where $x_{c u}$ is the limit deformation with monotonic loading, $F_{y}$ is the yield strength of components, $x_{m}$ and $E_{h}$ is the realistic maximum displacement and cumulative hysteretic dissipation energy, respectively, and $\beta$ is the empirical coefficient, and taken as 0.15 in this study.

However, the disadvantages of Park-Ang model are also obvious, the major deficiencies include: 1) The linear combination mode adopted in this model is lack of sufficient theoretical basis, and it is just a semi-empirical model. The inaccuracy is also manifest in the determination of energy dissipation factors; 2) In general, it is only suitable for static and part dynamic damage analysis of structural components, and the suitability for the time history analysis of total structural damage is worse; 3 ) The limit value do not strictly convergence, and the damage index is not equal to 0 in the elastic stage, and it is usually greater than 1 in the ultimate bearing capacity stage, which seriously affects the damage evaluation precision. 4) It cannot represent the effect of cyclic amplitude variation on the hysteretic dissipation energy during loading, which is called the loading path effect. For the problems above, researchers have revised the original model constantly, but they cannot completely improve all the defects [30-31]. In light of that, the following seismic damage model based on elasticplastic energy dissipation different rate is proposed.

Under an external force with small amplitude, the structure or component generates elastic deformation and corresponding strain energy. At this moment, if the force is withdrawn, the structure will return to the initial displacement without any damage. If the external force is strong, the component or structure will yield and damage, and the strain energy will be dominated by the plasticity energy, and the damage will be more significant as the amplitude of the force increases. If the structure is strengthened to avoid yielding, i.e., the system stay at the ideal elastic state, the damage still does not occur. It is obvious that the form and degree of the damage have a substantial connection with the differences value between the ideal elastic deformation energy of the structure and the actual elastic-plastic deformation energy, and the related differences ratio can be used to represent the damage evolution. Similar to the ideas above, Krajcinovic [32] once proposed the damage theory of concrete and other materials from the perspective of energy loss. That is, the damage variable can be expressed by the ratio of the strain energy in the lossless state to the strain energy and the non-destructive strain energy in the damage state. Now this theory has been applied in material damage assessment and finite element analysis.

For the ideal elastic-plastic SDOF system showed in Fig. 5, the static stiffness of the elastic stage is considered to be $k_{\mathrm{e}}$, the post-yielding stiffness coefficient is $\alpha$, and $F_{y}$ and $u_{y}$ is the yield force and the yield displacement, respectively. When the structure is in the state of elastic-plastic, the force corresponding to the displacement $u_{m}$ is $F_{m}$, the current ductility coefficient is $\mu_{m}=u_{m} / u_{y}$, and the corresponding period is $T_{m}$. Assumed that the equivalent stiffness of the structure in the plastic state can be represented by the secant stiffness $k_{m}$, the damage index based on stiffness can be expressed as

$D_{k}=\frac{k_{e}-k_{m}}{k_{e}}=(1-\alpha)\left(1-\frac{1}{\mu_{m}}\right)=1-\left(\frac{T_{e}}{T_{m}}\right)^{2}$

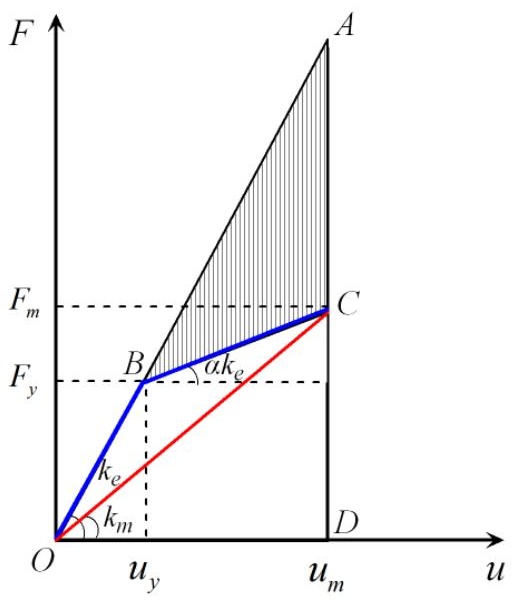

Fig. 5 Energy dissipation of ideal elastic-plastic system

As shown in Fig. 5, the area $S_{O B C D}$ is the actual elastic-plastic deformation energy $E_{F}$ when the structural displacement is $u_{m}$. The area $S_{O A D}$ is the ideal elastic deformation energy $E_{E}$, and the area $S_{A B C}$ is the difference between the two areas, i.e., the difference of elastic-plastic dissipation energy $E_{D}$. According to the elastic-plastic energy dissipation ratio presented by the concept mentioned above, the damage index can be expressed as in this way:

$D_{E}=\frac{E_{E}-E_{F}}{E_{E}}=\frac{S_{A B C}}{S_{O A D}}=(1-\alpha)\left(1-\frac{1}{\mu_{m}}\right)^{2}=\left(1-\frac{1}{\mu_{m}}\right)\left[1-\left(\frac{T_{e}}{T_{m}}\right)^{2}\right]$

It can be seen from the results above that both the damage index based on energy and the damage index based on stiffness can represent the important factors such as resilient force characteristics, maximum elastic-plastic deformation, ductility and period, etc., and the two forms are approximate. The difference between the two indices is that the former shows the square trend of the current ductility, while the latter reveals the linear characteristics of the current ductility, which is in line with their respective theoretical frameworks. In summary, it can be concluded that the damage models on the basis of energy, stiffness, displacement and cycle are closely related with the related representation forms but have different implications. Due to the approximate equivalence, the stiffness-based damage index produces a certain degree of deviation. However, the concept of the energy-based damage index is more rigorous, clear and comprehensive, which is the basis for constructing the most ideal damage model.

As for structural damage under the action of quasi-static forces like lowcycle reciprocating loading, it is generally considered that the cumulative hysteresis energy or system deformation energy can more accurately describe the cumulative damage degree during structural loading. Since the damage model based on elastic-plastic energy dissipation difference ratio involves the restoring force characteristics and displacement response, it can clearly represent the relationships between the deformation energy of the system including the accumulated hysteretic energy dissipation and the ideal elastic deformation energy. Therefore, some improvements on the damage model in the static monotonic force can make it applicable for damage assessment during quasi-static loading.

Let $i$ is the $i^{\text {th }}$ loading step in the loading process, and the structure or component has entered the stage of elastic-plastic under the external force $F(i)$. The base shear force $F_{F}(i)$ and the top displacement $u_{F}(i)$ of the structure can be produced by the experimental technique or nonlinear simulation analysis, so the 
equivalent elastic-plastic deformation energy of the total structure can be expressed as $E_{F}(i)=F_{F}(i) u_{F}(i)$, and the maximum displacement of the top of the elastic-plastic system is $u_{F m a x}$. If the external force $F(i)$ is multiplied by the reduction factort $\gamma$ to ensure that the structure only produces elastic deformation under the action of external force $\gamma F(i)$, and the result of top displacement and its maximum value are $u_{E 0}(i)$ and $u_{E O \max }$, respectively, the base shear force is $F_{E 0}(i)$. Let the amplitude modulation coefficient $\beta=u_{F \max } / u_{E O \max }$. The purpose is to make the maximum elastic displacement of the top of the structure reach $u_{F \max }$. To achieve this goal, $u_{E 0}(i)$ should be mutiplied by $\beta$ times to obtain the amplitude-modulated elastic displacement $u_{E}(i)=\beta u_{E 0}(i)$, and the corresponding amplitude base shear is $F_{E}(i)=\beta F_{E 0}(i)$. Therefore, according to the damage model proposed originally based on the ideal elastic-plastic energy dissipation ratio, the equivalent ideal elastic deformation of the structure under quasi-static force $F(i)$ has the following expression

$E_{E}(i)=F_{E}(i) u_{E}(i)=\beta^{2} F_{E 0}(i) u_{E 0}(i)$

It can be deduced that the structural energy damage index time-history that has entered the elastic-plastic state under the external force $F(t)$ can be expressed

$$
D_{F}(i)=\frac{E_{E}(i)-E_{F}(i)}{E_{E}(i)}=1-\frac{\sum_{i=s}^{n}\left|F_{F i} u_{F i}\right|}{\beta^{2} \sum_{i=s}^{n}\left|F_{E 0 i} u_{E 0 i}\right|}
$$

where $F_{F i}$ and $F_{E i}$ are the elastic-plastic state in the $i^{\text {th }}$ step and the base shear force in the ideal elastic state, respectively, $u_{F i}$ and $u_{E i}$ are the elastic-plastic state in the $i^{\text {th }}$ step and the top displacement in the ideal elastic state, respectively. $s$ is the number of loading steps when the structure transforms from the elastic state into the elastic-plastic state, and $n$ is the entire quantity of steps to be calculated. For structural damage undergoing low-cycle reciprocating loading, the damage index can be calculated separately for each hysteresis loop. If the structure has yielded before the hysteresis loading, $s$ takes 1 . The energy damage index fits the damage analysis of components or structures in different static loading modes, such as monotonic, low cycle reciprocating and pushover analysis, and its numerical value is strictly controlled between 0 and 1 . In the following research, this damage index will be utilized to estimate the damage degree of different connections in the context of reciprocating loading so as to evaluate the seismic performance of various connections more comprehensively.

\section{Simulation of seismic behavior different steel connections}

The seismic performance and damage properties of different types of connections are first verified by finite element method. The traditional connections, the weakened connections and the replacement connections with LYPS are simulated and analyzed by software ANSYS. The FEM models are established and the non-linear analysis under the low cycle reciprocating load is carried out to analyze the energy consumption ability of connections. The beam and column of the connection model are $\mathrm{H}$-shaped steel, the main material is Q345 steel, and the low yield metal is LY160 steel with better ductility. The section size of the column is HW $450 \mathrm{~mm} \times 300 \mathrm{~mm} \times 20 \mathrm{~mm} \times 12 \mathrm{~mm}$; the section size of the beam is $H N 400 \mathrm{~mm} \times 200 \mathrm{~mm} \times 12 \mathrm{~mm} \times 12 \mathrm{~mm}$. The size parameters $a, b, c$ and $R$ of the weakened joint are $125 \mathrm{~mm}, 280 \mathrm{~mm}, 45 \mathrm{~mm}$ and $125 \mathrm{~mm}$, respectively. Both ends of the column of each connection are applied fixed constraints, and the end of the beam is restrained by displacement and cyclic load. The incremental displacement control is adopted until the buckling failure of the member. The equivalent stress diagrams of different types of connections under the limit displacement are shown in Fig. 6-Fig. 8 .

According to the above results, it is found that when the ultimate displacement occur, the maximum stress on the traditional connection is concentrated at the junction of the beam end, and the plastic hinge at the beam end is formed, which causes obvious local buckling. The plastic hinge on the beam-weaken connection moves out to the weakening zone of the beam, which causes serious local buckling and lateral large deformation, and the connection is seriously damaged. The maximum stress of the replacement connection is also concentrated in the connection between the beam end and the column, but the corresponding plastic hinge moves to the zone of LYPS, the energy consumption and the local buckling mainly occur in the LYPS, and the damage of the main material is very small.
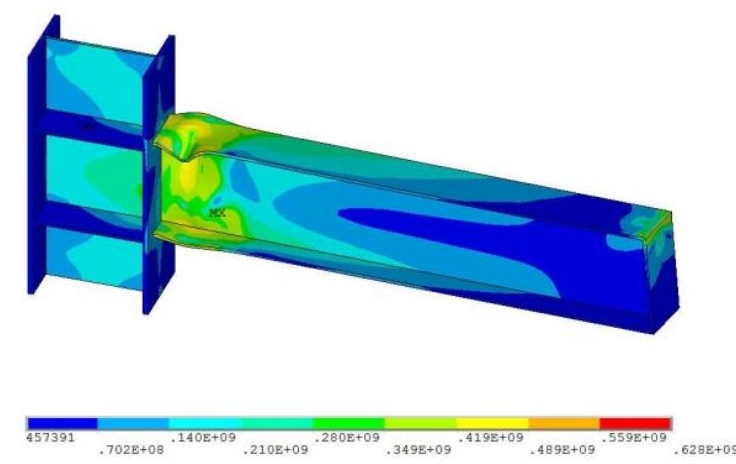

Fig. 6 Stress nephogram of traditional connection
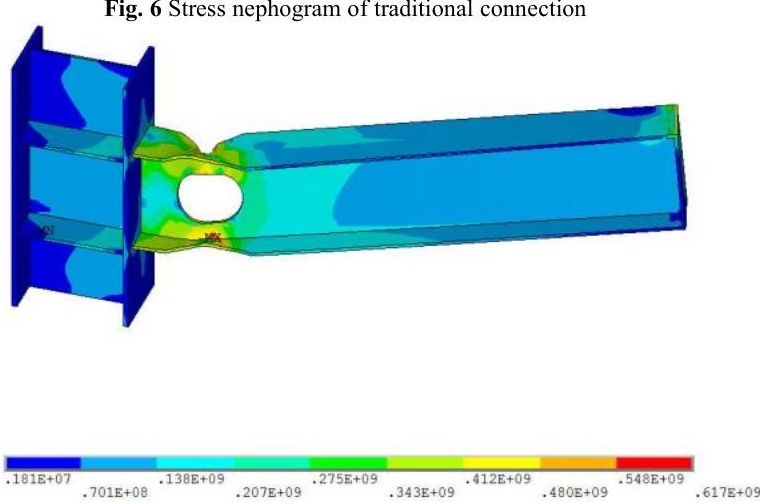

Fig. 7 Stress nephogram of beam-weaken connection
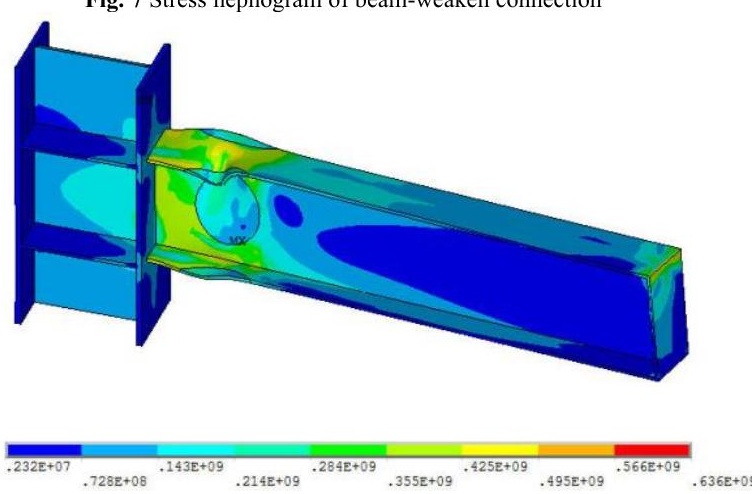

Fig. 8 Stress nephogram of replacement connections with LYPS

The hysteretic loops of different connections are shown in Fig. 9. It can be seen that the hysteresis areas of the traditional connection and the replacement connections are relatively full, while the hysteresis areas of the beam-weaken connection are significantly reduced, and the later bearing capacity drops rapidly, and the energy dissipation capacity is obviously insufficient.

To compare the energy consumption capacity of different connections intuitively, the Park-Ang index is selected to estimate the seismic performance of the connections under low cycle reciprocating load. The Park-Ang index and damage index based on elastic-plastic energy dissipation difference ratio can be calculated according to Eq. (10) and Eq. (14), respectively, the comparative data are shown in Fig. 10 and Fig. 11.

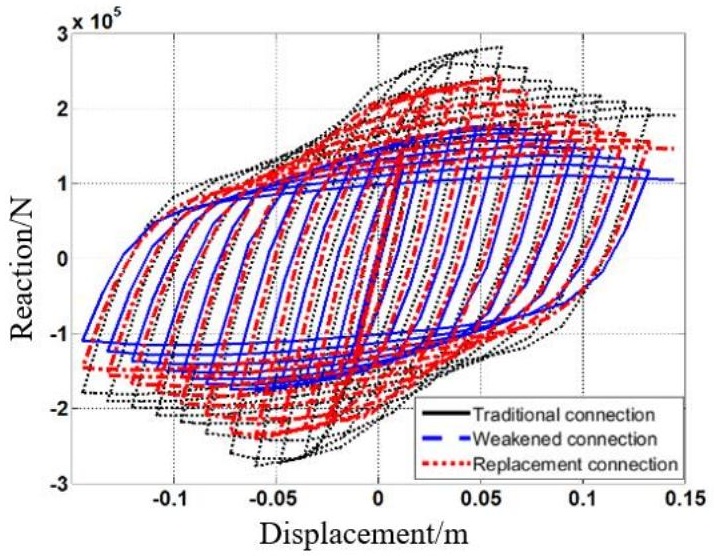

Fig. 9 Hysteresis curves of different connection 


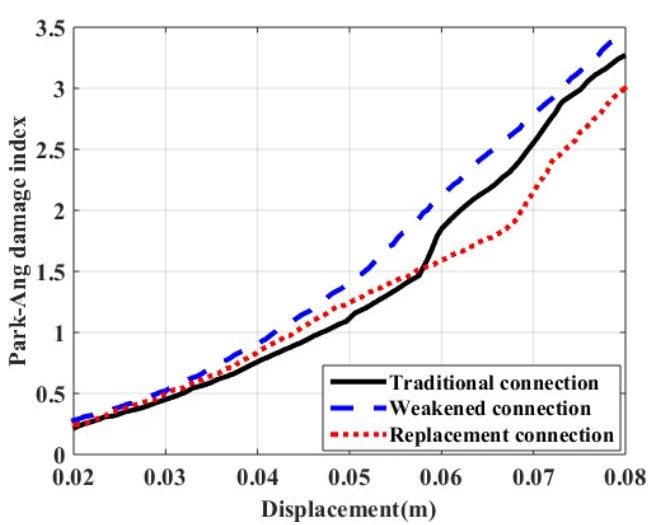

Fig. 10 Park-Ang damage index of different connections

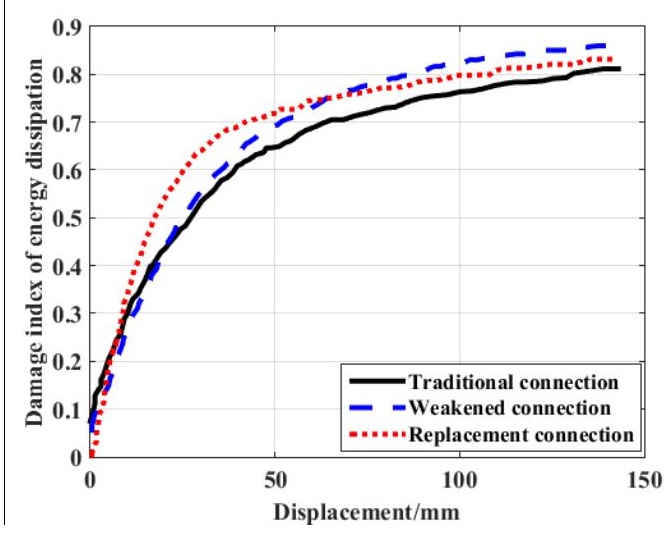

Fig. 11 Damage curves of energy dissipation

In addition, the equivalent viscous damping coefficient (EVDC) $\xi$ can also be used to characterize the damage evolution process of connections, and the relevant formula is given by

$\xi=\frac{E_{D}}{4 \pi E_{S}}$

where $E_{D}$ is the energy dissipated in one integral cyclic loading, equals to the area of the whole hysteresis loop, and $E_{S}$ is the maximum strain energy. The corresponding results are shown in Fig. 12.

It is evident that the EVDC of the traditional connection gradually increases under the low cycle reciprocating load, and it is relatively stable when the connection deforms greatly, but the damage index increases sharply at this time, which indicates that the ductility and the damping capacity of the traditional connection are obviously low, and the damage is serious. In addition, because the common finite element method cannot accurately simulate the brittle failure of the welds, the bearing capacity of the traditional connection is overestimated and the corresponding damage index is underestimated in the simulation. The EVDC of the weakened connection is larger, so it has strong damping capacity and ductility, but the damage is the most serious, local buckling failure occurs early and the carrying capacity is lost. The equivalent hysteretic damping ratio of the replacement connections with LYPS increases rapidly with the accumulation of hysteretic energy consumption. When the displacement is small, it is larger than the traditional connection, but its growth rate slows down with the increase of displacement, and smaller than the traditional connection when the displacement is large. The results show that the replacement connection can fully consume energy since the firstly yield of the LYPS under the reciprocating load, and the integrity of the filled steel connection can still retain due to the better elongation of the LYPS.

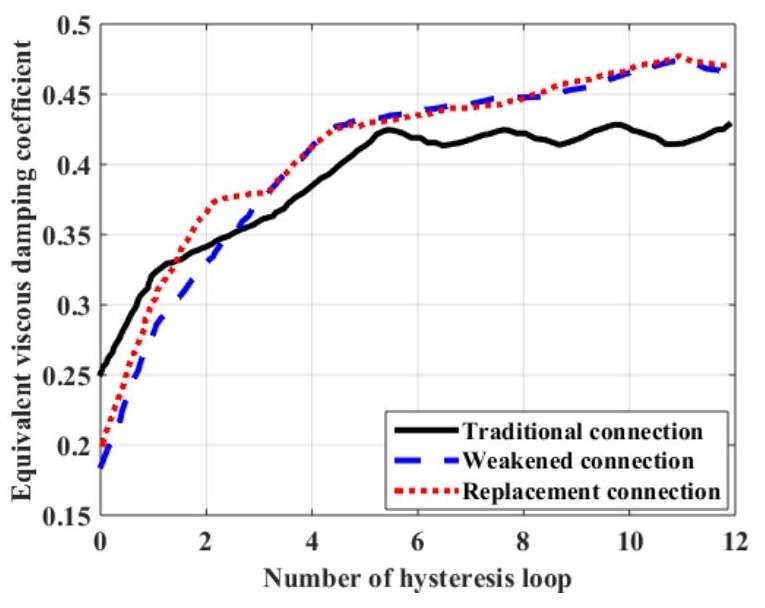

Fig. 12 Equivalent viscous damping coefficient of different connections

In conclusion, the replacement connection has excellent ductility and energy consumption capacity than other connections, and it can impel the plastic hinge move to the weakened zone of the beam, avoiding the emergence of plastic hinge at the connection to cause brittle fracture failure of the structure. Although the dog bone connection can make the plastic hinge move to the weakened zone of the beam, the bearing capacity of the connection declines obviously, which is easy to produce stress concentration and buckling deformation at the weakened part, and the ductility and the damping capacity in later stage is relatively insufficient. Hence, the replacement connection has better seismic performance than the other two connections, but the superior performance needs to be verified by static and dynamic tests.

\section{Test implementation and analysis}

\subsection{Specimen design and size parameters}

To further compare the actual seismic performance of steel structure connections of different structural forms, five full-scale steel structure connection models were designed and fabricated for the low cycle reciprocating static test. The models include one traditional steel structure connection, one weakened steel structure connection and three replacement connections, the specimen code of the connections is TC-1, WC-1, RC-1, RC-2 and RC-3, respectively. All the connections are composed of $\mathrm{H}$-shaped steel. The main structure of the test piece RC-3 is made of Q235 steel while the others are made of Q345 steel. The filling part is made of LY160 steel, the column section size is $250 \mathrm{~mm} \times 250 \mathrm{~mm} \times 14 \mathrm{~mm} \times 14 \mathrm{~mm}$ and the beam section size of the loaded beam $300 \mathrm{~mm} \times 200 \mathrm{~mm} \times 8 \mathrm{~mm} \times 12 \mathrm{~mm}$. Stiffening rib was set $200 \mathrm{~mm}$ away from the end of loading beam to prevent from buckling of loading section. The angle steel parts were arranged in the connection between beam web and column flange and connected by 10.9 grade high strength bolts, the surrounding area is fully welded, and the rest is welded. To compare and analyze the effect of different weakened dimensions on the seismic performance of steel connections, the RC-2 and RC-3 beam flanges and web weakening dimensions of the specimens were all enlarged. The specific material composition and parameters of each test specimen are provided in Fig. 1 and Table 1. In addition, the specific sizes of the connections are shown in Fig. 13.

Table 1

Specimen Types and parameters

\begin{tabular}{cccccc}
\hline Parameter & TC-1 & WC-1 & RC-1 & RC-2 & RC-3 \\
\hline Material & Q345 & Q345 & Q345 & Q345 & Q235 \\
$b / \mathrm{mm}$ & - & 225 & 225 & 280 & 280 \\
$c / \mathrm{mm}$ & - & 40 & 40 & 60 & 60 \\
$a / \mathrm{mm}$ & - & 130 & 130 & 102.5 & 102.5 \\
$R / \mathrm{mm}$ & - & 75 & 75 & 80 & 80 \\
\hline
\end{tabular}



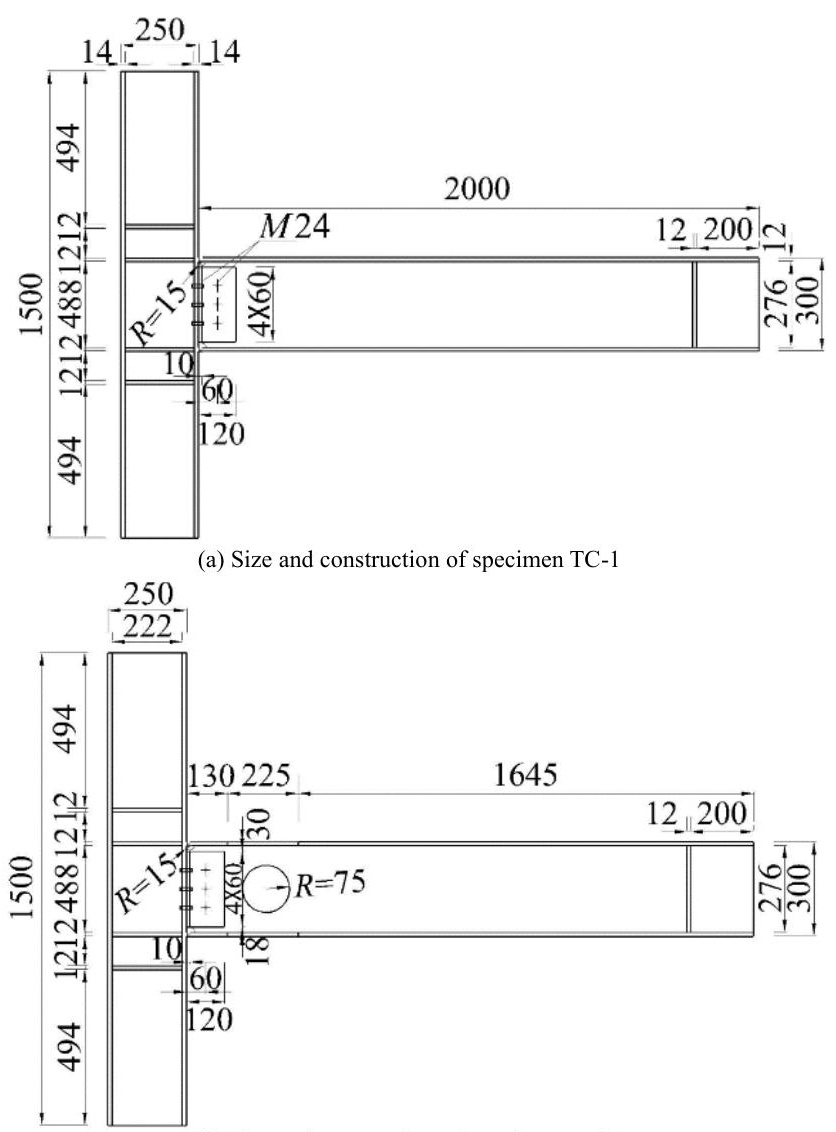

(b) Size and construction of specimen WC-1

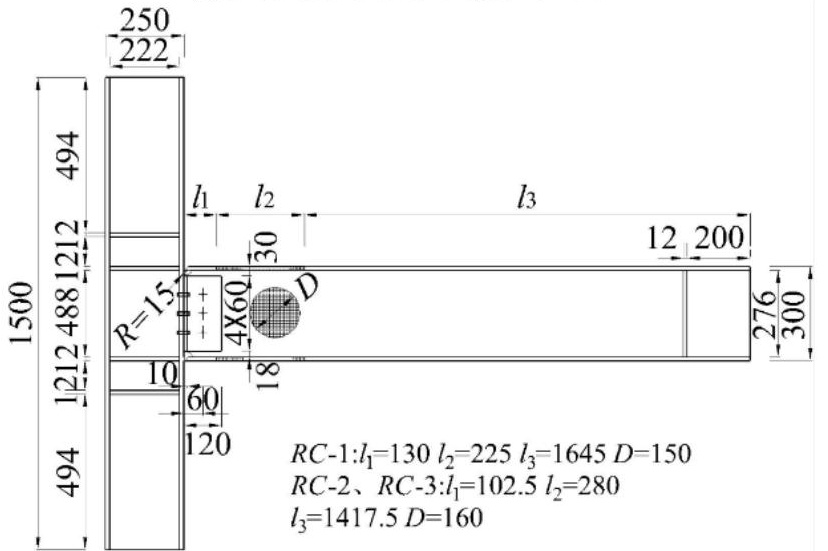

(c) Size and construction of specimens RC-1, RC-2 and RC-3

Fig. 13 Specimen structure diagram (Unit: $\mathrm{mm}$ )

\subsection{Loading scheme}

Not considering the benefits action of column axial force on the shear capacity of the connections, we adopt the beam end loading mode and avoid the axial force of the column. For this reason, the steel column of the connection was placed horizontally and the two ends are anchored on the ground, and the steel beam is placed vertically. The top of the beam was loaded by an electro hydraulic servo jack fixed against one side of the reaction wall. The hydraulic jack can bear $500 \mathrm{kN}$ of the reaction force. The displacement sensor was arranged $200 \mathrm{~mm}$ away from the outer end of the beam. Horizontal push-pull repeated load is controlled by incremental loading. The incremental step of displacement was $12 \mathrm{~mm}$ until the bearing capacity of the connections decreased below $85 \%$ of the peak load or the deformation of the connections is too large to continue loading. The loading scheme is shown in Fig. 14. In the figure, $\Delta$ is the displacement of loading end and $n$ is the total number of cycles of hysteretic energy dissipation loading.

During the test, the data were collected in real time, as the basis for controlling the loading and the result analysis. The data collected included reciprocating loading force and displacement of the bottom and the midpoint on the beam, the strain of the filling flange and the web, etc. The damage developing process and deformation characteristics are observed and recorded during the process of loading. The picture of the loading test site is shown in Fig. 15 .

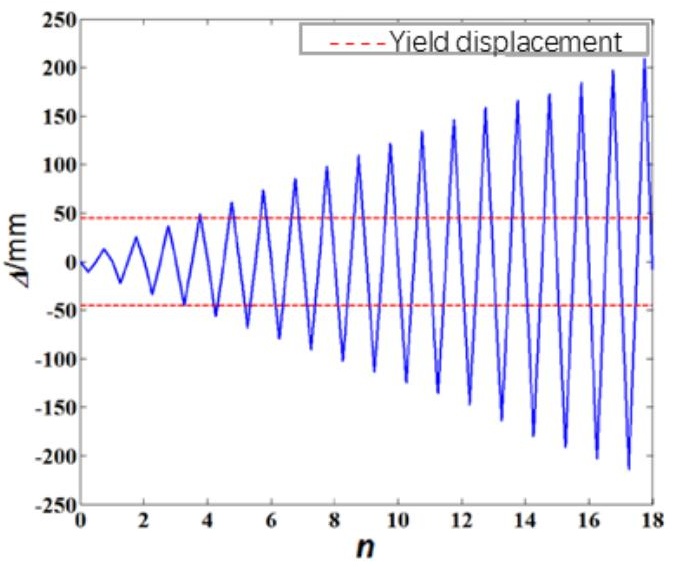

Fig. 14 Displacement loading plan

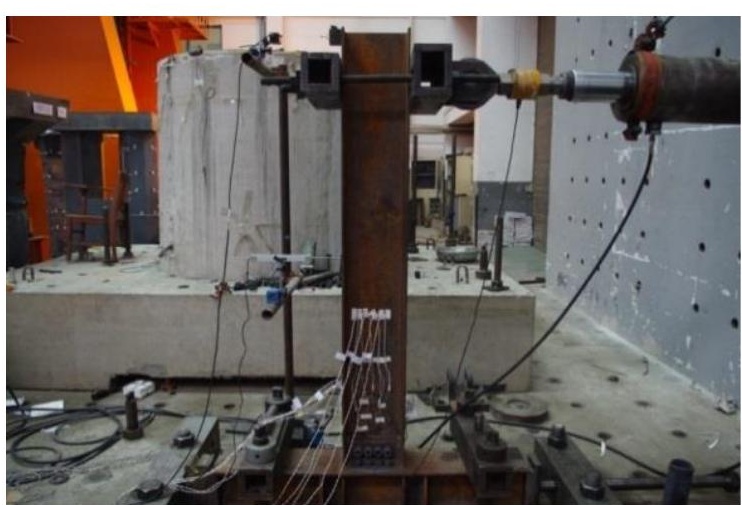

Fig. 15 Test loading diagram

\section{Expeirment phenomenon}

The failure patterns of the connections are shown in Fig. 16. In the experimental process, the specimen TC-1 firstly emerged plastic hinge at the flange of the connection, and then buckled. With the increase of displacement, the web of the beam also entered the yield state, and obvious deformation occurred. In the later stage of loading, the brittle cracks occurred on the weld between the column and the beam flange at the junction, the load dropped sharply and the specimen was destroyed, so that it could not continue to bear the load. 

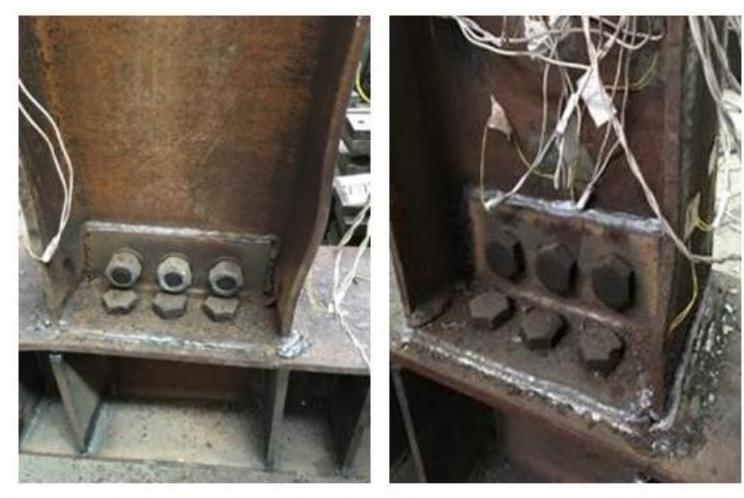

(a) Failure phenomenon of specimen TC-1

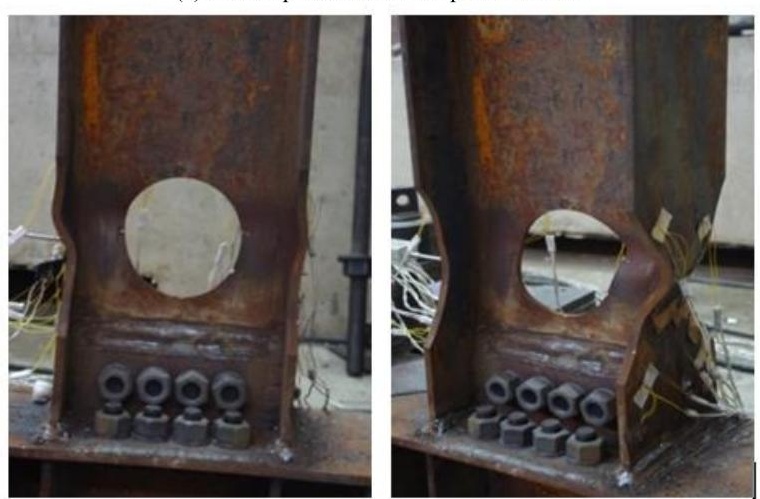

(b) Failure phenomenon of specimen WC-1

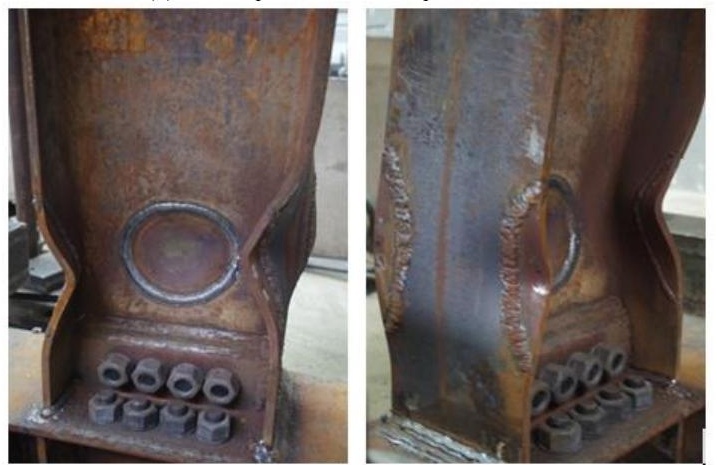

(c) Failure phenomenon of specimen RC-1

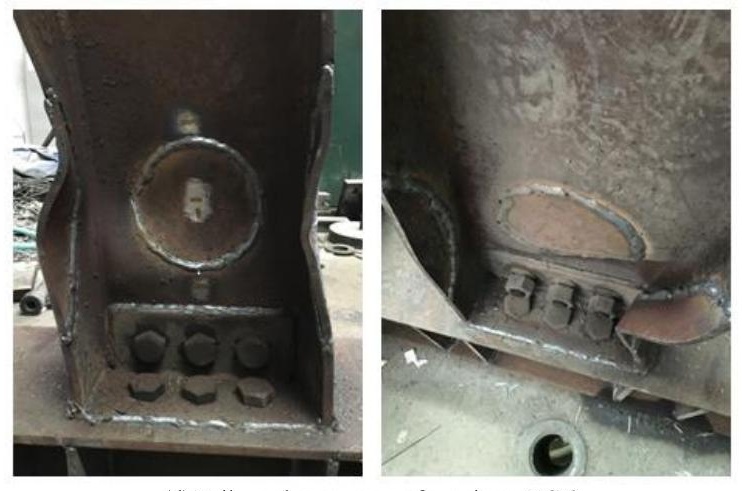

(d) Failure phenomenon of specimen RC-2

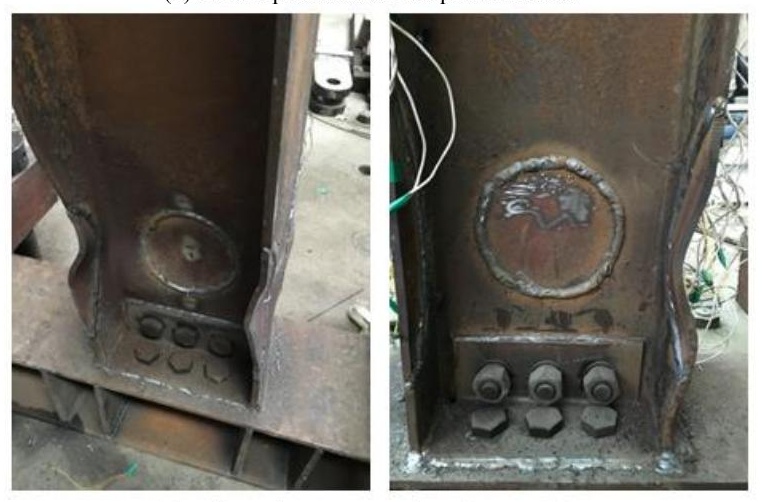

(e) Failure phenomenon of specimen RC-3

Fig. 16 Failure patterns of different specimens
The plastic hinge of specimen WC-1 did not occur at the beam-column connection, but moved outward to the weakened beam. In the initial stage of loading, the flanges of the weakened beam first entered the yield stage, and warping deformation occurred. With the increase of displacement, the local buckling deformation also occurred on the web of the weakened beam. During the subsequent loading, the deformation mainly concentrated on the weakened parts in the flange and web, and the growth was rapid, which caused the specimen to be unable to continue to bear the load. The connection is relatively intact, and the final failure is the beam damaged at the weakening part.

The failure mode of RC-1 is similar to that of WC-1. However, due to the weakened part is filled with the low-yield-point steel LY160, the plastic hinges emerged at the filling part of the beam flange and the warping deformation occurs firstly during the loading process. At this time, the web of the beam does not undergo obvious deformation. Subsequently, the deformation of the LYPS of the beam flange continued to increase, and at the same time, the filling web also entered the yield stage, and significant deformation occurred. At the end of loading, the connection between the main structure and the filling steel could also undergo local deformation.

As the weakened size of the test piece RC-2 is larger, the plastic hinge was generated earlier at the filled steel, the component entered the yield stage, and warpage deformation occurred at the filling beam flange. With the increase of loading displacement, the filling circle of the web began to bulge, and the main part remained intact. At the final stage of loading, the filling part of the specimen gradually failed due to large deformation, while the main part gradually produced obvious deformation.

Due to the main body of RC-3 is made of Q235 steel and the size of weakening is large. The overall load-bearing capacity of the connections is relatively low during loading. After the filling part undergoed large deformation, it loosed its load-bearing capacity. The main part continued to bear the load and the local buckling and the obvious deformation occured on the flange of the beam. The load of the component significantly decreased as the load continued.

The above experimental phenomena indicate that the yield deformation and energy dissipation of RC-1, RC-2 and RC-3 mainly occured in the LYPS, while the material damage of beam-column connection body was relatively small. In the following stage, as the displacement increases, the joint load did not decrease as significantly as WC-1, and it could still bear the load. In addition, though the RC-2 and RC-3 specimens had the effect of plastic hinge moving out due to their large weakening area, the load and energy dissipation capacity have decreased.

\section{Test results and analysis}

To analyze and compare the energy consumption capacity and damage features of different beam-column connections, the experimental data are analyzed. The hysteresis curves, skeleton curve, ductility coefficient, stiffness degradation curve and damage curve of different specimens are calculated and discussed separately.

\subsection{Analysis of hysteresis curve}

The hysteresis data of the connections are analyzed and the comparison results are shown in Fig. 17-Fig. 19. It is obvious that the hysteresis loop of the specimens that filled with LYPS are full and can still has satisfactory ductility and energy consumption capacity in the later stage. Because the specimen WC1 formed plastic hinge at the weakening part at the beginning of loading, the bearing capacity and the area of hysteresis loop decrease significantly, especially in the later period, so the energy dissipation capacity was obviously insufficient. Specimen TC-1 was relatively weak at the weld due to its large overall rigidity, it is the first one that have brittle crackings at the weld joint of beam column connection when the top displacement was loaded to $80 \mathrm{~mm}$, and unable to continue bearing and has worse energy dissipation performance. Due to the large weakening size of $\mathrm{RC}-2$, the plastic hinge was formed at the filling place too early. Compared with RC-1, the load and ductility of RC-2 were decreased. For the specimen RC-3 which used Q235 steel as the main body, the strength of the material was lower than that of Q345, which leads to the decline of the bearing capacity, but the ductility is excellent. 


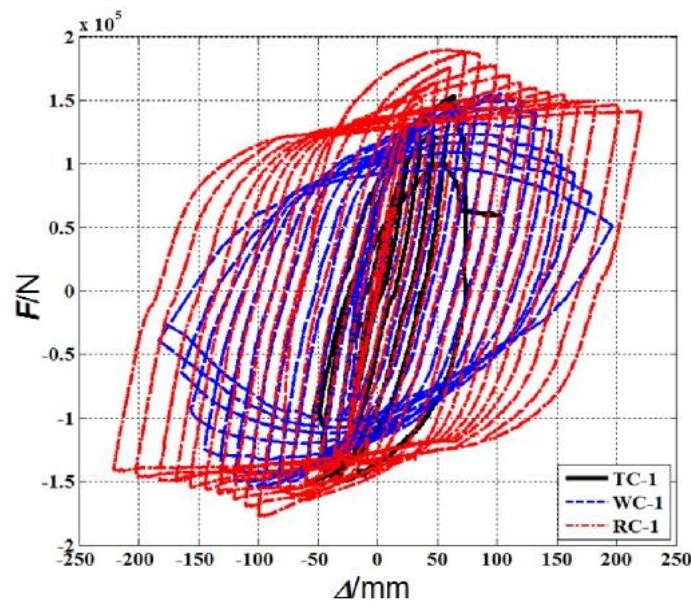

Fig. 17 Hysteresis curves of different connections

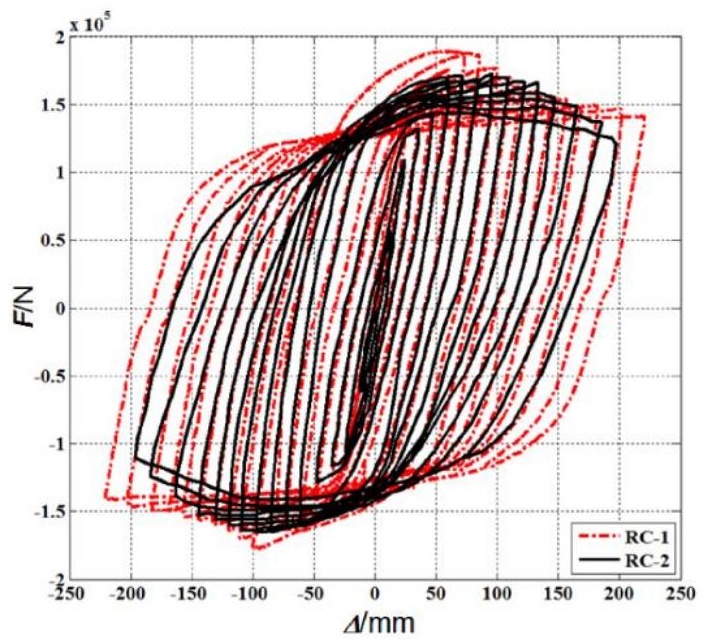

Fig. 18 Hysteresis curves of RC-1 and RC-2

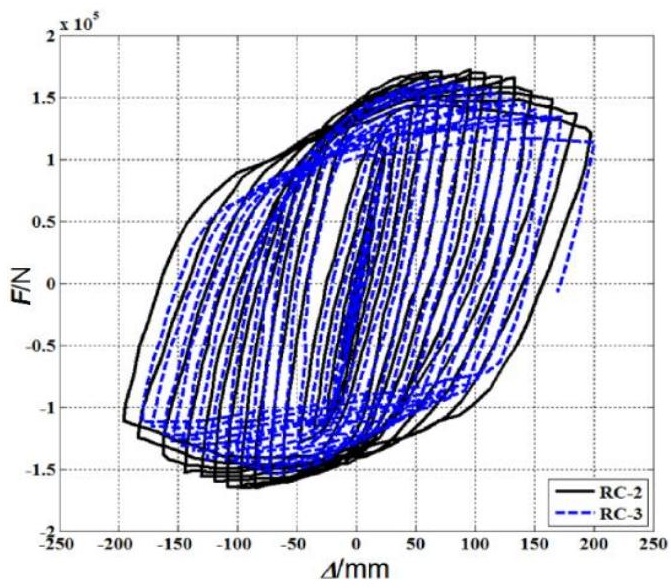

Fig. 19 Hysteresis curves of RC-2 and RC-3

\subsection{Skeleton Curve Analysis}

The skeleton curves of different connections are shown in Fig. 20. It indicates that the initial stiffness of specimen TC-1 is relatively large, and when the loading displacement reaches $47 \mathrm{~mm}$, it enters the yield stage, but when the displacement is $80 \mathrm{~mm}$, the weld cracks at the junction of the beam and the column, and the effective stiffness decreases sharply until the crack developed to complete failure. The load of specimen WC-1 is higher than that of TC-1 under brittle failure. After entering the yield stage, the strength decreases gradually and the stiffness decreases obviously in the later loading phase.

The replacement connections show good ductility and energy consumption capacity at the final stage of loading. Due to the large weakening size of RC-2, the main body of RC-3 is made of Q235 steel, and the load of the weakened joint is reduced after filling. Compared with the weakened specimens, the specimens filled with LYPS can significantly enhance the bearing capacity and the effective stiffness of the connection.

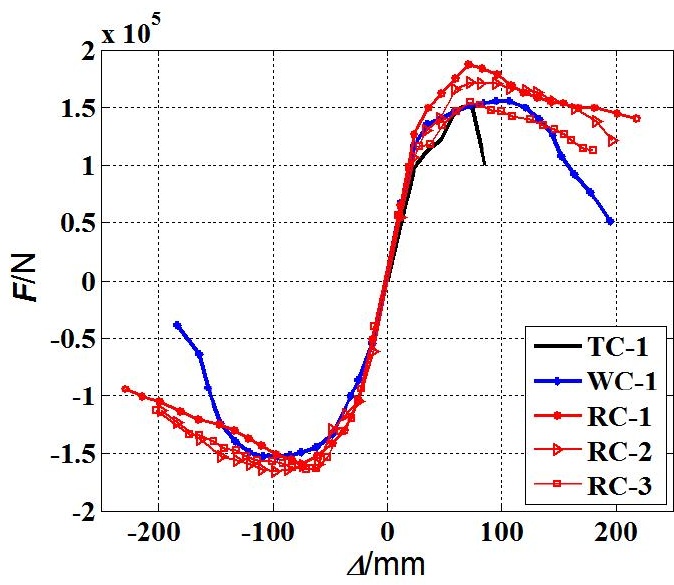

Fig. 20 Skeleton curves of different connections

\subsection{Ductility coefficient}

The displacement ductility coefficient is used to evaluate the ductility ability of connection specimens. It is generally believed that the larger the displacement ductility coefficient is, the better performance of connection specimen is. The displacement ductility factor $\mu$ of the specimen is expressed as

$\mu=\Delta_{u} / \Delta_{j}$

where $\Delta_{u}$ is the ultimate displacement of the specimen and $\Delta_{y}$ is the yield displacement.

The ductility coefficients of different specimens calculated according to Eq.(16) are shown in Table 2. The comparison data show that the failure load of RC-1 specimens increased from $132.22 \mathrm{kN}$ to $159.63 \mathrm{kN}$ on account of the effect of LYPS. The limit displacement increased from $138.45 \mathrm{~mm}$ to $159.63 \mathrm{~mm}$, and the ductility coefficient of RC-1 specimens is $14 \%$ higher than that of weakened connections. It is obvious that $\mathrm{RC}-1$ has good ductility and energy dissipation capacity, since RC-2 and RC-3 have large opening size and Q235 steel is used as the main material for $\mathrm{RC}-3$, the ductility coefficients decreased properly.

Table 2

Bearing capacity and ductility coefficient

\begin{tabular}{cccccc}
\hline Code & TC-1 & WC-1 & RC-1 & RC-2 & RC-3 \\
\hline$P_{y} / \mathrm{kN}$ & 125.77 & 134.44 & 153.29 & 154.97 & 136.50 \\
$\Delta_{\mathrm{y}} / \mathrm{mm}$ & 47.16 & 39.27 & 41.21 & 40.67 & 39.82 \\
$P_{\max } / \mathrm{kN}$ & 153.00 & 154.80 & 187.80 & 172.01 & 160.52 \\
$\Delta_{\max } / \mathrm{mm}$ & 74.00 & 107.17 & 73.64 & 72.81 & 72.47 \\
$P_{u} / \mathrm{kN}$ & 130.05 & 132.22 & 159.63 & 146.21 & 131.34 \\
$\Delta_{u} / \mathrm{mm}$ & 82.40 & 138.45 & 166.13 & 161.56 & 144.53 \\
$M$ & 1.75 & 3.52 & 4.03 & 3.97 & 3.63 \\
\hline
\end{tabular}

Note: $P_{y}$ is yield load, $\Delta_{\mathrm{y}}$ is yield displacement, $P_{\max }$ is peak load, $\Delta_{\max }$ is peak displacement, $P_{u}$ is failure load, $\Delta_{u}$ is failure displacement, $\mu$ is ductility coefficient.

\subsection{Stiffness degradation analysis}

Stiffness degradation is an important performance indicator for structural seismic performance evaluation. The stiffness referred in this study is the equivalent stiffness of the beam-column connection, that is, the slope of the line connecting the origin of the hysteresis curve with the peak load of a certain cycle (point on the skeleton curve). With the displacement continuously increase, the equivalent stiffness will continuously degrade. This phenomenon is called equivalent stiffness degradation. According to the hysteresis curve of the connection, the value of the equivalent stiffness to the maximum stiffness can be calculated, i.e., the equivalent stiffness degradation coefficient $K$ can be obtianed. The stiffness degradation curves are shown in Fig. 21.

It can be seen that the results of the forward and reverse loading of the specimens is not completely symmetrical, mainly due to the accumulated damage of the specimens in the process of reciprocating loading. With the 
increasement of loading displacement, the stiffness degradation of specimen TC-1 is the most significant, and the degradation rate is higher than that of the other two types of specimen in the later loading phase. The stiffness degradation coefficient of the weakened specimen WC-1 decreases significantly after buckling deformation occurs at the beam flange. When the deformation of the beam end reaches $100 \mathrm{~mm}-200 \mathrm{~mm}$, serious deformation occurs at the web openings, and the stiffness degradation coefficient will decrease significantly, and finally only about $6 \%$ of the initial stiffness. By contrast, the stiffness degradation of filled specimens is relatively slow, and the equivalent stiffness degradation coefficient of RC-1 develops slowest in the later stage, which has good ductility and energy dissipation capacity.

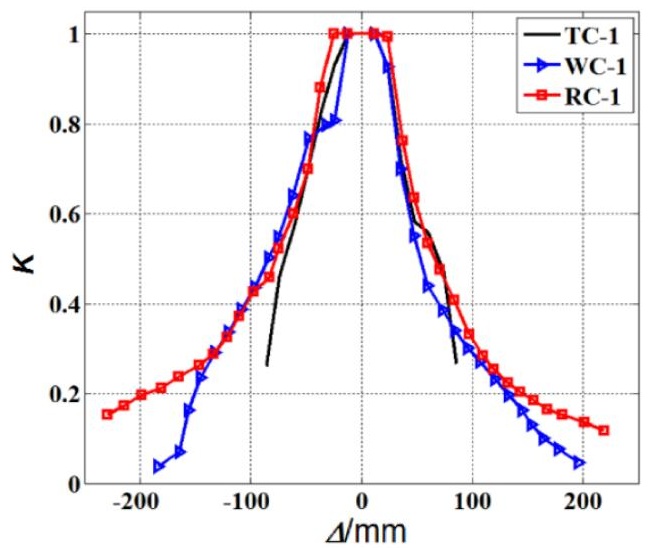

(a) Degradation comparison of traditional, weakened and filled nodes

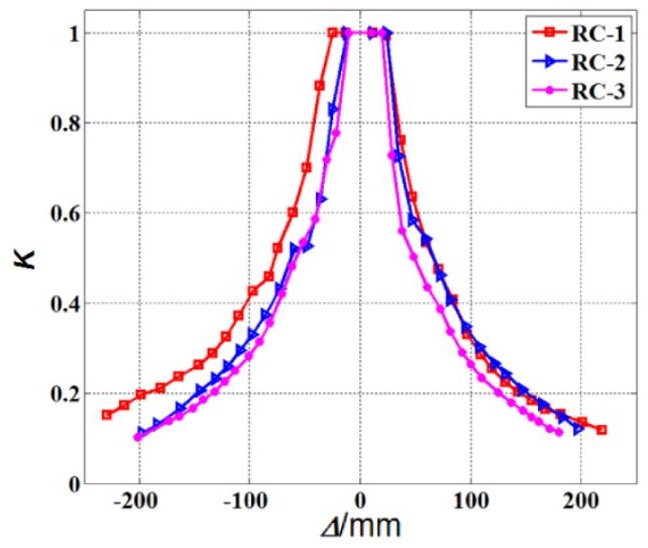

(b) Degradation comparison of three kinds of connections with different filling sizes

Fig. 21 Equivalent stiffness degradation curves

\subsection{Damage Analysis}

Park-Ang damage curve $D_{P}$ of three different components is calculated according to Eq. (11), as showed in Fig. 22. It is found that the stress concentration occur at the joint of beam and column for TC-1, and the damage developed fastest and the damage index is larger. When the beam end was loaded to $80 \mathrm{~mm}$, the damage rised sharply and ultimately was destroyed damages due to brittle cracking in the welding seams of the beam-column joint. For specimen WC-1, the deformation speed of the weakened areas in the flange and web were accelerated when the plastic hinge occured at the end of the beam. Subsequently, with the increase of the deformation at the weakening area, the loading damage rate increases continuously and the specimen ultimately destroyed. The damage evolutions of RC-1, RC-2 and RC-3 were similar, and the damage rate kept rising steadily in the middle and late loading period. Due to the main structure materials of RC-3 is Q235 steel and the size of weakening is large, the damage occured rapidly, but it is generally lower than that of TC-1 and WC-1. Hence, it is obvious that the LYPS at the filling zones has good damping effect and retarded the damage development speed. In addition, when Park-Ang damage index reaches 1 , all connections have not reached complete damage state, and the damage index of WC-1 and filled connections has reached 1.4 when it completely destroyed. It can be considered that using the Park-Ang damage index to evaluate connection damage usually overestimates the damage degree and lacks an accurate threshold range.

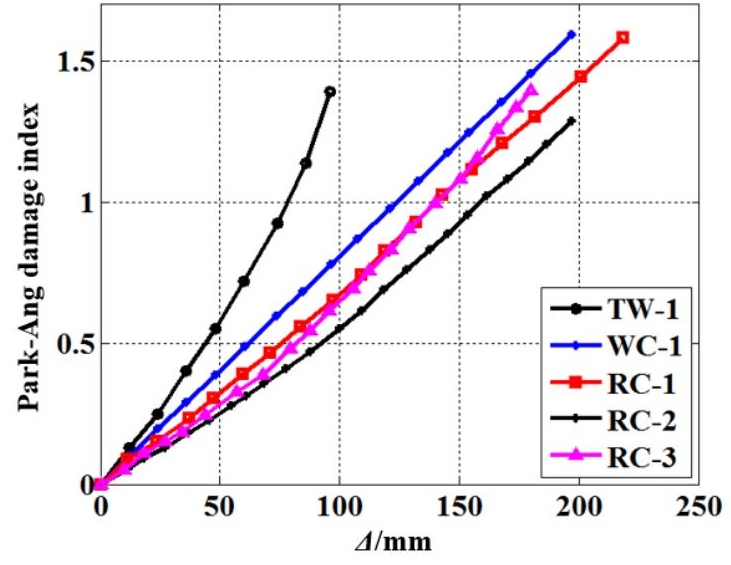

Fig. 22 Damage curves of Park-Ang model

The equivalent viscous damping coefficient $\xi$ is an important energy dissipation index in structural seismic performance analysis. The equivalent viscous damping coefficient of three different connections is calculated according to Eq. (15), as showed in Fig. 23. The energy consumption capacity of traditional connections is the worst, and the maximum of $\xi$ is 0.3 . The equivalent viscous damping coefficients of weakened connections and replacement connections were enhanced. In the early stage of loading, the weakened area in flange and web of the weakened connection yielded and deformed greatly. The energy dissipation of the weakened connection is stronger than that of the replacement connection. However, the deformation at the later stage of loading is too large to continue bearing, so the damping capacity was reduced. The LYPS in the replacement connections firstly yielded in the early stage of loading, but the deformation was small. In the late stage of loading, with the deformation incensement of LYPS, the energy consumption capacity of filled connections is better than that of weakened connections, and increased with the enlargement of displacement. It is obvious that replacement connections had better energy dissipation capacity.

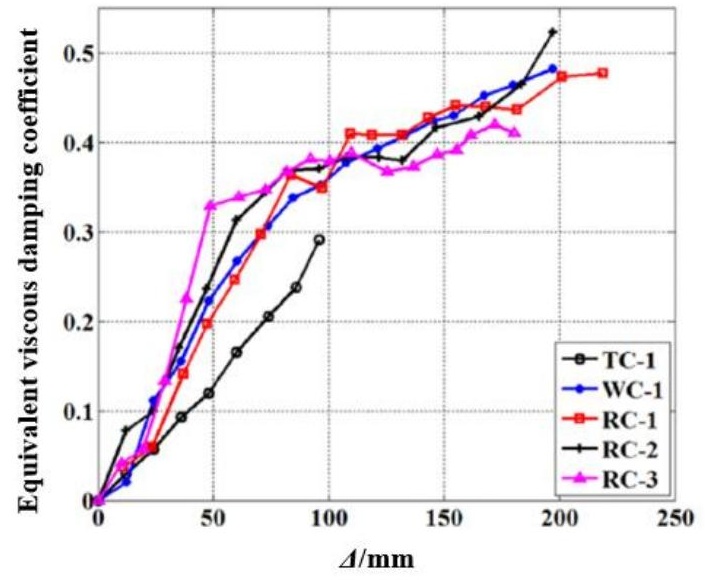

Fig. 23 Curves of equivalent viscous damping coefficien

According to Eq (12), the damage values $D_{E}$ of different specimens are calculated based on elastic-plastic energy dissipation ratio to evaluate the damage evolution process and damping capacity. The specific damage curves are compared in Fig. 24.

It can be found that the damage index of the specimen is strictly controlled between 0 and 1 . Although the damage of TC-1 is less than that of the other two connections in the early stage, when it is loaded to $70 \mathrm{~mm}$, the cracks occured in the welds at the junction of the members. Continuous loading leaded to complete cracking of the welding seams, and the component could not continue to bear the load and destroied, and the damage developed rapidly. The damage of replacement connections was always less than that of WC-1. The damage of weakened specimens and filled connections was increasing at the beginning of loading. When the displacement reached about $80 \mathrm{~mm}$, the damage rate begined to decrease, which is related to the failure of the connections. The maximum of the damage index reached about 0.9 , indicating that the test speciman had been completely destroyed at this time, and it also proves that the damage model can more realistically reveal the damage evolution law during the actual loading process. The low-yield-point steel in the replacement connections provides good 
energy absorbing and damping effect, and the damage of the speciman is effectively mitigated.
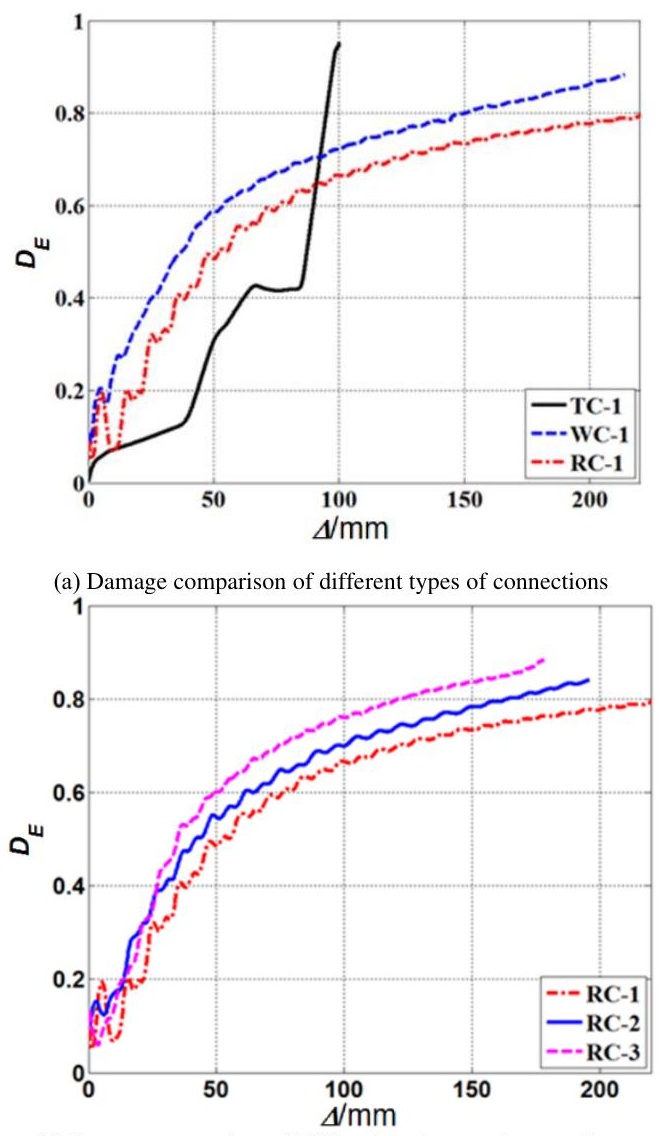

(b) Damage comparison of different replacement connections

Fig. 24 Comparison of damage curves of elastic-plastic energy dissipation ratio difference of specimens

It can be seen from the damage curves that the three damage evaluation models can represent the damage development law of the connection to a certain extent. The Park-Ang index exceeds 1 prematurely, and the damage develops rapidly with the increase of displacement. The equivalent hysteretic damping ratio and the damage curve based on the elastic-plastic energy dissipation ratio have the characteristics of gradual smoothness, and the value of the latter is strictly between $0 \sim 1$. The reason is that the denominator of energy damage term in Park-Ang model is a constant, and the numerator, which represents the cumulative hysteresis energy, will increase with the increase of hysteresis loops. Therefore, the value of energy item of this model actually represents the growth trend of hysteretic energy consumption, but does not fully indicate the damage evolution characteristics. In addition, the corresponding maximum is likely to exceed the upper limit of the damage threshold of 1 because the value is not the relative change rate of energy. On the contrary, the energy damage index can characterize the evolution process of damage according to the change rate of energy, which solves the above problems well, and its specific value and change rule are more accurate and intensive.

\section{Conclusions}

In view of the lack of seismic capacity and serious damage of the traditional steel connections subjected to earthquake, the research on the beam end weakened or beam end strengthened connections has attracted much attention. However, irreparable damage and lateral displacement will still occur in the improved connections. For the sake of improving the ductility and the bearing capacity of weakened connections and reduce the damag degree, a new pattern of replacement connection is presented in this study. For this new beam-column connection, the low-yield-point steel (LYPS) is selected to fill the weakened areas in the flange and web. In the earthquake, the LYPS firstly yields and dissipates enough energy, which can reduce the damage of main body.

The material test results show that the LYPS is superior to the ordinary steel in ductility and toughness, and it is indeed suitable for energy dissipation. This provides enough material guarantee for the seismic performance of new connection.
The seismic performance evaluation of steel structure connections should be carried out based on accuate damage index and damage model. In view of the shortcomings of the current earthquake damage models, a seismic damage model based on elastic-plastic energy dissipation different rate is presented. The mechanism of new damage index is clear and the threshold value is strict, which provides a good evaluation standard for damage evaluation.

Based on the experimental study and simulaton analysis of the traditional connections, weakened connections and replacement connections, the mechanical characteristics, failure patterns and seismic performance of steel connection members are obtained. The test results indicate that the mechanical behavior of the replacement connection with LYPS is different from that of traditional connections and weakened connections. Under the action of earthquake, the LYPS firstly yields and sufficiently consumes energy, thus the replacement connection has superior ductility, strength and energy consumption capacity. By reasonably design for the filling zone, the accumulative plastic deformation can be confined in the zone of the LYPS, and the serious damage and the large deformation in the beam is prevented. After the earthquake, the strengthening and maintenance of the connection can be completed quickly and simply, which can reflect and realize the concept of resilient structures.

The structure damage model based on elastic-plastic energy dissipation different rate can accurately represent the damage evolution law of the structure, and can be applied to different loading modes. At the same time, it can be strictly controlled between 0 and 1 . In additon, based on the design theory of weakened connetion, the seismic design process and formula of new connetion are put forward.

Due to the need for improvement in the structural design, parameter analysis and actual replacement process and method of the replacement conneciton, the relevant research, especially fine finite element modeling, simulation and dynamic analysis, also needs to be carried out in the future.

\section{Acknowledgments}

The financial support of National Natural Science Foundation of China Grant No.51878017 and No. 51678008 is greatly appreciated.

\section{Reference}

[1] Tsavdaridis. K. D, Pilbin C, Lau C. K. FE parametric study of RWS/WUF-B momen connections with elliptically-based beam web openings under monotonic and cyclic loading. Int J Steel Struct 2017,Vol.17,No.2,pp. 677-694.

[2] Akrami. V, Erfani. S . Review and Assessment of Design Methodologies for Perforated Steel Beams, J. Struct. Eng 2016,Vol.142,No.2.

[3] Saleh. A, Mirghaderi. SR, Zahrai. SM, Seyed Mehdi Zahrai, Cyclic testing of tubular web RBS connections in deep beams, Journal of Constructional Steel Research 2016,Vol.117,pp. 214-226.

[4] Ardavan A, Hajirasouliha I, Jazany. RA, Izadinia. M, Optimum drilled flange momen resisting connections for seismic regions, Journal of Constructional Steel Research 2015,Vol.112,pp. 325-338.

[5] Mehmet Alpaslan Köroğlu1, Ali Köken, Yunus Dere, Use of different shaped steel slit dampers in beam to column connections of steel frames under cycling loading, Advanced Steel Construction 2018,Vol.14,No.2,pp. 251-273

[6] Ali Koken, E. Tuba Hatipoglu, Investigation of the behavior of weakened and strengthened steel column-beam connections under seismic effects, Advanced Steel Construction 2014 Vol.10,No.0,pp. 1-13.

[7] Mohammad Davarpanah, Hamid Ronagh, Parham Memarzadeh, Farhad Behnamfar. "Cyclic behaviour of elliptical-shaped reduced web section connection", Structures, 2020,Vol.24,pp.955-973

[8] Momenzadeh S , Kazemi M T , Asl M H . Seismic performance of reduced web section moment connections. International journal of steel structures 2017,Vol.7,No.2,pp. 413-425.

[9] Saeed Erfani, Vahid Akrami, "A Nonlinear Macro model for Numerical Simulation of Perforated Steel Beams," International Journal of Steel Structures 2019,Vol.9,No.5,pp. 1605 1623.

[10] Saeed Erfani, Vahid Akrami. "Increasing Seismic Energy Dissipation of Steel Moment Frames Using Reduced Web Section (RWS) Connection", Journal of Earthquake Engineering, 2016,pp.1090-1112

[11] Garoosi AllahReza Moradi, TahamouliRoudsari Mehrzad, Hashemi Behrokh Hosseini, "Experimental evaluation of rigid connection with reduced section and replaceable fuse," Structures 2018,Vol.16,pp. 390-404

[12] Xiaodong Ji, Yandong Wang, Qifeng Ma, "Cyclic Behavior of Replaceable Steel Coupling Beams," Journal of Structural Engineering 2017,Vol.143,No.2.

[13] LU Xilin, CHEN Cong, "Research progress in structural systems with replaceable members," Earthquake Engineering and Engineering Dynamics 2014,Vol.34,No.1,pp. 27-36.

[14] Myoungsu Shin, Seung-Pil Kim, Arne Halterman, Mark Aschheim, "Seismic toughness and failure mechanisms of reduced web-section beams: Phase 1 tests," Engineering Structures 2017,Vol.141,pp. 198-216.

[15] Richards, Paul W. , and S. S. Oh . "Cyclic Behavior of Replaceable Shear Fuse Connection for Steel Moment Frames." Journal of Structural Engineering 2019, Vol.145. No.12.

[16]Ali K, Mehmet A K. Experimental Study on Beam-to-Column Connections of Steel Frame Structures with Steel Slit Dampers. Journal of Performance of Constructed Facilities, ASCE 2015,Vol.29,No.2,pp. 40-66.

[17] Ai-Lin Zhang, Guang-Hao Shangguan, Yan-Xia Zhang . "Experimental study of resilient prefabricated steel frame with All-bolted Beam-to-Column connections." Advanced Steel Construction 2020, Vol. 16, No. 3, pp. 255-271.

[18] Powell G H, Allahabadi R. Seismic damage prediction by deterministic method: concept and procedures. Earthquake Engineering and Structural Dynamics 1988,pp. 719-734. 
[19] Lei Xu1,Yuxin Liu. Inelastic analysis of steel frames accounting for stiffness degradations. Advanced Steel Construction 2006, Vol. 2, No. 4, pp. 355-373.

[20] Kratzig W B, Meyer I F, Meskouris K. Damage evolutionin reinforced concrete member under cyclic loading $[\mathrm{C}] /$ /Proceedings of 5th International Conference on Structural Safety and Reliability. San Francisco: American Society of Civil Engineers 1989, pp. 795-802.

[21] Huang, W, Zou M, Qian, J, Zhou, Z. Consistent damage model and performance-based assessment of structural members of different materials. Soil Dyn Earthq Eng 2018,Vol.109,pp. 266-272.

[22] HE Haoxiang, CONG Maolin, LV Yongwei. Earthquake Damage Assessment for RC Structures Based on Fuzzy Sets. Mathematical Problems in Engineering 2013,Vol.22.

[23] Wei Huang, Jiang Qian \& Zhi Zhou, "Seismic Damage Assessment of Steel Reinforced Concrete Members by a Modified Park-Ang Model," Journal of Asian Architecture and Building Engineering 2016,Vol.15,No.3,pp. 605-611.

[24] YU Yousheng, WANG Yan. Experimental Study On The Mechanical Property of Reduced Beam Section Connections of Steel Frames. Engineering Mechanics 2009,Vol.26,No.2,pp. 168-175.

[25] Huanjun Jiang, Shurong Li, Liusheng He, "Experimental Study on a New Damper Using Combinations of Viscoelastic Material and Low-Yield-Point Steel Plates," Frontiers in
Materials 2019, Vol.6.

[26] Zhang C , Zhang Z, Shi J . Development of high deformation capacity low yield strength stee shear panel damper. Journal of Constructional Steel Research 2012,Vol.75,pp. 116-130.

[27] Wang M , Fahnestock L A, Qian F. Experimental cyclic behavior and constitutive modeling of low-yield-point steels. Construction and Building Materials 2017,Vol.131,pp. 696-712.

[28] Meng Wang, Xiaogang Ke . "Seismic design of widening flange connection with fuses based on energy dissipation." Journal of Constructional Steel Research 2020, Vol. 170.

[29] FEMA.Recommended Seismic Design Criteria For New Steel Moment-Frame Building,FEMA-350.Washington D.C.:Federal Emergency Management Agency,2000

[30] Huanjun Jiang, Bo Fu, Xilin Lu, Linzhi Chen, "Seismic Damage Assessment of RC Members by a Modified Park-Ang Model," Advances in Structural Engineering 2015,Vol.18,No.3,pp 353-364.

[31] Huanjun Jiang, Bo Fu, Xilin Lu, Linzhi Chen, "Constant-Damage Yield Strength Spectra for RC Structures Using Modified Park-Ang Damage Model," Advances in Structural Engineering 2015,Vol.18,No.6,pp. 837-851.

[32] Krajcinovic D, Lemaitre J. Continuum damage mechanics theory and applications [M]. New York: Springer Verilag 1987. 233-294. 


\title{
DESIGN OPTIMIZATION OF LATTICE GIRDERS ACCORDING TO MEMBER AND JOINT-RELATED DESIGN CONSTRAINTS
}

\author{
Tugrul Talaslioglu* \\ Osmaniye Korkut Ata University, Department of Civil Engineering, 80000, Osmaniye/Turkey \\ *(Corresponding author: E-mail: ttalaslioglu@osmaniye.edu.tr, talaslioglu@cu.edu.tr)
}

\section{A B S T R A C T}

This study concerns with the design optimization of geometrically nonlinear lattice girders. The novelty of this study comes from simultaneously using the member and joint related design constraints, which are borrowed from the provisions of API RP2A-LRFD specification and defined depending on both member and joint strengths. A multi-objective design optimization approach named ImpNSGAII, which was improved in way of integrating both a neural network implementation and an automatic generating lattice girder tool for the search mechanism of NSGAII, is utilized in this study. Hence, this study purposes to investigate how to vary the optimality quality depending on the presence of joint strength-related design constraints. Thus, it is demonstrated that the presence of the joint strengthrelated design constraints causes to a divergence in the construction cost of optimal designs. Consequently, it is proved that the ImpNSGAII has a higher capability of exploring a conceptual lattice girder configuration in order to obtain an optimal design satisfying the economy, load-resistance and serviceability-related design conditions at the same time.
ART I CLE H IS T ORY

$\begin{array}{ll}\text { Received: } & \text { 12 June } 2020 \\ \text { Revised: } & \text { 2 February } 2021 \\ \text { Accepted: } & \text { 6 February } 2021\end{array}$

\section{K E Y W O R D S}

Multiple objectives;

Lattice girder;

Geometric nonlinearity;

API RP2A-LRFD ;

Member \& Joint Strength

\section{Introduction}

The steel lattice girders, members of which are connected to each other making use of a welding process, bolts and etc., are widely utilized in the structural engineering field (for example roofs, bridge, industrial applications etc.) [1]. In order to both increase its manufacturing accuracy and decrease its construction cost; they are preferably constructed in a manufacturing fabric of steel structures using a number of robots for the welding process [2]. Therefore, the effect of excessive welding process on the joint strength has to be considered in the design phase of lattice girder. Hence, the complexity in the design of lattice girders with respect to the generational design approach is correspondingly increased. Moreover, an increased demand to the cost-saving design of lattice girder causes to emerge the additional design complexities. In fact, these design complexities, which are exhaustively tackled in this section, constitutes the fundamentals of ImpNSGAII.

A generational design approach is also utilized in the design of steel lattice girders. It begins by deciding a certain geometric and topologic configuration of lattice girder since the various conceptual models such as Warren, Pratt and etc. has been successfully utilized to represent its framing configuration [3-4]. Following the decision on the conceptual model of lattice girder, its member cross-sectional properties are determined. Then, the sizes of lattice girder members are determined according to a database, which contains the cross-sectional properties of steel profiles. For this purpose, the member responses are computed using a linear structural analysis method. However, when the deformation in the geometrical shape of lattice girder is large, the structural responses are not correctly computed. Because, the large deformations of joints cause to arise the additional responses in the lattice girder members. Therefore, an appropriate approach is the usage of a non-linear structural analysis method for the computation of the member and joint responses. [5-8]. Following the computation of member responses, the capacities of member strengths is checked according to an available national or international design code [9]. Therefore, the designer's experience has a big importance in this stage in order to reduce the number of trials.

This generational design procedure has still been applied to determine the most suitable construction of lattice girder. However, the best way for the exploration of a cost-effective lattice girder design in a lower trial number is the inclusion of an optimization process into the design procedure [10-11].

In the optimal design of steel structures, the economy is provided in a way of arranging the cross-sectional properties of its members for a lower weight of steel structures. In this generational sizing optimization procedure, the member cross-sectional properties are determined by checking the member stress and joint displacement values according to their pre-specified upper values [12]. Although there is a big variety in the steel profiles with different cross-sectional shapes and properties, the circular-hollow-shaped cross-sections are preferably utilized to represent the size type design variables. Because, their torsional strengths are higher than those with open cross-sections [13-16]. It was shown that an execution of this generational sizing optimization procedure causes to decrease the number of feasible solutions [17]. Furthermore, it was also demonstrated that involving the shape and geometry of lattice girder into the optimal design procedure leads to the exploration of optimal design with higher economic, serviceability and load-resistance capability. Particularly, it was also shown that the stability capacity of steel structure was increased through the various arrangements in its current geometrical form [18]. Therefore, using a conceptual model for the representation of lattice girder framing configurations provides a big advantage in introducing the shape and geometric properties of lattice girders. It is noted that the appropriateness of conceptual design model has a big importance on the construction of lattice girder in the manufacturing fabrics of steel structures due to its practically applicability into the real world [19]. Hence, the waste of time in the elimination of inappropriate optimal designs obtained is prevented.

The generational optimal design procedure is utilized in the design optimization of steel structures with single objective function, for example, weight minimization. But the designer preferences are correspondingly neglected [2021]. In order to handle this bottleneck, a multi-objective optimization procedure should be utilized in the optimal design of steel structures. Hence, it is possible to make a tradeoff analysis among the designer's preferences. Furthermore, the proposed multi-objective optimization approach has to also be capable of handling with the usage of mixing type of design variables due to the discrete nature of steel structures. Furthermore, it must own a simple but an effective search mechanism in order to reduce the computing time in the exploration of optimal designs with higher quality as well [17].

The effectiveness of any multi-objective optimization procedure depends on the properly assignment of their governing parameters. Thus, the computing performance of multi-objective optimization algorithm is correspondingly increased. But, the computing performance of proposed multi-objective optimization algorithm is degraded when the current parameter value set is utilized for the different optimization problem [22-24]. Thus, it is concluded that the adaptively usage of governing parameters is the most crucial issue in the evaluation of computing performance of multi-objective optimization algorithm since the form of solution space varies depending on the nature of optimization problem. The evaluation of multi-objective optimization procedures is distinguished from the ones with single objective due to the increased number of objective functions. The computing capability of any optimization procedure with single objective function is easily determined considering the convergence degree of optimal designs. However, the computing performance of multi-objective optimization procedure is assessed using a statistical test approach performed to evaluate the values of various quality criterions [25].

Particularly, the multi-objective optimization approaches that mimic the various nature-related phenomena such as, Darwin's evolutionary theory, livings of ants, bees, flying etc. are more successful in the design optimization of both steel structural and the other engineering applications [26]. Particularly, the genetic algorithm based multi-objective optimization algorithms achieve to 
take more attention in the various optimization-related fields due to their simple and effective search mechanisms [27].

This study concerns with the optimal design of geometrically nonlinear tubular lattice girders considering the provisions of "Recommended Practice for Planning, Designing and Constructing Fixed Offshore Platforms: Load and Resistance: Factor Design (API RP2A-LRFD 1993) [28]. It is noted that API RP2A-LRFD is a compact design code since it comprises the member and jointstrength-related design codes. The arc-length method is employed to analyze the structural system in order to compute nonlinear structural responses at each load steps. The arc-length approach is proven to be successful in the identification of limit points, which indicates the failure in the stability of structural system, thereby iteratively tracing an equilibrium path formed by incremental load and displacement values [18]. Hence, the higher complex nonlinear structural problems that exhibits snap-through or snap-back behavior are easily solved through its capability of easily predicting the limit points (bifurcation, branching and etc.). An improved multi-objective optimization approach (ImpNSGAII) is utilized to execute the optimization-related computations [17]. The fundamentals of ImpNSGAII are constituted on the computing procedure of nondominated sorting genetic algorithm II (NSGAII), which is basically governed by the genetic operators. The main future of ImpNSGAII is its ability of self adaptively adjusting the parameter values of genetic operators.

The novelty of this study comes from its being a first attempt to determine the load-resistance capability of the lattice girder at any load step of the nonlinear structural analysis approach thereby checking both member and joint strengths considering the provisions of API RP2A-LRFD specification [28]. The other novel aspect of this study is that the proposed optimal design approach does not penalized the objective functions. Hence, a waste of time consumed in the exploration of feasible designs is correspondingly prevented through this feature of the proposed design approach.

The presentation of optimal design results starts firstly by introducing a multi-objective optimization background. The computing steps of ImpNSGAII are defined in the subsequent sections. The design results outcome from the application examples, which were introduced in Reference [17], are also included. Then, a general summarization is reported in the section of "conclusion".

\section{The basic elements of proposed optimization procedure}

The design optimization of lattice girders that satisfies the economy, loadresistance and serviceability-related design conditions at the same time is carried out thereby minimizing the entire weight of lattice girder $f_{l}$ and joint displacements $f_{2}$ and maximizing its member forces $f_{3}$ (see Eqns. (1-3)). The proposed objective functions are formulated as:

$$
f_{1}=\min \left(\sum_{k=1}^{m}\left(w^{*} l\right){ }_{\mathrm{k}}\right) \quad(k=1, . ., m)
$$

$f_{2}=\min \left(d_{\mathrm{ij}}\right)$

$$
(i=1, . ., 6 \text { and } j=1, \ldots, n)
$$

$$
f_{3}=\max \left(f_{\mathrm{ij}}\right)
$$

The entire weight $W$ is computed considering the structural member length $l$ and its unit weight $w$ for each member $(1, . ., m)$.The properties of structural members with circular hollow shaped cross-sections are assigned from 37 different types-steel profiles. The joint displacements $d_{i j}(j=1, \ldots, n$ and $i=1, \ldots, 6)$ are defined for both each degree of freedom $i$ and joint $j$. The member forces $f_{i j}$, which contain "axial" $\&$ "shear" forces, "bending" $\&$ "torsional" moments, are obtained in the end of execution of nonlinear structural analysis.

The design constraints called as the member and joint related design constraints (MRDC and JRDC), are described using the member and joint strengthrelated inequalities. A unity value is assigned to represent these inequalities (see the sections of " $D$ " and " $E$ " in Reference [28]). For example, the inequalities ( $f_{t}$ $\leq \phi^{*} F$ ) for axial tension are represented by unities as Unity $=\left(\mathrm{f}_{t} / \phi^{*} F\right) \leq 1.0$.

In the following part, the details of design constraints are presented including their formulation numbers along with Tables and Figures no's located in provisions of API RP2A-LRFD specification [28].

i) Member strength-related unities for $m$ members $(k=1, \ldots m)$ :

Unity $^{k}{ }_{\text {Axial }}$ represents the member axial capacity, which defines a strength against tensile and compressive stresses occurred in lattice girder members (see the section of D.2.1-1 and D.2.2-1 in Reference [28]). It is defined by making use of "nominal yield strength" and "nominal axial compressive strength", respectively. Whereas the nominal yield strength has a pre-assigned value, the nominal axial compressive strength is determined depending on both "nominal yield strength" and "elastic\&inelastic local buckling strength" (stability issue). Therefore, the certain parameters, for example the effective length factor for the calculation of braced length along with the gyration diameter and the ratio as "diameter/thickness", manage the magnitude of nominal axial compressive strength. Thus, the availability of diagonal members against the stability problem and the assignment of members with higher thickness for the construction of lattice girder has a big contribution to the member axial capacity.

Unity $_{\text {Shear }}^{k}$ represents the member's shear capacity, which defines a strength against shear stress occurred in lattice girder member (see the section of D.2.4 1 in Reference [28]). The shear capacity of member is determined considering "nominal shear strength", which is indicated as a percentage of "nominal yield strength". As in the Unity ${ }_{\text {Axial }}$, the use of diagonal members provides to decrease the member forces, which comes from the external forces imposed on the corresponding nodes.

Unity $_{\text {AxialCompr\&BendingBuckling }}^{k}$ represents the member's combined axial compressive and bending buckling capacities, which defines the strengths against both compressive and bending stresses (see the section of D.3.2-2 [28]). This unity is computed depending on "euler buckling strength" and "nominal axial compressive strength" (stability issue) along with "nominal bending strength". The computing details about "nominal bending strength" are given in the introduction of Unity ${ }_{\text {Axial }}$, above. The nominal bending strength is calculated depending on a ratio "diameter/thickness" and "elastic\&plastic section modulus". Thus, the availability of diagonal members not only provides a positive contribution to this unity, but the use of members with higher thickness and plastic section modulus also increases the capacity of this unity.

Unity $^{k}{ }_{\text {AxialCompr\&BendingYield }}$ represents the member's combined axial tensile and bending yield capacities, which defines the strengths against both tensile and bending forces (see the section of D.3.1-1 in Reference [28]). This unity is computed depending on "nominal inelastic buckling strength" and "nominal bending strength". The computing details about these strengths are given in the introduction of Unity ${ }_{\text {AxialCompr\&BendingBuckling }}$ and Unity ${ }_{\text {Axial }}{ }_{\text {, respectively. Thus, the }}$ availability of diagonal members and the use of members with higher thickness and plastic section modulus provides an increase in the capacity of this unity.

ii) Joint strength-related unities for $n$ joint $(j=1, \ldots, n)$ :

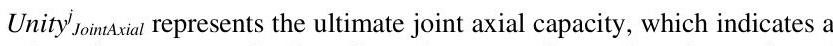
strength against compressive\&tensile and moment forces (see the section of E.3-2 in Reference [28]). Thus, the joint axial capacity is not only determined depending on axial forces, but also, in-plane and out-plane bending forces occurred in lattice girder members along with the joint types (K,T,Y and etc.). Considering, Table E.3-1 and Table E.3-2 in Reference [28], it is seen that Kshaped connections makes more contribution in the capacity of joint axial and thus leads to a decrease in the value of its unity (see Fig. E.3.2 in Reference [28]). Moreover, the contribution of T and Y-shaped connections are lower with respect to K-shaped connections. If a vertical member, axial force of which equals to zero, is connected with only one diagonal member at a joint, this joint is defined as $\mathrm{T}$ and/or T\&Y. Therefore, the inclusion of diagonal members into the construction of lattice girder leads to an increase in the joint axial capacity. Particularly, the joint axial capacity, which is obtained by multiplying the "chord design factor" and "ultimate strength factor" is factorized by a parameter "connection resistance factor". In fact, both connection resistance factor and ultimate strength factor are determined the joint types (K, T, Y and etc.) along with the thickness and diameters of chord and brace members.

Unity $_{\text {JointAxial\&Bending }}$ represents the joint axial and bending capacities (see E.3-4 in Reference [28]). In fact, this unity is computing depending on the ultimate joint axial and bending moment capacities without omitting the parameter "connection resistance factor".

Unity $_{\text {JointYield }}$ represents the joint yield capacity (see the section of E.3-1 in Reference [28]). The strength of joint yield is determined depending on both the pre-defined yield values of brace and chord members and joint geometric properties (brace angle, thickness and diameters of brace and chord members).

It is mentioned that the thickness and diameters of chord and brace members have a big effect on the unity values which are utilized to define JRDCs. In his regard, some arrangements for these cross-sectional properties of chord and brace members provides an increase in the capacities of joint-related strengths as:

i) The thickness of chord member must be higher with respect to its diameter. ii) The thickness of chord member must be higher than brace members' iii) The diameter of chord member must be higher than brace members' iv) Particularly, the lower angle $\theta$ between chord and brace members leads to an increase in the capacity of Unity ${ }_{\text {JointYield }}$ (see Eqn. E.3-1 in Reference [28]). In this study, the lower value of middle height, which is indicated by $\operatorname{Par}_{\mathrm{H} 2}$ is utilized to indicate a lower angle $\theta$. In fact, it has to be also noted that an increase in the middle height of lattice girder causes the occurrence of stability-related structural problem.

If any unities defined for the member and joint strength exceed " 1 ", then nonlinear structural analysis is stopped at the corresponding loading step number. At the corresponding loading step number, maximum member force and 
joint displacement values are utilized to determine both the load-resistance capability and joint displacements for the automatically assigned lattice girder configuration. It is mentioned that the arc-length method is utilized for the analysis of structural responses. For this purpose, a finite element analysis tool, ANSYS is employed to compute the responses for the current lattice girder configuration [17].

Furthermore, the design flexibility of proposed optimal design approach is improved thereby including an automatic lattice girder generating tool into the optimization of lattice girder designs taking into consideration of proposed constraints mentioned above. A typical lattice girder model is used to generate various lattice girders. Thus, it is possible to carry out not only sizing but also topologic and shape optimization at the same time. The size type design variables
D1-D4 and their cross-sectional properties are chosen from 37 different circular-hollow-shaped cross-sections and assuming their limit values Par $_{U D V}$ and $\operatorname{Par}_{L D V}$ in a range of 1-37 (see Reference [17]). The topology type design variables, limits of which are defined by $\operatorname{Par}_{D N U}$ and $P a r_{D N L}$, is governed by a ratio as (length of span $L S$ / division number $\operatorname{Par}_{D N}$ ). Two shape type design variables for two heights of lattice girder $\mathrm{H} 1$ and $\mathrm{H} 2$ are defined by two parameters Par $_{H I}$, $\operatorname{Par}_{\mathrm{H} 2}$. Their limits are determined by the parameters $\operatorname{Par}_{\mathrm{HIU}}, \operatorname{Par}_{\mathrm{HIL}}, \mathrm{Par}_{\mathrm{H} 2 \mathrm{U}}$ and $\operatorname{Par}_{H 2 L}$, respectively. A further detail about both the generation of various lattice girders and the assignment of the design-related parameters in connection with both the proposed generating tool and ANSYS is found in Reference [17].

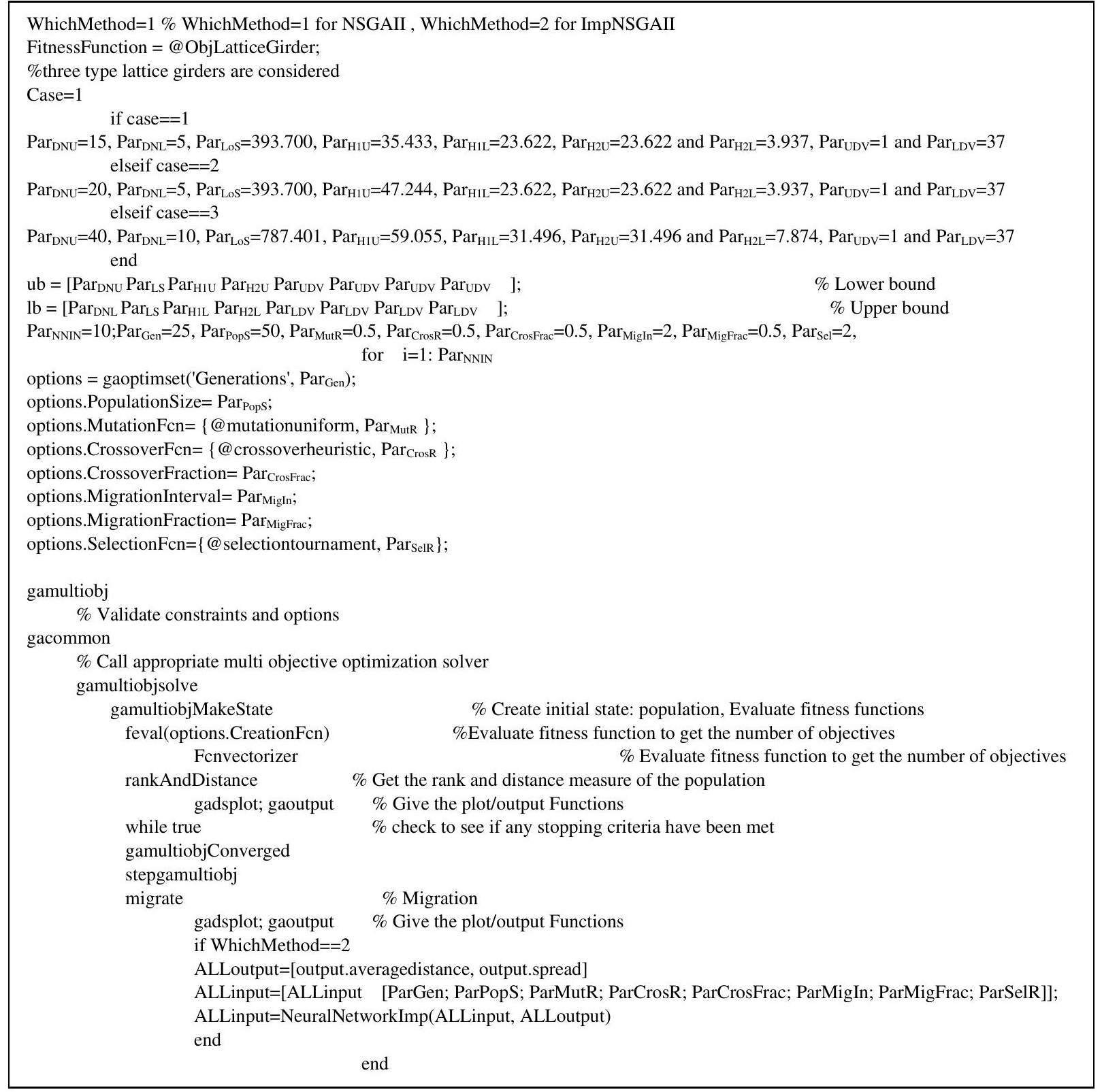

Fig. 1 A Matlab Script for ImpNSGAII and NSGAII

\section{An improved multi-objective optimization algorithm named Imp-}

\section{NSGAII}

It is mentioned that the nature-inspired multi-objective algorithms are mostly preferred in the design optimization of structural engineering applications due to their both higher search capabilities and simple search mechanisms. Particularly, the genetic algorithms (GAs), a branch of evolutionary algorithms has been accomplished to take more attention in the various engineering areas, particularly structural engineering applications [29-36]. Therefore, their fundamentals have been frequently utilized to arrange the basic elements of multiobjective optimization approaches.
The genetic algorithm approach completely mimics the main fundamentals of Darwian's evolutionary theory. Firstly, the decision (design) variables of optimization problem are appropriately coded in a chromosome. Then, the objective functions, which evaluate fitness (an indicator for the quality of chromosome), are determined depending on the preferences of designer. A number of individuals composed from chromosomes are gathered to form a population. Then, the individuals with a higher fineness values are selected, mutated and reproduced to form the next population. This generation process called evolution is stopped when a termination condition, for example a predefined generation number is fulfilled. This simple but effective search strategy of genetic algorithm has played a big role in the emergence of trend multi-objective optimization algorithms. The most popular one of these algorithms is NSGAII due to 
having a wide range usage in the various scientific fields [27]. The working principle of NSGAII is fundamentally based on the usage of genetic operators of GAs (crossover, mutation and selection) in the generation of promising individuals for next populations. Firstly, it is assumed that the individuals are collected in the different sparse and crowded regions of solution space. Then, the individuals are ranked considering the locations of these regions. In other words, crowding distance values of individuals are ranked taking into account of pareto ranking mechanism, which is responsible to assign a rank value began from 1 to the individuals. Thus, the best ranking individuals are selected and re-produced in order to generate the next populations. Therefore, the governing parameter values of genetic operators have a big impact on the computing capability of NSGAII. Although it is possible to determine the appropriate values of genetic operator parameters thereby trying their different combination sets, this approach will become not to be practical taking into account of its usage for a different design problem. In order to overcome this bottleneck, NSGAII is improved in a way of being utilized the neural network [17]. ImpNSGAII is basically based on adapting the parameter values of genetic operators throughout the evolutionary search thereby measuring the approximating and diversity degree of individuals in current population. The computing steps of ImpNSGAII are accordingly coded in MATLAB [37].

According to the pseudo code in Fig. 1, the fitness functions $f 1, f 2$ and $f 3$ coded in a separate toolbox "FitnessFunction" are computed considering the population $x^{0}$, which is arranged according to the limits of design variables $l b \& u b$ (see Eqns. (4-6)). Although the maximum design variable number "numberOfVariables" is taken as 8 (see Eqns. (4-6)), it is noted that the size of row matrix named $\operatorname{ParDN}$ is determined depending on the number of size type design variables. The current optimization procedure named NSGAII and coded in MATLAB [37] is essentially governed by a structure field, option. This structural filed contains both the genetic operators and their corresponding parameter values. Firstly, the toolbox "Gamultiobj", which contains the upper and lower limits of constraints along with the corresponding parameter names and values, is activated. Thus, the fitness functions are correspondingly computed considering the pre-defined design constraints. The toolbox "gamultiobjsolve", which automatically runs the two toolboxes "GamultiobjMakeState" and "stepgamultiobj" has a responsibility of computing the procedure of NSGAII. In fact, "GamultiobjMakeState", which is responsible to perform both the genetic operations such as selection, crossover, mutation and the quality measuring-related computation, is utilized in run of "stepgamultiobj".(see ROUTINE2 for a further detail about "GamultiobjMakeState" in Reference [17]). The toolbox "gamultiobjsolve" firstly runs the other toolbox "GamultiobjMakeState" for forming the beginning population in a way of utilizing options.CreationFen, calculate the fitness functions by "fcnvectorizer" and correspondingly order the fitness functions by "rankAndDistance". Following activation of "stepgamultiobj", the main generation is terminated depending on the value of parameter "options". Generations. It is noted that it is defined a number of termination options in the command "gamultiobjConverged". "Stepgamultiobj" is employed to execute the genetic operations (see ROUTINE1 in Reference [17]). It is noted that two toolboxes "gadsplot" and "gaoutput" can be utilized to plot a number of different outputs, following the execution of migration-related operations.

$$
x^{0}=[\underbrace{f i x\left(x_{1}^{0}\right),}_{\operatorname{Par}_{D N}} L S, x_{\operatorname{Par}_{H 1} \text { and } \operatorname{Par}_{H 2}^{0}, x_{3}^{0}}^{f i x\left(x_{4}^{0}\right), f i x\left(x_{5}^{0}\right), f i x\left(x_{6}^{0}\right), f i x\left(x_{7}^{0}\right)}]
$$

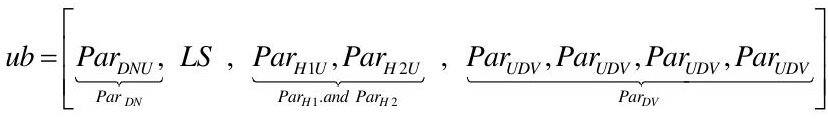

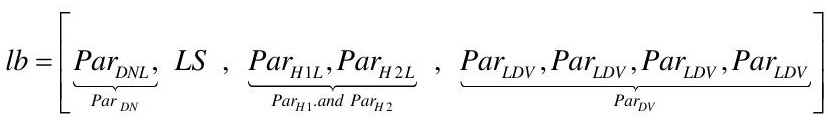

The governing parameters of both ImpNSGAII and NSAGAII are defined in the structure field "options" as "options.Genarations" Par, "options. PopulationSize" Par $r_{2}$, "options. MutationFcn \{@mutationuniform.\}" Par 3 , “options. CrossoverFcn \{@ crossoverheuristic.\}" Par 4 , "options. CrossoverFraction" Par, "options. MigrationInterval" Par 6 , "options. MigrationFraction" Par 7 , "options. SelectionFcn\{@selectiontournament.\}" Par

Table 1

\begin{tabular}{|c|c|c|c|c|c|c|c|c|c|c|}
\hline \multirow[b]{2}{*}{ Governing Parameters } & \multicolumn{10}{|c|}{$\operatorname{Par}_{\text {NNIN }}(\operatorname{ImpNSGAII)}$} \\
\hline & 1 & 2 & 3 & 4 & 5 & 6 & 7 & 8 & 9 & 10 \\
\hline $\operatorname{Par}_{1}$ & 22 & 3 & 20 & 19 & 21 & 16 & 15 & 11 & 17 & 4 \\
\hline $\mathrm{Par}_{2}$ & 36 & 42 & 34 & 34 & 30 & 29 & 30 & 26 & 15 & 16 \\
\hline $\mathrm{Par}_{3}$ & 0.7099 & 0.4629 & 0.7059 & 0.6367 & 0.5906 & 0.4630 & 0.4550 & 0.4258 & 0.9034 & 0.4446 \\
\hline $\mathrm{Par}_{4}$ & 0.4990 & 0.3951 & 0.7810 & 0.4712 & 0.2297 & 0.8838 & 0.9060 & 0.1529 & 0.2113 & 0.3037 \\
\hline Par $_{5}$ & 0.7356 & 0.7848 & 0.5574 & 0.7881 & 0.7740 & 0.2621 & 0.3183 & 0.6292 & 0.2972 & 0.4280 \\
\hline Par 6 & 2 & 4 & 3 & 3 & 4 & 3 & 4 & 2 & 2 & 5 \\
\hline $\operatorname{Par}_{7}$ & 0.3316 & 0.8239 & 0.9441 & 0.9397 & 0.9543 & 0.5917 & 0.2362 & 0.6962 & 0.5181 & 0.8556 \\
\hline Pars $_{8}$ & 0.5863 & 0.4983 & 0.9625 & 0.1392 & 0.4255 & 0.8895 & 0.6899 & 0.4745 & 0.4170 & 0.6502 \\
\hline
\end{tabular}

The Governing Parameter Values of ImpNSGAII and NSGAII

Governing Parameters

$\begin{array}{lc}\text { Par }_{1} & 100 \\ \text { Par }_{2} & 50 \\ \text { Par }_{3} & 0.5 \\ \text { Par }_{4} & 0.5 \\ \text { Par }_{5} & 0.5 \\ \text { Par }_{6} & 5 \\ \text { Par }_{7} & 0.5 \\ \text { Par } & \end{array}$

See the definitions of abbreviations for the governing parameters in Section 3

\section{Discussion of results}

In this study, the member and joint-related strength design constraints are taken from API RP2A-LRFD specification [28]. The influences of MRDC and JRDC on the optimality qualities of designs are investigated. Furthermore, the computing capability of ImpNSGAII is also compared by NSGAII algorithm including the other optimization approaches proposed in Literature. A bench- mark lattice girder and a general lattice girder, configuration of which are automatically generated depending on a user-defined loading adjustment and spanning length are devised as the application design examples. In fact, these design problems were also optimized considering only MRDC in Reference [17]. Thus, it was shown that the optimal configurations of lattice girders simultaneously satisfied the economy, load-resistance and serviceability-related design conditions. It is noted that the load-resistance capability of lattice girders is determined according to the member forces. 
Table 2

Extreme Optimal Designs (OD) and Corresponding Design (D) Values (Design Example 1)

\begin{tabular}{|c|c|c|c|c|c|c|c|c|c|c|c|c|c|c|c|c|c|}
\hline & \multicolumn{17}{|c|}{ Size Type Design Variables ${ }^{a 1}$} \\
\hline & $\bar{a}$ & ธิ & $\hat{\omega}$ & 苞 & $\ddot{a}$ & ฉ̊ & $\hat{\theta}$ & $\stackrel{\circ}{\circ}$ & คิ & $\stackrel{\circ}{a}$ & $\overline{\bar{D}}$ & $\frac{2}{0}$ & $\frac{m}{a}$ & $\frac{\Delta}{\Delta}$ & $\frac{n}{n}$ & $\frac{0}{a}$ & $\bar{a}$ \\
\hline $\begin{array}{l}\text { OD1 } \\
\text { (MW) }\end{array}$ & 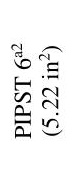 & 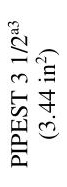 & 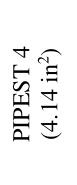 & 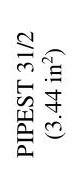 & 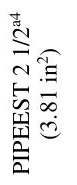 & 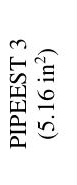 & 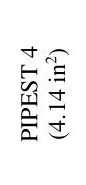 & 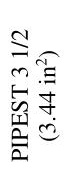 & 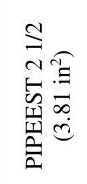 & 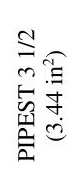 & 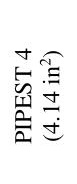 & 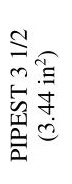 & 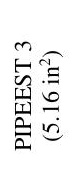 & 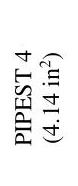 & 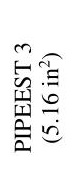 & 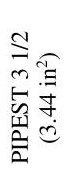 & 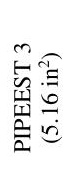 \\
\hline $\begin{array}{l}\text { OD2 } \\
\text { (MJD) }\end{array}$ & 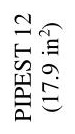 & 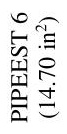 & 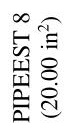 & 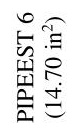 & 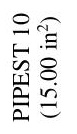 & 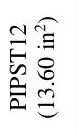 & 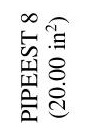 & 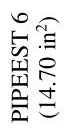 & 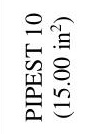 & 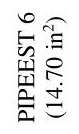 & 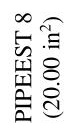 & 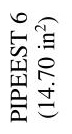 & 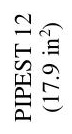 & 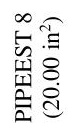 & 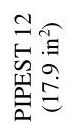 & 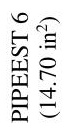 & 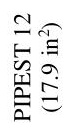 \\
\hline $\begin{array}{l}\text { OD3 } \\
\text { (MEF) }\end{array}$ & 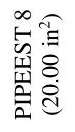 & 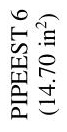 & 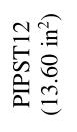 & 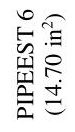 & 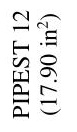 & 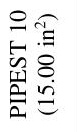 & 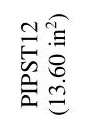 & 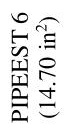 & 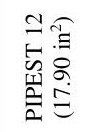 & 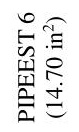 & 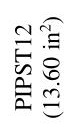 & 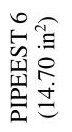 & 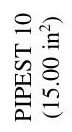 & 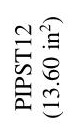 & 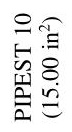 & 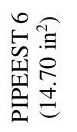 & 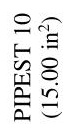 \\
\hline $\begin{array}{l}\text { Ref. [38] } \\
\quad\left(\mathrm{in}^{2}\right)\end{array}$ & $\begin{array}{l}\vec{D} \\
\infty \\
\underline{n}\end{array}$ & $\frac{\infty}{\circ}$ & $\stackrel{\circ}{\circ}$ & $\frac{8}{0}$ & $\frac{i}{\infty}$ & $\begin{array}{l}5 \\
0 \\
n \\
n\end{array}$ & ָे & $\frac{8}{0}$ & 商 & $\frac{8}{0}$ & 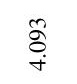 & $\frac{8}{0}$ & 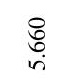 & $\underset{\check{8}}{\overline{8}}$ & $\begin{array}{l}0 \\
6 \\
i \\
i\end{array}$ & $\frac{8}{0}$ & $\begin{array}{l}\text { D̃ } \\
\infty \\
n \\
n\end{array}$ \\
\hline $\begin{array}{l}\text { Ref. [39] } \\
\quad\left(\mathrm{in}^{2}\right)\end{array}$ & ڤ్ & $\frac{8}{0}$ & 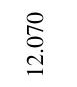 & $\frac{8}{0}$ & $\underset{\infty}{\infty}$ & $\begin{array}{l}\text { ర్ } \\
n \\
n \\
n\end{array}$ & $\stackrel{\varrho}{\sigma}$ & $\frac{8}{\stackrel{8}{0}}$ & $\stackrel{n}{\stackrel{2}{r}}$ & $\frac{8}{9}$ & 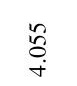 & $\frac{8}{0}$ & $\underset{n}{n}$ & 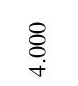 & $\begin{array}{l}\infty \\
n \\
n \\
n \\
n\end{array}$ & $\frac{8}{0}$ & $\begin{array}{l}\hat{\hat{n}} \\
\text { in }\end{array}$ \\
\hline \multirow[t]{2}{*}{$\begin{array}{l}\text { Ref. [40] } \\
\quad\left(\mathrm{in}^{2}\right)\end{array}$} & $\begin{array}{l}\stackrel{0}{\infty} \\
\qquad \\
\end{array}$ & $\frac{3}{0}$ & 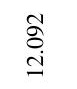 & $\frac{8}{6}$ & $\underset{\infty}{\infty}$ & 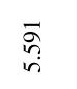 & $\stackrel{n}{\frac{n}{a}}$ & $\frac{8}{0}$ & $\frac{2}{2}$ & $\frac{8}{0}$ & $\stackrel{゚}{\stackrel{\circ}{0}}$ & $\frac{8}{6}$ & $\begin{array}{l}\stackrel{R}{6} \\
\dot{r}\end{array}$ & 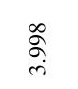 & 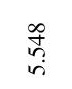 & $\frac{\wp}{0}$ & $\begin{array}{l}n \\
n \\
n\end{array}$ \\
\hline & \multicolumn{5}{|c|}{ Entire Weight } & \multicolumn{4}{|c|}{ Joint Displacement } & \multicolumn{6}{|c|}{ Maximum Member Force and Stress } & \multicolumn{2}{|c|}{$\begin{array}{c}\text { Load Step } \\
\text { Number }\end{array}$} \\
\hline $\begin{array}{l}\text { Des } 1 \\
(M W)\end{array}$ & \multicolumn{5}{|c|}{$\begin{array}{l}2515.895 \mathrm{lb}^{\mathrm{a} 1} \\
1539.907 \mathrm{lb}^{a 5}\end{array}$} & \multicolumn{4}{|c|}{$\begin{array}{l}1.217 \mathrm{in}^{\mathrm{a} 1} \\
1.492 \mathrm{in}^{a 5}\end{array}$} & \multicolumn{6}{|c|}{$\begin{array}{c}240.033^{\mathrm{a} 1} \text { and } 25.87 \mathrm{ksi}^{\mathrm{a} 1} \\
239.958 \text { and } 29.83 \mathrm{ksi}^{a 5}\end{array}$} & \multicolumn{2}{|c|}{$\begin{array}{l}2^{\mathrm{a} 1} \\
2^{a 5}\end{array}$} \\
\hline Des2 $(M J D)$ & \multicolumn{5}{|c|}{$\begin{array}{l}9416.272 \mathrm{lb} \\
6386.020 \mathrm{lb}\end{array}$} & & $\begin{array}{l}0.28 \\
1.9\end{array}$ & & & \multicolumn{6}{|c|}{$\begin{array}{l}240.000 \text { and } 6.200 \mathrm{ksi} \\
1239.191 \text { and } 47.89 \mathrm{ksi}\end{array}$} & \multicolumn{2}{|c|}{3} \\
\hline $\operatorname{Des} 3(M E F)$ & \multicolumn{5}{|c|}{$9134.793 \mathrm{lb}$} & & $\begin{array}{l}1.6 \\
1.5\end{array}$ & & & \multicolumn{3}{|c|}{1240.472 and $36.80 \mathrm{ksi}$} & & & & \multicolumn{2}{|c|}{$\begin{array}{l}3 \\
3\end{array}$} \\
\hline Ref. [38] & \multicolumn{5}{|c|}{$2580.81 \mathrm{lb}$} & \multicolumn{4}{|c|}{ N/A } & \multicolumn{6}{|c|}{ N/A } & \multicolumn{2}{|c|}{ N/A } \\
\hline Ref. [39] & \multicolumn{5}{|c|}{$2581.89 \mathrm{lb}$} & \multicolumn{4}{|c|}{ N/A } & \multicolumn{6}{|c|}{ N/A } & \multicolumn{2}{|c|}{ N/A } \\
\hline Ref. [40] & \multicolumn{5}{|c|}{$2581.94 \mathrm{lb}$} & \multicolumn{4}{|c|}{ N/A } & \multicolumn{6}{|c|}{ N/A } & \multicolumn{2}{|c|}{ N/A } \\
\hline $\begin{array}{l}\text { a1: According } \\
\text { a2: PIPST (Sta } \\
\text { a3: PIPEST (E } \\
\text { a4: PIPEEST } \\
\text { a5: According }\end{array}$ & $\begin{array}{l}\text { Displac } \\
\text { lard Tub } \\
\text { a Stron } \\
\text { ouble-Ex } \\
\text { Displac }\end{array}$ & $\begin{array}{l}\text { ent, M } \\
\text { Ir Cross } \\
\text { ubular } \\
\text { Strons } \\
\text { ent, M }\end{array}$ & $\begin{array}{l}\text { ber and } \\
\text { ections) } \\
\text { oss-sect } \\
\text { ubular ( } \\
\text { ber-relat }\end{array}$ & $\begin{array}{l}\text { ns) } \\
\text { oss-sec } \\
\text { d Desi }\end{array}$ & Design & & & & $\begin{array}{l}\text { MW: Mi } \\
\text { MJD: Mi } \\
\text { MMF: }\end{array}$ & $\begin{array}{l}\text { mum W } \\
\text { mum Jo } \\
\text { ximum }\end{array}$ & $\begin{array}{l}\text { ght Valu } \\
\text { t Displa } \\
\text { ember F }\end{array}$ & $\begin{array}{l}\text { ment } \mathrm{Va} \\
\text { e Value }\end{array}$ & & & & & \\
\hline
\end{tabular}

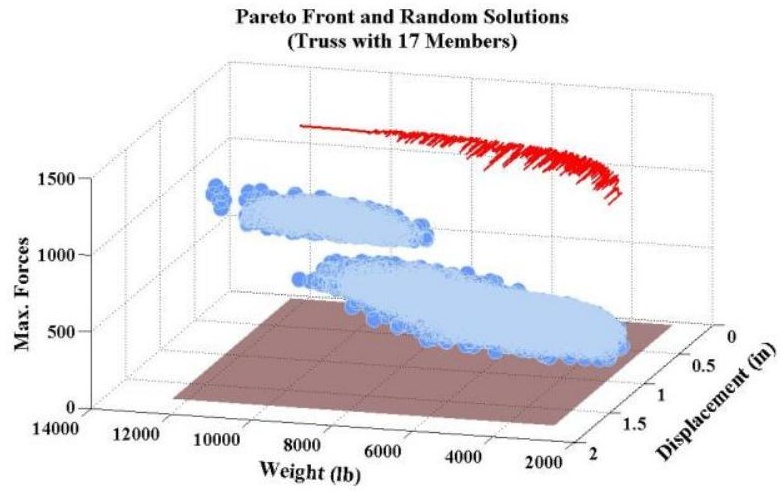

Fig. 2 True Pareto front Design Example 1

\subsection{A benchmark lattice girder design}

This structural system is subject to a joint load of $100 \mathrm{kipf}$ on the joint number 9. It is defined as Design Example 1. The optimal design this simple lattice girder was firstly carried out in References [38-40].

True pareto front with a red color obtained using JRDC\&MRDC is presented Fig. 2. The governing parameters of relatively successful ImpNSGAII and NSGAII is presented in Table 1.

In order to make a further investigation into the influence of JRDC on the optimality quality of designs obtained, some extreme designs are tabulated in Table 2. Considering Table 2, the minimum values of entire weight obtained using JRDC are higher than ones obtained using MRDC. It is clear that an inclusion of JRDC into the design constraints causes to increase the construction cost of optimal design.

This claim is also confirmed considering Fig. (3-5). Considering Fig. (3-5), it is shown that the termination number of load steps is almost 3 for both MRDC and JRDC. But, the unity values of JRDC are higher than the MRDC (see Fig. 
$3 \mathrm{~g}$ and $5 \mathrm{~g}$ ). Thus, it is said that the influence of JRDC on the quality of optimal design has a big impact compared to MRDC.

When the unity values in Fig. (3-5) are considered, it is observed two design constraints named axial compression\&bending buckling and joint yield has a big effect on the optimality quality of extreme designs compared MRDC due to their higher values (see Fig. 3c,4c,5c,3g, 4g and 5g). In case of using the JRDC and MRDC at the same time, it is also shown that the axial forces have a relatively higher importance on the optimality quality of extreme designs due to their higher values (see Fig. 3a,3c,4a,4c,5a and 5c).
Moreover, the variation of their unity values with respect to the member (element) and joint (node) number is also sketched using bar-charts in Fig. 6. Considering Fig. 6, it is seen that the load step numbers indicated the termination of nonlinear structural responses are identical for both MRDC and JRDC.

The important reason behind the similarity between results obtained is the fixed geometry and framing configuration of benchmark design example with 17 members. It is expected that a change in the framing configuration of benchmark lattice girder leads to an activation of different JRDC and MRDC. This expected result will be examined in the next design example with varying geometry and framing configurations.

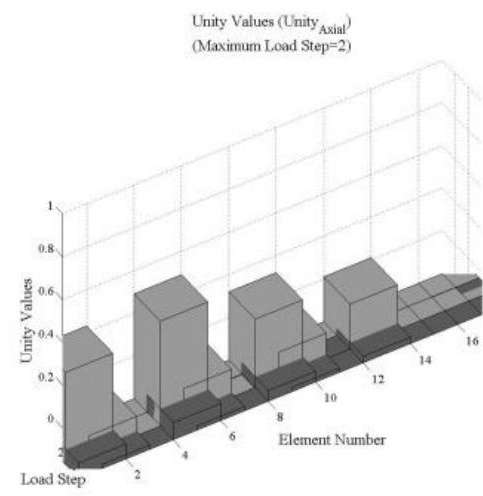

(a)

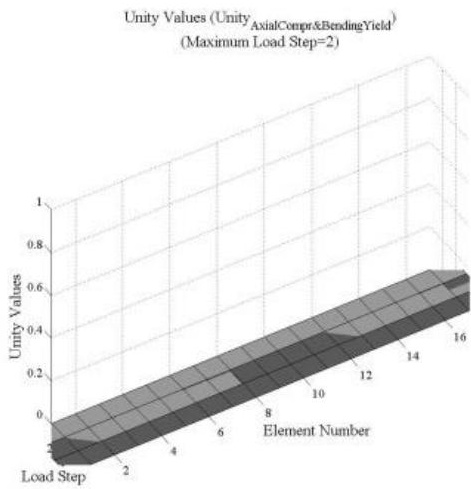

(d)

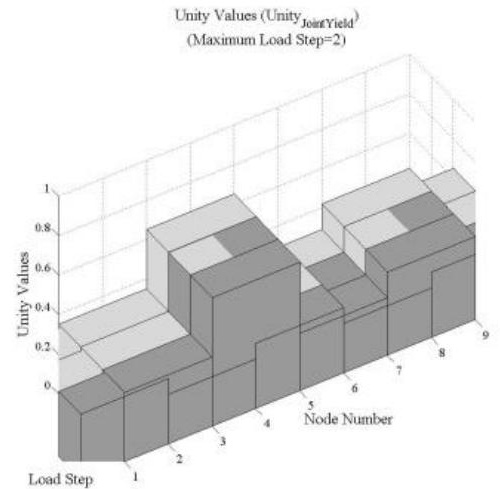

(g)

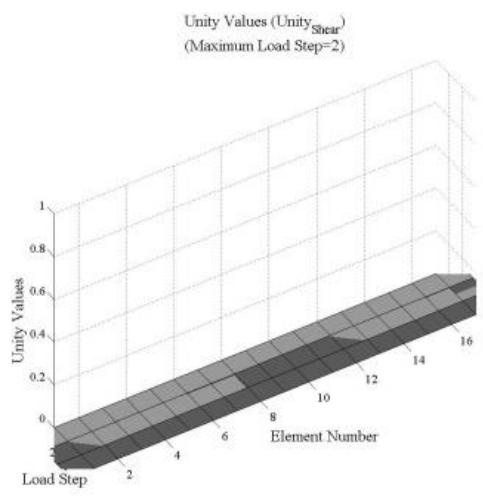

(b)

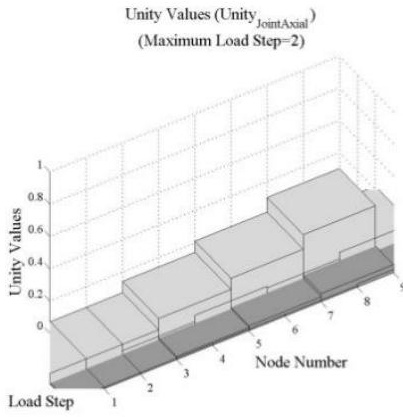

(e)

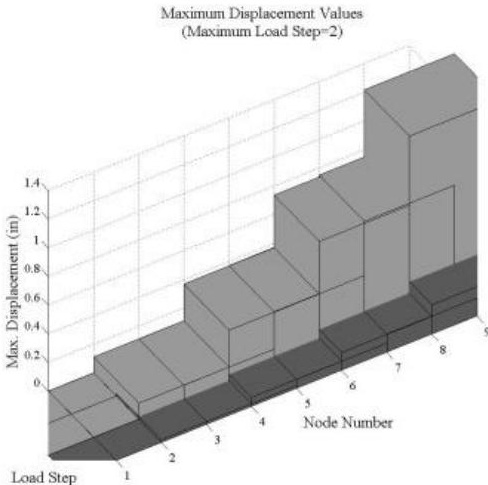

(h)

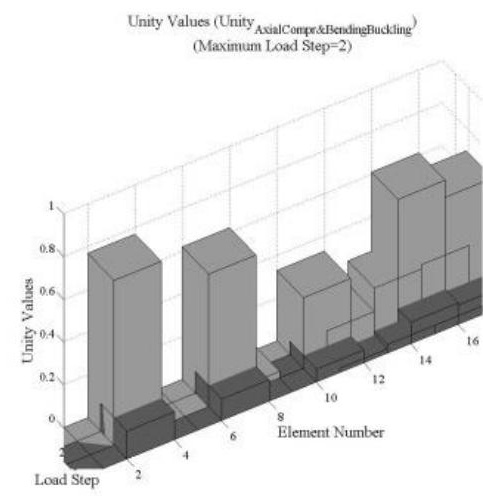

(c)

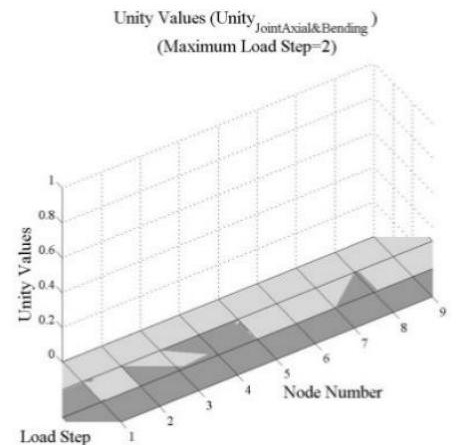

(f)

Fig. 3 Variation in The Unity Values of MRDC (a-d), JRDC (e-g), Join Displacements (h) According to Load Steps Obtained for Minimum Weight (see Design Example 1in Table 2) 


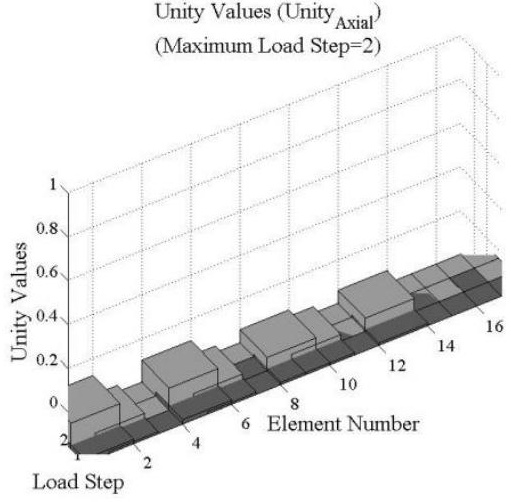

(a)

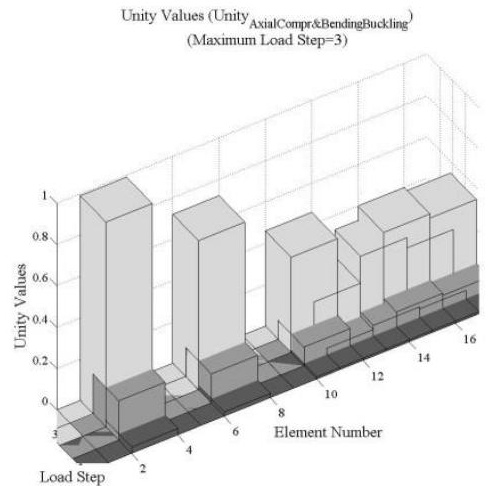

(c)

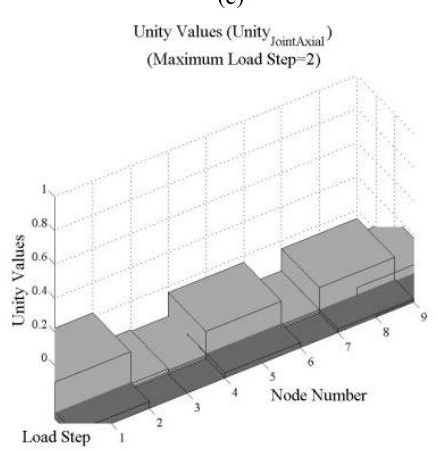

(e)

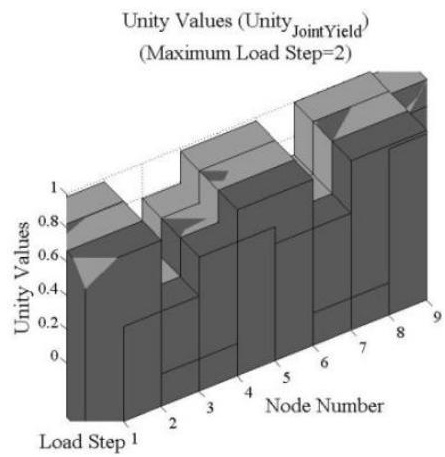

(g)

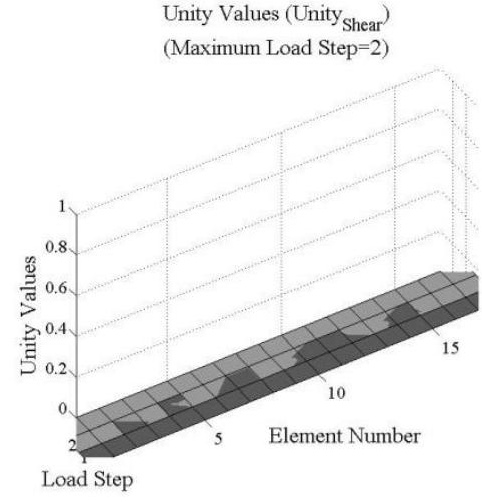

(b)

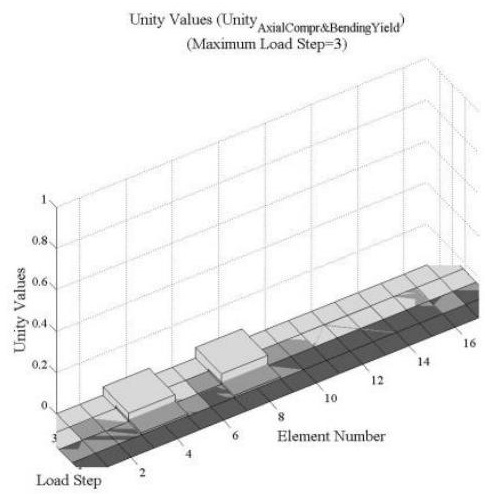

(d)

Unity Values (Unity JointAxiale Bending $_{\text {) }}$

(Maximum Load Step=2)

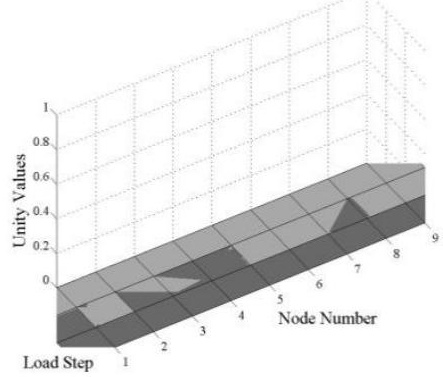

(f)

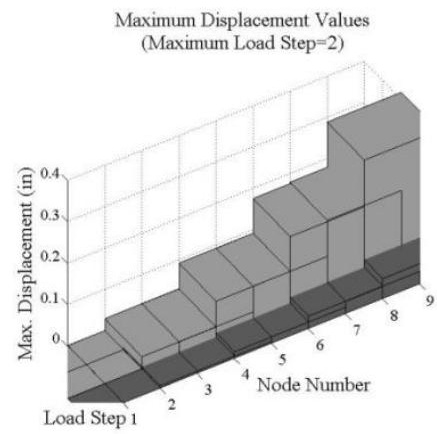

(h)

Fig. 4 Variation in The Unity Values of MRDC (a-d), JRDC (e-g), Join Displacements (h) According to Load Steps Obtained for Minimum Displacement (see Design Example 1in Table 2) 


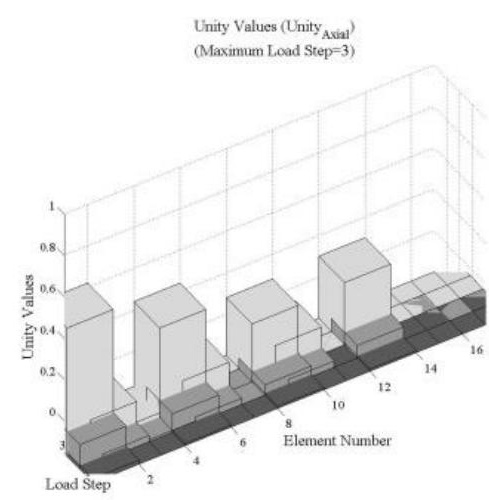

(a)

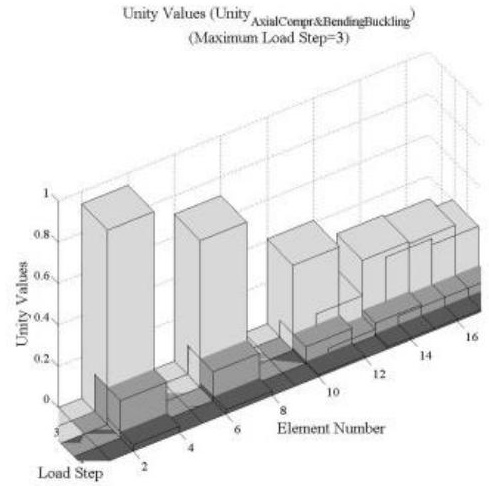

(c)

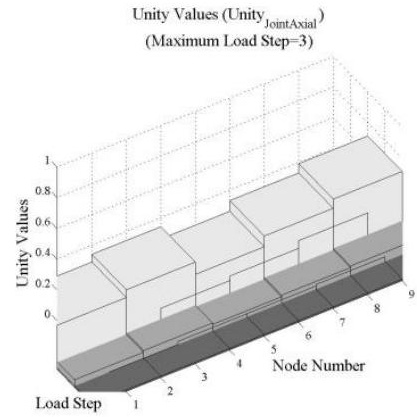

(e)

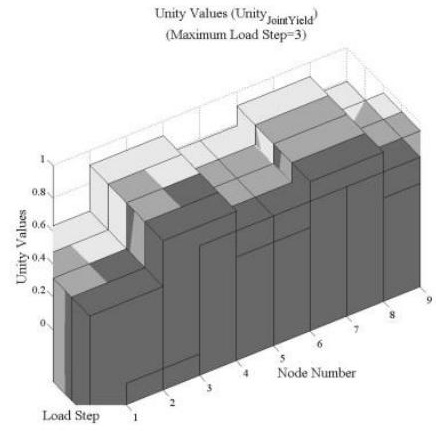

(g)

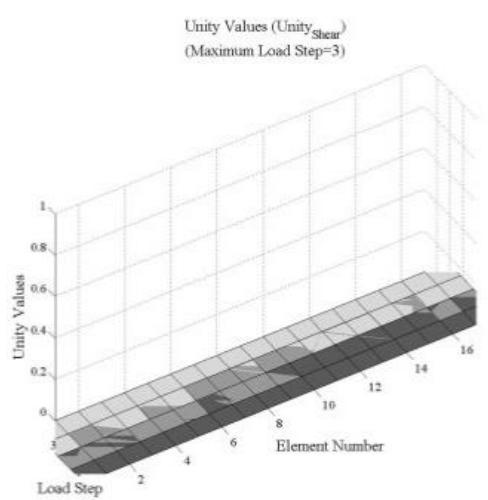

(b)

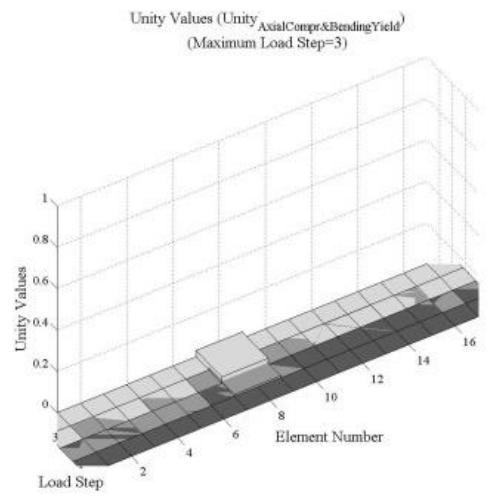

(d)

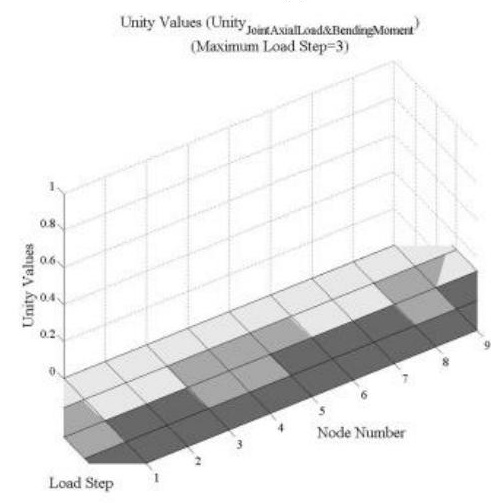

(f)

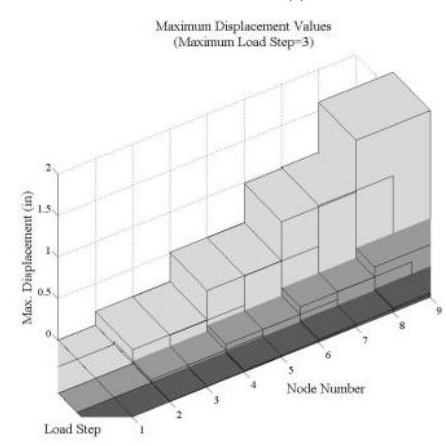

(h)

Fig. 5 Variation in The Unity Values of MRDC (a-d), JRDC (e-g), Join Displacements (h) According to Load Steps Obtained for Maximum Critical Load (see Design Example 1 in Table 


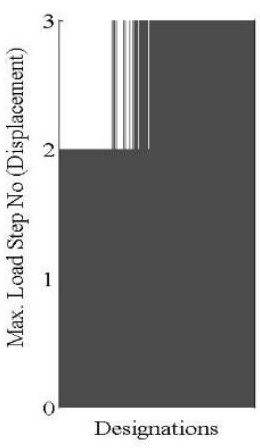

(a)

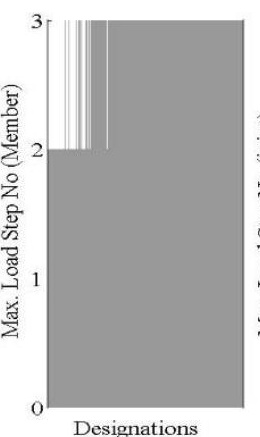

(b)

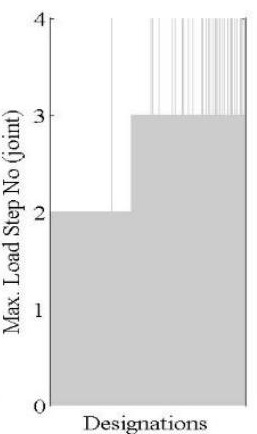

(c)
Fig. 6 The Maximum Load Step Numbers (see Table 2)

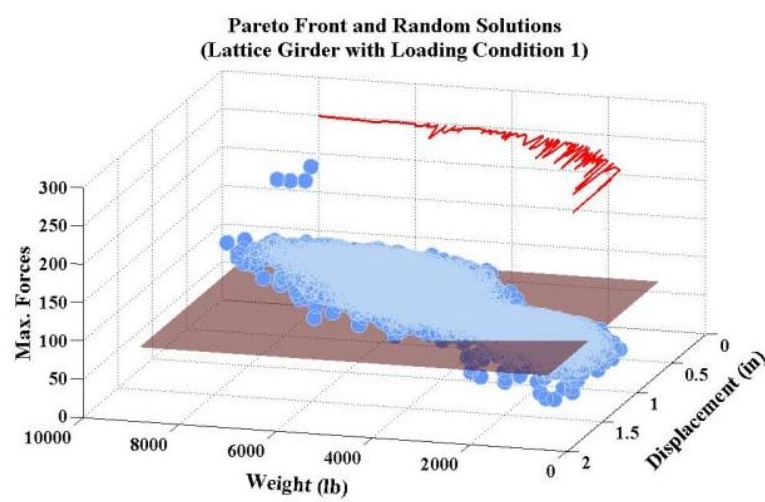

(a)

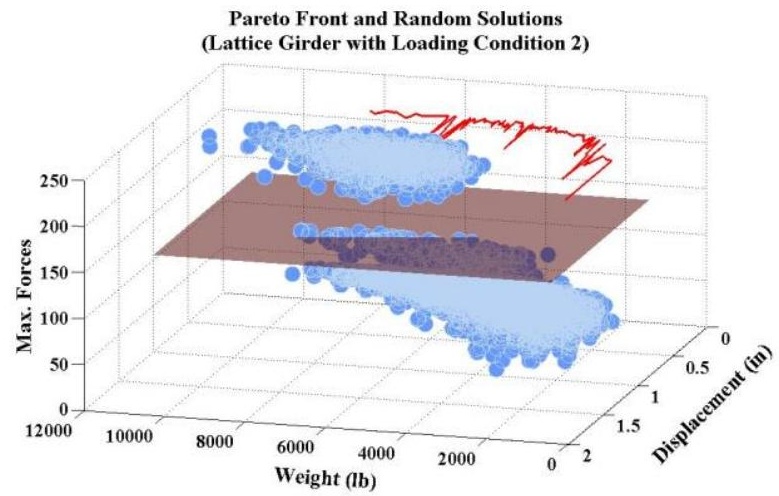

(b)

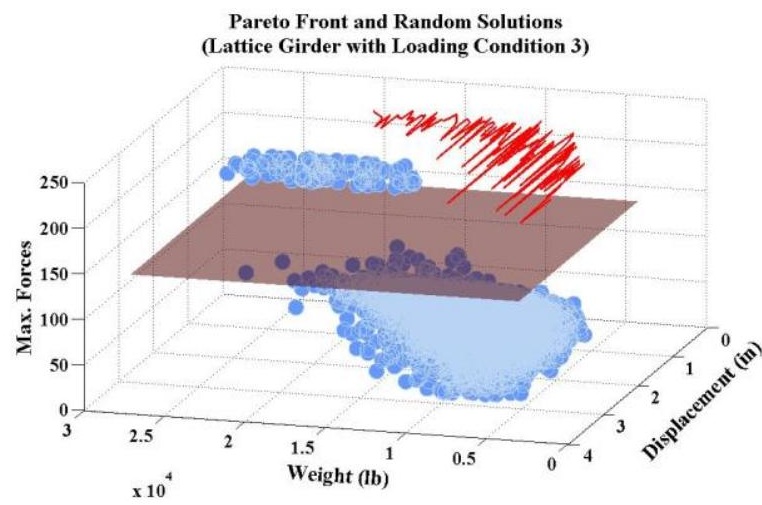

(c)

Fig.7 True Pareto Fronts for Lattice Girder1 (a) and Lattice Girder2 (b) and Lattice

Girder3 (a)

\subsection{A general lattice girder}

In this design example, a lattice girder with three spanning lengths and loading adjustments are automatically generated at the design stage and defined as Design Example 2 (see Table 3). Hence, it will be possible to determine the relative effectiveness of JRDC and MRDC on the quality of optimal design. For this purpose, the upper joints of lattice girder, numbers of which is obtained assuming as (length of span $L S$ /division number $\operatorname{Par}_{\mathrm{DN}}$ ). The design complexity of lattice girder is sequentially increased in a way of applying three different combination cases of total load and spanning length to the lattice girder automatically generated (see Table 3). Hence, the influence of JRDC on the optimality quality of lattice girder designs is also investigated depending on the severe loading conditions and spanning lengths.

True pareto fronts obtained using JRDC\&MRDC are presented Fig. 7 for three different loading\&spanning cases. The governing parameters of relatively successful ImpNSGAII and NSGAII is presented in Table 4.

The results obtained from the design optimization of lattice girder, which has an increasing design complexity (see Tables (5-6)) are firstly categorized considering the proposed design unities along with the three different loading\&spanning cases and figured in Fig. (8-14) instead of presenting all of the unity values as in section of benchmark lattice girder design. Then, these results are summarized in the following two different grouping (see Table 7). Moreover, the variation in the load steps with respect to the multiple objective functions considering the optimal designs obtained from the execution of proposed optimization tool is also included (see Fig. 15).

The influence of JRDC on the optimality quality of optimal designs is investigated in conjunction with MRDC. The variation in MRDC and JRDC unities are presented in Fig. (8-14) The extreme optimal designs are reported for three cases of lattice girder in Tables (5-6) and also summarized in Table 7 considering the critical values of related unities. It is noted that the optimal designs in Table 6 corresponds to the feasible design solutions corresponding to the higher load value. The tabulated data in Tables (5-6) contains the resulted size type design variables $D 1-D 4$, shape type design variables $\operatorname{Par}_{H 1}, P{ }_{H 2}$, topology type design variables Par $_{D N}$ of lattice girders including their objective function values and corresponding framing representations. Furthermore, the each of these extreme optimal designs is sketched using bar charts to illustrate the varying values of JRDC and MRDC-related unities with respect to the load steps outcome from the nonlinear structural analysis (see Fig. 15).

It is mentioned that the cross-sectional properties for the members of lattice girders assigned in a way of using the steel profiles which contains 37 different circular-hollow-shaped cross-sections. These circular-hollow-shaped cross-sections are categorized in three different type class: "standard", "extra strong" and "double extra strong". In fact, this categorization is made depending on an increase in the cross-sectional thickness and related cross-sectional properties.

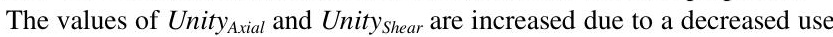
of diagonal members in the construction of tubular lattice girder, which have a responsibility to decrease both the shear and the axial forces of each members connected to a single node. In fact, the other negative effect is arisen from the use of steel profiles with standard type tubular cross-sections instead of double extra and extra strong ones (see Fig. (8-9) and Tables (5-6)). In general, the weight minimization is not only one of the main reasons behind the higher values of these unities, but the maximization of forces has also a relative responsibility (see Table 7).

The increased assignment of steel profiles with the standard type tubular cross-sections to the member of lattice girder causes to increase the values of Unity $_{\text {AxialCompr\&BendingBuckling }}$ and Unity AxialCompr\&BendingYield $_{\text {due to the decrease in the }}$ two profile cross-sectional properties, the diameter and the plastic section modulus (see Fig. (10-11) and Tables (5-6)). In general, the weight minimization has a responsibility of increasing the values of these unities (see Table 7).

The use of steel profiles with decreased diameter and thickness as a chord member rather than a brace member causes to an increase in the values of Unity $y_{\text {JointAxial }}$ and Unity JointAxial\&Bending $($ see Fig. (12-13) and Tables (5-6)). The maximization of member forces has a main responsibility in the increase of these unities. But it is also noted that this increase is also relatively arisen from the weight minimization (see Table 7).

An increase in the middle height of lattice girder along with the use of decreased cross-sectional thickness for the chord members, which is indicated by $\operatorname{Par}_{H 2}$, causes to elevate the values of Unity ${ }_{\text {JointYield }}$ (see Fig. 14 and Table 7-8). Whereas the minimization of joint displacement generally leads to an increase in the value of Unity JointYield, the weight minimization also increases this unity value (see Table 7).

The contribution of JRDC to the optimal lattice girder design is also clarified by examining the maximum load step numbers (see Fig. 7). Considering Fig. 7, it is seen that the load steps numbers corresponding to both JRDC and MRDC are equally terminated. This result implies that the inclusion of JRDC into the current design constraints regarding to MRDC affects the quality of optimal designs. Furthermore, the obvious evidence that supports this claim has already presented with the lower values of maximum member forces obtained using JRDC with respect to the higher maximum member forces obtained using the MRDC (see Tables (5-6)). 
Table 3

The Proposed Lattice Girder Patterns and Corresponding Values of Their Design Variables

\begin{tabular}{|c|c|c|c|}
\hline & Lattice Girder 1 & Lattice Girder 2 & Lattice Girder 3 \\
\hline \multicolumn{4}{|c|}{ Arrangements for Spanning, Loading and Material Conditions } \\
\hline \multicolumn{4}{|c|}{ Assignments to Describe The General Structural System } \\
\hline Total Load Value & 70 kipf & 140 kipf & $150 \mathrm{kipf}$ \\
\hline Length of Span & $393.70 \mathrm{in.}$ & 393.70 in. & 787.40 in. \\
\hline Maximum Node Deflection. & \multicolumn{3}{|l|}{3.94 in } \\
\hline Material Yield Value & \multicolumn{3}{|l|}{$36 \mathrm{ksi}$} \\
\hline Elasticity Module & \multicolumn{3}{|l|}{$29732 \mathrm{ksi}$} \\
\hline \multicolumn{4}{|c|}{ Arrangements for Size Type Parameter $\operatorname{Par}_{\mathrm{ND}}$} \\
\hline $\operatorname{Par}_{\mathrm{ND}}$ & 4 & 4 & 4 \\
\hline $\operatorname{Par}_{\text {UDV }}$ & 37 & 37 & 37 \\
\hline $\operatorname{Par}_{\text {LDV }}$ & 1 & 1 & 1 \\
\hline \multicolumn{4}{|c|}{ Arrangements for Topology Type Parameter Par $_{\mathrm{ND}}$} \\
\hline Par $_{\text {UDN }}$ & 15 & 20 & 40 \\
\hline $\operatorname{Par}_{\text {LDN }}$ & 5 & 5 & 10 \\
\hline \multicolumn{4}{|c|}{ Arrangements for Shape Type Parameters $\operatorname{Par}_{\mathrm{H} 1}$ and $\mathrm{Par}_{\mathrm{H} 2}$} \\
\hline $\mathrm{Par}_{\mathrm{UH} 2}$ & 35.433 in. & 47.244 in. & 59.055 in. \\
\hline $\mathrm{Par}_{\mathrm{LH} 2}$ & 23.622 in. & 23.622 in. & 31.496 in. \\
\hline $\mathrm{Par}_{\mathrm{UH} 1}$ & 23.622 in. & 23.622 in. & 31.496 in. \\
\hline $\mathrm{Par}_{\mathrm{LH} 1}$ & 3.937 in. & 3.937 in. & 7.874 in. \\
\hline
\end{tabular}

Table 4

The Governing Parameter Values of ImpNSGAII and NSGAII

\begin{tabular}{|c|c|c|c|c|c|c|c|c|c|c|c|}
\hline & \multirow[b]{2}{*}{ Governing Parameters } & \multicolumn{10}{|c|}{$\operatorname{Par}_{\text {NNIN }}$ (ImpNSGAII) } \\
\hline & & 1 & 2 & 3 & 4 & 5 & 6 & 7 & 8 & 9 & 10 \\
\hline Par $_{I}$ & & 11 & 2 & 13 & 23 & 20 & 6 & 2 & 17 & 19 & 4 \\
\hline Par $_{2}$ & & 26 & 30 & 45 & 35 & 23 & 37 & 45 & 49 & 25 & 38 \\
\hline $\mathrm{Par}_{3}$ & & 0.9395 & 0.5844 & 0.5096 & 0.9253 & 0.2656 & 0.8872 & 0.4593 & 0.2620 & 0.6779 & 0.7484 \\
\hline $\mathrm{Par}_{4}$ & & 0.5498 & 0.3828 & 0.2768 & 0.7763 & 0.2533 & 0.6058 & 0.1762 & 0.8198 & 0.5180 & 0.2030 \\
\hline Par5 & & 0.4906 & 0.2777 & 0.7328 & 0.1986 & 0.6586 & 0.3603 & 0.5689 & 0.2499 & 0.4431 & 0.4590 \\
\hline Par $_{6}$ & & 2 & 2 & 3 & 3 & 3 & 4 & 3 & 3 & 5 & 2 \\
\hline $\operatorname{Par}_{7}$ & & 0.3672 & 0.5450 & 0.3270 & 0.9784 & 0.2720 & 0.4395 & 0.4759 & 0.1527 & 0.7711 & 0.6486 \\
\hline \multirow{2}{*}{\multicolumn{2}{|c|}{ Par }} & 0.6337 & 0.5551 & 0.4679 & 0.4774 & 0.4204 & 0.1606 & 0.4266 & 0.9318 & 0.3035 & 0.8082 \\
\hline & & \multicolumn{10}{|c|}{$\operatorname{Par}_{\text {NNIN }}=1$ (NSGAII) } \\
\hline & Governing Parameters & \multicolumn{10}{|c|}{1} \\
\hline Par $_{I}$ & & \multicolumn{10}{|c|}{100} \\
\hline $\mathrm{Par}_{2}$ & & \multicolumn{10}{|c|}{50} \\
\hline $\mathrm{Par}_{3}$ & & \multicolumn{10}{|c|}{0.5} \\
\hline $\mathrm{Par}_{4}$ & & \multicolumn{10}{|c|}{0.5} \\
\hline Par $_{5}$ & & \multicolumn{10}{|c|}{0.5} \\
\hline Par6 & & \multicolumn{10}{|c|}{5} \\
\hline $\mathrm{Par}_{7}$ & & \multicolumn{10}{|c|}{0.5} \\
\hline Pars & & \multicolumn{10}{|c|}{0.5} \\
\hline
\end{tabular}


Table 5

Extreme Optimal Design (OD) Values (Design Example 2)

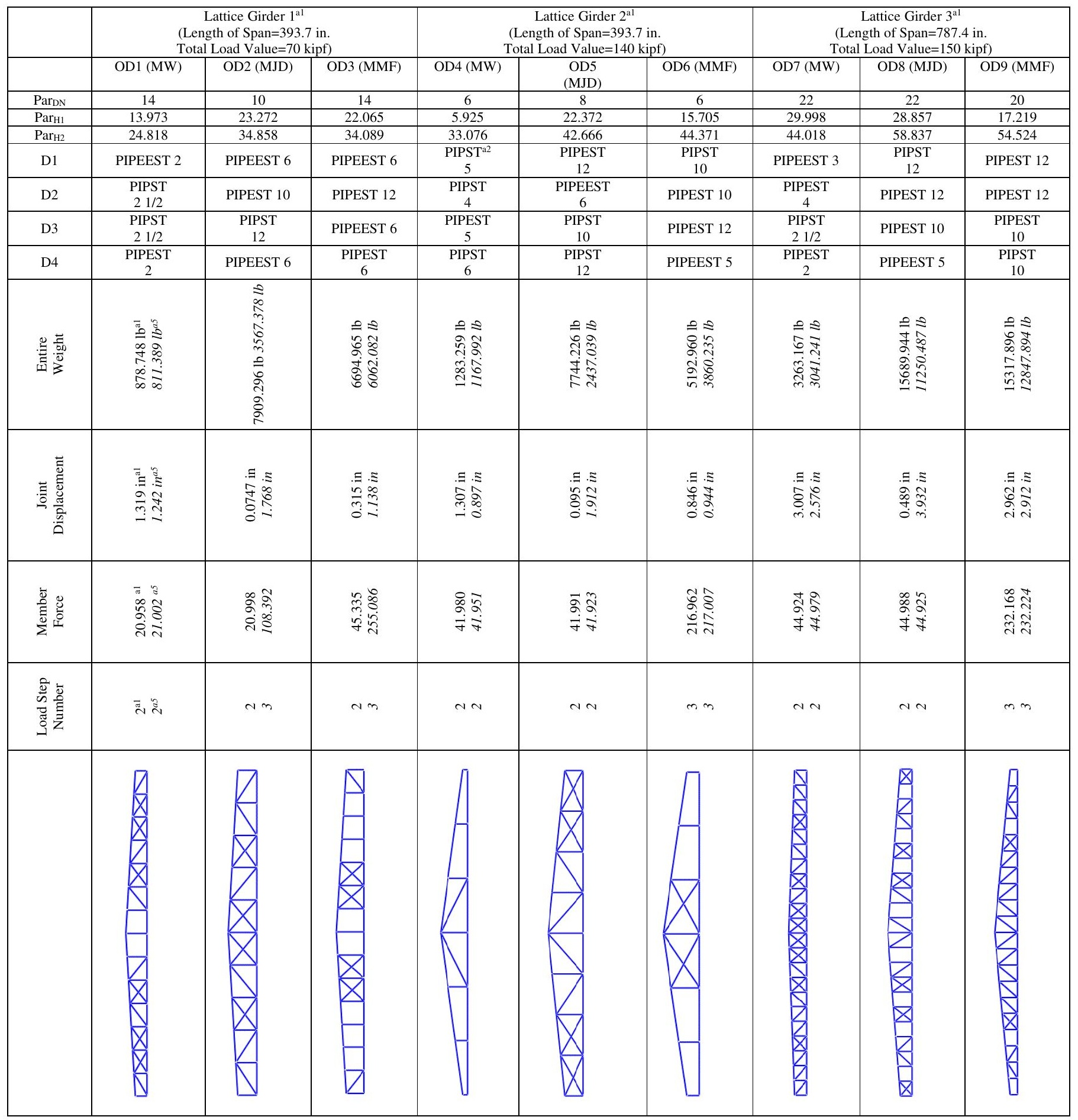

See the definitions for sub\&superscripts and other abbreviations in Table 2 
Table 6

Extreme Optimal Design (OD) Values (Design Example 2)

\begin{tabular}{|c|c|c|c|c|c|c|c|c|c|}
\hline & \multicolumn{3}{|c|}{$\begin{array}{c}\text { Lattice Girder }^{\text {al }} \\
\text { (Length of Span=393.7 in. } \\
\text { Total Load Value=70 kipf) }\end{array}$} & \multicolumn{3}{|c|}{$\begin{array}{c}\text { Lattice Girder } 2^{\text {al }} \\
\text { (Length of Span=393.7 in. } \\
\text { Total Load Value=140 kipf) }\end{array}$} & \multicolumn{3}{|c|}{$\begin{array}{c}\text { Lattice Girder } 3^{\text {al }} \\
\text { (Length of Span=787.4 in. } \\
\text { Total Load Value=150 kipf) }\end{array}$} \\
\hline & OD10 (MW) & OD11 (MJD) & OD12 (MMF) & OD13 (MW) & OD14 (MJD) & OD15 (MMF) & OD16 (MW) & OD17 (MJD) & OD18 (MMF) \\
\hline Par $_{\mathrm{DN}}$ & $6^{a 1}$ & 6 & 14 & 6 & 6 & 6 & 16 & 30 & 20 \\
\hline ParH1 & $15.731^{\mathrm{a} 1}$ & 19.692 & 22.065 & 10.819 & 17.521 & 15.705 & 20.036 & 27.091 & 17.219 \\
\hline $\mathrm{Par}_{\mathrm{H} 2}$ & $34.739^{\mathrm{a} 1}$ & 32.518 & 34.089 & 42.646 & 45.525 & 44.371 & 59.027 & 58.437 & 54.524 \\
\hline D1 & $\begin{array}{c}\text { PIPST } \\
10 \\
\end{array}$ & PIPEST 12 & $\begin{array}{c}\text { PIPEEST } \\
6\end{array}$ & $\begin{array}{c}\text { PIPST } \\
10 \\
\end{array}$ & PIPEST 12 & $\begin{array}{c}\text { PIPST } \\
10 \\
\end{array}$ & $\begin{array}{c}\text { PIPEST } \\
12\end{array}$ & PIPEST 12 & $\begin{array}{c}\text { PIPEST } \\
12 \\
\end{array}$ \\
\hline D2 & $\begin{array}{c}\text { PIPST } \\
6 \\
\end{array}$ & PIPEST 12 & $\begin{array}{c}\text { PIPEST } \\
12 \\
\end{array}$ & $\begin{array}{c}\text { PIPST } \\
10 \\
\end{array}$ & PIPEST 12 & $\begin{array}{c}\text { PIPEST } \\
10 \\
\end{array}$ & $\begin{array}{c}\text { PIPST } \\
12 \\
\end{array}$ & PIPEST 12 & $\begin{array}{c}\text { PIPEST } \\
12 \\
\end{array}$ \\
\hline D3 & $\begin{array}{c}\text { PIPEST } \\
3\end{array}$ & $\begin{array}{c}\text { PIPST } \\
10\end{array}$ & PIPEEST 6 & $\begin{array}{c}\text { PIPEST } \\
10\end{array}$ & PIPEEST 4 & $\begin{array}{c}\text { PIPEST } \\
12\end{array}$ & $\begin{array}{c}\text { PIPST } \\
8\end{array}$ & PIPEEST 5 & $\begin{array}{c}\text { PIPEST } \\
10\end{array}$ \\
\hline D4 & $\begin{array}{c}\text { PIPEST } \\
31 / 2 \\
\end{array}$ & $\begin{array}{c}\text { PIPST } \\
12 \\
\end{array}$ & $\begin{array}{c}\text { PIPEST } \\
6 \\
\end{array}$ & $\begin{array}{c}\text { PIPST } \\
12 \\
\end{array}$ & PIPEST 10 & $\begin{array}{c}\text { PIPEEST } \\
5 \\
\end{array}$ & PIPEEST 5 & PIPEST 10 & $\begin{array}{c}\text { PIPST } \\
10 \\
\end{array}$ \\
\hline 莺莒 & 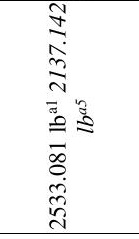 & 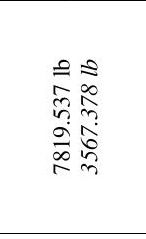 & 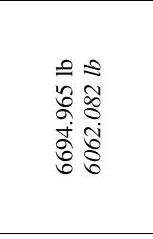 & 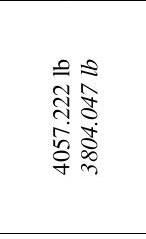 & 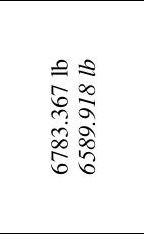 & 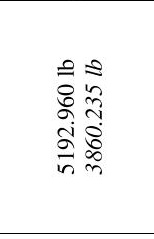 & 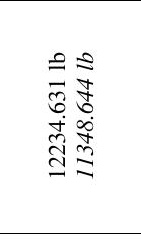 & 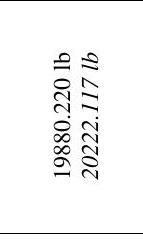 & 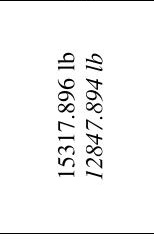 \\
\hline 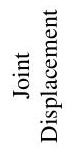 & 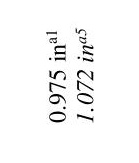 & 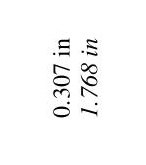 & $\begin{array}{l}\Xi: \Xi \\
n=\infty \\
m= \\
0=\end{array}$ & 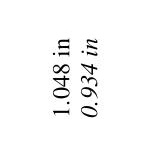 & 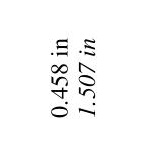 & 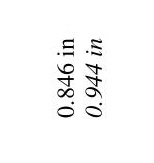 & 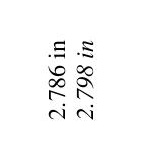 & 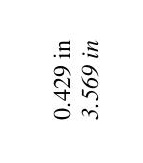 & 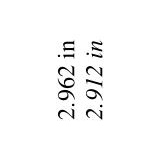 \\
\hline 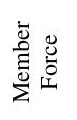 & 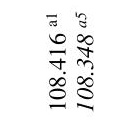 & 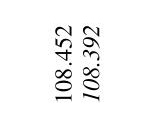 & 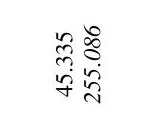 & 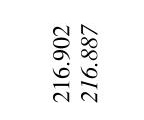 & 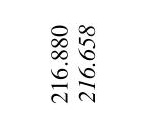 & 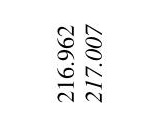 & 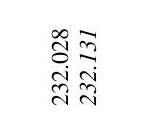 & 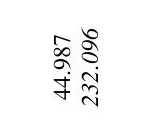 & 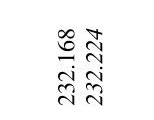 \\
\hline 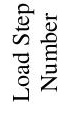 & ప్లె & $m n$ & $N m$ & $m n$ & $m n$ & $m n$ & $m n$ & $N m$ & $m n$ \\
\hline & W & X & $\triangle$ & $\square$ & V & 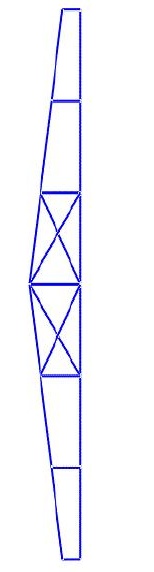 & $\triangle$ & 罗 & 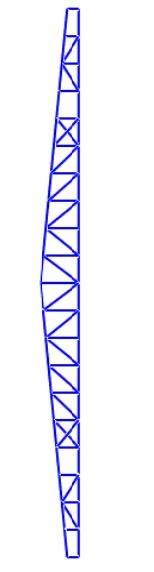 \\
\hline
\end{tabular}


Table 7

The Categorization of Extreme Optimal Designs Considering The Critical Unities (see Table 5-6)

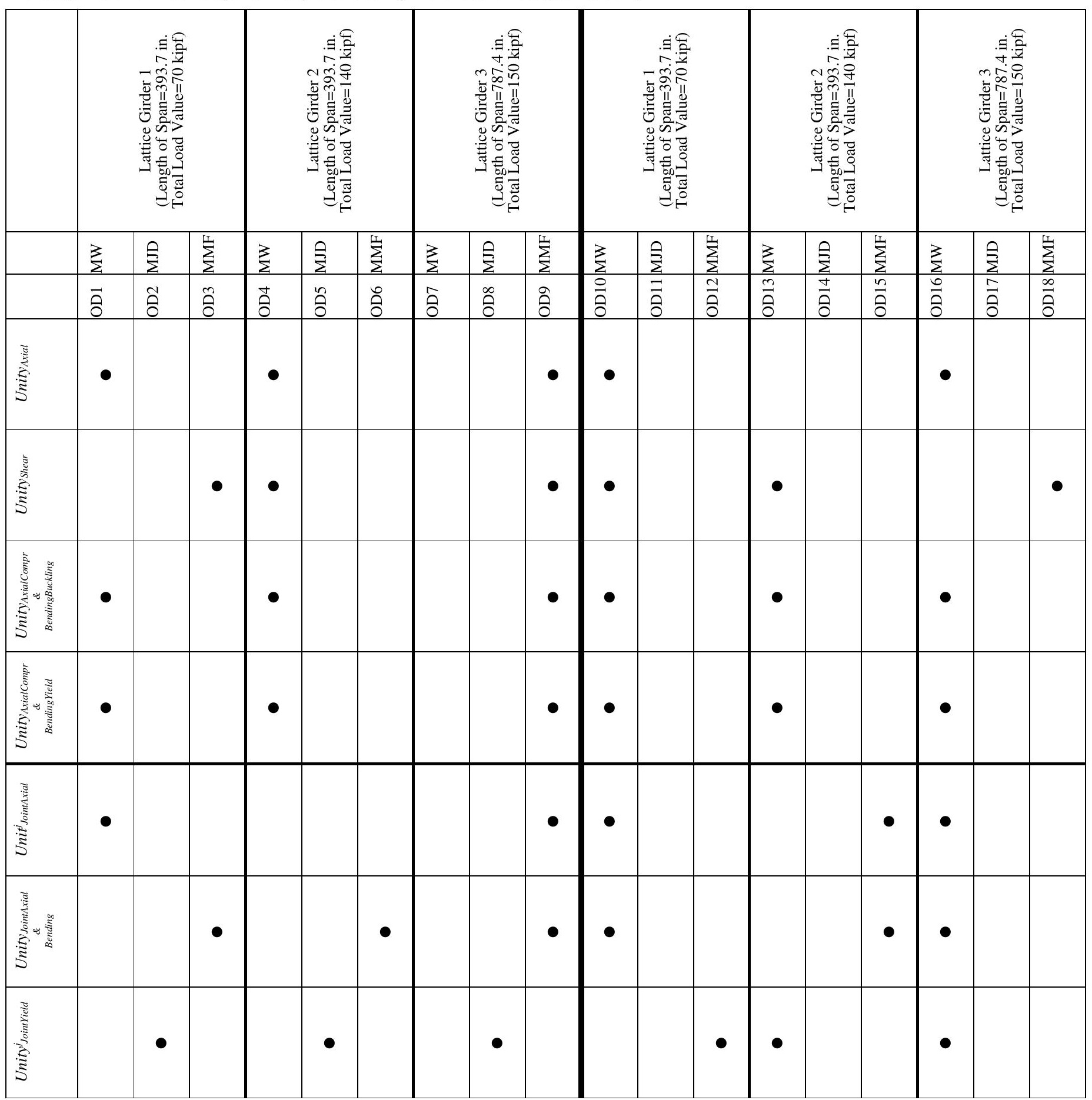

See the definitions for abbreviations in Table 2 


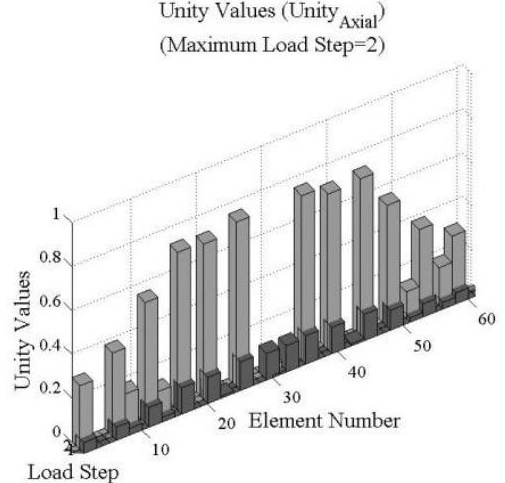

(a)

Unity Values (Unity ${ }_{\text {Axial }}$ ) (Maximum Load Step=3)

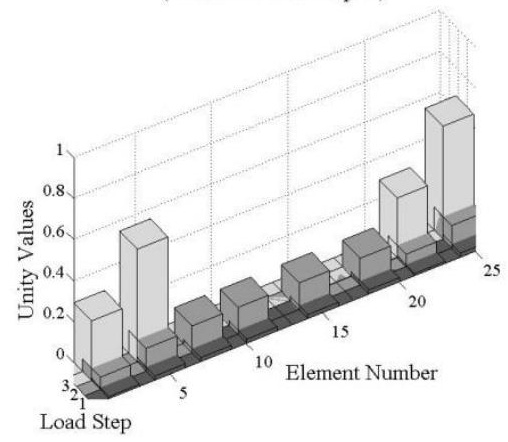

(d)

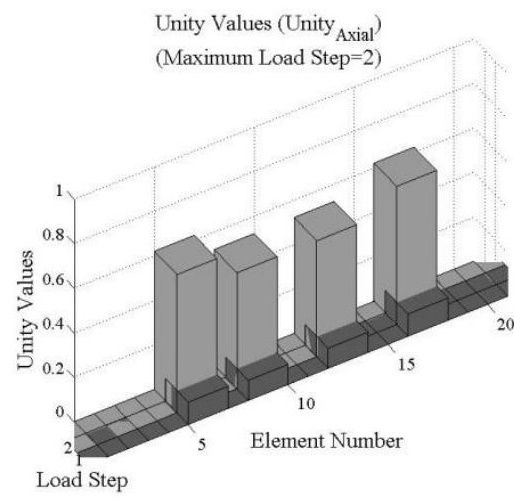

(b)

Unity Values (Unity ${ }_{\text {Axial }}$ )

(Maximum Load Step=3)

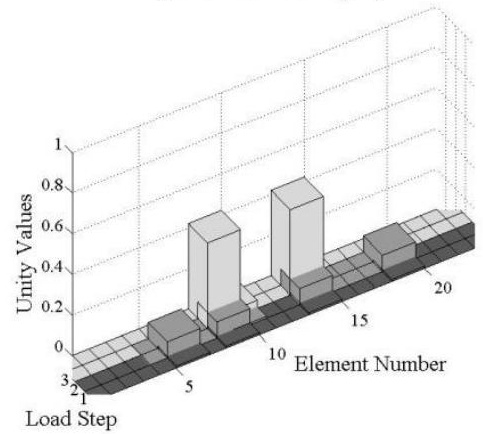

(e)
Unity Values (Unity (Maximum Load Step=3)

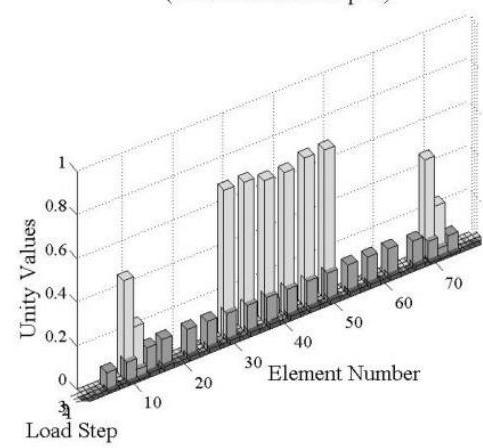

(c)

Unity Values (Unity ${ }_{\text {Axial }}$ ) (Maximum Load Step=3)

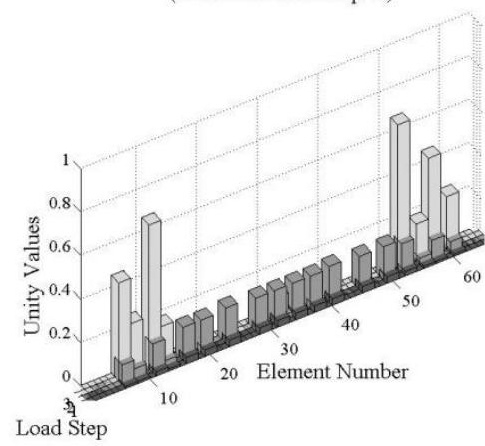

(f)

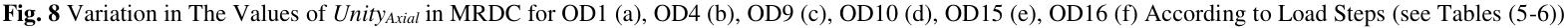

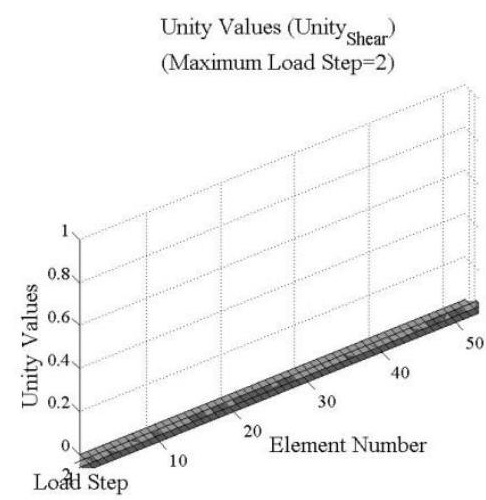

(a)

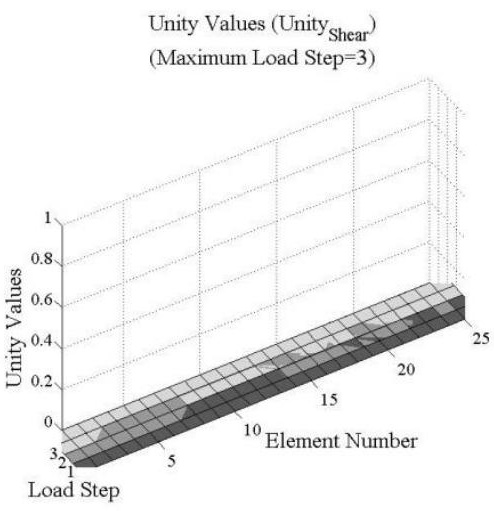

(d)

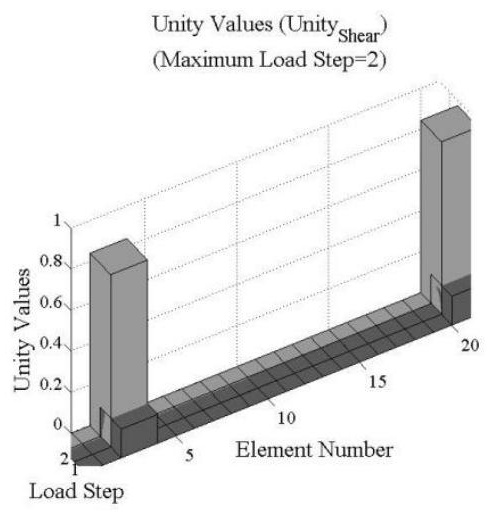

(b)

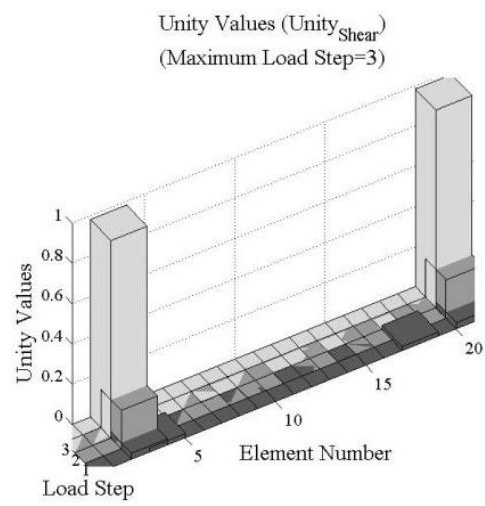

(e)

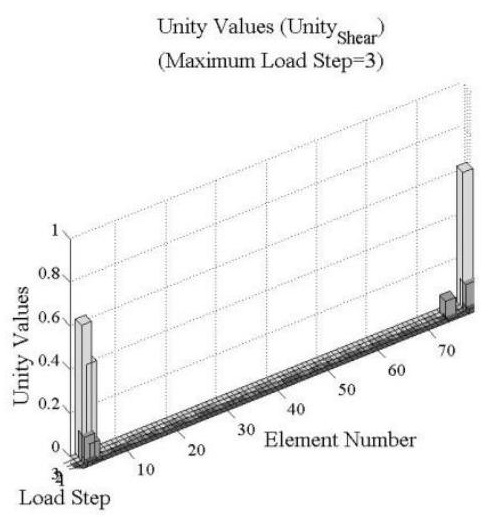

(c)

Unity Values (Unity ${ }_{\text {Shear }}$ ) (Maximum Load Step=3)

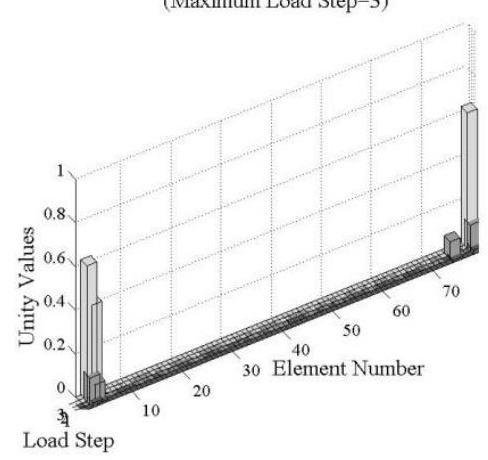

(f)

Fig. 9 Variation in The Values of Unityshear in MRDC for OD3 (a), OD4 (b), OD9 (c), OD10 (d), OD13 (e), OD18 (f) According to Load Steps (see Tables (5-6)) 
Unity Values (Unity AxialCompr\&BendingBuckling $_{\text {) }}$ (Maximum Load Step=2)

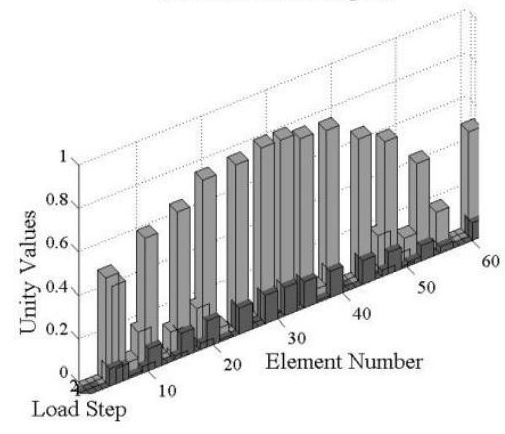

(a)

Unity Values (Unity ${ }_{\text {AxialCompr\&BendingBuckling }}$ (Maximum Load Step=3)

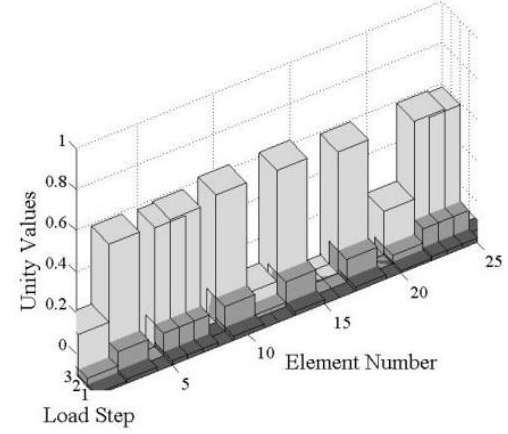

(d)
Unity Values (Unity AxialCompr\&BendingBuckling) (Maximum Load Step=2)

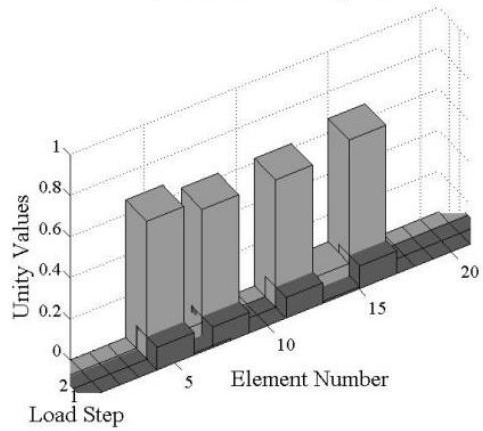

(b)

Unity Values (Unity ${ }_{\text {AxialCompr\&BendingBuckling }}$ ) (Maximum Load Step=3)

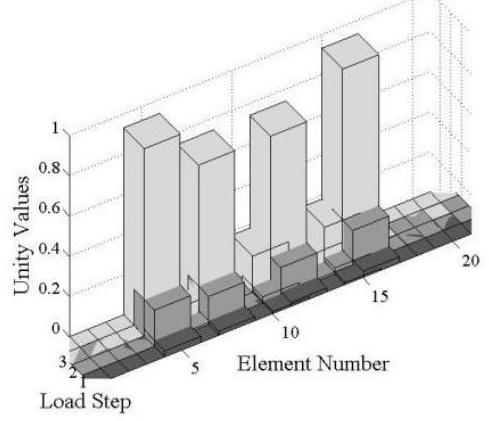

(e)
Unity Values (Unity ${ }_{\text {AxialCompr\&BendingBuckling }}$ ) (Maximum Load Step=3)

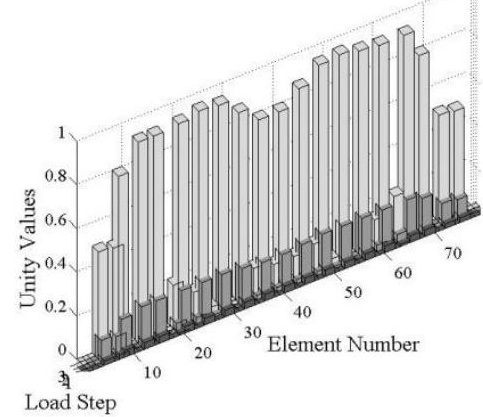

(c)

Unity Values (Unity AxialCompr\&BendingBuckling $_{\text {) }}$ (Maximum Load Step=3)

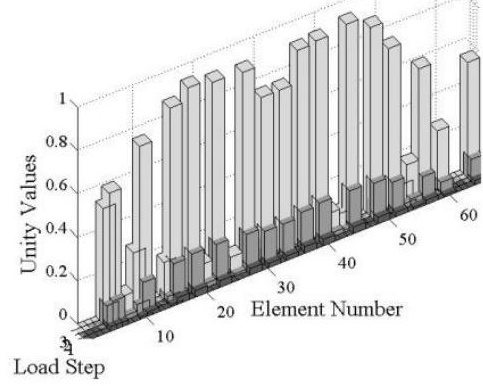

(f)

Fig. 10 Variation in The Values of UnityAxialCompression\&BendingBuckling in MRDC for OD1 (a), OD4 (b), OD9 (c), OD10 (d), OD13 (e), OD16 (f) According to Load Steps (see Tables (5-6))

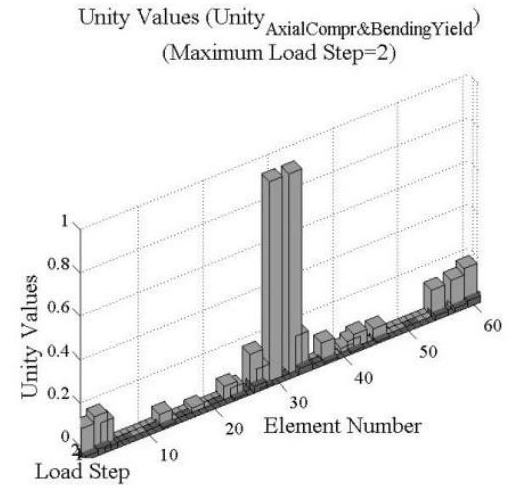

(a)

Unity Values (Unity ${ }_{\text {AxialCompr\&BendingYield }}$ (Maximum Load Step=3)

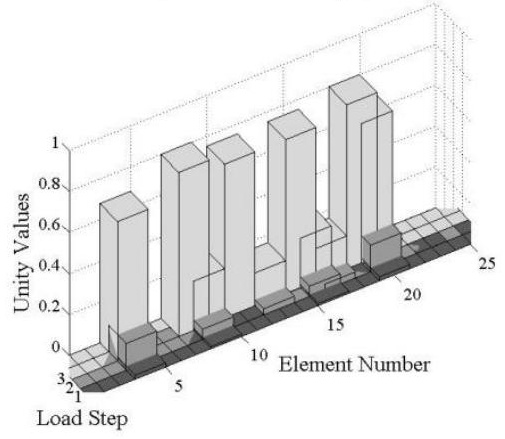

(d)

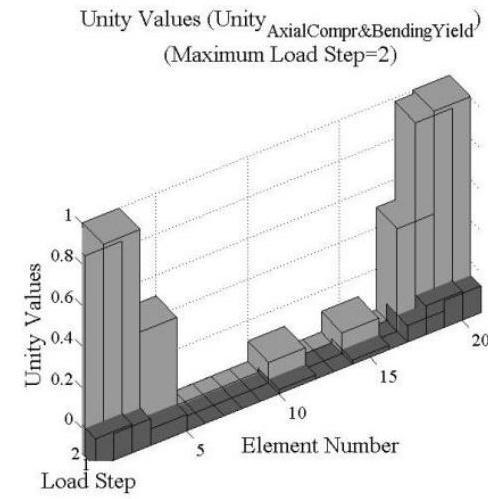

(b)

Unity Values (Unity ${ }_{\text {AxialCompr\&BendingYield }}$ (Maximum Load Step=3)

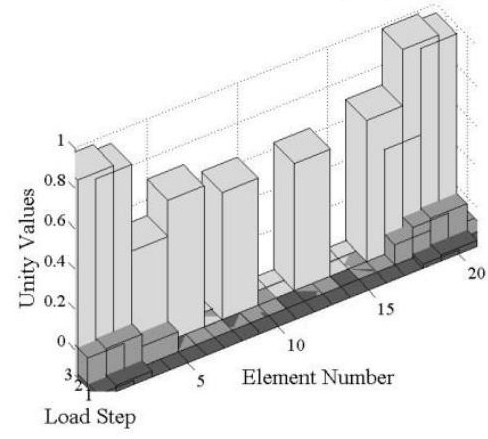

(e)

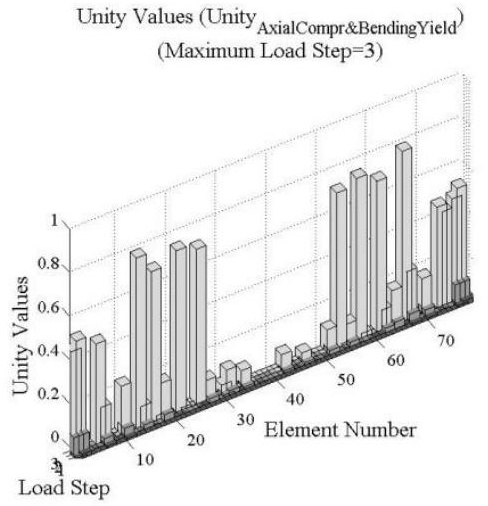

(c)

Unity Values (Unity ${ }_{\text {AxialCompr\&BendingYield }}$ ) (Maximum Load Step=3)

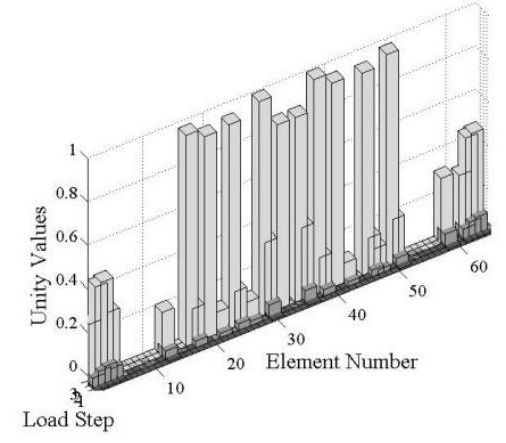

(f)

Fig. 11 Variation in The Values of UnityAxialCompression\&BendingYield in MRDC for OD1 (a), OD4 (b), OD9 (c), OD10 (d), OD13 (e), OD16 (f) According to Load Steps (see Tables (5-6)) 


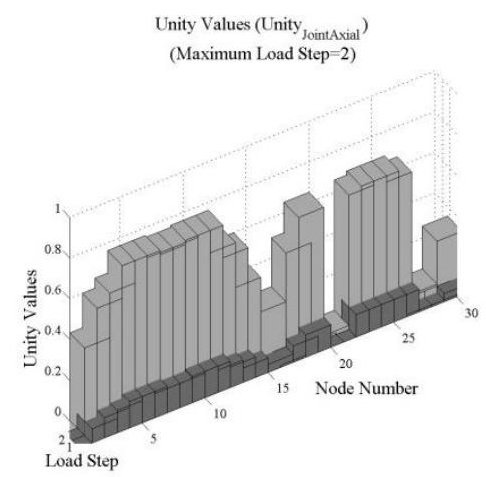

(a) Unity Values (Unity ${ }_{\text {JointAxial }}$ )
(Maximum Load Step=3)

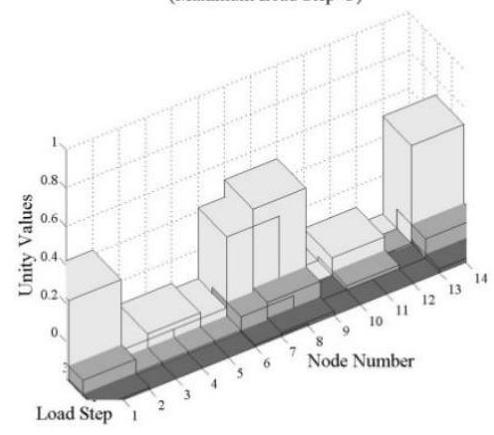

(d)

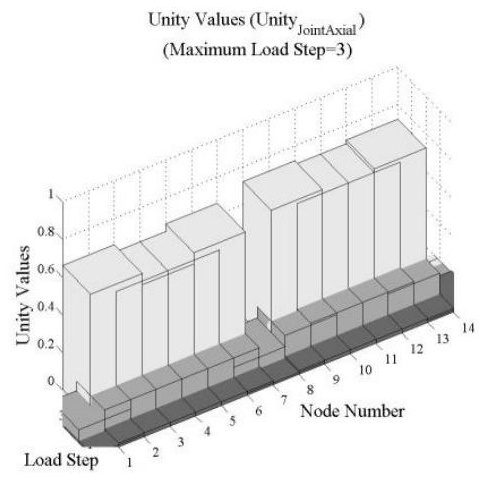

(b)

Unity Values (Unity JointAxial ) (Maximum Load Step=3)

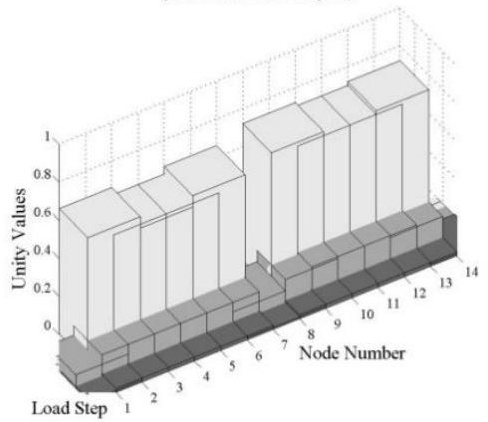

(e)

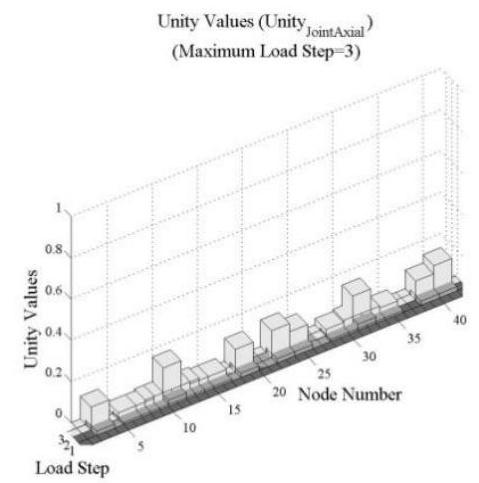

(c)

Unity Values (Unity JointAxial ) (Maximum Load Step=3)

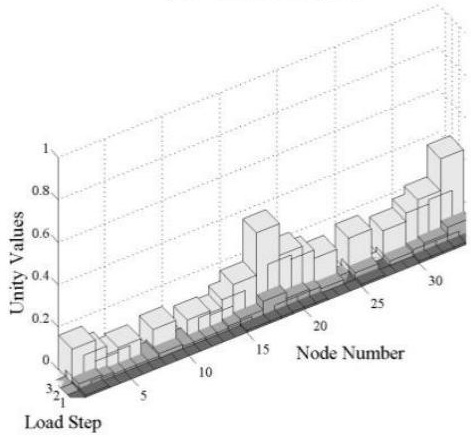

(f)

Fig. 12 Variation in The Values of Unity Jointaxial in JRDC for OD1 (a), OD6 (b), OD9 (c), OD10 (d), OD15 (e), OD16 (f) According to Load Steps (see Tables (5-6))

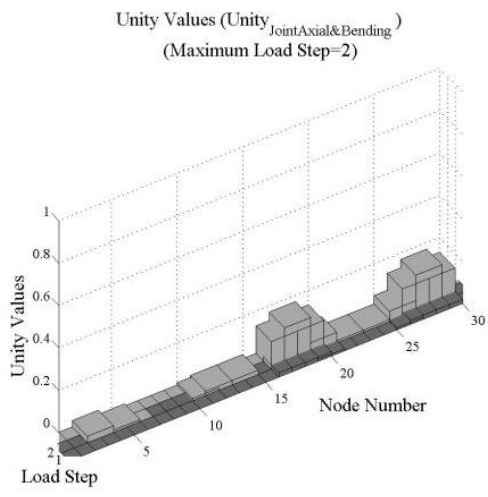

(a)

Unity Values (Unity JointAxialkBending $_{\text {) }}$ (Maximum Load Step $=3$ )

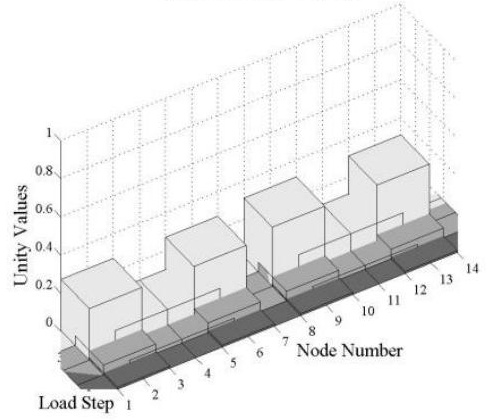

(d)

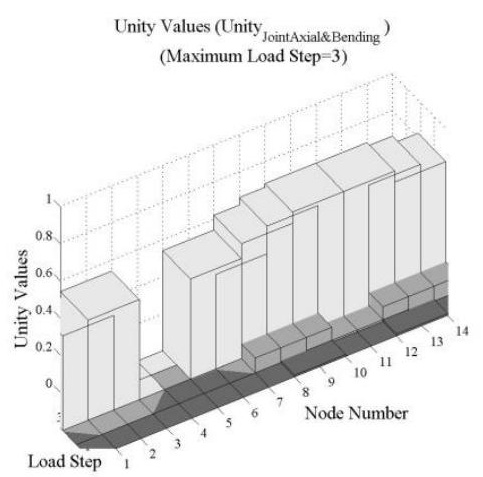

(b)

Unity Values (Unity JointAxial\&Bending $_{\text {) }}$ (Maximum Load Step=3)

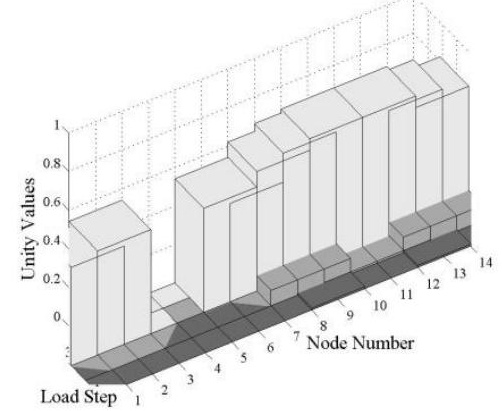

(e)

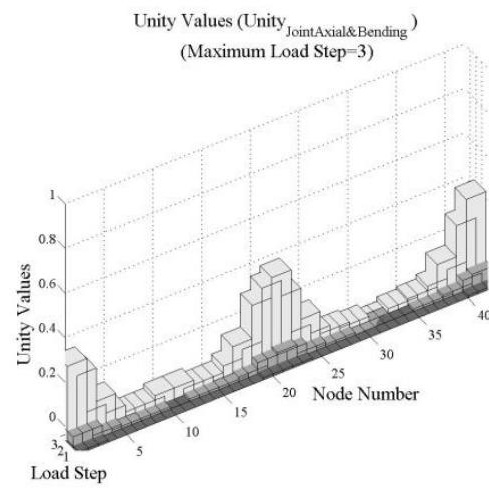

(c)

Unity Values (Unity (Maximum Load Step=3)

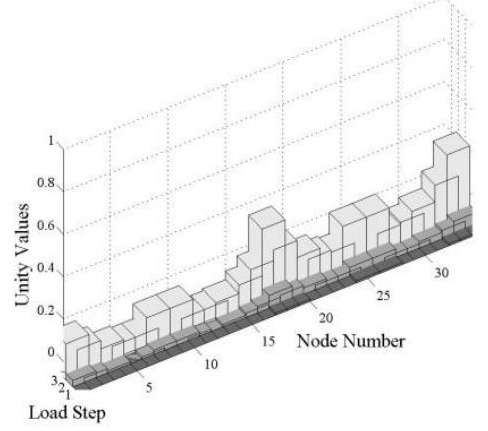

(f)

Fig. 13 Variation in The Values of Unity JointAxial\&Bending in JRDC for OD3 (a), OD6 (b), OD9 (c), OD10 (d), OD15 (e), OD16 (f) According to Load Steps (see Tables (5-6)) 


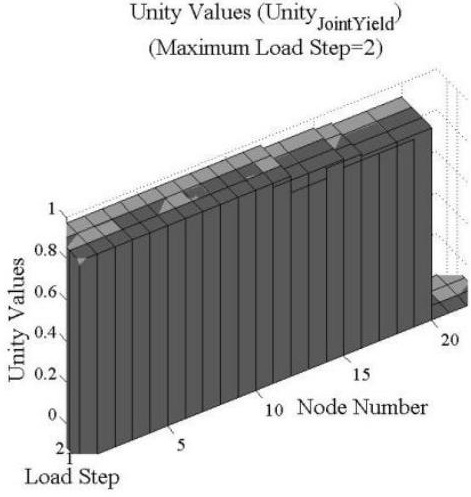

(a)

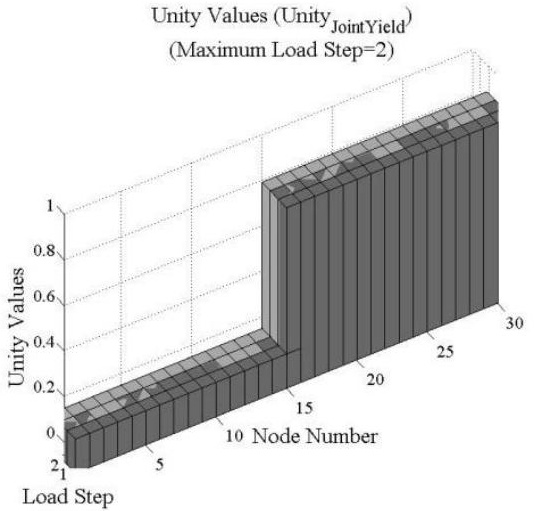

(d)

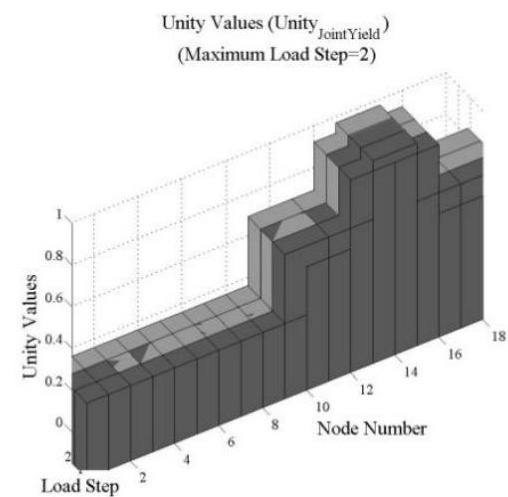

(b)

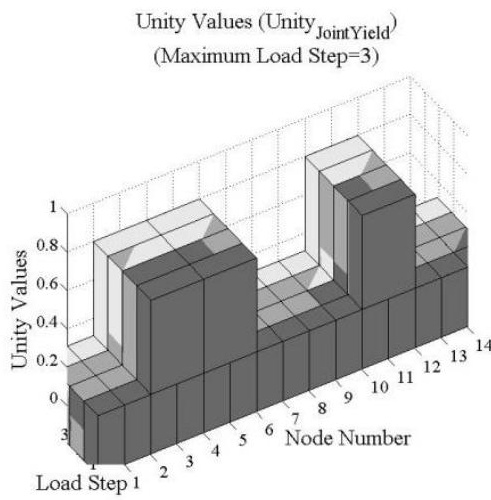

(e)

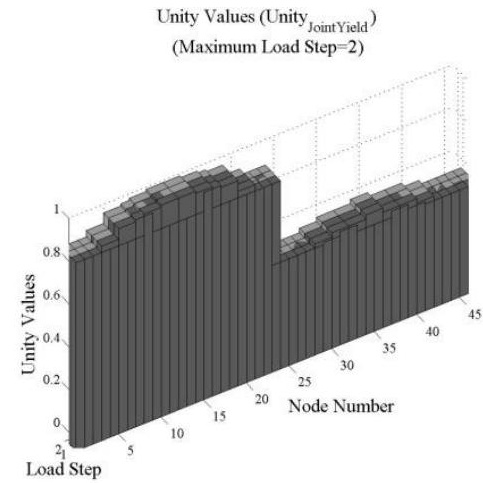

(c)

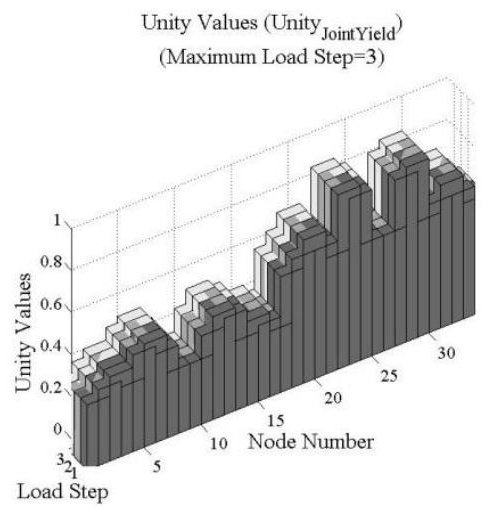

(f)

Fig. 14 Variation in The Values of Unity $y_{\text {JointYield }}$ in JRDC for OD2 (a), OD5 (b), OD8 (c), OD12 (d), OD13 (e), OD16 (f) According to Load Steps (see Tables (5-6))

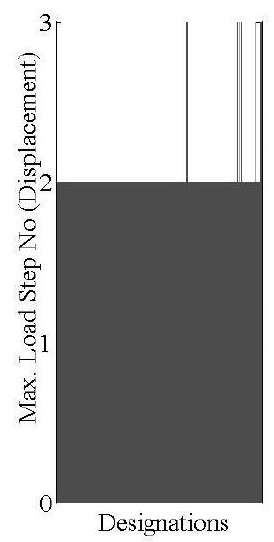

(a)

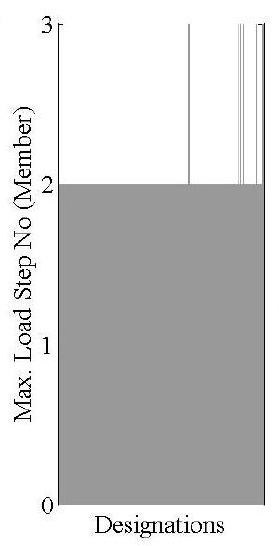

(b)

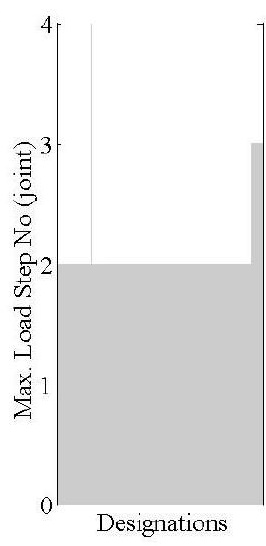

(c)

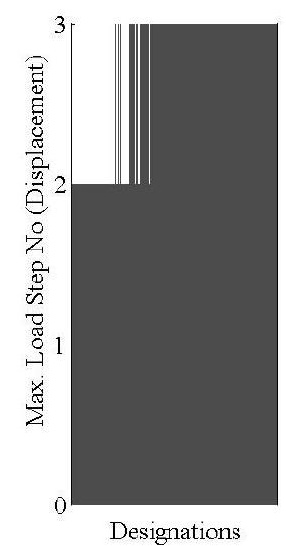

(d)

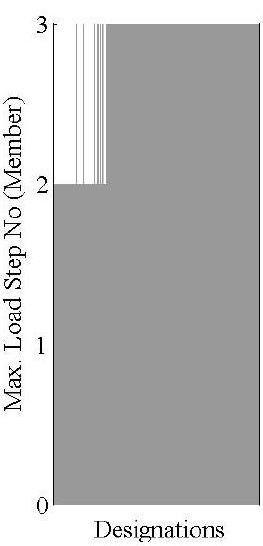

(e)

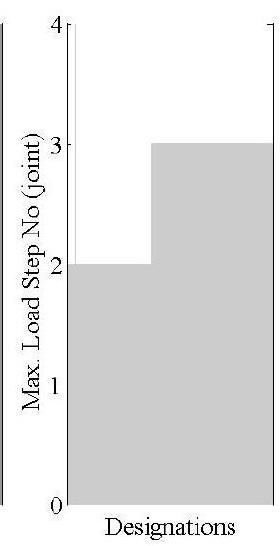

(f)

Fig. 15 The Maximum Load Step Numbers (Lattice Girder 2 (a-c) and (Lattice Girder 2 (d-f)) (see Tables (5-6))

\section{Conclusion}

The design of geometrically nonlinear lattice girders was optimized using the optimization tool named ImpNSGAII, which was obtained in a way of hybridizing the optimization algorithm named NSGAII and a neural network approach [17]. The member-related design constraints (MRDC) were taken from the provisions of API RP2A-LRFD specification [28]. In this study, the design complexity for the proposed optimal design approach in Reference [17] is increased thereby including the joint-related design constraints (JRDC) into the current design constraints. Hence, the influence of JRDC on the optimality quality of designs is investigated. Furthermore, the computing efficiencies of both ImpNSGAII and NSGAII are also compared by optimizing the benchmark lattice girder and general lattice girder. The following primary observations are summarized as given below: i) In spite of increasing the design complexity, ImpNSGAII achieves to obtain the optimal designs with higher load-resistance, economic and serviceability features through its self-adaptive mechanism. However, the simultaneous use of JRDC along with MRDC causes a divergence in the construction cost of tubular lattice girder due to an increase in the entire weight of optimal lattice girder.

ii) It is shown that an inclusion of diagonal members into the framing configuration of automatically generated lattice girder increases the capacities of both member and joint-related strengths. However, the lack of diagonal members in the framing configuration of lattice girder along with an assignment of relatively lower cross-sectional thickness to the members causes to increase the sensitivity in both member and joint-related unities.

iii) It is observed that the joint yield-related design constraint achieves to be the most determinative one among the other joint-related design constraints due to its higher values. 
iv) Considering the extreme optimal designs, the solely use of proposed three objective functions, entire weight of lattice girder, its joint displacements and its member forces causes to prevent a tradeoff analysis among these objective functions. But, it is shown that a simultaneous use of these multiple objective functions correspondingly provides both to make a concise and reasonable evaluation of MRDC and JRDC-related design constraints and to obtain optimal lattice girder designs with relatively higher joint and member strength capacities.

Consequently, this challenging optimal design approach achieves to explore the optimal lattice girder designs with higher load-resistance capability thereby increasing the design reliability through the usage of JRDC along with MRDC. Therefore, ImpNSGAII is recommended to obtain an optimal design configuration for the lattice girder according to a pre-defined spanning length and loading adjustment.

\section{References}

[1] Nageim, H.K. and Macginley, T.J., Steel structures, practical design studies, 3th ed. EF Spon Press, 2005.

[2] Groover, M.P., Fundamentals of modern manufacturing, materials, processes and systems, 4th ed. John Wiley and Sons Inc., 2010

[3] Owens, G.W., Steel Designer's Manual, 6th ed. Blackwell Science, 2005.

[4] Nelson, JKa and McCormac, J.C., Structural Analysis: Using Classical and Matrix Methods, 3th ed. John Wiley and Sons Inc., 2003.

[5] Kaveh, A. and Talatahari, S., "Optimal design of schwedler and ribbed domes via hybrid big bang-big crunch algorithm", Journal of Constructional Steel Research, 66(3), pp. 412-419, 2010

[6] Carbas, S. and Saka, M.P., "Optimum topology design of various geometrically nonlinear latticed domes using improved harmony search method", Structural and Multidisciplinary Optimization, 45(3), pp. 377-399, 2012.

[7] Jorabchi, K. and Suresh, K., "A robust method to pass limit-point instability", Finite Elements in Analysis and Design, 47(11), pp. 1253-1261, 2011

[8] Koohestani, K., "A hybrid method for efficient solution of geometrically nonlinear structures", International Journal of Solid and Structures, 50(1), pp. 21-29, 2013

[9] Nelson, J.K. and McCormac, J.C., "Structural Analysis: Using Classical and Matrix Methods", 3th ed. John Wiley and Sons Inc., 2003.

[10] Rao, S.S., "Engineering Optimization: Theory and Practice", 4th ed., John Wiley and Sons Inc., 2009.

[11] Arora, J., "Introduction to Optimum Design", 3th ed., Academic Press, 2011.

[12] Saka, M.P. and Dogan, E. "Recent Developments in Metaheuristic Algorithms: A Review", Computational Technology Reviews, 5, pp. 31-78, 2012. doi:10.4203/ctr.5.2.

[13] Packer, J.A. and Henderson, J.E. "Hollow structural section connections and trusses: a design guide", Canadian institute of steel construction, 1997

[14] Wardenier, J., Dutta, D., Yeomans, N., Packer, J.A. and Bucak, Ö. International Committee for Research and Technical Support for Hollow Section Structure: CIDECT Design Guide 6, for structural hollow sections in mechanical applications, 1998.

[15] Wardenier, J., International Committee for Research and Technical Support for Hollow Section Structure: Hollow sections in structural applications, 2001

[16] Kurobane. Y., Packer, J.A., Wardenier, J. and Yeomans, N., International Committee for Research and Technical Support for Hollow Section Structure: CIDECT, Design Guide 9, for structural hollow section column connections, 2005.

[17] Talaslioglu, T. "Optimization of geometrically nonlinear lattice girders. Part I: considering member strengths, Journal of Civil Engineering and Management", 21(4), pp. 423-443, 2015, DOI: $10.3846 / 13923730.2014 .890648$
[18] Talaslioglu, T. "Global stability-based design optimization of truss structures using multiple objectives", Sadhana Proceedings in engineering sciences, 38(1), pp. 37-68, 2013.

[19] Merritt, F.S. and Ricketts, J.T., Building Design and Construction Handbook, 6th ed McGraw-Hill, 2000.

[20] Bailey, B. and Raich, A.M. "Modeling of user design preferences in multiobjective optimization of roof trusses", Journal of Computing Civil Engineering, 26, pp. 584-596, 2012.

[21] Sanchis, J., Martínez, M.A., Blasco, M.X. and Reynoso-Meza G. "Modeling preferences in multi-objective engineering design", Engineering Applications of Artificial Intelligence, 23(8), pp. 1255-1264, 2010.

[22] Laumanns, M., Thiele, L. and Zitzler, E. "An efficient, adaptive parameter variation scheme for metaheuristics based on the epsilon-constraint method", European Journal of Operational Research, 169, pp. 932-942, 2006.

[23] Noll,e L. and Bland, J.A. "Self-adaptive stepsize search for automatic optimal design", Knowledge-Based Systems, 29, pp. 75-82, 2012.

[24] Pholdee, N and Bureerat S. "Hybridization of real-code population-based incremental learning and differential evolution for multi-objective design of trusses", Information Sciences, 223 , pp. 136-152, 2013

[25] Tan, K.C., Lee, T.H. and Khor, E.F. "Evolutionary Algorithms for Multi-Objective Optimization: Performance Assessments and Comparisons", Artificial Intelligence Review, 17(4), pp. 253-290, 2002

[26] Gustavo, R.Z., Nebro, A.J., Luna, F. and Coello, C.A.C. "A survey of multi-objective metaheuristics applied to structural optimization", Structural and Multidisciplinary Optimization, 49, pp. 537-558, 2014, DOI 10.1007/s00158-013-0996-4.

[27] Coello, C.A., Lamont, G.B. and Van Veldhuizen D.A. "Evolutionary algorithms for solving multi-objective problems". Springer.Davison B., 2007.

[28] American Petroleum Institute (API): API RP2A-LRFD, Recommended Practice for Planning, Designing and Constructing Fixed Offshore Platforms. Load and Resistance Factor Design, $1^{\text {st }}$ Edition, 1993.

[29] Srinivas, N. and Deb, K. "Multiobjective function optimization using nondominated sorting genetic algorithms", Evol. Comput., 2, pp. 221-248, 1995

[30] Talaslioglu, T. "Optimal dome design considering member-related design constraints". Front. Struct. Civ. Eng. 13, pp. 1150-1170 2019, https://doi.org/10.1007/s11709-019-0543-5

[31] Talaslioglu, T. "Design Optimization of Tubular Lattice Girders", Adv. Steel Constr, 15(3), pp. 274-287, 2019 ttps://doi.org/10.18057/IJASC.2019.15.3.8

[32] Talaslioglu, T. "Optimal design of steel skeletal structures using the enhanced genetic algorithm methodology", Front. Struct. Civ. Eng., 13, pp. 863-889, 2019, https://doi.org/10.1007/s11709-019-0523-9

[33] Talaslioglu, T. "A Unified Optimal Design Approach for Geometrically Nonlinear Skeletal Dome Structures" Periodica Polytechnica Civil Engineering, 63(2), pp. 518-540, 2019 https://doi.org/10.3311/PPci.13329

[34] Talaslioglu, T. "A comparative study of multi-objective evolutionary metaheuristics for lat tice girder design optimization" Structural Engineering and Mechanics, 77(3), 2021, DOI https://doi.org/10.12989/sem.2021.77.3.001

[35] Saka, M.P. and Geem, V.Z. "Mathematical and Metaheuristic Applications in Design Optimization of Steel Frame Structures: An Extensive Review", Mathematical Problems in Engineering, 2013, http://dx.doi.org/10.1155/2013/271031

[36] Gandomi, A.H., Yang, X.S., Talatahari S and Alavi, A.H. "Metaheuristic Applications in Structures and Infrastructures", Elsevier, 2013

[37] MATLAB, Natick, Massachusetts: The MathWorks Inc, 2015.

[38] Lee, K.S. and, Geem, Z.W. "A new structural optimization method based on the harmony search algorithm", Computer and Structure, 82, pp. 781-98, 2004.

[39] Khot, N.S. and Berke, L. "Structural optimization using optimality criteria methods" in Atre E et al. (Eds.) New directions in optimum structural design, John Wiley \& Sons Inc., 1984.

[40] Li, L.J., Huang, Z.B., Liu, F. and Wu, Q.H. "A heuristic particle swarm optimizer for optimization of pin connected structures", Computers and Structures, 85, pp. 340-349, 2007.

A comparative study of multi-objective evolutionary metaheuristics for lattice girder design optimization 


\title{
PROGRESSIVE COLLAPSE MECHANISM OF STEEL FRAMED-STRUCTURES SUBJECTED TO A MIDDLE-COLUMN LOSS
}

\author{
Wen-Jin Zhang ${ }^{1}$, Guo-Qiang Li ${ }^{1,2}$ and Jing-Zhou Zhang 1,* \\ ${ }^{1}$ College of Civil Engineering, Tongji University, 1239 Siping Road, Shanghai 200092, China \\ ${ }^{2}$ State Key Laboratory for Disaster Reduction in Civil Engineering, Tongji University, 1239 Siping Road, Shanghai 200092, China \\ *(Corresponding author: E-mail: jzzhang1992@163.com)
}

\section{A B S T RA C T}

This paper analytically deals with the collapse resistance of steel framed-structures due to a middle column loss. The fourstage resistance-displacement relationships are proposed for both the bare steel frame and the braced steel frame. The reliability of the analytical method is verified against numerical analyses. Parametric studies are conducted to investigate the effects of frame height, span and stiffness ratio of beam to column on the collapse resistance of the frame. It is concluded that the yielding capacity, ultimate capacity, post-yielding stiffness and ultimate displacement of the steel frames can be reasonably predicted by the analytical method with acceptable errors. It is found that a greater number of storeys, shorter span of beams and larger beam to column stiffness ratio ensure better performances of the frame against collapse. Moreover, even though the bracing system can enhance the lateral stiffness of the main steel frame with certain extents, it reduces the collapse resistance and failure displacement of the frame because the column at the base-storey prematurely loses its stability.
A R T I C LE H I S T ORY

$\begin{array}{ll}\text { Received: } & \text { 25 December } 2020 \\ \text { Revised: } & \text { 5 May 2021 } \\ \text { Accepted: } & 7 \text { May } 2021\end{array}$

\section{K E Y W O R D S}

Progressive collapse;

Steel braced frame;

Middle column loss;

Catenary action;

Plastic hinge

\section{Introduction}

The term "progressive collapse" refers to the phenomenon where the structure disproportionally or completely collapses even due to the limited local failures of certain load-bearing members. In 1976, measurements on enhancing the structural robustness against collapse were first proposed in British Building Regulations [1] after the catastrophic collapse of Ronan Point Tower [2]. Afterwards, collapses of Alfred P. Murrah building [3] and World Trade Center Towers [4] in USA further facilitated developments of safety design of structures [5-7]. Two methods are proposed in building regulations to enhance the robustness of structures in the event of column losses, namely, indirect and direct methods. For the indirect methods, constructive measures (e.g. ductility detail and system redundancy) are required to ensure sufficient connectivity among structural components [5]. For the direct methods, the robustness of structures to resist progressive collapse is explicitly assessed [7]. In the Alternate Path Method, as a common direct approach, different columns, especially those at corner or along the edge of the building, are removed to investigate the resistance of the remaining structure to guarantee alternative load transferring paths.

Steel framed-structures are widely used in various buildings due to their high constructional efficiency and excellent seismic performance [8]. Research on progressive collapse resistance of steel framed-structures has been successively launched in the last decades [9-17]. Li et al. [11] tested three twostorey four-span planar steel frames in a case of a sudden middle column loss. A three-hinged column and steel hammer system was specially design to achieve a sudden column loss scenario. The dynamic effects on the structural behavior, final deformation modes and load redistributing path of the frame after the column-removal stage were studied. Jiang et al. [13] investigated the structural behaviors of planar steel frames under a localized fire scenario with extensive numerical analyses. Three typical collapse modes were found, namely failure of high load ratio member, tensile force-induced failure and cantilever beam failure. Jiang et al. [16] studied the dynamic responses of steel columns with rotational and axial restraints under a fire scenario. The results of parametric analyses by varying axial and rotational stiffness, column slenderness and load ratio showed that typical dynamic responses of the frame occurred even in a static fire scenario, especially when the axial and rotational restraints of the column were small and the load ratio was large. The above mentioned research mainly focused on the bare steel frame, in real circumstances, however, steel bracing systems are always employed to enhance the lateral stiffness and therefore increase the redundancies of the frame in the event of collapse. The reasonability and reliability of applying the conclusions drawn from bare steel frame to steel frame with bracing systems remain to be verified.

The collapse mechanisms of steel frames with bracing systems have been studied by many researchers [18-26]. Jiang et al.[18] numerically investigated the robustness of steel frames with vertical and hat bracing systems. It was found that hat bracing system enhances the collapse resistance of the frame by more reasonably redistributing the gravity loads in columns. However, the vertical bracing system arranging at edge bays has a negative effect on the collapse resistance of the frame due to its negative contribution to spread local damages to global collapse. Talebi et al. [21] studied the effects of buckling restrained bracing systems (BRBs) on the global performances of the steel frame under a fire scenario. It was suggested that BRBs provided a greater collapse time to the frame due to an induced larger stiffness. Compared with other bracing systems, the BRBs more efficiently maintain the stability of the frame after the sudden column removal scenario. Asgarian and Rezvani [24] proposed an Extend Progressive Collapse Analysis (EPCA) algorithm to evaluate the robustness of steel frames with concentrically bracing systems. The failure mode, minimum residual capacity and the most devastating column loss scenario of the frame can be obtained with the aid of EPCA. Chen et al. [26] studied the contribution of hat bracing system to the resistance of a steel frame under several sudden column loss scenarios. The numerical dynamic analyses indicated that hat bracing system reduces the vertical displacement at the column-removal location by up to $90 \%$.

In the above literatures, the effects of bracing systems on the steel frame in the collapse event are mainly considered by numerical analyses. The EPCA method indeed gave a comprehensive algorithm to evaluate the robustness of steel structures, however, it still needs huge numerical analyses. The essential aim of research on collapse evaluation is to facilitate practical safety design of structures. Analytical method with simple calculations are therefore more necessary. However, such analytical studies focusing on the collapse resistance of steel frame with bracing systems are rare in the literature.

Accordingly, this paper analytically deals with the collapse resistance of steel framed-structures due to a middle column loss. A four-stage resistancedisplacement relationship is proposed for the steel frame with and without bracing systems. The reliability of the analytical method is verified against numerical analyses. Parametric studies are further launched to investigate the effects of frame height, span and stiffness ratio of beam to column on the collapse resistance of the frame. The differences of the collapse mechanisms of the bare and braced frames are also elaborated.

\section{Collapse process of bare and braced frames}

When the middle column at the base-storey of the frame fails due to explosion, impact or even fire actions, the gravity loads initially suffered by the middle column are bridged over by the steel beams to the adjacent columns of the frame. At small deflections, the bending action in steel beams is the main mechanism to resist loads, while at large deflections, the catenary action enhances the resistance of the beam with great extent. Fig. 1 (a) and Fig. 1 (b) indicate the middle-column-removal scenario for the bare and braced steel 
frames, respectively. It should be noted that only two spans of the bare frame are considered. This is due to the following reasons. First, even though the frame has more than two spans in real cases, it is conservative to ignore the restraints from those spans. Second, because only two spans of frames are considered in the braced frame, to achieve a fair comparison on the collapse resistance of the two types of frames, only two spans of the bare frame are considered. Actually, for bare frames with more than two spans, the restraints from other spans can be considered into the spring elements at the beam ends and the analytical method proposed is still applicable. Moreover, the spans of the beams at the two sides of the removed column are assumed to be the same. This is because this paper mainly studies the collapse mechanism of the bare and braced steel frame and considering the unequal span of the beams will make the deduction process of the analytical method extremely complicated.

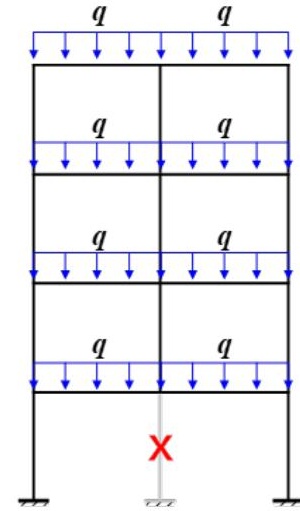

(a) Bare frame structure

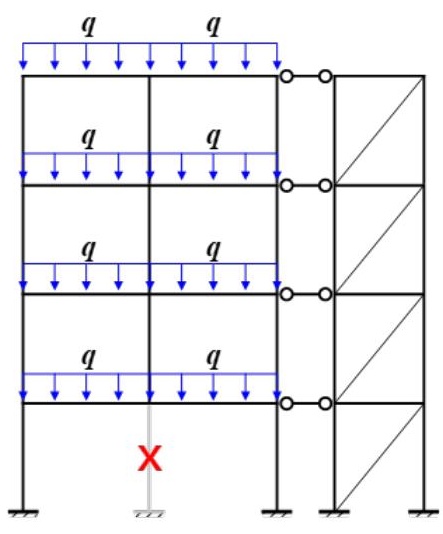

(b) Braced frame structure
Fig. 1 The middle column loss scenario for the bare and braced steel frames

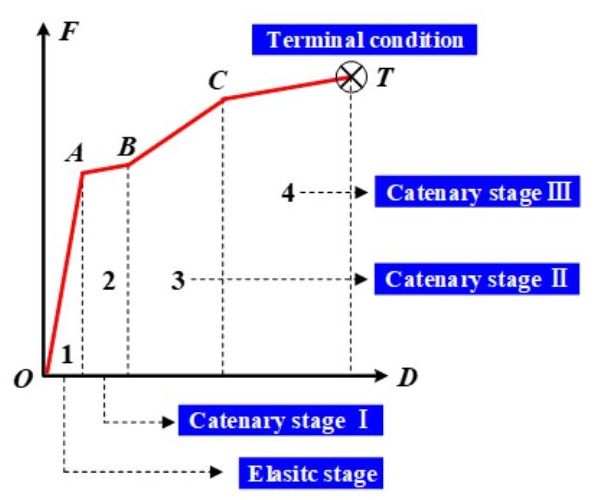

Fig. 2 Resistance-vertical displacement relationship of the steel framed-structures
Fig. 2 shows the simplified resistance-vertical displacement relationship of the frame ( $F-D$ curve) due to a middle column loss. Four stages, namely, elastic stage, catenary stage $I$, catenary stage $I I$ and catenary stage $I I I$ are presented. The structural behavior for the bare and braced frames are the same in elastic stage and catenary stage $I$, while due to the lateral restraints provided by bracing systems, the mechanism of braced frame is different from that of bare frame in catenary stages $I I$ and $I I I$.

In elastic stage $O A$, the frame remains in its elastic status. As shown in Fig. 3 (a), the state when the plastic hinges occur at the bottom beam indicates the end of the elastic stage. Considering that the lateral displacement of the bottom columns is small, the contribution of bracing system to the resistance of steel frames can be ignored. Therefore, it is assumed that the $F$ - $D$ curves in this stage of the frames with and without bracing system are the same.

In catenary stage $I$, as shown in Fig. 3(b) and Fig. 4(a), the plastic hinges at both ends of the bottom beam developed, while the columns remain in elastic state. At this stage, the second-order effect of gravity loads due to geometry nonlinearity on the resistance of the frame starts to be considered. Meanwhile, the gravity loads are partially resisted by the tensile action in steel beams. The lateral displacement of each floor is assumed to be the same with that of the base floor. Therefore, only catenary action in the steel beams at the base floor is considered.

In catenary stage $I I$, with the vertical displacement at the column-removal location increasing, the catenary action in the steel beam will result in a significant inward deflection of the column. Therefore, the plastic hinge will appear at the bottom of the column at the first storey. The deformation configurations for the bare and braced steel frames are presented in Fig. 3 (c) and Fig. 4 (b), respectively. The column tops at the base-storey still remain elastic. For the braced frame, the constraints from bracing systems intensify the lateral displacement at the column top farther from the braces, while the column adjacent to the bracing systems remains in elastic state due to the limited deformation. Therefore, the plastic hinge only occurred at the bottom of column A, as Fig. 4 (b) shows.

In catenary stage $I I I$, plastic hinges at the column top of the base-storey emerged. The final failure modes of the bare and braced steel frames are shown in Fig. 3 (d) and Fig. 4 (c), respectively. At the end of this stage, the frame fails to sustain more loads due to lack of stability considering that the second-order effect due to gravity loads significantly decreases the resistance of the frame. For the braced frame, the column adjacent to the braces still remains in elastic, while most plastic damages concentrate at the column ends on the other side. It is noted that the stability of the frame is determined by the vertical loads and lateral displacement at the column top. Although the bracing system increases the lateral stiffness and optimizes seismic performance of the frame, it fails to guarantee a greater collapse resistance of the frame. This is because the bracing system intensifies the lateral displacement at the column top further from it, leading to a premature failure of the frame. In practical engineering, the ultimate state of the frame may be governed by many conditions, such as shear failures of beam-column connections, tensile fractures of beam ends and beam-column connections. Herein it is determined by the loss of global stability of the column at the base-storey due to the second-order effects of gravity loads.

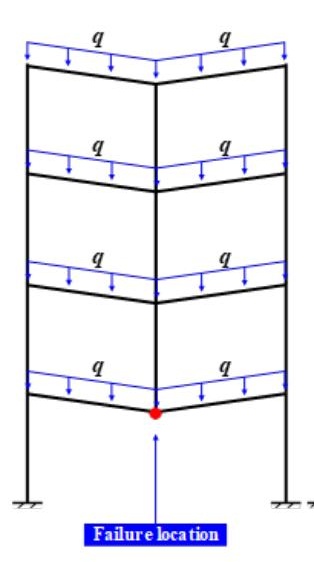

(a) Elastic stage

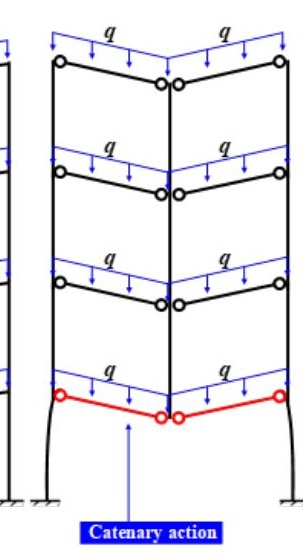

(b) Catenary stage $I$

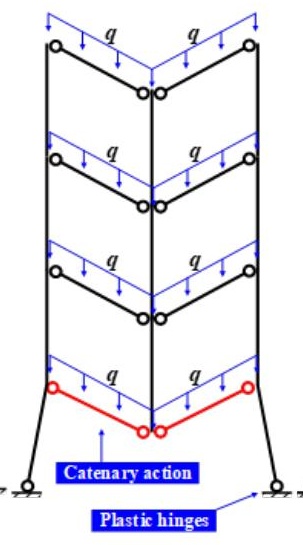

(c) Catenary stage $I I$

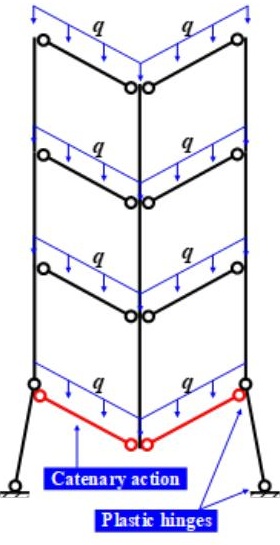

(d) Catenary stage III

Fig. 3 Four stages of symmetric planar frame structure's collapse mechanism 


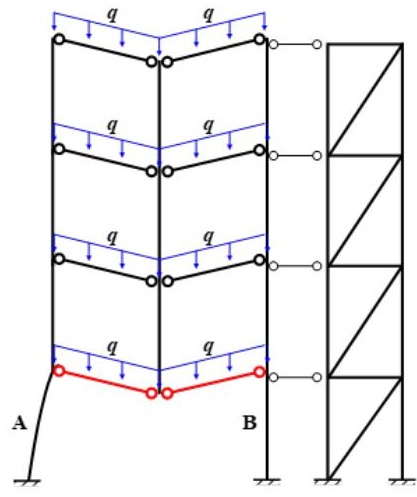

(a) Catenary stage $I$

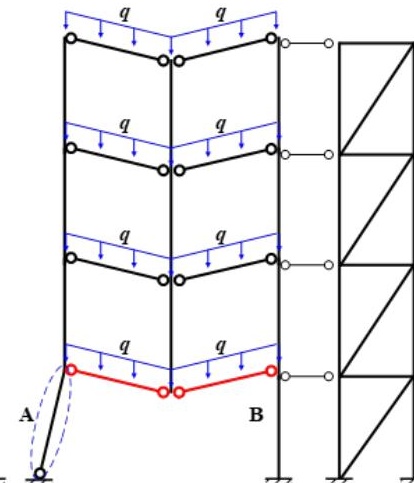

(b) Catenary stage $I I$

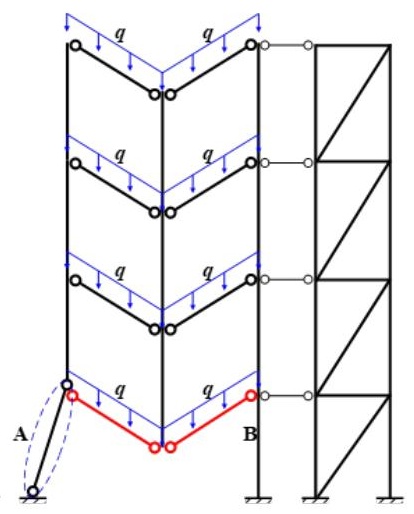

(c) Catenary stage III

Fig. 4 Three catenary stages of planar braced frame structure

\section{Analytical method of collapse resistance for bare steel framed-} structures

\subsection{Elastic stage}

\subsubsection{Elastic stiffness}

Due to the elastic and linear assumption, the total elastic stiffness, denoted as $k_{e}$, can be calculated as the sum of equivalent stiffness provided by frame beams:

$k_{e}=\Sigma k_{b i}$

where $k_{b i}$ is the equivalent vertical stiffness of the frame beam $i$.

Fig. 5 shows the simplified model to determine the equivalent stiffness $k_{b i}$. The rotational restraints provided by the columns are denoted by $k_{d i}$. At the column-removal location, only vertical displacement is allowed and thus the rotation at the beam end can be assumed to be fully restrained. $k_{b i}$ is given as follow:

$$
k_{b i}=\varphi_{b i} \frac{12 i_{b}}{L^{2}}
$$

where $L$ is the span of the steel beam; $i_{b}$ is the linear stiffness of the beam; $\varphi_{b i}$ is the stiffness reduction factor accounting for the partial restraints $k_{d i}$ provided by the columns, which is given by:

$$
\varphi_{b i}=\frac{1-2 \frac{i_{b i}}{k_{d i}}}{1+\frac{i_{b i}}{k_{d i}}}
$$

For regular frames with same height at each storey, the approximate value of $k_{d i}$ for beams at different storeys is given in Table 1

\section{Table 1}

The approximate value of $k_{d}$ for regular structures with uniform story height

\begin{tabular}{cccc}
\hline Number of story & Beam at $2^{\text {nd }}$ story & Beam at normal stories & Beam at top story \\
\hline $\mathrm{N}=1$ & $4 i_{c}$ & $4 i_{c}$ & $4 i_{c}$ \\
$\mathrm{~N}=2$ & $10 i_{c}$ & $10 i_{c}$ & $6 i_{c}$ \\
$\mathrm{~N}>2$ & $10 i_{c}$ & $12 i_{c}$ & $6 i_{c}$ \\
\hline
\end{tabular}

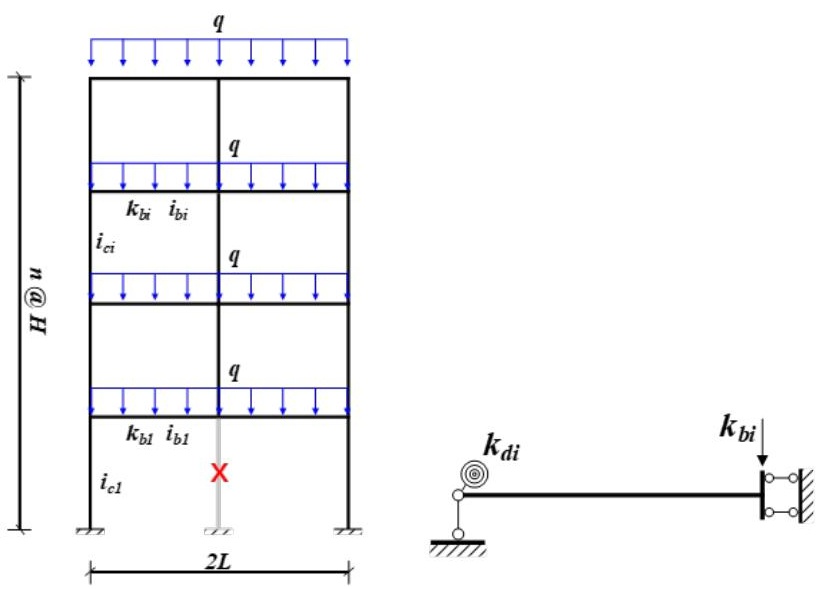

$\begin{array}{ll}\text { (a) Framed-structure due to a middle column loss } & \text { (b) Equivalent beam model }\end{array}$

Fig. 5 The simplified model of equivalent elastic stiffness

\subsubsection{Yielding capacity}

The resistance of the frame at the end of elastic stage is determined by its yielding capacity. Considering that for practical framed-structures, the columns are stronger than beams, the plastic hinges hence emerge at the beam ends near the beam-column connections. The yielding capacity of the frame $F_{y}$ is given by:

$F_{y}=\Sigma F_{b y i}$

where $F_{\text {byi }}$ represents the yielding capacity of each beam, which can be calculated as:

$F_{b y i}=\frac{M_{r, y b i}+M_{l, y b i}}{L_{b i}}$

where $L_{b i}$ is the span of the beam $i, M_{r, y b i}$ and $M_{l, y b i}$ are the plastic moments at the right and left ends of the beam $i$ (shown in Fig. 6), respectively.

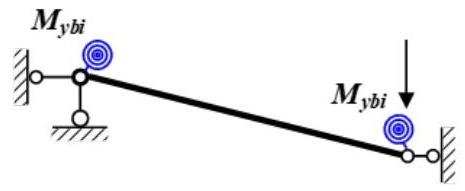

Fig. 6 Plastic hinges at the ends of frame beams 


\subsection{Catenary stage I}

In the catenary stage $I$, the resistance of the frame is calculated by accounting for two contributions, including the bending action (yielding capacity $F_{y}$ ) and the catenary action in steel beams. The enhancement due to catenary action is denoted as $F_{G}$.

\subsubsection{The equivalent link model}

At catenary stage, the horizontal component of the tensile force in steel beams is suffered by the steel columns. To investigate the contribution of catenary action to the resistance of the frame $F_{G}$, an equivalent link model is proposed, as shown in Fig. 7. The frame beams at the base-storey are simplified into links $\mathrm{AB}$ and $\mathrm{BC}$. The restraints due to side columns are simplified into axial springs $\mathrm{DE}$ and $\mathrm{AD}$ with stiffness $k_{e l}$ and $k_{e 2}$, respectively. The effective stiffness of the spring systems $k_{e}$ is given by:

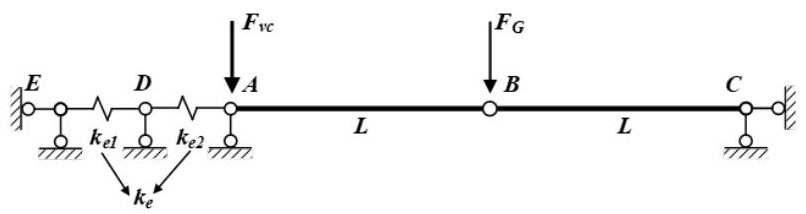

Fig. 7 The equivalent link model for catenary stage $I$

$k_{e}=\frac{1}{\frac{1}{k_{e 1}}+\frac{1}{k_{e 2}}}$

Taking the second-order effect of gravity loads into account, the axial stiffness of the springs $k_{e 1}$ and $k_{e 2}$ are given by:

$k_{e i}=\varphi_{c i} \frac{12 i_{c i}}{H_{1}^{2}}-\frac{0.5 F_{G}+F_{v c}}{H_{1}}(i=1,2)$

$F_{v c}=0.5\left(P+F_{y}\right)$

where $F_{v c}$ is the total vertical loads suffered by the column top at the base-storey; $P$ is the gravity loads from upper storeys; $i_{c i}$ is the linear stiffness of the column at the base-storey. The first item on the right of Eq. 7 represents the equivalent lateral stiffness of the column at the base-storey (shown in Fig. 8 (a)). The second item indicates the detrimental influence of the second-order effect due to gravity loads on the lateral stiffness of the column. $\varphi_{c i}$ is the reduction factor of the equivalent lateral stiffness for the column at the base-storey considering that the columns at upper storeys fail to fully restrain the column top at the basestorey (shown in Fig. 8 (b)). For regular frames with same height at each storey, the value of $\varphi_{c i}$ can be designated as 0.4 .

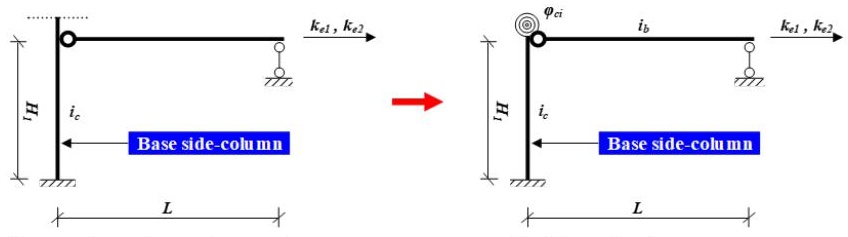

(a) Restraints of the column at base-storey

(b) The reduction factor $\varphi_{c i}$

Fig. 8 Model simplification for $k_{e l}$ and $k_{e 2}$

3.2.2. The relationship between $F_{G}$ and $\delta$

Fig. 9 gives the deformation configuration of the equivalent link model during the catenary stage $I . \Delta$ is the total lateral displacement of the equivalent spring; $\theta$ is the chord rotation of the beam at the base-story; $\delta$ is the vertical displacement at the column-removal location.

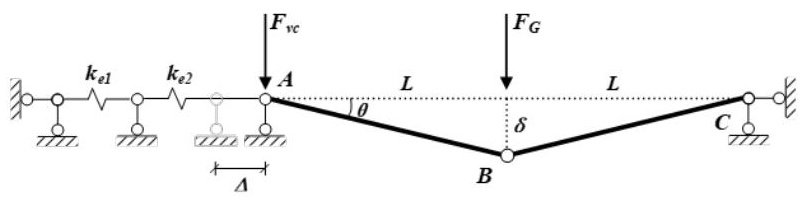

Fig. 9 Deformation configuration of the equivalent link model during catenary stage $I$
According to the deformation compatibility, the axial elongation of the beams at the base-storey is given by:

$\frac{2 L-\Delta}{2 \cos \theta}=\frac{F_{G} L}{2 E A \sin \theta}+L$

where $E$ and $A$ are the elastic modulus and section area of the beam, respectively. Based on the force equilibrium at the beam end A, the tensile force in the spring equals to the horizontal component of that in the beam, which is given by:

$$
k_{e} \Delta=\frac{F_{G}}{2 \tan \theta}
$$

Substituting Eq. 9 into Eq. 10, yielding:

$\tan \theta-\sin \theta=\frac{F_{G}}{2 E A}+\frac{F_{G}}{4 L k_{e}}$

The relationship between $\Delta$ and $\delta$ is given by:

$$
\delta=\frac{2 L-\Delta}{2} \tan \theta+H_{1}\left(1-\sqrt{\frac{H_{1}^{2}}{H_{1}^{2}+\Delta^{2}}}\right)
$$

In Eq. 12, the first item on the right indicates the vertical displacement at the column-removal location due to the chord rotation of the steel beam. The second item represents the effect of rotation of the column at the base-storey on the vertical displacement. For a given $F_{G}$, the rotation $\theta$ and lateral displacement $\Delta$ of the beam can be determined by Eq. 11 and Eq. 10, respectively. The vertical displacement $\delta$ at the column-removal location can hence be calculated by Eq 12. The total resistance of the frame $F_{c}$ is given by:

$$
F_{c}=F_{G}+\lambda_{a} \cdot F_{y}
$$

where $\lambda_{a}$ denotes the detrimental effect of the tensile force on the sectional plastic moment of the steel beam at the base-storey, which is given by [27]:

$\lambda_{a}=\frac{F_{p}-N}{F_{p}}$

where $F_{p}$ is the tensile yielding capacity of the beam section; $N$ is the tensile force in the beam.

\subsection{Catenary stage II}

In catenary stage $I I$, the resistance mechanism in the column at the basestorey is different from that in catenary stage $I$ considering that the plastic hinge occurs at the column bottom due to the increasing lateral displacement of it. As shown in Fig. 10, a modified link model is proposed wherein the plastic hinge occurring at the column bottom is considered. Similarly, the effective lateral stiffness of the side columns $k_{e}^{\prime}$ is given by:

$$
k_{e}^{\prime}=\frac{1}{\frac{1}{k_{e 1}^{\prime}}+\frac{1}{k_{e 2}^{\prime}}}
$$

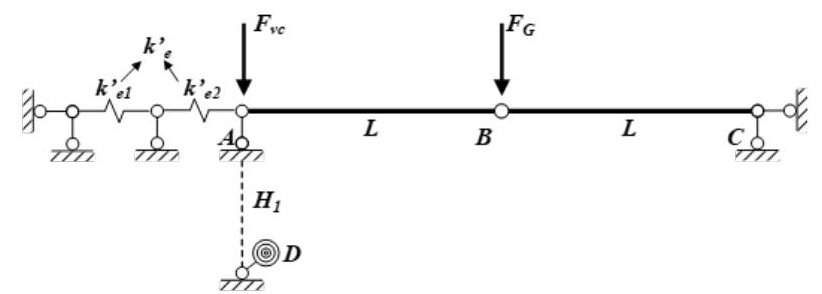

Fig. 10 The equivalent link model for catenary stage $I I$ 
where $k_{e l}^{\prime}$ and $k_{e 2}^{\prime}$ represent the lateral stiffness of side-columns with plastic hinges at the bottom of the base-storey, wherein the second-order effect of gravity loads is considered. The plastic hinges occurring at the column bottom are simplified into perfectly-elastoplastic rotational springs located at point $D$. The rigid link $A D$ is used to transfer the resistance of the plastic hinges to point $A$, which represents the column top at the base-storey. $k_{e i}^{\prime}(i=1,2)$ is given by:

$k_{e i}^{\prime}=\varphi_{e i}^{\prime} \frac{3 i_{c i}}{H_{1}^{2}}-\frac{0.5 F_{G}+F_{v c}}{H_{1}}(i=1,2)$

where $\varphi_{c i}^{\prime}$ is the modified reduction factor of the lateral stiffness of the column at the base-storey considering the unideal restraints provides by columns in upper stories, which is shown in Fig. 11. For regular frames with same height at each storey, the value of $\varphi_{c i}$ can be designated as 0.2 .

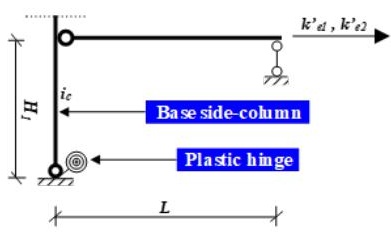

(a) Restraints of the column at base-storey

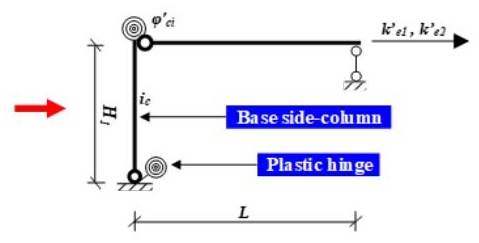

(b) The modified reduction factor $\varphi_{c i}^{\prime}$
Fig. 11 Calculation configuration of $k_{e l}^{\prime}$ and $k_{e 2}^{\prime}$ in catenary stage $I I$

Fig. 12 shows the deformation configuration of the steel beam at the basestorey. Similarly, based on the force equilibrium condition at point A:

$k_{e}^{\prime} \Delta+\frac{M_{y c}}{H_{1}}=\frac{F_{G}}{2 \tan \theta}$

where $M_{y c}$ is the plastic bending capacity at the bottom of the steel column.

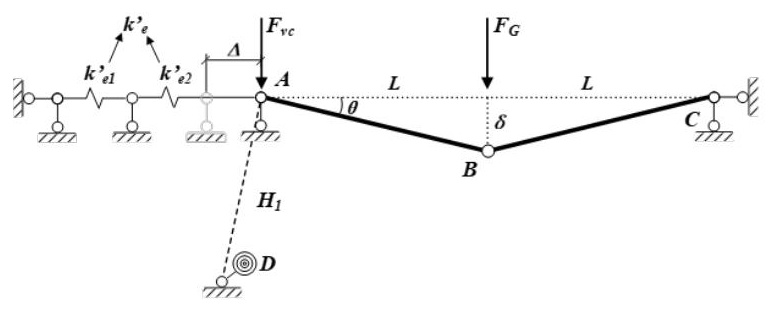

Fig. 12 Equilibrium state of the equivalent link model during catenary stage $I I$

The deformation compatibility condition of the beam at the base-storey yields that:

$\tan \theta-\sin \theta=\frac{F_{G}}{2 E A}+\frac{F_{G} H_{1}-2 M_{y c} \tan \theta}{4 L H_{1} k_{e}^{\prime}}$

The relationship between $\delta$ and $\Delta$ is further given by:

$\delta=\frac{2 L-\Delta}{2} \tan \theta+H_{1}\left(1-\sqrt{\frac{H_{1}^{2}}{H_{1}^{2}+\Delta_{1}^{2}}}\right)$

Similarly, for a given $F_{G}$, the rotation $\theta$ and lateral displacement $\Delta$ of the beam can be determined by Eq. 18 and Eq. 17, respectively. The vertical displacement at the column-removal location can be calculated by Eq. 19. The total resistance of the frame $F_{c}$ is determined by Eq. 13 .

3.4. Catenary stage III

At catenary stage $I I I$, plastic hinges occur at both ends of the columns at the base-storey and the whole structure approach the utilmate capacity due to the second-order effect of gravity loads.
3.4.1. The additional vertical force at failure location, $F_{F G}$

The deformation configuration of the bare steel frame at catenary stage III is shown in Fig. 13. With the increase of the lateral displacement at the beam ends $A$ and $C$, the resultant shear force in side-columns at upper stories $F_{v_{-} \text {uppeer }}$ will result in additional vertical force at point $B$, which is denoted as $F_{F G}$, which increases the axial force of the steel beam at the base-storey.

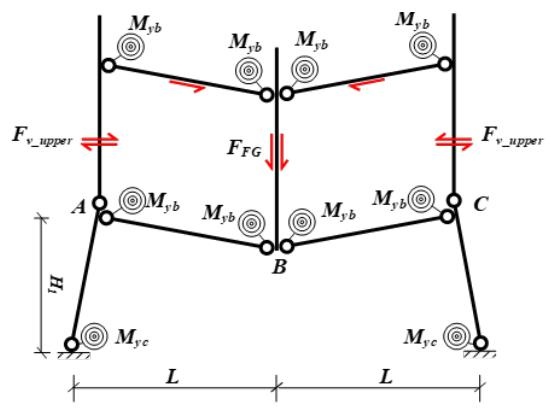

Fig. 13 The mechanism of $F_{F G}$ for catenary stage $I I$

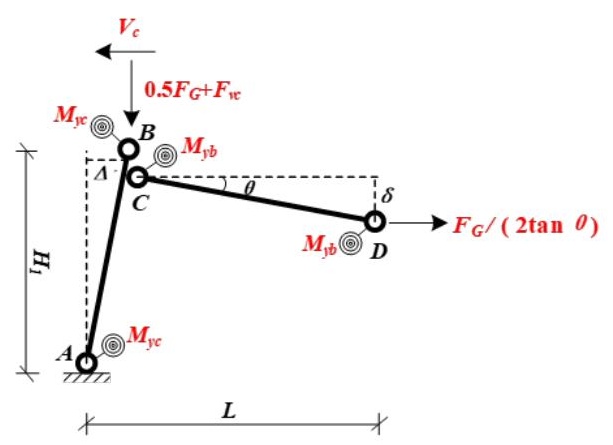

Fig. 14 Deformation configuration of the link model for catenary stage III (half model)

The determination of $F_{v \_u p p e r}$ is given by:

$F_{v_{-} u p p e r} \approx \varphi_{m y c} \frac{M_{y c}}{H_{1}}$

where $\varphi_{m y c}$ is the equivalent factor considering the influence of the frame height, whose value is designated as 0.7 for the regular bare frame structures with same storey height. Therefore, $F_{F G}$ is determined as:

$F_{F G}=2 F_{v_{-} \text {upper }} \tan \theta$

\subsubsection{The relationship between $F_{G}$ and $\delta$}

Fig. 14 shows the deformation configuration of the equivalent link halfmodel for the steel beam at the base-storey. $V_{c}$ is the shear force in columns at upper storeys. $M_{y c}$ and $M_{y b}$ are the plastic bending capacities at both ends of the column and beam, respectively. $\Delta$ ' is the lateral displacement of the column top on single side at base-storey, corresponding to the point B in Fig. 14. Based on the deformation compatibility condition:

$\frac{L-\Delta^{\prime}}{\cos \theta}=L+\frac{L}{2 E A \sin \theta}\left(F_{G}+F_{F G}\right)$

The moment-equilibrium condition about point $B$ yields:

$2 M_{y c}-M_{y b}+V_{c} \cdot H_{1}=H_{1} \cdot \frac{F_{G}+F_{F G}}{2 \tan \theta}+\left(0.5 F_{G}+F_{v c}\right) \cdot \Delta^{\prime}$

The value of $V_{c}$ can be calculated as:

$V_{c}=\varphi_{c}^{\prime \prime} \frac{M_{y c}}{H_{1}}$ 
where $\varphi{ }^{\prime \prime}{ }_{c}$ is the shear force reduction factor, taking the influence of the sidecolumns in upper stories into account, the value of which is given by 1.50 for regular structures with same storey-height. From Eq. 22 Eq. 24, the relationship between $\theta$ and $F_{G}$ can be obtained:

$\tan \theta-\sin \theta=\frac{F_{G}+F_{F G}}{2 E A}+\frac{2 \tan \theta\left(2 M_{y c}-M_{y b}+V_{c} \cdot H_{1}\right)-\left(F_{G}+F_{F G}\right) H_{1}}{2 L\left(0.5 F_{G}+F_{v c}\right)}$

Furthermore, the relationship between $\Delta$ ' and $\left(\theta, F_{G}\right)$ during catenary stage III is given in Eq. 26 and the relationship between $\delta$ and $\Delta^{\prime}$ is given in Eq. 27.

$\Delta^{\prime}=\frac{2 \tan \theta \cdot\left(2 M_{y c}-M_{y b}+V \cdot H_{1}\right)-\left(F_{G}+F_{F G}\right) H_{1}}{2 \tan \theta \cdot\left(0.5 F_{G}+F_{v c}\right)}$

$\delta=\left(L-\Delta^{\prime}\right) \cdot \tan \theta+H_{1}\left(1-\sqrt{\frac{H_{1}^{2}}{H_{1}^{2}+\Delta^{\prime 2}}}\right)$

For a given $F_{G}$, the rotation $\theta$ and lateral displacement $\Delta^{\prime}$ of the beam can be determined by Eq. 25 and Eq. 26, respectively. The vertical displacement at the column-removal location can be calculated by Eq. 27. The structure resistance $F_{c}$ is given by Eq. 13 .

\subsection{Resistance-displacement curve}

Fig. 2 shows the determinations of the resistance-displacement relationship of the bare steel frame due to a middle column loss ( $F-D$ curve). At the end of the elastic stage (Point $A$ ), the resistance of the frame is determined by Eq. 4 Eq. 5. Point $B$ is obtained by intersecting the resistance-displacement curves for catenary stages $I$ and $I I$. Similarly, the intersection of the resistancedisplacement curves for catenary stages $I I$ and $I I I$ is defined as point C. Point T corresponds to the ultimate state of the frame, wherein Eq. 25 Eq. 27 fail to have solutions. In practical engineering, other instances such as the fracture of frame beams, the failure of beam-column joints or local buckling of column components, will bring the final collapse ahead of time and decrease the capacity of bare steel frame structure, which are not to be discussed in this paper.

\section{Analytical method of collapse resistance for braced steel framed- structures}

The resistance-displacement relationships for bare and braced steel frames are the same for elastic stage and catenary stage $I$, while due to the restraints provided by the bracing system, the resistance-displacement relationships for the two structural systems are significantly different at catenary stages II and III.

\subsection{Catenary stage II for the braced steel frame}

\subsubsection{The equivalent link model}

Fig. 15 shows the equivalent link model of beams at the base-storey for the braced frame. In Fig. 16, spring with axial stiffness $k_{b e l}$ indicates the lateral restraint from side columns away from the bracing systems. Spring with axial stiffness $k_{b e 2}$ represents the lateral restraint from the bracing systems together with the side columns adjacent to the bracing system. The second-order effect of gravity loads is accounted for by rigid link DE. Due to the limited deformation, the columns close to the bracing systems are assumed to remain in elastic state.

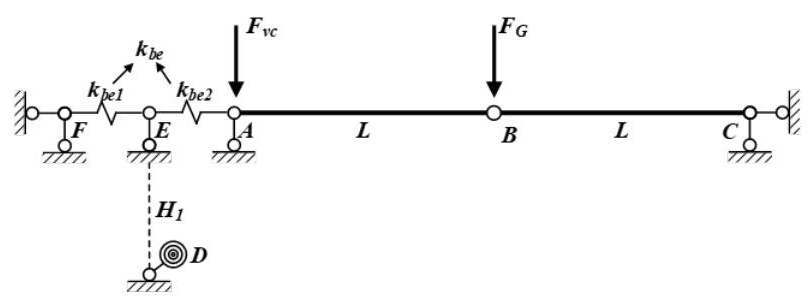

Fig. 15 The equivalent link model for braced frame structures during catenary stage $I I$

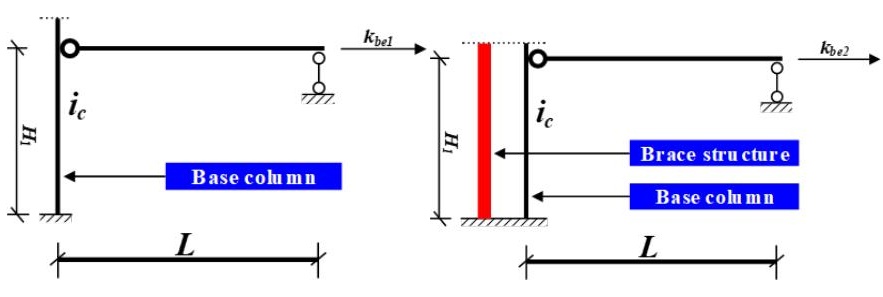

(a) $\boldsymbol{k}_{b e 1}$

(b) $k_{b e 2}$

Fig. 16 The configuration of $k_{b e l}$ and $k_{b e 2}$

The calculation method of $k_{b e l}, k_{b e 2}$ is given by:

$k_{b e 1}=k_{e 1}^{\prime}$

$k_{b e 2} \approx k_{e 2}+\varphi_{c i} \frac{12 i_{b r}}{H_{1}^{2}}$

where $\varphi_{c i}$ is the reduction factor of the equivalent lateral stiffness in Eq. 7, $i_{b r}$ is the linear stiffness of the bracing systems at the base-storey.

\subsubsection{The displacement-resistance curve during catenary stage II}

The deformation configuration of the equivalent link model for the braced frame during catenary stage $I I$ is shown in Fig. 17. Similarly, based on the deformation compatibility of the beam $\mathrm{AB}$ and $\mathrm{BC}$ and force equilibrium condition at the beam end $\mathrm{A}$, the following equations can be derived:

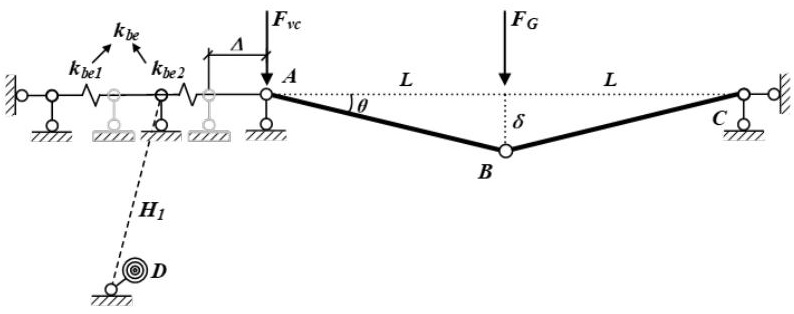

Fig. 17 The deformation configuration of equivalent link model of brace structures

$\frac{2 L-\Delta}{2 \cos \theta}=\frac{F_{G} L}{2 E A \sin \theta}+L$

$\Delta=\frac{F_{G}}{2 \tan \theta k_{b e 2}}+\left(\frac{F_{G}}{2 \tan \theta}-\frac{M_{y c}}{H_{1}}\right) / k_{b e 1}$

Yielding that:

$\delta=\frac{2 L-\Delta}{2} \tan \theta+H_{1}\left(1-\sqrt{\frac{H_{1}^{2}}{H_{1}^{2}+\Delta^{2}}}\right)$

For a given $F_{G}$, the chord rotation $\theta$ of the beam can be determined by substituting Eq. 30 into Eq. 31. The vertical displacement at the columnremoval location can be calculated by Eq. 32. The total resistance of the frame $F_{c}$ is determined by Eq. 13 .

\subsection{Catenary stage III}

During the catenary stage $I I I$, the plastic hinges occur at both ends of the side column away from the bracing systems. The instability of this column indicates the ultimate limit state of the frame. Fig. 18 shows the deformation configuration of the braced frame at the first-storey during catenary stage III. $\Delta_{b 1}$ and $\Delta_{b 2}$ represent the lateral displacement of the column top away from and close to the bracing system at the base-storey, respectively. The mechanism against collapse of the braced frame at this stage is shown in Fig. 19. $F_{v_{-} \text {upperl }}$ and $F_{v_{u} \text { upper } 2}$ represent the shear force in side columns from upper storeys. For simplification, the chord rotation of beam $\mathrm{CD}$ is assumed to be the same as that 
of beam DE. Considering that the lateral stiffness of bracing systems is great enough so that the shear force in the adjacent columns $F_{v_{\nu} \text { upper } 2}$ can be ignored. $F_{v_{\perp} \text { upper } 1}$ is given by:

$$
F_{v_{-} u p p e r 1} \approx \varphi_{m y c} \frac{M_{y c}}{H_{1}}
$$

where $\varphi_{m y c}$ is explained in Eq. 20. The additional vertical force at the columnremoval location $F_{F G}$ is calculated as:

$F_{F G} \approx F_{v_{-} \text {upper } 1} \tan \theta$

Based on the moment-equilibrium condition of column $\mathrm{AB}$ and deformation compatibility condition of beam CD (in Fig. 18):

$2 M_{y c}-M_{y b}+V_{b c 1} \cdot H_{1}=H_{1} \cdot \frac{F_{G}+F_{F G}}{2 \tan \theta}+\left(0.5 F_{G}+F_{v c}\right) \cdot \Delta_{b 1}$

$\frac{2 L-\Delta_{b 1}-\Delta_{b 2}}{2 \cos \theta} \approx L+\frac{F_{G}+F_{F G}}{2 E A \sin \theta} L$

$\Delta_{b 2}$ can be determined by linear-elastic principle:

$\Delta_{b 2}=\frac{F_{G}}{2 k_{e 2} \tan \theta}$

$V_{b c l}$ is given by:

$V_{b c 1}=\varphi_{c}^{\prime \prime} \frac{M_{y c}}{H_{1}}$

where $\varphi{ }^{\prime}{ }_{c}$ is explained in Eq. 24. According to Eq. 35 Eq. 38, the relationship between $F_{G}$ and $\theta$ can be figured out. Meanwhile, $\Delta_{b l}$ and $\delta$ is given in Eq. 39 and Eq. 40 , respectively.

$\Delta_{b 1}=\frac{2 \tan \theta \cdot\left(2 M_{y c}-M_{y b}+V_{b c 1} \cdot H_{1}\right)-\left(F_{G}+F_{F G}\right) H_{1}}{2 \tan \theta \cdot\left(0.5 F_{G}+F_{v c}\right)}$

$\delta=\frac{2 L-\Delta_{b 1}-\Delta_{b 2}}{2} \cdot \tan \theta+H_{1}\left(1-\sqrt{\frac{H_{1}^{2}}{H_{1}^{2}+\Delta_{b 1}^{2}}}\right)$

The determination of the resistance-displacement relationship for the braced frame is the same with that for the bare frame. The details are introduced in Section 3.5.

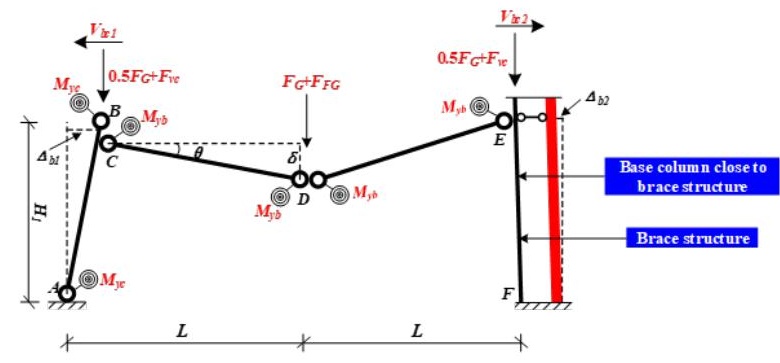

Fig. 18 The deformation configuration of the braced frame during catenary stage III

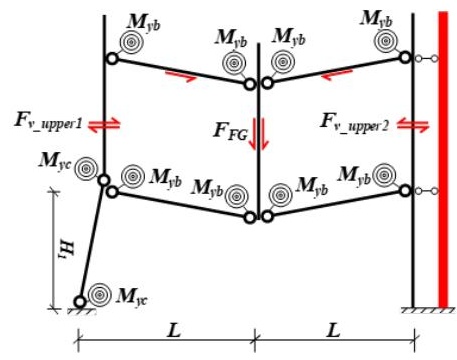

Fig. 19 The mechanism of the braced frame during catenary stage $I I I$

It should be noted that the beam at each storey is assumed to suffer from the same uniformly distributed load herein. In practical engineering, the uniformly distributed load may be different at each storey. However, considering that the collapse state of the frame is controlled by the stability of the columns at the first storey and only the total gravity load from upper storeys is required to quantify the second-order effect, the proposed method is still applicable.

\section{Numerical analysis}

The accuracy of the proposed analytical method is verified by numerical analyses by using the finite elment software ABAQUS. Parametric studies are launched to further investigate the collapse mechanism of the steel frame in the event of a middle column loss.

\subsection{Finite element models}

As shown in Fig. 20, the numerical bare and braced reference frames are six-storey with a span of $6 \mathrm{~m}$ and storey height of $3.6 \mathrm{~m}$. The section dimensions of the beams and columns in the frames are correspondingly identical. The steel beams and columns are simulated by two-node beam elements (B21). For the braced frame, the "Coupling" Command is employed to connect the bracing system and the main frame. The mesh size of the columns and beams are assigned as 1/4 of their section height. The bi-linear stress-strain relationship with kinematic hardening is employed to model the characteristics of steel. The yielding stress of the steel is $345 \mathrm{MPa}$ and the post-yielding stiffness is $6.18 \times 10^{3} \mathrm{MPa}$. The bottoms of the columns are fully restrained. The linear distributed load applied on the beams is $20 \mathrm{kN} / \mathrm{m}$. Displacement-controlled loading is applied at the column-removal location to obtain the resistancedisplacement relationship of the frame. The target vertical displacement is assigned as $3.0 \mathrm{~m}$ at the column-removal location. The general static procedure is used and the geometric nonlinearity is considered for large deflections. It should be noted that the effect of the initial geometric imperfection of the column is not considered. This is because the second-order effect of the gravity load is mainly induced by the lateral displacement at the top of the column.

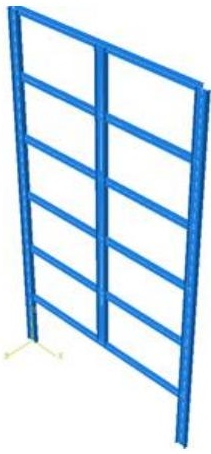

(a) Bare steel frame

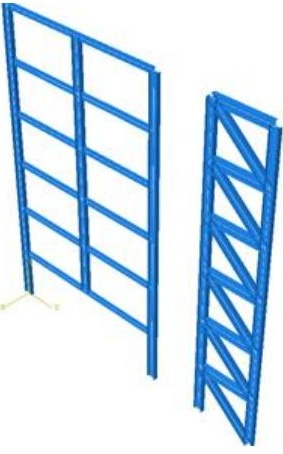

(b) Braced steel frame
Fig. 20 Finite element models of the two structural systems

\subsection{Parametric study scheme}

In the parametric studies, the target structural parameters are the span of the beam, number of storey and the relative stiffness ratio of beam to column in the frame. The details of the parameters for the bare and braced frames are shown in Table 2 and Table 3 , respectively. 
Table 2

Details of the parametric study for the bare frames

\begin{tabular}{|c|c|c|c|c|c|}
\hline No. of bare frame model & Number of storey & Span & Stiffness ratio & Beam section & Column section \\
\hline FS6B6R $1^{*}$ & 6 & 6 & 0.17 & $\mathrm{H} 400 \times 200 \times 14 \times 10$ & \multirow{7}{*}{$\mathrm{H} 600 \times 300 \times 14 \times 10$} \\
\hline FS6B7R1 & 6 & 7 & 0.17 & $\mathrm{H} 430 \times 200 \times 14 \times 10$ & \\
\hline FS6B8R1 & 6 & 8 & 0.17 & $\mathrm{H} 440 \times 220 \times 14 \times 10$ & \\
\hline FS4B6R1 & 4 & 6 & 0.17 & $\mathrm{H} 400 \times 200 \times 14 \times 10$ & \\
\hline FS8B6R1 & 8 & 6 & 0.17 & $\mathrm{H} 400 \times 200 \times 14 \times 10$ & \\
\hline FS6B6R2 & 6 & 6 & 0.34 & $\mathrm{H} 500 \times 250 \times 14 \times 10$ & \\
\hline FS6B6R3 & 6 & 6 & 0.60 & $\mathrm{H} 600 \times 300 \times 14 \times 10$ & \\
\hline
\end{tabular}

Table 3

Details of the parametric study for the braced frames

\begin{tabular}{|c|c|c|c|c|c|c|}
\hline No. of bare frame model & Number of storey & Span & Stiffness ratio & Beam section & Column section & Brace components \\
\hline BS6B6R $1^{* * *}$ & 6 & 6 & 0.17 & $\mathrm{H} 400 \times 200 \times 14 \times 10$ & \multirow{7}{*}{$\mathrm{H} 600 \times 300 \times 14 \times 10$} & \multirow{7}{*}{$\mathrm{H} 600 \times 300 \times 14 \times 10$} \\
\hline BS6B7R1 & 6 & 7 & 0.17 & $\mathrm{H} 430 \times 200 \times 14 \times 10$ & & \\
\hline BS6B8R1 & 6 & 8 & 0.17 & $\mathrm{H} 440 \times 220 \times 14 \times 10$ & & \\
\hline BS4B6R1 & 4 & 6 & 0.17 & $\mathrm{H} 400 \times 200 \times 14 \times 10$ & & \\
\hline BS8B6R1 & 8 & 6 & 0.17 & $\mathrm{H} 400 \times 200 \times 14 \times 10$ & & \\
\hline BS6B6R2 & 6 & 6 & 0.34 & H $500 \times 250 \times 14 \times 10$ & & \\
\hline BS6B6R3 & 6 & 6 & 0.60 & $\mathrm{H} 600 \times 300 \times 14 \times 10$ & & \\
\hline
\end{tabular}

\subsection{Verification of the analytical method}

\subsubsection{The collapse mechanism}

Fig. 21 presents the deformation configuration of bare and braced reference frames (FS6B6R1 and BS6B6R1) when the vertical displacement at the middlecolumn-loss location reaches $3.0 \mathrm{~m}$. Fig. 22 shows the comparisons between the resistance-displacement relationships for the bare and braced frames. The findings are summarized as follows:

a. A reasonable beam-to-column stiffness ratio ensures that plastic hinges occur at both ends of the steel beams, wherein the catenary action can effectively develop. Little damage is found in the steel columns from upper storeys.

b. The bracing systems provides great lateral restraints to the adjacent columns and those columns remain in elastic even at large deflections. However, for the bare frame, plastic hinges occur in the column ends at both sides due to its symmetric deformation.

c. The displacement-resistance relationships of the two frames can be divided into four stages. The elastic stage and catenary stage $I$ for the curves are identical for bare and braced frames. This further verifies the rationality of the assumption in the analytical method.

d. The bracing systems leads to a damage concentration at the column away from the bracing systems and thus reduce the ultimate bearing capacity of the frame with certain extent. Moreover, the failure displacement at the column-removal location of the braced frame is $36.5 \%$ smaller than that of the bare frame and the ultimate bearing capacity of the braced frame is $5.3 \%$ lower than that of the bare frame.

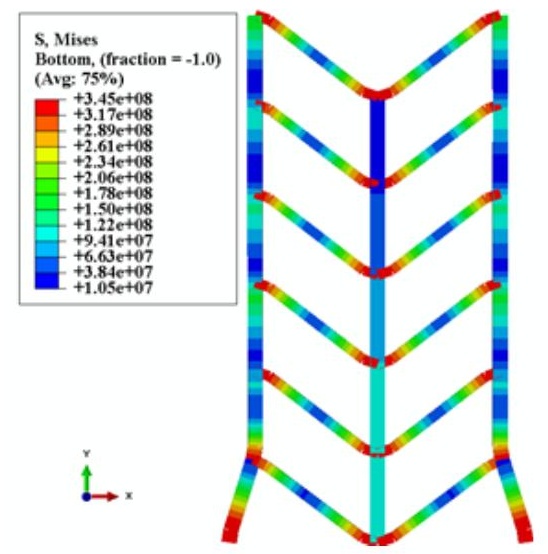

(a) FS6B6R1

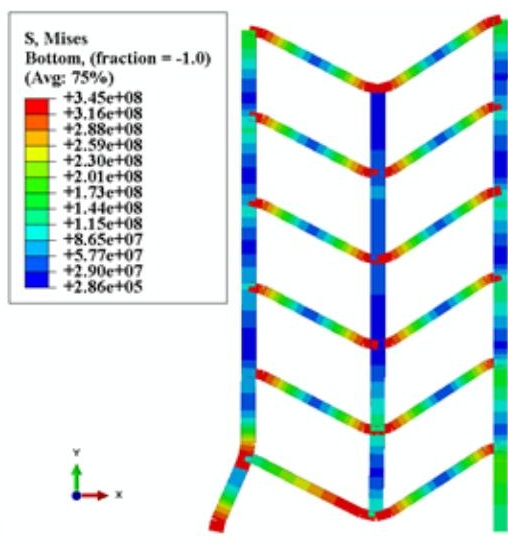

(b) BS6B6R1

Fig. 21 The deformation of bare and braced reference frames due to a middle column loss 


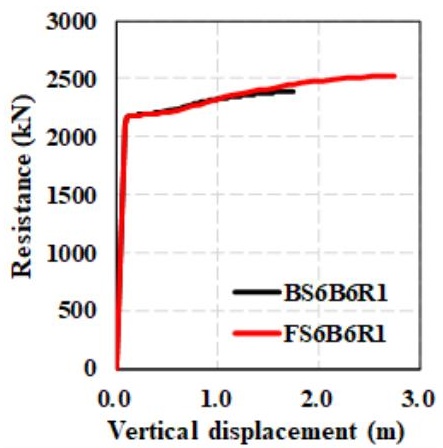

Fig. 22 The displacement-resistance curve comparison

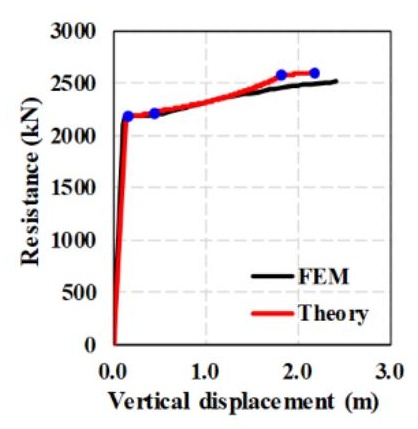

(a) FS6B6R1

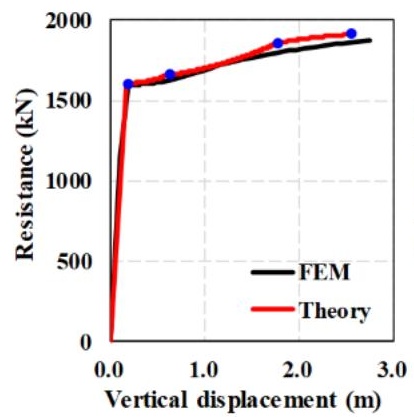

(e) FS6B8R1

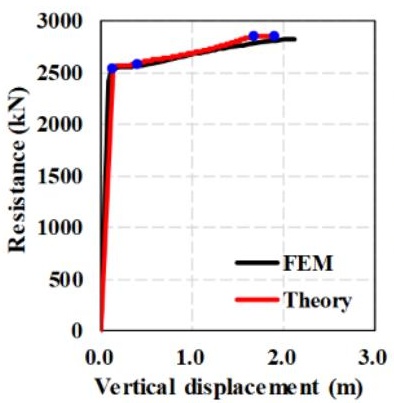

(i) FS8B6R1

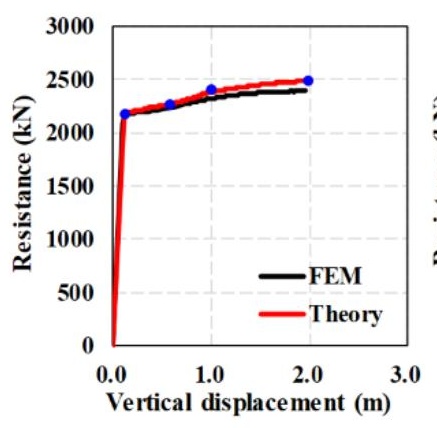

(b) BS6B6R1

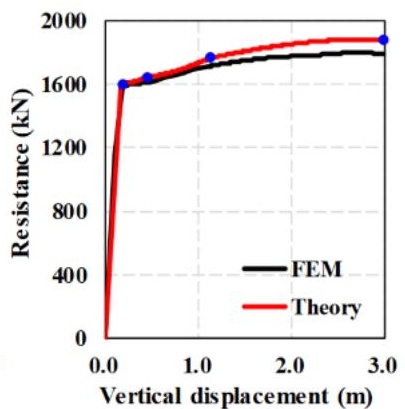

(f) BS6B8R1

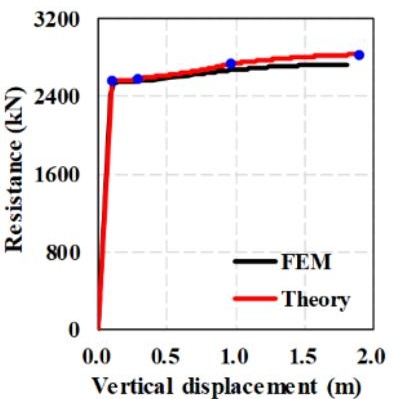

(j) BS8B6R1

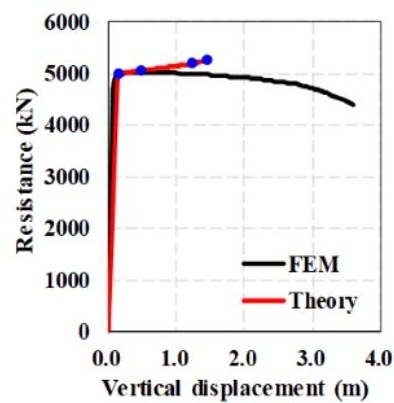

(m) FS6B6R3

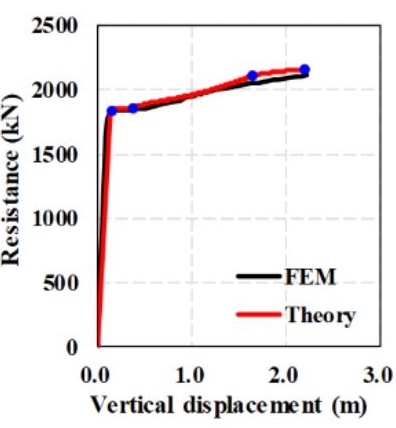

(c) FS6B7R1

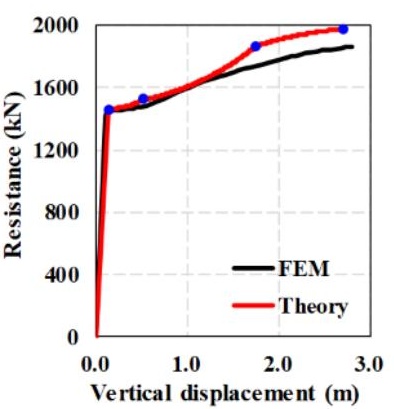

(g) FS4B6R1

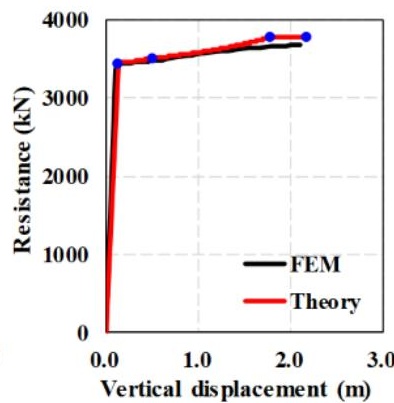

(k) FS6B6R2

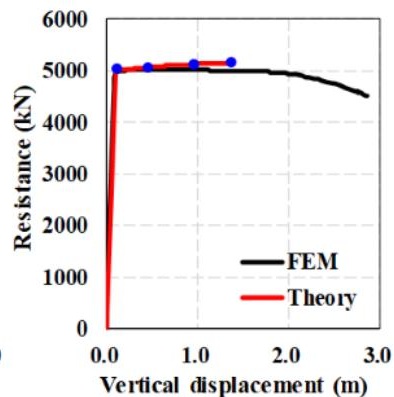

(n) BS6B6R3

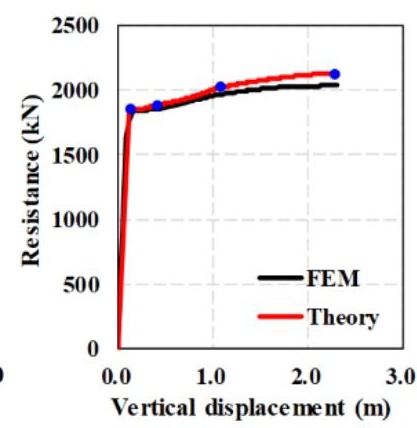

(d) BS6B7R1

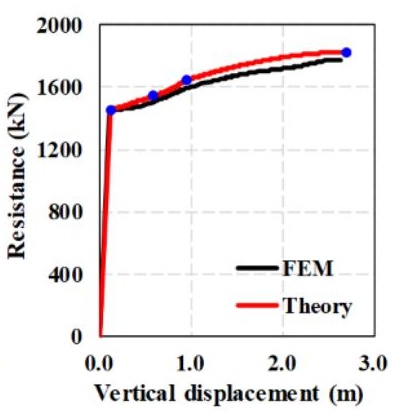

(h) BS4B6R1

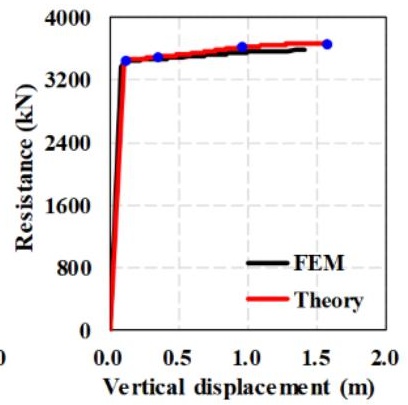

(l) BS6B6R2

Fig. 23 Comparisons on the numerical and analytical resistance-displacement curves of the studied frames 
Table 4

The results of pushdown analysis for the frames with and without bracing system

\begin{tabular}{|c|c|c|c|c|c|c|c|c|}
\hline Case & $F_{y_{-} F E M}(\mathrm{kN})$ & $F_{y_{-} \text {theory }}(\mathrm{kN})$ & $F_{C_{-} F E M}(\mathrm{kN})$ & $F_{c_{-} \text {theory }}(\mathrm{kN})$ & $\Delta_{v_{-} F E M}(\mathrm{~m})$ & $\Delta_{v_{-} \text {theory }}(\mathrm{m})$ & {$\left[F_{c}\right]$} & {$\left[\Delta_{v}\right]$} \\
\hline FS6B6R1 & 2182 & 2185 & 2511 & 2603 & 2.409 & 2.165 & $3.5 \%$ & $-11.3 \%$ \\
\hline FS6B7R1 & 1846 & 1847 & 2111 & 2160 & 2.233 & 2.219 & $2.3 \%$ & $-0.6 \%$ \\
\hline FS6B8R1 & 1605 & 1606 & 1869 & 1911 & 2.738 & 2.535 & $2.2 \%$ & $-8.0 \%$ \\
\hline FS4B6R1 & 1464 & 1465 & 1863 & 1973 & 2.789 & 2.671 & $5.6 \%$ & $-4.4 \%$ \\
\hline FS8B6R1 & 2559 & 2560 & 2827 & 2857 & 2.120 & 1.900 & $1.0 \%$ & $-11.6 \%$ \\
\hline FS6B6R2 & 3461 & 3463 & 3682 & 3789 & 2.097 & 2.160 & $2.8 \%$ & $2.9 \%$ \\
\hline FS6B6R3 & 5014 & 5015 & 5021 & 5244 & 3.600 & 1.432 & $4.3 \%$ & $-151.4 \%$ \\
\hline BS6B6R1 & 2184 & 2194 & 2389 & 2486 & 1.961 & 1.953 & $3.9 \%$ & $-0.4 \%$ \\
\hline BS6B7R1 & 1846 & 1846 & 2041 & 2131 & 2.305 & 2.271 & $4.2 \%$ & $-1.5 \%$ \\
\hline BS6B8R1 & 1605 & 1604 & 1803 & 1882 & 2.977 & 2.986 & $4.2 \%$ & $0.3 \%$ \\
\hline BS4B6R1 & 1464 & 1463 & 1773 & 1825 & 2.616 & 2.661 & $2.9 \%$ & $1.7 \%$ \\
\hline BS8B6R1 & 2559 & 2558 & 2723 & 2831 & 1.807 & 1.876 & $3.8 \%$ & $3.7 \%$ \\
\hline BS6B6R2 & 3461 & 3461 & 3579 & 3677 & 1.411 & 1.562 & $2.7 \%$ & $9.7 \%$ \\
\hline BS6B6R3 & 5014 & 5011 & 5024 & 5147 & 2.872 & 1.355 & $2.4 \%$ & $-112.0 \%$ \\
\hline \multicolumn{9}{|l|}{ Notes: } \\
\hline \multicolumn{9}{|c|}{ (1) $F_{y_{-} F E M}$ represents the numerical yielding capacity of the structures } \\
\hline \multicolumn{9}{|c|}{ (2) $F_{y_{-} \text {theory }}$ represents the analytical yielding capacity of the structures } \\
\hline \multicolumn{9}{|c|}{ (3) $F_{C_{-} F E M}$ represents the numerical ultimate capacity of the structures } \\
\hline \multicolumn{9}{|c|}{ (4) $F_{c_{-} \text {theory }}$ represents the analytical ultimate capacity of the structures } \\
\hline \multicolumn{9}{|c|}{ (5) $\Delta_{V_{-} F E M}$ represents the numerical failure vertical displacement at the column-removal location } \\
\hline \multicolumn{9}{|c|}{ (6) $\Delta_{c_{-} \text {theory }}$ represents theanalytical failure vertical displacement at the column-removal location } \\
\hline \multicolumn{9}{|c|}{ (7) $\left[F_{c}\right]$ represents the relative difference of the ultimate capacity between the numerical and analytical results } \\
\hline (8) $\left[\Delta_{v}\right]$ represe & elative differe & the failure disp & ent between $n$ & and analy & & & & \\
\hline
\end{tabular}

\subsubsection{Verifications of the analytical method}

The comparisons of the numerical and analytical resistance-displacement relationships for the bare and braced frames are shown in Fig. 23. The collapse of the frame is due to the destabilizing of the column at the first storey for Fig. 23(a)- Fig. 23(1). To further quantify the performance of the analytical method, the comparisons of the yielding capacity, ultimate capacity, and ultimate displacement of the frames with and without bracing system are given in Table 4. The findings can be drawn as follows:

a. The four-stage resistance-displacement relationship can capture the main collapse mechanisms during the column-removal process for the bare and braced steel frames. The yielding capacity, the ultimate capacity, the postyielding stiffness and the ultimate displacement of the frame can be reasonably predicted by the analytical method with acceptable errors.

b. For the bare and braced steel frames, the analytical resistance-displacement relationships during the elastic stage and catenary stage $I$ are almost identical with those from the numerical analyses. While the analytical method tends to slightly overestimate the resistance of the frame at catenary stage II and III. This is because the plastic regions are assumed to concentrate at the ends of the beams and columns in the analytical method.
Moreover, the remaining regions of the beams and columns are assumed to be in elastic state.

c. The ultimate capacity of the frames increase when the number of the storey increases. A smaller span and larger section dimension of the beam ensure a higher ultimate capacity of the frame.

d. In Table 4, the ultimate capacity of FS6B6R3 and BS6B6R3 obtained by analytical method are much lower than that obtained by numerical analysis. This is because the section dimension of the beams is relatively great and the plastic hinges firstly develop at the middle of columns, rather than the column ends at the base-storey. Fig. 24 gives the collapse configuration, wherein the final failure mode of the frame is mainly governed by the component buckling, rather than the instability of the columns, which is beyond discussion in this paper.

It should be noted that the collapse resistance of the steel frame is studied based on a static column-removal scenario herein. The dynamic amplification effect is not considered. In real cases, however, the methodology in this manuscript can be easily extended to account for the dynamic amplification effect based on the energy conservation principle [28-30].

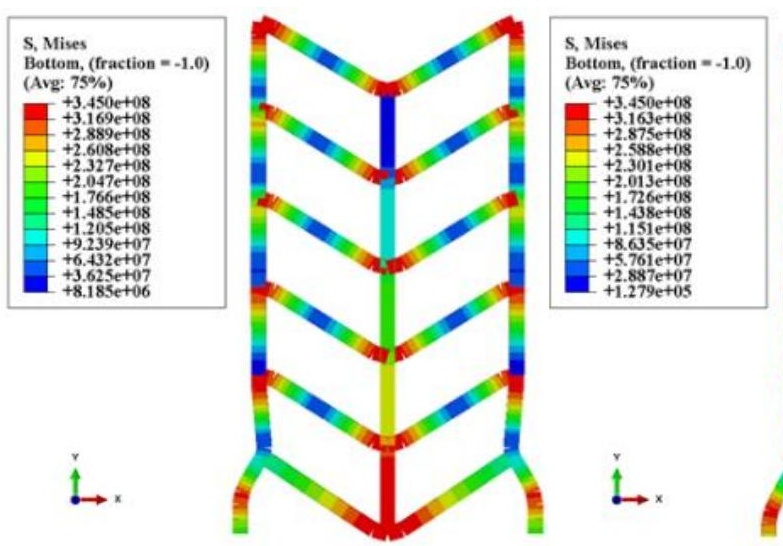

(a) FS6B6R3
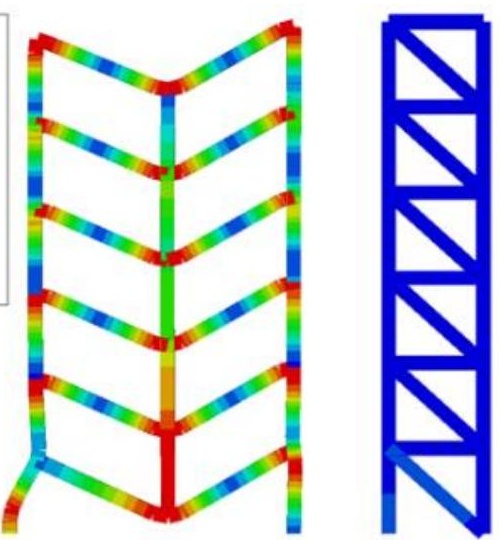

(b) BS6B6R3

Fig. 24 The progressive collapse due to the component buckling of the columns 


\section{Conclusion}

This paper analytically studies the collapse resistance of bare and braced steel frames due to a middle column loss. A four-stage resistance-displacement relationships are proposed for both the bare and braced steel frame during the column-removal process. The accuracy of the analytical method is verified against numerical analyses. The following conclusions can be drawn:

(1) The bracing system enhances the lateral stiffness of the frame with certain extents, however, due to a damage concentration on the columns away from it, it reduces the collapse resistance of the frame at large deflections and leads to smaller failure displacement of the frame due to the loss of stability of the column.

(2) The yielding capacity, ultimate capacity, post-yielding stiffness and ultimate displacement of the frame can be reasonably predicted by the analytical method with acceptable errors.

(3) At large deflections, the catenary action in steel beams enhances the

\section{References}

[1] Office of the Deputy Minister. The building regulations 2000. London (UK), 2004

[2] Pearson C, Delatte N. Ronan point apartment tower collapse and its effect on building codes. Journal of Performance of Constructed Facilities 2005; 19(2): 172-177.

[3] Corley WG, Sr PFM, Sozen MA, Thornton CH. The Oklahoma City Bombing Summary and Recommendations for Multihazard Mitigation. Journal of Performance of Constructed Facilities 1998; 12(3): 100-112.

[4] Bazant ZP, Zhou Y. Why did the World Trade Center collapse? - Simple analysis. Journal of Engineering Mechanics; 128(1): 2-6.

[5] ASCE. Minimum design loads for buildings and other structures. Reston, 2005.

[6] GSA. Progressive collapse analysis and design guidelines for new federal office buildings and major modernization projects. Washington, DC, 2013.

[7] DoD. Unified facilities criteria: design of structures to resist progressive collapse. Washington, DC, 2010.

[8]Li G, Zhang J, Jiang J. Multi-Storey Composite Framed-Structures due to Edge-Column Loss. Advanced Steel Construction 2020; 16(1): 20-29.

[9] Jiang B, Li G, Li L, Izzuddin BA. Experimental Studies on Progressive Collapse Resistance of Steel Moment Frames under Localized Furnace Loading. Journal of Structural Engineering 2018; 144(2): 4017190.

[10] Li HH, Zhang BY, Cai XH. Assessment of Design Requirements Against Progressive Collapse in UFC 4-023-03: Numerical Simulation. Advanced Steel Construction 2018; 14(4): 514-538.

[11] Li G, Li L, Jiang B, Lu Y. Experimental study on progressive collapse resistance of steel frames under a sudden column removal scenario. Journal of Constructional Steel Research 2018; 147: 1-15.

[12] Meng B, Li LD, Zhong WH, Hao JP, Tan Z. Enhancing collapse-resistance of steel frame joints based on folded axillary plates. Advanced Steel Construction 2021; 17(1): 84-94.

[13] Jiang B, Li G, Usmani A. Progressive collapse mechanisms investigation of planar steel moment frames under localized fire. Journal of Constructional Steel Research 2015; 115: 160-168.

[14] Li GQ, Zhang Y, Yang TC, Jiang J, Lu Y, Chen SW. Effect of Blast-Induced Column Failure Pattern on Collapse Behavior of Steel Frames. Advanced Steel Construction 2018; 14(3): 377-391.

[15] Stylianidis PM, Nethercot DA, Izzuddin BA, Elghazouli AY. Robustness assessment of frame structures using simplified beam and grillage models. Engineering Structures 2016; 115: 78-95. resistance of the frame, while the second-order effect of gravity loads impedes the increase of the resistance of the frame. During elastic stage and catenary stage $I$, no obvious difference is observed for the resistance-displacement relationship of the bare and braced frames. The bracing systems mainly influence the resistance of the frame at catenary stages II and III.

(4) The ultimate capacity of the frame mainly depends on the number of storeys, span of the beams and the beam to column stiffness ratio of the frame. A greater number of storeys, shorter span of beams and larger beam to column stiffness ratio generally ensure better performances of the frame against collapse.

\section{Acknowledgements}

The works in this paper was sponsored by the Thirteen-Five Science and Technology Support Program with grant 2016YFC0701203. It is necessary to express the sincere gratitude of the writers to the sponsors.

[16] Jiang BH, Li GQ, Izzuddin BA. Dynamic performance of axially and rotationally restrained steel columns under fire. Journal of Constructional Steel Research 2016; 122: 308-315.

[17] Gao S, Xu M, Guo L, Zhang S. Behavior Of CFST-Column To Steel-Beam Joints in the Scenario of Column Loss. Advanced Steel Construction 2019; 15(1): 47-54.

[18] Jiang J, Li G, Usmani A. Effect of Bracing Systems on Fire-Induced Progressive Collapse of Steel Structures Using OpenSees. Fire Technology 2015; 51(5): 1249-1273.

[19] Tsai M. A performance-based design approach for retrofitting regular building frames with steel braces against sudden column loss. Journal of Constructional Steel Research 2012; 77: $1-11$

[20] Eletrabi H, Marshall JD. Catenary action in steel framed buildings with buckling restrained braces. Journal of Constructional Steel Research 2015; 113: 221-233.

[21] Talebi E, Tahir MM, Zahmatkesh F, Kueh ABH, Said AM. Fire Resistance of a Damaged Building Employing Buckling Restrained Braced System. Advanced Steel Construction 2018; 14(1): $1-21$.

[22] Naji A, Ommetalab MR. Horizontal bracing to enhance progressive collapse resistance of steel moment frames. The Structural Design of Tall and Special Buildings 2019; 28(5): e1563.

[23] Asgarian B, Hashemi Rezvani F. Progressive collapse analysis of concentrically braced frames through EPCA algorithm. Journal of Constructional Steel Research 2012; 70: 127 136.

[24] Li G, Dong Z, Li H. Simplified Collapse-Prevention Evaluation for the Reserve System of Low-Ductility Steel Concentrically Braced Frames. Journal of Structural Engineering 2018 , 144(040180717):

[25] Chen J, Peng W, Ma R, He M. Strengthening of Horizontal Bracing on Progressive Collapse Resistance of Multistory Steel Moment Frame. Journal of Performance of Constructed Facilities 2012; 26(5): 720-724.

[26] Jiang J, Li G. Mitigation of Fire-Induced Progressive Collapse of Steel Framed Structures Using Bracing Systems. Advanced Steel Construction 2019; 15(2): 192-202.

[27] Izzuddin BA. A Simplified Model for Axially Restrained Beams Subject to Extreme Loading. International Journal of Steel Structures 2005; 5(5): 421-429.

[28] Izzuddin BA, Vlassis AG, Elghazouli AY, Nethercot DA. Progressive collapse of multistorey buildings due to sudden column loss -Part I: Simplified assessment framework. Engineering Structures 2008; 30: 1308-1318.

[29] Wang W, Wang JJ, Sun X, Bao Y. Slab effect of composite subassemblies under a column removal scenario. J CONSTR STEEL RES. 2017; 129: 141-155.

[30] Fu QN, Tan KH, Zhou XH, Yang B. Numerical simulations on three-dimensional composite structural systems against progressive collapse. J CONSTR STEEL RES 2017; 135: 125-136. 


\title{
LINE-ELEMENT FORMULATION FOR UPHEAVAL BUCKLING ANALYSIS OF BURIED SUBSEA PIPELINES DUE TO THERMAL EXPANSION
}

\author{
Ji-Hui Ning ${ }^{1}$, Si-Wei Liu ${ }^{2}$, Jian-Hong Wan ${ }^{1}$ and Wei Huang $1,3 *$ \\ 'School of Civil Engineering, Sun Yat-Sen University, Guangzhou, China \\ ${ }^{2}$ Depatment of Civil and Environmental Engineering, The Hong Kong Polytechnic University, Hong Kong, China \\ ${ }^{3}$ Southern Marine Science and Engineering Guangdong Laboratory, Zhuhai, China \\ * (Corresponding author: E-mail: huangw288@mail.sysu.edu.cn)
}

\section{A B S T RA C T}

Subsea pipeline is the critical component in the offshore systems for transporting oil and gas from resource sites to ports Its structural failure will be a disaster of heavily polluting the environment leading to unpredictable losses. The mediums inside subsea pipelines are conventionally heated in service for easier transporting after increasing fluidity, resulting in accumulative thermal expansion of the pipeline to induce thermal expansion, triggering upheaval buckling. It is crucial when designing subsea pipelines but always challenging to evaluate rigorously because of the complexities in such consideration. A pipeline might length for miles, while the numerical analysis model using conventional solid finite elements is huge in computational expense, making the successful analysis very time-consuming. This research innovatively develops a new line element, namely the pipeline element, featuring the explicit considerations of soil-pipe interactions and thermal expansion. This element is numerically efficient by eliminating modeling buried soils. The element derivation procedure is elaborated with details, while a Newton-Raphson typed numerical analysis procedure is proposed for nonlinear analysis of pipelines subjected to thermal expansion. An Updated-Lagrangian description is employed for facilitating large deflections. Three groups of examples are provided to demonstrate the numerical robustness of the proposed method. Finally, a case study is given to identify the vital influential factors to the thermal upheaval buckling of pipelines.
A R T I C LE H IS TORY

$\begin{array}{ll}\text { Received: } & \text { 11 April } 2021 \\ \text { Revised: } & \text { 21 May 2021 } \\ \text { Accepted: } & \text { 21 May 2021 }\end{array}$

\section{K E Y W O R D S}

Line element;

Upheaval buckling;

Subsea pipelines;

Numerical;

Buckling

\section{Introduction}

Subsea pipelines are usually buried by shallow soils to avoid environmental damages in terms of water scouring, corrections and ocean sea creatures attacking etc[1,2]. However, it is more likely to accumulate heats along with the lengthening of the pipeline when it is buried by soils that may cause the cumulative thermal expansion to trigger buckling [3]. This phenomenon is named upheaval buckling [4-6], as illustrated in Fig. 1, which is critical for designing subsea buried pipelines. Nevertheless, such design consideration is sometimes difficult because it is significantly affected by several crucial factors, including the initial out-of-plumpness of pipelines, the depth of buried soils, and the tightness of seabed etc., leading to the rigorous analysis of upheaval buckling difficult. This topic has gained continuous attentions and studied by several researchers for a decade [7-11], which is still popular up to date.

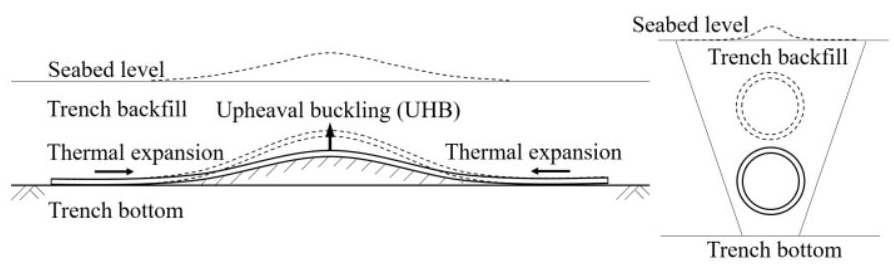

Fig. 1 Upheaval buckling of a buried pipeline by the cumulative thermal expansion

Experiments on studying subsea buried pipeline buckling have been initiated in the mid-1990s. For example, Maltby and Calladin [12,13] constructed a small-sized model for investigating upheaval buckling of buried pipelines and proposed a refined Gurson-Tvergaard-Needleman (GTN) model for theoretical analysis. Slightly later, Taylor and Tran [14] investigated the isolated prop and contact undulation imperfection topologies for determining their influences on in-service buckling of buried pipelines. Armaghani et al. [15] studied the buckling of pipelines affected by the soil reinforcement on resisting the uplift of buried pipelines. Schaminee [16] carried out full-size physical tests on buried pipelines to reveal the mechanisms of pipeline upheaval buckling. Karampour and Albermani [17] examined the propagation buckling, pure bending and buckle interaction in subsea buried pipelines. Recently, Vazouras et al. [18] executed a parametric physical test on studying the influential factors that affect buckling of sea pipelines in service. Through these experimental investigations, the dominant factors affecting upheaval buckling of buried pipelines due to thermal expansion are identified: embedment depths, pipeline geometries, and relative densities and stiffnesses of buried soils.

Besides conducting physical tests using the scaled-down models, several simplified computational methods are proposed based on the idealized assumptions. Hobbs [19] adopted an elastic Euler-Bernoulli beam to study lateral and upheaval buckling due to environmental temperature change and the tube pressure and provided an analytical solution. Shortly after, Taylor and Gan [20] proposed a calculation method to study the upheaval buckling behavior of submarine pipelines with structural imperfections and deformation-dependent axial friction resistance, providing more rational predictions than the previous mathematical methods using idealized pipelines. Ju and Kyriakides [21] investigated the upheaval buckling due to thermal expansion by including a rigid foundation with small, initial geometric imperfections through their derived formulations. Ballet and Hobbs [22] conducted studies for the asymmetric buckling of pipelines due to thermal expansion by solving the partial differential equations. Recently, by establishing mathematical models, Wang et al. [23] studied the upheaval buckling behavior of submarine pipelines with a free span. These methods are based on empirical assumptions with certain limitations for practical use, leading to the design of pipelines usually over-conservative.

Although the pipeline's structural form is simple, the accurate analysis for its upheaval buckling is usually complicated. The full length of a pipeline is difficult to be included in the analysis model to reflect the cumulative thermal expansion. Thereby, some semi-empirical design methods have been proposed, such as Palmer et al. [24] and Friedmann and Debouvry [25], to simplify the analysis problems, where the buckling length is empirically defined via the experimental tests. This design method has been extensively used up to date, but it is sometimes difficult to be executed since the buckling length is hard to be assumed accurately. Therefore, the advanced Finite-Element Analysis (FEA) method using sophisticated shell and solid elements [26-28] is employed to tackle such an analysis problem of accurately identifying the upheaval buckling of pipelines to thermal expansion.

FEA method using shell and solid elements is generally considered one of the most accurate approaches to analyze upheaval buckling of buried subsea pipelines. Pipeline and its surrounding soils are modeled by fine-meshed solid and shell elements, as shown in Fig. 2 (a). Several researchers have used this method to study upheaval buckling of buried subsea pipelines. For example, Klever et al. [29] proposed dedicated FE models for analyzing the upheaval buckling response of submarine pipelines. Zhang et al. [30] studied the upheaval buckling behaviors of pipeline segments with different Out-of-Straight (OOS) and different imperfection shapes. Robert and Thusyanthan [31] introduced a well-constructed FE model for investigating the uplift mobilization of buried pipelines in sands. Xu and Lin [32] established a sophisticated solid element model for exploring the initial stress influences on the upheaval buckling. Chen et al. [33] constructed a FE model to study the thermal upheaval buckling of pipelines considering topographic step imperfections. Liang et al. [34] employed the FEA method to study the upheaval behavior of surface-laid subsea pipelines on a sunken seabed. Their studies indicate the difficulties when using 
the FEA method for practical design because the enormous computational expense makes the FEA methods mainly limited to research applications. Moreover, the number of cases is usually enormous considering the complicated combination of environmental loads in the engineering application, which is similar as the mooring design (Stanisic et al. [35]). Therefore, it brings an urgent need to develop an efficient FEA method applicable to design large scale pipeline systems in offshore engineering.
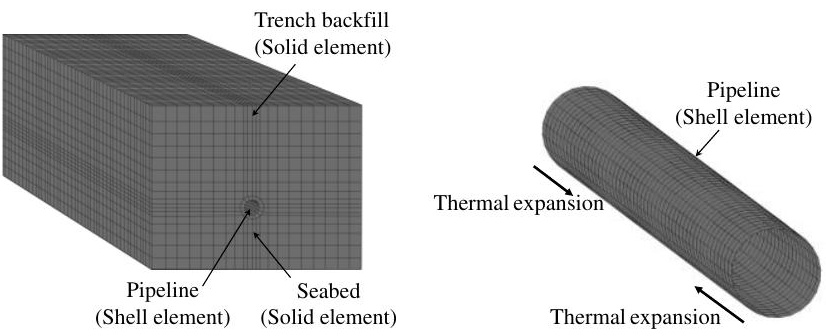

(a) Solid and shell elements modeling method

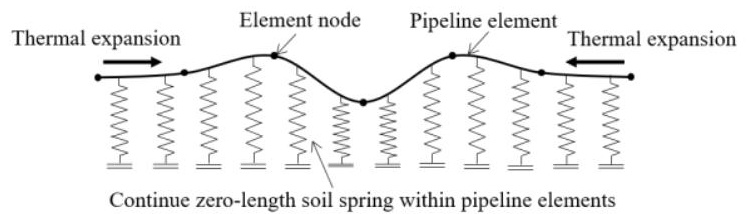

(b) Proposed pipeline element modeling method

Fig. 2 Two different finite element modeling methods

Against the background, this research derives a pipeline element (see Fig. 2 (b)), featuring by the explicit consideration of soil-pipe interactions and considering thermal expansion at the evaluated temperatures, which is numerically efficient by eliminating sophisticatedly modeling buried soils and pipe sections. The element derivation procedure is elaborated with details, while a NewtonRaphson typed analysis procedure is proposed for nonlinear simulation of a pipeline subjected to thermal expansion. An Updated-Lagrangian description is employed for determining the equilibrium conditions according to the last known status for facilitating large deflections. Three groups of examples are presented for demonstrating the analysis accuracy and robustness of the proposed method. Finally, case studies are given to examine the influential factors that affect the upheaval buckling of pipelines.

\section{Assumptions and definitions}

Based on the Euler-Bernoulli assumption, a pipeline element is derived by considering soil stiffness and thermal expansions. The following assumptions are made in the present study, which should not certainly be limited to its practical application. These assumptions are given by: (1) conservative loads are assumed; (2) strain is small, but the deflection can be arbitrarily large using the Updated-Lagrangian (UL) description; (3) surrounding soils are represented by the Winkler-typed springs without the interactions among soil springs; (4) thermal expansion is considered accumulatively; (5) the equilibrium conditions are determined based on the deformed shape; and (6) planar analysis is executed for considering buckling at one-direction, while the spatial analysis method will be presented in the coming research.

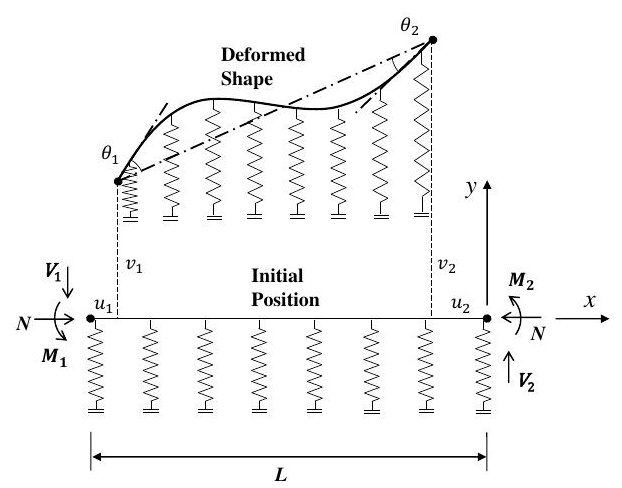

Fig. 3 Forces and degree of freedoms within a pipeline element

\section{Line element formulation}

Line element formulation is efficient in numerical analysis by condensing a three-dimensional entity into a one-dimensional model that reflects the structural behaviors along the member length. Conventional line element only simulates structural member that needs to be improved for properly analyzing a subsea buried pipeline, where the soil stiffness and thermal expansions are to be considered. This paper adopts the Euler-Bernoulli assumption and formulates a new line element, namely the pipeline element, for representing the structural properties of a subsea buried pipeline by integrating the continuous soil springs along the member length in the element formulations, as illustrated in Fig. 3. The corresponding element formulations are derived with details and presented in this section.

\subsection{Element forces and deformations}

The pipeline element's axial and lateral deformations along the element length can be described by the following interpolating polynomials,

$$
\left\{\begin{array}{l}
u(x) \\
v(x)
\end{array}\right\}=\left[\begin{array}{cccccc}
\delta_{1} & 0 & 0 & \delta_{2} & 0 & 0 \\
0 & \delta_{3} & \delta_{4} & 0 & \delta_{5} & \delta_{6}
\end{array}\right]\left\{\begin{array}{llllll}
u_{1} & v_{1} & \theta_{1} & u_{2} & v_{2} & \left.\theta_{2}\right\}^{T}
\end{array}\right.
$$

in which, $u(x)$ and $v(x)$ denote the displacements along the element's $x$ - and $y$ - axes, respectively; $u_{1}$ and $u_{2}$ represent the nodal translations along the $x$-axis $v_{1}$ and $v_{2}$ describe the nodal movements along the $y$-axis; $\theta_{1}$ and $\theta_{2}$ are nodal rotations at the element ends; and the coefficients $\delta_{1}$ to $\delta_{6}$ are expressed as,

$\delta_{1}=1-\frac{x}{L}$

$\delta_{2}=\frac{x}{L}$

$\delta_{3}=1-\left(\frac{x}{L}\right)^{2}+2\left(\frac{x}{L}\right)^{3}$

$\delta_{4}=x-\frac{2 x^{2}}{L}+\frac{x^{3}}{L^{2}}$

$\delta_{5}=3\left(\frac{x}{L}\right)^{2}-2\left(\frac{x}{L}\right)^{3}$

$\delta_{6}=-\frac{x^{2}}{L}+\frac{x^{3}}{L^{2}}$

in which, $L$ represents the length of an element and $x$ is the coordinate in the $x$ axis.

The strain tensors can be expressed according to the Green-Lagrangian strain description, and given as,

$\varepsilon_{x}=\varepsilon_{x}^{L}+\varepsilon_{x}^{N}+\varepsilon_{t h}=\frac{\partial u(x)}{\partial x}-y \frac{\partial^{2} v(x)}{\partial x^{2}}+\frac{1}{2}\left(\frac{\partial v(x)}{\partial x}\right)^{2}+\alpha \Delta t$

$\varepsilon_{x y}=\varepsilon_{x y}^{N}=-\frac{1}{2} \frac{\partial u(x)}{\partial x} \frac{\partial v(x)}{\partial x}+\frac{y}{2} \frac{\partial^{2} v(x)}{\partial x^{2}} \frac{\partial v(x)}{\partial x}$

in which, the superscripts $L$ and $N$ are representing the linear and nonlinear portions, respectively; $\varepsilon_{x}$ is the normal strain; and $\varepsilon_{x y}$ is the shear strain in the $x-y$ plane. $\alpha$ denotes the thermal expansion coefficient; while, $\Delta t$ is the temperature difference.

The following relation is expressed by introducing Hooke's material law and given by,

$\sigma_{x}=E \varepsilon_{x}$ 
in which $E$ is the Young's modulus.

Besides the nodal forces and moments, the stresses on the cross-section along the element length, i.e. $\sigma_{x}$ and $\tau_{x y}$, can be expressed as,

$\sigma_{x}=\frac{N}{A}+\left[M_{1}\left(1-\frac{x}{L}\right)-M_{2} \frac{x}{L}\right] \frac{y}{I}+E \alpha \Delta t$

$\tau_{x y}=\frac{V}{A}=\frac{M_{1}+M_{2}}{A L}$

where, $N$ denotes the axial load; $M_{1}$ and $M_{2}$ describe the bending moments at the left and the right ends, respectively; $I$ is the moment of inertia; and, $A$ is the cross-section area.

\subsection{Formulation of total potential energy}

The total potential energy is formulated and written by,

$\Pi=U_{E}+U_{S}+U_{T}-W$

in which, $\Pi$ denotes the total potential energy; $U_{E}$ is the element strain energy; $U_{S}$ is the energy induced by surrounding soil; $U_{T}$ is the energy due to thermal expansion; and $W$ is the work conducted by the external loads.

The element strain energy is calculated by the formulation below,

$U_{E} \approx \frac{1}{2} \int_{V}\left(E\left(\varepsilon_{x}^{L}\right)^{2}+2 \sigma_{x} \varepsilon_{x}^{N}+\tau_{x y} \varepsilon_{x y}^{N}\right) d v$

$=\frac{1}{2} \int_{0}^{L} E A\left(\frac{\partial u(x)}{\partial x}\right)^{2}+E I\left(\frac{\partial^{2} v(x)}{\partial x^{2}}\right)^{2} d x+\frac{1}{2} \int_{0}^{L} P\left(\frac{\partial v(x)}{\partial x}\right)^{2} d x$

$-\int_{0}^{L} \frac{V}{A}\left(\frac{\partial u(x)}{\partial x} \frac{\partial v(x)}{\partial x}\right) d x$

The energy taken by the surrounding soils can be computed by,

$U_{S}=\int_{0}^{L} \int_{0}^{v} P(v) d v d x=\int_{0}^{L} \int_{0}^{v} \int_{0}^{v} k(v) d v d v d x=\frac{1}{2} \int_{0}^{L} k(v) v^{2} d x$

in which $P(v)$ is the soil resisting force by referring to the specified vertical deflection (Fig. 4); $v$ is the vertical deflection; $k(v)$ is the tangential value on the soil-pipeline interaction curve by referring to specified vertical deflection.

As shown in Fig. 4, the soil-pipeline interaction curve is highly nonlinear and difficult to be described by an analytical expression. Therefore, the GaussLegendre method is used in this paper to calculate the energy absorbed by the soil, and its analytical expression is as follow,

$U_{S}=\frac{1}{2} \int_{0}^{L} k(v) v^{2} d x \approx \frac{1}{2} \sum_{i=1}^{n} A_{i} k\left(v_{i}\right) v_{i}^{2}$

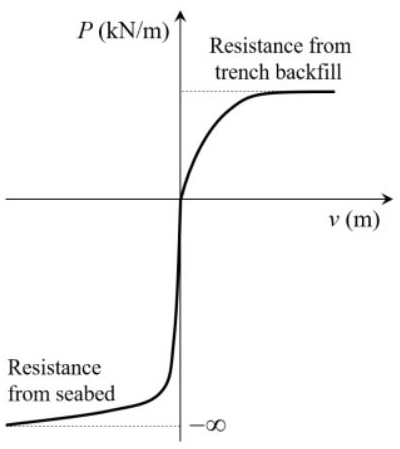

Fig. 4 Soil-pipeline interaction curve

where $A_{i}$ is the weight factors of the $i^{\text {th }}$ Gaussian point; $v_{i}$ is the vertical displacement of the $i^{\text {th }}$ Gaussian point; $n$ represents the number of Gaussian points, which is taken as 4 in this paper.

Thermal energy, also referred to as internal energy of subsea pipeline, is given by:
$U_{T}=\int_{V} E \varepsilon_{t h} \alpha \Delta t d v$

The work conducted by the external forces is given as follow,

$W=\sum_{i=1}^{6} F_{i} u_{i}$

where $u_{i}$ is the $i^{\text {th }}$ degree of freedom; and $F_{i}$ is the $i^{\text {th }}$ corresponding nodal force.

According to the minimum potential energy principal, the following equation can be obtained,

$\delta \prod=\frac{\partial \prod}{\partial u_{i}}+\frac{\partial \prod}{\partial F_{i}} \frac{\partial F_{i}}{\partial u_{i}}=0$

To eliminate the errors accumulated in the incremental-iterative numerical procedure, the secant relations, obtained by the minimum potential energy method, are used for computing element resisting forces.

\subsection{Secant relations}

The secant relations can be derived to calculate the resisting forces resulting from both subsea pipeline and its surrounding soils to predict the equilibrium conditions in the numerical procedure. The resisting forces are given by the following equations,

$\{R\}=\left\{R^{E}\right\}+\left\{R^{S}\right\}$

where

$\left\{R^{E}\right\}=\left\{\begin{array}{llllll}F_{x 1} & V_{1}^{E} & M_{1}^{E} & F_{x 2} & V_{2}^{E} & M_{2}^{E}\end{array}\right\}$

$\left\{R^{S}\right\}=\left\{\begin{array}{llllll}0 & V_{1}^{S} & M_{1}^{S} & 0 & V_{2}^{S} & M_{2}^{S}\end{array}\right\}$

in which, $F_{x 1}$ and $F_{x 2}$ are the axial resisting forces at the element ends; $M_{1}^{E}$ and $M_{2}^{E}$ denote the bending resistances from the element; $M_{1}^{S}$ and $M_{2}^{S}$ are the bending resistances resulting from the external soil pressures at the element ends; $V_{1}^{E}$ and $V_{2}^{E}$ are the shear force resistances from the elements' ends; $V_{1}^{S}$ and and $V_{2}^{S}$ are the external shear force resistances from the soils.

The element forces are calculated by the first variation of the total potential energy given as,

$F_{x 1}=\frac{E A}{L}\left(u_{1}-u_{2}\right)+\frac{\left(M_{1}^{E}+M_{2}^{E}\right)}{L^{2}}\left(-v_{1}+v_{2}\right)$

$F_{x 2}=\frac{E A}{L}\left(-u_{1}+u_{2}\right)+\frac{\left(M_{1}^{E}+M_{2}^{E}\right)}{L^{2}}\left(v_{1}-v_{2}\right)$

$M_{1}^{E}=\frac{6 E I}{L^{2}}\left(v_{1}-v_{2}\right)+\frac{2 E I}{L}\left(2 \theta_{1}+\theta_{2}\right)+\frac{N}{10}\left(v_{1}-v_{2}\right)+\frac{L N}{30}\left(4 \theta_{1}-\theta_{2}\right)$

$M_{2}^{E}=\frac{6 E I}{L^{2}}\left(v_{1}-v_{2}\right)+\frac{2 E I}{L}\left(\theta_{1}+2 \theta_{2}\right)+\frac{N}{10}\left(v_{1}-v_{2}\right)+\frac{L N}{30}\left(-\theta_{1}+4 \theta_{2}\right)$

$V_{1}^{E}=\frac{\left(M_{1}^{E}+M_{2}^{E}\right)}{L^{2}}\left(-u_{1}+u_{2}\right)+\frac{12 E I}{L^{3}}\left(v_{1}-v_{2}\right)+\frac{6 E I}{L^{2}}\left(\theta_{1}+\theta_{2}\right)$

$+\frac{6 N}{5 L}\left(v_{1}-v_{2}\right)+\frac{N}{10}\left(\theta_{1}-\theta_{2}\right)$ 
$V_{2}^{E}=\frac{\left(M_{1}^{E}+M_{2}^{E}\right)}{L^{2}}\left(u_{1}-u_{2}\right)+\frac{12 E I}{L^{3}}\left(-v_{1}+v_{2}\right)+\frac{6 E I}{L^{2}}\left(-\theta_{1}-\theta_{2}\right)$

$+\frac{6 N}{5 L}\left(-v_{1}+v_{2}\right)+\frac{N}{10}\left(-\theta_{1}-\theta_{2}\right)$

The axial force $N$ can be calculated by including the thermal expansion force as,

$N=-\frac{1}{2}\left(F_{x 1}-F_{x 2}\right)+E A \alpha \Delta t$

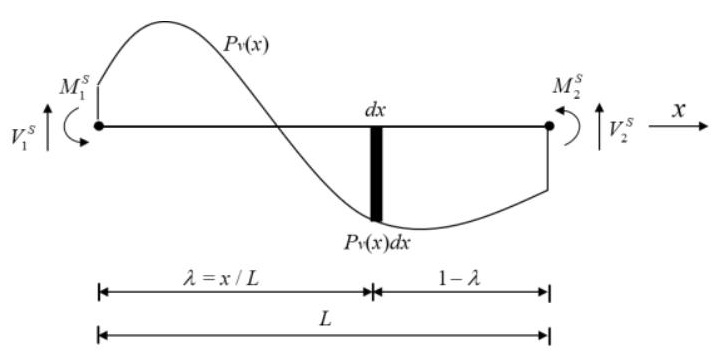

Fig. 5 Element end forces caused by surrounding soil

Fig. 5 shows the bending moments and shear forces at the end of the element induced by the surrounding soil, which can be expressed as follows,

$$
\begin{aligned}
M_{1}^{S} & =\int_{0}^{L} x\left(1-\frac{x}{L}\right)^{2} P_{v}(x) d x \\
& =\int_{0}^{1} \lambda(1-\lambda)^{2} P_{v}(\lambda L) L^{2} d \lambda \approx L^{2} \sum_{i=1}^{4} \alpha_{i} P_{v}\left(x_{i}\right)
\end{aligned}
$$

$$
\begin{aligned}
M_{2}^{S} & =-\int_{0}^{L} \frac{x^{2}}{L^{2}}(L-x) P_{v}(x) d x \\
& =-\int_{0}^{1} \lambda^{2}(1-\lambda) P_{v}(\lambda L) L^{2} d \lambda \approx-L^{2} \sum_{i=1}^{4} \beta_{i} P_{v}\left(x_{i}\right) \\
V_{1}^{S} & =\int_{0}^{L}\left(\frac{3 x}{L}+\frac{L-x}{L}\right)\left(1-\frac{x}{L}\right)^{2} P_{v}(x) d x \\
& =\int_{0}^{1}(2 \lambda+1)(1-\lambda)^{2} P_{v}(\lambda L) L d \lambda \approx L \sum_{i=1}^{4} \chi_{i} P_{v}\left(x_{i}\right)
\end{aligned}
$$

$$
\begin{aligned}
V_{2}^{S} & =-\int_{0}^{L}\left(\frac{x}{L}+\frac{3(L-x)}{L}\right)\left(\frac{x}{L}\right)^{2} P_{v}(x) d x \\
& =-\int_{0}^{1}(3-2 \lambda) \lambda^{2} P_{v}(\lambda L) L d \lambda \approx-L \sum_{i=1}^{4} \gamma_{i} P_{v}\left(x_{i}\right)
\end{aligned}
$$

where the four coefficients $\alpha_{i}, \beta_{i}, \chi_{i}$, and $\gamma_{i}$ are given in Table 1 .

\subsection{Tangent stiffness matrices}

The element stiffness matrices are formulated by the second variation of the total potential equation to predict the incremental nodal deformations, which are given by,

$\delta^{2} \Pi=\frac{\partial^{2} \prod_{i}}{\partial u_{i} \partial u_{j}} \delta u_{i} \delta u_{j}$

The element stiffness matrix $\left[k_{E}\right]$ can be re-written into four parts as,

$$
\left[k_{E}\right]=\left[k_{L}\right]+\left[k_{G}\right]+\left[k_{s}\right]+\left[k_{r_{n}}\right]
$$

where $\left[k_{L}\right]$ is the linear stiffness part; $\left[k_{G}\right]$ is the geometric stiffness part; $\left[k_{s}\right]$ is the soil stiffness matrix; and, $\left[k_{T h}\right]$ is the thermal expansion matrix.
The linear and geometric stiffness matrices can be written as,

$$
\begin{aligned}
& {\left[k_{L}\right]=\left[\begin{array}{cccccc}
\frac{E A}{L} & 0 & 0 & -\frac{E A}{L} & 0 & 0 \\
& \frac{12 E I}{L^{3}} & \frac{6 E I}{L^{2}} & 0 & -\frac{12 E I}{L^{3}} & \frac{6 E I}{L^{2}} \\
& & \frac{4 E I}{L} & 0 & -\frac{6 E I}{L^{2}} & \frac{2 E I}{L} \\
S . & & & \frac{E A}{L} & 0 & 0 \\
& Y . & & & \frac{12 E I}{L^{3}} & -\frac{6 E I}{L^{2}} \\
& & & & & \frac{4 E I}{L}
\end{array}\right]} \\
& {\left[k_{G}\right]=\left[\begin{array}{cccccc}
\frac{N}{L} & -\frac{M_{1}+M_{2}}{L^{2}} & 0 & -\frac{N}{L} & \frac{M_{1}+M_{2}}{L^{2}} & 0 \\
& \frac{6 N}{5 L} & \frac{N}{10} & \frac{M_{1}+M_{2}}{L^{2}} & -\frac{6 N}{5 L} & \frac{N}{10} \\
& & \frac{2 L N}{15} & 0 & -\frac{N}{10} & -\frac{L N}{30} \\
S . & & & \frac{N}{L} & -\frac{M_{1}+M_{2}}{L^{2}} & 0 \\
& Y . & & & \frac{6 N}{5 L} & -\frac{N}{10} \\
& M . & & & \frac{2 L N}{15}
\end{array}\right]}
\end{aligned}
$$

The soil stiffness matrix is given by,

$$
\left[k_{S}\right]=\left[\begin{array}{cccccc}
0 & 0 & 0 & 0 & 0 & 0 \\
& \sum_{i=1}^{4} \mu_{i i} k_{v i} L & \sum_{i=1}^{4} \mu_{2 i} k_{v i} L^{2} & 0 & \sum_{i=1}^{4} \mu_{3 i} k_{v i} L & \sum_{i=1}^{4} \mu_{4 i} k_{v i} L^{2} \\
& & \sum_{i=1}^{4} \mu_{5 i} k_{v i} L^{3} & 0 & \sum_{i=1}^{4} \mu_{6 i} k_{v i} L^{2} & \sum_{i=1}^{4} \mu_{7 i} k_{v i} L^{3} \\
S . & & & 0 & 0 & 0 \\
& Y . & & & \sum_{i=1}^{4} \mu_{8 i} k_{v i} L & \sum_{i=1}^{4} \mu_{9 i} k_{v i} L^{2} \\
& & & & & \sum_{i=1}^{4} \mu_{10 i} k_{v i} L^{3}
\end{array}\right]
$$

where the coefficients $\mu_{1 i}$ to $\mu_{10 i}$ are given in Table 2 .

The thermal matrix can be written as,

$$
\left[k_{T h}\right]=\left[\begin{array}{cccccc}
\frac{E A \alpha \Delta t}{L} & 0 & 0 & -\frac{E A \alpha \Delta t}{L} & 0 & 0 \\
& \frac{6 E A \alpha \Delta t}{5 L} & \frac{E A \alpha \Delta t}{10} & 0 & -\frac{6 E A \alpha \Delta t}{5 L} & \frac{E A \alpha \Delta t}{10} \\
& & \frac{2 E A L \alpha \Delta t}{15} & 0 & -\frac{E A \alpha \Delta t}{10} & -\frac{E A L \alpha \Delta t}{30} \\
S . & & & 0 & 0 & 0 \\
& Y . & & & \frac{6 E A \alpha \Delta t}{5 L} & -\frac{E A \alpha \Delta t}{10} \\
& & M . & & & \frac{2 E A L \alpha \Delta t}{15}
\end{array}\right]
$$

\section{Updated-lagrangian method}

\subsection{Transformation matrices}

Since the subsea buried pipelines could exhibit large deformations under the ultimate limit state, especially for simulating the upheaval buckling, the 
equilibrium condition through the Updated Lagrangian (UL) description is established and illustrated in Fig. 6.

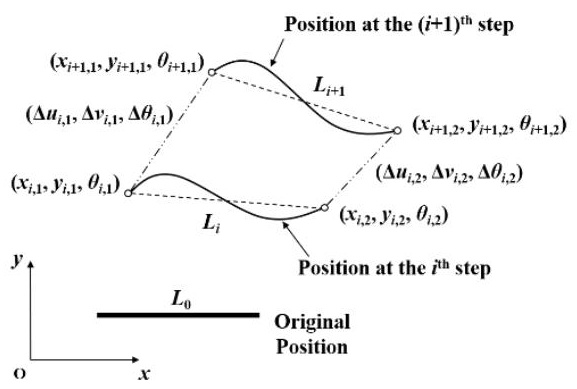

Fig. 6 Updated-Lagrangian (UL) method for large deflections

Table 1

Coefficients $\alpha_{i}, \beta_{i}, \chi_{i}$, and $\gamma_{i}$ in the secant relations

\begin{tabular}{ccccc}
\hline & \multicolumn{4}{c}{ Gaussian point ID } \\
\cline { 2 - 5 } Location $x / L$ & 1 & 2 & 3 & 4 \\
\cline { 2 - 5 } & 0.06943 & 0.33001 & 0.66999 & 0.93057 \\
\hline$\alpha$ & 0.01046 & 0.04830 & 0.02379 & 0.00078 \\
$\beta$ & 0.00078 & 0.02379 & 0.04830 & 0.01046 \\
$\chi$ & 0.17153 & 0.24298 & 0.08310 & 0.00240 \\
$\gamma$ & 0.00240 & 0.08310 & 0.24298 & 0.17153 \\
\hline
\end{tabular}

Table 2

Coefficients $\mu_{1 i}$ to $\mu_{10 i}$ in the soil stiffness [ks]

\begin{tabular}{ccccc}
\hline & \multicolumn{4}{c}{ Gaussian point ID } \\
\cline { 2 - 5 } Location $x / L$ & 1 & 2 & 3 & 4 \\
\cline { 2 - 5 } & 0.06943 & 0.33001 & 0.66999 & 0.93057 \\
\hline$\mu_{1}$ & 0.16916 & 0.18106 & 0.02118 & 0.00003 \\
$\mu_{2}$ & 0.01031 & 0.03599 & 0.00606 & 0.00001 \\
$\mu_{3}$ & 0.00237 & 0.06192 & 0.06192 & 0.00237 \\
$\mu_{4}$ & -0.00077 & -0.01773 & -0.01231 & -0.00014 \\
$\mu_{5}$ & 0.00063 & 0.00716 & 0.00174 & 0.00000 \\
$\mu_{6}$ & 0.00014 & 0.01231 & 0.01773 & 0.00077 \\
$\mu_{7}$ & -0.00005 & -0.00352 & -0.00352 & -0.00005 \\
$\mu_{8}$ & 0.00003 & 0.02118 & 0.18106 & 0.16916 \\
$\mu_{9}$ & -0.00001 & -0.00606 & -0.03599 & -0.01031 \\
$\mu_{10}$ & 0.00000 & 0.00174 & 0.00716 & 0.00063 \\
\hline
\end{tabular}

The Updated-Lagrangian (UL) method is achieved by updating the transformation relations between the local and global coordinate system with the latest configuration. The transformation matrix $[L]_{i}$ is written as,

$$
[L]_{i}=[L]_{i-1}[\Delta L]_{i}
$$

The transformation matrix $[L]_{0}$ is determined by,

$$
[L]_{0}=\left[\begin{array}{ll}
{\left[L^{\prime}\right]_{0}} & \\
& {\left[L^{\prime}\right]_{0}}
\end{array}\right]
$$

in which

$$
\left[L^{\prime}\right]_{0}=\left[\begin{array}{ccc}
\frac{x_{0,2}-x_{0,1}}{L_{0}} & -\frac{y_{0,2}-y_{0,1}}{L_{0}} & 0 \\
\frac{y_{0,2}-y_{0,1}}{L_{0}} & \frac{x_{0,2}-x_{0,1}}{L_{0}} & 0 \\
0 & 0 & 1
\end{array}\right]
$$

$L_{0}=\sqrt{\left(x_{0,2}-x_{0,1}\right)^{2}+\left(y_{0,2}-y_{0,1}\right)^{2}}$

where the first subscript 0 denotes the original position; and, the second subscripts 1 and 2 represent the element nodes.

The updated transformation matrix $\Delta[L]_{i}$ is updated by,

$[\Delta L]_{i}=\left[\begin{array}{ll}{\left[\Delta L^{\prime}\right]_{i}} & \\ & {\left[\Delta L^{\prime}\right]_{i}}\end{array}\right]$

where

$$
\begin{aligned}
& {\left[\Delta L^{\prime}\right]_{i}=\left[\begin{array}{ccc}
\sqrt{1-\left(\frac{\Delta v_{i, 2}-\Delta v_{i, 1}}{L_{i}}\right)^{2}} & -\frac{\Delta v_{i, 2}-\Delta v_{i, 1}}{L_{i}} & 0 \\
\frac{\Delta v_{i, 2}-\Delta v_{i, 1}}{L_{i}} & \sqrt{1-\left(\frac{\Delta v_{i, 2}-\Delta v_{i, 1}}{L_{i}}\right)^{2}} & 0 \\
0 & 1 \\
0 & \\
L_{i}=\sqrt{\left(L_{i-1}+\Delta u_{i, 2}-\Delta u_{i, 1}\right)^{2}+\left(\Delta v_{i, 2}-\Delta v_{i, 1}\right)^{2}}
\end{array}\right]}
\end{aligned}
$$

in which $\Delta u_{i, 1}$ and $\Delta u_{i, 2}$ are the incremental nodal axial deformation; and, $\Delta v_{i, 1}$ and $\Delta v_{i, 2}$ are the incremental nodal vertical displacements.

\subsection{Formulation of the global tangent stiffness matrix}

After obtaining the element stiffness matrix, the global stiffness matrix is assembled by summing up the element stiffness matrix given as,

$$
[K]=\sum_{i=1}^{N E L E}\left([L]_{i}\left(\left[k_{L}\right]+\left[k_{G}\right]+\left[k_{S}\right]+\left[k_{T h}\right]\right)[L]_{i}^{T}\right)
$$

where $[K]$ denote the global tangent stiffness matrix; while $N E L E$ is the element number.

\subsection{Newton-Raphson typed numerical procedure}

A Newton-Raphson method, using the incremental-iterative solution procedure, is adopted by updating the tangent stiffness matrix during the iteration. The incremental nodal displacements can be calculated as,

$$
\{\Delta U\}=\{\Delta F\}[K]^{-1}
$$

in which, $\{\Delta U\}$ denote the incremental nodal displacements; while $\{\Delta F\}$ represents the unbalanced forces.

The element nodal displacement can be calculated by,

$\{\Delta u\}=[L]_{i}\{\Delta U\}$

in which, $\{\Delta u\}$ is the element nodal displacement vector.

The resisting forces in this analysis at each load-increment can be obtained at the $i^{t h}$ position according to the last-known status at the $(i-1)^{\text {th }}$ position. The global resisting force can be summed up by,

$\{R\}_{i}=\{R\}_{i-1}+\sum_{i=1}^{N E L E}[L]_{i}^{T}\{\Delta r\}$

where $\{R\}_{i-1}$ denote the global resisting force vector at the $(i-1)^{t h}$ step; while, $\{\Delta r\}$ describes the element resisting force vector.

An incremental-iterative analysis procedure, via the Newton-Raphson typed numerical method, is developed, which is schematically presented in Fig. 7. The Newton-Raphson procedure is to divide the nonlinear problem into a 
series of linear solutions. One or more times of iterations are required at each load increment to minimize the numerical errors, which can be measured by the norm of the unbalanced force vector $\Delta F$,

$$
\{\Delta F\}=\{F\}_{i}-\{R\}_{i}
$$

The expression of convergence criterion with respect to the residual forces and displacements are introduced,

$$
\{\Delta U\}^{T}\{\Delta U\} \leq T O L \times\{U\}^{T}\{U\}
$$

$$
\{\Delta F\}^{T}\{\Delta F\} \leq T O L \times\{R\}^{T}\{R\}
$$

in which $T O L$ is the convergence tolerance.

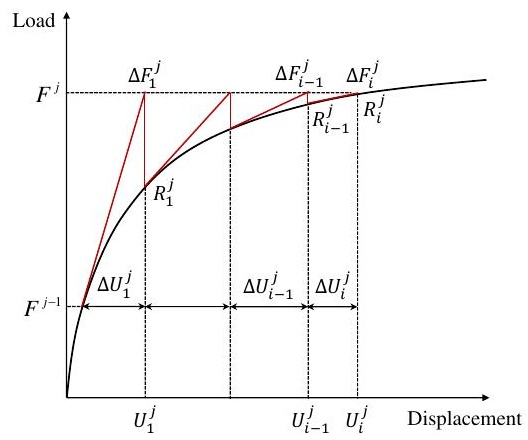

Fig. 7 Newton-Raphson typed numerical procedure

\section{Numerical analysis procedure}

The numerical analysis procedure is proposed to determine the critical temperature to trigger the upheaval buckling of pipelines, illustrated in Fig. 8. As can be seen from the flowchart, the analysis procedure contains two steps. The first analysis step is to determine initial deformation and stress within the pipeline, while the second step is to apply the cumulative temperature to the pipeline until triggering the buckling.

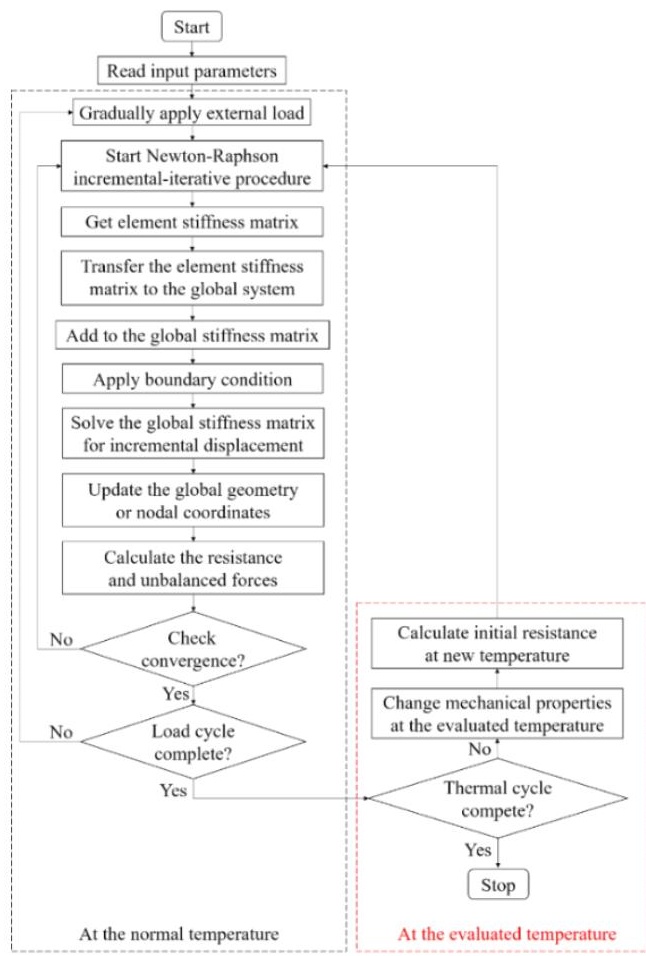

Fig. 8 An incremental-iterative analysis procedure

\section{Verification examples}

Three groups of examples are provided for examining the analysis accuracy and numerical robustness of the proposed numerical algorithms in capturing buckling behaviors of pipelines due to thermal expansion

6.1. Example 1-Upheaval buckling of pipelines in soft soil due to thermal expansion

In this example, the upheaval buckling behaviors of a series of pipelines in soft soil (see Fig. 9) due to thermal expansion are computed by the analytical solutions. The results will be used as benchmarks for validating the proposed numerical algorithms. The analytical solution derived by $\mathrm{Li}$ et al. [36] to compute the buckling strength of a buried pipeline under thermal expansion can be written as,

$$
P_{c r}=E A \alpha \Delta t_{c r}=\frac{\pi^{2} E I}{L_{c r}{ }^{2}}+k_{s p} \frac{L_{c r}{ }^{2}}{\pi^{2}}
$$

where, $\Delta t_{c r}$ is the critical temperature to trigger the upheaval buckling; $\alpha$ is the thermal expansion coefficient; $E$ is the Young's modulus; $A$ is the section area; $I$ is the moment of inertia; $k_{s p}$ is the stiffness of soil springs; and $L_{c r}$ is the critical buckling length.

This equation can be rewritten as follow for determining the critical temperature onset of triggering the upheaval buckling,

$\Delta t_{c r}=\left(\frac{\pi^{2} E I}{L_{c r}{ }^{2}}+k_{s p} \frac{L_{c r}{ }^{2}}{\pi^{2}}\right) \frac{1}{\alpha E A}$

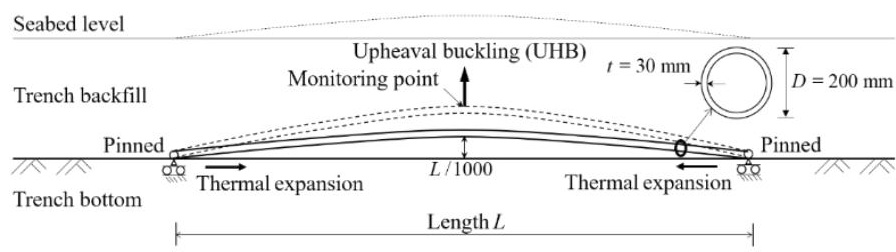

Fig. 9 Upheaval buckling of a buried pipe with both ends pinned

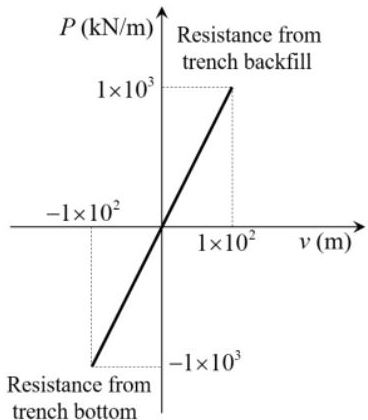

Fig. 10 Soil-pipeline interaction curve of a buried pipe with both ends pinned

Six pipelines are studied for investigating their upheaval buckling behaviors under thermal expansion, and they are all using the circular hollow section with the diameter and the wall thickness as $200 \mathrm{~mm}$ and $30 \mathrm{~mm}$, respectively. The material is steel, and the Young's modulus, the Possion's ratio and the thermal expansion coefficients are $205 \mathrm{GPa}, 0.3$ and $1.2 \times 10^{-5} \mathrm{~m} / \mathrm{m} \cdot{ }^{\circ} \mathrm{C}$, respectively. The lengths of the pipelines are varied with different values, given as $6 \mathrm{~m}$, $7 \mathrm{~m}, 8 \mathrm{~m}, 10 \mathrm{~m}, 15 \mathrm{~m}$ and $20 \mathrm{~m}$. The pipelines are embedded in trench backfill with the soil stiffness as $10 \mathrm{kN} / \mathrm{m}^{2}$. The soil-pipeline interaction curve in this example is shown in Fig. 10.

The buckling length is critical for assessing the buckling of pipelines. For simplicity, these pipelines are pinned at both ends (as shown in Fig. 9), and the buckling lengths are their member lengths. The buckling analyses for these pipelines are performed by the proposed numerical method, where two cases of using 2 and 4 elements to model a pipeline are studied. It is observed from Table 3 that, the proposed method is with high analysis accuracy and the error of using 4 elements to model a long pipeline is less than $0.08 \%$. The nonlinear buckling analysis is conducted for these pipelines, and the load versus deflection curves 
are plotted in Fig. 11. The present study confirms the analysis accuracy of the proposed method in determining the critical load of triggering the upheaval buckling of a pipeline.

Table 3

Critical temperatures to trigger buckling of the pipelines

\begin{tabular}{cccccc}
\hline \multirow{2}{*}{ Length $(\mathrm{m})$} & Theoretical & \multicolumn{5}{c}{ Present Study } \\
\cline { 2 - 6 } & Solution & 2 Elements & Difference & 4 Elements & Difference \\
\cline { 2 - 6 } & $\Delta t c r\left({ }^{\circ} \mathrm{C}\right)$ & $\Delta t c r\left({ }^{\circ} \mathrm{C}\right)$ & $(\%)$ & $\Delta \operatorname{tcr}\left({ }^{\circ} \mathrm{C}\right)$ & $(\%)$ \\
\hline 6 & 86.03 & 86.69 & 0.773 & 86.10 & 0.080 \\
7 & 63.78 & 64.27 & 0.766 & 63.83 & 0.079 \\
8 & 49.52 & 49.89 & 0.755 & 49.55 & 0.078 \\
10 & 33.21 & 33.45 & 0.718 & 33.23 & 0.074 \\
15 & 19.40 & 19.50 & 0.537 & 19.41 & 0.033 \\
20 & 17.94 & 17.99 & 0.296 & 17.95 & 0.020 \\
\hline Mean $(\%)$ & & & 0.641 & & 0.061 \\
SD $(\%)$ & & & 0.427 & & 0.060 \\
\hline
\end{tabular}

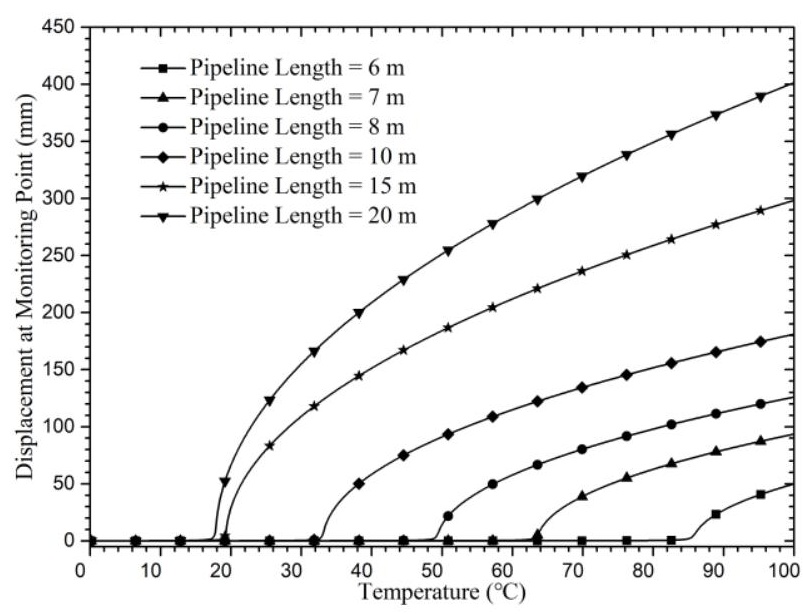

Fig. 11 Buckling behaviors of the pipelines due to thermal expansions

\subsection{Example 2-Thermal upheaval buckling of long buried sea pipelines}

This example investigates the upheaval buckling behavior of buried pipelines with different out-of-straightness and different initial imperfection shapes. The analysis problem is illustrated in Fig. 12.

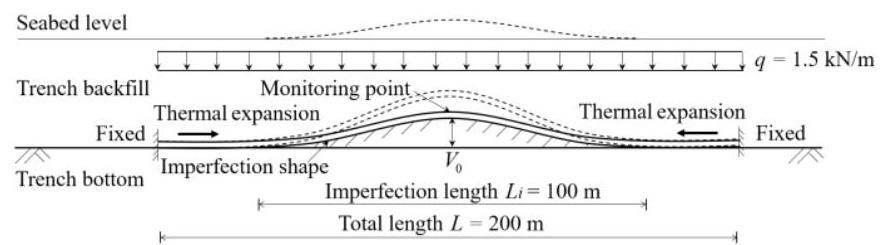

Fig. 12 Pipeline model resting on the semi-rigid seabed

The pipelines are made by steel and the Young's modulus, the Poisson's ratio, and the thermal coefficient are $207 \mathrm{GPa}, 0.3$, and $1.17 \times 10^{-5} \mathrm{~m} / \mathrm{m} \cdot{ }^{\circ} \mathrm{C}$, respectively. Six pipelines are studied for investigating their upheaval buckling behaviors under thermal expansion, and they are all using the circular hollow section with the diameter and the wall thickness as $457 \mathrm{~mm}$ and $14.3 \mathrm{~mm}$, respectively. The total length of these pipelines is $200 \mathrm{~m}$, and the initial imperfection length is $100 \mathrm{~m}$. In the proposed pipeline element method, one element per 2 meters is used to simulate the pipeline, and the two ends of the pipeline are fixed.

Assuming that the pipeline is placed on a semi-rigid seabed and the sum of the trench backfill and the pipeline's self-weight is $1.5 \mathrm{kN} / \mathrm{m}$, the soil-pipeline interaction curve is shown in Fig. 13. So if the downward displacement of the pipeline is $1 \times 10^{-5} \mathrm{~m}$, the resistance of the seabed is $2000 \mathrm{kN} / \mathrm{m}$, which is a relative large value that can satisfy the rigid seabed assumption.

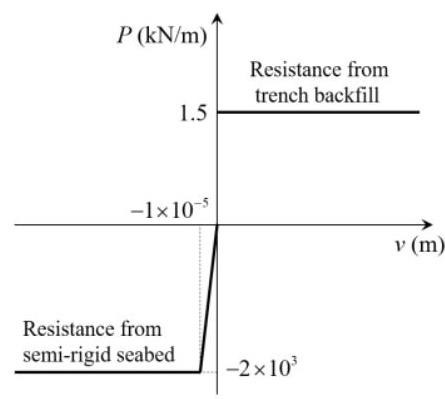

Fig. 13 Soil-pipeline interaction curve of buried pipeline with both ends fixed

Two out-of-straightness are employed in this example, such as 1/100 and $1 / 200$, to investigate the pipelines' upheaval buckling behavior. For each value of out-of-straightness, the pipeline has three initial imperfection shapes, which the following equations can determine:

Imperfection Shape Type 1,

$V_{i}^{1}(x)=\left\{\begin{array}{l}V_{0}\left(\frac{8}{3}\left(\frac{2 x}{L_{i}}\right)^{2}+3 \frac{2 x}{L_{i}}+1\right)\left(1-\frac{2 x}{L_{i}}\right)^{3}, 0 \leq x \leq \frac{L_{i}}{2} \\ V_{0}\left(\frac{8}{3}\left(\frac{2 x}{L_{i}}\right)^{2}-3 \frac{2 x}{L_{i}}+1\right)\left(1+\frac{2 x}{L_{i}}\right)^{3},-\frac{L_{i}}{2} \leq x \leq 0\end{array}\right.$

Imperfection Shape Type 2,

$V_{i}^{2}(x)=\frac{V_{0}}{2}\left(1+\cos \left(\frac{2 \pi x}{L_{i}}\right)\right),-\frac{L_{i}}{2} \leq x \leq \frac{L_{i}}{2}$

Imperfection Shape Type 3,

$V_{i}^{3}(x)=\left\{\begin{array}{l}V_{0}\left(4 \frac{2 x}{L_{i}}+1\right)\left(\frac{2 x}{L_{i}}-1\right)^{4}, 0 \leq x \leq \frac{L_{i}}{2} \\ -V_{0}\left(4 \frac{2 x}{L_{i}}-1\right)\left(\frac{2 x}{L_{i}}+1\right)^{4},-\frac{L_{i}}{2} \leq x \leq 0\end{array}\right.$

The whole analysis process is divided into two steps. In the first step, the unit submerged weight is applied, and then the temperature is gradually increased to the target temperature, which is set to $100^{\circ} \mathrm{C}$ in this example.

This example's analytical results will be compared with those of Zeng et al. [37] using the commercial finite element software ABAQUS. The FEA model of Zeng et al. simulates the pipeline using the Timoshenko beam element (PIPE21) and the rigid element (R2D2) to simulate the rigid seabed and the contact between the pipeline and the seabed was simulated by surface-to-surface contact. The comparison results of temperature-displacement curves at the monitoring point are shown in Fig. 14 and Fig. 15. The results show that the proposed pipeline element method using one element per two meters can accurately capture the pipeline's upheaval buckling behavior.

\subsection{Example 3-Thermal upheaval buckling of unburied sea pipelines with free span}

Due to the complex seabed conditions, pipelines' free span is inevitable, which may result in upheaval buckling failure of a pipeline under service conditions. In this example, a submarine pipeline with a $32 \mathrm{~m}$ long free span is selected to study the deformation of the whole process of pipeline heating. The analytical model is shown in Fig. 16.

The pipeline material is steel with Young's modulus of $207 \mathrm{GPa}$, Poisson's ratio of 0.3 , and a thermal expansion coefficient of $1.1 \times 10^{-5} \mathrm{~m} / \mathrm{m} \cdot{ }^{\circ} \mathrm{C}$. The tube diameter is $381 \mathrm{~mm}$, and the thickness is $12 \mathrm{~mm}$. The length of the free span is $32 \mathrm{~m}$, and the total length of the pipeline is 50 times the length of the free span. One element per 2 meters is used to model the pipeline in the proposed pipeline element method. Since the pipeline is not buried by the backfill in this example, it is assumed that the pipeline is pinned at both ends. Except for the free span, the rest of the pipeline is placed on the semi-rigid seabed, and the soil-pipeline interaction curve is shown in Fig. 17. The unit self-weight of the pipeline is $1.0 \mathrm{kN} / \mathrm{m}$.

The whole analysis process is divided into two steps. Firstly, the self-weight 
of the pipeline is applied to produce the initial deformation. Then, the temperature is gradually increased to the target temperature of $100^{\circ} \mathrm{C}$.

This example's analytical results will be compared with those of Chen et al. [38] using the commercial finite element software ABAQUS. Chen et al. simulate the pipeline with a beam element (B21), and the rigid contact surface (R2D2) simulates the rigid seabed. The temperature versus displacement of the pipeline for the whole heating process is shown in Fig. 18. Since the pipeline deformation far from the free span is minimal, only $200 \mathrm{~m}$ lengths in the middle span are taken to show the results. It can be seen from Fig. 18 that the overall results are in good agreement with those of Chen et al. However, the position of the free span part of the pipeline obtained by the proposed method is slightly below than that observed from Chen et al. This is probably because Chen et al. used the fully restrained boundary condition in the numerical simulation, while the seabed condition modeled in the proposed method is semi-rigid. In general, the results obtained from the proposed pipeline element method show in good agreement with that of using discrete spring element model, which verifies the accuracy of the proposed method.

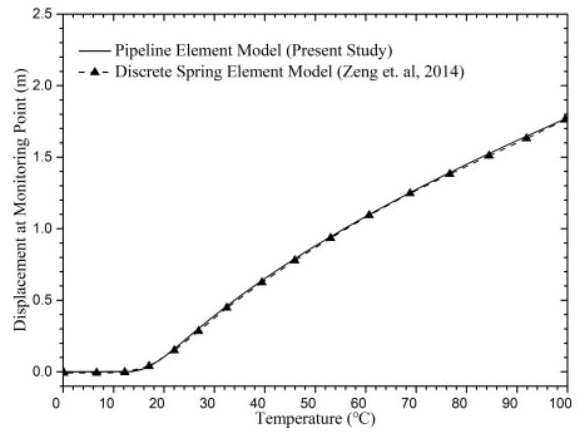

(a) Imperfection Shape Type 1

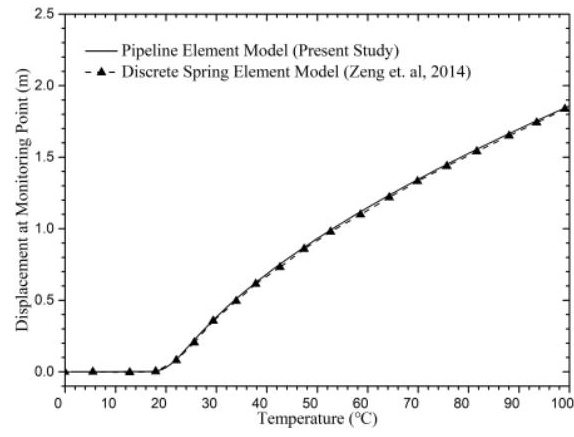

(b) Imperfection Shape Type 2

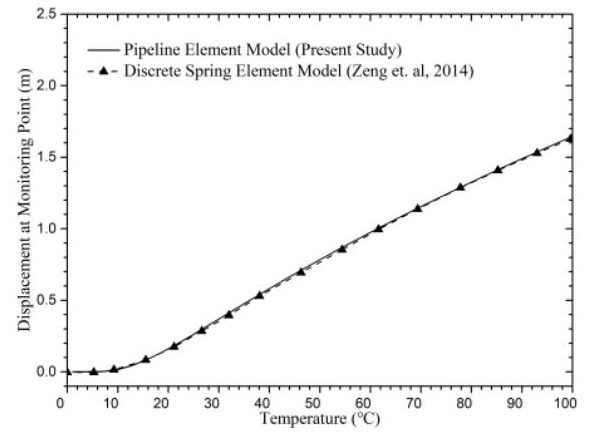

(c) Imperfection Shape Type 3

Fig. 14 Out-of-straightness equal to $1 / 100$

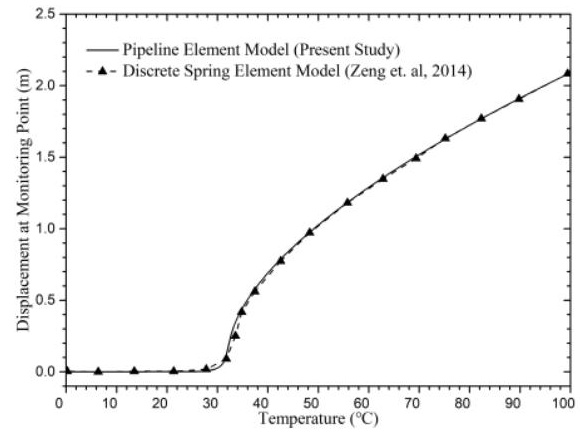

(a) Imperfection Shape Type 1

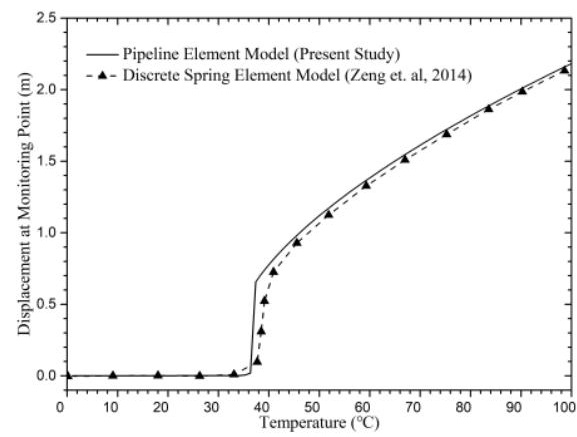

(b) Imperfection Shape Type 2

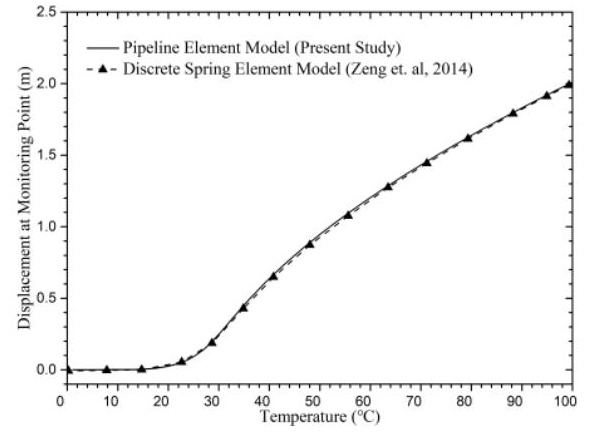

(c) Imperfection Shape Type 3

Fig. 15 Out-of-straightness equal to $1 / 200$

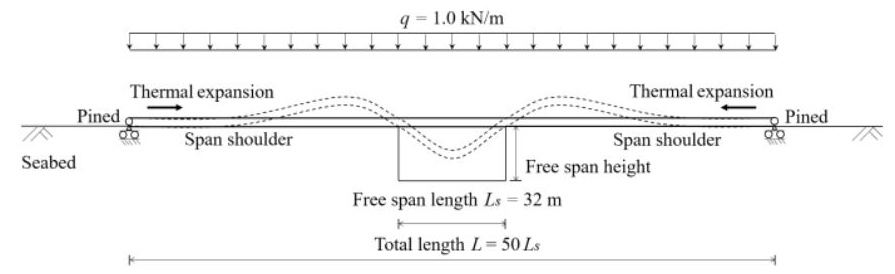

Fig. 16 Pipeline model with free span

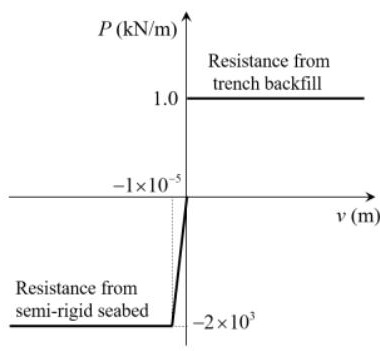

Fig. 17 Soil-pipeline interaction curve of pipeline with free span

\section{Case studies}

In this section, a case study investigating the influential factors related to the upheaval buckling of the pipeline due to thermal expansion is expected. Four variables are defined, i.e., the unit submerged weight, the tube diameter, the imperfection length, and the imperfection amplitude. Accordingly, eleven pipelines are modeled to reflect the variations of these four influential factors, whose analysis properties are tabulated in Table 4 .

Table 4

The variables in the parametric study for thermal upheaval buckling

\begin{tabular}{|c|c|c|c|c|c|}
\hline Pipeline & \multirow[t]{2}{*}{ Variables } & $\begin{array}{c}\text { Unit submerged } \\
\text { weight }\end{array}$ & Diameter & $\begin{array}{c}\text { Imperfection } \\
\text { length }\end{array}$ & $\begin{array}{c}\text { Imperfection } \\
\text { amplitude }\end{array}$ \\
\hline No. & & $q(\mathrm{kN} / \mathrm{m})$ & $D(\mathrm{~mm})$ & $L_{i}(\mathrm{~m})$ & $V_{0}(\mathrm{~m})$ \\
\hline PL-1 & Unit & 1.5 & 273 & 20 & 0.1 \\
\hline PL-2 & submerged & 2.0 & 273 & 20 & 0.1 \\
\hline PL-3 & weight & 2.5 & 273 & 20 & 0.1 \\
\hline PL-4 & & 1.5 & 323 & 20 & 0.1 \\
\hline PL-5 & Diameter & 1.5 & 355 & 20 & 0.1 \\
\hline PL-6 & & 1.5 & 381 & 20 & 0.1 \\
\hline PL-7 & Imperfection & 1.5 & 381 & 40 & 0.3 \\
\hline PL-8 & leng & 1.5 & 381 & 60 & 0.3 \\
\hline PL-9 & & 1.5 & 381 & 70 & 0.3 \\
\hline PL-10 & Imperfection & 1.5 & 381 & 70 & 0.4 \\
\hline PL-11 & amplitude & 1.5 & 381 & 70 & 0.6 \\
\hline
\end{tabular}


These pipelines are $160 \mathrm{~m}$ long with both fixed end conditions and made by steel tubes with the Young's modulus, the Poisson's ratio and the thermal expansion coefficient are $207 \mathrm{GPa}, 0.3$ and $1.17 \times 10^{-5} \mathrm{~m} / \mathrm{m} \cdot{ }^{\circ} \mathrm{C}$, respectively. These pipelines are all using a circular hollow section with a wall thickness of $12 \mathrm{~mm}$. They are located on the semi-rigid foundation and modeled by the proposed pipeline elements, where the element length is 2 meters. There is an initial imperfection amplitude $V_{i}(x)$ in the middle region of the pipeline model, which

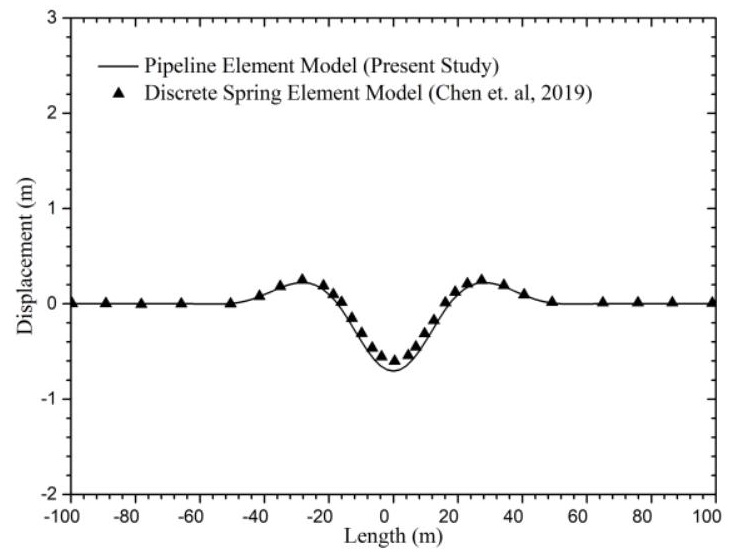

(a) Temperature difference $=29.01^{\circ} \mathrm{C}$

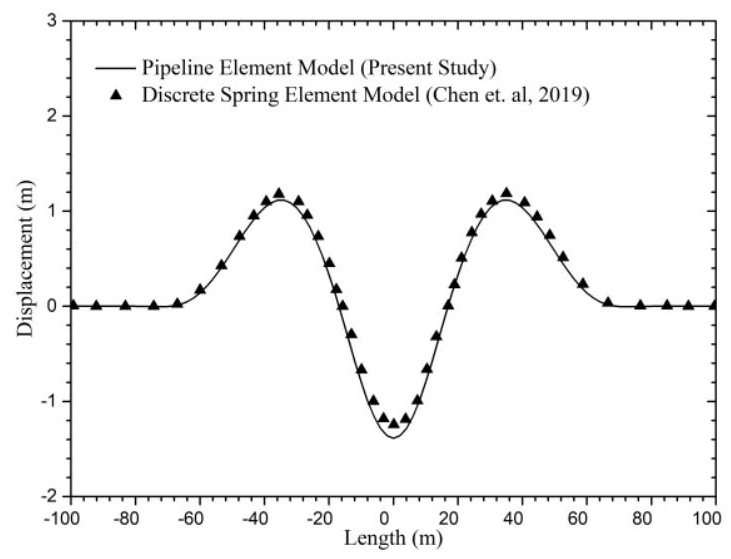

(c) Temperature difference $=64.04^{\circ} \mathrm{C}$ can be defined as the following equation,

$V_{i}(x)=V_{0}\left(\cos \left(2 \pi x / L_{i}\right)+1\right) / 2$

where $V_{0}$ is the maximum amplitude of imperfection; $L_{i}$ is the imperfection length; $x$ is the distance from the middle point of the pipeline model (Fig. 19).

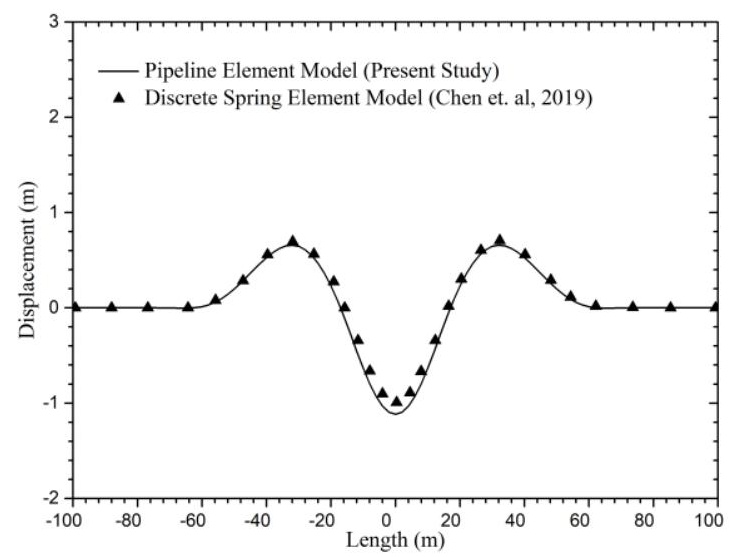

(b) Temperature difference $=42.71^{\circ} \mathrm{C}$

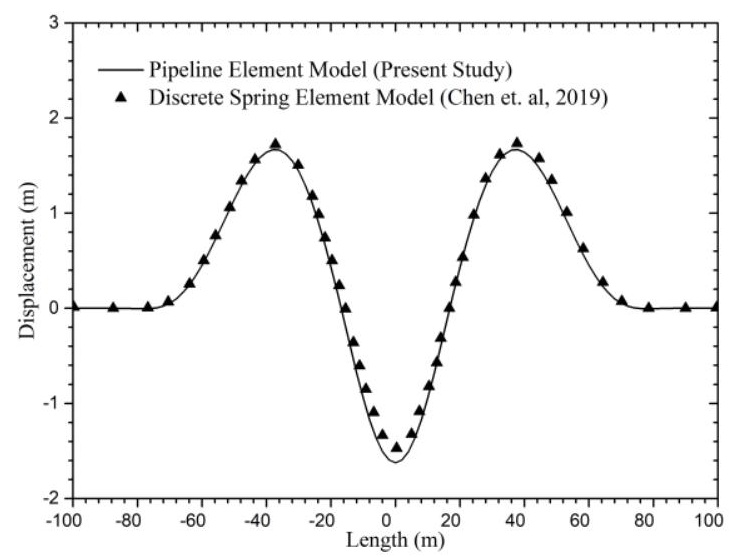

(d) Temperature difference $=94.04^{\circ} \mathrm{C}$

Fig. 18 Displacement of pipeline under different temperature

Seabed level
Trench backfill
Fixed
Trench bottom
Thermal expansion

Fig. 19 Pipeline model with initial imperfection

Each pipeline segment is loaded by downward line force $q$ to model the unit submerged weight. Meanwhile, each pipeline segment is loaded by thermal expansion till the temperature difference reaches up to $100^{\circ} \mathrm{C}$, and the temperature versus displacement curve of the middle point of each pipeline is obtained.

The parametric study results for these eleven pipelines are plotted in Fig. 20, from where the following observations are given:

(1) As shown in Fig. 20 (a), the critical temperature affects by the unit submerged weight, while the increment of the unit submerged weight will increase the critical temperature dramatically. Before the temperature reaches the critical temperature, the vertical displacement at the pipelines' middle point changes very little as the temperature increases. However, when the temperature reaches the critical temperature, the vertical displacement at the pipelines' middle point increases rapidly until a new equilibrium condition is reached. Then, as the temperature rises, the displacement at the pipelines' middle point increases slowly again. After the pipeline's buckling occurs, the larger the unit submerged weight is at the same temperature, the smaller the pipeline's vertical displacement.
(2) It can be seen from Fig. 20 (b) that the increment of tube diameter can effectively raise the critical temperature of the upheaval buckling of pipelines. Unlike the influence of unit submerged weight on pipe upheaval buckling, after the pipeline's buckling occurs, the larger the tube diameter, the larger the displacement at the pipeline's middle point at the same temperature.

(3) For a given initial imperfection amplitude $\left(V_{0}=0.3 \mathrm{~m}\right)$ of pipeline, as shown in Fig. 20 (c), when the imperfection length is small $(\mathrm{Li}=40 \mathrm{~m})$ the vertical displacement at the middle point of the pipeline is slowly developed with the temperature increase. When the imperfection length is longer $(\mathrm{Li}=70 \mathrm{~m})$, there is a critical temperature at which the displacement in the pipeline's middle span increases sharply.

(4) As illustrated in Fig. 20 (d), for a given initial imperfection length ( $L$ $=70 \mathrm{~m})$ when the imperfection amplitude is small $\left(V_{0}=0.3 \mathrm{~m}\right)$, a critical temperature will appear during the process of heating the pipeline, and the vertical displacement at the middle point of the pipeline will increase sharply at this temperature. When the imperfection amplitude is larger $\left(V_{0}=0.6 \mathrm{~m}\right)$, the pipeline's vertical displacement will not increase sharply but will increase slowly with temperature.

\section{Conclusion}

In this paper, considering the nonlinear soil-structure interaction responses, a newline element, namely pipeline element, is proposed for efficient analysis of the upheaval buckling for pipelines due to thermal expansion. The buried soils are modeled by the springs distributed continuously along with the element and are directly integrated into the element formulations. The element tangent stiffness matrix and secant relations are formulated with the details provided. Another distinct feature is the direct simulation of thermal expansion acting to 
the pipeline via the thermal stiffness matrix, whose derivation is elaborated. Three groups of examples are given to examine the proposed method. Finally, a case study is given to identify the influential factors to the upheaval buckling. The conclusions drawn from this paper are summarized as following:

- A new line element, named pipeline element, is developed and verified by three groups of examples. A case study is given to investigate the influence of several factors such as the unit submerged weight, the tube diameter, the imperfection length, and the imperfection amplitude.

- The unit submerged weight influences the critical temperature dramatically, and an increase in the unit submerged weight increases the critical temperature.

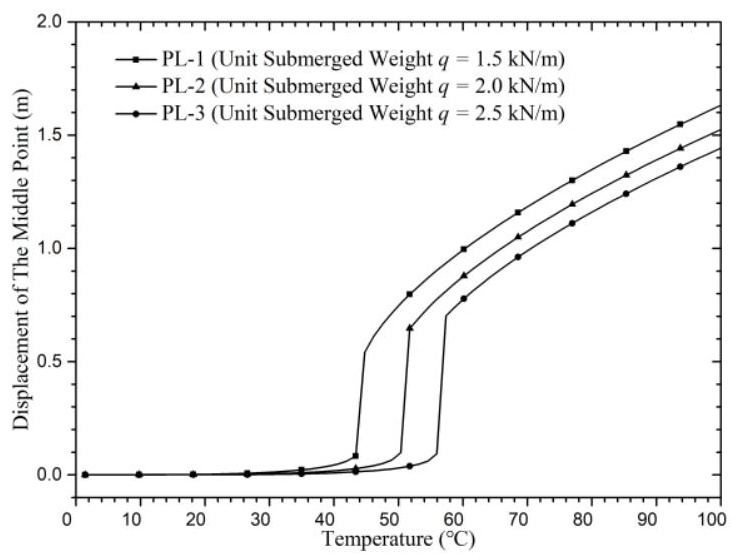

(a) Influenced by the unit submerged weight

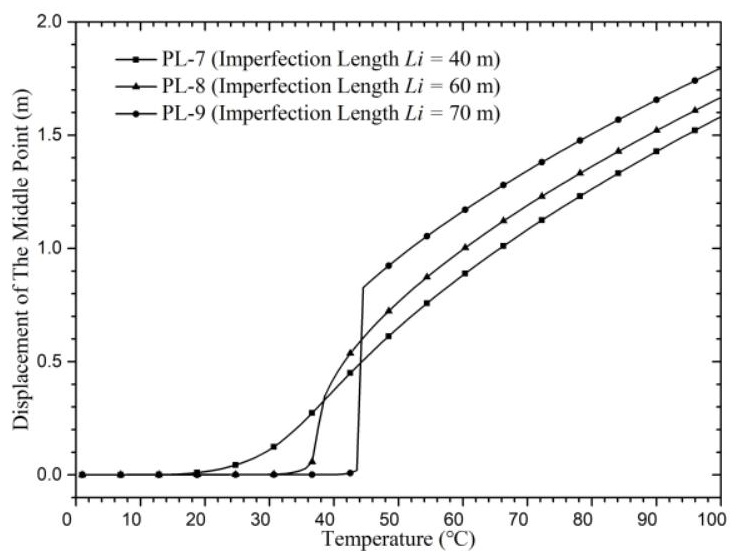

(c) Influenced by the imperfection length
- As the tube diameter increases, the pipeline's critical temperature will increase, and the critical displacement will become larger.

- The out-of-straightness and imperfection shape of the pipeline have a big influence on the upheaval buckling behavior. When the out-of-straightness is small, or the imperfection shape is not compacted, the jump buckling will occur. When the out-of-straightness is large or the imperfection shape is compacted, there is no critical temperature but the first lift-off temperature.

This research improves the numerical efficiency for analyzing the pipeline's upheaval buckling due to thermal expansion significantly. With the availability of this method, the stability design of the subsea buried pipelines for preventing the upheaval buckling, due to thermal expansion, could be more reliable and effective.

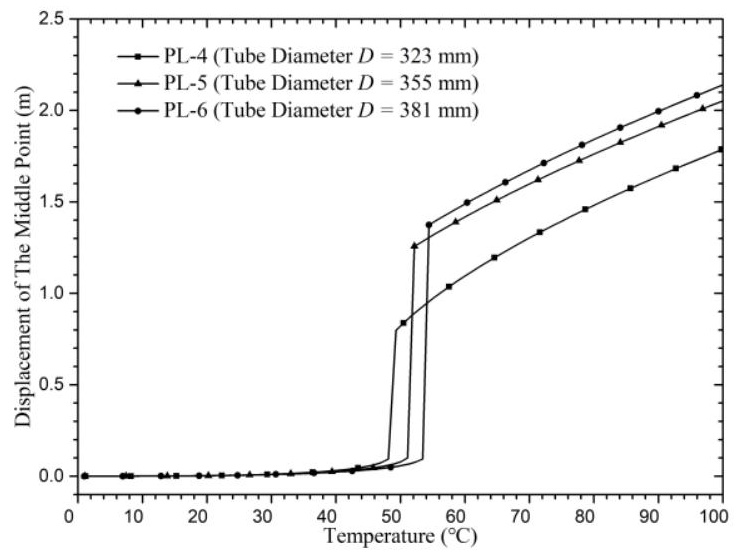

(b) Influenced by the tube diameter

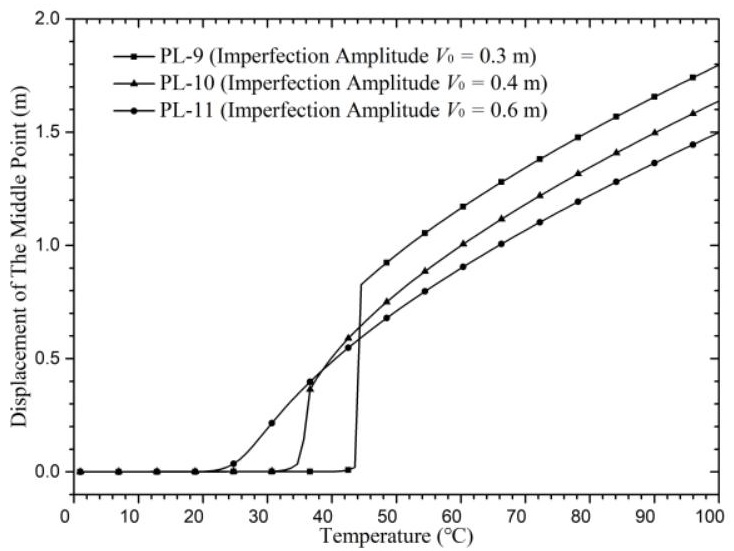

(d) Influenced by the imperfection amplitude

Fig. 20 Displacement of middle point changing with the temperature considering different factors

\section{Acknowledgement}

This research is partially supported by the National Natural Science Foundation of China (No. 52008410), the Basic and Applied Basic Research Foundation of Guangdong Province (No. 2019A1515110969), and the Natural Science Foundation of Guangdong Province (No. 2021A1515011734).

\section{References}

[1] Hong Z.H., Liu W.B. and Xu B.B., "Research on the pipeline walking caused by cyclic increasing soil friction for free deep-sea submarine pipelines laid on even seabed", Marine Structures, 75, 102873, 2021.

[2] Netto T.A. and Estefen S.F., "Buckle arrestors for deepwater pipelines", Marine Structures, 9(9), 873-883, 1996.

[3] Nielsen N.J.R., Lyngberg B. and Pedersen P.T., Upheaval buckling failures of insulated buried pipelines: a case story, Offshore Technology Conference, Houston, 1990.

[4] Guijt J., Upheaval buckling of offshore pipelines: overview and introduction, Offshore Technology Conference, Houston, 1990.

[5] Wang Z.K. and Heijden G.H.M., "Snap behaviour in the upheaval buckling of subsea pipelines under topographic step imperfection", Marine Structures, 69, 102674, 2020.

[6] Wang Z.K., Heijden G.H.M. and Tang Y.G., "Localised upheaval buckling of buried subsea pipelines", Marine Structures, 60, 165-185, 2018.

[7] Fernández-Valdés D., Vázquez-Hernández A.O., Ortega-Herrera J.A., Ocampo-Ramírez A. and Hernández D., "FEM-based evaluation of friction and initial imperfections effects on sandwich pipes local buckling", Marine Structures, 72, 102769, 2020.

[8] Terndrup Pedersen P. and Juncher Jensen J., "Upheaval creep of buried heated pipelines with initial imperfections", Marine Structures, 1, 11-12, 1988

[9] Wang F.C. and Han L.H., "Analytical behavior of carbon steel-concrete-stainless steel double-skin tube (DST) used in submarine pipeline structure", Marine Structures, 63, 99-116, 2019

[10] Wang Z.K., Tang Y.G. and Heijden G.H.M., "Analytical study of distributed buoyancy sections to control lateral thermal buckling of subsea pipelines", Marine Structures, 58, 199-222, 2018.

[11] Xu T., Lauridsen B. and Bai Y., "Wave-induced fatigue of multi-span pipelines", Marine Structures, 12, 83-106, 1999

[12] Maltby T.C. and Calladine C.R., "An investigation into upheaval buckling of buried pipelines - I. Experimental apparatus and some observations", International Journal of Mechanical Sciences, 37(9), 943-963, 1995

[13] Maltby T.C. and Calladine C.R., "An investigation into upheaval buckling of buried pipelines - II. Theory and analysis of experimental observations", International Journal of Mechanical Sciences, 37(9), 965-983, 1995.

[14] Taylor N. and Tran V., "Experimental and theoretical studies in subsea pipeline buckling", Marine Structures, 9, 211-257, 1996

[15] Armaghani D.J., Faizi K., Hajihassani M., Mohamad E.T. and Nazir R., "Effects of soil reinforcement on uplift resistance of buried pipeline", Measurement, 64, 57-63, 2015.

[16] Schaminee P., Zorn N. and Schotman G., Soil response for pipeline upheaval buckling analyses: full-scale laboratory tests and modelling, Offshore Technology Conference, Houston, 1990.

[17] Karampour H. and Albermani F., "Experimental and numerical investigations of buckle interaction in subsea pipelines", Engineering Structures, 66, 81-88, 2014. 
[18] Vazouras P., Tsatsis A. and Dakoulas P., "Thermal Upheaval Buckling of Buried Pipelines: Experimental Behavior and Numerical Modeling", Journal of Pipeline Systems Engineering and Practice, 12(1), 04020057, 2021.

[19] Hobbs R.E., "In-Service Buckling of Heated Pipelines", Journal of Transportation Engineering, 110(2), 175-189, 1984.

[20] Taylor N. and Gan A.B., "Submarine pipeline buckling-imperfection studies", Thin-Walled Structures, 4(4), 295-323, 1986.

[21] Ju G.T. and Kyriakides S., "Thermal buckling of offshore pipelines", Offshore Mechanics and Arctic Engineering, 110(4), 355-364, 1988.

[22] Ballet J.P. and Hobbs R.E., "Asymmetric effects of prop imperfections on the upheaval buckling of pipelines", Thin-Walled Structures, 13(5), 355-373, 1992.

[23] Wang Z.K., Tang Y.G., Yang J.G. and Soares G., "Analytical study of thermal upheaval buckling for free spanning pipelines", Ocean Engineering, 218, 108220, 2020.

[24] Palmer A., Ellinas C., Richards D. and Guijt J., Design of submarine pipelines against upheaval buckling, Offshore Technology Conference, Houston, 1990.

[25] Friedmann Y. and Debouvry B., "Analytical design method helps prevent buried pipe upheaval", Pipeline Industry, 75, 63-68, 1993.

[26] Bodaghi M. and Saidi A.R., "Levy-type solution for buckling analysis of thick functionally graded rectangular plates based on the higher-order shear deformation plate theory", Applied Mathematical Modelling, 34(11), 3659-3673, 2010.

[27] Bodaghi M. and Saidi A.R., "Buckling behavior of standing laminated Mindlin plates subjected to body force and vertical loading", Composite Structures, 93(2), 538-547, 2011.

[28] Bodaghi M. and Saidi A.R., "Thermoelastic buckling behavior of thick functionally graded rectangular plates", Archive of Applied Mechanics, 81(11), 1555-1572, 2011.

[29] Klever F.J., Van Helvoirt L.C. and Sluyterman A.C., A dedicated finite-element model for analyzing upheaval buckling response of submarine pipelines, Offshore Technology Conference, Houston, 1990.

[30] Zhang X.H. and Duan M.L., "Prediction of the upheaval buckling critical force for imperfect submarine pipelines", Ocean Engineering, 109, 330-343, 2015.

[31] Robert D.J. and Thusyanthan N.I., "Numerical and experimental study of uplift mobilization of buried pipelines in sands", Journal of Pipeline Systems Engineering and Practice, 6(1), 04014009,2015

[32] Xu L.G. and Lin M., "Numerical study on critical axial forces of upheaval buckling for initially stressed submarine pipelines on uneven seabed", Ocean Engineering, 145, 344-358, 2017.

[33] Chen Z.H., Yang J.G. and Wang Z.K., "Numerical study on upheaval buckling for surface laid subsea pipelines with topographic step imperfection", Applied Ocean Research, 101, laid subsea pipeli

[34] Liang Z., Lu X. and Zhang J., "Thermal vertical buckling of surface-laid submarine pipelines on a sunken seabed", Ocean Engineering, 173, 331-344, 2019.

[35] Stanisic D., Efthymiou M., Kimiaei M., and Zhao W.H., "Design loads and long term distribution of mooring line response of a large weathervaning vessel in a tropical cyclone environment", Marine Structures, 61, 361-80, 2018.

[36] Li X.Y., Wan J.H., Liu S.W. and Zhang L.M., "Numerical formulation and implementation of Euler-Bernoulli pile elements considering soil-structure-interaction responses", International Journal for Numerical and Analytical Methods in Geomechanics, 44, 1903-1925, 2020.

[37] Zeng X.G., Duan M.L. and Che X.Y., "Critical upheaval buckling forces of imperfect pipelines", Applied Ocean Research, 45, 33-39, 2014.

[38] Chen Z.H., Yang J.G. and Liu Z.S., "Experimental and numerical investigation on upheaval buckling of free-span submarine pipeline", Advanced Steel Construction, 15(4), 323-328, 2019. 